\title{
EFFECTS OF CHEMISTRY AND OTHER VARIABLES ON CORROSION AND STRESS CORROSION CRACKING IN HANFORD DOUBLE-SHELL TANKS
}

\section{Feng Gui, Colin Scott and Sean Brossia}

CC Technologies, Inc. for CH2M HILL Hanford Group, Inc.

Richland, WA 99352

U.S. Department of Energy Contract DE-AC27-99RL14047

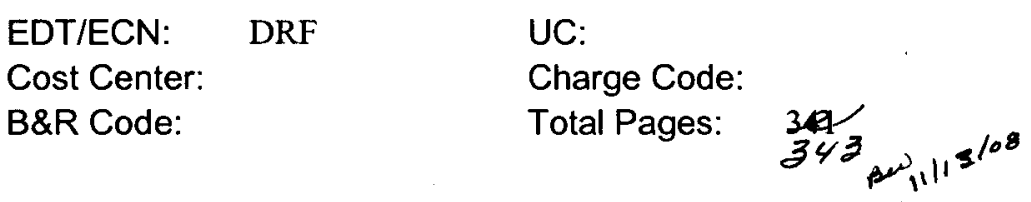

Key Words: laboratory testing, cyclic potentiodynamic polarization test, slow strain rate test, crack growth rate test, tank waste simulants, open circuit potential, localized corrosion, pitting, stress corrosion cracking, double-shell tank, 241-AP-105, 241-SY-103, 241-AW-105, 241-AZ-102, 241-SY-101, 241-AN-107, 241-AY-101

Abstract: Laboratory testing was performed to develop a comprehensive understanding of the corrosivity of the tank wastes stored in Double-Shell Tanks using simulants primarily from Tanks 241-AP-105, 241-SY-103 and 241-AW-105. Additional tests were conducted using simulants of the waste stored in 241-AZ-102, 241-SY-101, 241-AN-107, and 241-AY-101. This test program placed particular emphasis on defining the range of tank waste chemistries that do not induce the onset of localized forms of corrosion, particularly pitting and stress corrosion cracking. This document summarizes the key findings of the research program.

TRADEMARK DISCLAIMER. Reference herein to any specific commercial product, process, or service by trade name, trademark, manufacturer, or otherwise, does not necessarily constitute or imply its endorsement, recommendation, or favoring by the United States Government or any agency thereof or its contractors or subcontractors.

Printed in the United States of America. To obtain copies of this document, contact: Document Control Services, P.O. Box 950 , Mailstop H6-08, Richland WA 99352, Phone (509) 372-2420; Fax (509) 376-4989.
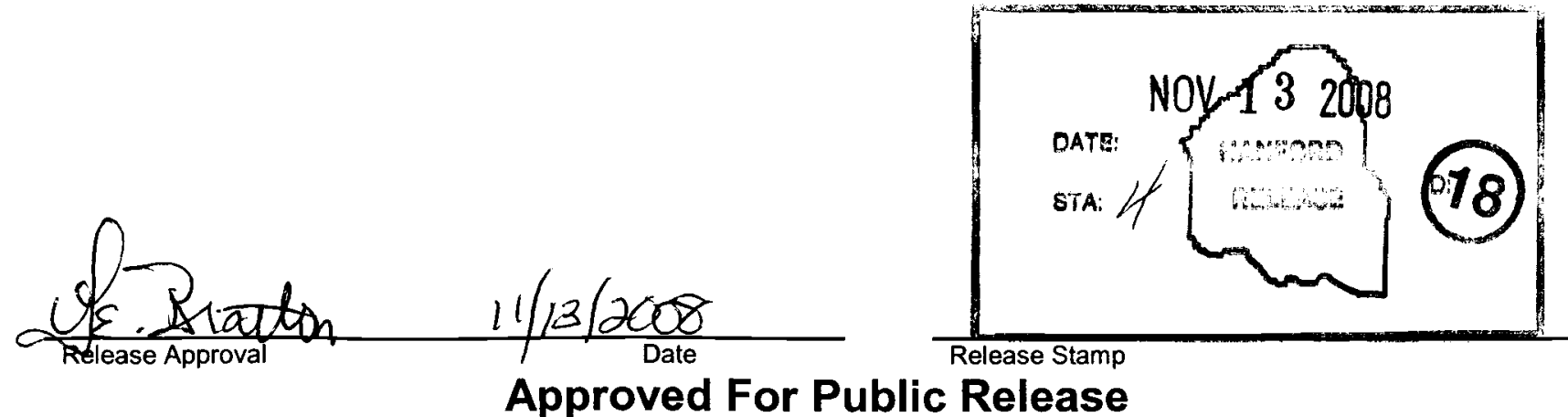
RPP-RPT-37505, Rev. 0

\title{
EFFECTS OF CHEMISTRY AND OTHER VARIABLES ON CORROSION AND
} STRESS CORROSION CRACKING IN HANFORD DOUBLE-SHELL TANKS

\author{
September 2008
}

prepared by

\section{Technologies, Inc. - A DNV Company \\ 5777 Frantz Road \\ Dublin, Ohio 43017-1386}

prepared for

CH2M HILL Hanford Group, Inc. 


\section{EXECUTIVE SUMMARY}

The Hanford reservation contains approximately 50-million gallons of liquid legacy radioactive waste from cold war weapons production that is stored in 177 underground storage tanks. Current plans call for vitrification of the waste and final disposal in a geologic repository at Yucca Mountain. The double-shelled carbon steel tanks presently used for storage will continue in operation until a vitrification plant is constructed and waste processing operations are completed. Due to various chemical reactions taking place inside the tanks, the waste chemistries will tend to change over time. Although the changes occur slowly, the waste compositions will be altered because of the current estimate for storage of waste, which goes beyond 2035 .

In addition, the present chemistries for some of the tank waste types are no longer in specification with respect to corrosion mitigation (e.g., maintaining $\mathrm{pH}$ levels above 12). Thus, there is concern within the U.S. Department of Energy (DOE), oversight groups, and regulatory bodies that tank integrity may have been or may become compromised given these changes in chemistry. Furthermore, if tank integrity is potentially compromised, there is a need to define mitigation strategies. Additional resources would be required to mitigate potential leaks and conduct repairs. The objective of this work was to finalize the range of conditions where the tank steel is susceptible to localized corrosion and stress corrosion cracking (SCC) in the Double-Shell Tanks (DSTs) using primarily simulants of wastes stored in various tanks, in particular Tanks 241-AP-105, 241-SY-103 and 241-AW-105. The chemistries in these tanks cover a broad range of waste chemistries in the tank farm including low nitrate concentration wastes, low nitrite to nitrate ratio wastes, and wastes containing high halide concentrations. These tanks were specifically selected because they provide bounding compositions of aggressive ions. In addition, testing was conducted in simulants of wastes from Tank 241-AZ-102 and 241-SY-101 to test the impact of specific aggressive ions. Tank 241-AN-107 and Tank 241-AY-101 simulants were tested to complement results from previous corrosion studies with respect to carbonate $\mathrm{SCC}$ and $\mathrm{pH}$ impact on corrosion susceptibility, respectively. The work involved a series of cyclic potentiodynamic polarization (CPP), slow strain rate tests (SSRTs) and crack growth rate (CGR) tests in the waste simulants on a plate of American Association of Railways Tank Car (AAR TC) 128 Grade B steel, which is believed to have similar properties to the waste tanks.

Based on the work conducted, the key findings of the research are listed below.

- $\quad$ The SCC potency of the waste simulants for the three tanks studied followed the trends previously established for nitrate-based simulants. SCC only occurred at relatively high applied potentials (e.g., $0 \mathrm{mV}$ vs. SCE) or at low nitrite/nitrate concentrations ratios.

- $\quad$ Limited CGR testing performed in AY-101 simulants indicated that stress intensity factors above $45 \mathrm{ksi}$ in were necessary for crack propagation to occur in the waste simulants tested.

- Though at current tank conditions the Present Supernate Composition (PSC) simulant for tank 241-AP-105 (AP-105-PSC) showed a low propensity for corrosion, the tank steel exposed to the Tank AP-105-PSC simulant at elevated temperatures and under anodically 
polarizing conditions demonstrated a susceptibility to SCC and localized corrosion at the liquid/vapor interface. Long-term immersion tests indicated that the steel was susceptible to corrosion at the liquid/vapor interface even at open circuit potential (OCP), but the extent at room temperature was not as severe as at elevated temperatures (e.g., $50^{\circ} \mathrm{C}$ ). The AP-105-PSC is the only simulant in which SCC was observed in a SSRT performed at OCP. Local chemistry changes (nitrite depletion or $\mathrm{pH}$ drop) may be responsible for the interfacial attack, though the precise mechanism is unclear at this time. The liquid/vapor interface attack indicates that localized corrosion is possible in simulants with high $\mathrm{pH}$, and this should be considered in any future corrosion mitigation strategies.

- The Present Interstitial Liquid (PIL) for Tank 241-SY-103 (SY-103-PIL) simulant, which has the upper limit of chloride concentration of the DSTs, appears to be benign with respect to corrosion and SCC relative to the AP-105-PSC and previously tested Tank 241-AN-107 simulants and the PIL for Tank 241-AY-102 (AY-102PIL) simulant. Any possible corrosion liability associated with the high chloride content, appears to be offset by the relatively high nitrite content.

- The PIL for Tank 241-AW-105 (AW-105-PIL) simulant, which has the upper limit of fluoride concentration, also appears to be benign with respect to tank steel SCC. However, some localized corrosion has been observed at the liquid/vapor interface.

- The AZ-102 simulant, tested at the higher temperature of $77^{\circ} \mathrm{C}$, appears to be benign with respect to SCC, confirming the inhibitory nature of nitrite. The AZ-102 simulant has a high nitrite/nitrate ratio of 8.4 . 


\section{TABLE OF CONTENTS}

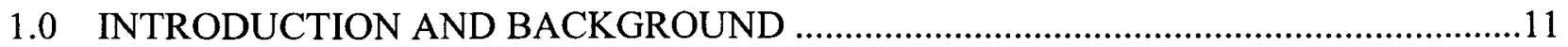

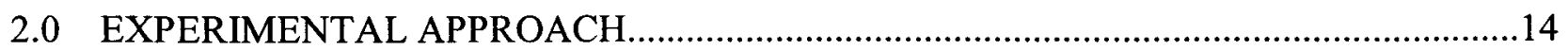

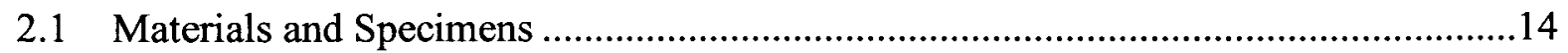

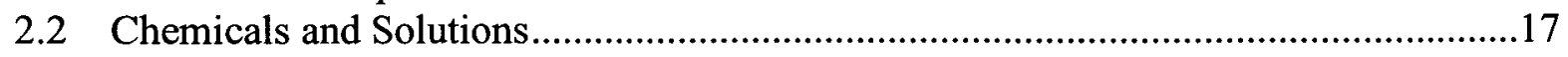

3.0 OPEN CIRCUIT POTENTIAL MONITORING, POTENTIOSTATIC AND

CYCLIC POTENTIODYNAMIC POLARIZATION TESTING ..................................18

3.1 Slow Strain Rate Testing ..................................................................................20

$3.2 \mathrm{~K}_{\mathrm{thSCC}}$ and Crack Growth Rate Testing using Compact Tension Specimens .............20

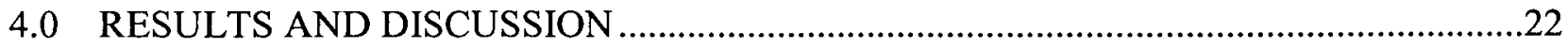

4.1 Electrochemical Polarization Behavior in Tank 241-AP-105 Based

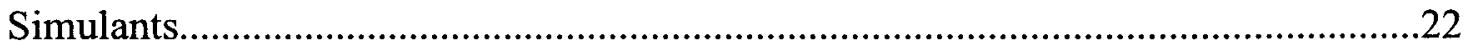

4.1.1 Cyclic Potentiodynamic Polarization Behavior ..........................................22

4.1.2 Liquid/Vapor Interfacial Corrosion in AP-105-PSC ....................................26

4.2 Slow Strain Rate Testing in Tank 241-AP-105 Based Simulants.............................41

4.3 Electrochemical Polarization Behavior in Tank 241-SY-103-PIL Based

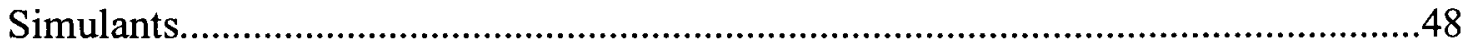

4.4 Slow Strain Rate Testing in Tank 241-SY-103-PIL Based Simulants ........................49

4.5 Electrochemical Polarization Behavior in Tank 241-AW-105 Based

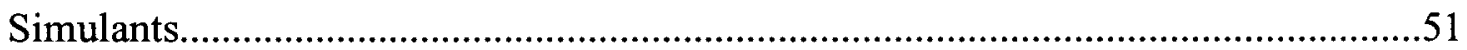

4.6 Slow Strain Rate Testing in Tank 241-AW-105 Based Simulants ............................53

4.7 Slow Strain Rate Testing in Tank 241-AN-107 Based Simulants............................59

4.8 Electrochemical Polarization Behavior in Tank 241-AZ-102 Based Simulant ...........61

4.9 Slow Strain Rate Testing in Tank 241-AZ-102 Based Simulant..............................62

4.10 Electrochemical Polarization Behavior in Tank 241-SY-101 Based Simulant ..........63

4.11 Slow Strain Rate Testing in Tank 241-SY-101 Based Simulant ................................64

4.12 Electrochemical Polarization Behavior in Tank 241-AY-101-CSL Simulant.............66

4.13 Slow Strain Rate Testing in Tank 241-AY-101-CSL Based Simulant........................68

4.14 Dynamic-K Testing in 5M NaNO 3 and Tank 241-AY-101-PSC Based

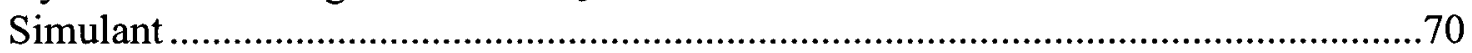

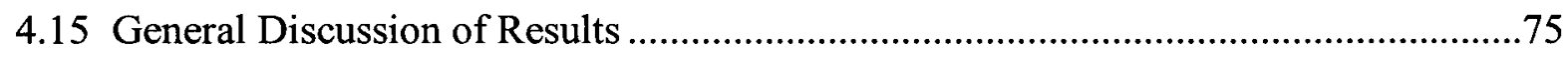

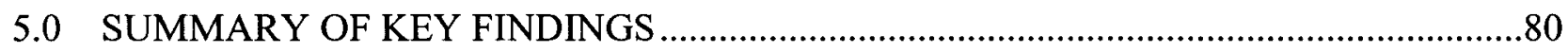

\section{LIST OF APPENDICES}

Appendix A - Simulant Recipes, Certificates for Chemicals and QA Documents

Appendix B - Cyclic Potentiodynamic Polarization (CPP) Testing Data

Appendix C - Slow Strain Rate Test Data and Micrographs

Appendix D - Crack Growth Rate Test Data 


\section{LIST OF FIGURES}

Figure 1. Photomicrographs of (a) the Microstructure of the AAR TC 128 Grade B Tank Car Steel Used for the Current Work and Previous AY-102 and AP101 Work, and (b) the Microstructure of the ASTM A537 Class 2 Steel used for Previous AN-105 and AN-107 Work.

Figure 2. Engineering Drawing of the Cyclic Potentiodynamic Polarization (CPP) Specimen (Units in Inches).

Figure 3. Engineering Drawing of the Slow Strain Rate Test Specimen (Units in Inches)

Figure 4. Engineering Drawing of the Crack Growth Rate Specimen (Units in Inches).

Figure 5. A Photograph of One of the CGR Specimens Following Side-Grooving..... 16

Figure 6. The CPP Curve in Nitrogen Deaerated AP-105-PSC Simulant $\left(\mathrm{T}=50^{\circ} \mathrm{C}\right.$ and $\mathrm{pH}>13)$.

Figure 7. CPP Curves in Nitrogen Deaerated AP-105 Mixed and Evaporated Simulants at $\mathrm{pH} 14$ and $50^{\circ} \mathrm{C}$.

Figure 8. CPP Curves Obtained in Nitrogen Deaerated AP-105 Evaporated and Mixed with Nitrite-to-nitrate Concentration Ratio of $0.1\left(\mathrm{pH} 12+\right.$ and $\left.\mathrm{T}=50^{\circ} \mathrm{C}\right)$.

Figure 9. A Comparison of CPP Curves in Nitrogen Deaerated AP-105-PSC Simulant at Different Nitrite and Nitrate Concentrations $\left(\mathrm{pH}=13+, \mathrm{T}=50^{\circ} \mathrm{C}\right)$.

Figure 10. Sample Appearance after CPP Testing in AP-105-PSC Simulant under Quiescent Air Conditions $\left(\mathrm{pH}=13+, \mathrm{T}=50^{\circ} \mathrm{C}\right.$ ).

Figure 11. The Change in the Current as a Function of Time when the Partially Immersed Sample Was Held at $0 \mathrm{mV}$ vs. SCE (AP-105-PSC, $\mathrm{pH}>13, \mathrm{~T}=50^{\circ} \mathrm{C}$, Quiescent Air Conditions).

Figure 12. The Sample Appearance after 50 Hours of Potentiostatic Testing at $0 \mathrm{mV}$ vs. SCE in the AP-105-PSC Simulant ( $\mathrm{pH}>13, \mathrm{~T}=50^{\circ} \mathrm{C}$, Quiescent Air Conditions).

Figure 13. Current as a Function of Time for Fully Immersed Sample Polarized at $0 \mathrm{mV}$ vs. SCE in AP-105-PSC Simulant $\left(\mathrm{T}=50^{\circ} \mathrm{C}, \mathrm{pH}>13\right)$ Under Quiescent Air Conditions.

Figure 14. A Comparison of the Change in the Current as a Function of Time in the Potentiostatic Tests Conducted in AP-105-PSC Simulants with Different Nitrite Concentrations at $50^{\circ} \mathrm{C}$ and Quiescent Air Conditions.

Figure 15. The Sample Appearance after Potentiostatic Test at $0 \mathrm{mV}$ (vs. SCE) in the AP-105-PSC Simulant with 0.6 M Nitrite for 50 Hours (Sample Partially Immersed) at $50^{\circ} \mathrm{C}$ Under Quiescent Air Conditions.

Figure 16. A Comparison of the Current Density as a Function of Time in the Potentiostatic Tests Conducted at $0 \mathrm{mV}$ (vs. SCE) in Quiescent and Nitrogen Purged AP-105-PSC Simulants at $50^{\circ} \mathrm{C}$.

Figure 17. The Sample Appearance after Potentiostatic Test at $0 \mathrm{mV}$ (vs. SCE) in Nitrogen Deaerated AP-105-PSC Simulant for 50 hours (Sample Partially Immersed) at $50^{\circ} \mathrm{C}$.

Figure 18. The Current Density as a Function of Time in the Potentiostatic Tests Conducted at $0 \mathrm{mV}$ (vs. SCE) in AP-105-PSC Simulants with the Head Space of the Test Cell Purged with Nitrogen at $50^{\circ} \mathrm{C}$. 
Figure 19. The Sample Appearance after the Potentiostatic Tests Conducted at $0 \mathrm{mV}$ (vs. SCE) in AP-105-PSC Simulants with the Head Space of the Test Cell Purged with Nitrogen at $50^{\circ} \mathrm{C}$

Figure 20. Current as a Function of Time in Potentiostatic Tests Conducted at Different

Temperature Levels and Quiescent Air Conditions.

Figure 21. Current Density as a Function of Time in the Potentiostatic Tests Conducted in AP-105-PSC Simulants Under Quiescent Air Conditions at (a) $0 \mathrm{mV}$ (vs. SCE, $50^{\circ} \mathrm{C}$ ) and $100 \mathrm{mV}$ (vs. OCP, $50^{\circ} \mathrm{C}$ ); (b) $50 \mathrm{mV}$ (vs. OCP, Room Temperature) and $0 \mathrm{mV}$ (vs. SCE, Room Temperature).

Figure 22. Sample Appearance after 50 Hours Potentiostatic Testing in AP-105-PSC Simulant at Different Potentials (Under Quiescent Air Conditions, Room Temperature). (a) $0 \mathrm{mV}$ vs. SCE; (b) $50 \mathrm{mV}$ vs. OCP (-160 mV vs. SCE).

Figure 23. Corrosion Rate Calculated Based on Weight Loss for the Samples Partially Immersed in the AP-105-PSC Simulants Under Freely Corroding Conditions for More than Three Months $\left(\mathrm{T}=50^{\circ} \mathrm{C}\right.$ Unless Noted Otherwise).

Figure 24. The Appearance of the Sample (a) and the Cross Section of a Corroded Site

(b) after Exposed in AP-105-PSC under Quiescent Air Conditions (Sample Partially Immersed, $\mathrm{T}=50^{\circ}$, EL1196-83).

Figure 25. The Appearance of the Sample (a) and the Cross Section of a Corroded Site

(b) after Exposed in AP-105-PSC under Quiescent Air Conditions (Sample

Partially Immersed, Room Temperature, EL1196-97) at OCP.

Figure 26. A Comparison of CPP Curves in Nitrogen Deaerated AP-105-PSC Simulant

at Different Nitrite and Nitrate Concentrations $\left(\mathrm{pH}=13+, \mathrm{T}=50^{\circ} \mathrm{C}\right)$.

Figure 27. The Sample Appearance after CPP Testing in Nitrogen Deaerated AP-105-

PSC with No Nitrite and $3.85 \mathrm{M}$ Nitrate $\left(\mathrm{pH}=13+, \mathrm{T}=50^{\circ} \mathrm{C}\right)$.

Figure 28. A Comparison of the CPP Curves Obtained in the AP-105-PSC Simulant under Different Aeration Conditions using Fully Immersed Samples.

Figure 29. The Pit on the Sample Tested in the AP-105-PSC Simulant Under Quiescent

Air Conditions and at $50^{\circ} \mathrm{C}(\mathrm{pH}=13+)$.

Figure 30. The Stress-Strain Behavior of Samples Tested in AP-105-PSC Based

Simulants at $0 \mathrm{mV}$ vs. SCE and at OCP (-249 $\mathrm{mV}$ vs. SCE).

Figure 31. An Electron-Micrograph of a Secondary Crack in Test Sample SSRT-51

Performed in AP-105-PSC Standard Simulant at $50^{\circ} \mathrm{C}, \mathrm{pH} 13+$, and at OCP ($249 \mathrm{mV}$ vs. SCE).

Figure 32. A Stereo-Micrograph of the Test Sample from SSRT-51 Performed in

AP-105-PSC Standard Simulant at $50^{\circ} \mathrm{C}, \mathrm{pH} 13+$, and at OCP $(-249 \mathrm{mV}$ vs. $\mathrm{SCE}$ ).

Figure 33. A Stereo-Micrograph of the Test Sample from SSRT-60 Performed in AP-105-PSC Standard Simulant at $50^{\circ} \mathrm{C}, \mathrm{pH} 13+$, and at OCP $(-277 \mathrm{mV}$ vs.

$\mathrm{SCE})$. The test was stopped at the ultimate tensile strength.

Figure 34. Electron-Micrograph of the Fracture Surface of Test Sample from SSRT-53

Performed in AP-105-PSC Standard Simulant at $50^{\circ} \mathrm{C}, \mathrm{pH} 13+$, and at $0 \mathrm{mV}$ vs.

SCE.

Figure 35. Stereo-Micrograph of the Test Sample from SSRT-53 Performed in AP-105-

PSC Standard Simulant at $50^{\circ} \mathrm{C}, \mathrm{pH} 13+$, and at $0 \mathrm{mV}$ vs. SCE. 
Figure 36. Photograph of the Test Sample from SSRT-54 Performed in AP-105-PSC

Standard Simulant at $50^{\circ} \mathrm{C}, \mathrm{pH} 13+$, and at $0 \mathrm{mV}$ vs. SCE.

Figure 37. Photograph and Schematic of the Test Cell and Sample Indicating Regions

of Corrosion (Schematic Not To Scale).

Figure 38. A CPP Curve in Deaerated SY-103-PIL Simulant $\left(\mathrm{pH}>13\right.$ and $\left.\mathrm{T}=50^{\circ} \mathrm{C}\right)$.

Figure 39. The Stress-Strain Behavior of Samples Tested in SY-103-PIL Based Simulants at $0 \mathrm{mV}$ vs. SCE and at OCP $(-424 \mathrm{mV}$ vs. SCE).

Figure 40. Stereo-Micrograph of the Test Sample from SSRT-57 Performed in SY-103-

PIL Standard Simulant at $50^{\circ} \mathrm{C}, \mathrm{pH} 14$, at a Potential of $0 \mathrm{mV}$ vs. SCE. The yellow dashed circles indicate axial microcracks observed on the shaft of the sample.

Figure 41. Electron-Micrograph of the Fracture Surface of Test Sample from SSRT-57

Performed in SY-103-PIL Standard Simulant at $50^{\circ} \mathrm{C}, \mathrm{pH} 14$, at a Potential of 0 $\mathrm{mV}$ vs. SCE.

Figure 42. A CPP Curve in Deaerated AW-105-PIL Simulant $\left(\mathrm{pH}>13\right.$ and $\left.\mathrm{T}=50^{\circ} \mathrm{C}\right) \ldots \ldots \ldots \ldots . . . . . .52$

Figure 43. A CPP Curve in Deaerated AW-105-PSC Simulant $\left(\mathrm{pH}>13\right.$ and $\left.\mathrm{T}=50^{\circ} \mathrm{C}\right)$..........5 52

Figure 44. Stress-Strain Behavior of Samples Tested in AW-105-PIL Based Simulants at $0 \mathrm{mV}$ vs. SCE and at OCP $(-290 \mathrm{mV}$ vs. SCE).

Figure 45. Stereo-Micrograph of the Test Sample from SSRT-56 Performed in AW-105-PIL Standard Simulant at $50^{\circ} \mathrm{C}, \mathrm{pH} 13+$, at OCP $(-290 \mathrm{mV}$ vs. SCE).

The yellow dashed circles indicate axial microcracks observed on the shaft of the sample.

Figure 46. Electron-Micrograph of the Fracture Surface of Test Sample from SSRT-56 Performed in AW-105-PIL Standard Simulant at $50^{\circ} \mathrm{C}$, pH $13+$, at OCP $(-290 \mathrm{mV}$ vs. SCE).

Figure 47. Electron-Micrograph of an Axial Micro-Crack on the Shaft of Test Sample from SSRT-56 Performed in AW-105-PIL Standard Simulant at $50^{\circ} \mathrm{C}, \mathrm{pH} 13+$, at OCP (-290 mV vs. SCE).

Figure 48. Electron-Micrograph of the Fracture Surface of Test Sample from SSRT-58

Performed in AW-105-PIL Standard Simulant at $50^{\circ} \mathrm{C}, \mathrm{pH} 13+$, at $0 \mathrm{mV}$ vs.

SCE.

Figure 49. Stereo-Micrograph of the Shaft of Test Sample from SSRT-58 Performed in AW-105-PIL Standard Simulant at $50^{\circ} \mathrm{C}$, pH 13+, at $0 \mathrm{mV}$ vs. SCE. ............................56

Figure 50. Stress-Strain Behavior of Samples Tested in AW-105-PSC "6X" Simulant at

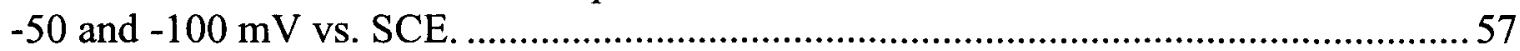

Figure 51. Photograph of the Test Sample from SSRT-74 Performed in AW-105-PSC 6X Simulant at $50^{\circ} \mathrm{C}, \mathrm{pH} 13+$, at a Potential of $-100 \mathrm{mV}$ vs. SCE.

Figure 52. Electron-Micrograph of the Fracture Surface of Test Sample from SSRT-74 Performed in AW-105-PSC 6 X Simulant at $50^{\circ} \mathrm{C}$, pH $13+$, at a Potential of -100 $\mathrm{mV}$ vs. SCE.

Figure 53. Stereo-Micrograph of the Test Sample from SSRT-75 Performed in AW-105-PSC $6 \mathrm{X}$ Simulant at $50^{\circ} \mathrm{C}, \mathrm{pH} 13+$, at a Potential of $-50 \mathrm{mV}$ vs. SCE. .58

Figure 54. Stress-Strain Behavior of Samples Tested in AN-107 Based Simulants at various potentials. 
Figure 55. Electron-Micrograph of the Fracture Surface of Test Sample from SSRT-48

Performed in AN-107 Standard Simulant at $50^{\circ} \mathrm{C}, \mathrm{pH} 11$, at a Potential of -765

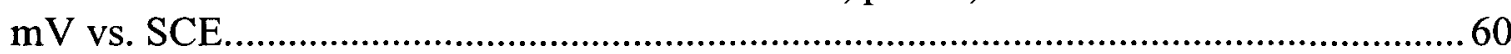

Figure 56. CPP Curve in Deaerated $\mathrm{AZ}-102$ Simulant $\left(\mathrm{pH}>12\right.$ and $\left.\mathrm{T}=77^{\circ} \mathrm{C}\right) \ldots \ldots \ldots \ldots \ldots \ldots \ldots . . . \ldots 1$

Figure 57. The Stress-Strain Behavior of the Sample Tested in AZ-102 Simulants at OCP (-239 $\mathrm{mV}$ vs. SCE).

Figure 58. Electron-Micrograph of the Fracture Surface of Test Sample from SSRT-61

Performed in AZ-102 Simulant at $77^{\circ} \mathrm{C}$, pH $12+$, at a Potential of $-239 \mathrm{mV}$ vs.

SCE.

Figure 59. CPP curves in deaerated SY-101 simulant at $\mathrm{pH} 13+$ and $50^{\circ} \mathrm{C}$

Figure 60. Stress-Strain Behavior of the Sample Tested in SY-101 Simulant at OCP

( $-206 \mathrm{mV}$ vs. SCE).

Figure 61. Electron-Micrograph of the Fracture Surface of Test Sample from SSRT-67

Performed in SY-101 Simulant at 50, $\mathrm{pH} \mathrm{13+}$, at a Potential of $-206 \mathrm{mV}$ vs.

SCE.

Figure 62. A Comparison of CPP Curves in the Deaerated AY-101-CSL Simulant at

Different $\mathrm{pH}$ Levels and Temperatures.

Figure 63. Appearance of the Sample after CPP test in the Deaerated AY-101-CSL

Simulant at $50^{\circ} \mathrm{C}$ and $\mathrm{pH}$ 11.8. (a) Before Cleaning; (b) After cleaning.

Figure 64. The Appearance of the Sample after CPP Test in AY-101-CSL Simulant at pH 12.3 and $50^{\circ} \mathrm{C}$.

Figure 65. Stress-Strain Behavior of the Sample Tested in AY-101-CSL Simulant at OCP (-181 mV vs. SCE).

Figure 66. Electron-Micrograph of the Fracture Surface of Test Sample from SSRT-69 Performed in AY-101-CSL Simulant at $50^{\circ}, \mathrm{pH} 11.8$, at a Potential of $-181 \mathrm{mV}$ vs. SCE.

Figure 67. Plot of DCPD Calculated Crack Length as a Function of Time for CT-17

Performed in $5 \mathrm{M} \mathrm{NaNO}_{3}$ at Open Circuit Potential. The Displacement was Held

Constant Following Loading to a Nominal K $\sim 25 \mathrm{ksi}$ in.

Figure 68. Load as a Function of Time for CT-17 Performed in $5 \mathrm{M} \mathrm{NaNO}_{3}$ at Open Circuit Potential. The Displacement was Held Constant Following Loading to a Nominal $\mathrm{K} \sim 25 \mathrm{ksi} \backslash \mathrm{in}$.

Figure 69. Plot of DCPD Calculated Crack Length as a Function of Time for CT-18 Performed in AY-101-PSC Simulant at $0 \mathrm{mV}$ vs. SCE. The Displacement was Held Constant Following Loading and Adjustment to a Nominal $\mathrm{K} \sim 45 \mathrm{ksi}$ in.

Figure 70. Load as a Function of Time for CT-18 Performed in AY-101-PSC Simulant at $0 \mathrm{mV}$ vs. SCE. The Displacement was Held Constant Following Loading and Adjustment to a Nominal $\mathrm{K} \sim 45 \mathrm{ksi}$ in.

Figure 71. Electron-Micrograph of the Fracture Surface of Test Sample from CT-17 Performed in $5 \mathrm{M} \mathrm{NaNO} 3$ at $50^{\circ}$, at $\mathrm{OCP}(+107 \mathrm{mV}$ vs. SCE $)$. The sample was held at a constant displacement for $\sim 80$ days following a constant displacement rate slow loading to a nominal $\mathrm{K}$ of $25 \mathrm{ksi}$ in.

Figure 72. Electron-Micrograph of the Fracture Surface of Test Sample from CT-18 Performed in AY-101 Simulant at $50^{\circ}$, at $0 \mathrm{mV}$ vs. SCE. The sample was held at a constant displacement for $\sim 150$ days following a constant displacement rate slow loading to a nominal $\mathrm{K}$ of $45 \mathrm{ksi}$ in. 
Figure 73. Susceptibility of Materials to Pitting Corrosion as a Function of Nitrite and Nitrate Concentration. The Symbols Represent Various Simulant Chemistries

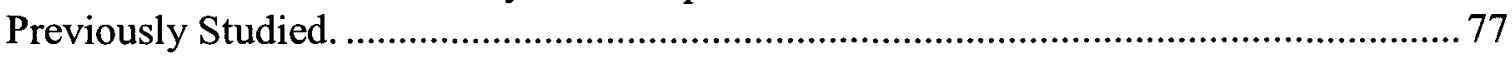

Figure 74. Estimated CGR vs. Potential in the Investigated Simulants.

Figure 75. A Plot of Nitrite/nitrate Ratio vs. Applied Test Potential Indicating

Conditions for SCC Susceptibility. Only Nitrate Based simulant Results Are Included.

\section{LIST OF TABLES}

Table 1. A List of the Concentrations of the Main Constituents in Different Simulants. ......... 13

Table 2. Chemical Specifications for AAR TC128 Grade B Tank Car Steel.......................... 14

Table 3. Mechanical Specifications for AAR TC128 Grade B Tank Car Steel. ...................... 14

Table 4. The Concentrations of Chemicals Used in Preparation of the Simulants................... 19

Table 5. A Summary of Electrochemical Tests Performed in AP-105-PSC Based

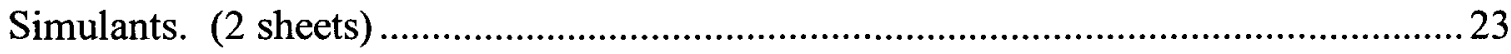

Table 6. The Bulk pH Values of the Simulant after the Long-Term Immersion Tests. ............. 38

Table 7. The Equilibrium Potential of Nitrite and Nitrate Redox Couple as a Function of

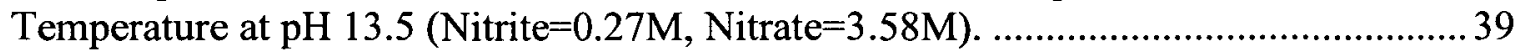

Table 8. A Summary of Slow Strain Rate Tests Performed in AP-105 Based Simulants.......... 42

Table 9. A Summary of Electrochemical Test Performed in SY-103-PIL Based

Simulant.

Table 10. A Summary of Slow Strain Rate Tests Performed in SY-103-PIL Based

Simulants

Table 11. A Summary of Electrochemical Test Performed in AW-105 Based Simulant...........51

Table 12. A Summary of Slow Strain Rate Tests Performed in AW-105 Based

Simulants....

Table 13. A Summary of Slow Strain Rate Tests Performed in AN-107 Based

Simulants

Table 14. A Summary of Electrochemical Test Performed in AZ-102 Based Simulant............61

Table 15. A Summary of Slow Strain Rate Tests Performed in AZ-102 Simulant................... 62

Table 16. A Summary of Electrochemical Test Performed in SY-101 Based Simulant. ............63

Table 17. Summary of Slow Strain Rate Tests Performed in SY-101 Simulants......................64

Table 18. Summary of Electrochemical Test Performed in AY-101-CSL Based

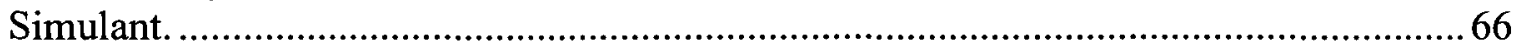

Table 19. A Summary of Slow Strain Rate Tests Performed in AY-101-CSL Simulant...........68

Table 20. A Summary of the Dynamic-K Tests Performed................................................... 70

Figure B-17. A Comparison of the CPP Curves Obtained with and without Using a

Crevice Former (AP105-PSC, $\mathrm{pH}>13, \mathrm{~T}=50^{\circ} \mathrm{C}$ )

Table B-3. A Summary of Electrochemical Test Performed in SY103-PIL Based

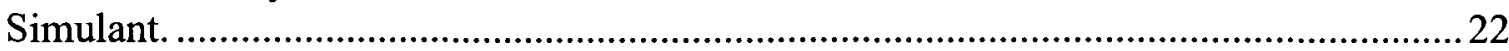

Table B-4. A Summary of Electrochemical Test Performed in AW105 Based Simulant......... 22

Table B-5. A Summary of Electrochemical Test Performed in AZ102 Based Simulant. .........23

Table B-6. A Summary of Electrochemical Test Performed in SY101 Based Simulant. .......... 24

Table B-7. A Summary of Electrochemical Test Performed in AY101-CSL Based

Simulant. 


\section{LIST OF TERMS}

\section{Abbreviations and Acronyms}

AAR TC

ASTM

CGR

CPP

CT

DCPD

DI

DOE

$\mathrm{K}_{\mathrm{ISCC}}$

$\mathrm{K}_{\text {th }}$

$\mathrm{K}_{\mathrm{thSCC}}$

OCP

PIL

PSC

$\mathrm{SCC}$

SCE

SEM

SSR

SSRT

TIC

\section{Units}

${ }^{\circ} \mathrm{C}$

${ }^{\circ} \mathrm{F}$

$\mathrm{h}$

in.

ksi

ksi $\sqrt{\text { in }}$

$\mathrm{M}$

$\mathrm{mM}$

$\mathrm{mV}$

sec
American Association of Railways Tank Car

American Society for Testing and Materials

Crack Growth Rate

Cyclic Potentiodynamic Polarization

Compact Tension

Direct Current Potential Drop

Deionized

U.S. Department of Energy

Stress intensity factor for stress corrosion cracking

Threshold stress intensity factor

Threshold stress intensity factor for stress corrosion cracking

Open Circuit Potential

Present Interstitial Liquid

Present Supernate Composition

Stress Corrosion Cracking

Saturated Calomel Electrode

Scanning Electron Microscope

Slow Strain Rate

Slow Strain Rate Test

Total Inorganic Carbon

degrees Celsius

degrees Fahrenheit

hour

inch

kilopounds per square inch

ksi square root inch

molarity

milli-molar

millivolt

second 


\subsection{INTRODUCTION AND BACKGROUND}

The Hanford tank reservation contains approximately 50 million gallons of liquid legacy radioactive waste from cold war weapons production that is stored in 177 underground storage tanks. Current plans call for vitrification of the waste and final disposal in a geologic repository at Yucca Mountain. The carbon steel DSTs presently used for storage will continue in operation until a vitrification plant is constructed and waste processing operations are completed.

The waste chemistries in the storage tanks are grouped according to their main constituents, such as nitrite/nitrate-based and carbonate-based chemistries. Most of the wastes are highly alkaline in nature, typically with $\mathrm{pH}$ values between 12 and 14 . Under alkaline conditions, carbon steels will tend to be passive and undergo relatively slow rates of uniform corrosion. However, carbon steels can become susceptible to localized corrosion (e.g., pitting) and SCC in the presence of certain aggressive constituents, such as chloride and nitrate, even in these passive conditions ${ }^{1}$. The original Single-Shell Tanks (SSTs) at Hanford experienced some SCC failures because of the presence of high concentrations of nitrate in the waste and high residual stresses near the welds in the tanks. Research at Hanford and Savannah River Laboratories demonstrated that cracking could be prevented by post weld heat treating the tanks and maintaining the waste at a high $\mathrm{pH}(>13)$, which were practices incorporated into construction and operation of the tanks respectively. Although most wastes stored in the DSTs are currently within specification and will remain within specification for the next 20 years, there will be cases in which the chemistry will be out of specification (i.e., $\mathrm{pH}$ levels below 12). This transformation is a result of waste chemistries changing over time due to various chemical reactions taking place inside the tanks. These out of specification conditions could also develop during waste transfer and mixing operations. Thus, there is concern within DOE, oversight groups, and regulatory bodies that tank integrity could be compromised given these chemistry changes. If tank integrity is threatened, there is a need to define mitigation strategies. Additional resources would be required to mitigate potential leaks as well as conduct repairs.

Thus far, research has been conducted with waste simulants for Tanks 241-AN-107 (AN-107), 241-AN-102 (AN-102), 241-AY-101 (AY-101) and 241-AY-102 (AY-102) using the simulants developed for the wastes in these tanks. The AN-107, AN-102, and AY-101 simulants have nitrate-based chemistries with high concentrations of nitrite and nitrate (typically $>1.3 \mathrm{M}$ nitrate). The AY-102 stimulant has a carbonate-based chemistry as the carbonate concentration is considerably higher than the nitrite and nitrate concentrations (typically in the order of $1 \mathrm{M}$ carbonate, vs. mM nitrate concentration).

Research conducted at $\mathrm{CC}$ Technologies in $\mathrm{AN}-107^{2}$ simulants revealed that a nitrite concentration above $1 \mathrm{M}$ considerably reduced the susceptibility of carbon steel to pitting corrosion and SCC. Although the current $\mathrm{pH}$ value of the interstitial liquid in the salt cake/sludge in AN-107 is out of specifications ( $\mathrm{pH} 11$ rather than 13), the laboratory testing demonstrated that the $\mathrm{pH}$ did not have a significant impact on either localized corrosion or SCC

\footnotetext{
${ }^{1}$ R. N. Parkins, and R. Usher, The Effect of Nitrate Solutions in Producing Stress Corrosion Cracking in Mild Steel, Proceedings Frist International Congress on Metallic Corrosion. London, U.K.: Butterworths (1962): 296-302.

${ }^{2}$ Hanford Tanks 241-AN-107 and 241-AN-102: Effect of Chemistry and Other Variables on Corrosion and Stress Corrosion Cracking, CC Technologies Inc, September 8, 2006.
} 
of carbon steel in the range of 10 to 13.5 . SCC was commonly observed at an applied potential of $-100 \mathrm{mV}$ (vs. SCE) or above. This potential range is more positive than the OCP of the steel in the simulants. Furthermore, the concentration of the corrosion and SCC inhibitor nitrite is gradually increasing in the $\mathrm{AN}-107$ waste from the initial concentration of $1.2 \mathrm{M}$ to $2.3 \mathrm{M}$ in the predicted endpoint chemistry. Thus, the tank chemistry in AN-107 is self-inhibiting owing to the increasing nitrite concentration with time. The implication of this research is that adjustments to the $\mathrm{pH}$ of the interstitial liquid in the salt cake/sludge to high levels is unnecessary (specifications stipulate $\mathrm{pH}$ between 12 and 14). Applications of these findings to interstitial liquid was immediate, but changes to control of the supernate liquid will only be possible if it can be shown that corrosion at the liquid/air interface and vapor space will be unaffected.

The work in AY $-101^{3}$ and AY-102 $2^{4}$ simulants indicated that these chemistries were largely benign with respect to localized corrosion. As with the AN-107 simulants, nitrite is a potent inhibitor to localized corrosion for these simulants. In nitrate-based AY-101, SCC was observed only at relatively high applied potentials (e.g., $0 \mathrm{mV}$ vs. SCE). In carbonate-based AY-102, however, SCC was observed both at high potentials ( $0 \mathrm{mV}$ vs. SCE) and at potentials near $-800 \mathrm{mV}$ vs. SCE where an active-passive transition was noted on CPP curves. Fortunately, corrosion potential monitoring of steel in the carbonate-based simulants suggested that the OCP of the steel will be far more positive than $-800 \mathrm{mV}$ vs. SCE. These results indicated the necessity to monitor the corrosion potential of the tank wall.

In the present work, the localized and SCC corrosion behavior of steel in waste simulants for Tanks 241-AP-105 (AP-105), 241-SY-103 (SY-103), 241-AW-105 (AW-105), 241-AZ-102 (AZ-102), 241-SY-101 (SY-101), AN-107 and AY-101 were investigated. The AP-105- PSC contains high nitrate $(3.58 \mathrm{M})$ and low nitrite $(0.27 \mathrm{M})$ concentrations. It has the lowest nitriteto-nitrate concentration ratio among all simulants that have been investigated thus far. The SY103 and AW-105 PILs (SY-103-PIL and AW-105-PIL) represent wastes with bounding chloride $(0.5 \mathrm{M})$ and fluoride $(0.58 \mathrm{M})$ levels, respectively. Chloride is known to contribute to pitting behavior in steels. Fluoride is expected to be detrimental to the tank steel as well. The AW-105 simulant has low nitrite $(0.12 \mathrm{M})$ and nitrate $(0.42 \mathrm{M})$ concentrations, whereas the SY-103 simulant is high in both nitrite $(2.91 \mathrm{M})$ and nitrate $(1.97 \mathrm{M})$. These differences are expected to have a significant influence on the corrosion and SCC behavior of the tank steel. The various chemistries of simulants investigated in this work are listed in Table 1 and compared with other chemistries studied previously.

The SY-101 simulant also has a low nitrite-to-nitrate concentration ratio and raised a concern for the susceptibility of the tank steel to localized corrosion and SCC. The AN-107 simulant was previously studied to examine its propensity for corrosion. The simulant was investigated to test susceptibility to carbonate SCC because of the high carbonate concentration of $1.4 \mathrm{M}$. The AZ-102 simulant represents a tank chemistry at the other extreme: the nitrite-to-nitrate ratio is a relatively high 8.4 , with a nitrate content of $0.105 \mathrm{M}$ and a nitrite content of $0.883 \mathrm{M}$. The

\footnotetext{
${ }^{3}$ Hanford Tank AY-101: Effect of Chemistry and Other variables on Corrosion and Stress Corrosion Cracking, CC Technologies Inc, January 2008.

${ }^{4}$ Hanford Tanks AY-102 and AP101: Effect of Chemistry and Other Variable on Corrosion and Stress Corrosion Cracking, CC Technologies, September $7^{\text {th }} 2007$.
} 
supernate and interstitial liquid in Tank 241-AY-101 was investigated in previous programs. In this work, the condensate surface layer (CSL) in Tank AY-101 (AY-101-CSL), which has a relatively low nitrite-to-nitrate ratio $(0.2)$, was studied.

This report summarizes the results obtained for the chemistries described above. The scope of the test program includes a series of CPP, SSRTs, and CGR tests on a plate of AAR TC 128 Grade B steel. AAR TC128 Grade B steel has similar properties to the steels used in constructing the DSTs.

The results from this work in conjunction with those obtained in other previous research programs for other tanks will help expand understanding of the roles of nitrite and nitrate (both absolute concentrations and ratio), and the roles of high chloride and fluoride in the corrosion process. Based on these results, strategies may be formulated about possible mitigation schemes.

Table 1. A List of the Concentrations of the Main Constituents in Different Simulants.

\begin{tabular}{|c|c|c|c|c|c|c|c|c|c|c|}
\hline Acronym & Simulant & $\mathrm{AlO}_{2}^{-}$ & $\mathrm{SO}_{4}{ }^{2-}$ & $\mathrm{NO}_{2}^{-}$ & $\mathrm{NO}_{3}^{-}$ & TIC & $\mathrm{Cl}^{-}$ & $\mathbf{F}^{-}$ & $\mathbf{O H}^{-}$ & $\mathbf{p H}$ \\
\hline AY-102-PIL & Present Interstitial Liquid & 0.002 & 0.018 & 0.001 & 0.002 & 1.021 & 0.004 & 0.003 & 0.001 & 11 \\
\hline AP101-TSC & $\begin{array}{l}\text { Transferred Supernatant } \\
\text { Composition }\end{array}$ & 0.31 & 0.029 & 0.98 & 2.13 & 0.47 & 0.05 & 0.09 & 2.61 & $14+$ \\
\hline AY-102-CSC & $\begin{array}{l}\text { Combined Supernatant } \\
\text { Composition }\end{array}$ & 0.29 & 0.028 & 0.938 & 1.967 & 0.477 & 0.046 & 0.084 & 2.42 & $14+$ \\
\hline AY-102-ACS & Aged Combined Supernatant & 0.29 & 0.028 & 1.27 & 1.635 & 1.118 & 0.046 & 0.084 & 1.24 & $14+$ \\
\hline AY-102-AIL & Aged Interstitial Liquid & 0.002 & 0.009 & 0.001 & 0.002 & 0.935 & 0.004 & 0.003 & 0.001 & 11 \\
\hline AY-102-ATL & Aged Total Liquid & 0.37 & 0.027 & 1.20 & 1.532 & 1.242 & 0.043 & 0.079 & 0.96 & $14+$ \\
\hline AY-101-PIL & Present Interstitial Liquid & - & 0.305 & 0.847 & 0.057 & 1.842 & 0.011 & 0.068 & 0.001 & 11 \\
\hline AY-101-PSC & Present Supernatant Composition & 0.107 & 0.020 & 0.205 & 1.33 & 0.201 & 0.018 & 0.014 & 0.71 & $13+$ \\
\hline AP-105-PSC & Present Supernatant Composition & 0.15 & 0.047 & 0.270 & 3.58 & 0.326 & 0.03 & 0.009 & 0.18 & $13+$ \\
\hline SY-103-PIL & Present Interstitial Liquid & 2.06 & 0.017 & 2.91 & 1.97 & 0.123 & 0.50 & - & 2.43 & 14 \\
\hline AW-105-PIL & Present Interstitial Liquid & 0.02 & 0.014 & 0.12 & 0.42 & 0.097 & 0.01 & 0.58 & 0.45 & $13+$ \\
\hline $\begin{array}{l}\text { AP-105- } \\
\text { Mixed }\end{array}$ & Mixed Simulant & 0.195 & 0.04 & 0.413 & 2.857 & 0.274 & 0.039 & 0.026 & 0.95 & $13+$ \\
\hline $\begin{array}{l}\text { AP-105- } \\
\text { Evaporated }\end{array}$ & Evaporated Simulant & 0.347 & 0.072 & 0.736 & 5.087 & 0.489 & 0.069 & 0.047 & 1.67 & 14 \\
\hline AZ-102 & AZ-102 Simulant & 0.007 & 0.186 & 0.883 & 0.105 & 0.619 & - & 0.0520 & - & $12+$ \\
\hline AW-105-PSC & Present Supernate Composition & 0.0065 & 0.005 & 0.064 & 0.44 & 0.108 & 0.008 & 0.156 & 0.26 & $13+$ \\
\hline SY-101 & SY-101 Simulant & 0.1407 & 0.02 & 0.203 & 0.931 & 0.133 & 0.023 & 0.028 & 0.66 & $13+$ \\
\hline AY-101-CSL & Condensate Surface Layer & 0.0153 & 0.002 & 0.037 & 0.181 & 0.147 & 0.006 & 0.002 & 0.005 & 11.82 \\
\hline
\end{tabular}




\subsection{EXPERIMENTAL APPROACH}

\subsection{MATERIALS AND SPECIMENS}

All test specimens were fabricated from a $2^{\prime} \times 2^{\prime} \times 1^{\prime \prime}$ as-supplied plate of AAR TC Grade B steel. This is similar in composition and mechanical properties to the A515 Grade 60 steel used in the Hanford AY-101 double-shelled underground storage tank construction. The plate was supplied to $\mathrm{CC}$ Technologies by ARES Corporation. Chemical and mechanical specifications for AAR TC 128 Grade B tank car steel are shown in Table 2 and Table 3, respectively; however, no efforts were made to confirm these values. Figure 1 (a) shows a photomicrograph of the AAR TC128 Grade B Tank Car Steel used in this investigation. This steel was also used in previous AY-102, AP101, and AY-101 work. For comparison, Figure 1 (b) shows the microstructure of the American Society for Testing and Materials (ASTM) A537 Class 2 steel used previously for Tank 241-AN-105 and AN-107 work. The most significant difference between the two microstructures is the presence of pearlite bands in the tank car steel which is commonly observed in hot rolled steels.

Table 2. Chemical Specifications for AAR TC128 Grade B Tank Car Steel.

\begin{tabular}{|c|c|c|c|c|c|c|c|}
\hline \multicolumn{10}{|c|}{ Element } \\
\hline & C & Mn & P & S & Si & Cu & Fe \\
\hline Max. & 0.50 & 1.35 & 0.040 & 0.05 & 0.30 & 0.35 & balance \\
\hline Min. & -- & -- & -- & -- & -- & -- & -- \\
\hline
\end{tabular}

Table 3. Mechanical Specifications for AAR TC128 Grade B Tank Car Steel.

\begin{tabular}{|c|c|c|c|}
\hline & $\begin{array}{c}\text { Ultimate Tensile Strength } \\
\text { (psi) }\end{array}$ & $\begin{array}{c}\mathbf{0 . 2 \%} \text { Offset } \\
\text { Yield Strength (psi) }\end{array}$ & $\begin{array}{c}\text { Elongation } \\
\text { in 2" (\%) }\end{array}$ \\
\hline Max. & 101,000 & -- & -- \\
\hline Min. & 81,000 & 50,000 & 21.0 \\
\hline
\end{tabular}


Figure 1. Photomicrographs of (a) the Microstructure of the AAR TC 128

Grade B Tank Car Steel Used for the Current Work and Previous

AY-102 and AP101 Work, and (b) the Microstructure of the ASTM A537

Class 2 Steel used for Previous AN-105 and AN-107 Work.

(a)

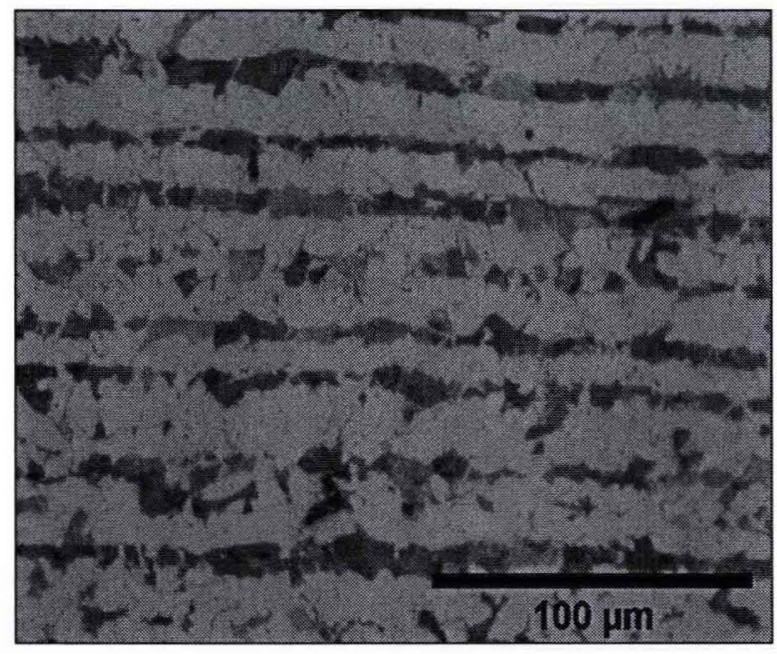

(b)

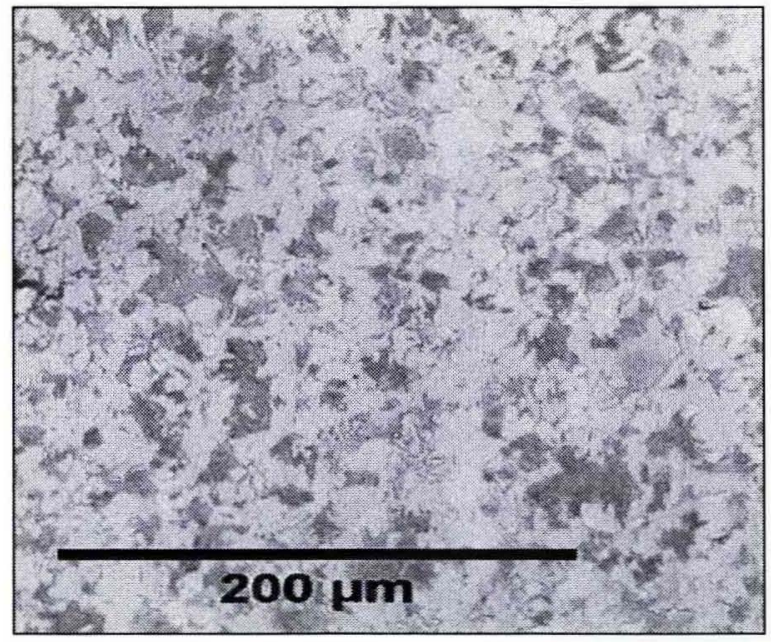

Three main specimen geometries were utilized in this work. A schematic representation of the CPP specimens, SSRT specimens, and CGR specimens are shown in Figure 2, Figure 3, and Figure 4, respectively. The specimens were fabricated by Metal Samples Company in Munford, AL and Metcut Research, Inc., in Cincinnati, Ohio. Material close to the flame cuts at the edges of the plates was avoided for specimen fabrication to ensure consistent microstructures. SSRT specimens were fabricated such that the longitudinal axis was aligned with the plate rolling direction (i.e., longitudinal orientation). Compact tension (CT) specimens were fabricated such that the pre-crack was in the plate rolling direction (i.e., transverse-longitudinal orientation). 
Figure 2. Engineering Drawing of the Cyclic Potentiodynamic Polarization (CPP) Specimen (Units in Inches).

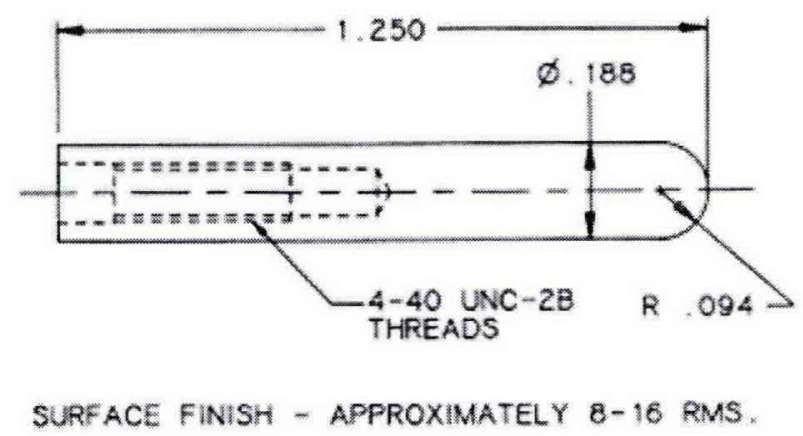

Figure 3. Engineering Drawing of the Slow Strain Rate Test Specimen (Units in Inches).

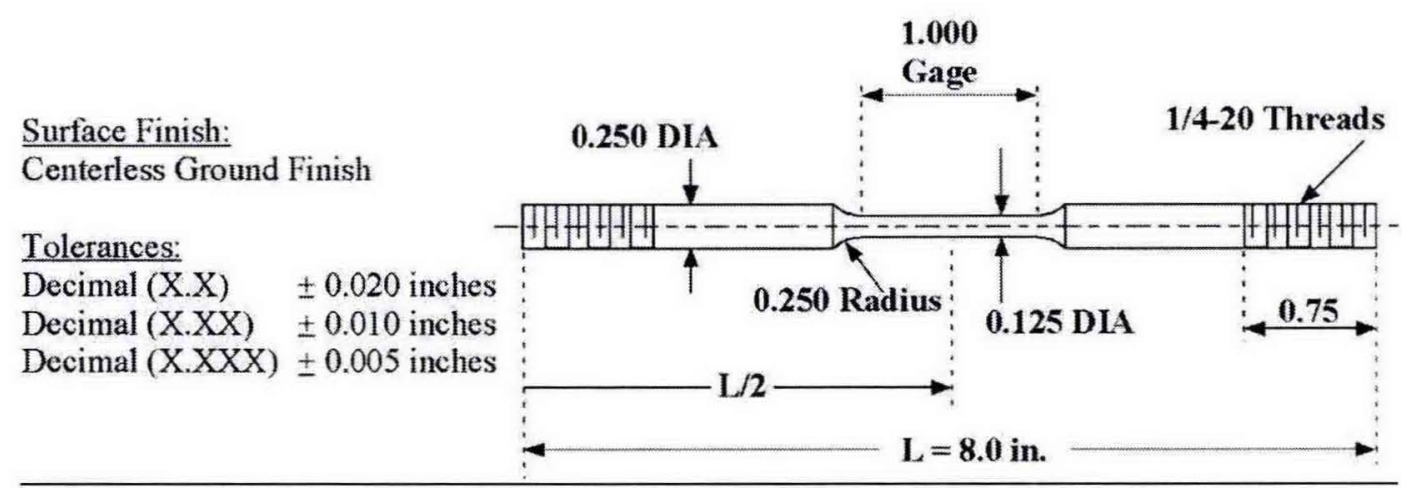

Figure 4. Engineering Drawing of the Crack Growth Rate Specimen (Units in Inches).
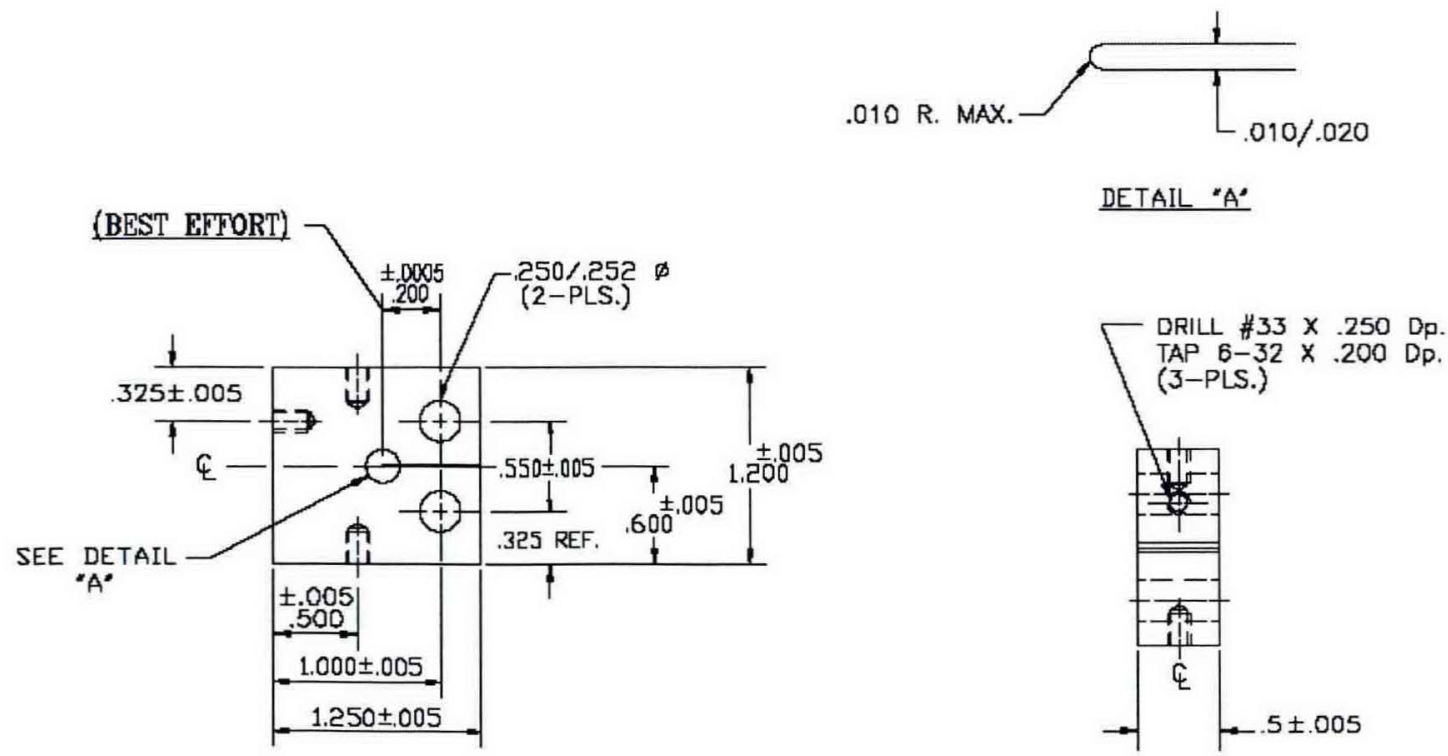
The dimensions of the CT specimens shown in the figure below are a standard size, and consistent with the dimensions used for CT samples in previous constant load experiments. Constant displacement rate tests previously used were again employed to determine the CGR and the threshold stress intensity for SCC $\left(\mathrm{K}_{\mathrm{thSCC}}\right)$. All specimens were side-grooved (Figure 5) following the guidelines provided in ASTM E1820-06 $1^{5}$ to ensure crack growth did not diverge significantly from the pre-crack direction and to promote plane strain conditions. This standard recommends a total reduction in cross-section of the crack plane of $20 \%$ of the width of the test sample, with an included angle of $90^{\circ}$ or less, and a root radius of $<=0.02 \pm 0.01$ in. Figure 5 shows a digital photograph of the CT sample machined with side-grooves.

Figure 5. A Photograph of One of the CGR Specimens Following Side-Grooving.

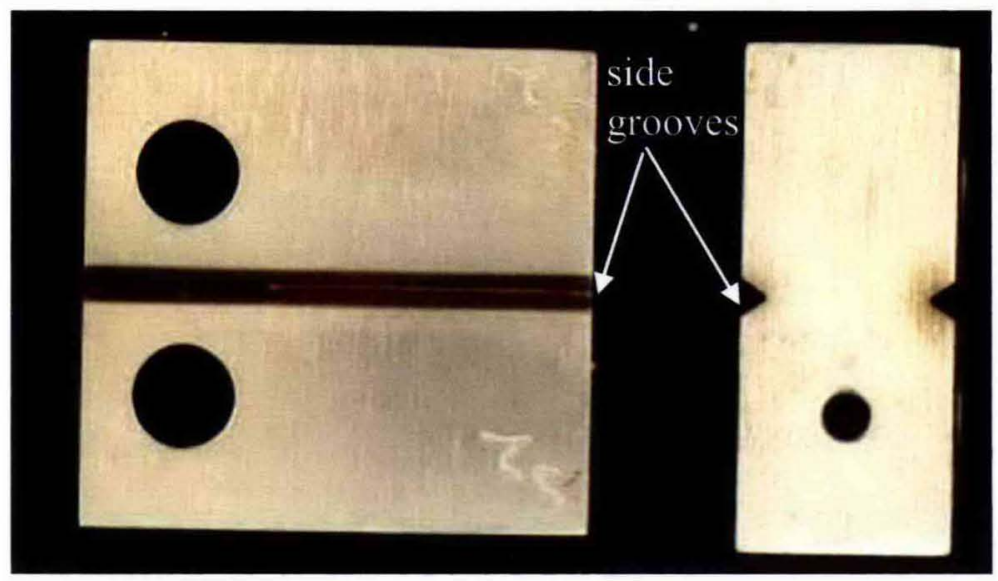

\subsection{CHEMICALS AND SOLUTIONS}

The chemistries used in this work with AP-105, SY-103 and AW-105 were "present" chemistries. The aged chemistries for the tanks studied are not expected to be significantly different from the present chemistries due to the small concentration of organic carbon compounds $(0.05 \mathrm{M})$. That is, the oxidation of organic carbon compounds, when present at such low quantities, will not significantly alter the carbonate, hydroxide, nitrate, or nitrite concentrations. The presence and concentration of these species are believed to play critical roles in the corrosivity of the simulants.

As stated previously, the simulants that were chosen for evaluation were selected to bind the effects of various tank chemistry compositions, such as the effects of chloride, fluoride, and nitrite/nitrate ratio. All of the simulants are considered chemically stable and did not require continuous agitation prior to being used. The $\mathrm{pH}$ of each simulant was adjusted after initial mixing using either sodium hydroxide (Noah), or nitric acid $\left(\mathrm{HNO}_{3}\right)$ or acetic acid $\left(\mathrm{CH}_{3} \mathrm{COOH}\right)$. If the difference between the measured $\mathrm{pH}$ and the target $\mathrm{pH}$ was large, nitric acid was favored over acetic acid; however, acetic acid was most commonly used because of the small adjustments that were typically required.

\footnotetext{
${ }^{5}$ ASTM E1820-06e1, 2006, Standard Test Method for Measurement of Fracture Toughness, American Society for
} Testing and Materials, ASTM International, West Conshohocken, PA. 
For each simulant a standard chemistry and several modified chemistries were often investigated. The standard chemistry was used to establish the baseline localized corrosion and SCC behavior. The modified chemistries were used to explore the role of certain species, such as nitrite, nitrate, and sulfate, on the localized corrosion and SCC behavior of the material. The chemicals used to mix the baseline simulants (i.e., without modifications) as well as the concentrations used are listed in Table 4. The rows containing some of the key species of interest are shaded. Note that in some cases simulants were mixed using the baseline chemistry, and then $\mathrm{pH}$ balanced. The $\mathrm{pH}$ balance will change the hydroxide concentration, and influence the proportions of carbonate and bicarbonate present in the solution.

\subsection{OPEN CIRCUIT POTENTIAL MONITORING, POTENTIOSTATIC AND CYCLIC POTENTIODYNAMIC POLARIZATION TESTING}

CPP testing was performed according to the guidelines set forth in ASTM G61-86e1. ${ }^{6}$ Samples were either fully immersed or partially immersed in the simulants. When the samples were partially immersed, a liquid/vapor interface was created so that the corrosion phenomena at the interface could be investigated.

Prior to testing, the specimens were prepared to a 600 grit surface finish, ultrasonically cleaned with isopropanol for five minutes, rinsed with DI water, and then dried with nitrogen. Prior to introducing the specimen to the test cell, the test solution was added. In cases where testing above room temperature was conducted, the solution was then heated to the desired temperature $\left(50^{\circ} \mathrm{C}\left[122^{\circ} \mathrm{F}\right]\right.$ or $\left.77^{\circ} \mathrm{C}\left[170^{\circ} \mathrm{F}\right]\right)$. The test solution was then purged with the desired test gas for approximately one hour prior to specimen introduction and testing unless the test was conducted under quiescent conditions. A saturated calomel electrode (SCE) was usually used as the reference electrode with a salt bridge to separate the reference electrode from the testing environment. This was done so that the reference electrode could be maintained at room temperature. In a few limited cases, a $\mathrm{Ag} / \mathrm{AgCl}$ wire reference electrode was used. For tests where polarization was required, a platinized niobium wire was used as the counter electrode.

The OCP, CPP, and potentiostatic tests were performed under two different conditions - (1) quiescent in air conditions (i.e., no gas purging and the cell was open), (2) gas purging conditions (nitrogen, high purity Ar or compressed "zero" air containing no $\mathrm{CO}_{2}$ ). In a set of long-term immersion tests to investigate the susceptibility of the steel to interfacial corrosion in the AP-105-PSC simulants, the head space of the cell was blanketed with compressed "zero" air (no $\mathrm{CO}_{2}$ ), nitrogen or argon so that the mixing of the interface chemistry with the bulk solution could be minimized. The quiescent conditions and compressed air purging aimed to provide oxygen to the simulants, and in many cases were used to investigate the role of oxygen in both CPP and corrosion at the liquid/vapor interface. Nitrogen and argon purging were used to maintain deaerated conditions (i.e., the oxygen reduction reaction was minimized or eliminated). For the deaerated experiments the cathodic reactions were dominated either by other reducible species in the solution (i.e., nitrite or nitrate) or water reduction (assuming the potential was sufficiently negative).

\footnotetext{
${ }^{6}$ ASTM G61-86e1, 2003, Standard Test Method for Conducting Cyclic Potentiodynamic Polarization Measurements for Localized Corrosion Susceptibility of Iron-, Nickel-, or Cobalt-Based Alloys, American Society for Testing and Materials, ASTM International, West Conshohocken, PA.
} 
Table 4. The Concentrations of Chemicals Used in Preparation of the Simulants.

\begin{tabular}{|c|c|c|c|c|c|c|c|c|c|c|}
\hline \multirow[t]{2}{*}{ Chemical } & \multirow[t]{2}{*}{ Formula } & $\begin{array}{l}\text { AP-105- } \\
\text { PSC }\end{array}$ & $\begin{array}{c}\text { AP- } \\
\text { 105- } \\
\text { Mixed } \\
\end{array}$ & $\begin{array}{c}\text { AP-105- } \\
\text { Evaporated }\end{array}$ & $\begin{array}{l}\text { SY-103- } \\
\text { PIL }\end{array}$ & SY-101 & $\begin{array}{c}\text { AW- } \\
\text { 105-PIL }\end{array}$ & $\begin{array}{l}\text { AW-105- } \\
\text { PSC }\end{array}$ & AZ-102 & $\begin{array}{l}\text { AY- } \\
101- \\
\text { CSL }\end{array}$ \\
\hline & & $\begin{array}{c}\text { Molarity } \\
\text { (M) } \\
\end{array}$ & $\begin{array}{c}\text { Molarity } \\
(\mathbf{M})\end{array}$ & Molarity (M) & $\begin{array}{c}\text { Molarity } \\
(\mathbf{M}) \\
\end{array}$ & $\begin{array}{c}\text { Molarity } \\
\text { (M) }\end{array}$ & $\begin{array}{c}\text { Molarity } \\
(\mathbf{M}) \\
\end{array}$ & $\begin{array}{c}\text { Molarity } \\
\text { (M) }\end{array}$ & $\begin{array}{c}\text { Molarity } \\
\text { (M) }\end{array}$ & $\begin{array}{c}\text { Molarity } \\
(\mathbf{M})\end{array}$ \\
\hline Sodium Aluminate: & $\mathrm{NaAlO}_{2} .2 \mathrm{H}_{2} \mathrm{O}$ & 0.15 & 0.195 & 0.3470 & 2.06 & 0.1407 & 0.0160 & 0.0065 & 0.0070 & 0.0153 \\
\hline Sodium Chloride & $2 . \mathrm{NaCl}$ & 0.0308 & 0.039 & 0.0690 & 0.4960 & 0.0228 & 0.0102 & 0.0083 & -2. & 0.0064 \\
\hline Sodium Fluoride & $\mathrm{NaF}$ & 0.0091 & 0.026 & 0.0470 & 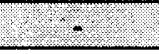 & 0.0277 & 0.5810 & 0.156 & 0.0520 & 0.0015 \\
\hline Sodium Chromate & $\mathrm{Na}_{2} \mathrm{CrO}_{4}$ & 0.0106 & 0.008 & 0.0140 & 0.0010 & 0.0021 & 0.0002 & 0.00004 & 0.0130 & 0.0003 \\
\hline Sodium Phosphate, 12-Hydrate & $\mathrm{Na}_{3} \mathrm{PO}_{4} .12 \mathrm{H}_{2} \mathrm{O}$ & 0.0301 & 0.03 & 0.0530 & 0.0275 & 0.0984 & 0.0032 & 0.0045 & - & 0.0059 \\
\hline Potassium Nitrate & $\mathrm{KNO}_{3}$ & 0.0133 & 0.13 & 0.23 & 0.1280 & 0.0069 & 0.2180 & 0.1444 & 0.0710 & -2 \\
\hline Sodium Sulfate & $\mathrm{Na}_{2} \mathrm{SO}_{4}$ & 0.0472 & 0.04 & 0.072 & 0.0167 & 0.0196 & 0.0139 & 0.0053 & 0.1860 & 0.0021 \\
\hline Sodium Formate & $\mathrm{NaHCOO}$ & 0.0100 & 0.0115 & 0.016 & 0.1880 & - & 0.0033 & 0.0021 & - & - \\
\hline Sodium Acetate Trihydrate & $\mathrm{NaCH}_{3} \mathrm{COO} .3 \mathrm{H}_{2} \mathrm{O}$ & 0.0075 & 0.0105 & - & 0.0439 & - & 0.0062 & 0.0023 & - & - \\
\hline Sodium Oxalate & $\mathrm{Na}_{2} \mathrm{C}_{2} \mathrm{O}_{4}$ & 0.0075 & 0.0115 & 0.016 & 0.0044 & 0.0244 & 0.0032 & 0.0017 & 0.0170 & 0.0014 \\
\hline Sodium Nitrate & $\mathrm{NaNO}_{3}$ & 3.5644 & 2.727 & 4.857 & 1.8400 & 0.9244 & 0.2010 & 0.2956 & 0.0340 & 0.1810 \\
\hline Sodium Nitrite & $\mathrm{NaNO}_{2}$ & 0.2700 & 0.413 & 0.736 & 2.9100 & 0.2027 & 0.1240 & 0.0638 & 0.8830 & 0.0368 \\
\hline Sodium Carbonate & $\mathrm{Na}_{2} \mathrm{CO}_{3}$ & 0.3260 & 0.274 & 0.489 & 0.1230 & 0.1328 & 0.0966 & 0.1076 & 0.6070 & 0.147 \\
\hline Glycolic Acid & $\mathrm{C}_{2} \mathrm{H}_{4} \mathrm{O}_{3}$ & 0.0075 & 0.0115 & - & 0.0334 & - & - & 0.0010 & - & - \\
\hline Sodium Hydroxide & NaOH & 0.1761 & 0.952 & 1.67 & 2.43 & 0.6555 & 0.4502 & 0.2630 & -2 & 0.0051 \\
\hline Cobaltous Nitrate & $\mathrm{Co}\left(\mathrm{NO}_{3}\right)_{2}$ & - & - & - & - & - & 0.0000242 & - & - & - \\
\hline Nickel Nitrate & $\mathrm{Ni}\left(\mathrm{NO}_{3}\right)_{2}$ & - & - & - & - & - & 0.00007 & - & - & - \\
\hline Boric Acid & $\mathrm{H}_{3} \mathrm{BO}_{3}$ & - & - & - & - & 0.0008 & 0.0006 & 0.0003 & - & - \\
\hline Potassium Molybdate & $\mathrm{K}_{2} \mathrm{MoO}_{4}$ & - & - & - & - & - & 0.00003 & 0.00001 & 0.0005 & - \\
\hline Zirconyl Nitrate & $\mathrm{ZrO}\left(\mathrm{NO}_{3}\right)_{2}$ & - & - & - & - & - & 0.0000049 & - & - & - \\
\hline Tributyl phosphate & $\mathrm{C}_{12} \mathrm{H}_{27} \mathrm{O}_{4} \mathrm{P}$ & - & - & - & - & - & 0.0049 & - & - & - \\
\hline 1-Butanol & $\mathrm{C}_{4} \mathrm{H}_{9} \mathrm{OH}$ & - & - & - & - & - & 0.0125 & - & - & - \\
\hline Dibutyl Phosphate & $\mathrm{C}_{8} \mathrm{H}_{19} \mathrm{O}_{4} \mathrm{P}$ & - & - & - & - & - & 0.0125 & - & - & - \\
\hline Ammonium Acetate & $\mathrm{NH}_{4} \mathrm{CH}_{3} \mathrm{COO}$ & - & 0.0040 & 0.008 & - & - & - & - & - & - \\
\hline Iron Nitrate, 9-Hydrate & $\mathrm{Fe}\left(\mathrm{NO}_{3}\right)_{2} \cdot 9 \mathrm{H}_{2} \mathrm{O}$ & - & - & 0.00002 & - & - & - & - & - & - \\
\hline Zinc Nitrate, 6-Hydrate & $\mathrm{Zn}\left(\mathrm{NO}_{3}\right)_{2} \cdot 6 \mathrm{H}_{2} \mathrm{O}$ & - & - & 0.00007 & - & - & - & 0.00003 & - & - \\
\hline Sodium Bicarbonate & $\mathrm{NaHCO}_{3}$ & - & - & - & - & - & - & - & 0.0120 & - \\
\hline
\end{tabular}


Prior to CPP and potentiostatic testing, the OCP was monitored for 18 hours. The start potential for the CPP tests was $-100 \mathrm{mV}$ vs. OCP. The scan was reversed at $1 \mathrm{~V}$ vs. SCE or if the current reached $1 \mathrm{~mA} / \mathrm{cm}^{2}$. A scan rate of $0.17 \mathrm{mV} / \mathrm{s}(0.6 \mathrm{~V} / \mathrm{h})$ was used. For the potentiostatic testing, the sample was polarized to an anodic potential for the desired amount of time.

When a test was completed, the specimen was removed from the test solution, rinsed with deionized (DI) water, and then dried with nitrogen gas. If visible corrosion products were present on the specimen surface, the specimen was ultrasonically cleaned in acetone for five minutes, rinsed with DI water, and dried with nitrogen. The post-test appearance of the specimen was photographically documented to show any evidence of corrosion attack. In some cases, the test specimen was examined using a scanning electron microscope (SEM) in addition to examination using optical stereomicroscopy. Finally, the tested specimens were stored in separate specimen bags in a desiccator for possible further analysis.

\subsection{SLOW STRAIN RATE TESTING}

All SSRTs were performed according to the guidelines provided in ASTM G129-00 ${ }^{7}$ using cylindrical tensile specimens at a constant extension rate of $10^{-6}$ in/in-s (unless otherwise noted). To perform the tests, the specimen was placed in a Teflon ${ }^{\circledR}{ }^{8}$ test cell and the load was applied using grips that entered the cell through sliding seals. This assembly was then inserted into the load frame, after which the solution of interest was introduced and heated to $50{ }^{\circ} \mathrm{C}$. Tests were conducted at open circuit or at an applied potential against a SCE reference electrode that was maintained at room temperature using a Luggin probe/salt bridge filled with the test solution. A platinum flag was used as a counter electrode. All of the SSRTs were performed under quiescent air conditions; i.e., exposed to air with no gas sparging.

The test specimens were pulled to failure. The stress-strain curves provided in the following results sections are for reference purposes. However, the time-to-failure and the strain-at-failure of the specimens did not always clearly indicate the presence of SCC. Also, the degree of SCC was not easily established from these parameters. Therefore, the occurrence of SCC was always confirmed by both visual inspection and SEM examination. Examination of the specimens after failure consisted of examination in a stereographic optical microscope at $10-63 \mathrm{x}$, and a SEM. The fracture surface of each of the test samples was examined using the SEM to identify regions of intergranular fracture, indicative of high $\mathrm{pH} \mathrm{SCC}$.

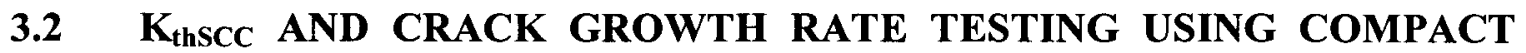 TENSION SPECIMENS}

$\mathrm{K}_{\text {thSCC }}$ and CGR tests were performed using pre-cracked $1 / 2-\mathrm{T}$ ( 0.5 inch wide) $\mathrm{CT}$ specimens (Figure 5). The objective of these tests was to determine the $\mathrm{K}_{\mathrm{thSCC}}$ for the steel in various

\footnotetext{
${ }^{7}$ ASTM G129-00, 2006, Standard Practice for Slow Strain Rate Testing to Evaluate the Susceptibility of Metallic Materials to Environmentally Assisted Cracking, American Society for Testing and Materials, ASTM International, West Conshohocken, PA.

${ }^{8}$ Teflon ${ }^{\circledR}$ is a registered trademark of DuPont in the United States and other countries.
} 
simulants. The $\mathrm{K}_{\mathrm{thSCC}}$ could then be related to the maximum $\mathrm{K}_{\mathrm{I}}$ expected for a variety of flaw sizes in the tank. This would aid in the determination as to whether or not there is an integrity concern for the tank. The CGRs estimated in these tests can also be used to approximate the time for any growing flaw to go through-wall. The term $\mathrm{K}_{\text {thSCC }}$ refers to a "threshold." The term $\mathrm{K}_{\mathrm{ISCC}}$ is not used because the test procedure utilized for this investigation does not satisfy the requirements of ASTM E1820. In particular, samples were not wide enough to ensure plane strain conditions, which are necessary for a valid $\mathrm{K}_{\mathrm{ISCC}}$ determination.

Previous tank chemistry studies had been performed using a constant tensile load. Constant tensile load testing was not performed in the current investigation because of the difficulties associated with the determination of $\mathrm{K}_{\text {thSCC }}$ in tank waste simulants with this technique. Results from previous testing showed some inconsistencies in estimated $\mathrm{K}_{\mathrm{thSCC}}$ from the different tests. In some cases, direct current potential drop (DCPD) indicated negative crack growth due to build up of corrosion product in the crack mouth. To avoid the difficulties, the approach was modified to a "dynamic-K" test. The dynamic K-tests were initiated with a constant displacement rate rather than a constant load. At the onset of cracking or a predefined $K$, the displacement was held constant for several weeks or months. Tests were concluded when evidence of crack growth and a declining $\mathrm{K}$ were observed or a sufficient length of time had elapsed ( $\sim 5$ months) to imply no cracking in the test sample. The advantage of the technique is that both $\mathrm{K}_{\text {thSCC }}$ and CGR can be estimated from the same test data, provided that some crack growth occurs during the test.

The dynamic-K tests were performed using the same loading frames as those used in the SSRTs. The dynamic-K tests were run at approximately $5 \times 10^{-8} \mathrm{in} / \mathrm{s}$, which was substantially slower than the nominal extension rate of $10^{-6} \mathrm{in} / \mathrm{s}$ used for SSRTs. The time frame for the dynamic load experiments ranged from several weeks to several months because of the slow loading rate to a specified $\mathrm{K}$ value and longer hold time. Comparatively, the constant load tests typically concluded within 30 days.

Dynamic-K experiments were conducted at $50^{\circ} \mathrm{C}$ in Teflon cells that contained the desired solutions. Tests were carried out either at open circuit or an applied potential. The OCPs were continuously monitored with a high impedance voltmeter and a reference electrode (SCE). The reference electrode was maintained at room temperature in a separate container that was connected to the test cell by means of a Luggin probe/salt bridge filled with the test solution. For the tests at applied potential, a platinum flag counter electrode was included in the test cell while a potentiostat was used to maintain the potential at the desired value.

The applied load and displacement for the test samples were monitored and recorded continuously throughout the experiments. Additionally, the DCPD was monitored as a means to estimate crack growth in situ. The DCPD technique involves the application of a constant current (in this case 20A) through the specimen while the potential drop across the two sides of the crack is recorded. Any crack propagation during the test will increase the resistance across the sample and this will be reflected by a change in potential drop. The increase in crack length is calculated from the potential drop and sample geometry using the Johnson equation?

\footnotetext{
9 Johnson, H. H. "Calibrating the Electric Potential Method for Studying Slow Crack Growth," Materials Research and Standards, Volume 5, No 9, September 1965, pp 442-445.
} 
RPP-RPT-37505, Rev. 0

To monitor crack propagation and growth, both the DCPD measurements and load measurements were used. A significant DCPD (beyond the noise in the data) was interpreted as crack growth. A reduction in the loading rate during loading or a reduction in load during the hold time was also interpreted as crack growth, as it indicates an increase in specimen compliance. Tests were carried out until cracking was detected by load and/or DCPD measurements or until a predefined limit of $\mathrm{K}$ was reached.

Following testing, the samples were sectioned longitudinally. Half of the sample was mounted and prepared for metallographic examination, while the other half of the sample was cooled in liquid nitrogen, and then overloaded to failure. The fracture surfaces were examined using the SEM for evidence of intergranular fracture features, which are indicative of SCC as described above for the SSRT specimens.

The morphology of the fracture surfaces observed in the SEM reveals whether crack growth has occurred. In particular, facture surfaces were examined for intergranular features, which are indicative of high pH SCC. Four types of fracture surfaces are expected during examination of the samples: transgranular fatigue (pre-crack), transgranular ductile (tearing during the test), intergranular (SCC), and transgranular brittle overload (fracture of the specimen in liquid nitrogen). From the inspection of the fracture surfaces, the known test conditions, and the load and DCPD data, estimates of both $\mathrm{K}_{\mathrm{thSCC}}$ and CGRs are generated provided there was some crack propagation. If no crack propagation is observed, then it is known that $\mathrm{K}_{\mathrm{thSCC}}$ is higher than the $\mathrm{K}$ applied in the test.

\subsection{RESULTS AND DISCUSSION}

\subsection{ELECTROCHEMICAL POLARIZATION BEHAVIOR IN TANK 241-AP- 105 BASED SIMULANTS}

Table 5 summarizes the results of the electrochemical tests conducted in FY2008 AP-105-PSC based simulants, including standard AP-105-PSC simulants, AP-105-Evaporated simulants, and AP-105-Mixed simulants as well as their modified versions.

\subsubsection{Cyclic Potentiodynamic Polarization Behavior}

Figure 6 (a) is the CPP curve obtained with a fully immersed specimen in deaerated AP-105-PSC at $50^{\circ} \mathrm{C}$ and at $\mathrm{pH}$ above 13. This simulant contains $0.27 \mathrm{M}$ nitrite ion and $3.58 \mathrm{M}$ nitrate ion (nitrite-to-nitrate concentration ratio of 0.075 ). As shown in Figure 6 (a), the polarization curve showed a wide passive region before the increase in the current. This area of increased current is shown with more detail in Figure 6 (b). A small positive hysteresis loop was observed but no pitting corrosion was noted on the post-test sample. This implied that the increase in current at approximately $500 \mathrm{mV}$ (vs. SCE) was not associated with localized corrosion but the oxidation of electro-active species in this simulant. 
Table 5. A Summary of Electrochemical Tests Performed in AP-105-PSC Based Simulants. (2 sheets)

\begin{tabular}{|c|c|c|c|c|c|c|c|c|c|c|c|c|}
\hline Base Chemistry & pH & $\begin{array}{l}\mathrm{NO}_{2}^{-} \\
(\mathrm{M})\end{array}$ & $\begin{array}{l}\mathrm{NO}_{3}^{-} \\
(\mathrm{M})\end{array}$ & $\begin{array}{l}\text { TIC } \\
\text { (M) }\end{array}$ & $\begin{array}{l}\mathrm{OH}^{-} \\
(\mathrm{M})^{*}\end{array}$ & $\begin{array}{c}\mathrm{Cl}^{-} \\
(\mathrm{M})\end{array}$ & $\begin{array}{c}F \\
(\mathbf{M})\end{array}$ & $\begin{array}{c}\mathrm{T} \\
\left({ }^{\circ} \mathrm{C}\right)\end{array}$ & $\begin{array}{l}\text { Aeration } \\
\text { condition }\end{array}$ & Testing type & Visual & $\begin{array}{c}\text { Sample ID } \\
\text { (\#EL1196-) }\end{array}$ \\
\hline AP-105-PSC & $>13$ & 0.27 & 3.58 & 0.326 & 0.176 & 0.03 & 0.009 & 50 & $\mathrm{~N}_{2}$ purging & $\begin{array}{c}\text { CPP } \\
\text { Full immersion }\end{array}$ & No pitting & 54 \\
\hline AP-105-PSC & $>13$ & 0.27 & 3.58 & 0.326 & 0.176 & 0.03 & 0.009 & 50 & $\mathrm{~N}_{2}$ purging & $\begin{array}{c}\text { CPP } \\
\text { Full immersion }\end{array}$ & No pitting & 60 \\
\hline AP-105-PSC & $>13$ & 0.27 & 3.58 & 0.326 & 0.176 & 0.03 & 0.009 & 50 & $\mathrm{~N}_{2}$ purging & Potentiostatic at $0 \mathrm{mV}$ & No pitting & 63 \\
\hline AP-105-PSC & $>13$ & 0.27 & 3.58 & 0.326 & 0.176 & 0.03 & 0.009 & 50 & $\mathrm{~N}_{2}$ purging & $\begin{array}{c}\text { CPP } \\
\text { Full immersion }\end{array}$ & Crevice corrosion & 64 \\
\hline AP-105-PSC & $>13$ & 0.27 & 3.58 & 0.326 & 0.176 & 0.03 & 0.009 & 50 & $\mathrm{~N}_{2}$ purging & Potentiostatic at $0 \mathrm{mV}$ & Crevice corrosion & 65 \\
\hline AP-105-PSC & $>13$ & 0.27 & 3.58 & 0.326 & 0.176 & 0.03 & 0.009 & 50 & Quiescent Air & $\begin{array}{c}\text { Potentiostatic at } 0 \mathrm{mV} \text {, half } \\
\text { immersion }\end{array}$ & $\begin{array}{c}\text { Severe attack at } \\
\text { liquid/vapor interface }\end{array}$ & 66 \\
\hline AP-105-PSC & $>13$ & 0.6 & 3.58 & 0.326 & 0.176 & 0.03 & 0.009 & 50 & Quiescent Air & $\begin{array}{l}\text { Potentiostatic at } 0 \mathrm{mV} \text {, half } \\
\text { immersion }\end{array}$ & Corrosion & 72 \\
\hline AP-105-PSC & $>13$ & 0.27 & 3.58 & 0.326 & 0.176 & 0.03 & 0.009 & 50 & $\mathrm{~N}_{2}$ purging & $\begin{array}{l}\text { Potentiostatic at } 0 \mathrm{mV} \text {, half } \\
\text { immersion }\end{array}$ & Corrosion & 73 \\
\hline AP-105-PSC & $>13$ & 0.27 & 3.58 & 0.326 & 0.176 & 0.03 & 0.009 & 50 & Quiescent Air & $\begin{array}{c}\text { CPP } \\
\text { Half immersion }\end{array}$ & Corrosion & 75 \\
\hline AP-105-PSC & $>13$ & 0.27 & 3.58 & 0.326 & 0.176 & 0.03 & 0.009 & Room & Quiescent Air & $\begin{array}{c}\text { Potentiostatic at } 0 \mathrm{mV} \text {, half } \\
\text { immersion }\end{array}$ & Corrosion & 76 \\
\hline AP-105-PSC & $>13$ & 0.27 & 3.58 & 0.326 & 0.176 & 0.03 & 0.009 & 50 & Quiescent Air & $\begin{array}{l}\text { Potentiostatic at } 100 \mathrm{mV} \text { vs. } \\
\text { OCP, half immersion }\end{array}$ & Corrosion & 77 \\
\hline AP-105-PSC & $>13$ & 0.27 & 3.58 & 0.326 & 0.176 & 0.03 & 0.009 & Room & Quiescent Air & $\begin{array}{c}\text { CPP } \\
\text { Full immersion }\end{array}$ & No pitting & 81 \\
\hline AP-105-PSC & $>13$ & 0.27 & 3.58 & 0.326 & 0.176 & 0.03 & 0.009 & 50 & Quiescent air & $\begin{array}{c}\text { Potentiostatic at } 0 \mathrm{mV} \\
\text { Half immersion }\end{array}$ & Minor corrosion & 91 \\
\hline AP-105-PSC & $>13$ & 0.27 & 3.58 & 0.326 & 0.176 & 0.03 & 0.009 & 50 & Zero air purging & $\begin{array}{c}\text { OCP } \\
\text { Half immersion }\end{array}$ & Corrosion & 84 \\
\hline AP-105-PSC & $>13$ & 0.27 & 3.58 & 0.326 & 0.176 & 0.03 & 0.009 & 50 & $\begin{array}{l}\text { High Purity Ar } \\
\text { purging }\end{array}$ & $\begin{array}{c}\text { OCP } \\
\text { Half immersion }\end{array}$ & Corrosion & 85 \\
\hline AP-105-PSC & $>13$ & 0.27 & 3.58 & 0.326 & 0.176 & 0.03 & 0.009 & 50 & $\mathrm{~N}_{2}$ purging & $\begin{array}{c}\text { OCP } \\
\text { Half immersion }\end{array}$ & Corrosion & 86 \\
\hline AP-105-PSC & $>13$ & 0.27 & 3.58 & 0.326 & 0.176 & 0.03 & 0.009 & 50 & Quiescent air & $\begin{array}{c}\text { OCP } \\
\text { Half immersion }\end{array}$ & Interface attack & 83 \\
\hline
\end{tabular}

* This reflects the concentration prior to $\mathrm{pH}$ adjustment. 
Table 5. A Summary of Electrochemical Tests Performed in AP-105-PSC Based Simulants. (2 sheets)

\begin{tabular}{|c|c|c|c|c|c|c|c|c|c|c|c|c|}
\hline Base Chemistry & pH & $\begin{array}{l}\mathrm{NO}_{2}^{-} \\
\text {(M) }\end{array}$ & $\begin{array}{l}\mathrm{NO}_{3}^{-} \\
\text {(M) }\end{array}$ & $\begin{array}{l}\text { TIC } \\
\text { (M) }\end{array}$ & $\begin{array}{l}\mathrm{OH}^{-} \\
(\mathbf{M})^{*}\end{array}$ & $\begin{array}{c}\mathrm{Cl}^{-} \\
(\mathbf{M})\end{array}$ & $\begin{array}{c}F^{-} \\
(\mathbf{M})\end{array}$ & $\begin{array}{c}T \\
\left({ }^{\circ} \mathrm{C}\right)\end{array}$ & $\begin{array}{l}\text { Aeration } \\
\text { condition }\end{array}$ & Testing type & Visual & $\begin{array}{c}\text { Sample ID } \\
\text { (\#EL1196-) }\end{array}$ \\
\hline AP-105-PSC & $>13$ & 0.27 & 3.58 & 0.326 & 0.176 & 0.03 & 0.009 & Room & Quiescent air & $\begin{array}{c}\text { Potentiostatic at } 50 \mathrm{mV} \text { vs. } \\
\text { OCP } \\
\text { Half immersion }\end{array}$ & Corrosion & 92 \\
\hline AP-105-PSC & $>13$ & 0 & 3.85 & 0.326 & 0.176 & 0.03 & 0.009 & 50 & $\mathrm{~N}_{2}$ purging & $\begin{array}{c}\text { CPP } \\
\text { Full immersion }\end{array}$ & Pitting & 93 \\
\hline AP-105-Mixed & $>13$ & $\begin{array}{c}0.41 \\
3\end{array}$ & $\begin{array}{c}2.85 \\
7\end{array}$ & 0.274 & 0.952 & $\begin{array}{c}0.03 \\
9\end{array}$ & 0.026 & 50 & $\mathrm{~N}_{2}$ purging & $\begin{array}{c}\mathrm{CPP} \\
\text { Full Immersion }\end{array}$ & No pitting & 98 \\
\hline AP-105-Evaporated & 14 & $\begin{array}{c}0.73 \\
6\end{array}$ & $\begin{array}{c}5.08 \\
7\end{array}$ & 0.489 & 1.67 & $\begin{array}{c}0.06 \\
9\end{array}$ & 0.047 & 50 & $\mathrm{~N}_{2}$ purging & $\mathrm{CPP}$ & No pitting & 99 \\
\hline $\begin{array}{l}\text { AP-105-Evaporated } \\
(\text { Nitrite/Nitrate }=0.1)\end{array}$ & 14 & 0.51 & $\begin{array}{c}5.08 \\
7\end{array}$ & 0.489 & 1.67 & $\begin{array}{c}0.06 \\
9\end{array}$ & 0.047 & 50 & $\mathrm{~N}_{2}$ purging & $\begin{array}{c}\text { CPP } \\
\text { Full immersion }\end{array}$ & No pitting & 105 \\
\hline $\begin{array}{c}\text { AP-105-Mixed } \\
\text { (Nitrite/Nitrate }=0.1 \text { ) }\end{array}$ & $>13$ & 0.28 & $\begin{array}{c}2.85 \\
7 \\
\end{array}$ & 0.274 & 0.952 & $\begin{array}{c}0.03 \\
9\end{array}$ & 0.026 & 50 & $\mathrm{~N}_{2}$ purging & $\begin{array}{c}\mathrm{CPP} \\
\text { Full immersion }\end{array}$ & No pitting & 106 \\
\hline AP-105-PSC & $>13$ & 0.27 & 3.58 & 0.326 & 0.176 & 0.03 & 0.009 & 50 & $\begin{array}{l}\text { Zero air } \\
\text { Blanket }\end{array}$ & $\begin{array}{c}\text { OCP } \\
\text { Half immersion }\end{array}$ & Minor corrosion & 94 \\
\hline AP-105-PSC & $>13$ & 0.27 & 3.58 & 0.326 & 0.176 & 0.03 & 0.009 & 50 & $\begin{array}{l}\text { High Purity Ar } \\
\text { blanket }\end{array}$ & $\begin{array}{c}\text { OCP } \\
\text { Half immersion }\end{array}$ & Minor corrosion & 95 \\
\hline AP-105-PSC & $>13$ & 0.27 & 3.58 & 0.326 & 0.176 & 0.03 & 0.009 & 50 & $\mathrm{~N}_{2}$ blanket & $\begin{array}{c}\text { OCP } \\
\text { Half immersion }\end{array}$ & Minor corrosion & 96 \\
\hline AP-105-PSC & $>13$ & 0.27 & 3.58 & 0.326 & 0.176 & 0.03 & 0.009 & Room & Quiescent air & $\begin{array}{c}\text { OCP } \\
\text { Half immersion }\end{array}$ & Interface attack & 97 \\
\hline AP-105-PSC & $>13$ & 0.27 & 3.58 & 0.326 & 0.176 & 0.03 & 0.009 & 50 & Quiescent air & $\begin{array}{c}\text { CPP } \\
\text { Full immersion }\end{array}$ & Pitting & 102 \\
\hline
\end{tabular}


Figure 6. The CPP Curve in Nitrogen Deaerated AP-105-PSC Simulant $\left(\mathrm{T}=\mathrm{50}^{\circ} \mathrm{C}\right.$ and $\left.\mathrm{pH}>13\right)$.

(a)

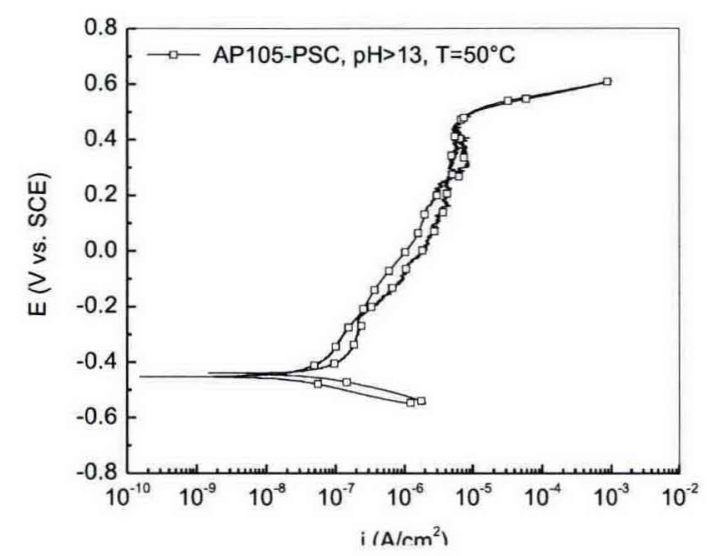

(b)

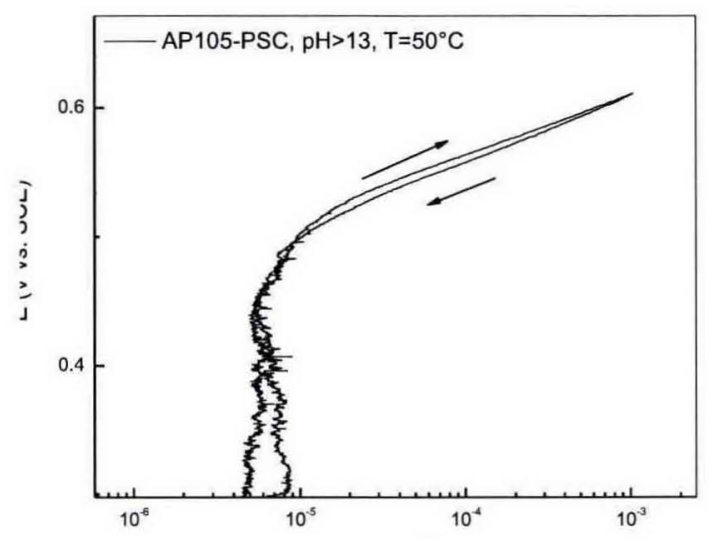

Figure 7 shows a comparison of the CPP curves obtained in deaerated AP-105 mixed and evaporated simulants at $50^{\circ} \mathrm{C}$. These simulants have a higher nitrite-to-nitrate ratio $(0.14)$ than the standard AP-105 simulant (0.075). The CPP curves showed a tiny hysteresis loop. No pitting corrosion was observed on the sample after CPP testing. Similar to the observation in AP-105-PSC, therefore, the hysteresis loop was not associated with localized corrosion but most likely with the electrochemical oxidation and reduction of other electro-active species in the simulants.

Figure 8 is a comparison of the CPP curves obtained in the AP-105 evaporated and mixed simulants with nitrite-to-nitrate concentration ratio of 0.1 . No clear positive hysteresis loops were noted in either CPP curves and the samples tested in both simulants did not show any indication of localized corrosion.

Figure 7. CPP Curves in Nitrogen Deaerated AP-105 Mixed and Evaporated Simulants at $\mathrm{pH} 14$ and $50^{\circ} \mathrm{C}$.

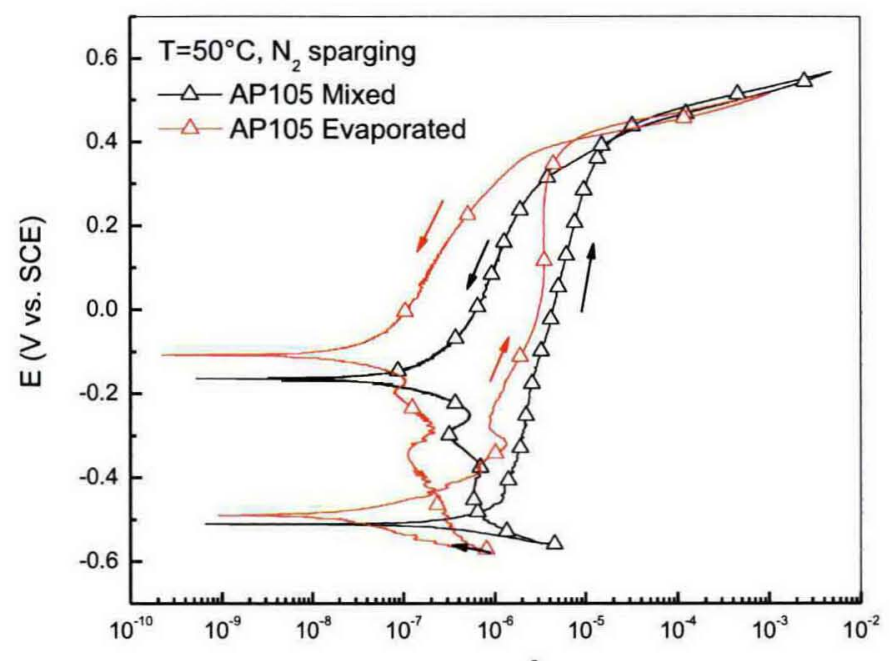


Figure 8. CPP Curves Obtained in Nitrogen Deaerated AP-105 Evaporated and Mixed with Nitrite-to-nitrate Concentration Ratio of $0.1\left(\mathrm{pH} 12+\right.$ and $\left.\mathrm{T}=50^{\circ} \mathrm{C}\right)$.

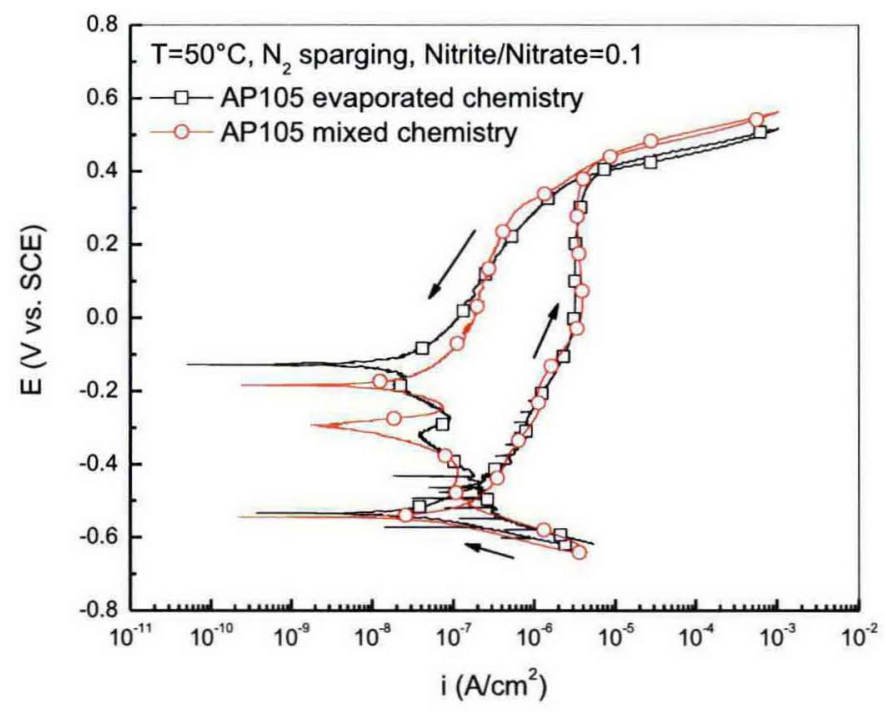

The lack of localized attack on the samples tested in the AP-105 based simulants was likely a result of relatively high hydroxide concentration and the combined inhibition from both nitrite and other inhibitory species. In the previous AN-107 program, at nitrite/nitrate ratio of 0.095 , a value slightly higher than that in AP-105-PSC, severe pitting was noted and the repassivation potential was more negative than OCP. Although the nitrite/nitrate concentration ratio in the AP-105-PSC is lower than 0.095 , the $\mathrm{pH}$ was significantly higher than the AN-107 simulant. Furthermore, other inhibitory species, such as aluminate, were present in the AP-105 simulant but not in the AN-107 simulants. The combined effect from all these differences very possibly caused the difference in the observed polarization behavior (i.e., different repassivation potential and the extent of localized attack). Similarly, although the nitrate concentration in the evaporated simulant is $5.087 \mathrm{M}$, a significantly higher value than other simulants investigated to date, no pitting corrosion was noted on the CPP specimen. Thus, it appears that nitrite, combined with other inhibitory species (e.g., hydroxide, aluminate), efficiently inhibited localized corrosion in the evaporated simulant.

\subsubsection{Liquid/Vapor Interfacial Corrosion in AP-105-PSC}

Figure 9 is a comparison of the CPP curves obtained in AP-105-PSC simulant when the specimen was partially immersed in quiescent air conditions and fully immersed in deaerated conditions. The sample was partially immersed to create a liquid/vapor interface that simulated the sample configuration in the SSRTs. In the SSRTs, which were all performed in quiescent air conditions, a liquid/vapor interface was present and severe attack at the interface was observed after polarizing to $0 \mathrm{mV}$ vs. SCE at $50^{\circ} \mathrm{C}$ for approximately 60 hours in the AP-105-PSC simulant. Details of the SSRT results are discussed in the following section. Also, the investigation of corrosion at the interface could provide insight into the integrity evaluation of the waste storage tanks because a liquid/vapor interface will be present at the supernate level in the tank. As 
mentioned above, a slightly positive hysteresis loop was observed when the sample was fully immersed in the deaerated simulant. However, the CPP curve for the partially immersed specimen in quiescent conditions exhibited a large hysteresis. The post-test inspection of the partially immersed sample revealed corrosion at the bottom of the sample, near the liquid/vapor interface, and the portion exposed to the vapor phase (Figure 10). The attack at the liquid/vapor interface was further investigated in a set of potentiostatic tests, as will be discussed below.

Figure 9. A Comparison of CPP Curves in Nitrogen Deaerated AP-105-PSC Simulant at Different Nitrite and Nitrate Concentrations $\left(\mathrm{pH}=13+, \mathrm{T}=50^{\circ} \mathrm{C}\right)$.

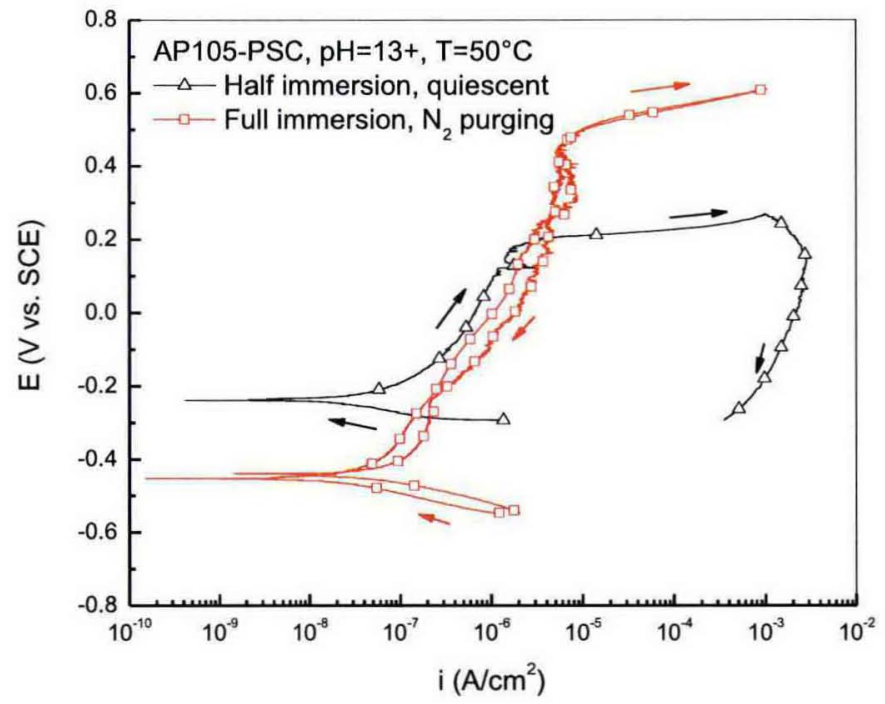

Figure 10. Sample Appearance after CPP Testing in AP-105-PSC Simulant under Quiescent Air Conditions ( $\left.\mathrm{pH}=\mathbf{1 3}+, \mathrm{T}=50^{\circ} \mathrm{C}\right)$.
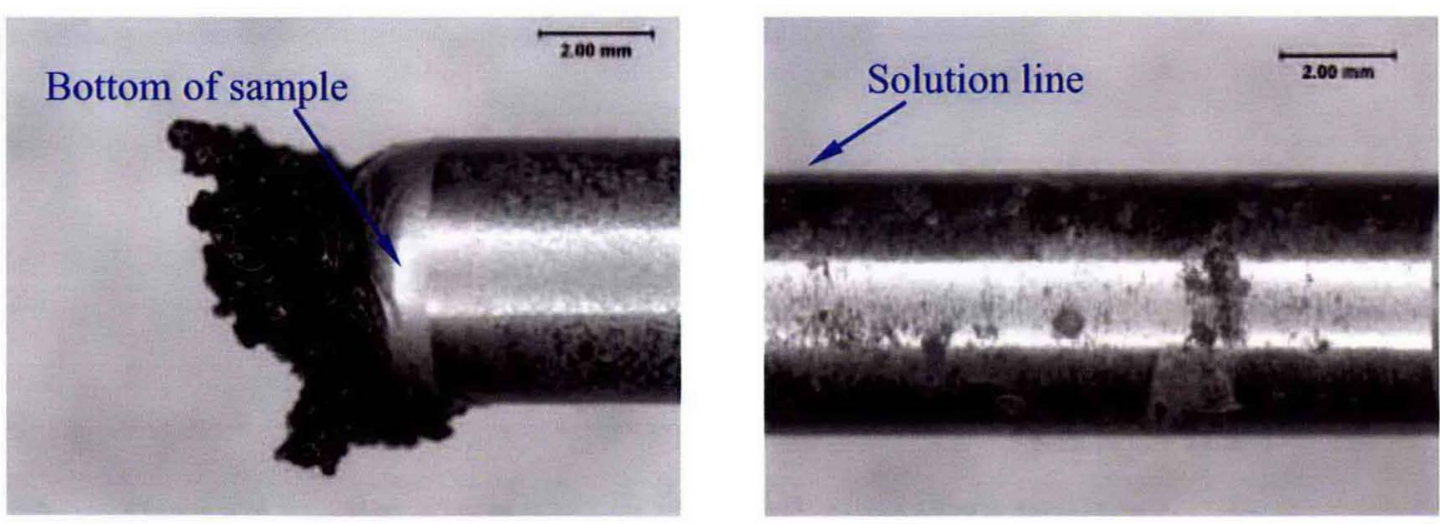
Figure 11 shows the current change as a function of time when a partially immersed sample was polarized at $0 \mathrm{mV}$ vs. $\mathrm{SCE}$ for 50 hours $\left(\mathrm{pH}>13, \mathrm{~T}=50^{\circ} \mathrm{C}\right)$ in an AP-105-PSC simulant under quiescent conditions. The current measured in the potentiostatic test showed a sharp increase shortly after the potentiostatic test began. Severe corrosion attack was noted on the sample at the liquid/vapor interface, as shown in Figure 12 (a). Corrosion attack was also observed on the specimen areas that were above the liquid/vapor interface (Figure $12(\mathrm{~b})$ ). The observed corrosion attack was similar to that observed on the SSRT sample when exposed to the same simulant under quiescent air conditions. In contrast, no corrosion was noted on a fully immersed sample in the same environment and conditions. The measured current density remained low indicating passive conditions throughout the test, as shown in Figure 13.

Figure 11. The Change in the Current as a Function of Time when the Partially Immersed Sample Was Held at $0 \mathrm{mV}$ vs. SCE (AP-105-PSC, $\mathrm{pH}>13, \mathrm{~T}=50^{\circ} \mathrm{C}$, Quiescent Air Conditions).

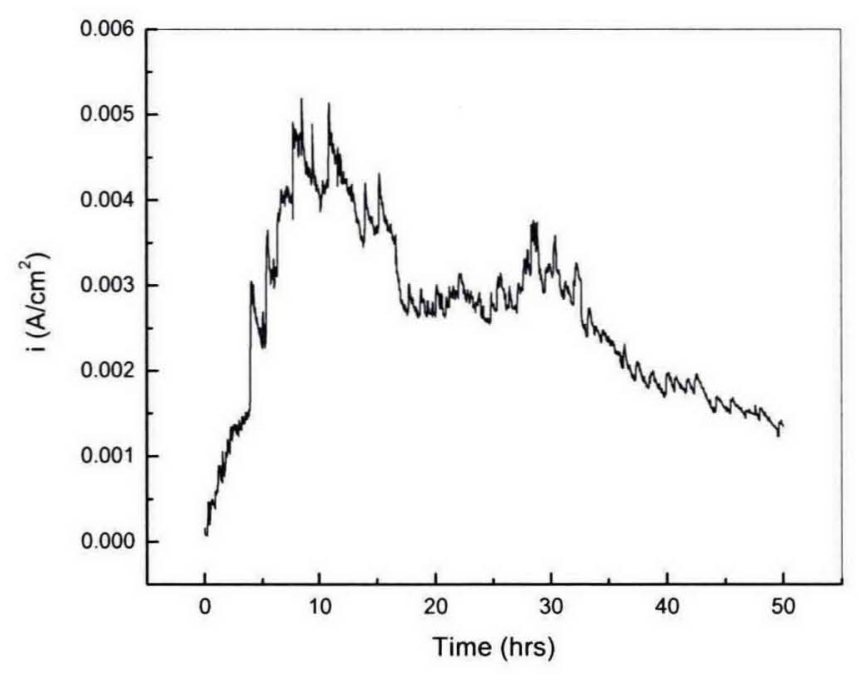


Figure 12. The Sample Appearance after 50 Hours of Potentiostatic Testing at 0 $\mathrm{mV}$ vs. SCE in the AP-105-PSC Simulant $\left(\mathrm{pH}>13, \mathrm{~T}=50^{\circ} \mathrm{C}\right.$, Quiescent Air Conditions).

(a) Corrosion at Liquid/vapor Interface; (b) Corrosion on the Portion above the Liquid/vapor Interface.

(a)

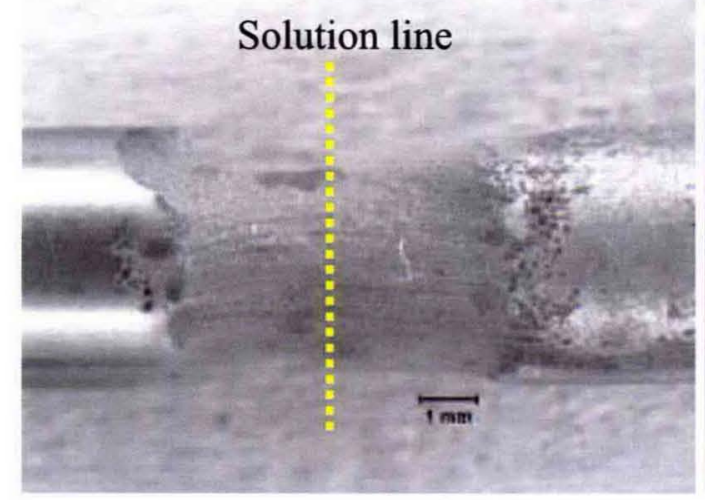

(b)

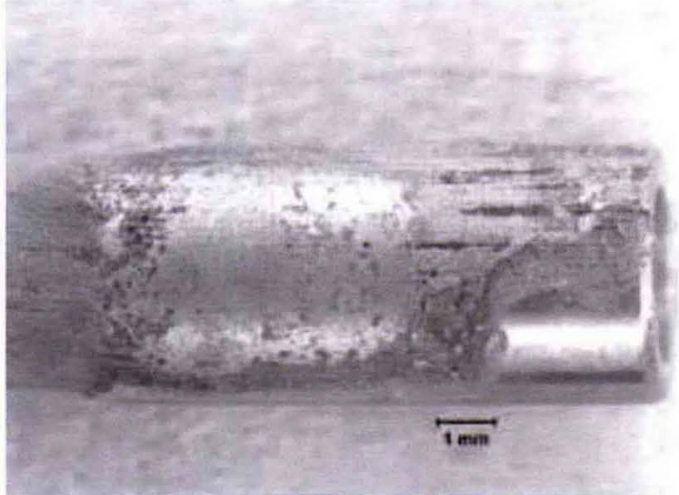


RPP-RPT-37505, Rev. 0

Figure 13. Current as a Function of Time for Fully Immersed Sample Polarized at $\mathbf{0 ~ m V}$ vs. SCE in AP-105-PSC Simulant $\left(\mathrm{T}=50^{\circ} \mathrm{C}, \mathrm{pH}>13\right)$ Under Quiescent Air Conditions.

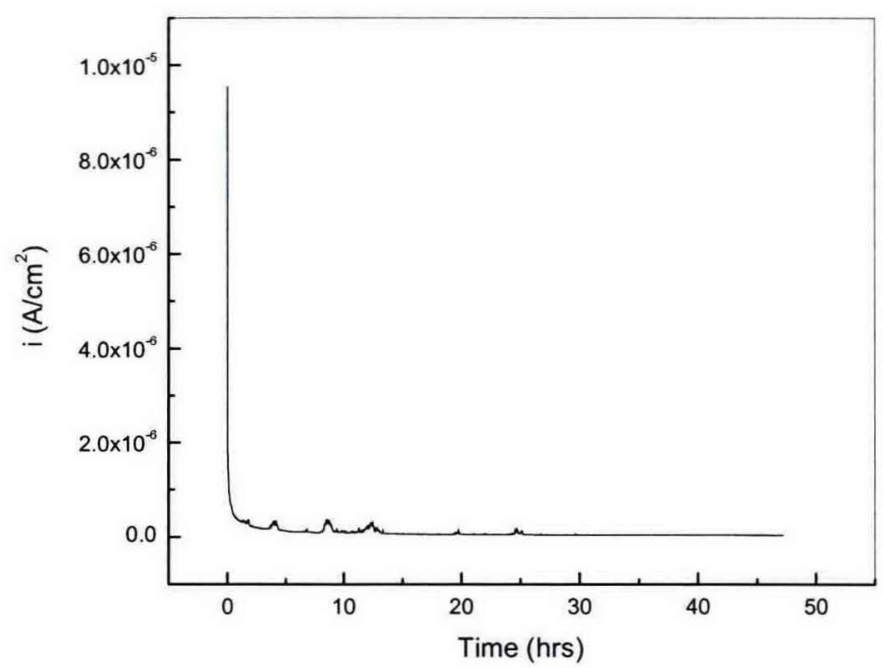

The contrasting results of severe corrosion attack for the partially immersed specimen and no corrosion attack for the fully immersed specimen are likely related to chemical reactions occurring at the interface. Typically, materials corrode more readily (at a higher rate) at a liquid/vapor interface than in the bulk in an aggressive environment. This is because oxygen is more readily available at the interface than in the bulk solution, allowing oxygen to contribute more significantly to the cathodic reaction (assuming oxygen reduction dominates the cathodic kinetics). However, when a sample is polarized to a noble potential (e.g., $0 \mathrm{mV}$ vs. SCE as it was in these experiments), it is expected that all the cathodic reactions would be displaced to the counter electrode. This indicates that the fully immersed and partially immersed specimen should have similar cathodic reactions (as well as similar anodic reactions). Therefore, it is possible that some unknown reactions at the interface created a locally aggressive environment that resulted in severe corrosion attack of the partially immersed specimen.

While corrosion attack was noted at the liquid/vapor interface in quiescent air, the extent of corrosion attack was greatly decreased when the nitrite concentration was increased to $0.6 \mathrm{M}$. The observed decrease in current density with the higher nitrite concentration is shown in Figure 14. Minimal corrosion attack was observed for this condition as shown in Figure 15.

Similarly, the current densities under deaerated conditions were lower than under quiescent conditions for the AP-105-PSC simulant with $0.27 \mathrm{M}$ nitrite, as shown in Figure 16. The corrosion attack on the samples tested in deaerated simulants was also less severe than that observed under quiescent air conditions (see Figure 17). Additionally, the corrosion attack was noted to be less severe when the solution was actively sparged with nitrogen (Figure 16 and Figure 17). Note that in the test for the sample shown in Figure 17, though, the interface was actively disturbed and mixed with the bulk solution under the gas purging. 
Figure 14. A Comparison of the Change in the Current as a Function of Time in the Potentiostatic Tests Conducted in AP-105-PSC Simulants with Different Nitrite Concentrations at $50^{\circ} \mathrm{C}$ and Quiescent Air Conditions.

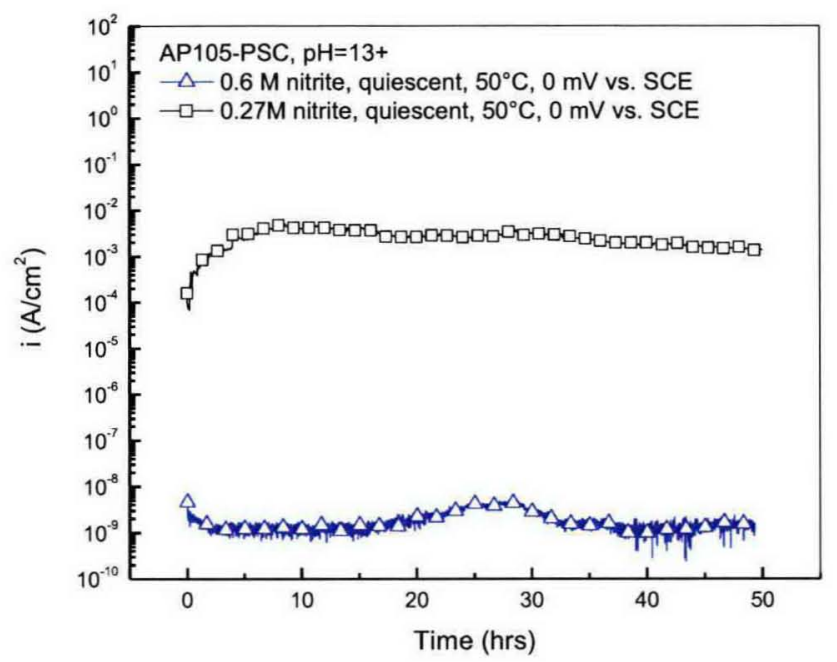

Figure 15. The Sample Appearance after Potentiostatic Test at $0 \mathrm{mV}$ (vs. SCE) in the AP-105-PSC Simulant with $0.6 \mathrm{M}$ Nitrite for 50 Hours (Sample Partially Immersed) at $5^{\circ} \mathrm{C}$ Under Quiescent Air Conditions.
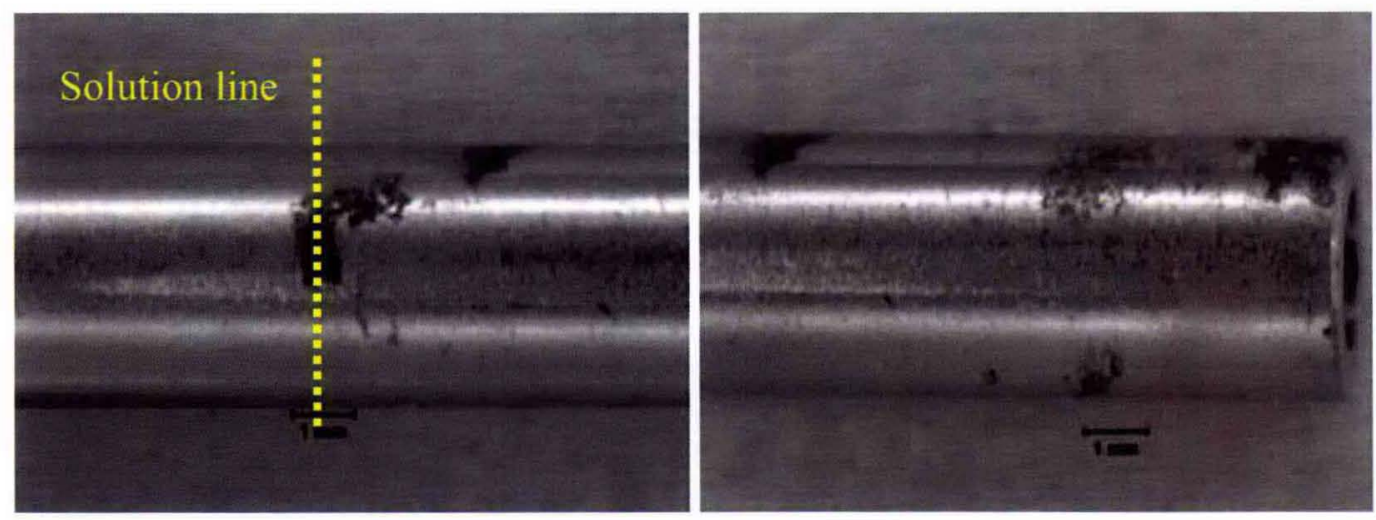
Figure 16. A Comparison of the Current Density as a Function of Time in the Potentiostatic Tests Conducted at $0 \mathrm{mV}$ (vs. SCE) in Quiescent and Nitrogen Purged AP-105-PSC Simulants at $50^{\circ} \mathrm{C}$.

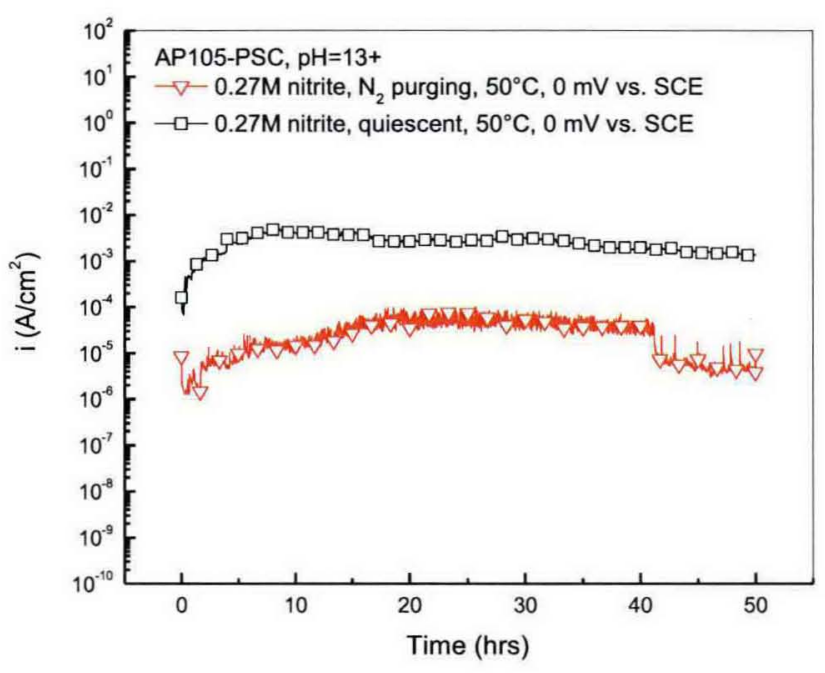

Figure 17. The Sample Appearance after Potentiostatic Test at $0 \mathrm{mV}$ (vs. SCE) in Nitrogen Deaerated AP-105-PSC Simulant for 50 hours (Sample Partially Immersed) at $50^{\circ} \mathrm{C}$.
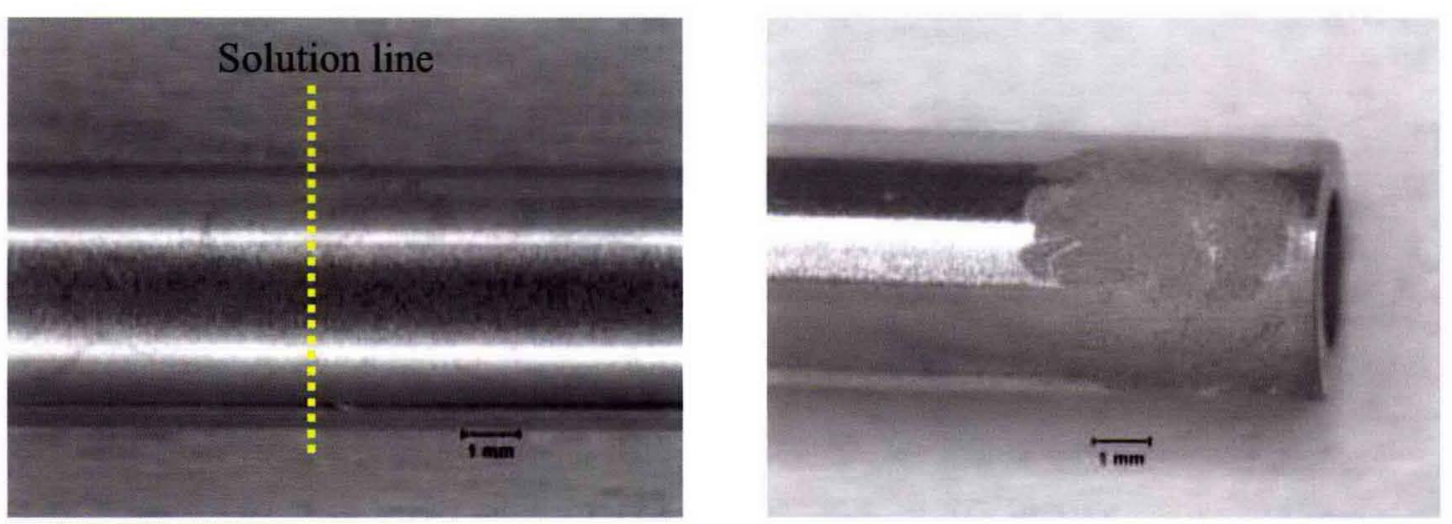

Initially, it was thought that the rapid corrosion observed at the liquid/air interface was linked to the oxidation of nitrite in the presence of oxygen. However, corrosion at the interface was still observed in one test in which the head space of the test cell was purged with nitrogen to eliminate oxygen (i.e., the solution was not agitated). The current change as a function of time is shown in Figure 18 and the sample appearance after the potentiostatic test is shown in Figure 19. This demonstrated that the attack at the interface at $0 \mathrm{mV}$ vs. SCE could still occur in the absence of oxygen. It also indicated that the role of nitrogen when actively purging the simulant was to primarily mix the bulk solution and the interface environment so that the local aggressive environment could be eliminated. Thus, it seems necessary to have a stable liquid/vapor interface to maintain the local chemistry at the interface in order to observe the corrosion attack as shown in Figure 12. 
Figure 18. The Current Density as a Function of Time in the Potentiostatic Tests Conducted at $0 \mathrm{mV}$ (vs. SCE) in AP-105-PSC Simulants with the Head Space of the Test Cell Purged with Nitrogen at $50^{\circ} \mathrm{C}$.

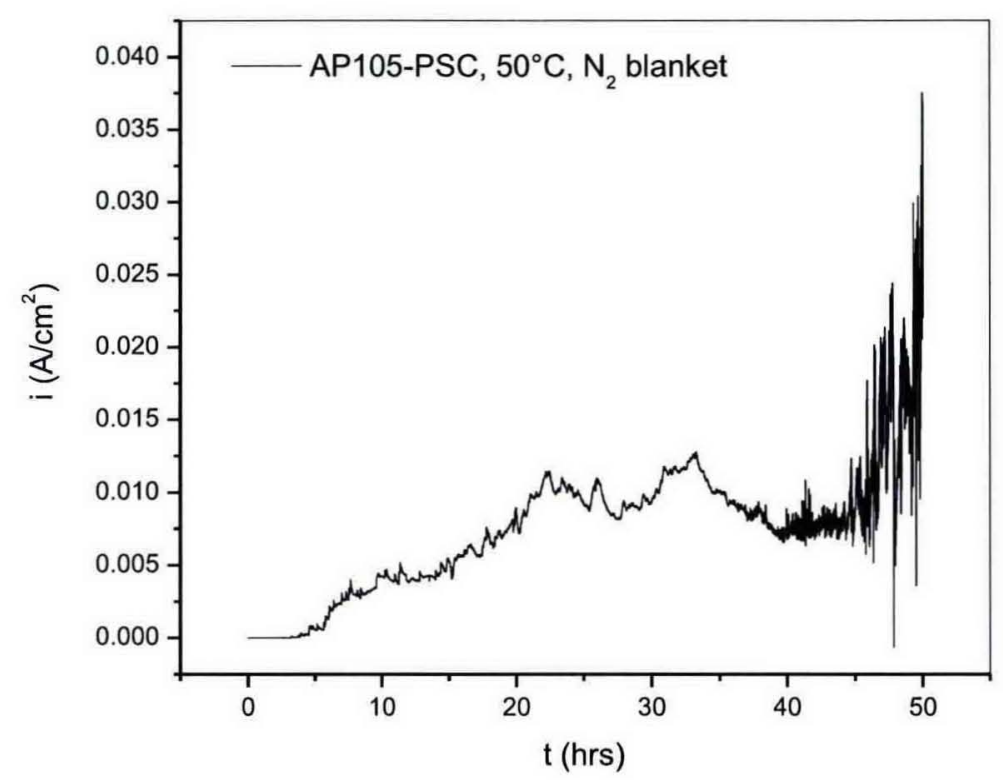

Figure 19. The Sample Appearance after the Potentiostatic Tests Conducted at $0 \mathrm{mV}$ (vs. SCE) in AP-105-PSC Simulants with the Head Space of the Test Cell Purged with Nitrogen at $50^{\circ} \mathrm{C}$.

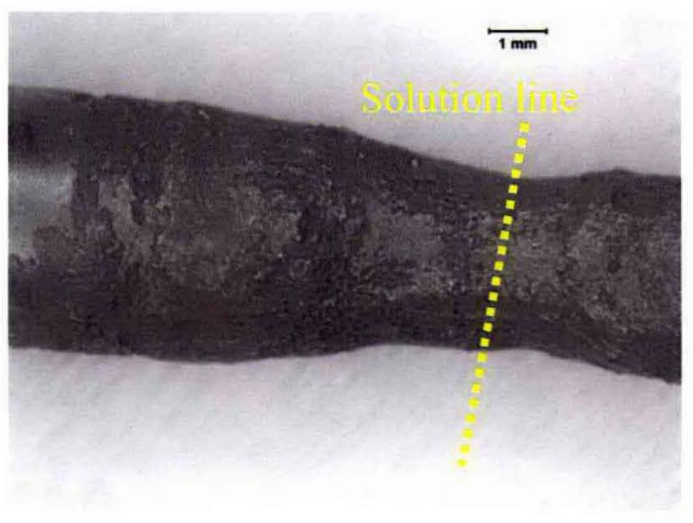


The extent of corrosion attack at the liquid/vapor interface at a polarized potential decreased significantly with a decrease in temperature from $50^{\circ} \mathrm{C}$ to room temperature. Figure 20 shows a comparison of the current density as a function of time at room temperature $\left(\sim 25^{\circ} \mathrm{C}\right)$ and $50^{\circ} \mathrm{C}$ at $0 \mathrm{mV}$ vs. SCE with quiescent air in the head space. Although corrosion was noted when the solution was at room temperature and at $0 \mathrm{mV}$ vs. SCE, the extent of corrosion was much less severe compared to $50^{\circ} \mathrm{C}$ and $0 \mathrm{mV}$ vs. SCE (Figure 22 (a) vs. Figure 12). The current density at room temperature did increase dramatically after approximately 33 hours of exposure (Figure 20), while at a temperature of $50^{\circ} \mathrm{C}$ under the same conditions, the current increased within the first few hours, indicating the onset of corrosion.

The applied potential also had an impact on the onset of corrosion initiation at the liquid/vapor interface. Figure 21 shows that corrosion initiation took approximately 10 hours to appear at the interface when polarized to $100 \mathrm{mV}$ vs. OCP $\left(-204 \mathrm{mV}\right.$ vs. SCE) at $50^{\circ} \mathrm{C}$ and under quiescent air conditions. Comparatively, the current increased (i.e., corrosion initiated) within a few hours at $0 \mathrm{mV}$ vs. SCE at $50^{\circ} \mathrm{C}$ in quiescent air conditions. A similar trend was observed at room temperature. In Figure 21 (b), the current did not increase within 50 hours of exposure at room temperature with an applied potential of $50 \mathrm{mV}$ vs. OCP $(-160 \mathrm{mV}$ vs. SCE). However an increase in the current was noted after 33 hours at room temperature and an applied potential of $0 \mathrm{mV}$ vs. SCE. Figure 22 (b) shows minimal corrosion attack at the interface for the $50 \mathrm{mV}$ vs. OCP potentiostatic polarization at room temperature and quiescent air conditions. As expected from the current transient data, the corrosion attack for the $0 \mathrm{mV}$ vs. SCE, room temperature, quiescent air case (Figure 22 (a)) was more severe; however, the overall corrosion damage to both specimens was not substantial.

Figure 20. Current as a Function of Time in Potentiostatic Tests Conducted at Different Temperature Levels and Quiescent Air Conditions.

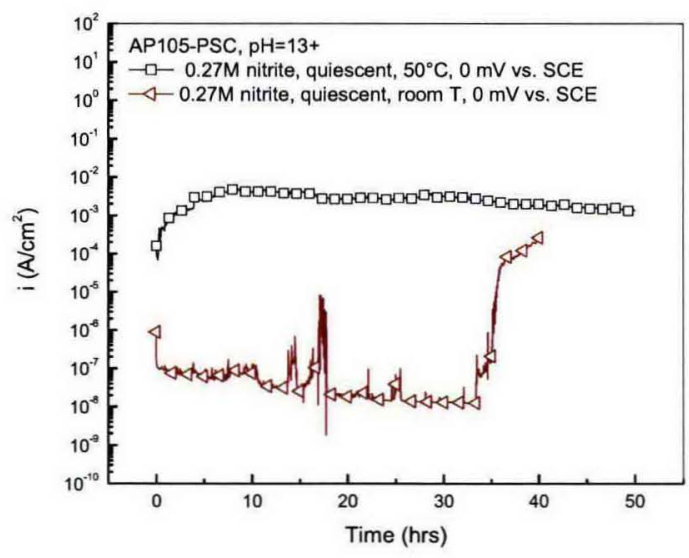


Figure 21. Current Density as a Function of Time in the Potentiostatic Tests Conducted in AP-105-PSC Simulants Under Quiescent Air Conditions at (a) $0 \mathrm{mV}$ (vs. SCE, $50^{\circ} \mathrm{C}$ ) and $100 \mathrm{mV}$ (vs. $\mathrm{OCP}, 50^{\circ} \mathrm{C}$ ); (b) $50 \mathrm{mV}$ (vs. OCP, Room Temperature) and $0 \mathrm{mV}$ (vs. SCE, Room Temperature).

(a)

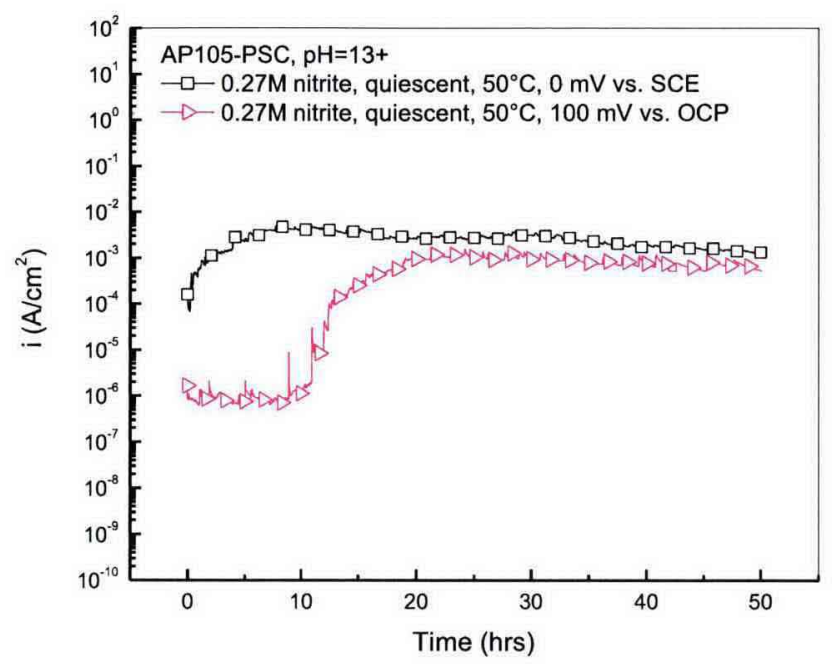

(b)
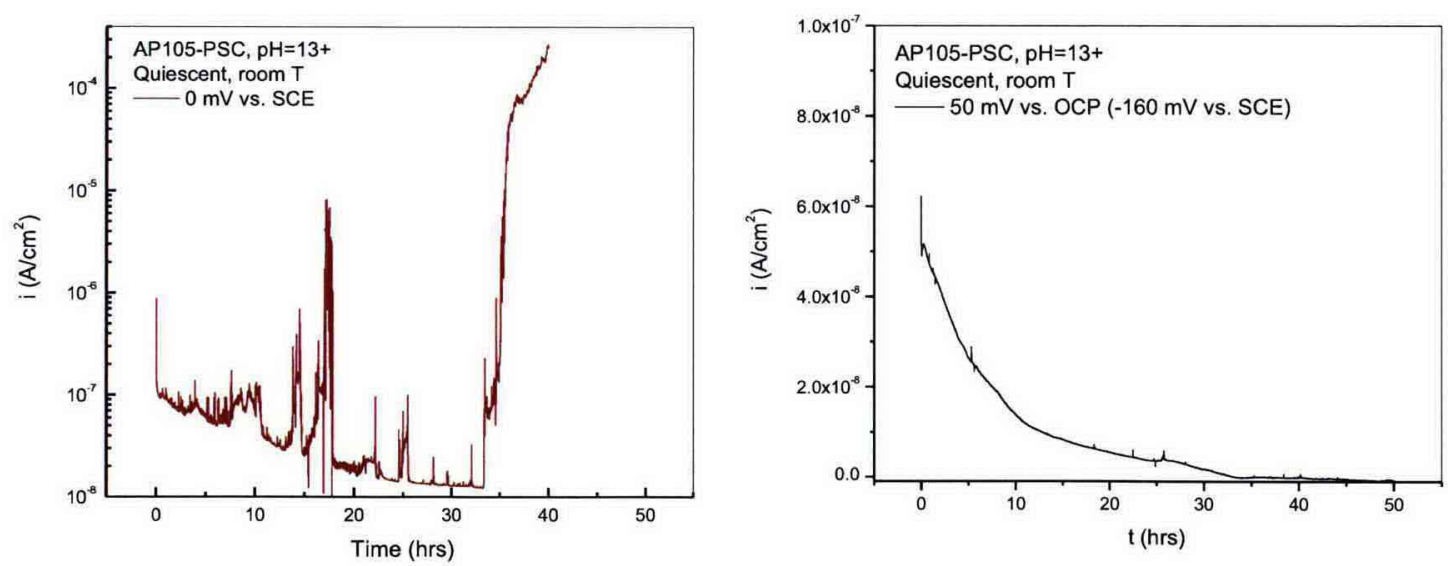
Figure 22. Sample Appearance after 50 Hours Potentiostatic Testing in AP-105-PSC Simulant at Different Potentials (Under Quiescent Air Conditions, Room Temperature). (a) $0 \mathrm{mV}$ vs. SCE; (b) $50 \mathrm{mV}$ vs. OCP (-160 mV vs. SCE).

(a)

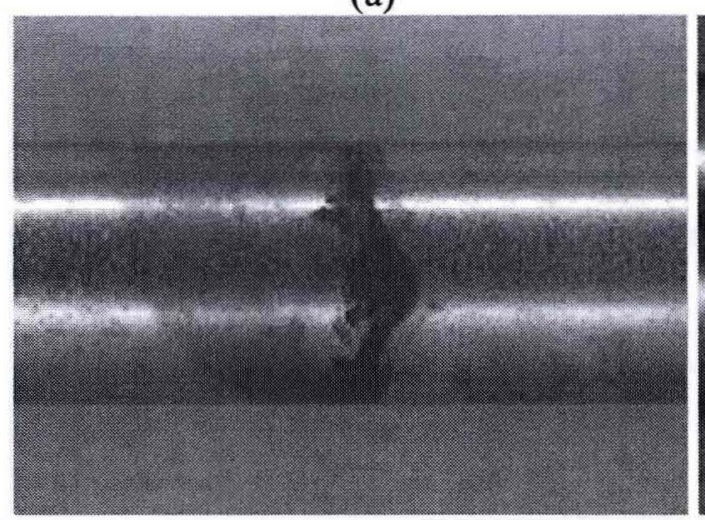

(b)

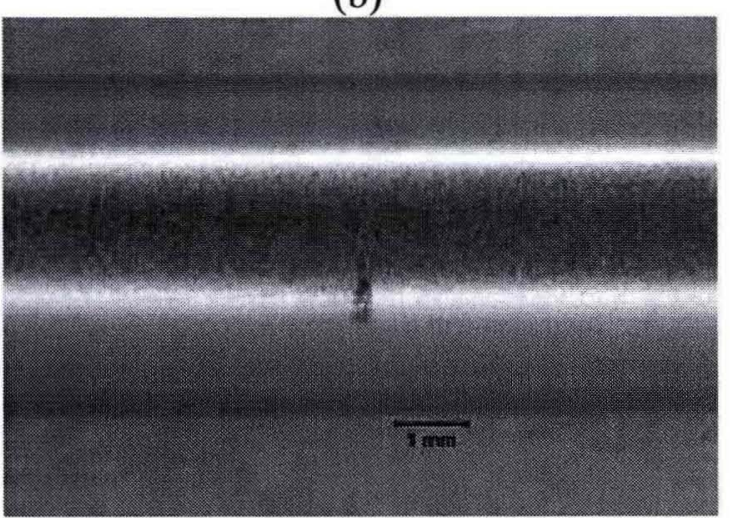

To further investigate the corrosion attack at the liquid/vapor interface in the AP-105-PSC simulant, long-term immersion tests were performed with the samples partially immersed in the simulant to create a liquid/vapor interface. The effect of gas purging (through the bulk solution and the cell head space), temperature levels (room and $50^{\circ} \mathrm{C}$ ), gas types (quiescent, compressed zero air, nitrogen and argon) on the interfacial corrosion susceptibility and extent were of particular interest. Figure 23 compares the corrosion rates of the samples that were partially immersed in the AP-105-PSC simulant at different conditions. It should be noted that the corrosion rate was calculated using the exposed surface area. This tends to underestimate the corrosion rate since the corrosion attack usually focused at the liquid/vapor interface or a few local sites. The samples exposed to the simulant open to the ambient air showed evident attack at the liquid/vapor interface (Figure 24 and Figure 25) and the extent of corrosion was less at room temperature. The corrosion rates at the other conditions (e.g., purged with nitrogen, argon and compressed zero air) did not differ from each other significantly. Additionally, the corrosion attack on the samples partially immersed in the actively sparged simulants were mainly located on the portion exposed to the vapor space region. Conversely, the corrosion was widely spread to the entire sample surface in cases where the solution remained stagnant or only the head space of the cell was purged with gases. These differences in the amount and mode of attack may suggest that the mixing of the bulk solution and the interface solution may have prevented the formation of a relatively aggressive environment adjacent to the sample surface.

It was also noted that the samples exposed to solutions with oxygen behaved differently. When the solution was open to the ambient air, the corrosion attack was more severe at an elevated temperature than at room temperature. In the case where the oxygen was introduced by actively purging the solution using zero air (i.e., air without $\mathrm{CO}_{2}$ ), the corrosion was minor as the mixing of the interface with the bulk likely prevented the locally aggressive environment from forming. When the head space of the cell was purged with zero air, the corrosion attack was still not as severe as that in the solution open to the ambient air. Since the $\mathrm{pH}$ of the bulk solution did not change dramatically after the exposure, as shown in Table 6, it is not clear whether the local $\mathrm{pH}$ change at the interface played a significant role on the initiation of the attack at the interface. 
Figure 23. Corrosion Rate Calculated Based on Weight Loss for the Samples Partially Immersed in the AP-105-PSC Simulants Under Freely Corroding Conditions for More than Three Months $\left(\mathrm{T}=50^{\circ} \mathrm{C}\right.$ Unless Noted Otherwise).

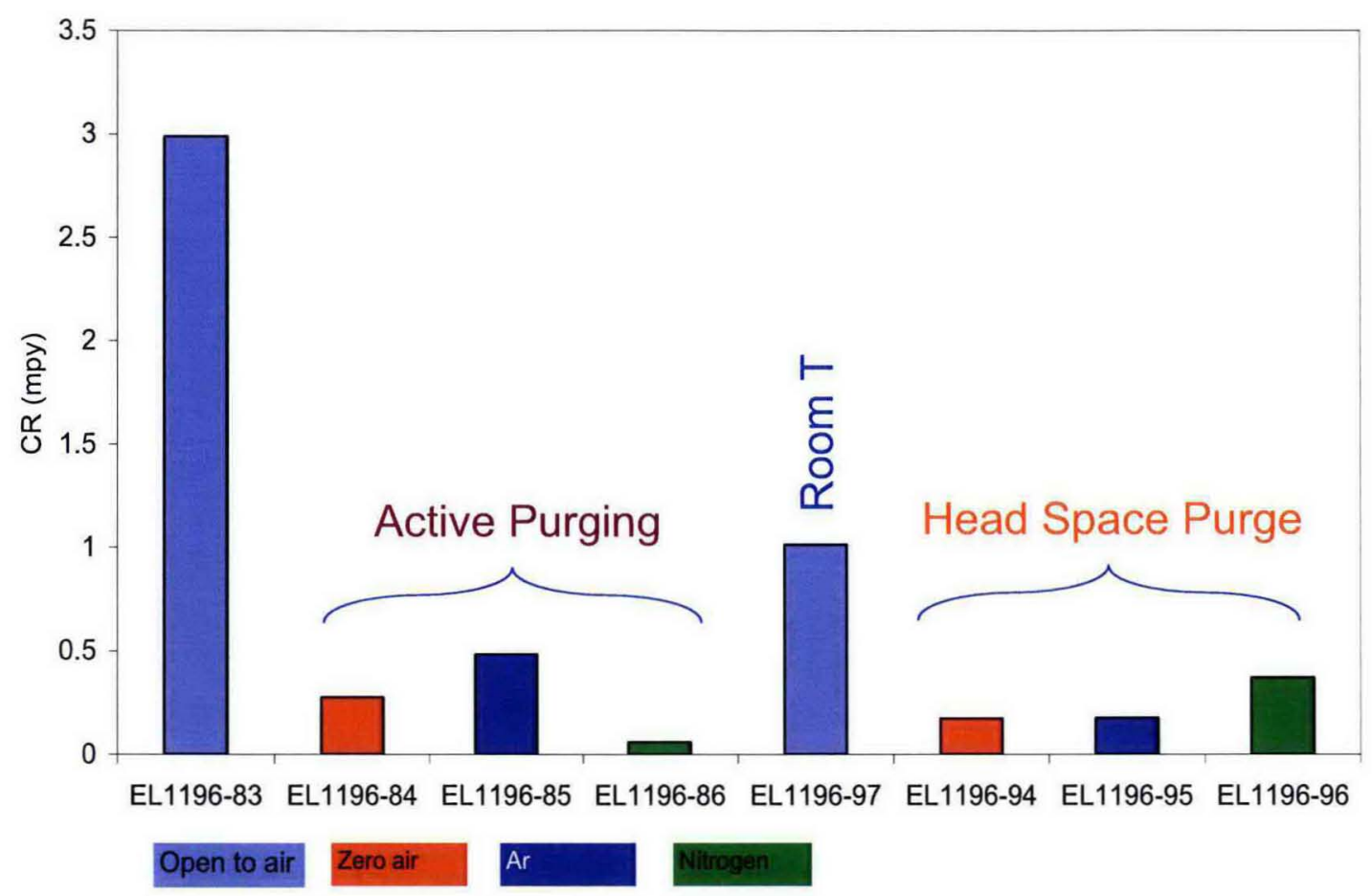

Figure 24. The Appearance of the Sample (a) and the Cross Section of a Corroded Site (b) after Exposed in AP-105-PSC under Quiescent Air Conditions (Sample Partially Immersed, $\mathrm{T}=\mathbf{5 0}^{\circ}$, EL1196-83).

(b)

(a)
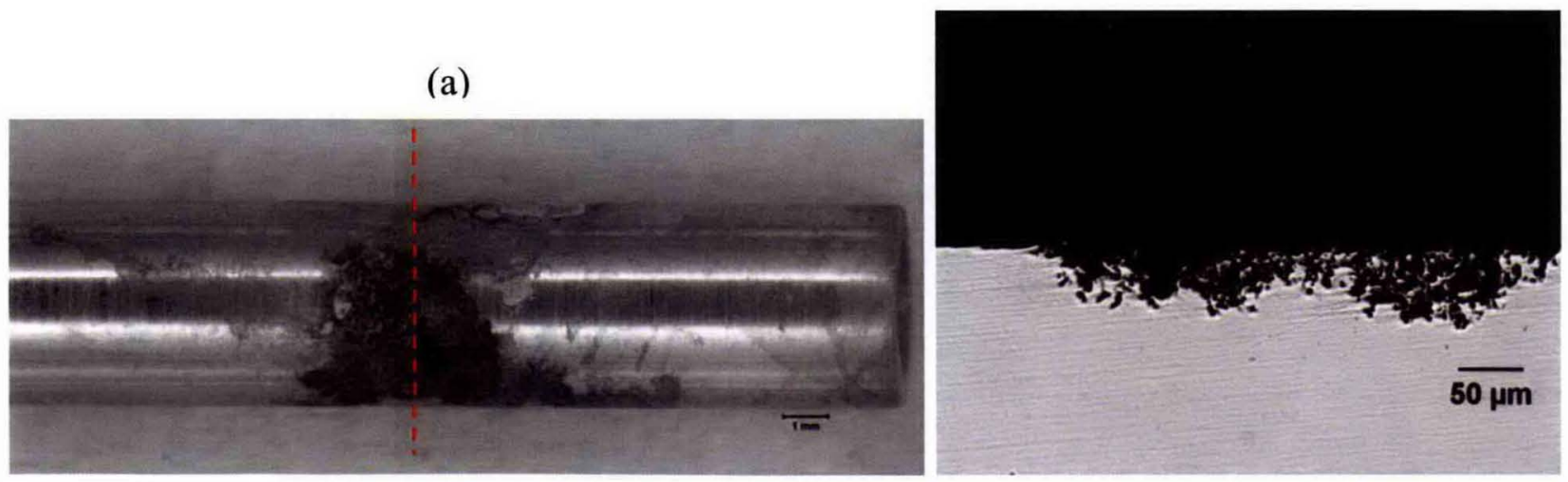
Figure 25. The Appearance of the Sample (a) and the Cross Section of a Corroded Site (b) after Exposed in AP-105-PSC under Quiescent Air Conditions (Sample Partially Immersed, Room Temperature, EL1196-97) at OCP.

(b)

(a)
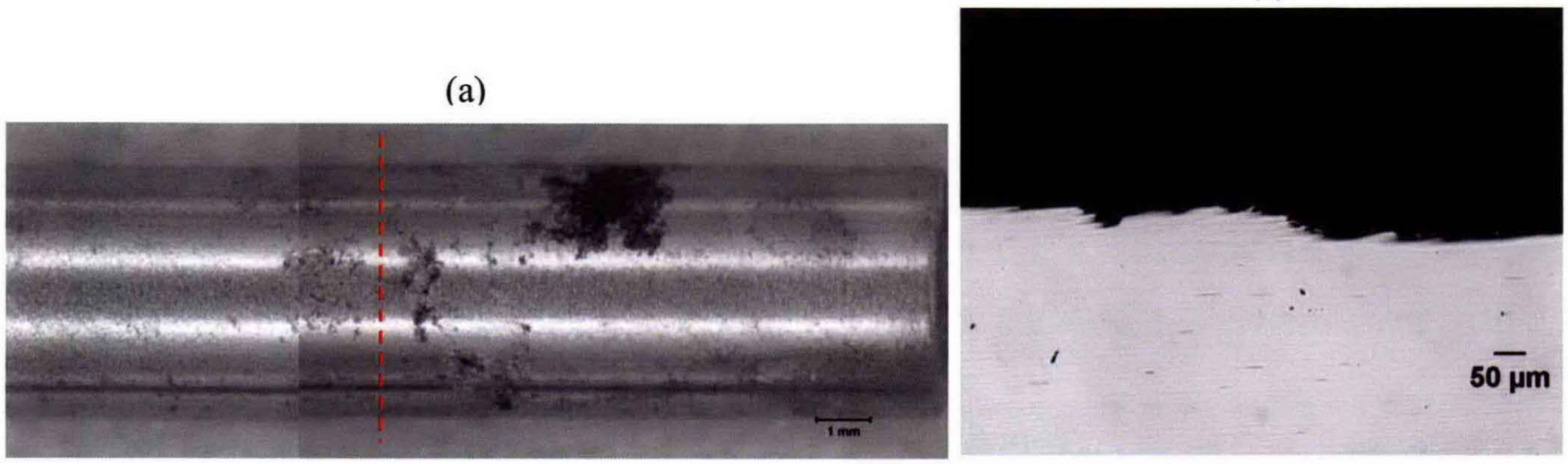

Table 6. The Bulk pH Values of the Simulant after the Long-Term Immersion Tests.

\begin{tabular}{|c|c|}
\hline Exposed sample & Solution $\mathbf{p H}$ after test \\
\hline EL1196-83 & 13.28 \\
\hline EL1196-84 & 13.23 \\
\hline EL1196-85 & 13.32 \\
\hline EL1196-86 & 13.21 \\
\hline EL1196-97 & 13.32 \\
\hline EL1196-94 & 13.4 \\
\hline EL1196-95 & 13.44 \\
\hline EL1196-96 & 13.38 \\
\hline
\end{tabular}

The interfacial corrosion appears to be a complicated process and the exact mechanism is still uncertain without conducting a comprehensive investigation. Based on the results obtained to date in the present work, several mechanisms are possible, as discussed below.

\section{(a). Nitrite depletion through oxidation at a polarized potential}

Severe attack at the interface in deaerated AP-105-PSC simulants at polarized potentials above OCP may be able to convert the inhibitory nitrite locally to nitrate. Thus, a locally aggressive environment could be formed. It has been demonstrated above that the interfacial attack strongly depends on the applied potential. Typically, a more positive polarized potential led to more severe attack with a shorter initiation time. The depletion of nitrite could be linked to the oxidation of nitrite to nitrate via the electrochemical reaction below: 
$\mathrm{NO}_{2}^{-}+\mathrm{H}_{2} \mathrm{O} \rightarrow \mathrm{NO}_{3}^{-}+2 \mathrm{H}^{+}+2 e^{-}$

$E\left(N_{2}^{-} / N O_{3}^{-}\right)=0.835-0.000198 T p H+0.000099 T \log \left(\left[N O_{3}^{-}\right] /\left[N O_{2}^{-}\right]\right)$

The equilibrium potential for this half reaction is listed in Table 7. Clearly, a polarization of 0 $\mathrm{mV}$ vs. SCE and $50 \mathrm{mV}$ vs. OCP (-160 mV vs. SCE) are both sufficiently noble to oxidize nitrite to nitrate and the oxidation is still thermodynamically possible even at some OCPs. Although nitrite oxidation can occur anywhere on the immersed electrode surface, the local depletion can be compensated by the nitrite in the bulk solution through mass transport. At the liquid/vapor interface, however, the mass transport may be limited such that a local low nitrite environment can be maintained to form an aggressive environment.

Table 7. The Equilibrium Potential of Nitrite and Nitrate Redox Couple as a Function of Temperature at $\mathrm{pH} 13.5($ Nitrite $=0.27 \mathrm{M}$, Nitrate $=3.58 \mathrm{M})$.

\begin{tabular}{cc}
\hline $\mathrm{T}\left({ }^{\circ} \mathrm{C}\right)$ & $\mathrm{E}(\mathrm{V}$ vs. SCE $)$ \\
\hline 25 & -0.170 \\
\hline 50 & -0.235 \\
\hline
\end{tabular}

To illustrate that the depletion of nitrite and a corresponding increase in nitrate concentration compared to the bulk AP-105-PSC simulant solution could lead to a more corrosive environment, a modified AP-105-PSC simulant was created in which the nitrite was removed and the nitrate concentration was increased to $3.85 \mathrm{M}$. This high nitrate content represents complete conversion of nitrite to nitrate. CPP testing showed an open hysteresis loop (Figure 26) with severe localized corrosion attack noted, as shown in Figure 27. Clearly, the depletion of nitrite can lead to a very aggressive environment. The CPP curve shows a repassivation potential more negative then the OCP, indicating that localized corrosion may occur at open circuit. This could be a plausible explanation for the observation of severe corrosion in the vapor phase and interfacial regions on some samples.

Figure 26. A Comparison of CPP Curves in Nitrogen Deaerated AP-105-PSC Simulant at Different Nitrite and Nitrate Concentrations $\left(\mathrm{pH}=13+, \mathrm{T}=50^{\circ} \mathrm{C}\right)$.

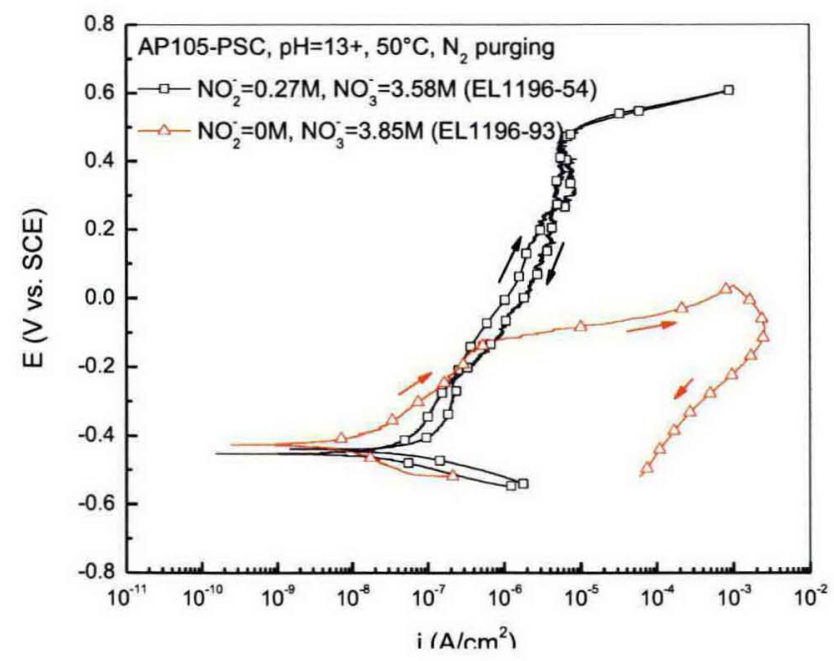


Figure 27. The Sample Appearance after CPP Testing in Nitrogen Deaerated AP-105-PSC with No Nitrite and $3.85 \mathrm{M}$ Nitrate $\left(\mathrm{pH}=13+, \mathrm{T}=50^{\circ} \mathrm{C}\right)$.

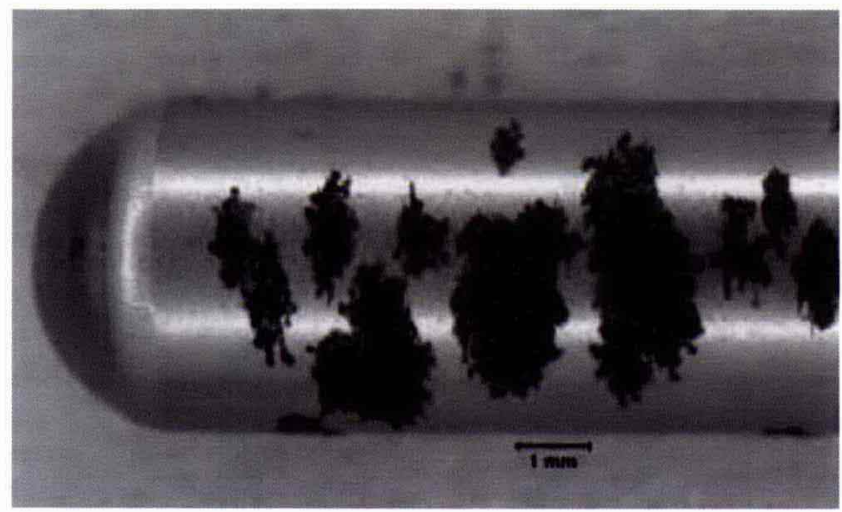

\section{(b). Oxygen enhanced corrosion and possible nitrite depletion}

In general, increased oxygen concentration results in higher corrosion rates. Furthermore, the role of oxygen is uncertain in the process of nitrite depletion. Oxygen may be a promoter for the nitrite depletion to aid in creating a more corrosive environment. As shown Figure 28, the CPP curve in AP-105-PSC simulant under quiescent air conditions and $50^{\circ} \mathrm{C}$ showed a positive hysteresis loop and the sample showed pitting corrosion (Figure 29). In the long-term immersion tests, however, the samples immersed in the simulants purged by compressed zero air (no $\left.\mathrm{CO}_{2}\right)$ did not show appreciable corrosion attack. These observations seem to indicate that the presence of oxygen may have no strong influence on the liquid/vapor corrosion process. Rather, the presence of $\mathrm{CO}_{2}$ in the quiescent air coupled with evident corrosion, and the lack of $\mathrm{CO}_{2}$ and observable corrosion in the zero air (and nitrogen), suggests that $\mathrm{CO}_{2}$ may be the controlling species in liquid/vapor corrosion process.

Figure 28. A Comparison of the CPP Curves Obtained in the AP-105-PSC Simulant under Different Aeration Conditions using Fully Immersed Samples.

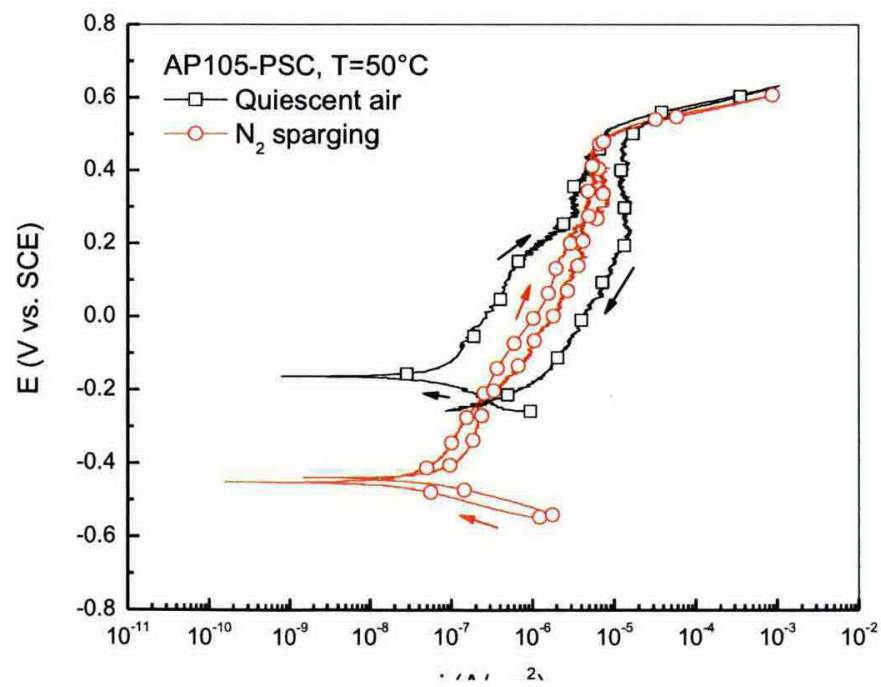


Figure 29. The Pit on the Sample Tested in the AP-105-PSC Simulant Under Quiescent Air Conditions and at $50^{\circ} \mathrm{C}(\mathrm{pH}=13+)$.

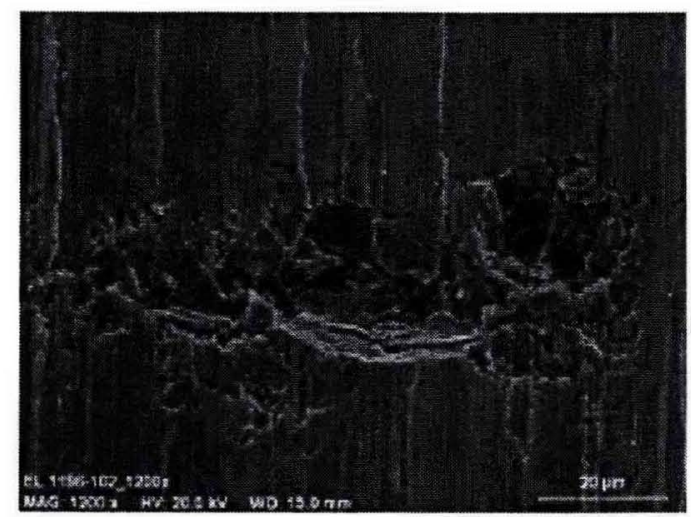

\section{(b). Local $\mathrm{pH}$ change causes an aggressive environment}

In the long-term immersion tests, the samples immersed in the simulants under quiescent conditions (open to air) showed appreciable interface attack. However, when the solution or the cell head space was purged with zero air (compressed air without $\mathrm{CO}_{2}$ ), the corrosion attack was minimal. This may indicate that the attack at the interface was due to a change in the interfacial $\mathrm{pH}$ resulting from reaction with $\mathrm{CO}_{2}$ in the air.

The results of the four tests in which oxygen and carbon dioxide were both excluded from the test systems with the AP-105 simulant at $50^{\circ} \mathrm{C}$ imply that one or both of these gases are required for rapid corrosion at the liquid air interface. The results of the two tests carried out with air from which carbon dioxide has been removed imply that the carbon dioxide content of air is the key factor in determining the rate of the interfacial corrosion process. Because in the absence of carbon dioxide the corrosion rate was low and since the bulk $\mathrm{pH}$ at the conclusion of these tests was observed to be similar, it seems that interfacial corrosion is a localized phenomena and that the rate of transport of hydroxide ion from the bulk solution to the corrosion site is insufficient to neutralize the acidic influence of carbon dioxide in unmixed solutions. However, no confirmatory chemical analysis has been performed to validate the proposed $\mathrm{CO}_{2} / \mathrm{pH}$ reduction mechanism.

\subsection{SLOW STRAIN RATE TESTING IN TANK 241-AP-105 BASED SIMULANTS}

Table 8 summarizes the results of SSRTs performed in AP-105 based simulants. Variants include "mixed" and "evaporated" simulants. Tests were performed at $50^{\circ} \mathrm{C}$, at potentials of $0 \mathrm{mV}$ and $-250 \mathrm{mV}$ vs. SCE, and at OCP. In two cases the tests were stopped at the ultimate tensile strength of the steel, in order to study the role of the strain in the development of intergranular SCC in the gage sections of the samples. Replicate tests were conducted for some conditions. 
Table 8. A Summary of Slow Strain Rate Tests Performed in AP-105 Based Simulants.

\begin{tabular}{|c|c|c|c|c|c|c|c|c|c|}
\hline $\begin{array}{l}\text { Test } \\
\text { ID }\end{array}$ & Base Chemistry & pH & $\begin{array}{c}\text { Temp } \\
\left({ }^{\circ} \mathrm{C}\right)\end{array}$ & $\begin{array}{l}\text { Pot } \\
(\mathrm{mV})\end{array}$ & $\begin{array}{l}\text { OCP } \\
(\mathrm{mV})\end{array}$ & $\begin{array}{c}\text { Failure } \\
\text { Strain } \\
(\%)\end{array}$ & $\begin{array}{l}\text { Failure } \\
\text { Time } \\
\text { (hrs) }\end{array}$ & $\begin{array}{l}\text { SEM Surface } \\
\text { Exam }\end{array}$ & $\begin{array}{c}\text { Estimated CGR } \\
(\mathrm{mm} / \mathrm{sec})\end{array}$ \\
\hline 50 & AP-105-PSC & $13+$ & 50 & 0 & -242 & 15.0 & 41.6 & $\begin{array}{l}\text { Visual } \\
\text { cracking }\end{array}$ & \\
\hline 51 & AP-105-PSC & $13+$ & 50 & $\mathrm{OCP}$ & -249 & 22.3 & 62.1 & $\begin{array}{l}\text { Secondary } \\
\text { Crack IG }\end{array}$ & $1.3 \times 10^{-7}$ \\
\hline 52 & AP-105-PSC & $13+$ & 50 & $\mathrm{OCP}$ & -289 & 21.5 & 62.1 & Ductile* & - \\
\hline 53 & AP-105-PSC & $13+$ & 50 & 0 & -259 & 16.3 & 49.2 & $\begin{array}{l}\text { Visual } \\
\text { cracking }\end{array}$ & $3 \times 10^{-6}$ \\
\hline 54 & AP-105-PSC & $13+$ & 50 & 0 & -287 & 19.4 & 53.8 & $\begin{array}{l}\text { Visual } \\
\text { cracking }\end{array}$ & \\
\hline 59 & $\begin{array}{l}\text { AP-105- } \\
\text { Evaporated }\end{array}$ & $13+$ & 50 & OCP & -510 & 21.2 & 59.0 & Ductile & - \\
\hline 60 & AP-105-PSC** & $13+$ & 50 & $\mathrm{OCP}$ & -277 & - & - & No cracking & - \\
\hline 62 & $\begin{array}{l}\text { AP-105- } \\
\text { Evaporated } \\
\text { (ratio 0.1) }\end{array}$ & $13+$ & 50 & OCP & -333 & 23.3 & 64.7 & Ductile & - \\
\hline 63 & $\begin{array}{l}\text { AP-105-Mixed } \\
\text { (ratio } 0.1 \text { ) }\end{array}$ & $13+$ & 50 & OCP & -259 & 23.2 & 64.3 & Ductile & - \\
\hline 64 & AP-105-Mixed & $13+$ & 50 & $\mathrm{OCP}$ & -312 & 21.7 & 60.3 & Ductile & - \\
\hline 65 & AP-105-PSC** & $13+$ & 50 & -250 & -281 & - & - & No cracking & - \\
\hline
\end{tabular}

*Secondary cracks were re-examined using the SEM, no apparent intergranular features

** Test was stopped at ultimate tensile stress

Figure 30 shows a plot of the stress-strain data from two of the slow strain rate tests, SSRT 50 and 51, performed in the AP-105-PSC base simulant. The specimens failed at 15.0 and $22.3 \%$ strain. The former failure strain is lower than expected for this grade of steel, and is indicative of reduced cross-sectional area associated with severe corrosion attack during the testing. Visual and stereographic examination of the test specimens indicated severe corrosion, though the nature of the corrosion was not typical of the corrosion that had been observed in previous testing. 
Figure 30. The Stress-Strain Behavior of Samples Tested in AP-105-PSC Based Simulants at $0 \mathrm{mV}$ vs. SCE and at OCP (-249 $\mathrm{mV}$ vs. SCE).

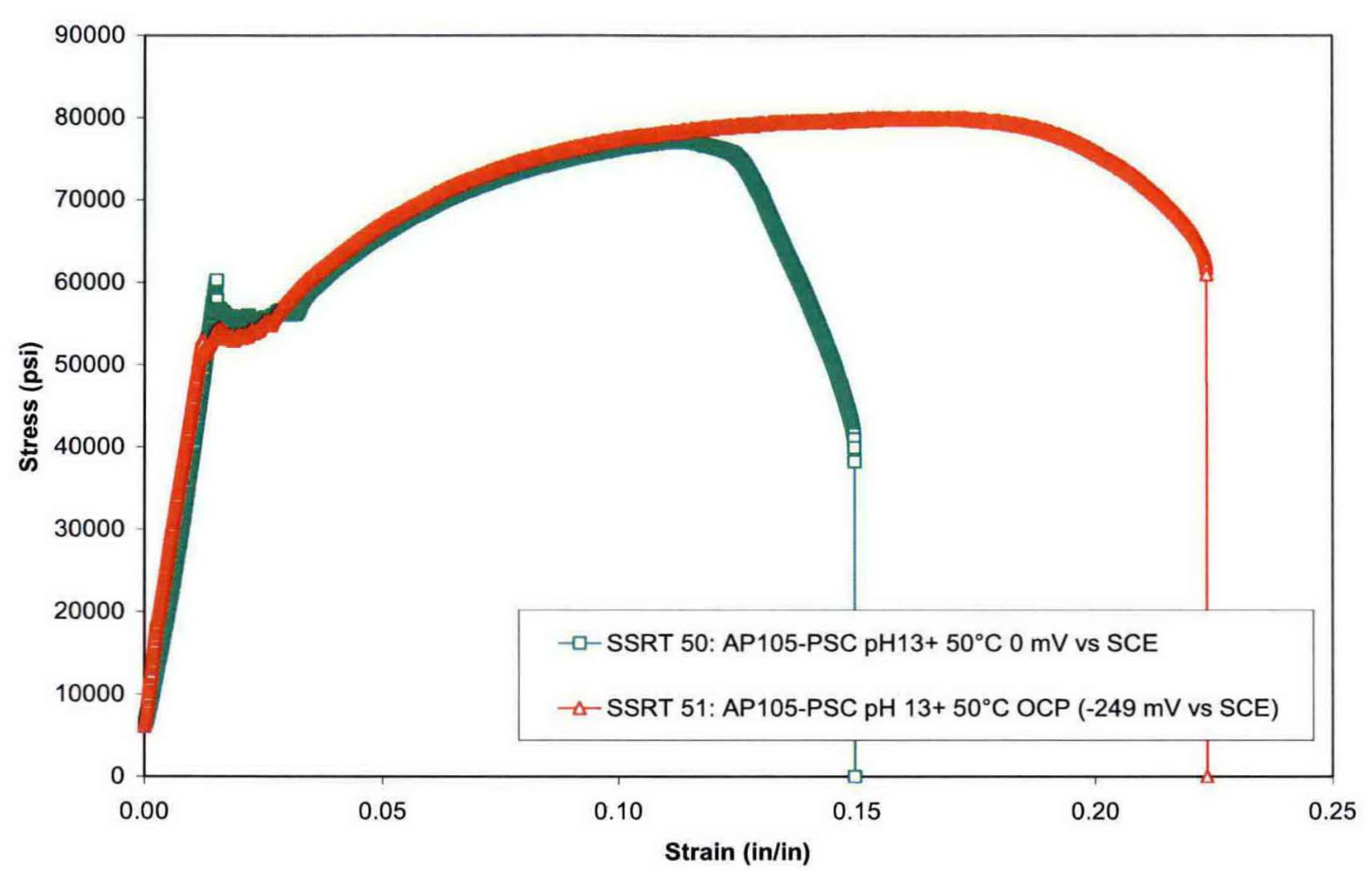

A fracture surface examination of the samples tested at OCP (SSRT 51 and SSRT 52) indicated ductile failure. However, in SSRT 51, with an OCP of $-249 \mathrm{mV}$ vs. SCE, secondary crack examination showed intergranular features, indicative of high pH SCC (Figure 31). Similar behavior has been observed in previous testing, for example testing in modified AY-102 simulants with high nitrate contents when the specimen was polarized between -200 to $-300 \mathrm{Mv}$ vs. SCE. In addition, some tarnishing was seen on the shafts of samples as shown in Figure 32.

The intergranular features observed in the secondary cracks in the shaft of SSRT 51, tested in AP-105-PSC simulant at OCP, were unexpected. SCC has not been observed in any tests performed at OCP in waste simulants, including AN-107. One thought is that the sample may have been overly strained to enable the formation of the side cracks. This overly strained condition is unlikely to be relevant under normal tank operations. To investigate the role of strain, SSRT 60 was performed in AP-105-PSC simulant at OCP, but the test was stopped at the ultimate tensile strength. Post-test examination did not reveal any evidence of secondary cracking (Figure 33). 
Figure 31. An Electron-Micrograph of a Secondary Crack in Test Sample SSRT-51 Performed in AP-105-PSC Standard Simulant at $50^{\circ} \mathrm{C}$, $\mathrm{pH} \mathrm{13+}$, and at $\mathrm{OCP}$ (-249 mV vs. SCE).

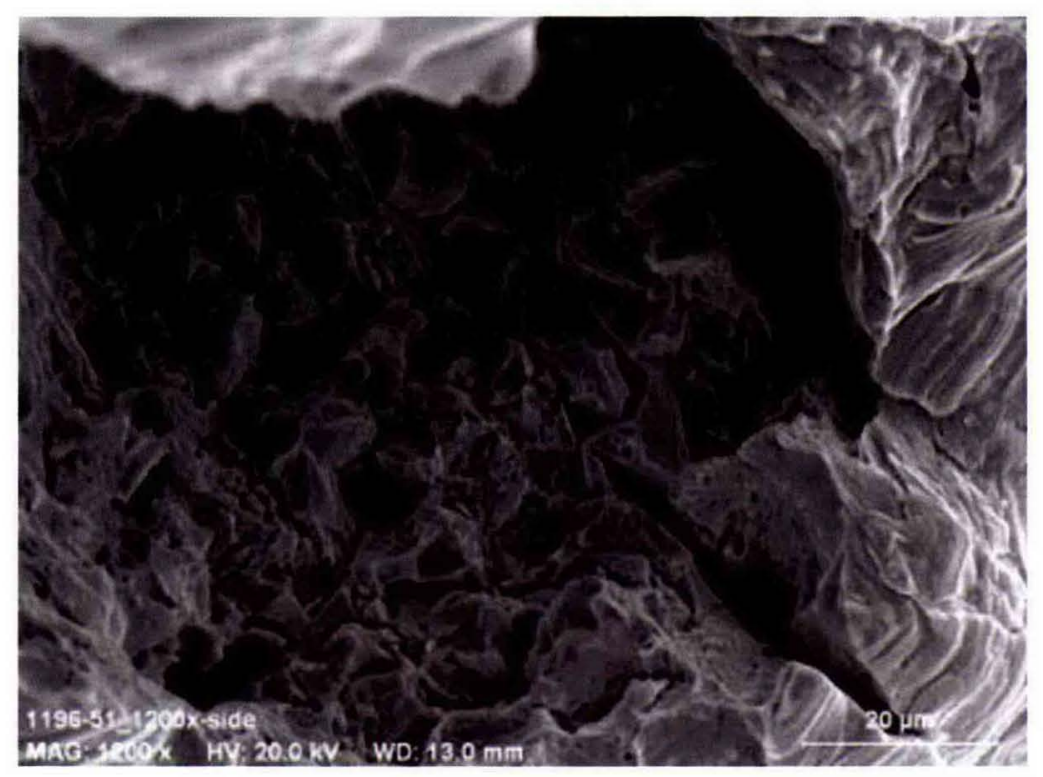

Figure 32. A Stereo-Micrograph of the Test Sample from SSRT-51 Performed in AP-105-PSC Standard Simulant at $50^{\circ} \mathrm{C}$, pH 13+, and at OCP (-249 $\mathrm{mV}$ vs. SCE).

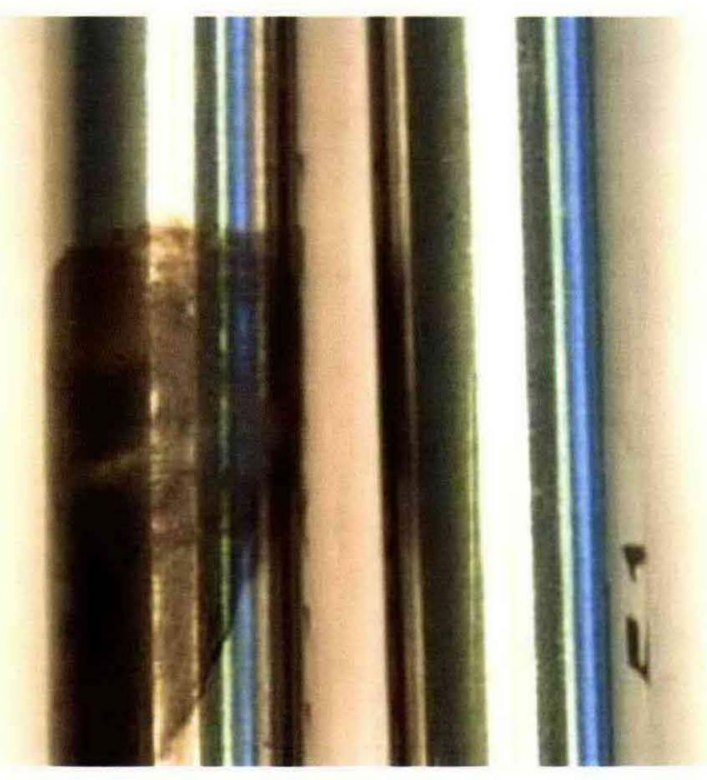


Figure 33. A Stereo-Micrograph of the Test Sample from SSRT-60 Performed in

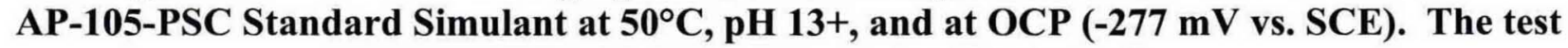
was stopped at the ultimate tensile strength.

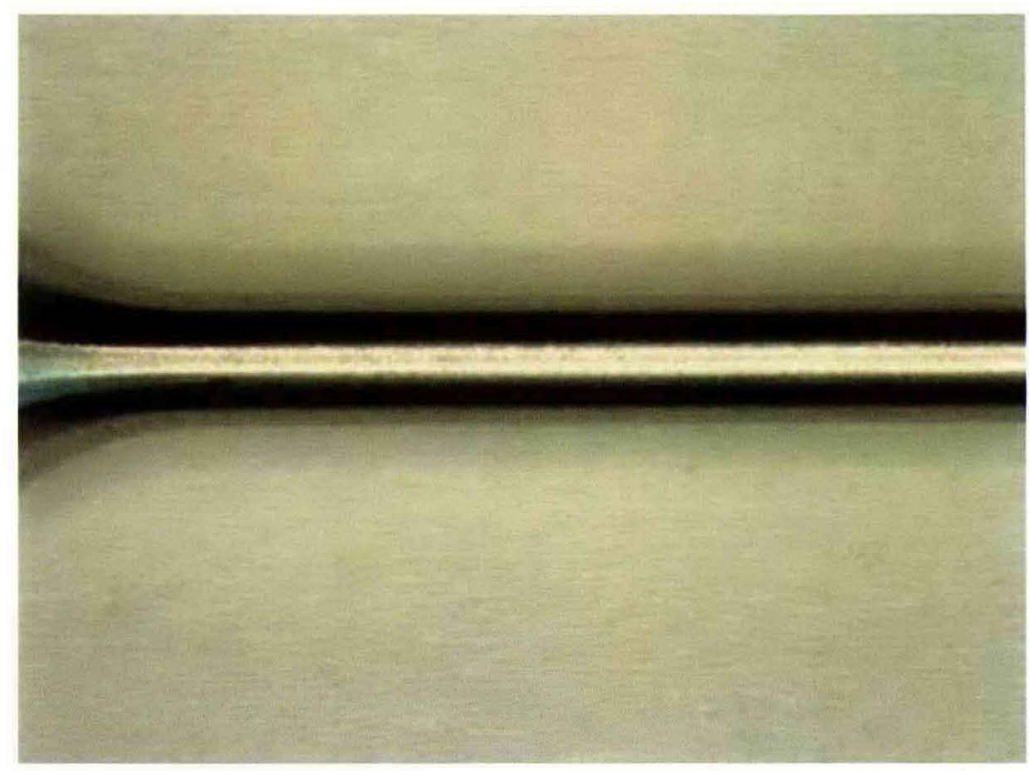

It was also noted that the OCP in SSRT 51 was $-249 \mathrm{mV}$ and the OCP in SSRT 52 was $-289 \mathrm{mV}$ vs. SCE. The test performed at the more noble potential was the one that had intergranular features. To determine if the more noble potential and/or the increased strain was primarily responsible for the SCC at OCP, SSRT 65 was performed in AP-105-PSC simulant at $-250 \mathrm{mV}$ vs. SCE, and stopped at the ultimate tensile strength. No secondary cracking was observed, indicating the SCC in SSRT 51 was most likely influenced by the high strain.

Examination of the fracture surface of the samples tested at $0 \mathrm{mV}$ vs. SCE in the AP-105-PSC simulant showed intergranular features, indicative of high pH SCC (Figure 34). The observation of SCC at $0 \mathrm{mV}$ vs. SCE is expected in a nitrate-based simulant, based on the results obtained in the previous testing programs. Previous testing had demonstrated that steels were susceptible to SCC in simulants containing high concentrations of nitrate and with low concentrations of inhibiting nitrite. 
Figure 34. Electron-Micrograph of the Fracture Surface of Test Sample from SSRT-53 Performed in AP-105-PSC Standard Simulant at $50^{\circ} \mathrm{C}$, $\mathrm{pH} 13+$, and at $0 \mathrm{mV}$ vs. SCE.

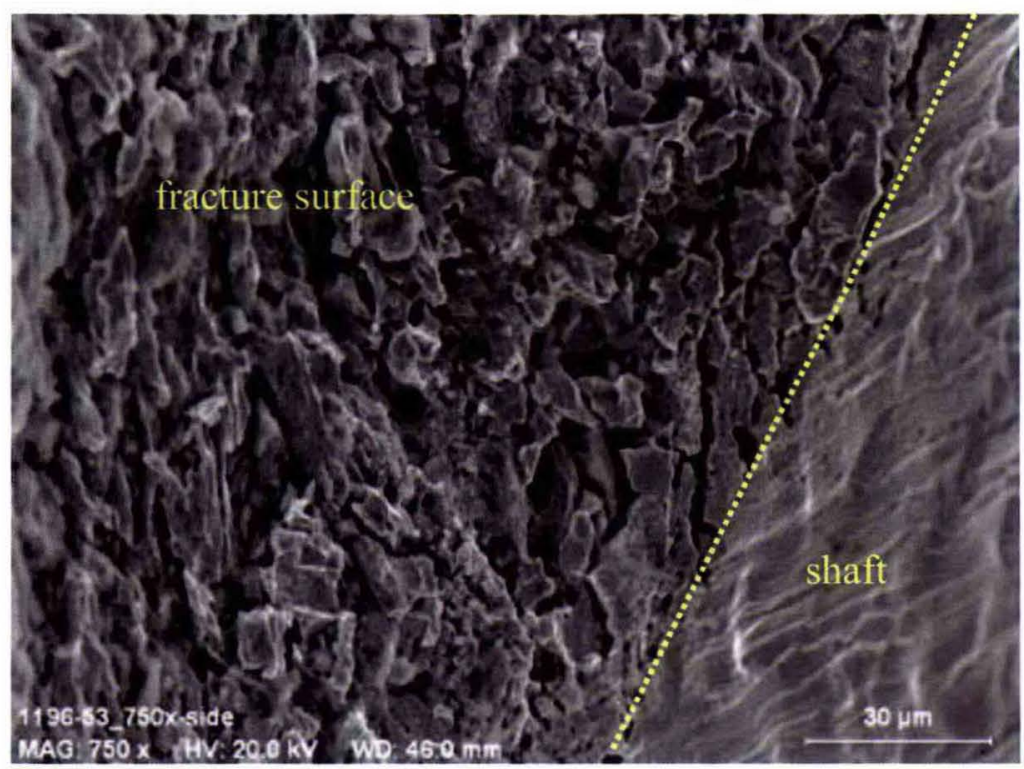

Visual examination of the samples tested under polarizing conditions ( $0 \mathrm{mV}$ vs. SCE) also revealed severe corrosion on the sample above the gauge section (Figure 35 and Figure 36). A close examination of the SSRT cell indicated that the corroded section was at the liquid/vapor interface (Figure 37). Similar corrosion attack was observed in replicate tests. The discussion in the earlier section suggests the attack at the interface may be a result of the depletion of the inhibiting species (e.g., nitrite) or a reduction in the interfacial $\mathrm{pH}$, both of which would result in the formation of a locally aggressive environment.

Significant corrosion has not been observed during SSR testing except under highly aggressive conditions in modified AN-107 simulants. Re-examination of the samples from testing in AN-107 with decreased nitrite concentrations showed severe corrosion along the entire length on the test sample, as opposed to just at the liquid/vapor interface. For those tests in the AN-107 program, however, the nitrite concentration was lower than $0.27 \mathrm{M}$ while the simulant contained comparable amount of nitrate. Thus, the environment was sufficiently aggressive to attack the entire immersed portion. In the case of AP-105-PSC, it seems the nitrite concentration is near a threshold level below which localized corrosion could initiate. Therefore, the corrosion was observed at the liquid/vapor interface where even a slight decrease in nitrite or drop in $\mathrm{pH}$ could change its concentration to be below the threshold leading to an aggressive environment.

Corrosion attack was also seen near the base of several test samples. This attack was originally believed to be crevice corrosion associated with the seal between the test cell and sample.

However, further examination indicated the corrosion was higher up on the sample than the test cell seal. Because a significant amount of corrosion product was observed at the interface (Figure 36), it was speculated that corrosion products may have accumulated at the base of the test cell and contributed to creating an occluded region. This hypothesis, however, was not studied further but is supported by the observation of corrosion products at the location of heavy corrosion. What is unclear is if the buildup of corrosion products is the cause or the result (or both) of the corrosion reaction at this location. 
Figure 35. Stereo-Micrograph of the Test Sample from SSRT-53 Performed in AP-105-PSC Standard Simulant at $50^{\circ} \mathrm{C}, \mathrm{pH} 13+$, and at $0 \mathrm{mV}$ vs. SCE.

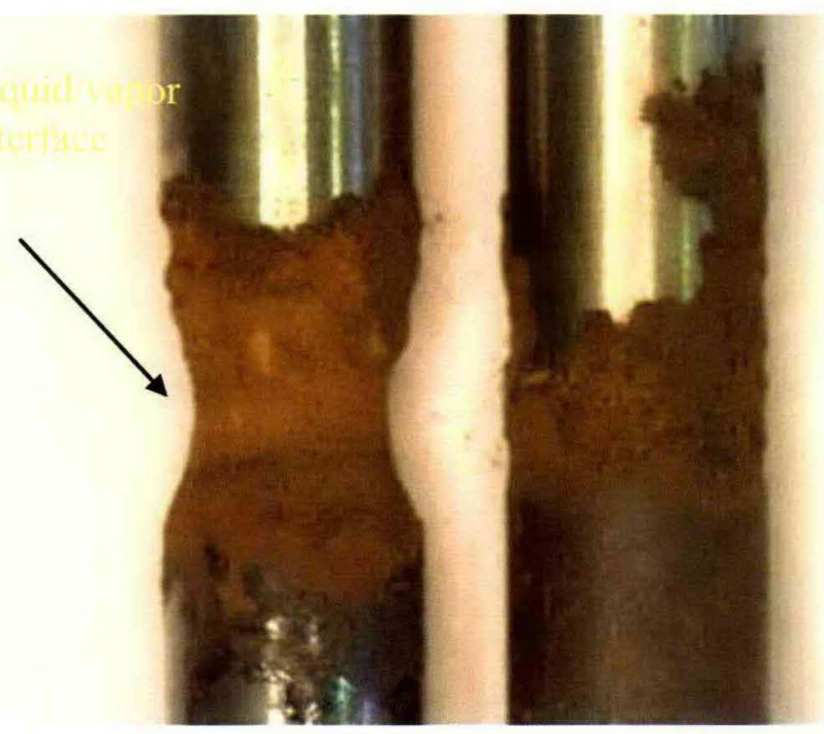

Figure 36. Photograph of the Test Sample from SSRT-54 Performed in AP-105-PSC Standard Simulant at $50^{\circ} \mathrm{C}, \mathrm{pH} 13+$, and at $0 \mathrm{mV}$ vs. SCE.

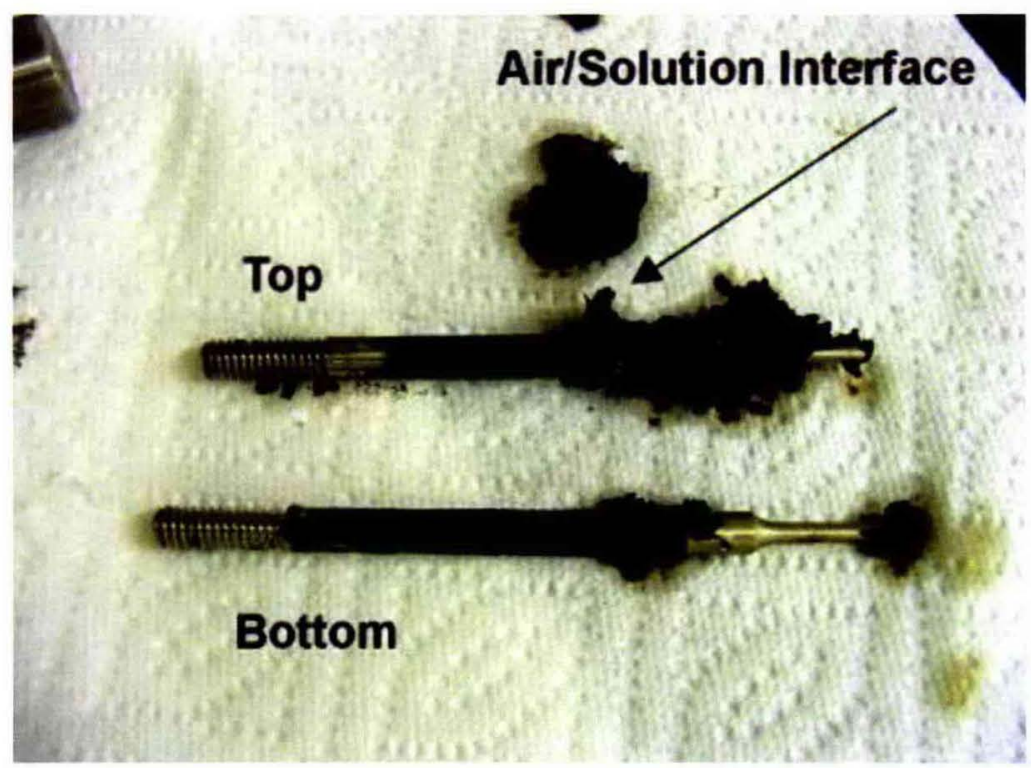


Figure 37. Photograph and Schematic of the Test Cell and Sample Indicating Regions of Corrosion (Schematic Not To Scale).

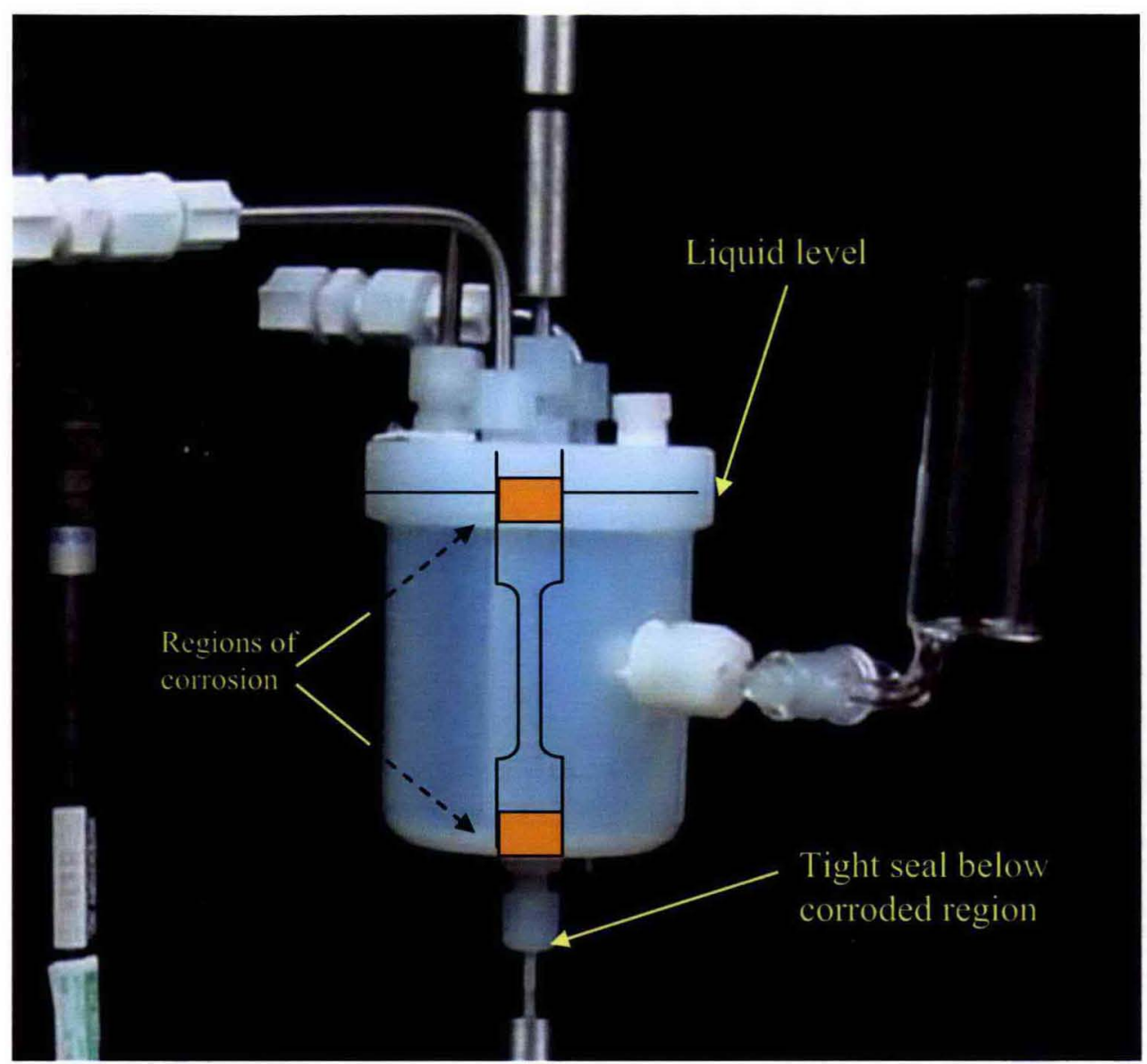

Tests performed in the AP-105 variants, that is mixed and evaporated simulants (SSRT 64 and SSRT 59, respectively), showed no evidence of SCC. These simulants have nitrite/nitrate ratios of $\sim 0.14$, so it was expected there may be SCC based on previous testing in the simulants with low nitrite contents. The simulants were modified to further decrease the nitrite/nitrate ratio to 0.1 to study the SCC sensitivity to the chemistry. SSRT 63 and SSRT 62, performed in mixed and evaporated simulants with a decreased nitrite content showed no evidence of SCC. Note that all of these tests were performed at OCP, and potentials were lower than potentials at which SCC has typically been observed.

\subsection{ELECTROCHEMICAL POLARIZATION BEHAVIOR IN TANK 241-SY-103-PIL BASED SIMULANTS}

Table 9 summarizes the results of a CPP test conducted in the SY-103-PIL baseline simulant that investigated the susceptibility of the steel to localized corrosion in a simulant containing high chloride $(0.5 \mathrm{M})$. The chloride concentration in this simulant is the highest among the simulants that have been investigated thus far. No tests were performed in modified SY-103-PIL simulants. 
Table 9. A Summary of Electrochemical Test Performed in SY-103-PIL Based Simulant.

\begin{tabular}{|c|c|c|c|c|c|c|c|c|c|c|c|}
\hline $\begin{array}{c}\text { Base } \\
\text { Chemistry }\end{array}$ & $\mathbf{p H}$ & $\begin{array}{c}\mathrm{NO}_{2}^{-} \\
(\mathbf{M})\end{array}$ & $\begin{array}{c}\mathbf{N O}_{3}^{-} \\
(\mathbf{M})\end{array}$ & $\begin{array}{c}\text { TIC } \\
(\mathbf{M})\end{array}$ & $\begin{array}{c}\mathbf{O H}^{-} \\
(\mathbf{M})\end{array}$ & $\begin{array}{c}\mathrm{Cl}^{-} \\
(\mathbf{M})\end{array}$ & $\begin{array}{c}\mathbf{F}^{-} \\
(\mathbf{M})\end{array}$ & $\begin{array}{c}\mathbf{T} \\
\left({ }^{\circ} \mathbf{C}\right)\end{array}$ & $\begin{array}{c}\text { Aeration } \\
\text { condition }\end{array}$ & Visual & $\begin{array}{c}\text { Sample ID } \\
\text { (\#EL1196-) }\end{array}$ \\
\hline $\begin{array}{c}\text { SY-103- } \\
\text { PIL }\end{array}$ & $>13$ & 2.91 & 1.97 & 0.123 & 2.43 & 0.5 & 0 & 50 & $\mathrm{~N}_{2}$ purging & No pitting & 89 \\
\hline
\end{tabular}

Figure 38 shows the CPP curve obtained in deaerated SY-103-PIL simulant at $50^{\circ} \mathrm{C}$ with a pH above 13. The CPP curve showed a negative hysteresis loop. No pitting corrosion was noted on the samples during post-test inspection. This phenomenon could indicate that there are other inhibiting species present in this simulant (e.g., 2.91 M nitrite in SY-103-PIL and/or pH 13), even though the chloride concentration in this simulant is high, $0.5 \mathrm{M}$.

Figure 38. A CPP Curve in Deaerated SY-103-PIL Simulant ( $\mathrm{pH}>13$ and $\left.\mathrm{T}=50^{\circ} \mathrm{C}\right)$.

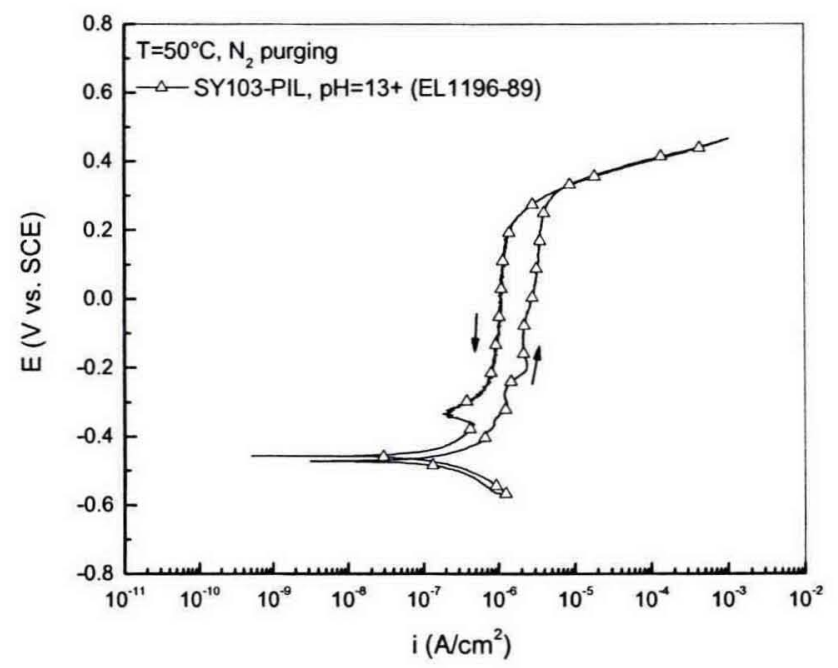

\subsection{SLOW STRAIN RATE TESTING IN TANK 241-SY-103-PIL BASED SIMULANTS}

Table 10 summarizes the results of the slow strain rate tests performed in SY-103-PIL simulants in quiescent air. Tests were performed at $50^{\circ} \mathrm{C}$, and potentiostatically polarized to $0 \mathrm{mV}$ vs. SCE or at OCP. Both tests were performed in the standard SY-103-PIL simulant. This simulant has high nitrate $(1.97 \mathrm{M})$ and nitrite $(2.91 \mathrm{M})$ concentrations, as well as a high chloride $(0.5 \mathrm{M})$ concentration.

Table 10. A Summary of Slow Strain Rate Tests Performed in SY-103-PIL Based Simulants.

\begin{tabular}{|c|c|c|c|c|c|c|c|c|c|}
\hline $\begin{array}{c}\text { Test } \\
\text { ID }\end{array}$ & Base Chemistry & $\mathbf{p H}$ & $\begin{array}{c}\text { Temp } \\
\left({ }^{\circ} \mathbf{C}\right)\end{array}$ & $\begin{array}{c}\text { Pot } \\
(\mathbf{m V})\end{array}$ & $\begin{array}{c}\text { OCP } \\
(\mathbf{m V})\end{array}$ & $\begin{array}{c}\text { Failure } \\
\text { Strain } \\
(\%)\end{array}$ & $\begin{array}{c}\text { Failure } \\
\text { Time } \\
(\mathbf{h r s})\end{array}$ & $\begin{array}{c}\text { SEM Surface } \\
\text { Exam }\end{array}$ & $\begin{array}{c}\text { Estimated CGR } \\
(\mathbf{m m} / \mathbf{s e c})\end{array}$ \\
\hline 55 & SY-103-PIL & 14 & 50 & $\mathrm{OCP}$ & -424 & 22.0 & 61.2 & Ductile & - \\
\hline 57 & SY-103-PIL & 14 & 50 & 0 & -477 & 22.4 & 62.2 & Ductile & - \\
\hline
\end{tabular}


Figure 39 is a plot of the stress-strain data from the two tests. When polarized to $0 \mathrm{mV}$ vs. SCE the SSRT specimen failed at $22.4 \%$ strain. The specimen that was tested at open circuit failed at $22.0 \%$ strain. No evidence of SCC was observed in either of the tests. Both stereoscopic (Figure 40) and electron microscopic (Figure 41) examinations displayed ductile fracture features. Examination of the secondary microcracks observed in the gauge section of the specimen indicated no intergranular features. These results are consistent with CPP results already discussed. That is, although chloride concentration is elevated in this simulant, other inhibiting chemicals may still be able to prevent SCC.

Figure 39. The Stress-Strain Behavior of Samples Tested in SY-103-PIL Based Simulants at $0 \mathrm{mV}$ vs. SCE and at OCP (-424 $\mathrm{mV}$ vs. SCE).

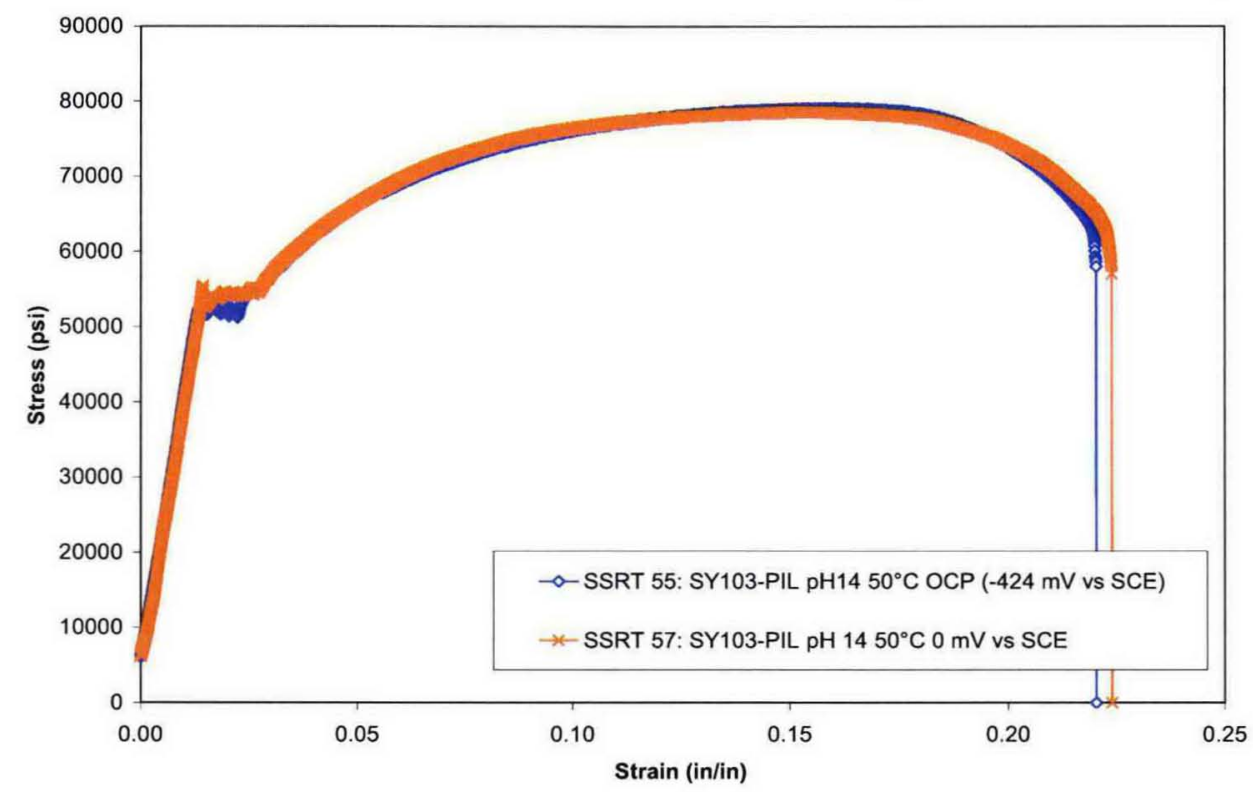

Figure 40. Stereo-Micrograph of the Test Sample from SSRT-57 Performed in SY-103-PIL Standard Simulant at $50^{\circ} \mathrm{C}, \mathrm{pH} 14$, at a Potential of $0 \mathrm{mV}$ vs. SCE. The yellow dashed circles indicate axial microcracks observed on the shaft of the sample.

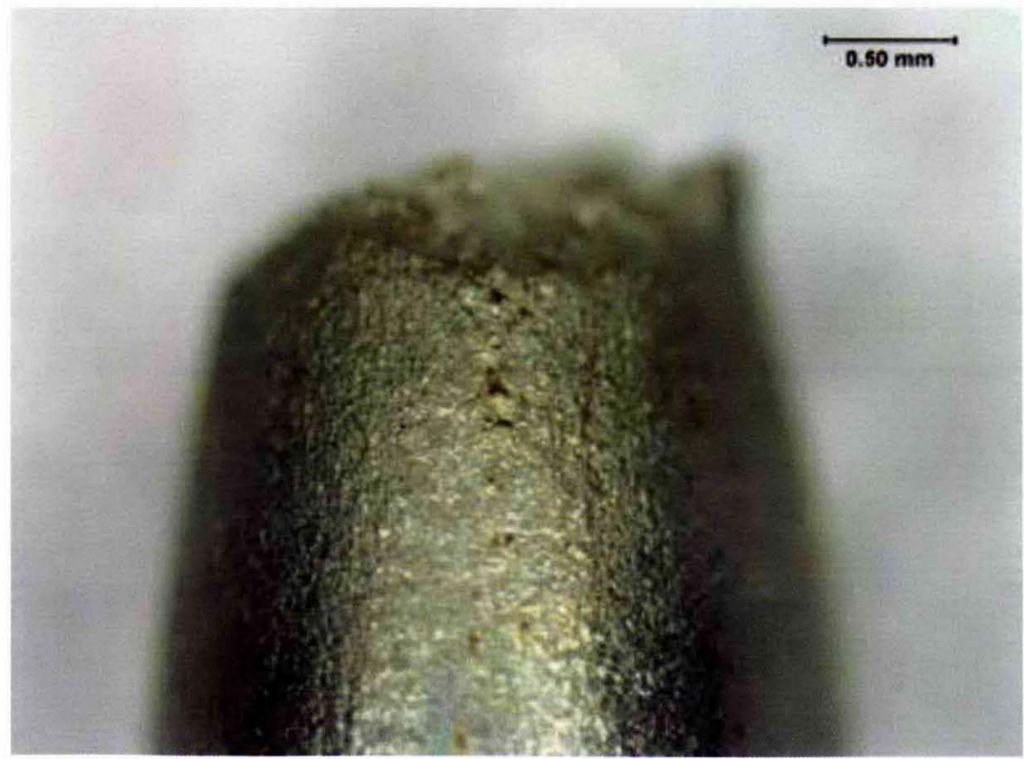


Figure 41. Electron-Micrograph of the Fracture Surface of Test Sample from SSRT-57 Performed in SY-103-PIL Standard Simulant at $50^{\circ} \mathrm{C}$, pH 14, at a Potential of $0 \mathrm{mV}$ vs. SCE.

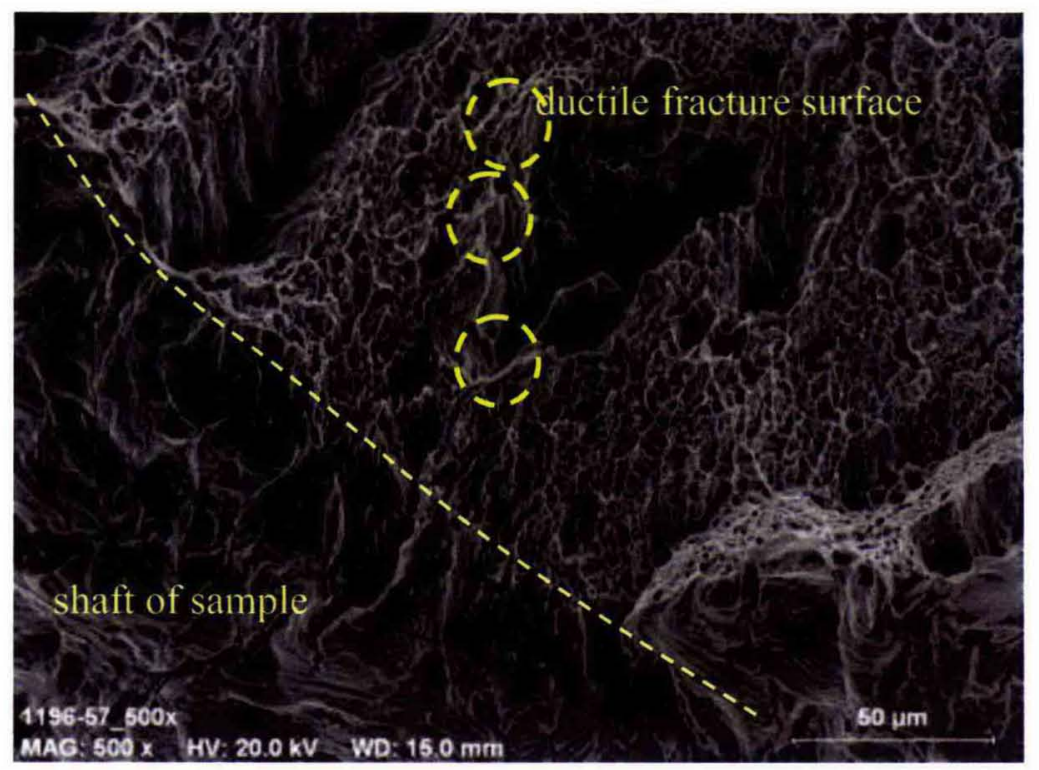

\subsection{ELECTROCHEMICAL POLARIZATION BEHAVIOR IN TANK 241-AW-105 BASED SIMULANTS}

Table 11 summarizes the CPP test conducted in the AW-105 baseline simulant. These tests were aimed at investigating the susceptibility of the steel to localized corrosion in simulants containing high fluoride concentrations $(0.58 \mathrm{M}$ fluoride in the AW-105-PIL simulant) or a low nitrite-tonitrate concentration ratio (Nitrite/nitrate of 0.145 in the AW-105-PSC simulant). No tests were performed using modified AW-105 simulants.

Table 11. A Summary of Electrochemical Test Performed in AW-105 Based Simulant.

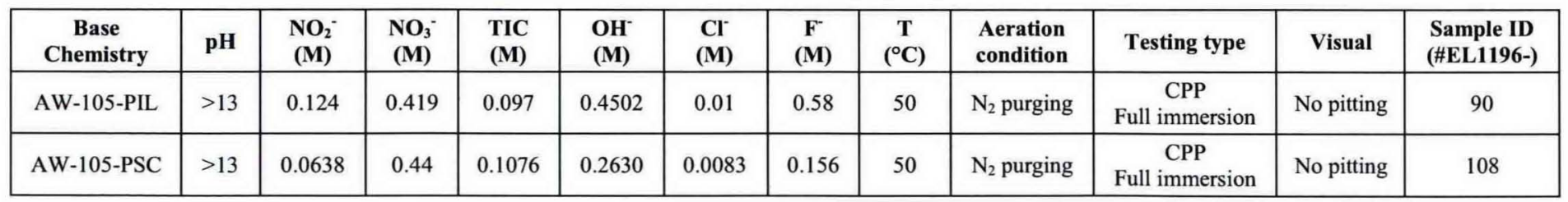

Figure 42 shows the CPP curve obtained in deaerated AW-105-PIL simulant at $50^{\circ} \mathrm{C}$ with a pH above 13. The CPP curve showed a negative hysteresis loop and no pitting corrosion was noted on the samples during post-test inspection even though the fluoride concentration in this simulants is as high as $0.58 \mathrm{M}$. This indicates that either there are other inhibiting species present in these simulant (e.g., pH 13) or that the concentration of the aggressive species (e.g., nitrate at $0.42 \mathrm{M}$ ) is below a critical threshold above which localized corrosion would occur. 
Figure 42. A CPP Curve in Deaerated AW-105-PIL Simulant $\left(\mathrm{pH}>13\right.$ and $\left.\mathrm{T}=50^{\circ} \mathrm{C}\right)$.

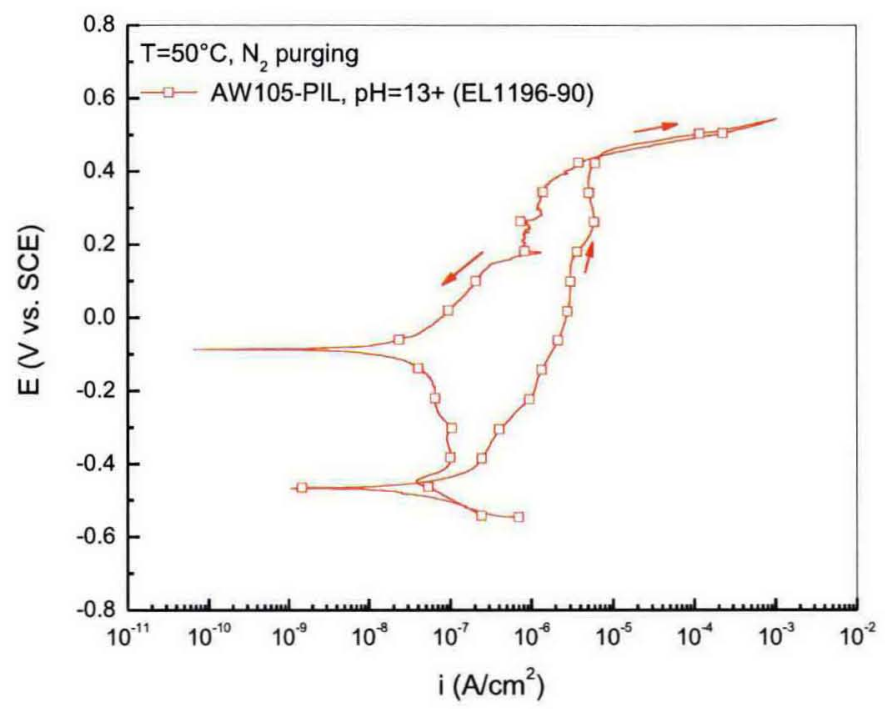

Figure 43 is a CPP curves in deaerated AW-105-PSC simulant at $50^{\circ} \mathrm{C}$. Again, no clear positive hysteresis loop was observed on the curve and the sample did not show any indication of localized corrosion. The lack of localized corrosion on the samples suggests that even though the nitrite/nitrate ratio in this simulants is lower than other simulants investigated before, other inhibitory species present in these simulants were able to efficiently prevent localized corrosion. Additionally, the benign nature of these simulants with respect to localized corrosion may be a result of the relatively low concentration of the aggressive nitrate.

Figure 43. A CPP Curve in Deaerated AW-105-PSC Simulant $\left(\mathrm{pH}>13\right.$ and $\left.\mathrm{T}=50^{\circ} \mathrm{C}\right)$.

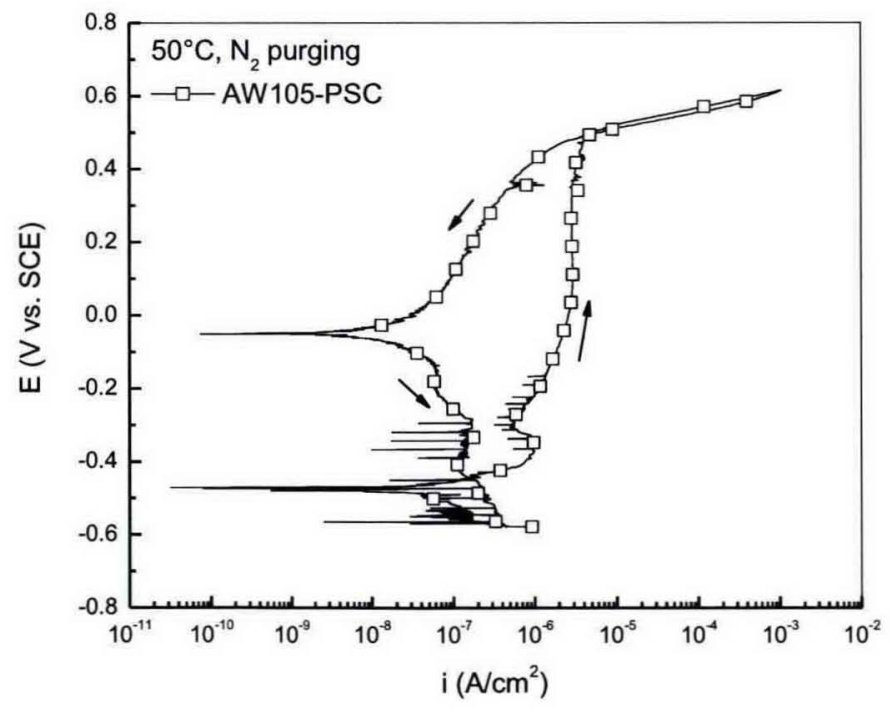




\subsection{SLOW STRAIN RATE TESTING IN TANK 241-AW-105 BASED SIMULANTS}

Table 12 summarizes the results of the SSRTs performed in AW-105 based simulants. Tests were performed at $50^{\circ} \mathrm{C}$ and at $\mathrm{OCP}$ or potentiostatically polarized to $0 \mathrm{mV}$ vs. SCE. Two tests were performed in the base AW-105-PIL simulant. This simulant has a low nitrate $(0.42 \mathrm{M})$ and nitrite $(0.12 \mathrm{M})$ concentration, as well as a high fluoride $(0.58 \mathrm{M})$ content. Six tests were performed in AW-105-PSC or PSC-modified simulant. The PSC simulant has a low nitrate $(0.44 \mathrm{M})$ and low nitrite $(0.06 \mathrm{M})$ concentration. The PSC -modified tests were performed with either half the typical nitrite, or with three times the typical nitrite and six times the typical nitrate. These modifications were made to study the nitrite / nitrate ratio versus potential relationship.

Table 12. A Summary of Slow Strain Rate Tests Performed in AW-105 Based Simulants.

\begin{tabular}{|c|c|c|c|c|c|c|c|c|c|}
\hline $\begin{array}{c}\text { Test } \\
\text { ID }\end{array}$ & Base Chemistry & $\mathbf{p H}$ & $\begin{array}{c}\text { Temp } \\
\left({ }^{\circ} \mathbf{C}\right)\end{array}$ & $\begin{array}{c}\mathbf{P o t} \\
(\mathbf{m V})\end{array}$ & $\begin{array}{c}\mathbf{O C P} \\
(\mathbf{m V})\end{array}$ & $\begin{array}{c}\text { Failure } \\
\text { Strain } \\
(\%)\end{array}$ & $\begin{array}{c}\text { Failure } \\
\mathbf{T}) \\
(\mathbf{h r s})\end{array}$ & $\begin{array}{c}\text { SEM Surface } \\
\mathbf{E x a m}\end{array}$ & $\begin{array}{c}\text { Estimated CGR } \\
(\mathbf{m m} / \mathbf{s e c})\end{array}$ \\
\hline 56 & AW-105-PIL & $13+$ & 50 & OCP & -290 & 22.3 & 62.0 & Ductile & - \\
\hline 58 & AW-105-PIL & $13+$ & 50 & 0 & -193 & 21.7 & 60.3 & Ductile & - \\
\hline 66 & AW-105-PSC & $13+$ & 50 & OCP & -235 & 21.3 & 61.9 & Ductile & - \\
\hline 71 & AW-105-PSC & $13+$ & 50 & -100 & -269 & 23.4 & 65.1 & Ductile & - \\
\hline 72 & AW-105-PSC & $13+$ & 50 & -50 & -210 & 21.9 & 60.8 & Ductile & - \\
\hline 73 & $\begin{array}{c}\text { AW-105-PSC } \\
\text { (half nitrite) }\end{array}$ & $13+$ & 50 & -100 & -217 & 22.5 & 65.4 & Ductile & - \\
\hline 74 & AW-105-PSC “6X" & $13+$ & 50 & -100 & -257 & 22.1 & 61.3 & Ductile & - \\
\hline 75 & AW-105-PSC “6X" & $13+$ & 50 & -50 & -270 & 8.5 & 23.6 & $\begin{array}{l}\text { Visible } \\
\text { corrosion }\end{array}$ \\
\hline
\end{tabular}

Figure 44 is a plot of the stress-strain data from the two tests performed in AW-105-PIL. When polarized to $0 \mathrm{mV}$ vs. SCE, the SSRT specimen failed at $21.7 \%$ strain. The specimen that was tested at open circuit failed at $22.3 \%$ strain. Corrosion product was observed around axial microcracks along the shaft of the test sample that was performed at OCP (Figure 45). These microcracks have been observed in many of the previous test samples, and are attributed to grain boundary tearing. No intergranular features were observed during SEM examination, as shown in Figure 46 and Figure 47, though it is possible that such features corroded away prior to examination ( though this seems unlikely given the nominally benign nature of this simulant) The test performed at $0 \mathrm{mV}$ vs. SCE was also devoid of intergranular features on the fracture surface (Figure 48); however, there was some interfacial corrosion along the shaft of the test specimen at the liquid/vapor interface (Figure 49). Since the nitrite concentration in the AW-105-PIL is relatively low compared to other aggressive species, the attack at the interface may be due to a similar mechanism that led to the interface corrosion in the AP-105-PSC. That is, although the existing nitrite concentration was able to inhibit localized corrosion in the bulk solution, in the case that the nitrite concentration was decreased due to an unknown depletion mechanism at the interface, the environment could become aggressive to cause localized corrosion. 
Figure 44. Stress-Strain Behavior of Samples Tested in AW-105-PIL Based Simulants at $0 \mathrm{mV}$ vs. SCE and at OCP (-290 $\mathrm{mV}$ vs. SCE).

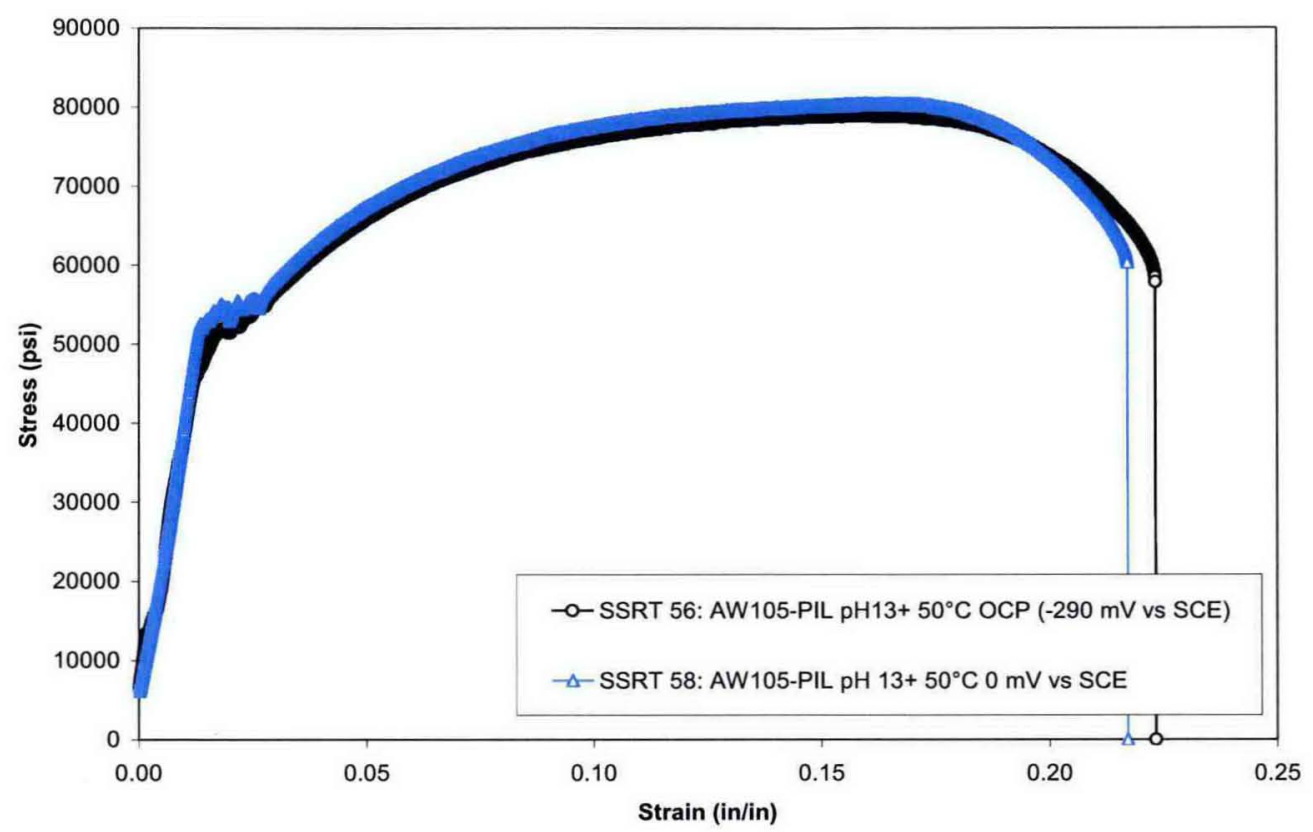

Figure 45. Stereo-Micrograph of the Test Sample from SSRT-56 Performed in AW-105-PIL Standard Simulant at $50^{\circ} \mathrm{C}$, $\mathrm{pH} \mathrm{13+}$, at $\mathrm{OCP}(-290 \mathrm{mV}$ vs. SCE). The yellow dashed circles indicate axial microcracks observed on the shaft of the sample.

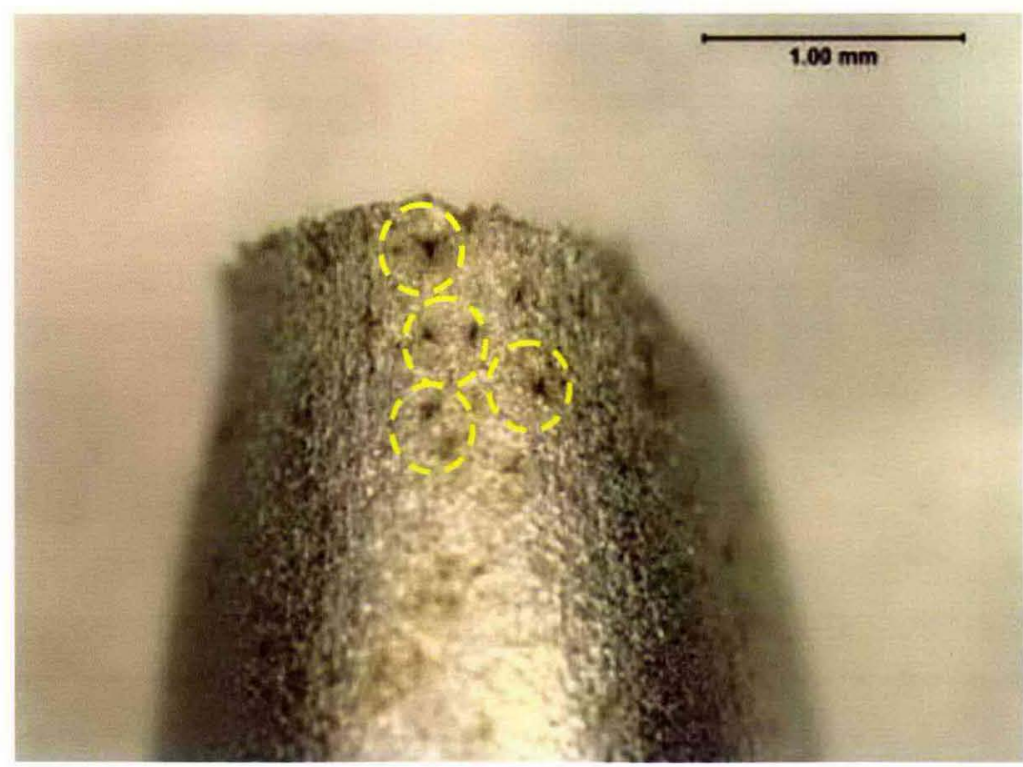


Figure 46. Electron-Micrograph of the Fracture Surface of Test Sample from SSRT-56 Performed in AW-105-PIL Standard Simulant at $50^{\circ} \mathrm{C}$, pH 13+, at OCP (-290 $\mathrm{mV}$ vs. SCE).

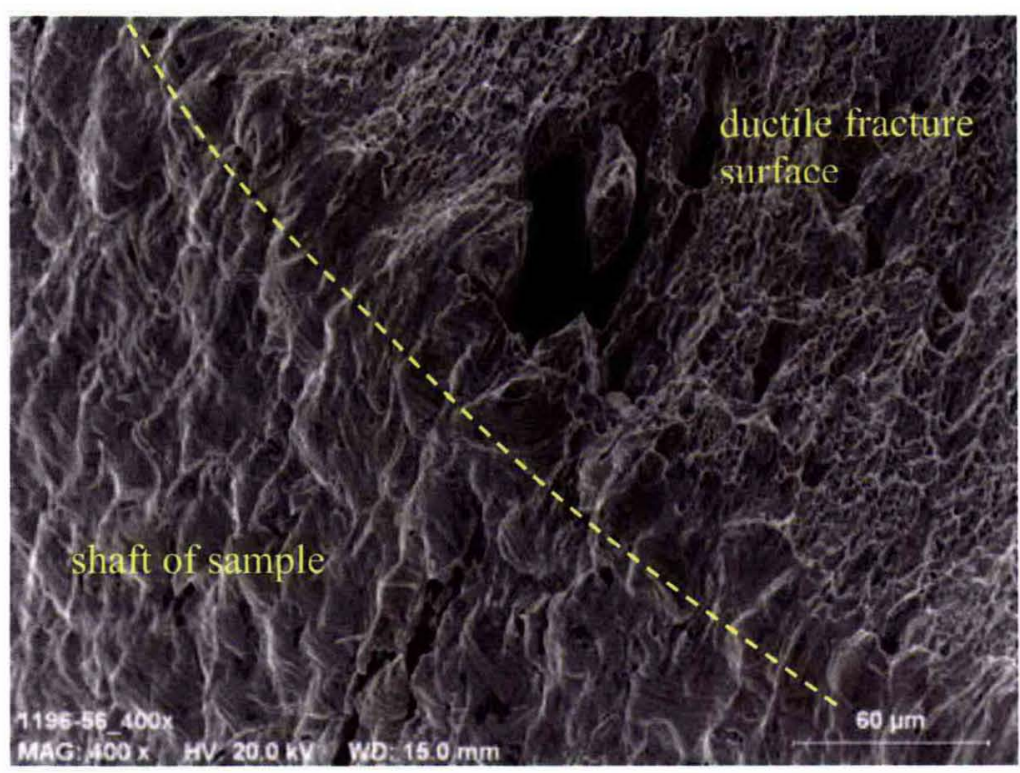

Figure 47. Electron-Micrograph of an Axial Micro-Crack on the Shaft of Test Sample from SSRT-56 Performed in AW-105-PIL Standard Simulant at $50^{\circ} \mathrm{C}$, pH 13+, at OCP (-290 $\mathrm{mV}$ vs. SCE).

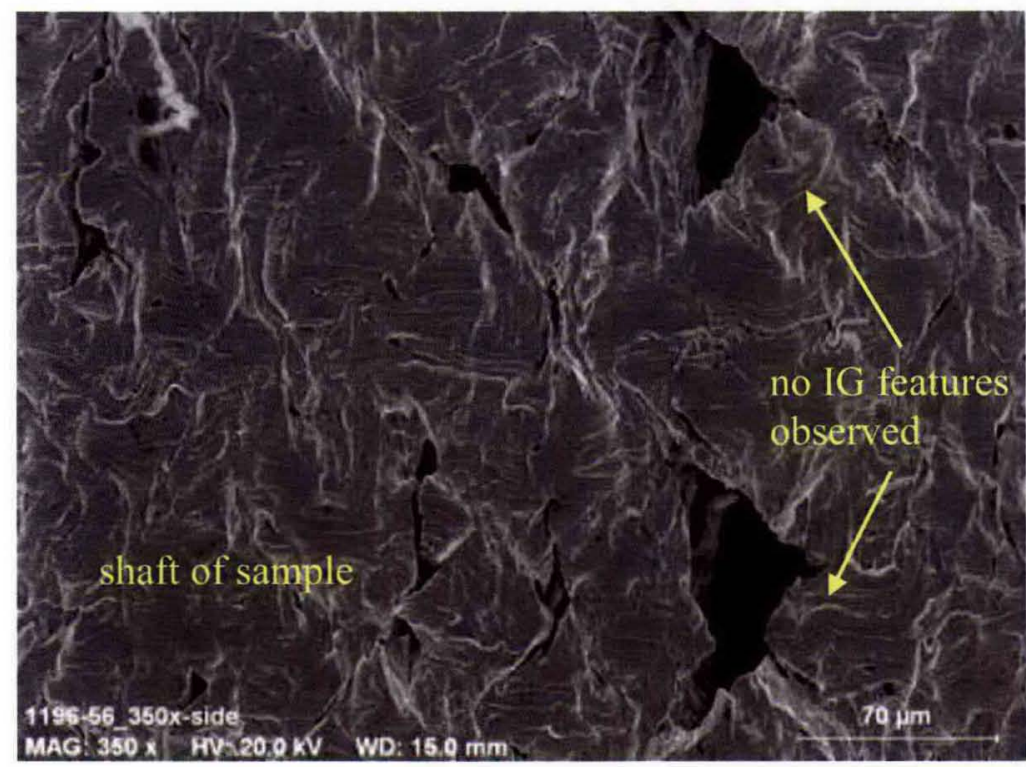


Figure 48. Electron-Micrograph of the Fracture Surface of Test Sample from SSRT-58 Performed in AW-105-PIL Standard Simulant at $50^{\circ} \mathrm{C}$, pH 13+, at $0 \mathrm{mV}$ vs. SCE.

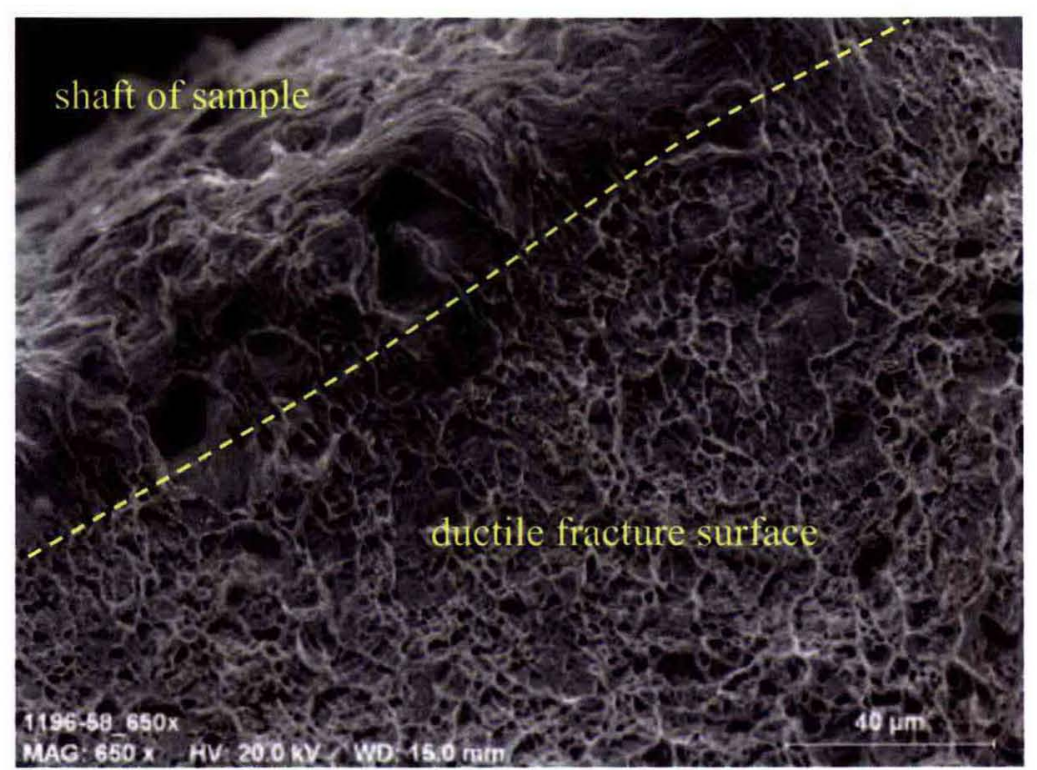

Figure 49. Stereo-Micrograph of the Shaft of Test Sample from SSRT-58 Performed in AW-105-PIL Standard Simulant at $50^{\circ} \mathrm{C}$, pH 13+, at $0 \mathrm{mV}$ vs. SCE.

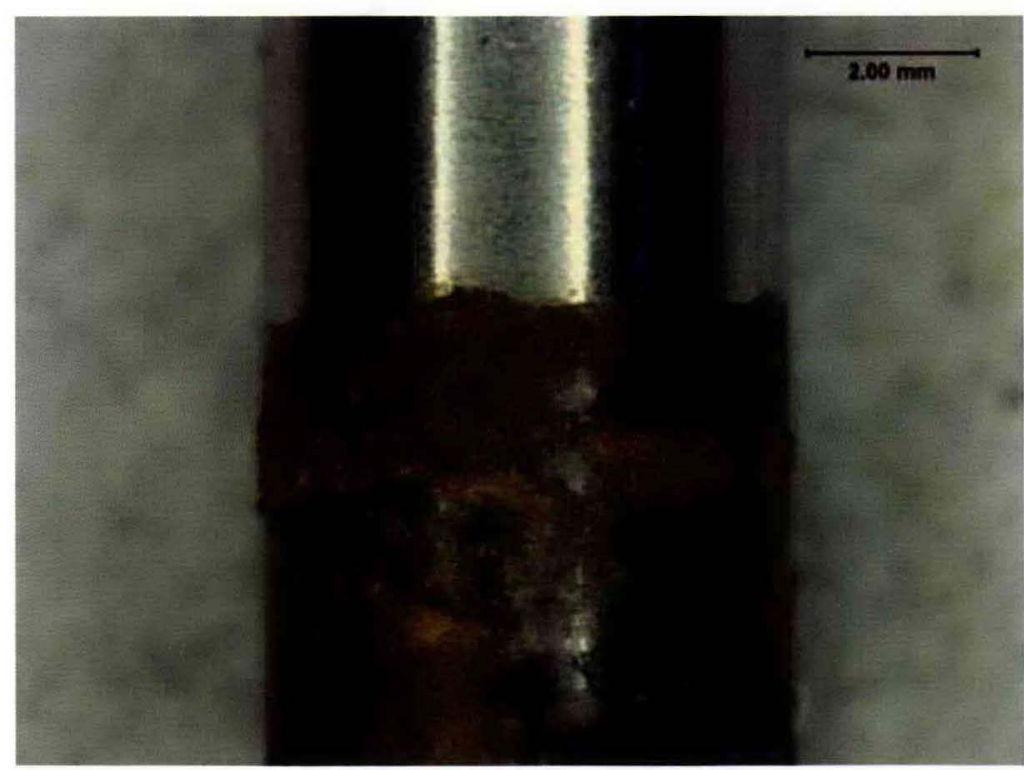

Tests in AW-105-PSC base simulants showed no evidence of SCC when performed at OCP, $-100 \mathrm{mV}$ or $-50 \mathrm{mV}$ vs. SCE. Failure occurred between 21.3 and $23.4 \%$. Tests in the " $6 \mathrm{X}$ " simulant were performed with the same nitrite/nitrate ratio as the "half nitrite" modified simulant, but with six times the absolute amounts of both nitrite and nitrate. This was done to explore the relations between nitrite / nitrate ratio and absolute nitrate content versus potential. Figure 50 is a plot of the stress-strain data from two of the tests performed in AW-105-PSC modified simulants. The test performed at $-100 \mathrm{mV}$ vs. SCE failed at $22.1 \%$ strain. Corrosion was observed at the liquid/vapor interface, but no intergranular features were observed on the fracture surface during 
SEM examination, see Figure 51 and Figure 52. The test performed at $-50 \mathrm{mV}$ vs. SCE failed at $8.5 \%$ strain, and severe corrosion was observed on the fracture surface and along its gauge length, see Figure 53. The results suggest that there is a "critical" potential between $-100 \mathrm{mV}$ and $-50 \mathrm{mV}$ vs. SCE necessary for significant corrosion to occur in this modified simulant.

Figure 50. Stress-Strain Behavior of Samples Tested in AW-105-PSC "6X" Simulant at $\mathbf{- 5 0}$ and $-\mathbf{1 0 0} \mathrm{mV}$ vs. SCE.

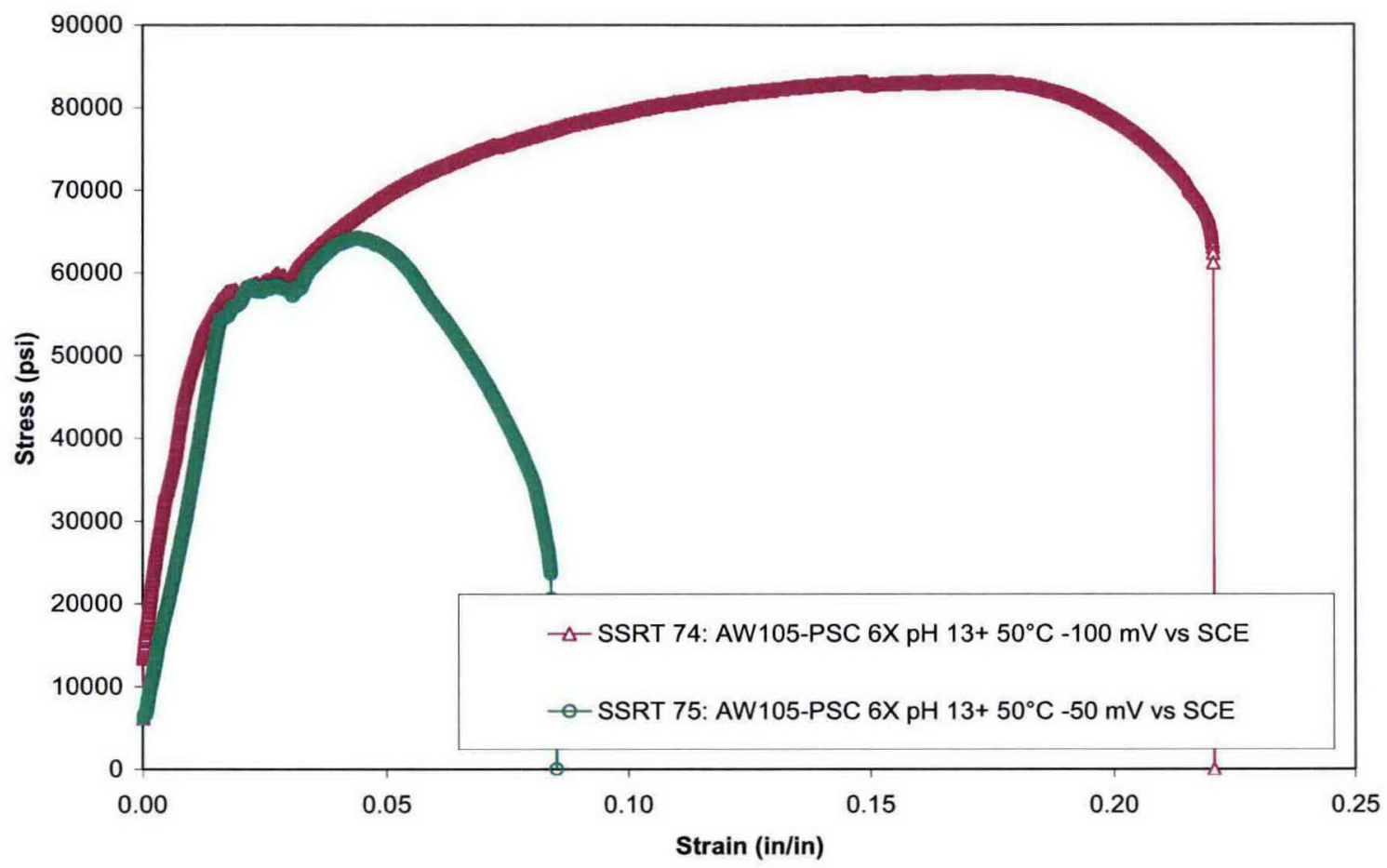

Figure 51. Photograph of the Test Sample from SSRT-74 Performed in AW-105-PSC 6X Simulant at $50^{\circ} \mathrm{C}, \mathrm{pH} 13+$, at a Potential of $-100 \mathrm{mV}$ vs. SCE.

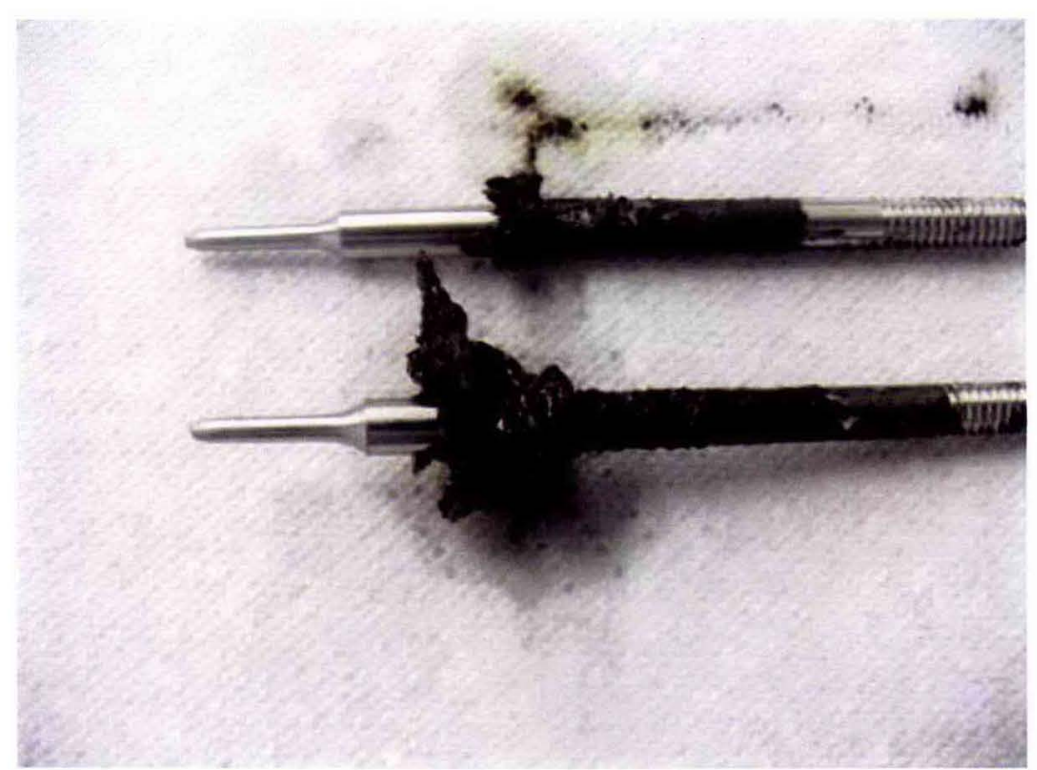


Figure 52. Electron-Micrograph of the Fracture Surface of Test Sample from SSRT-74 Performed in AW-105-PSC 6X Simulant at $50^{\circ} \mathrm{C}$, pH 13+, at a Potential of $-100 \mathrm{mV}$ vs. SCE.

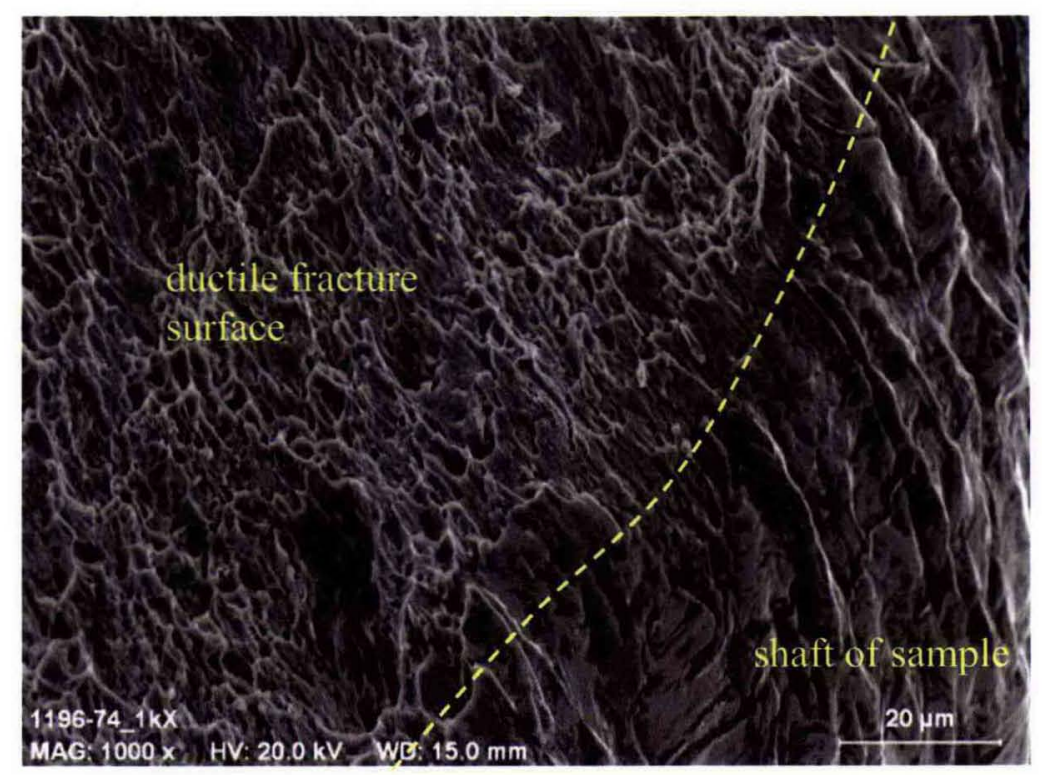

Figure 53. Stereo-Micrograph of the Test Sample from SSRT-75 Performed in AW-105-PSC 6X Simulant at $50^{\circ} \mathrm{C}$, pH 13+, at a Potential of $-50 \mathrm{mV}$ vs. SCE.

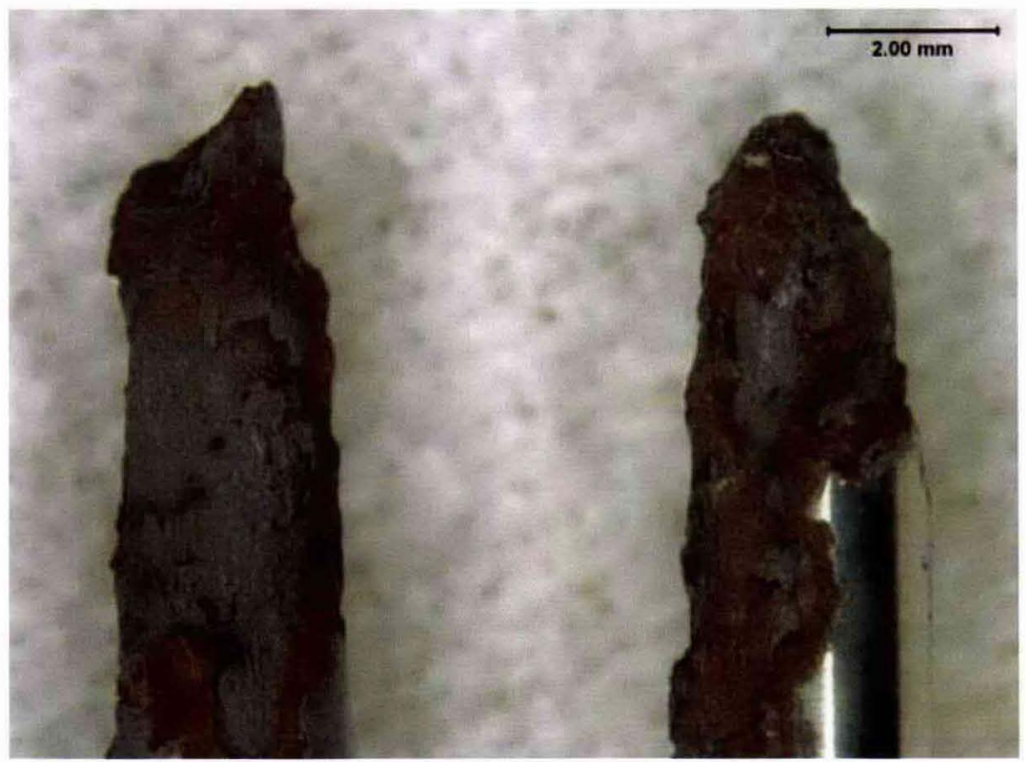




\subsection{SLOW STRAIN RATE TESTING IN TANK 241-AN-107 BASED SIMULANTS}

Table 13 summarizes the results of SSRTs performed in AN-107 simulants. Tests were performed at $50^{\circ} \mathrm{C}$ and potentiostatically polarized to potentials between -740 and $-790 \mathrm{mV}$ vs. SCE. The objective of these experiments was to test the propensity of carbonate cracking at low potentials since AN-107 simulant contains $1.4 \mathrm{M}$ carbonate. Previous testing in AY-102-PIL simulants with high carbonate $(1.021 \mathrm{M})$ contents indicated cracking at low potentials -750 to $-800 \mathrm{mV}$ vs. SCE. These potentials correspond to the active-passive transition range observed in the AY-102-PIL CPP curve from previous studies.

Table 13. A Summary of Slow Strain Rate Tests Performed in AN-107 Based Simulants.

\begin{tabular}{|c|c|c|c|c|c|c|c|l|l|}
\hline $\begin{array}{c}\text { Test } \\
\text { ID }\end{array}$ & Base Chemistry & $\mathbf{p H}$ & $\begin{array}{c}\text { Temp } \\
\left({ }^{\circ} \mathbf{C}\right)\end{array}$ & $\begin{array}{c}\text { Pot } \\
(\mathbf{m V})\end{array}$ & $\begin{array}{c}\text { OCP } \\
(\mathbf{m V})\end{array}$ & $\begin{array}{c}\text { Failure } \\
\text { Strain } \\
(\%)\end{array}$ & $\begin{array}{c}\text { Failure } \\
\text { Time } \\
(\mathbf{h r s})\end{array}$ & $\begin{array}{c}\text { SEM Surface } \\
\text { Exam }\end{array}$ & $\begin{array}{c}\text { Estimated CGR } \\
(\mathbf{m m} / \mathbf{s e c})\end{array}$ \\
\hline 47 & AN-107 & 11 & 50 & -740 & -315 & 22.5 & 62.9 & Ductile & - \\
\hline 48 & AN-107 & 11 & 50 & -765 & -296 & 21.4 & 61.6 & Ductile & - \\
\hline 49 & AN-107 & 11 & 50 & -790 & -274 & 22.0 & 61.1 & Ductile & - \\
\hline
\end{tabular}

Figure 54 is a plot of the stress-strain data from the three SSRTs. The samples all failed at strain from 21.4 to $22.5 \%$. No intergranular features were observed during SEM examination of any of these tests, suggesting the steel is not susceptible to cracking in $\mathrm{AN}-107$ at potentials where carbonate cracking was observed in AY-102-PIL simulants, see example (Figure 55). It should be pointed out that the OCP of steel in the AN-107 simulants were generally much higher than the tested potentials above because the cathodic reactions were likely dominated by nitrite and/or nitrate reduction that occurred at potentials much more positive than $-800 \mathrm{mV}$ vs. SCE. In carbonate-based waste simulants, an active-passive transition associated with the formation of carbonate films was observed at potentials near $-800 \mathrm{mV}$ vs. SCE and was not observed on the CPP curves in the AN-107 simulants. Therefore, these tested potentials were selected similar to the potentials in AY-102-PIL where carbonate cracking was observed. Based on the observations in AY-102-PIL, the potential range for carbonate cracking was near $-800 \mathrm{mV}$ vs. SCE and fairly narrow. In the $\mathrm{AN}-107$ simulants, the results above could indicate that cracking at these low potentials is not possible or the tested potentials may be away from any active/passive transition that may (or may not) be present. As mentioned above, because of the significant amount of nitrite and nitrate in AN-107 simulants, it is unlikely that the OCP of the tank steel would be anywhere near $-800 \mathrm{mV}$ vs. SCE and therefore the likelihood of the steel cracking at these low potentials is extremely small. Because of this, no further work was conducted to investigate the susceptibility of steel to carbonate cracking in AN-107 simulants. 
Figure 54. Stress-Strain Behavior of Samples Tested in AN-107 Based Simulants at various potentials.

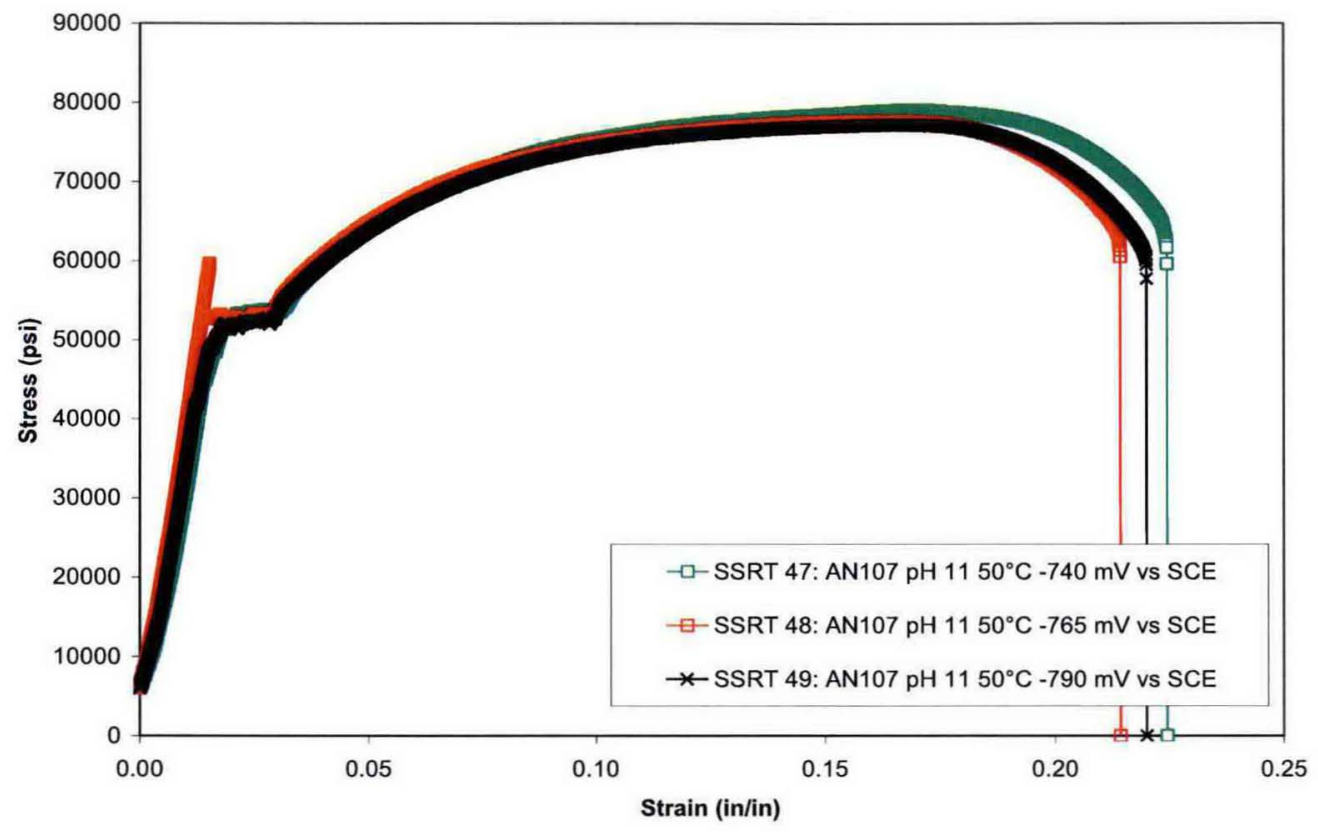

Figure 55. Electron-Micrograph of the Fracture Surface of Test Sample from SSRT-48 Performed in AN-107 Standard Simulant at $50^{\circ} \mathrm{C}, \mathrm{pH} 11$, at a Potential of $-765 \mathrm{mV}$ vs. SCE.

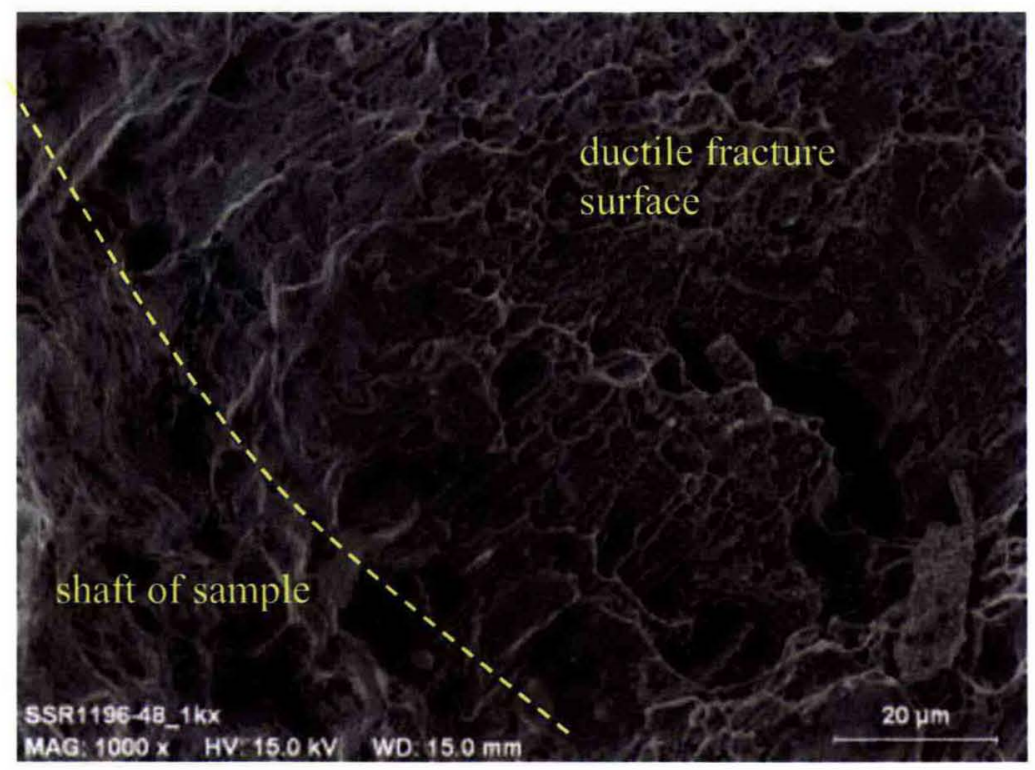




\subsection{ELECTROCHEMICAL POLARIZATION BEHAVIOR IN TANK 241-AZ- 102 BASED SIMULANT}

Table 14 summarizes the results of the CPP test conducted in the AZ-102 simulant that investigated the susceptibility of the steel to localized corrosion in simulants at a temperature level higher than $50^{\circ} \mathrm{C}$. The test temperature for $\mathrm{AZ}-102$ simulant was $77^{\circ} \mathrm{C}$, which represents the upper bound of the temperature levels in all waste simulants. No tests were performed using modified AZ-102 simulants.

Table 14. A Summary of Electrochemical Test Performed in AZ-102 Based Simulant.

\begin{tabular}{|c|c|c|c|c|c|c|c|c|c|c|c|c|}
\hline $\begin{array}{c}\text { Base } \\
\text { Chemistry }\end{array}$ & $\mathbf{p H}$ & $\begin{array}{c}\mathbf{N O}_{2}^{-} \\
(\mathbf{M})\end{array}$ & $\begin{array}{c}\mathbf{N O}_{3}^{-} \\
(\mathbf{M})\end{array}$ & $\begin{array}{c}\mathbf{T I C} \\
(\mathbf{M})\end{array}$ & $\begin{array}{c}\mathbf{O H}^{-} \\
(\mathbf{M})\end{array}$ & $\begin{array}{c}\mathbf{C l}^{-} \\
(\mathbf{M})\end{array}$ & $\begin{array}{c}\mathbf{F}^{-} \\
(\mathbf{M})\end{array}$ & $\begin{array}{c}\mathbf{T} \\
\left({ }^{\circ} \mathbf{C}\right)\end{array}$ & $\begin{array}{c}\text { Aeration } \\
\text { condition }\end{array}$ & Testing type & Visual & $\begin{array}{c}\text { Sample ID } \\
(\# E L 1196-)\end{array}$ \\
\hline $\mathrm{AZ}-102$ & $>12$ & 0.883 & 0.105 & 0.619 & - & - & 0.052 & 77 & $\mathrm{~N}_{2}$ purging & $\begin{array}{c}\text { CPP } \\
\text { Full immersion }\end{array}$ & $\begin{array}{c}\text { No } \\
\text { pitting }\end{array}$ & 103 \\
\hline
\end{tabular}

Figure 56 is the CPP curve obtained in the deaerated AZ-102 simulant at $77^{\circ} \mathrm{C}$. No clear positive hysteresis loop was observed and the sample did not show any indication of localized corrosion even at $77^{\circ} \mathrm{C}$. The lack of localized corrosion on the sample is consistent with the inhibitory role of nitrite, since the nitrite concentration in this simulant is significantly higher than nitrate and other aggressive species (nitrite-to-nitrate concentration ratio of 8.4).

Figure 56. CPP Curve in Deaerated $\mathrm{AZ}-102$ Simulant $\left(\mathrm{pH}>12\right.$ and $\left.\mathrm{T}=77^{\circ} \mathrm{C}\right)$.

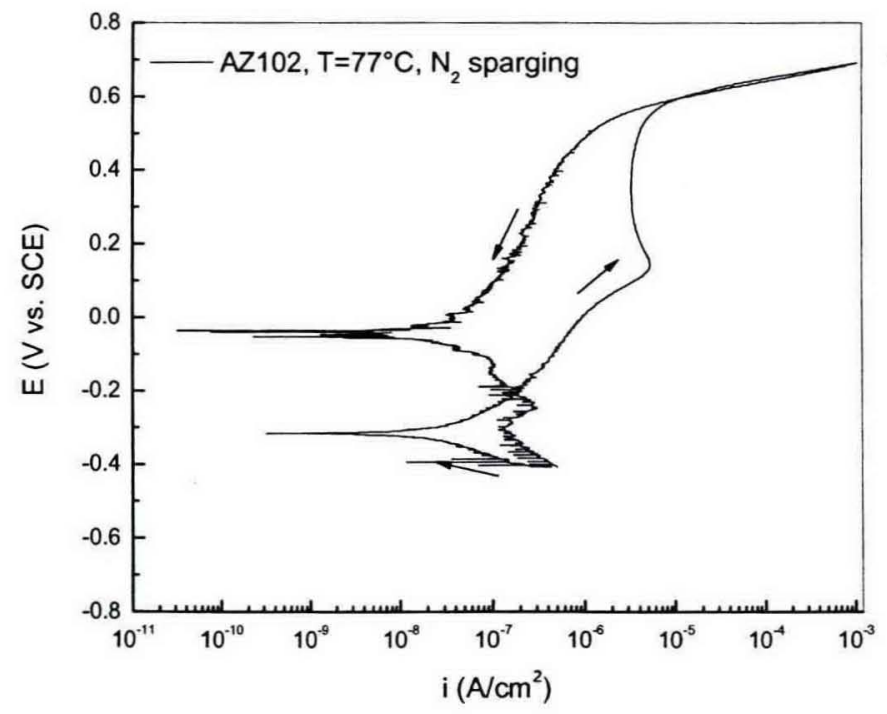




\subsection{SLOW STRAIN RATE TESTING IN TANK 241-AZ-102 BASED SIMULANT}

Table 15 summarizes the results of the slow strain rate test performed in the AZ-102 simulant. Only one test was performed, and it was at $77^{\circ} \mathrm{C}$ and at OCP. The standard AZ-102 simulant has high nitrite $(0.88 \mathrm{M})$ and low nitrate $(0.105 \mathrm{M})$ concentrations, and contains no halides.

Table 15. A Summary of Slow Strain Rate Tests Performed in AZ-102 Simulant.

\begin{tabular}{|c|c|c|c|c|c|c|c|c|c|}
\hline $\begin{array}{c}\text { Test } \\
\text { ID }\end{array}$ & Base Chemistry & $\mathbf{p H}$ & $\begin{array}{c}\text { Temp } \\
\left({ }^{\circ} \mathbf{C}\right)\end{array}$ & $\begin{array}{c}\text { Pot } \\
(\mathbf{m V})\end{array}$ & $\begin{array}{c}\text { OCP } \\
(\mathbf{m V})\end{array}$ & $\begin{array}{c}\text { Failure } \\
\text { Strain } \\
(\%)\end{array}$ & $\begin{array}{c}\text { Failure } \\
\text { Time } \\
(\mathbf{h r s})\end{array}$ & $\begin{array}{c}\text { SEM Surface } \\
\text { Exam }\end{array}$ & $\begin{array}{c}\text { Estimated CGR } \\
(\mathbf{m m} / \mathbf{s e c})\end{array}$ \\
\hline 61 & $\mathrm{AZ}-102$ & $12+$ & 77 & OCP & -239 & 21.0 & 58.3 & Ductile & - \\
\hline
\end{tabular}

The AZ-102 simulant has a very high nitrite/nitrate ratio (8.4) and no chlorides or fluorides, so no $\mathrm{SCC}$ or pitting was expected. In addition, the CPP curve exhibited no positive hysteresis. No localized corrosion was observed during post-test examination of the sample. The single SSRT in AZ-102 simulant failed at $21.0 \%$ strain (Figure 57). No evidence of SCC was observed on the fracture surface of the test sample during SEM examination (see Figure 58). The SSRT result and $\mathrm{CPP}$ test results are consistent with previous test results in which nitrite was demonstrated to be inhibitory towards localized corrosion and SCC.

Figure 57. The Stress-Strain Behavior of the Sample Tested in AZ-102 Simulants at OCP (-239 mV vs. SCE).

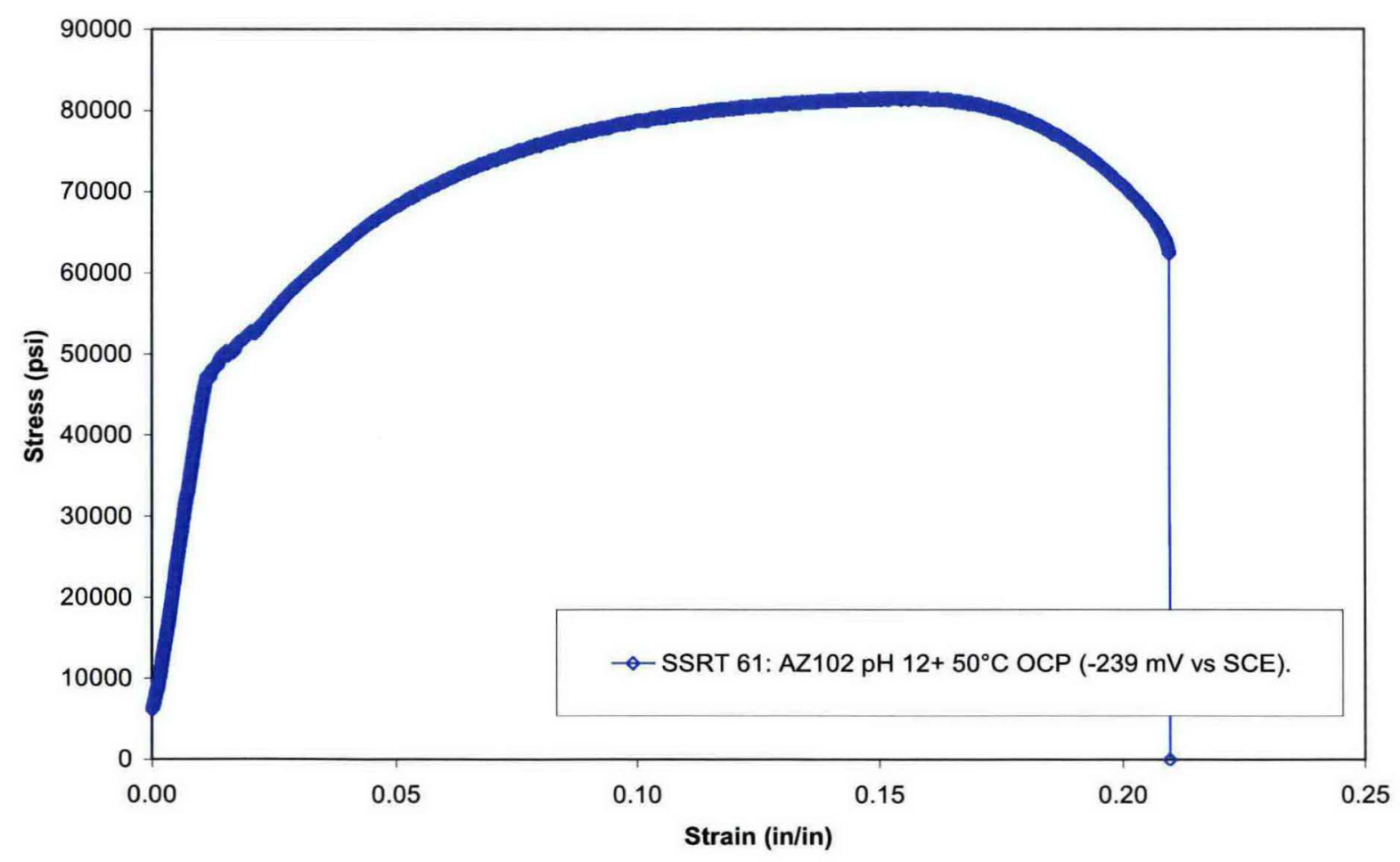


Figure 58. Electron-Micrograph of the Fracture Surface of Test Sample from SSRT-61 Performed in AZ-102 Simulant at $77^{\circ} \mathrm{C}$, pH 12+, at a Potential of $-239 \mathrm{mV}$ vs. SCE.

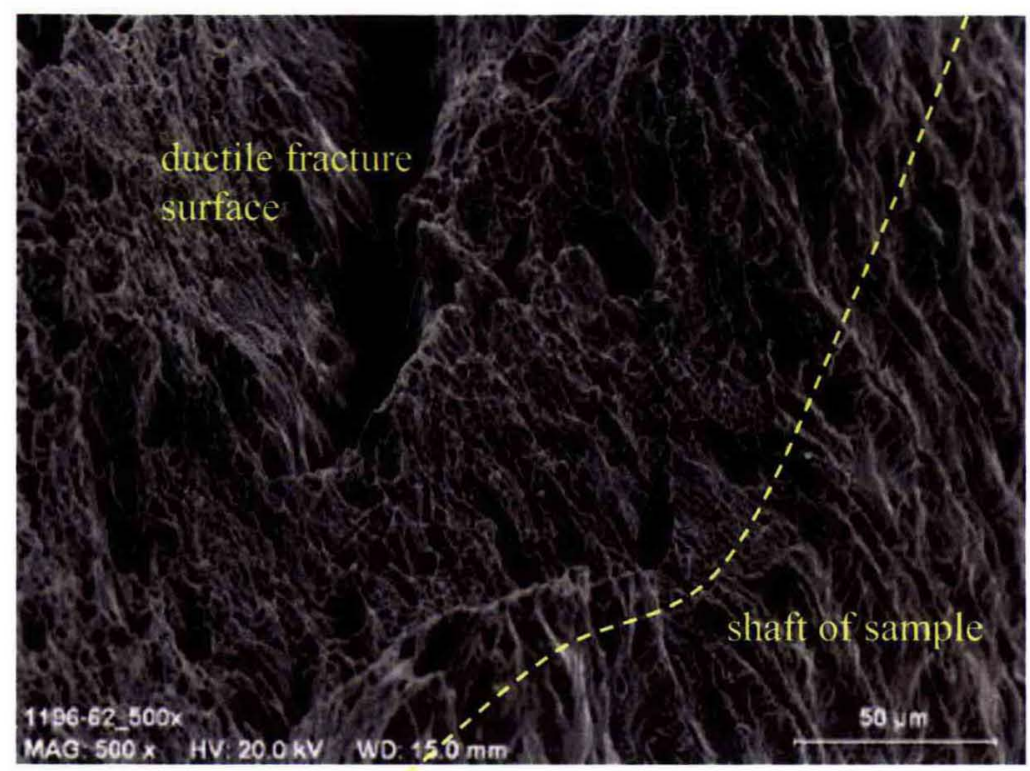

\subsection{ELECTROCHEMICAL POLARIZATION BEHAVIOR IN TANK 241-SY-101 BASED SIMULANT}

Table 16 summarizes the results of the CPP test conducted in the SY-101 simulant. The SY-101 simulant has a relatively lower nitrite-to-nitrate concentration ratio than other simulants being investigated. No tests were performed using modified SY-101 simulants.

Table 16. A Summary of Electrochemical Test Performed in SY-101 Based Simulant.

\begin{tabular}{|c|c|c|c|c|c|c|c|c|c|c|c|c|}
\hline $\begin{array}{c}\text { Base } \\
\text { Chemistry }\end{array}$ & $\mathbf{p H}$ & $\begin{array}{l}\mathrm{NO}_{2}^{-} \\
(\mathrm{M})\end{array}$ & $\begin{array}{l}\mathrm{NO}_{3}^{-} \\
(\mathrm{M})\end{array}$ & $\begin{array}{l}\text { TIC } \\
\text { (M) }\end{array}$ & $\begin{array}{l}\mathrm{OH}^{-} \\
\text {(M) }\end{array}$ & $\begin{array}{l}\mathrm{Cl}^{-} \\
\text {(M) }\end{array}$ & $\begin{array}{l}\mathrm{F}^{-} \\
\text {(M) }\end{array}$ & $\mathbf{T}\left({ }^{\circ} \mathbf{C}\right)$ & $\begin{array}{l}\text { Aeration } \\
\text { condition }\end{array}$ & Testing type & Visual & $\begin{array}{l}\text { Sample ID } \\
\text { (\#EL1196-) }\end{array}$ \\
\hline
\end{tabular}

Figure 59 is a CPP curve in deaerated SY-101 simulant at $50^{\circ} \mathrm{C}$. No positive hysteresis loop was observed on the curve and the sample did not show any indication of localized corrosion. The lack of localized corrosion on the samples suggests that even though the nitrite/nitrate ratio in this simulant is lower than other simulants investigated before, other inhibitory species present in this simulants were able to efficiently prevent localized corrosion. Additionally, the benign nature of this simulant with respect to localized corrosion may be a result of the relatively low concentration of the aggressive species. 
Figure 59. CPP curves in deaerated SY-101 simulant at $\mathrm{pH} 13+$ and $50^{\circ} \mathrm{C}$.

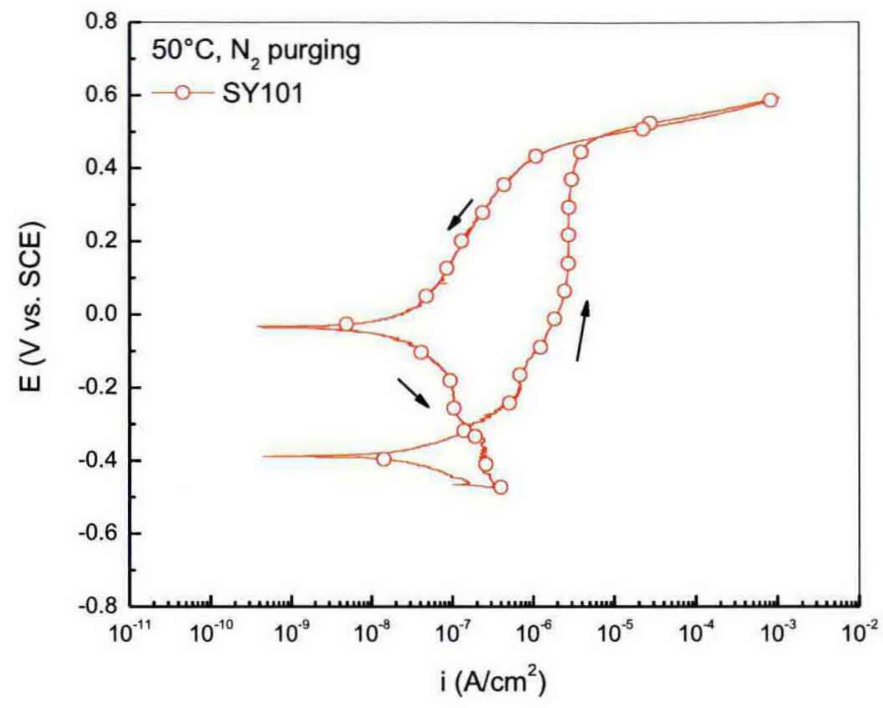

\subsection{SLOW STRAIN RATE TESTING IN TANK 241-SY-101 BASED SIMULANT}

Table 17 summarizes the results of the slow strain rate tests performed in the SY-101 simulant. Only one test was performed, and it was at $50^{\circ} \mathrm{C}$ and OCP. This simulant has high nitrate $(0.93 \mathrm{M})$ and low nitrite $(0.20 \mathrm{M})$ concentrations.

Table 17. Summary of Slow Strain Rate Tests Performed in SY-101 Simulants.

\begin{tabular}{|c|c|c|c|c|c|c|c|c|c|}
\hline $\begin{array}{c}\text { Test } \\
\text { ID }\end{array}$ & Base Chemistry & $\mathbf{p H}$ & $\begin{array}{c}\text { Temp } \\
\left({ }^{\circ} \mathbf{C}\right)\end{array}$ & $\begin{array}{c}\text { Pot } \\
(\mathbf{m V})\end{array}$ & $\begin{array}{c}\text { OCP } \\
(\mathbf{m V})\end{array}$ & $\begin{array}{c}\text { Failure } \\
\text { Strain } \\
(\%)\end{array}$ & $\begin{array}{c}\text { Failure } \\
\mathbf{T} \text { Time } \\
(\mathbf{h r s})\end{array}$ & $\begin{array}{c}\text { SEM Surface } \\
\text { Exam }\end{array}$ & $\begin{array}{c}\text { Estimated CGR } \\
(\mathbf{m m} / \mathbf{s e c})\end{array}$ \\
\hline 67 & SY-101 & $13+$ & 50 & OCP & -206 & 22.9 & 63.7 & Ductile & - \\
\hline
\end{tabular}

The SY-101 simulant has a relatively low nitrite/nitrate ratio (0.18), so SCC or pitting was considered possible. However, no positive hysteresis was observed in the CPP curve and no localized corrosion was observed during post-test examination of the sample. The single SSRT performed in SY-101 simulant failed at $22.9 \%$ strain (Figure 60). No evidence of SCC was observed on the fracture surface of the test sample during SEM examination (see Figure 61). 
Figure 60. Stress-Strain Behavior of the Sample Tested in

SY-101 Simulant at OCP (-206 mV vs. SCE).

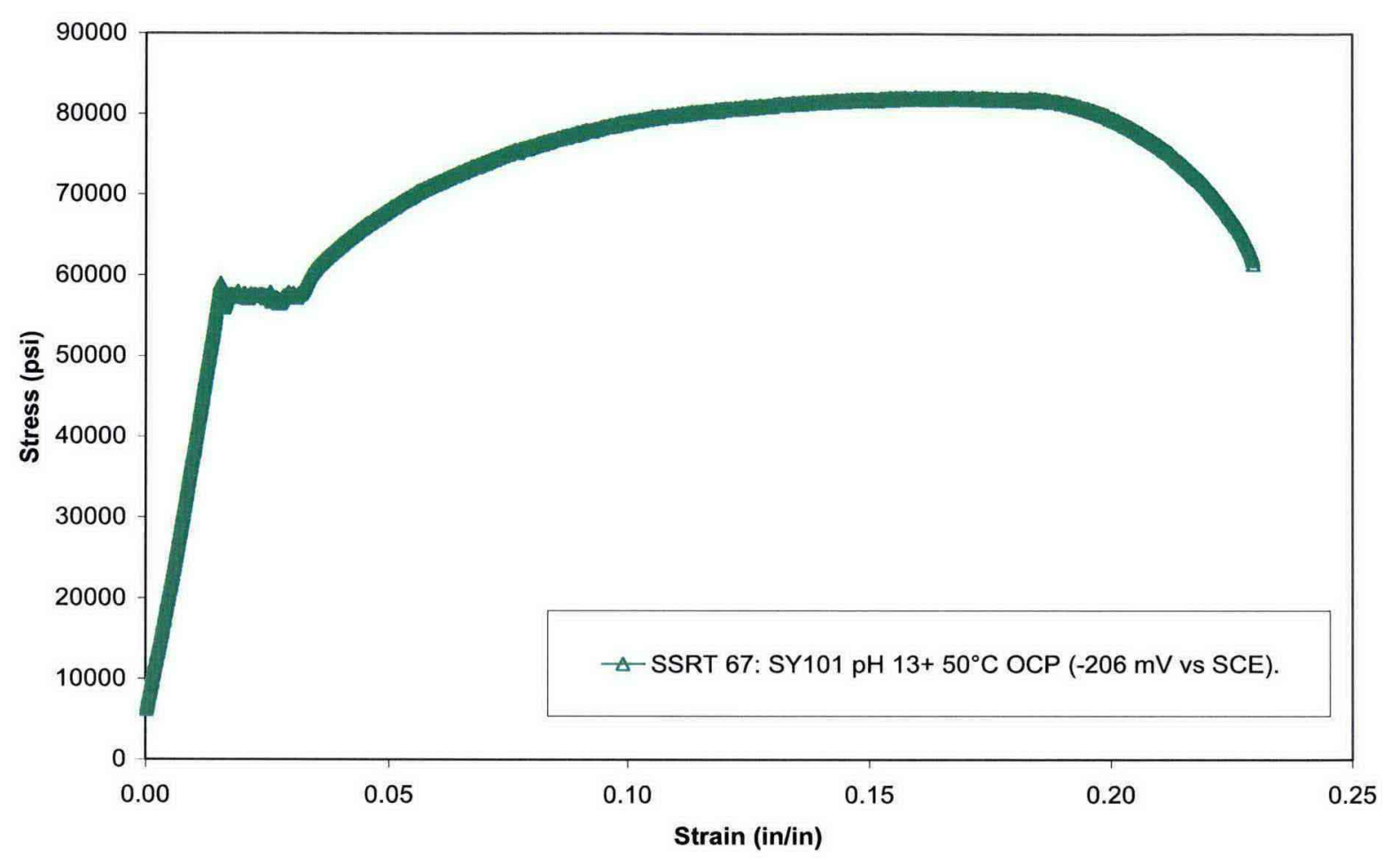

Figure 61. Electron-Micrograph of the Fracture Surface of Test Sample from SSRT-67 Performed in SY-101 Simulant at 50 ${ }^{\circ}$, pH 13+, at a Potential of -206 mV vs. SCE.

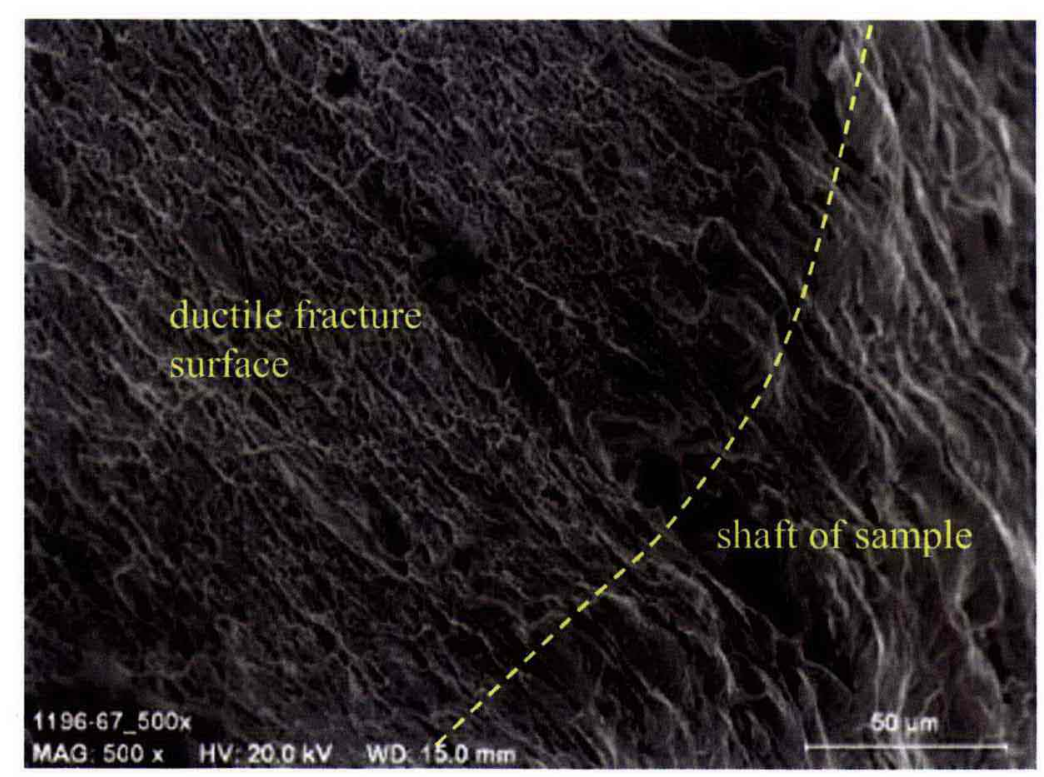




\subsection{ELECTROCHEMICAL POLARIZATION BEHAVIOR IN TANK 241-AY-101-CSL SIMULANT}

Table 18 summarizes the results of the CPP tests conducted in the standard AY-101-CSL simulants and the modified AY-101-CSL simulants. The tests performed in the standard AY-101-CSL simulants established the baseline of the susceptibility of the tank steel to localized corrosion whereas the tests in the modified AY-101-CSL simulants (with $\mathrm{pH}$ adjusted) were performed to understand the impact of $\mathrm{pH}$ on the localized corrosion susceptibility of the tank steel.

Table 18. Summary of Electrochemical Test Performed in AY-101-CSL Based Simulant.

\begin{tabular}{|c|c|c|c|c|c|c|c|c|c|c|c|c|}
\hline $\begin{array}{c}\text { Base } \\
\text { Chemistry }\end{array}$ & pH & $\begin{array}{l}\mathrm{NO}_{2}^{-} \\
(\mathrm{M})\end{array}$ & $\begin{array}{l}\mathrm{NO}_{3}^{-} \\
(\mathrm{M})\end{array}$ & $\begin{array}{l}\text { TIC } \\
\text { (M) }\end{array}$ & $\begin{array}{c}\mathbf{O H}^{-} \\
(\mathbf{M})^{*}\end{array}$ & $\begin{array}{l}\mathrm{Cl}^{-} \\
(\mathrm{M})\end{array}$ & $\begin{array}{l}\mathrm{F}^{-} \\
(\mathrm{M})\end{array}$ & $\begin{array}{c}\mathrm{T} \\
\left({ }^{\circ} \mathrm{C}\right) \\
\end{array}$ & $\begin{array}{c}\text { Aeration } \\
\text { condition }\end{array}$ & Testing type & Visual & $\begin{array}{l}\text { Sample ID } \\
\text { (\#EL1196-) }\end{array}$ \\
\hline AY-101-CSL & 11.8 & 0.0368 & 0.181 & 0.1474 & 0.0051 & 0.0064 & 0.0015 & 50 & $\mathrm{~N}_{2}$ purging & $\begin{array}{c}\text { CPP } \\
\text { Full immersion } \\
\end{array}$ & Pitting & 111 \\
\hline AY-101-CSL & 12.8 & 0.0368 & 0.181 & 0.1474 & 0.0051 & 0.0064 & 0.0015 & 50 & $\mathrm{~N}_{2}$ purging & $\begin{array}{c}\text { CPP } \\
\text { Full immersion }\end{array}$ & $\begin{array}{c}\text { No } \\
\text { Pitting }\end{array}$ & 112 \\
\hline AY-101-CSL & 11.8 & 0.0368 & 0.181 & 0.1474 & 0.0051 & 0.0064 & 0.0015 & Room & $\mathrm{N}_{2}$ purging & $\begin{array}{c}\text { CPP } \\
\text { Full immersion } \\
\end{array}$ & $\begin{array}{c}\text { No } \\
\text { Pitting }\end{array}$ & 113 \\
\hline AY-101-CSL & 12.3 & 0.0368 & 0.181 & 0.1474 & 0.0051 & 0.0064 & 0.0015 & 50 & $\mathrm{~N}_{2}$ purging & $\begin{array}{c}\text { CPP } \\
\text { Full immersion }\end{array}$ & Pitting & 115 \\
\hline
\end{tabular}

* This reflects the concentration prior to $\mathrm{pH}$ adjustment.

Figure 62 is a comparison of the CPP curves obtained in the AY-101-CSL simulants under different conditions. The CPP curve at $\mathrm{pH} 11.8$ and $50^{\circ} \mathrm{C}$ showed an open loop with the passivation potential below the OCP. This is consistent with the observation of severe localized corrosion on the sample after the CPP test, as shown in Figure 63. At room temperature and $\mathrm{pH}$ 11.8 , the CPP curve showed a negative hysteresis loop. The pitting corrosion noted at $50^{\circ} \mathrm{C}$ was not observed on the sample tested at the same $\mathrm{pH}$ but at room temperature. At $\mathrm{pH} 12.3$ and $50^{\circ} \mathrm{C}$, the CPP curve still exhibited an open loop even though the pitting potential was slightly higher than at $\mathrm{pH}$ 11.8. The sample showed severe localized corrosion after the CPP test, as shown in Figure 64. When the $\mathrm{pH}$ of the simulant was increased to 12.82 , the CPP curve was similar to that at room temperature and $\mathrm{pH} 11.8$ in that it showed a negative hysteresis loop. No pitting corrosion was noted at $\mathrm{pH} 12.8$, even at $50^{\circ} \mathrm{C}$. The testing results in the AY-101-CSL as a function of temperature and $\mathrm{pH}$ implied that the steel was susceptible to localized corrosion in this simulant at $50^{\circ} \mathrm{C}$ and $\mathrm{pH} 11.8$ despite the relatively low concentration of aggressive species (such as nitrate $=0.181 \mathrm{M}$ ). The pitting corrosion at this $\mathrm{pH}$, however, can be mitigated by decreasing the temperature. Furthermore, the results suggest that a threshold of $\mathrm{pH}$ exists above which pitting corrosion will not occur even at an elevated temperature $\left(50^{\circ} \mathrm{C}\right)$. This threshold appeared to be between $\mathrm{pH} 12.3$ and $\mathrm{pH} 12.8$, but was not precisely determined with the limited experimental cfforts conducted. 
Figure 62. A Comparison of CPP Curves in the Deaerated AY-101-CSL Simulant at Different pH Levels and Temperatures.

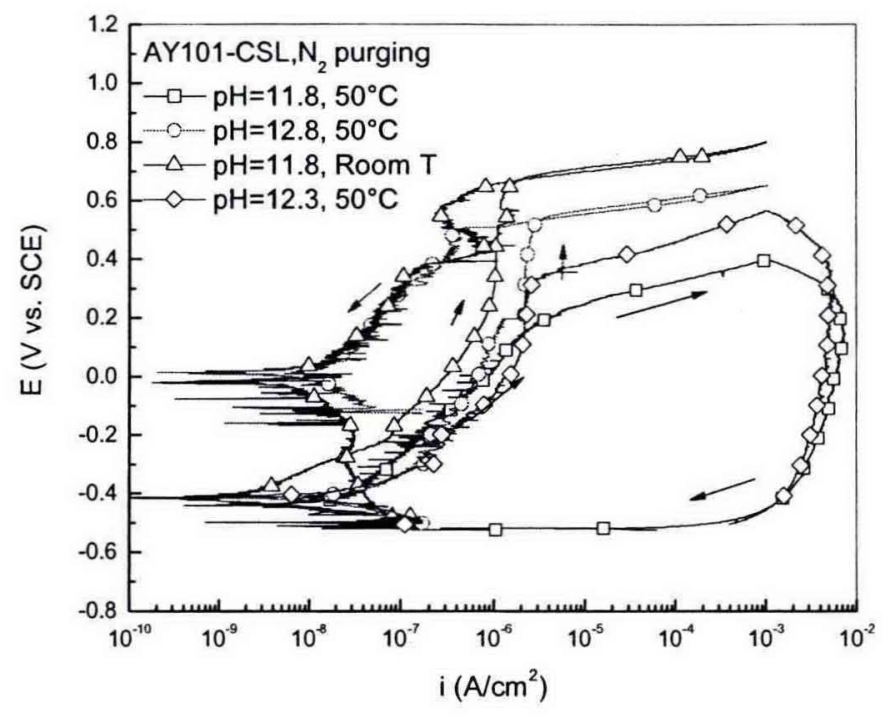

Figure 63. Appearance of the Sample after CPP test in the Deaerated AY-101-CSL Simulant at $50^{\circ} \mathrm{C}$ and $\mathrm{pH}$ 11.8. (a) Before Cleaning; (b) After cleaning.

(a)

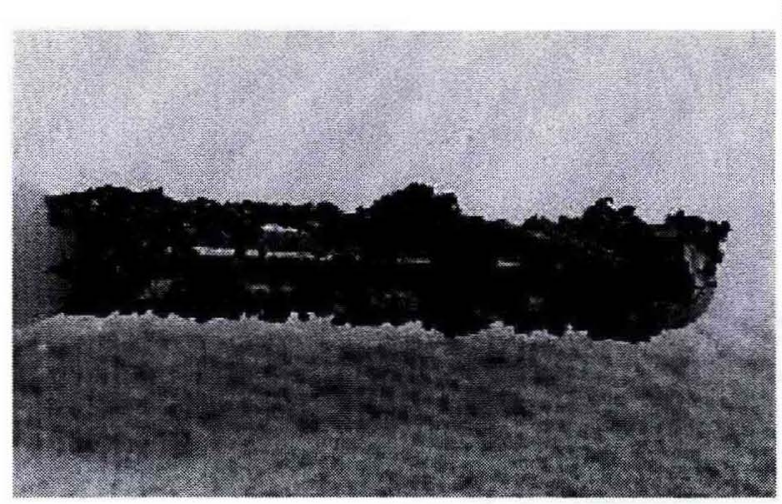

(b)

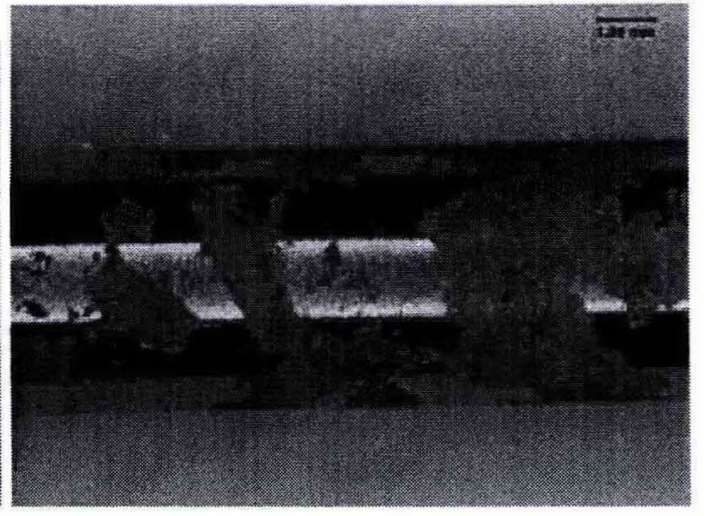


Figure 64. The Appearance of the Sample after CPP Test in AY-101-CSL Simulant at $\mathrm{pH} 12.3$ and $50^{\circ} \mathrm{C}$.

(a)

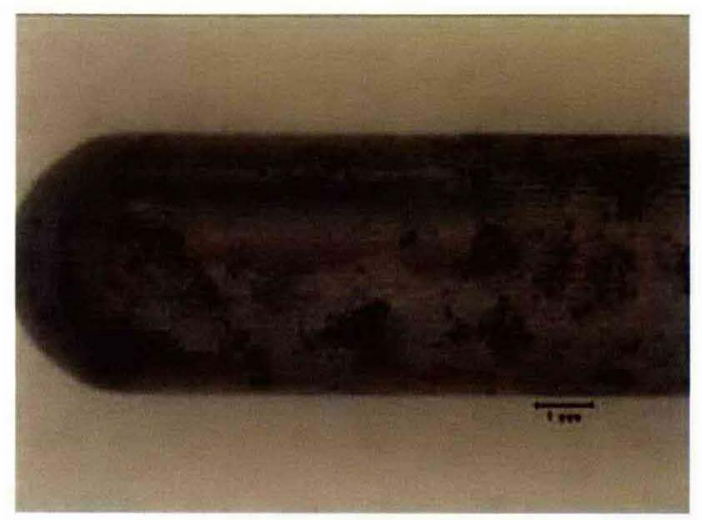

(b)

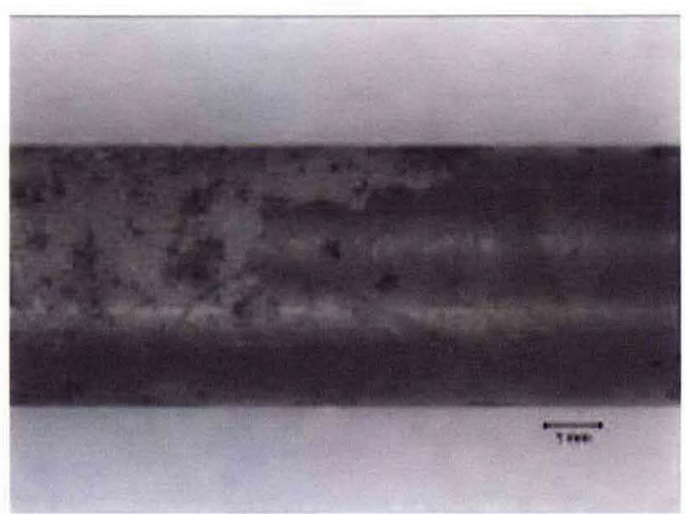

\subsection{SLOW STRAIN RATE TESTING IN TANK 241-AY-101- CSL BASED SIMULANT}

Table 19 summarizes the results of the slow strain rate tests performed in the AY-101-CSL simulant. Only one test was performed at $50^{\circ} \mathrm{C}$ and OCP. This simulant has low nitrate $(0.181 \mathrm{M})$ and nitrite $(0.0368 \mathrm{M})$ concentrations.

Table 19. A Summary of Slow Strain Rate Tests Performed in AY-101-CSL Simulant.

\begin{tabular}{|c|c|c|c|c|c|c|c|c|c|}
\hline $\begin{array}{c}\text { Test } \\
\text { ID }\end{array}$ & Base Chemistry & $\mathbf{p H}$ & $\begin{array}{c}\text { Temp } \\
\left({ }^{\circ} \mathbf{C}\right)\end{array}$ & $\begin{array}{c}\text { Pot } \\
(\mathbf{m V})\end{array}$ & $\begin{array}{c}\text { OCP } \\
(\mathbf{m V})\end{array}$ & $\begin{array}{c}\text { Failure } \\
\text { Strain } \\
(\%)\end{array}$ & $\begin{array}{c}\text { Failure } \\
\mathbf{T} \text { (ime } \\
(\mathbf{h r s})\end{array}$ & $\begin{array}{c}\text { SEM Surface } \\
\text { Exam }\end{array}$ & $\begin{array}{c}\text { Estimated CGR } \\
(\mathbf{m m} / \mathbf{s e c})\end{array}$ \\
\hline 69 & AY-101-CSL & 11.8 & 50 & OCP & -181 & 21.6 & 59.9 & Ductile & - \\
\hline
\end{tabular}

The one SSRT sample failed at $21.9 \%$ strain, and showed no evidence of SCC during SEM examination (Figure 65 and Figure 66). The simulant has a relatively low nitrate content, and it may be that there was insufficient nitrate to cause SCC. A large positive hysteresis was noted in CPP curve provided by electrochemical testing in the AY-101-CSL simulant at $\mathrm{pH} 11.8$ at $50^{\circ} \mathrm{C}$. These results indicate that evidence of pitting is not necessarily indicative of SCC susceptibility. Note that the SSRT was performed at OCP, and the combination of potential and limited test time may not have been sufficient to allow any localized corrosion to initiate. 
Figure 65. Stress-Strain Behavior of the Sample Tested in AY-101-CSL Simulant at OCP (-181 mV vs. SCE).

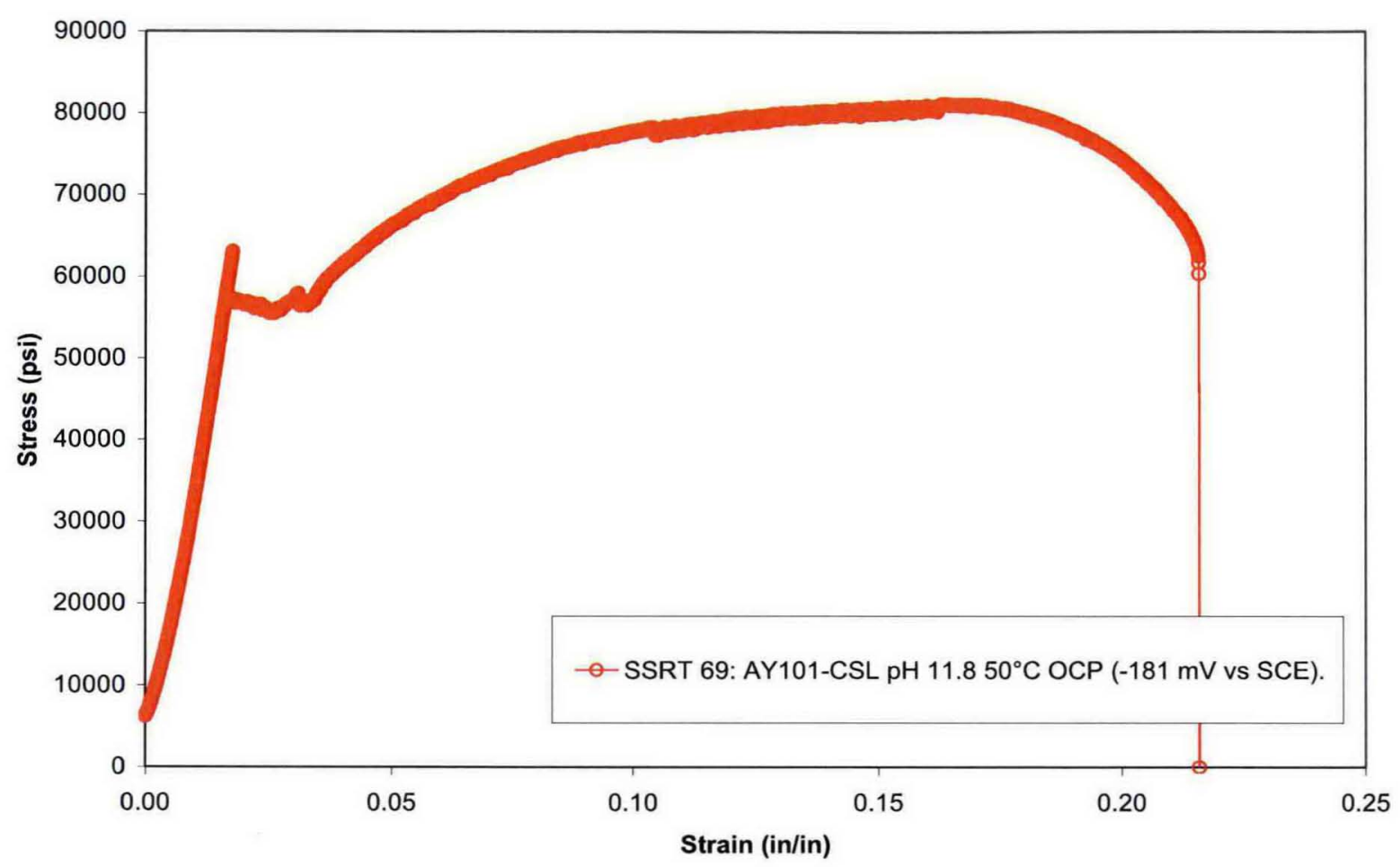

Figure 66. Electron-Micrograph of the Fracture Surface of Test Sample from SSRT-69 Performed in AY-101-CSL Simulant at 50 ${ }^{\circ}$, pH 11.8, at a Potential of $-181 \mathrm{mV}$ vs. SCE.

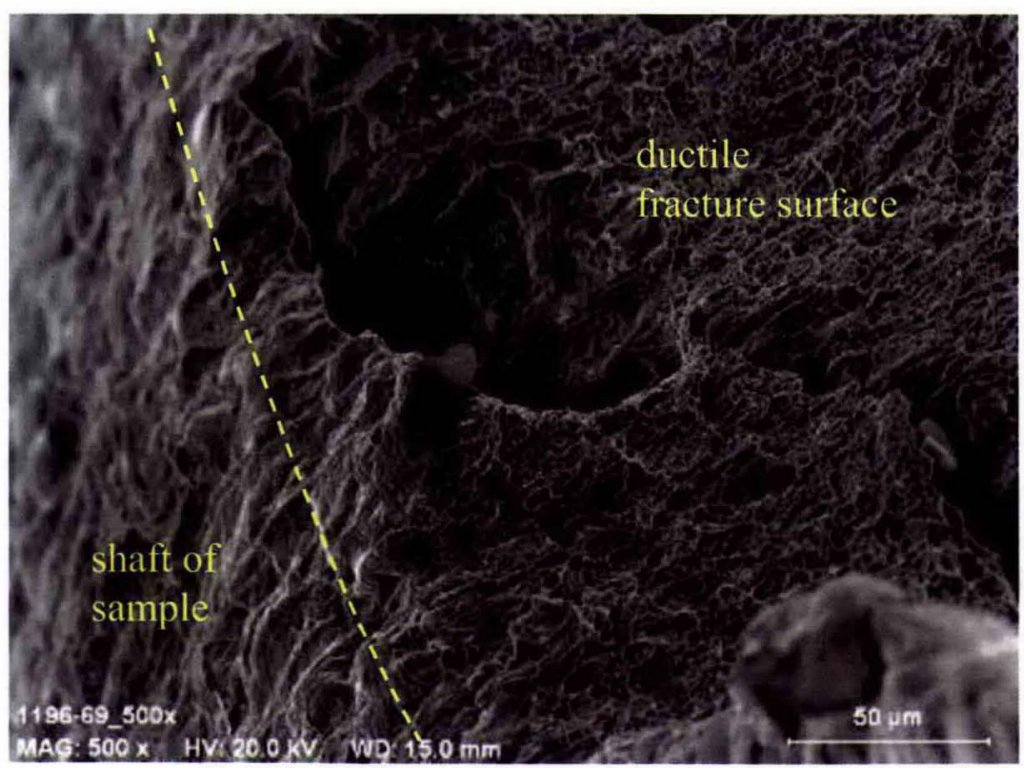




\subsection{DYNAMIC-K TESTING IN 5M NANO 3 AND TANK 241-AY-101-PSC BASED SIMULANT}

Table 20 summarizes the details of the two dynamic-K tests performed during this test program. The objectives of the two K-tests were (1) to investigate the effect of a hold time on crack growth initiation; and, (2) to aid in the determination of $\mathrm{K}_{\text {thSCC }}$ by measuring the nominal $\mathrm{K}_{\mathrm{I}}$ at which crack growth arrests under constant displacement conditions. With the test specimen geometry, both load and stress intensity reduce as a crack propagates under constant displacement conditions. A constant load during the test indicates the crack is not propagating. The crack's stability point and $\mathrm{K}_{\mathrm{thSCC}}$ can then be calculated from the test parameters. Previous tests performed for this program were not held sufficiently long for this phenomenon to occur.

CT-17 was performed in $5 \mathrm{M} \mathrm{NaNO}_{3}$ solution at $\mathrm{OCP}$ and at $50^{\circ} \mathrm{C}$. This solution has previously been shown to cause severe cracking. The sample was loaded at a constant displacement rate until both DCPD and load measurements indicated cracking. The loading was stopped and the sample was held at constant displacement for approximately 80 days. DCPD (Figure 67) and load measurements (Figure 68) indicated continued cracking of the sample during the test. The maximum CGR for this sample was estimated as $4.5 \mathrm{inch} /$ year $\left(1.4 \times 10^{-7} \mathrm{in} / \mathrm{sec}\right)$ based on DCPD data.

CT-18 was performed in AY-101-PSC simulant at $0 \mathrm{mV}$ vs. SCE and at $50^{\circ} \mathrm{C}$. Previous testing indicated no cracking in this environment for samples loaded to $40 \mathrm{ksi}$ in; however, the hold time was relatively short (approximately 30 days). The current investigation loaded the constant displacement sample to $45 \mathrm{ksi}$ in. DCPD (Figure 69) and load data (Figure 70) indicated that there may have been minor cracking in the sample, but it was not definitive because of the significant noise detected in the data. Note that a lower stress intensity ( $\left.40 \mathrm{ksi}{ }_{\mathrm{in}}\right)$ was accidently placed on the specimen for over a week near the onset of testing.

Table 20. A Summary of the Dynamic-K Tests Performed.

\begin{tabular}{|c|c|c|c|c|c|c|c|}
\hline $\begin{array}{c}\text { Test } \\
\text { ID }\end{array}$ & $\begin{array}{c}\text { Base } \\
\text { Chemistry }\end{array}$ & $\mathbf{p H}$ & $\begin{array}{c}\text { Temp } \\
\left({ }^{\circ} \mathbf{C}\right)\end{array}$ & Pot $(\mathbf{m V})$ & $\begin{array}{c}\text { OCP } \\
(\mathbf{m V})\end{array}$ & Test Type & Comments \\
\hline 17 & $5 \mathrm{M} \mathrm{NaNO}$ & 11 & 50 & $\mathrm{OCP}$ & +107 & $\begin{array}{c}\text { Load to above } \\
\mathrm{K}_{\text {thscc and hold }} \\
80 \text { days }\end{array}$ & $\begin{array}{l}\text { DCPD, load reduction and SEM } \\
\text { examination indicated significant cracking }\end{array}$ \\
\hline 18 & AY-101-PSC & 11 & 50 & 0 & -328 & $\begin{array}{c}\text { Load to } 45 \\
\text { ksivin and hold } \\
150 \text { days }\end{array}$ & $\begin{array}{l}\text { DCPD and load reduction indicated possible } \\
\text { minor cracking. Not confirmed by SEM } \\
\text { examination }\end{array}$ \\
\hline
\end{tabular}


Figure 67. Plot of DCPD Calculated Crack Length as a Function of Time for CT-17 Performed in 5M NaNO 3 at Open Circuit Potential. The Displacement was Held Constant Following Loading to a Nominal $\mathrm{K} \sim 25 \mathrm{ksi} V \mathrm{in}$.

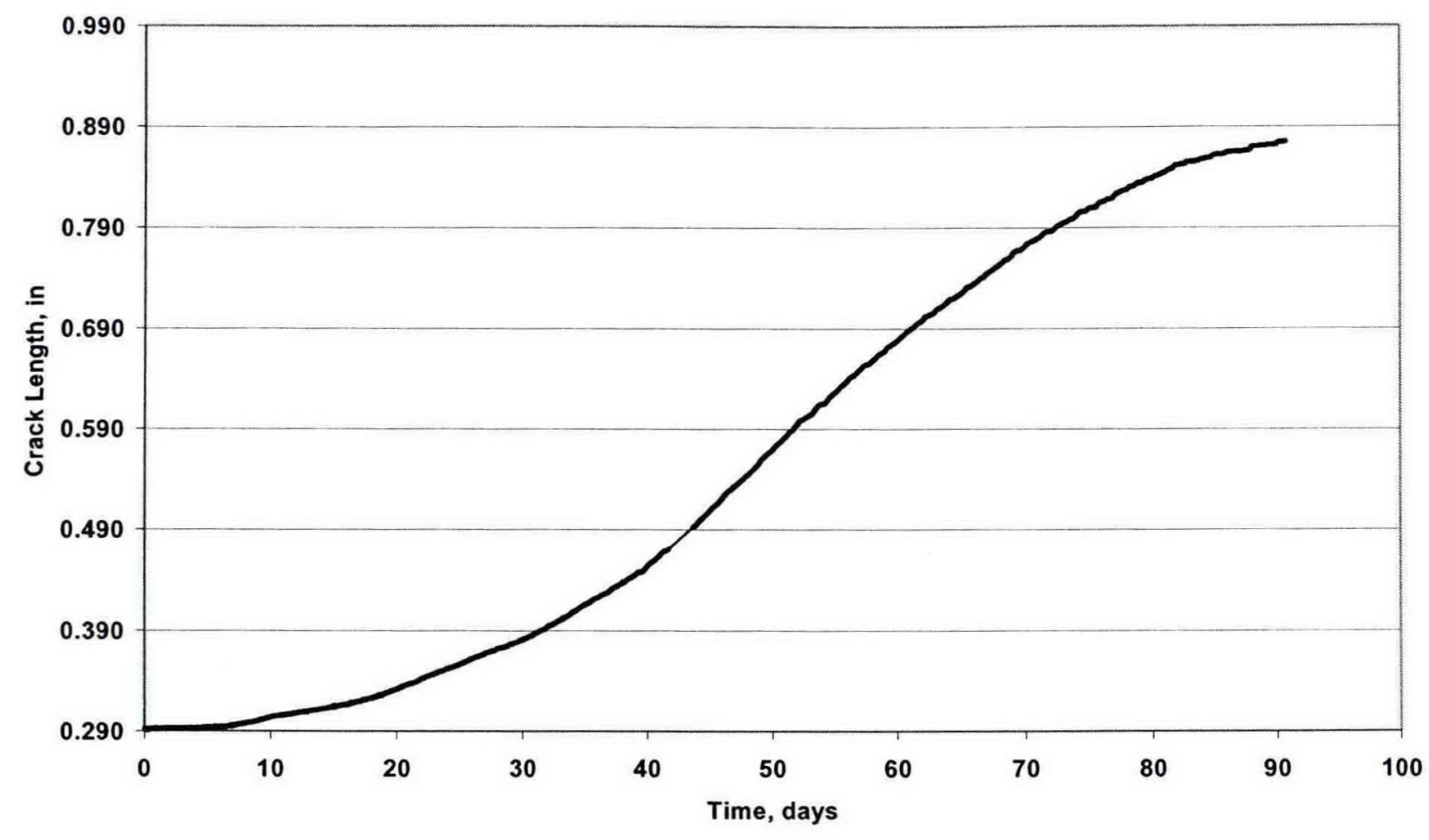

Figure 68. Load as a Function of Time for CT-17 Performed in $5 \mathrm{M} \mathrm{NaNO}$ at Open Circuit Potential. The Displacement was Held Constant Following Loading to a Nominal $\mathrm{K} \sim 25 \mathrm{ksi}$ in.

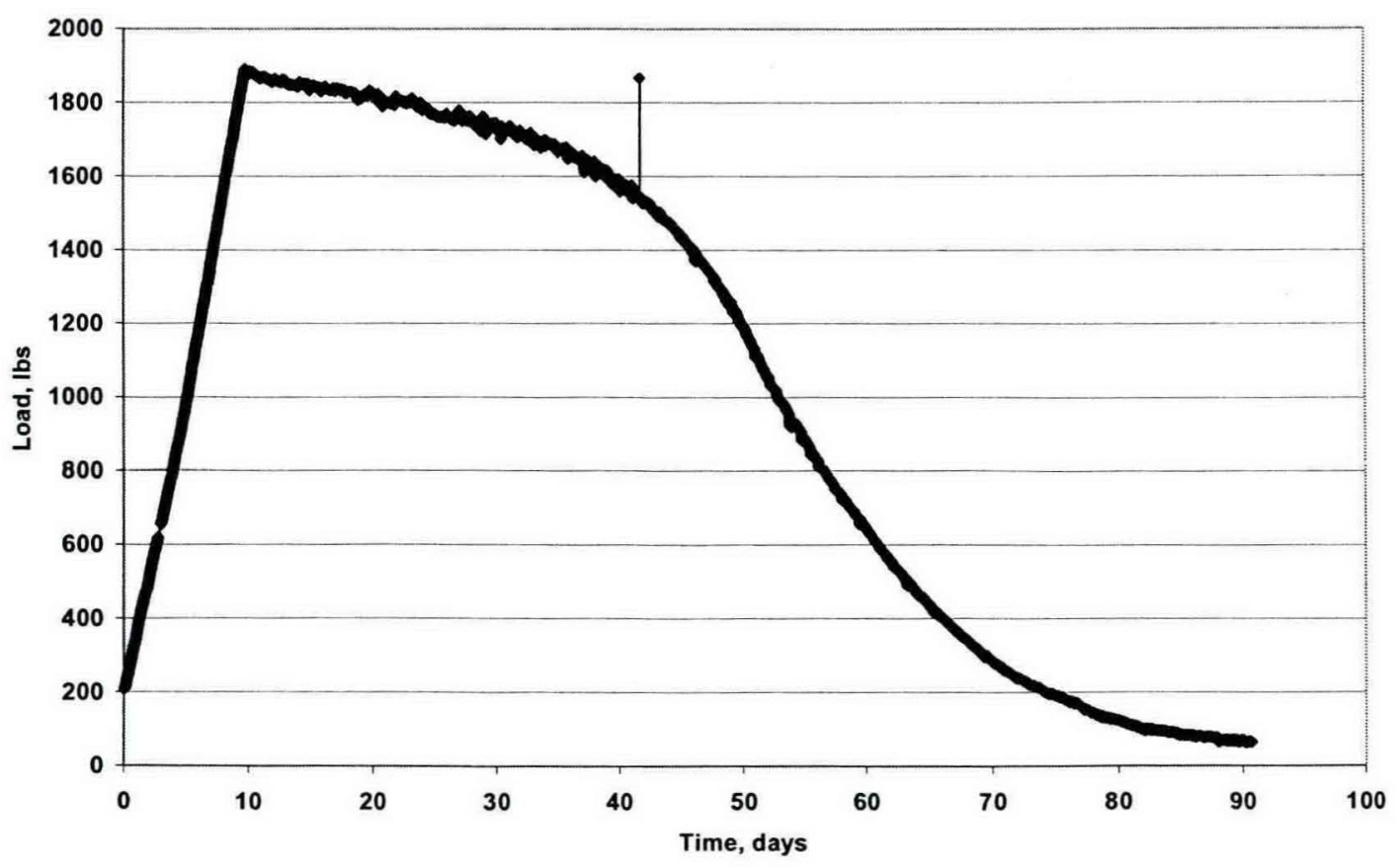


Figure 69. Plot of DCPD Calculated Crack Length as a Function of Time for CT-18 Performed in AY-101-PSC Simulant at $0 \mathrm{mV}$ vs. SCE. The Displacement was Held Constant Following Loading and Adjustment to a Nominal K $45 \mathrm{ksi} \sqrt{ }$ in.

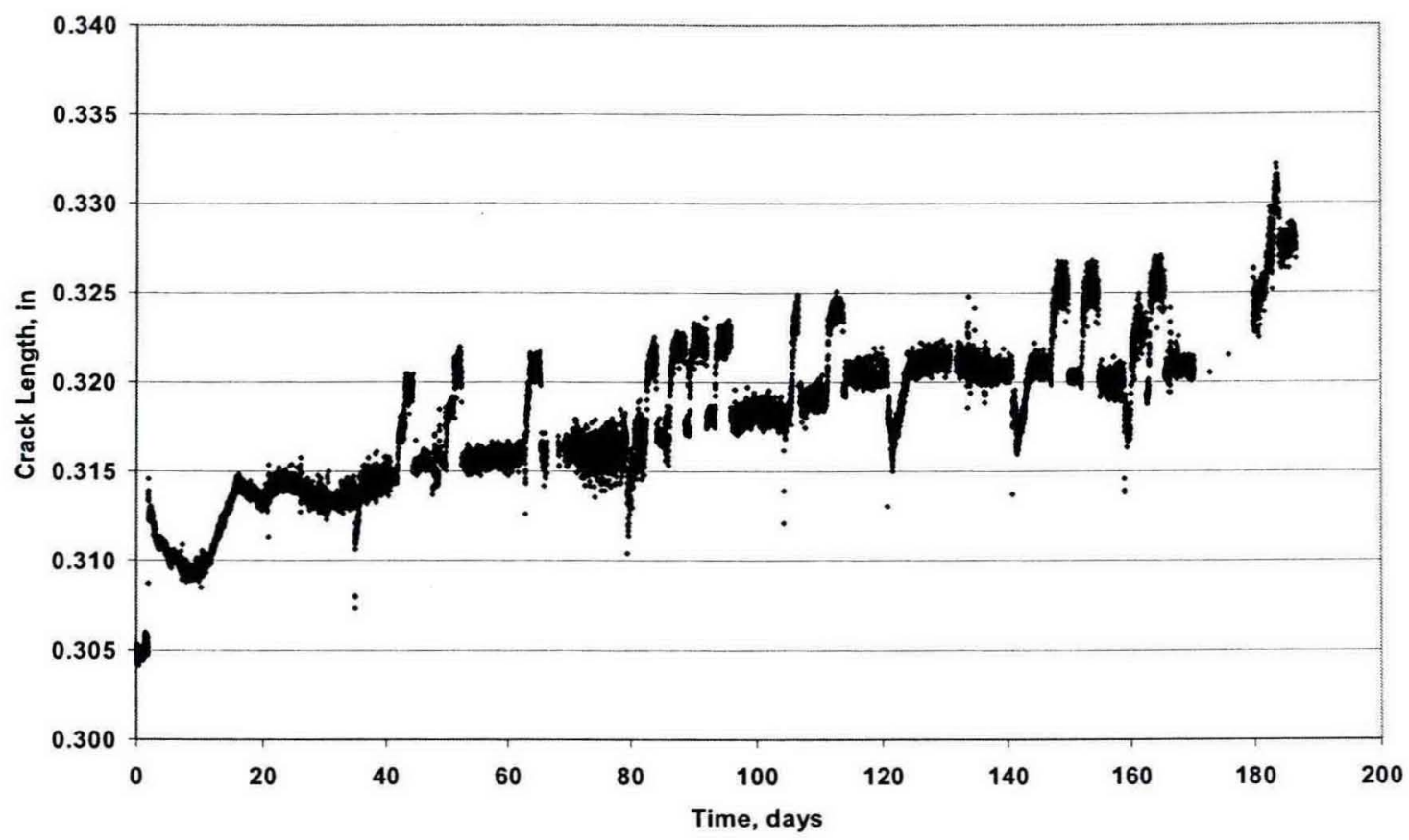

Figure 70. Load as a Function of Time for CT-18 Performed in AY-101-PSC Simulant at $0 \mathrm{mV}$ vs. SCE. The Displacement was Held Constant Following Loading and Adjustment to a Nominal K $45 \mathrm{ksi} \sqrt{ }$ in.

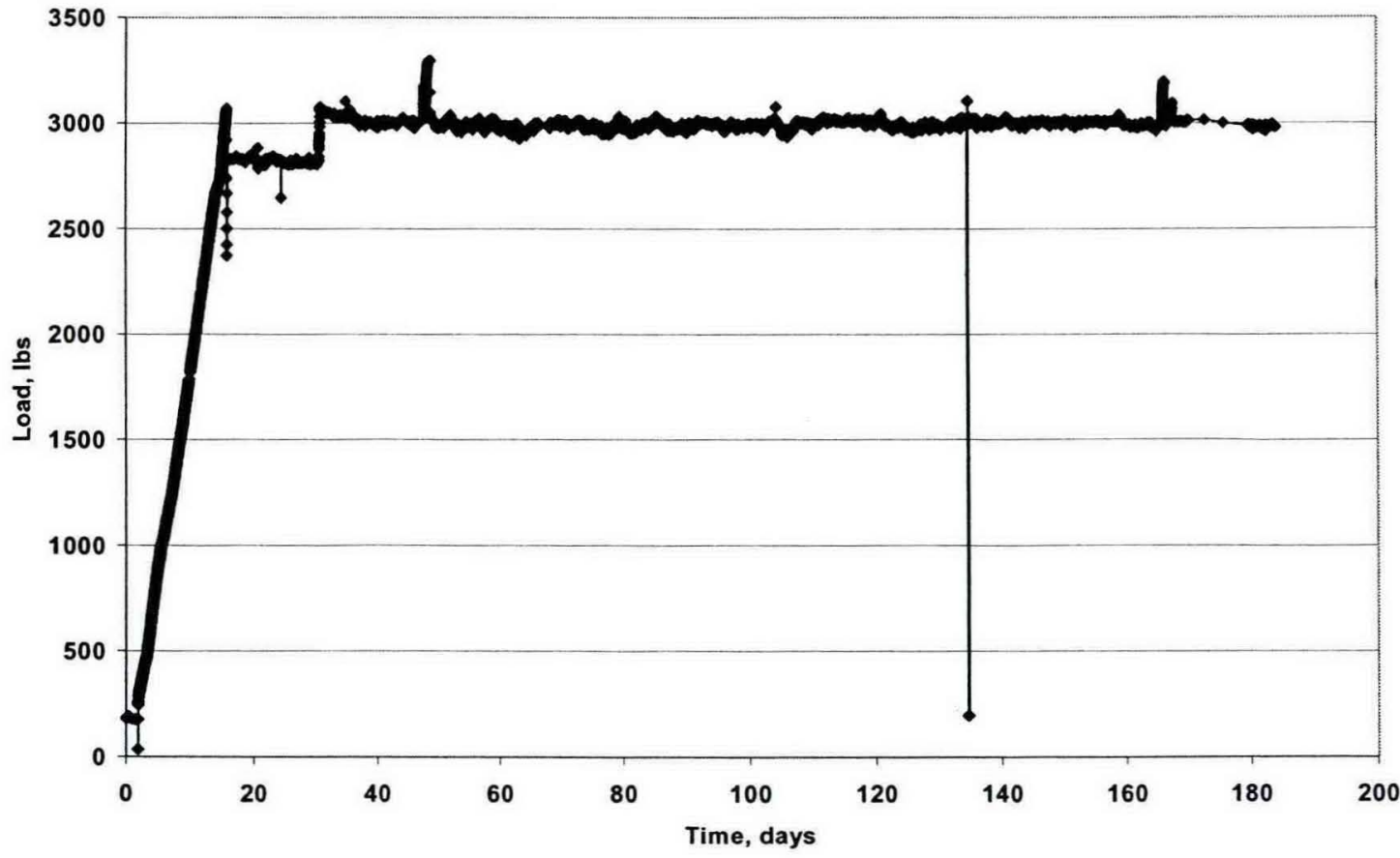


The fracture surfaces of the two K-test samples were examined using the SEM. Figure 71 is an electron-micrograph of the fracture surface of the test sample from CT-17, performed in $5 \mathrm{M}$ $\mathrm{NaNO}_{3}$ solution. $\mathrm{SCC}$ was confirmed by the presence of intergranular features. Figure 72 is an electron-micrograph of the fracture surface of the test sample from CT-18, performed in the AY-101 simulant with an applied potential of $0 \mathrm{mV}$ vs. SCE. No intergranular features were observed. This confirms the previous results, in which no SCC was detected in the AY-101 simulant loaded to $40 \mathrm{ksi} \sqrt{ }$ in and held for 30 days. This indicates that $\mathrm{K}_{\mathrm{thSCC}}$ is over $45 \mathrm{ksi} \sqrt{\mathrm{in}}_{\text {in }}$ this environment.

Figure 71. Electron-Micrograph of the Fracture Surface of Test Sample from CT-17 Performed in $5 \mathrm{M}$ NaNO3 at $50^{\circ}$, at OCP $(+107 \mathrm{mV}$ vs. SCE). The sample was held at a constant displacement for $\sim \mathbf{8 0}$ days following a constant displacement rate slow loading to a nominal $\mathrm{K}$ of $25 \mathrm{ksi}$ in.

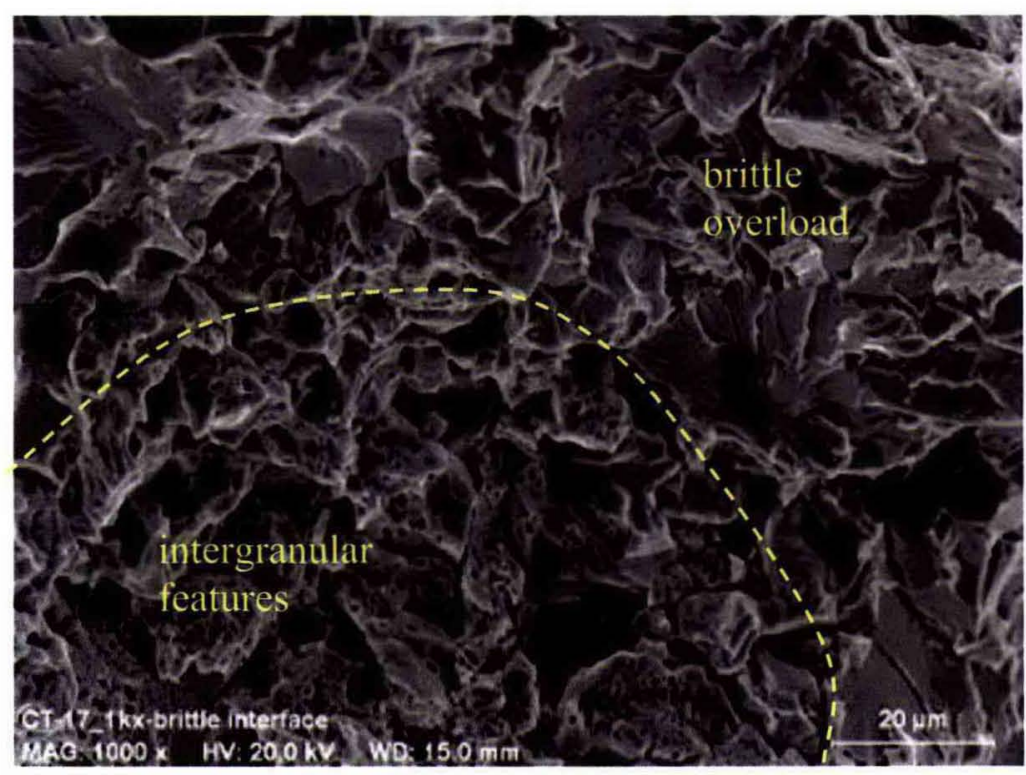


Figure 72. Electron-Micrograph of the Fracture Surface of Test Sample from CT-18 Performed in AY-101 Simulant at 50 ${ }^{\circ}$, at $0 \mathrm{mV}$ vs. SCE. The sample was held at a constant displacement for $\sim 150$ days following a constant displacement rate slow loading to a nominal $\mathrm{K}$ of $45 \mathrm{ksi} V \mathrm{in}$.

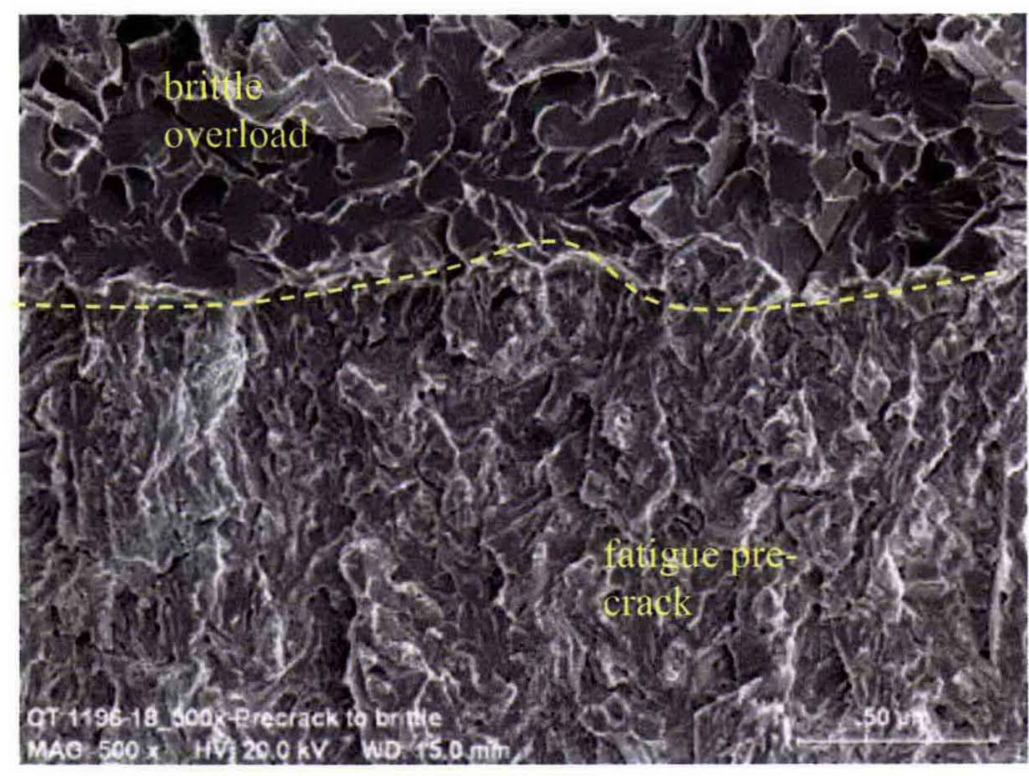

The lack of intergranular features in test CT-18 was unexpected, given the apparent crack growth indicated by the DCPD measurements. Post-test analysis of the DCPD data indicated some drift in the applied DCPD current occurred over the course of the test, resulting in potential drop changes on the order of a few tens of millivolts. This explains the apparent crack growth from the DCPD data calculations. Another possibility is that there was some minor ductile tearing during the long-term hold.

The recent K-tests were performed using a constant displacement rate slow loading and a longterm hold. This technique was developed to try to eliminate some of the inconsistencies observed in data from tests that were performed using constant loads tests. However, it has not yet been confirmed that the test technique provided conservative values of $\mathrm{K}_{\mathrm{thSCC}}$. The technique relies on crack arrest following some SCC propagation. The $\mathrm{K}_{\mathrm{thSCC}}$ calculation is then based on the final load and crack length values at arrest. To date, only one test (CT-17 performed in $5 \mathrm{M} \mathrm{NaNO}_{3}$ solution) has shown significant crack propagation and has been held for a long enough time to confirm crack arrest. Tests in various simulants have shown some minimal cracking, but not sufficient to provide a high level of confidence in the $\mathrm{K}_{\mathrm{thSCC}}$ estimates. The effect of loading rate on $\mathrm{K}_{\mathrm{th}}$ has also yet to be considered. Loading rate effects may influence the applied $\mathrm{K}$ at which SCC initiates, and the slower loading may produce artificially high $\mathrm{K}_{\mathrm{thSCC}}$ estimates, though this would go against results typically observed in SSRTs. If this is the case then it is even more important to allow any growing cracks to arrest. The microstructural mechanisms involved in SCC crack initiation become an important consideration.

The dynamic-K test used in the current program shows promise as a test technique, but there are some issues still to be resolved. One limitation is that the tests must be run for a sufficient period of time for cracking to initiate and to arrest. This has only been done with the $5 \mathrm{M} \mathrm{NaNO}_{3}$ 
solution. Given the low CGRs observed in some of the tests performed in waste simulants, tests would have to be performed for months, or years in some cases, in order to achieve the same results. A second limitation of the dynamic $\mathrm{K}$-test is that it has not been validated that the test results are conservative. There are few comparisons that can be made between the current results and previous years' results, as the tests were performed under different conditions. Previous constant load testing in AN-107 simulant indicated a $\mathrm{K}_{\text {thSCC }}$ of approximately $20 \mathrm{ksi} \sqrt{i n}_{\text {. }}$. However, the more recent dynamic K-test in AN-107 simulant implied a $\mathrm{K}_{\mathrm{thSCC}}$ closer to $35 \mathrm{ksi} \sqrt{i n}_{\mathrm{in}}$ as crack growth was minimal when loaded to that level and held for 30 days. Note that in the latter test, the sample was not held for sufficient time for the crack to arrest. It is possible that the crack would have continued to propagate and eventually arrested at K nearer to $20 \mathrm{ksi} V \mathrm{in}$. If so, the test techniques' results would have been self-consistent.

There are common features of the results of the constant load and dynamic- $\mathrm{K}$ tests that are encouraging. The CGRs measured in the waste simulant have been significantly less than those measured in the $5 \mathrm{M} \mathrm{NaNO}_{3}$ solution. Consistent with this is the higher $\mathrm{K}_{\text {thsCC }}$ estimates in the waste simulants. Although the technique requires some further validation to ensure conservatism, the current qualitative indications are that the tests are providing useful information.

In previous work, crack growth in constant load tests was identified by DCPD, examination in the stereo-microscope and metallographically. Many of the tests showed a minimal amount of crack growth and visual observations become subjective. It is very difficult to distinguish between fatigue pre-crack, ductile tearing at the crack tip, and intergranular SCC. In some cases, the results were inconsistent between techniques, and in general the conservative result was reported. The difficulties in distinguishing microstructural features led to the use of the SEM in post testexaminations.

\subsection{GENERAL DISCUSSION OF RESULTS}

The purpose of this work was to examine the effects of different tank farm operational variables (chemistry, temperature) on the propensity for localized corrosion and stress corrosion cracking. To accomplish this goal, a range of tank chemistry simulants and variations thereof have been examined in an attempt to bound certain tank farm characteristics and to better elucidate the controlling mechanisms and processes that may compromise tank integrity from a materials degradation perspective. In the course of this work, nitrite has been found to inhibit both localized corrosion and SCC whereas nitrate promotes these degradation modes. In the present work, the localized and SCC corrosion behavior of steel in waste simulants for Tanks 241-AP-105 (AP-105), 241-SY-103 (SY-103), 241-AW-105 (AW-105), 241-AZ-102 (AZ-102), 241-SY-101 (SY-101), AN-107 and AY-101 were investigated to better examine the effects of low nitritenitrate concentration ratios, high bounding chloride and fluoride concentrations, and low and high absolute nitrite and nitrate concentrations. The AP-105-PSC simulant has a unique chemistry that includes $0.27 \mathrm{M}$ nitrite and $3.58 \mathrm{M}$ nitrate (nitrite/nitrate ratio of 0.075 ). Although the nitrite concentration is less than $10 \%$ of the nitrate concentration, this chemistry appears to be more benign than some of the previously investigated simulants (e.g., $\mathrm{AN}-107$ ) at $\mathrm{pH}$ above 13 (assuming the nitrite concentration can be maintained). While this nitrite concentration seemed to play some inhibiting role, the previous discussion indicates that this concentration may be near a threshold of nitrite below which the nitrite will not be able to provide effective protection for the 
steel. Severe corrosion was observed at the liquid/vapor interface where the nitrite may have become depleted to a concentration below the threshold level for efficient inhibition or alternatively the $\mathrm{pH}$ was suppressed below a critical value.

Corrosion attack at the liquid/vapor interface strongly depends on temperature, potential, and liquid/vapor interface stability. The results obtained thus far indicate that the extent of corrosion could be decreased relative to test conditions at potentials near OCP or at temperatures near room temperature. The corrosion initiation time generally increased significantly for these conditions. However, the long-term immersion tests revealed that the corrosion at the liquid/vapor interface is likely even at room temperature. It appears that the $\mathrm{CO}_{2}$ present in the air may have played a role by changing the $\mathrm{pH}$ locally to create an aggressive environment locally at the liquid/vapor interface. No definitive conclusion can be drawn with respect to the initiation mechanism of the interfacial attack. Even though the experimental evidence indicated that potential, oxygen, and $\mathrm{CO}_{2}$ may play certain roles, a comprehensive understanding of the initiation mechanism is lacking.

Figure 73 summarizes the susceptibility of the steel to pitting corrosion as a function of inhibiting species and aggressive species in various simulants. Open symbols indicate that no pitting corrosion was observed after CPP testing. For AN-107 simulants, pitting corrosion was observed in all cases. However, the difference of repassivation potential and the OCP was considerably larger in some cases and thus the safety margin was sufficiently wide to prevent pitting under freely corroding conditions. Therefore, the tests that showed a $\mid$ Epit-OCP $\mid$ greater than $500 \mathrm{mV}$ are indicated with half-filled symbols, meaning that pitting corrosion was observed but a large safety margin (the difference between OCP and pitting potential) exists. Note that pitting corrosion was observed after polarizing to potentials higher than OCP during CPP testing. The conditions outlined in Figure 73 indicate that pitting might occur under the given environmental conditions. Therefore, Figure 73 should be used only as an illustrative tool to help understand the prospective roles of inhibiting and aggressive species.

Three zones are indicated in Figure 73: no pitting zone, pitting possible but unlikely zone, and pitting possible zone. AP-105-evaporated simulants were outliers that did not lead to localized corrosion at an extremely high nitrate concentration $(5.087 \mathrm{M})$. For illustrative purposes, dashed lines have been included in Figure 73 to qualitatively differentiate the pitting possible, pitting possible but unlikely, and no pitting regions. At each nitrate concentration level, there appears to be a critical nitrite level, above which the material was protected from localized corrosion. 
Figure 73. Susceptibility of Materials to Pitting Corrosion as a Function of Nitrite and Nitrate Concentration. The Symbols Represent Various Simulant Chemistries Previously Studied.

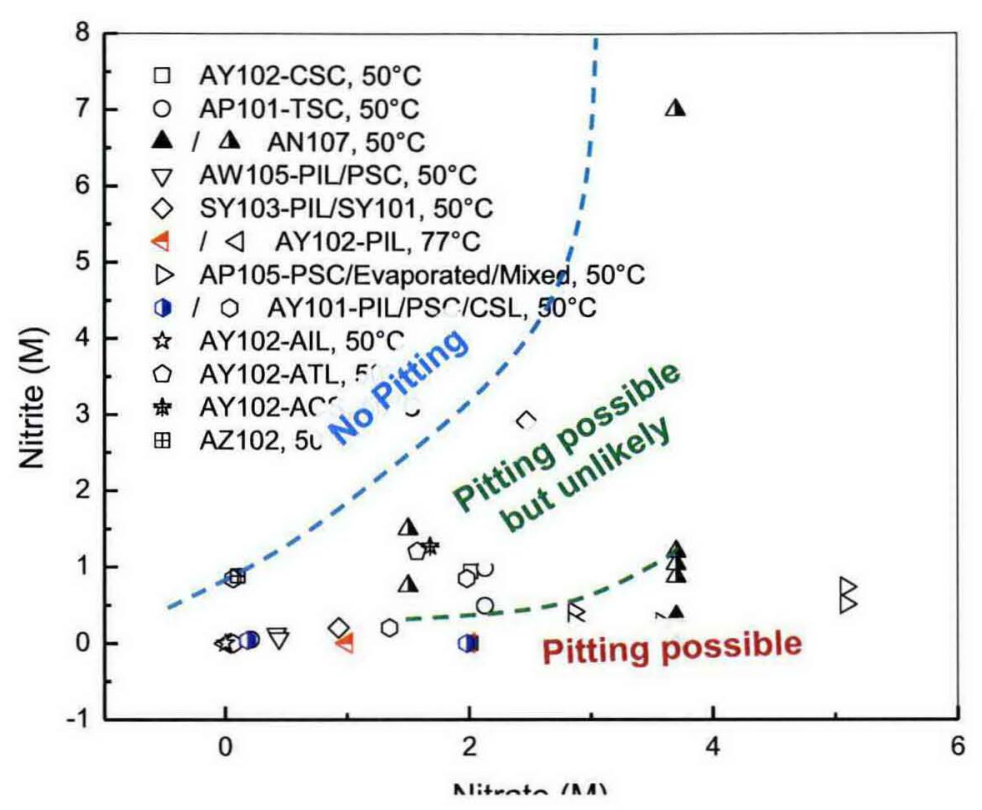

Figure 74 shows the estimated CGRs for tests that cracked as a function of applied potential in all simulants investigated. These data are primarily from SSRTs, with the one exception being the data point for the $5 \mathrm{M} \mathrm{NaNO}_{3}$ solution which was provided by a dynamic $-\mathrm{K}$ test. The new data obtained from the recent tests do not affect the general trend of the curve, which was developed using results from previous work. From previous testing, significant crack growth was only observed at potentials higher than $-100 \mathrm{mV}$ (vs. SCE) for the nitrate-based simulants (e.g., AY-101-PSC). Much slower CGRs were observed in carbonate-based simulants at potentials near -800 mV (vs. SCE). Similar slow CGRs were also observed in modified (increased nitrate) carbonate based simulants around -300 to $-200 \mathrm{mV}$ vs. SCE. The new data is seen in this third peak in the plot at $-249 \mathrm{mV}$ vs. SCE. This was generated from the one CGR experiment conducted in AP-105-PSC stimulant at OCP that showed cracking. 
Figure 74. Estimated CGR vs. Potential in the Investigated Simulants.

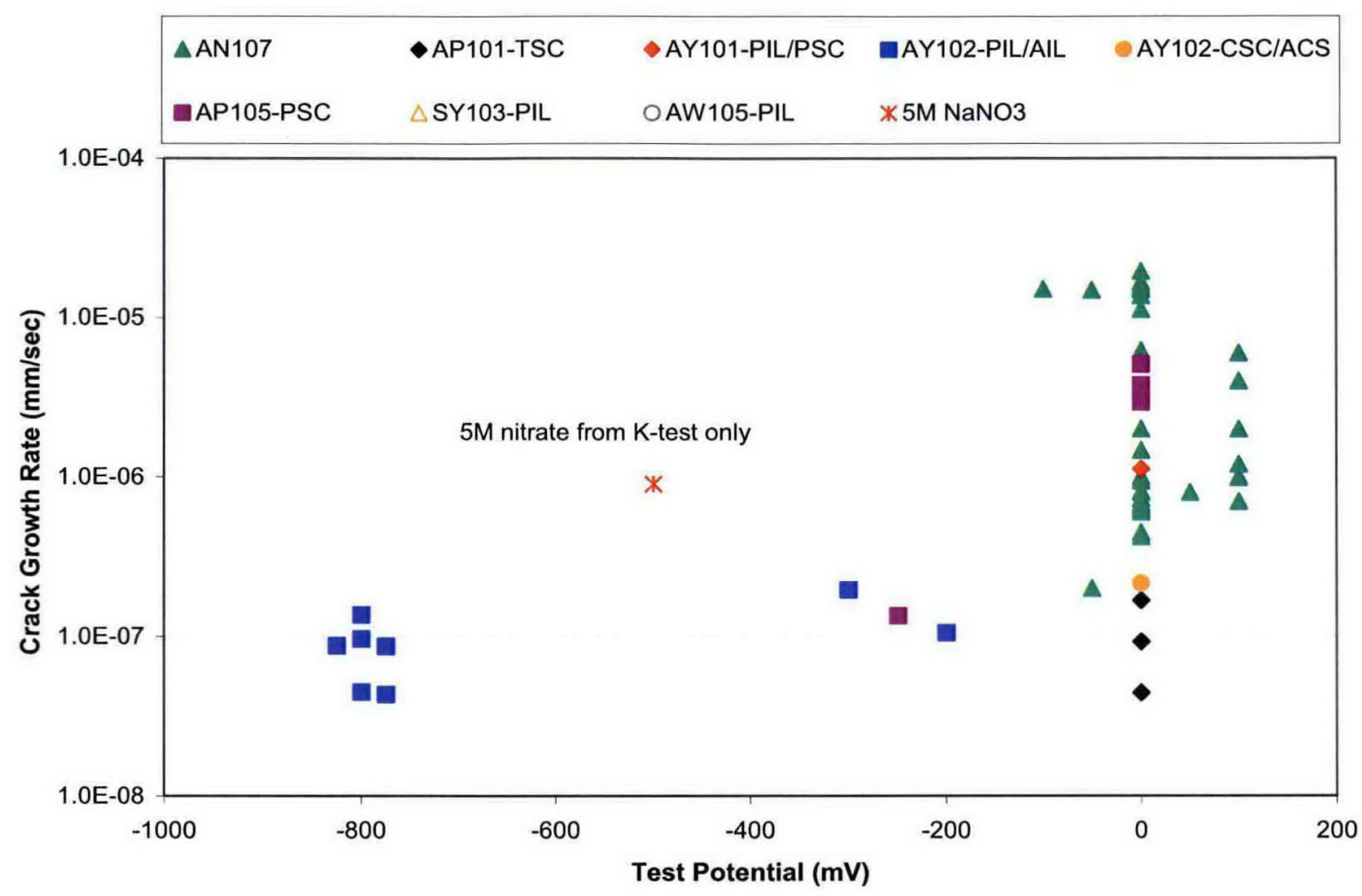

Figure 75 is a plot of the nitrite/nitrate ratio vs. applied test potential. This data indicates conditions for SCC susceptibility. A similar plot was developed during previous work, and has been updated to include the new test data. SSRTs that showed cracking are indicated by solid symbols and tests that showed no cracking are indicated by open symbols. The general trend for the nitrate-based simulants is that SCC susceptibility tends to increase with increasing potential and decrease with increasing nitrite concentration. There is a transitional region of SCC behavior at low nitrite/nitrate ratios between potentials of -200 and $-300 \mathrm{mV}$ vs. SCE which remains poorly defined.

The results of the AP-105-PSC, SY-103-PIL and AW-105 testing are consistent with the results from previous tests programs, as can be seen from Figure 75. The AP-105-PSC simulant has a very low nitrite/nitrate ratio (0.075), and did show evidence of SCC, even at the relatively low OCP potential (-249 $\mathrm{mV}$ vs. SCE). The AW-105-PIL simulant has a slightly higher nitrite/nitrate ratio (0.29) and showed no evidence of SCC, at a comparable potential ( $-290 \mathrm{mV}$ vs. SCE). These data help to further define the transitional region of the plot. The SY-103-PIL simulant has a much higher nitrite/nitrate ratio (1.47), and also shows no evidence of cracking, as the data in the Figure 75 would predict. The AW-105-PSC simulant and modified " $6 \mathrm{X}$ " simulant data further defines the critical region in low nitrite/nitrate ratio and higher potential $0 \mathrm{mV}$ to $-100 \mathrm{mV}$ vs. SCE region. Figure 75 indicates that SCC is possible in many of the simulants. However, it is important to realize that all but one of the tests that showed cracking behavior were anodically polarized. The one exception is the one of the two tests performed in AP-105-PSC at OCP that cracked. This is the only test that has shown evidence of cracking at OCP. This observation is important from a tank integrity perspective. 
Figure 75. A Plot of Nitrite/nitrate Ratio vs. Applied Test Potential Indicating Conditions for SCC Susceptibility. Only Nitrate Based simulant Results Are Included.

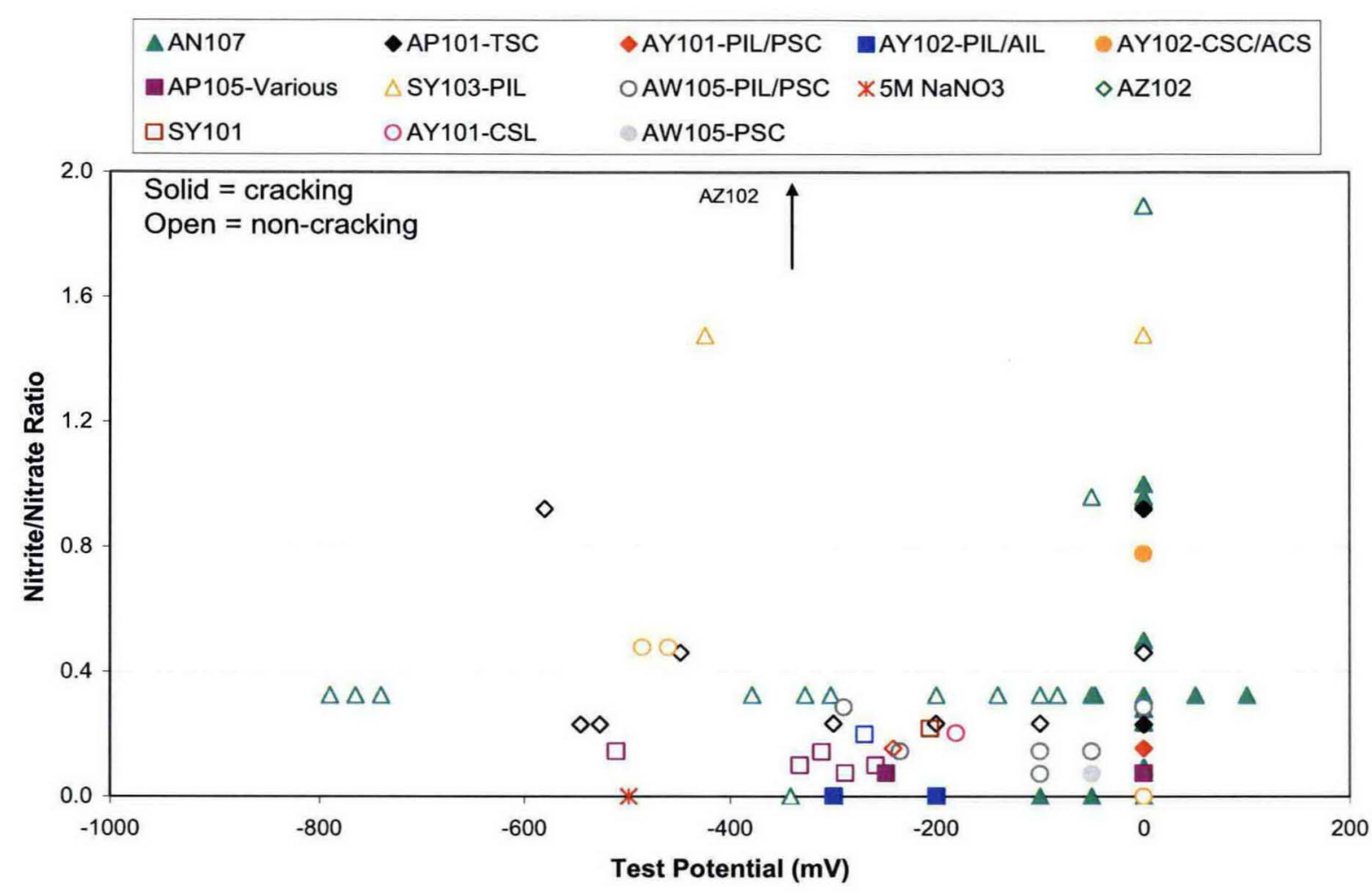

An important conclusion that was drawn from this test program is that localized corrosion at liquid/vapor interfaces is possible at high $\mathrm{pH}$. This indicates that the current requirements to maintain a high $\mathrm{pH}$ may not necessarily be sufficient to ensure long-term tank integrity. The interfacial corrosion is not currently well understood, and should be considered as a possible focus area for future work.

Based on the work conducted to date, it would seem that the risk of localized corrosion and SCC is relatively low under nominal tank operating conditions. There is, however, a possibility of SCC in achievable chemistries (these are chemistries similar to those already existing in the tank farm or those that may develop due to mixing/transfer operations) if a sufficiently noble potential is reached. This observation highlights the importance of the tank probe monitoring program. Also of significant note was the observation of rapid corrosion at the liquid/vapor interface which appears to be related to a drop in the interfacial $\mathrm{pH}$ due to the presence of $\mathrm{CO}_{2}$ in the head space. Because the corrosion rates observed with some simulants were quite rapid, additional efforts to explore optimal mitigation strategies for this interfacial region are recommended. 


\subsection{SUMMARY OF KEY FINDINGS}

Based on the work conducted, the key findings of the research are listed below.

- $\quad$ The SCC potency of the waste simulants for the three tanks studied followed the trends previously established for nitrate-based simulants. SCC only occurred at relatively high applied potentials (e.g., $0 \mathrm{mV}$ vs. SCE) or at low nitrite/nitrate concentrations ratios.

- $\quad$ Limited GCR testing performed in AY-101 simulants indicated that stress intensity factors above $45 \mathrm{ksi} \sqrt{\text { in }}$ were necessary for crack propagation to occur in the waste simulants tested.

- Though at current tank conditions the PSC for tank 241-AP-105 (AP-105-PSC) simulant of the tank showed a low propensity for corrosion. The tank steel exposed to the Tank AP-105-PSC simulant at elevated temperatures and under anodically polarizing conditions demonstrated a susceptibility to stress corrosion cracking (SCC) and localized corrosion at the liquid/vapor interface. Long-term immersion tests indicated that the steel was susceptible to corrosion at the liquid/vapor interface even at $\mathrm{OCP}$, but the extent at room temperature was not as severe as at elevated temperatures (e.g., $50^{\circ} \mathrm{C}$ ). The AP-105-PSC is the only simulant in which SCC was observed in a slow strain rate test (SSRT) performed at OCP. Local chemistry changes (nitrite depletion or $\mathrm{pH}$ drop) may be responsible for the interfacial attack, though the precise mechanism is unclear at this time. The liquid/vapor interface attack indicates that localized corrosion is possible in simulants with high $\mathrm{pH}$, and this should be considered in any future corrosion mitigation strategies.

- The PIL for Tank 241-SY-103 (SY-103-PIL) simulant, which has the upper limit of chloride concentration of the DSTs, appears to be benign with respect to corrosion and SCC relative to the AP-105-PSC and previously tested Tank 241-AN-107 simulants and the PIL for Tank 241-AY-102 (AY-102PIL) simulant. Any possible corrosion liability associated with the high chloride content, appears to be offset by the relatively high nitrite content.

- The PIL for Tank 241-AW-105 (AW-105-PIL) simulant, which has the upper limit of fluoride concentration, also appears to be benign with respect to tank steel SCC. However, some localized corrosion has been observed at the liquid/vapor interface.

- The AZ-102 simulant, tested at the higher temperature of $77^{\circ} \mathrm{C}$, appears to be benign with respect to SCC, confirming the inhibitory nature of nitrite. The AZ-102 simulant has a high nitrite/nitrate ratio of 8.4 . 
RPP-RPT-37505, Rev. 0

\section{APPENDIX A}

SIMULANT RECIPES, CERTIFICATES FOR CHEMICALS AND QA DOCUMENTS 


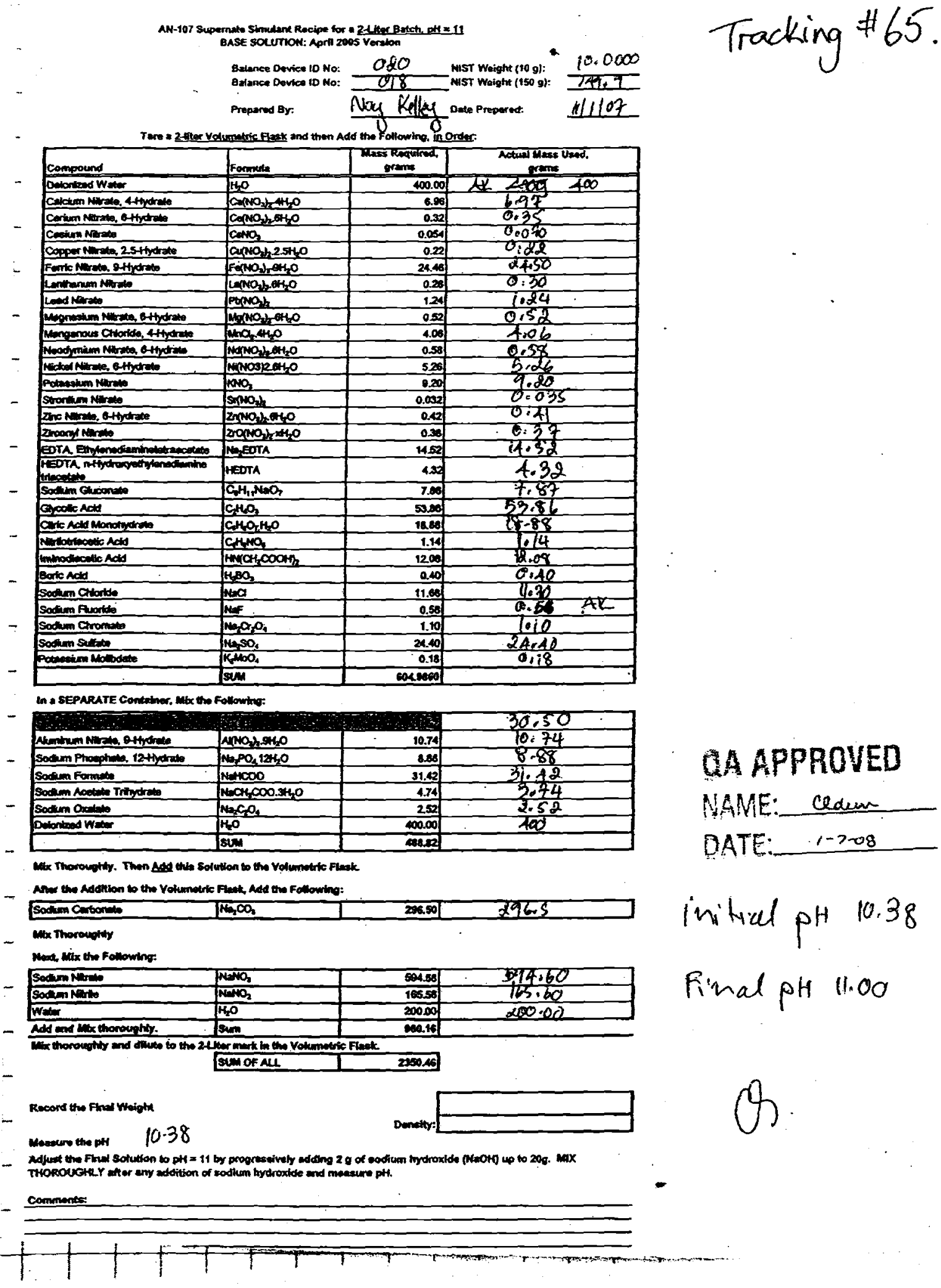




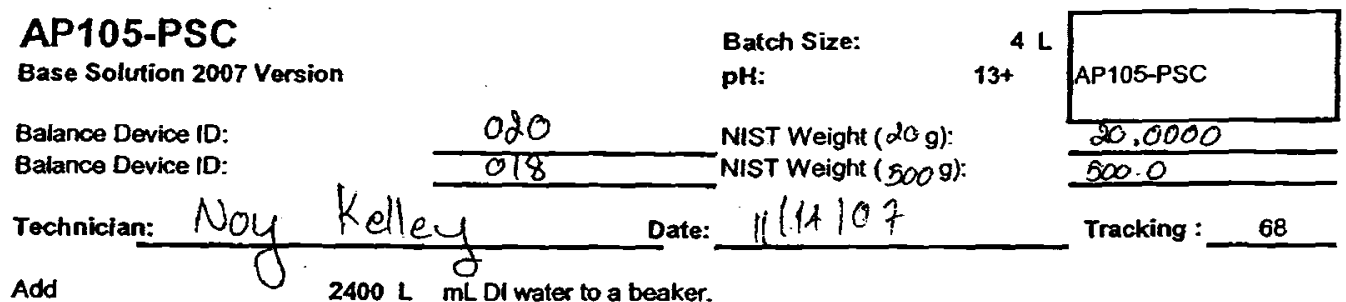

Insert Tefion stirbar and thermocouple, and place on stirrer / hotplate.

Tum on heater and adjust to $60^{\circ} \mathrm{C}\left( \pm 10^{\circ} \mathrm{C}\right)$.

Add the following chemicals and record their actual weights:

\begin{tabular}{|c|c|c|c|c|}
\hline Chemical & Formula & $\begin{array}{l}\text { Required } \\
\text { Mass }(g)\end{array}$ & $\begin{array}{l}\text { Actual } \\
\text { Mass (g) }\end{array}$ & Comments \\
\hline Sodium Akuminate & $\mathrm{NaAlO}_{2} \cdot 2 \mathrm{H}_{2} \mathrm{O}$ & 70.71 & $70 \cdot 71$ & \\
\hline Sodium Choride & $\mathrm{NaCl}$ & 7.20 & 7.20 & \\
\hline Sodium Fixoride & NaF & 1.53 & 53 & \\
\hline Sodium Chromate & $\sqrt{\mathrm{Na}_{2} \mathrm{CrO}_{4}}$ & 6.87 & 6.87 & \\
\hline Sodium Suffate & $\mathrm{Na}_{2} \mathrm{SO}_{4}$ & 26.82 & 26.83 & \\
\hline Sodium Phosphate, 12 +tydrate & $\mathrm{Na}_{3} \mathrm{PO}_{4} \mathbf{1 2 H}_{2} \mathrm{O}$ & 45.77 & 45.78 & \\
\hline Sodium Formate & $\mathrm{NaHCOO}$ & 2.72 & 2.72 & \\
\hline Sodkm Acetate Trihydrate & $\mathrm{NaCH}_{5} \mathrm{COO}, 3 \mathrm{H}_{2} \mathrm{O}$ & 4.08 & 7.09 & \\
\hline Sodium Oxalate & $\sqrt{\mathrm{Na}_{2} \mathrm{C}_{2} \mathrm{O}_{4}}$ & 4.02 & 7.91 & \\
\hline Sodfum Carbonate & $\mathrm{Na}_{2} \mathrm{CO}_{3}$ & 13821 & 138.2 & \\
\hline Sodfiun Nitrate & $\mathrm{NaNO}_{3}$ & 1211.75 & 721.8 & \\
\hline Potassium Nitrate & $\mathrm{KNO}_{3}$ & 5.38 & 3.41 & \\
\hline Sodium Nitite & $\mathrm{NaNO}_{2}$ & 74.52 & & \\
\hline Gycolic Acid & $\mathrm{C}_{2} \mathrm{H}_{1} \mathrm{O}_{3}$ & 3.23 & 23 & \\
\hline Sodium Hydroxide & $\mathrm{NaOH}$ & 28.18 & 28.18 & \\
\hline
\end{tabular}

* Sodium fluoride is highty taxic. Handle with caution.

1631.06

Adjust total solution volume to $\quad 3400 \mathrm{~mL}$ by adding DI water.

Adjust solution temperature to $50^{\circ} \mathrm{C}$ to $60^{\circ} \mathrm{C}$.

Filter solution by vacuum through medium glass filter. Handfe with caution, hot and caustic solution.

Rinse beaker with approxinatety $50 \mathrm{~mL}$ of Di water

Rinse filter with approximately $50 \mathrm{~mL}$ of DI water

Transfer final filtrate and inse solutions to large beaker with stir bar.

Measure and record initial pH AK +1.35 13.21

check the $\mathrm{pH}$ to make sure it is ofl $19 \mathrm{kt}$

Transfer to volumetric flask and include rinse with $D$ water. Alliow solution to coof

QA APPAOVES

NAME: Cedum

DATE: $\quad \rightarrow \infty 8$

Adjust final solution to volume of

$4 \mathrm{~L}$ with $\mathrm{DI}$ water, and $\mathrm{mix}$ thoroughty.

SUM Total chemicals (targot)

Total water (target)

Target Specific Density

$\begin{array}{cl}1630.98 \mathrm{~g} & \text { Total chemicals (actual) } \\ \mathrm{L} \mathrm{L} & \text { Total water (actual) }\end{array}$

1.41 Calculated density

\begin{tabular}{|l|l|l}
\hline 1631.06 & 3 \\
\hline 1.000 & \\
\hline
\end{tabular}

Check final solution pH and record.

$\mathrm{pH}=13.2$ Readjust if significantly different from target.

Comments: record any difficulties or discrepancles

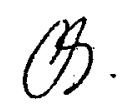

1 I 


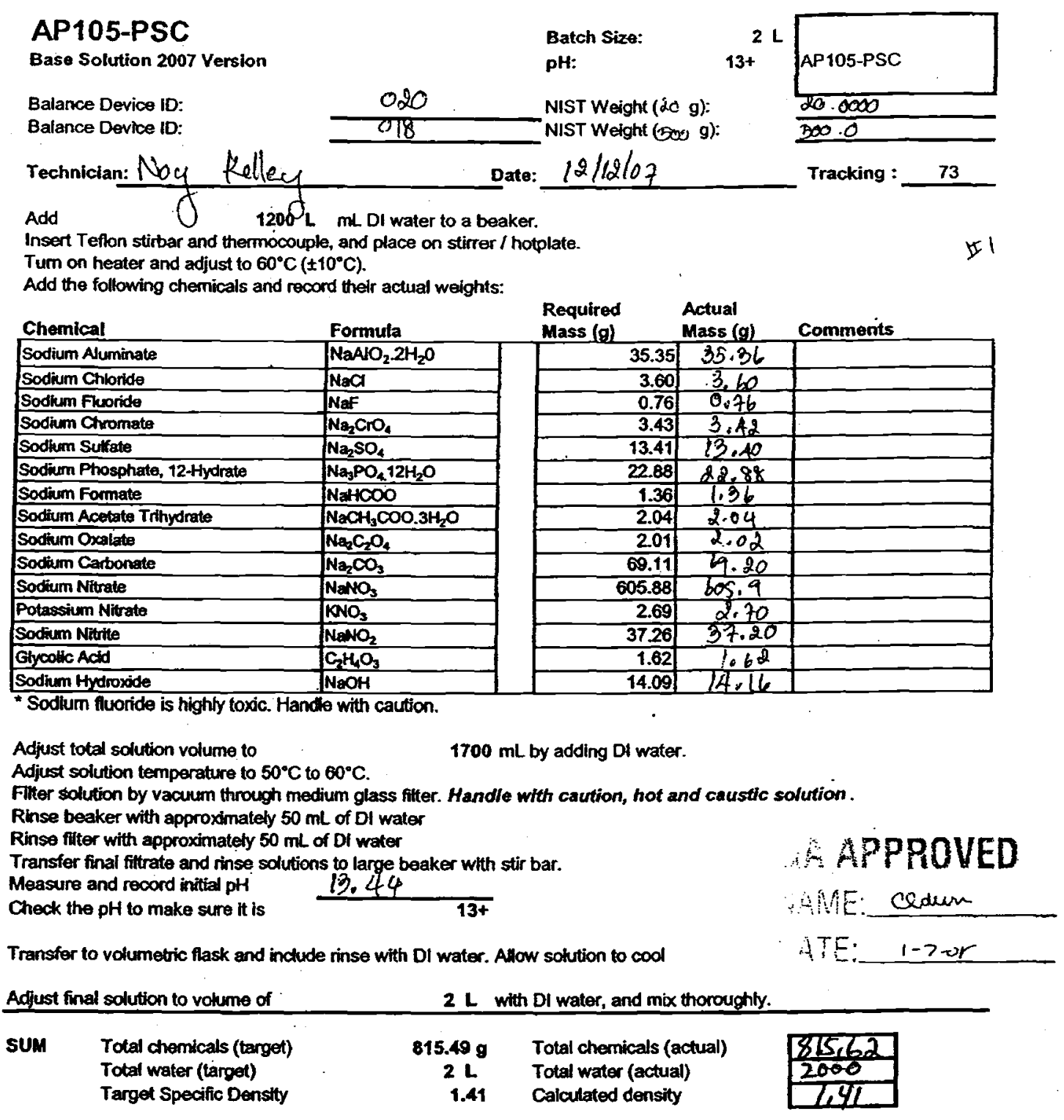

Check finat solution pH and record.

$\mathrm{pH}=$ i MApReadjust if significantly different from target

Comments: record any difficultes $\alpha$ discrepancies 


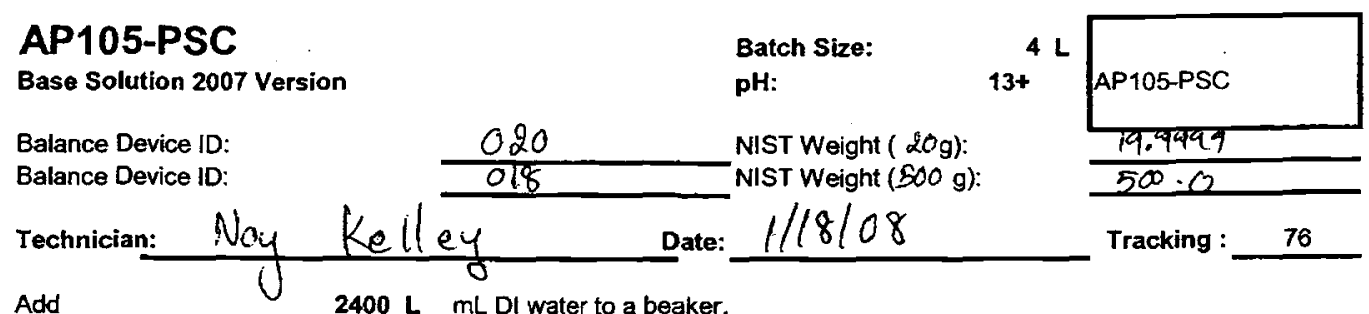

Insert Tefion stirbar and thermocouple, and place on stirrer / hotplate.

Tum on heater and adjust to $60^{\circ} \mathrm{C}\left( \pm 10^{\circ} \mathrm{C}\right)$.

Add the following chemicals and record their actual weights:

\begin{tabular}{|c|c|c|c|c|}
\hline Chemical & Formula & $\begin{array}{l}\text { Required } \\
\text { Mass (g) }\end{array}$ & $\begin{array}{l}\text { Actual } \\
\text { Mass (g) }\end{array}$ & Comments \\
\hline Sodium Aluminate & $\mathrm{NaAlO}_{2} \cdot 2 \mathrm{H}_{2} \mathrm{O}$ & \begin{tabular}{|r|}
70.71 \\
\end{tabular} & 70.71 & \\
\hline Sodium Chloride & $\mathrm{NaCl}$ & 7.20 & 7.20 & \\
\hline Sodium Fluoride & NaF & 1.53 & 1.53 & \\
\hline Sodium Chromate & $\mathrm{Na}_{2} \mathrm{CrO}_{4}$ & 6.87 & 6.87 & \\
\hline Sodium Sulfate & $\mathrm{Na}_{2} \mathrm{SO}_{4}$ & 26.82 & 26.82 & \\
\hline Sodium Phosphate, 12-Hydrate & $\mathrm{Na}_{3} \mathrm{PO}_{4} 12 \mathrm{H}_{2} \mathrm{O}$ & 45.77 & 45.77 & \\
\hline Sodium Formate & NaHCOO & 2.72 & 2.72 & \\
\hline Sodium Acetate Trihydrate & $\mathrm{NaCH}_{3} \mathrm{COO} .3 \mathrm{H}_{2} \mathrm{O}$ & 4.08 & 4.08 & \\
\hline Sodium Oxalate & $\mathrm{Na}_{2} \mathrm{C}_{2} \mathrm{O}_{4}$ & 4.02 & 7.02 & \\
\hline Sodium Carbonate & $\mathrm{Na}_{2} \mathrm{CO}_{3}$ & 138.21 & 138.3 & \\
\hline Sodium Nitrate & $\mathrm{NaNO}_{3}$ & 1211.75 & 121106 & \\
\hline Potassium Nitrate & $\mathrm{KNO}_{3}$ & 5.38 & 5,40 & \\
\hline Sodium Nitrite & $\mathrm{NaNO}_{2}$ & 74.52 & 74.6 & \\
\hline Glycolic Acid & $\mathrm{C}_{2} \mathrm{H}_{4} \mathrm{O}_{3}$ & 3.23 & 3.23 & Precipitation \\
\hline Sodium Hydroxide & $\mathrm{NaOH}$ & 28.18 & 28.25 & alsovolie y precipiblt \\
\hline
\end{tabular}

Adjust total solution volume to

Adjust solution temperature to $50^{\circ} \mathrm{C}$ to $60^{\circ} \mathrm{C}$.

$3400 \mathrm{~mL}$ by adding DI water

Filter solution by vacuum through medium glass fitter. Handle with caution, hot and caustic solution.

Rinse beaker with approximately $50 \mathrm{~mL}$ of DI water

Rinse filter with approximateiy $50 \mathrm{~mL}$ of DI water

Transfer final filtrate and rinse solutions to large beaker with stir bar.

Measure and record inftial pH $13_{3} 45$

Check the $\mathrm{pH}$ to make sure it is

Transfer to volumetric flask and include rinse with DI water. Allow solution to cool

QA APPROVED

NAME: Clduw

DATE: $2-5-08$

Adjust final solution to volume of

$4 \mathrm{~L}$ with DI water, and mix thoroughly.

Sum Total chemicals (target)

Total water (target)

Target Specific Density
$1630.98 \mathrm{~g}$ Total chemicals (actual)
$4 \mathrm{~L}$ Total water (actual)
1.41 Calculated density

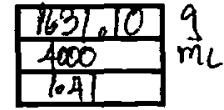

Check final solution $\mathrm{pH}$ and record.

$\mathrm{pH}=13,4$ ŚReadjust if significantly different from target.

Comments: record any difficulties or discrepancies 


\section{AP105-PSC}

Base Solution 2007 Version

Balance Device ID:

Balance Device ID:

Technician:

$$
\text { Noy }
$$

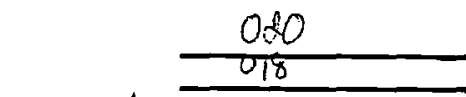

078

Date:
Batch Size:

pH:

NIST Weight ( $10 \mathrm{~g})$ : NIST Weight $(500 \mathrm{~g})$

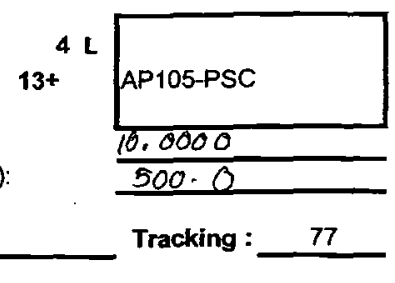

$2400 \mathrm{~L} \quad \mathrm{~mL} \mathrm{Dl}$ water to a beaker.

Add

Insert Teflon stirbar and thermocouple, and place on stirrer / hotplate.

Tum on heater and adjust to $60^{\circ} \mathrm{C}\left( \pm 10^{\circ} \mathrm{C}\right)$.

Add the following chemicals and record their actual weights:

\begin{tabular}{|c|c|}
\hline Chemical & Formula \\
\hline Sodium Aluminate & $\mathrm{NaAlO}_{2} \cdot 2 \mathrm{H}_{2} \mathrm{O}$ \\
\hline Sodium Chioride & $\mathrm{NaCl}$ \\
\hline Sodium Fluoride & $\mathrm{NaF}$ \\
\hline Sodium Chromate & $\mathrm{Na}_{2} \mathrm{CrO}_{4}$ \\
\hline Sodium Sulfate & $\mathrm{Na}_{2} \mathrm{SO}_{4}$ \\
\hline Sodium Phosphate, 12-Hydrate & $\mathrm{Na}_{3} \mathrm{PO}_{4} 12 \mathrm{H}_{2} \mathrm{O}$ \\
\hline Sodium Formate & NaHCOO \\
\hline Sodium Acetate Trihydrate & $\mathrm{NaCH}_{3} \mathrm{COO} .3 \mathrm{H}_{2} \mathrm{O}$ \\
\hline Sodium Oxalate & $\mathrm{Na}_{2} \mathrm{C}_{2} \mathrm{O}_{4}$ \\
\hline Sodium Carbonate & $\mathrm{Na}_{2} \mathrm{CO}_{3}$ \\
\hline Sodium Nitrate & $\mathrm{NaNO}_{3}$ \\
\hline Potassium Nitrate & $\mathrm{KNO}_{3}$ \\
\hline Sodium Nitrite & $\mathrm{NaNO}_{2}$ \\
\hline Glycolic Acid & $\mathrm{C}_{2} \mathrm{H}_{4} \mathrm{O}_{3}$ \\
\hline Sodium Hydroxide & $\mathrm{NaOH}$ \\
\hline
\end{tabular}

* Sodium fluoride is highly toxic. Handle with caution.

\begin{tabular}{|c|c|c|}
\hline $\begin{array}{l}\text { Required } \\
\text { Mass (g) }\end{array}$ & $\begin{array}{l}\text { Actual } \\
\text { Mass (g) }\end{array}$ & Comments \\
\hline 70.71 & 90.70 & \\
\hline 7.20 & 1220 & \\
\hline 1.53 & 9.55 & \\
\hline 6.87 & 6.84 & \\
\hline 26.82 & 26.84 & \\
\hline 45.77 & 40.80 & \\
\hline 2.72 & 2.72 & \\
\hline 4.08 & A.09 & \\
\hline 4.02 & 4,02 & \\
\hline 138.21 & 138.3 & \\
\hline 1211.75 & 1212 & \\
\hline 5.38 & 5.40 & \\
\hline 74.52 & 14.6 & \\
\hline 3.23 & 3.37 & Small precipitat \\
\hline 28.18 & 28,3 & Dissove aftes adukng \\
\hline
\end{tabular}

Adjust total solution volume to

$3400 \mathrm{~mL}$ by adding DI water.

Adjust solution temperature to $50^{\circ} \mathrm{C}$ to $60^{\circ} \mathrm{C}$.

Filter solution by vacuum through medium glass filter. Handle with caution, hot and caustic solution.

Rinse beaker with approximately $50 \mathrm{~mL}$ of DI water

Rinse filter with approximately $50 \mathrm{~mL}$ of DI water

Transfer final filtrate and rinse solutions to large beaker with stir bar.

Measure and record initial $\mathrm{pH} \quad 12.98$

Check the pH to make sure it is

Transfer to volumetric flask and include rinse with D/ water. Allow solution to cool

MAPPROVED

NAME: dedur

Adjust final solution to volume of

$4 \mathrm{~L}$ with DI water, and mix thoroughly.

SUM

Total chemicals (target)
Total water (target)

Total chemicals (actual)

Target Specific Density

$4 \mathrm{~L}$ Total water (actual)

1.41 Calculated density

$\frac{1631.73}{4000} \frac{9}{1041}$

Check final solution $\mathrm{pH}$ and record.

$\mathbf{p H}=12.98$ Readjust if significantly different from target.

Comments: record any difficulties or discrepancies 
AY101-PSC

Base Solution 2007 Version

Balance Device ID:

Balance Device ID:

Technician:

Add

Nay Kelley

त 1200

$1200 \mathrm{~L} \mathrm{~mL}$ D water to a beaker.

Insert Teflon stirbar and thermocouple, and place on stirrer / hotplate.

Turn on heater and adjust to $60^{\circ} \mathrm{C}\left( \pm 10^{\circ} \mathrm{C}\right)$.

Add the following chemicals and record their actual weights:

Chemical

Sodinum Alumniate

Sodium Chloride

Sodium Fluoride

Sodium Chromate

Sodium Sulfate

Sodium Phosphate, 12-Hydrate

Sodium Formate

Sodium Acetate Trihydrate

Sodium Oxalate

Sodium Carbonate

Sodium Nitrate

Sodium Nitrite

Sodium Silicate

Glycolic Acid

Sodlum Hydroxide

\begin{tabular}{ll}
\hline & $\mathrm{NaOH}$ \\
\hline
\end{tabular}

Formula

$\mathrm{NaAlO}_{2} \cdot 2 \mathrm{H}_{2} \mathrm{O}$

$\mathrm{NaCl}$

$\mathrm{NaF}$

$\mathrm{Na}_{2} \mathrm{CrO}_{4}$

$\mathrm{Na}_{2} \mathrm{SO}_{4}$

$\mathrm{Na}_{3} \mathrm{PO}_{4} 12 \mathrm{H}_{2} \mathrm{O}$

$\mathrm{NaHCOO}$

$\mathrm{NaCH}_{3} \mathrm{COO} .3 \mathrm{H}_{2} \mathrm{O}$

$\mathrm{Na}_{2} \mathrm{C}_{2} \mathrm{O}_{4}$

$\mathrm{Na}_{2} \mathrm{CO}_{3}$

$\mathrm{NaNO}_{3}$

$\mathrm{NaNO}_{2}$

$\mathrm{Na}_{2} \mathrm{SiO}_{3} .9 \mathrm{H}_{2} \mathrm{O}$

$\mathrm{C}_{2} \mathrm{H}_{4} \mathrm{O}_{3}$

dle with caution.

Adjust total solution volume to

Adjust solution temperature to $50^{\circ} \mathrm{C}$ to $60^{\circ} \mathrm{C}$.

Filter solution by vacuum through medium glass filter. Handle with caution, hot and caustic solution.

Rinse beaker with approximately $50 \mathrm{~mL}$ of DI water

Rinse filter with approximately $50 \mathrm{~mL}$ of DI water

Transfer final fittrate and rinse solutions to large peaker with stir bar.

Measure and record initial pH

Check the pH to make sure it is

$>13$

Batch Size:

pH:

2 L

$>13$

NIST Weight ( $1 O \mathrm{~g})$ :

NIST Weight ( $500 \mathrm{~g})$

Date: $\quad 2: 108$

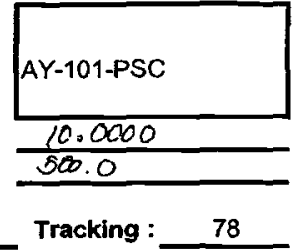

Tracking: $\quad 78$

Transfer to volumetric flask and include rinse with DI water. Allow solution to coo

QA APPROVED

non-standary

D) IE: $2-12-0$

Adjust final solution to volume of

$2 \mathrm{~L}$ with DI water, and mix thoroughly.

SUM

Total chemicals (target)

Total water (target)

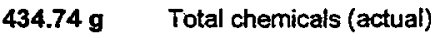

$2 \mathrm{~L}$ Total water (actual)

Target Specific Density

1.22

Calculated density

$434.91 \mathrm{~J}$

$\frac{2000}{1.22} \mathrm{~m}$

Check final solution $\mathrm{pH}$ and record.

$\mathrm{pH}=36$ keadjust if significantly different from target.

Comments: record any difficulties or discrepancies 


AP105-PSC
Base Solution 2007 Version
Balance Device ID:
Balance Device ID:

Adjust total solution volume to

Adjust solution temperature to $50^{\circ} \mathrm{C}$ to $60^{\circ} \mathrm{C}$.

$3400 \mathrm{~mL}$ by adding $\mathrm{DI}$ water.

Filter solution by vacuum through medium glass filter. Handle with caution, hot and caustic solution.

Rinse beaker with approximately $50 \mathrm{~mL}$ of DI water

Rinse filter with approximately $50 \mathrm{~mL}$ of D/ water

Transfer final filtrate and rinse solutions to large beaker with stir bar.

Measure and record initial pH $\quad 13,45$

Check the $\mathrm{pH}$ to make sure it is

13.45

Transfer to volumetric flask and include rinse with DI water. Allow solution to cool

QA APPROVED

NAME:Cedun

DATE: $2-15-08$

Adjust final solution to volume of

$4 \mathrm{~L}$ with DI water, and mix thoroughly.

SUM Total chemicals (target)

Total water (target)

$1634.03 \mathrm{~g}$ Total chemicals (actual)

Target Specific Density

$4 \mathrm{~L}$ Total water (actual)

1.41 Calculated density

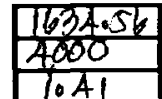

Check final solution $\mathrm{pH}$ and record.

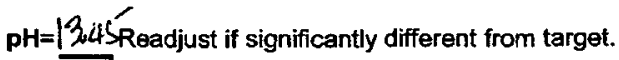

Comments: record any difficulties or discrepancies 


\section{AP105-PSC}

Base Solution 2007 Version

Balance Device ID:

Balance Device ID:

Technician: Noy

Add

O

\section{ion}

Batch Size:

pH:

NIST Weight ( $20 \mathrm{~g})$

NIST Weight (SOO g):

Date:

$2 / 14108$
$4 \mathrm{~L}$

$13+$

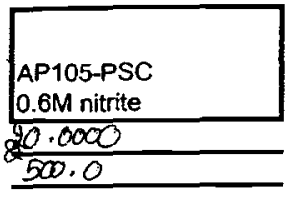

Tracking :

Insert Teflon stirbar and thermocouple, and place on stirrer / hotplate.

Turn on heater and adjust to $60^{\circ} \mathrm{C}\left( \pm 10^{\circ} \mathrm{C}\right)$.

Add the following chemicals and record their actual weights:

\begin{tabular}{|c|c|c|c|c|}
\hline Chemlcal & Formula & $\begin{array}{l}\text { Required } \\
\text { Mass (g) }\end{array}$ & $\begin{array}{l}\text { Actual } \\
\text { Mass (q) }\end{array}$ & Comments \\
\hline Sodium Aluminate & $\mathrm{NaAlO}_{2} \cdot 2 \mathrm{H}_{2} \mathrm{O}$ & 70.71 & 7,72 & \\
\hline Sodium Chloride & $\mathrm{NaCl}$ & 7.20 & $i-20$ & \\
\hline Sodium Fluoride & NaF & 1.53 & 1.53 & \\
\hline Sodium Chromate & $\mathrm{Na}_{2} \mathrm{CrO}_{4} 4 \mathrm{H}_{2} \mathrm{O}$ & 9.92 & 10.0 & \\
\hline Sodium Sulfate & $\mathrm{Na}_{2} \mathrm{SO}_{4}$ & 26.82 & 26.83 & \\
\hline Sodium Phosphate, 12-Hydrate & $\mathrm{Na}_{3} \mathrm{PO}_{4} 12 \mathrm{H}_{2} \mathrm{O}$ & 45.77 & 45.78 & \\
\hline Sodium Formate & NaHCOO & 2.72 & 2.72 & \\
\hline Sodium Acetate Trihydrate & $\mathrm{NaCH}_{3} \mathrm{COO} .3 \mathrm{H}_{2} \mathrm{O}$ & 4.08 & $4+09$ & \\
\hline Sodium Oxalate & $\mathrm{Na}_{2} \mathrm{C}_{2} \mathrm{O}_{4}$ & 4.02 & 2,04 & \\
\hline Sodium Carbonate & $\mathrm{Na}_{2} \mathrm{CO}_{3}$ & 138.21 & $138 \cdot 2$ & \\
\hline Sodium Nitrate & $\mathrm{NaNO}_{3}$ & 1211.75 & 1212 & \\
\hline Potassium Nitrate & $\mathrm{KNO}_{3}$ & 5.38 & 5,38 & \\
\hline Sodium Nitrite & $\mathrm{NaNO}_{2}$ & 165.60 & $165 \cdot 6$ & \\
\hline Glycolic Acid & $\mathrm{C}_{2} \mathrm{H}_{4} \mathrm{O}_{3}$ & 3.23 & 3.23 & \\
\hline Sodium Hydroxide & $\mathrm{NaOH}$ & 28.18 & 28,27 & \\
\hline
\end{tabular}

Adjust total solution volume to

$3400 \mathrm{~mL}$ by adding DI water.

Adjust solution temperature to $50^{\circ} \mathrm{C}$ to $60^{\circ} \mathrm{C}$

Filter solution by vacuum through medium glass filter. Handle with caution, hot and caustic solution.

Rinse beaker with approximately $50 \mathrm{~mL}$ of DI water

Rinse filter with approximately $50 \mathrm{~mL}$ of D/ water

Transfer final filtrate and rinse solutions to large beaker with stir bar.

Measure and record initial pH 13.52

Check the $\mathrm{pH}$ to make sure it is $13+$

Transfer to volumetric flask and include rinse with DI water. Allow solution to cool

QA APPROVED

NAME: Cedurs

DATE: $\quad 2-15-08$

Adjust final solution to volume of

$4 \mathrm{~L}$ with DI water, and mix thoroughly.

\begin{tabular}{clcl|c|c|c|}
\hline \multirow{2}{*}{ SUM } & Total chemicals (target) & $1725.11 \mathrm{~g}$ & Total chemicais (actual) & 725.54 \\
& Total water (target) & $4 \mathrm{~L}$ & Total water (actual) & 1000 \\
& Target Specific Density & 1.43 & Calculated density & 1043 \\
& & &
\end{tabular}

Check final solution $\mathrm{pH}$ and record.

$\mathrm{pH}=1352$ Readjust if significantly different from target.

Comments: record any difficulties or discrepancies 


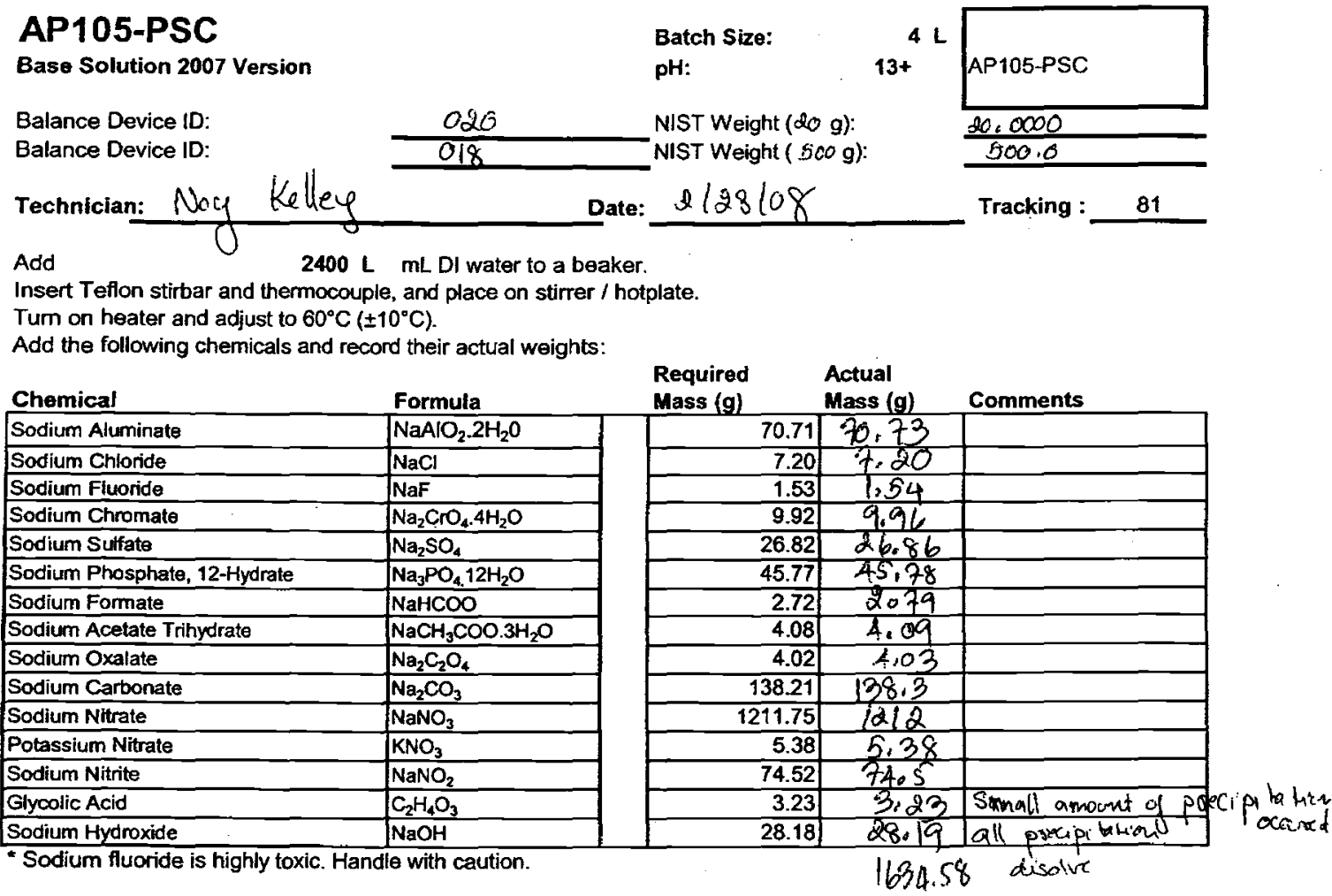

Adjust total solution volume to

Adjust solution temperature to $50^{\circ} \mathrm{C}$ to $60^{\circ} \mathrm{C}$.

$3400 \mathrm{~mL}$ by adding DI water.

Filter solution by vacuum through medium glass filter. Handle with caution, hot and caustic solution

Rinse beaker with approximately $50 \mathrm{~mL}$ of DI water

Rinse filter with approximately $50 \mathrm{~mL}$ of Dl water

Transfer final fitrate and rinse solutions to large beaker with stir bar.

Measure and record initial pH

Check the pH to make sure it is 1282

Transfer to volumetric flask and inctude rinse with DI water. Allow solution to cool

Adjust final solution to volume of $4 \mathrm{~L}$ with DI water, and mix thoroughly.

\begin{tabular}{llrll|}
\hline SUM & Total chemicals (target) & $1634.03 \mathrm{~g}$ & Total chemicals (actual) & 1634.58 \\
\hline Total water (target) & $4 \mathrm{~L}$ & Total water (actual) & 4000 \\
\hline Target Specific Density & 1.41 & Calculated density & 1.81 \\
\hline
\end{tabular}

Check final solution $\mathrm{pH}$ and record. $\mathrm{pH}=\underline{1338}$ Readjust if significantly different from target.

Comments: record any difficulties or discrepancies

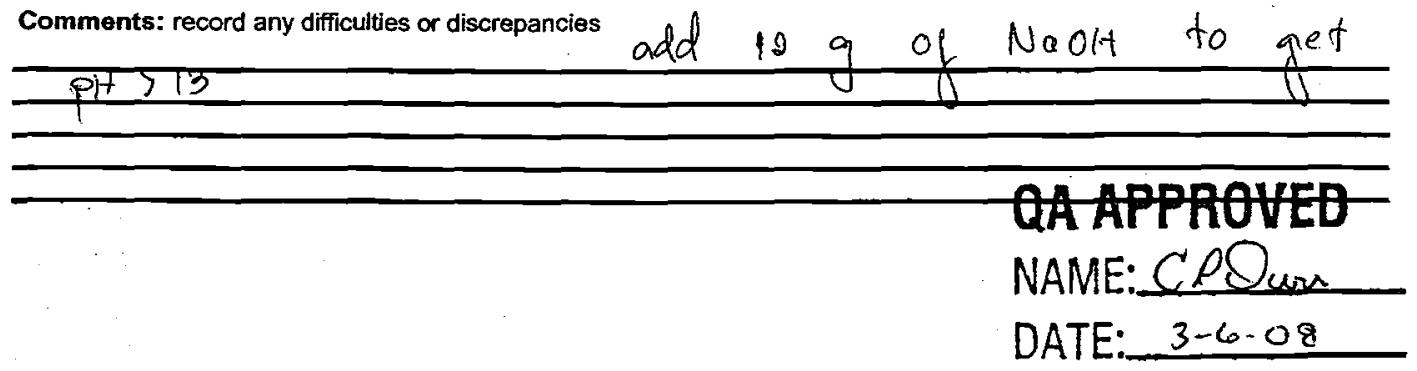




\section{AP105-PSC}

Base Solution 2007 Version

Balance Device ID:

Balance Device 1D:
Batch Size:

pH:

NIST Weight (\$o g):

NIST Weight ( 500 g):

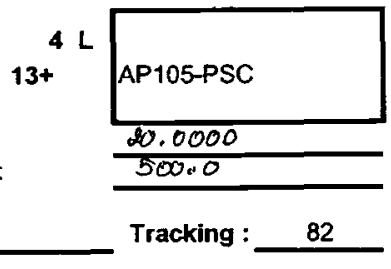

Tracking :

Technician:

Noy Kelley

Date:

$3 / 11 / 08$

$\mathrm{mL}$ DI water to a beaker.

Add

mocouple, and place on stirrer / hotplate.

Tum on heater and acjust to $60^{\circ} \mathrm{C}\left( \pm 10^{\circ} \mathrm{C}\right)$.

Add the following chemicals and record their actual weights:

\begin{tabular}{|c|c|}
\hline Chemical & Formula \\
\hline Sodium Aluminate & $\mathrm{NaAlO}_{2} \cdot 2 \mathrm{H}_{2} \mathrm{O}$ \\
\hline Sodium Chloride & $\mathrm{NaCl}$ \\
\hline Sodium Fluoride & $\mathrm{NaF}$ \\
\hline Sodium Chromate & $\mathrm{Na}_{2} \mathrm{CrO}_{4} \cdot 4 \mathrm{H}_{2} \mathrm{O}$ \\
\hline Socium Sulfate & $\mathrm{Na}_{2} \mathrm{SO}_{4}$ \\
\hline Sodium Phosphate, 12-Hydrate & $\mathrm{Na}_{3} \mathrm{PO}_{4} 12 \mathrm{H}_{2} \mathrm{O}$ \\
\hline Sodium Formate & $\mathrm{NaHCOO}$ \\
\hline Sodium Acetate Trihydrate & $\mathrm{NaCH}_{3} \mathrm{COO} .3 \mathrm{H}_{2} \mathrm{O}$ \\
\hline Sodium Oxalate & $\mathrm{Na}_{2} \mathrm{C}_{2} \mathrm{O}_{4}$ \\
\hline Sodium Carbonate & $\mathrm{Na}_{2} \mathrm{CO}_{3}$ \\
\hline Sodium Nitrate & $\mathrm{NaNO}_{3}$ \\
\hline Potassium Nitrate & $\mathrm{KNO}_{3}$ \\
\hline Sodium Nitrite & $\mathrm{NaNO}_{2}$ \\
\hline Glycolic Acid & $\mathrm{C}_{2} \mathrm{H}_{4} \mathrm{O}_{3}$ \\
\hline Sodium Hydroxide & $\mathrm{NaOH}$ \\
\hline
\end{tabular}

* Sodium fluoride is highly toxic. Handle with caution.

Adjust total solution volume to

Adjust solution temperature to $50^{\circ} \mathrm{C}$ to $60^{\circ} \mathrm{C}$.

Filter solution by vacuum through medium glass filter. Handle with caution, hot and caustic solution.

Rinse beaker with approximately $50 \mathrm{~mL}$ of DI water

Rinse filter with approximately $50 \mathrm{~mL}$ of DI water

Transfer final filtrate and rinse solutions to large beaker with stir bar.

Measure and record initial $\mathrm{pH}$

13.15

Check the $\mathrm{pH}$ to make sure it is

$13+$

Transfer to volumetric flask and include rinse with DI water. Allow solution to cool

Adjust final solution to volume of

$4 \mathrm{~L}$ with DI water, and mix thoroughly.

Mass (g) Mass (g) Comments

$\begin{array}{ll}\text { SuM } & \text { Total chemicals (target) } \\ & \text { Total water (target) } \\ & \text { Target Specific Density }\end{array}$
1634.03 g Total chemicals (actual)
4 L Total water (actual)
1.41 Calculated density

$\frac{1634.91}{1000}$

Check final solution $\mathrm{pH}$ and record.

$\mathrm{pH}=13,15$ Readjust if significantly different from target.

Comments: record any difficulties or discrepancies 
SY103-PIL

Base Solution 2008 Version

Balance Device ID:

Balance Device ID:

Technician: Emily

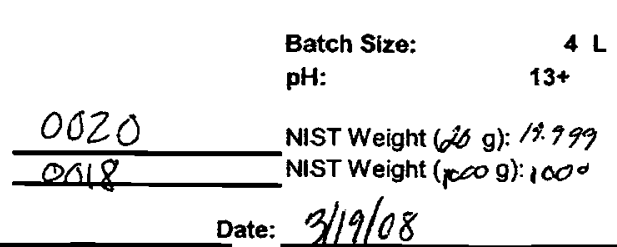

$4 \mathrm{~L}$ SY103-PIL

Add the following chemicals and record their actual weights:

\begin{tabular}{|c|c|c|c|c|}
\hline $\begin{array}{l}\text { Chemical } \\
\text { In the first container measure }\end{array}$ & Formula & $\begin{array}{l}\text { Required } \\
\text { Mass (g) } \\
\text { Dl water, heat to } 8\end{array}$ & $\begin{array}{l}\text { Actual } \\
\text { Mass (g) } \\
80-90^{\circ} \mathrm{C} \text { using }\end{array}$ & $\begin{array}{l}\text { Comments } \\
\text { hot-plate }\end{array}$ \\
\hline Sodium Aluminate & $\mathrm{Na}_{2} \mathrm{AlO}_{2}$ & 675.680 & 675.7 & \\
\hline Sodium Hydroxide & $\mathrm{NaOH}$ & 388.800 & 388.9 & \\
\hline \multicolumn{5}{|l|}{ In a separate container measure } \\
\hline Copper Nitrate 2.5-hydrate & $\mathrm{Cu}\left(\mathrm{NO}_{3}\right)_{2} \cdot 2.5 \mathrm{H}_{2} \mathrm{O}$ & 0.186 & 0.183 & \\
\hline Ferric Nitrate 9-hydrate & $\mathrm{Fe}\left(\mathrm{NO}_{3}\right)_{3}-9 \mathrm{H}_{2} \mathrm{O}$ & 0.808 & 0.809 & \\
\hline \multicolumn{5}{|c|}{ Add the following Organics (to the second container) } \\
\hline Sodium Acetate 3-hydrate & $\mathrm{NaCH}_{3} \mathrm{COO} .3 \mathrm{H}_{2} \mathrm{O}$ & 23.896 & 23.902 & \\
\hline Sodium Formate & $\mathrm{NaHCOO}$ & 51.144 & 51.146 & \\
\hline Glycolic Acid & $\mathrm{C}_{2} \mathrm{H}_{4} \mathrm{O}_{3}$ & 14.39 & 14.38 & \\
\hline Sodium Oxalate & $\mathrm{Na}_{2} \mathrm{C}_{2} \mathrm{O}_{4}$ & 2.358 & 2.359 & \\
\hline Citric Acid 1-hydrate & $\mathrm{C}_{6} \mathrm{H}_{6} \mathrm{O}_{7} \cdot \mathrm{H}_{2} \mathrm{O}$ & 16.643 & 16.64 & \\
\hline Disodium EDTA & $\mathrm{Na}_{2} \mathrm{C}_{10} \mathrm{H}_{14} \mathrm{O}_{8} .2 \mathrm{H}_{2} \mathrm{O}$ & 13.103 & 13.103 & \\
\hline HEDTA & $\mathrm{C}_{10} \mathrm{H}_{18} \mathrm{~N}_{2} \mathrm{O}_{7}$ & 4.897 & 4.89 & \\
\hline Nitrilotriacetic Acid & $\mathrm{C}_{8} \mathrm{H}_{9} \mathrm{NO}_{6}$ & 1.682 & 1.683 & \\
\hline Iminodiacetic Acid & $\mathrm{C}_{4} \mathrm{H}_{7} \mathrm{NO}_{2}$ & 10.542 & 10.544 & \\
\hline
\end{tabular}

Combine the two solutions into one container, maintain a temperature of $50^{\circ} \mathrm{C}$. Add the remaining chemicals.

Combine the two solutions into one container, maintain a temperature of $50^{\circ} \mathrm{C}$. Add the reme

\begin{tabular}{|l|l|}
\hline Boric Acid & $\mathrm{H}_{3} \mathrm{BO}_{3}$ \\
\hline Sodium Chromate & $\mathrm{Na}_{2} \mathrm{CrO}_{4} 4 \mathrm{H}_{2} \mathrm{O}$ \\
\hline Potassium Molybdate & $\mathrm{K}_{2} \mathrm{MoO}_{4}$ \\
\hline Potassium Nitrate & $\mathrm{KNO}_{3}$ \\
\hline Sodium Chloride & $\mathrm{NaCl}$ \\
\hline Sodium Nitrate & $\mathrm{NaNO}_{3}$ \\
\hline Sodium Nitrite & $\mathrm{NaNO}_{2}$ \\
\hline Sodium Phosphate, 12-Hydrate & $\mathrm{Na}_{3} \mathrm{PO}_{4} 1_{2} \mathrm{H}_{2} \mathrm{O}$ \\
\hline Sodium Sulfate & $\mathrm{Na}_{2} \mathrm{SO}_{4}$ \\
\hline Sodium Carbonate & $\mathrm{Na}_{2} \mathrm{CO}_{3}$ \\
\hline &
\end{tabular}

\begin{tabular}{|r|l|l|}
\hline 3.263 & 3.26 & \\
\hline 0.936 & 0.930 & \\
\hline 1.714 & 1.714 & \\
\hline 51.712 & 51.703 & \\
\hline 115.945 & 16.0 & \\
\hline 625.600 & 625.6 & \\
\hline 803.160 & 803.2 & \\
\hline 41.800 & 41.799 & \\
\hline 9.486 & 9.484 & \\
\hline 52.152 & 52.2 & \\
\hline
\end{tabular}

Filter solution by vacuum through medium glass filter. Handle with caution, caustic solution.

Rinse beaker with approximately $50 \mathrm{~mL}$ of $\mathrm{Dl}$ water

Rinse filter with approximately $50 \mathrm{~mL}$ of DI water

Transfer final filtrate and rinse solutions to large beaker with stir bar.

Transfer to volumetric flask and include rinse with DI water.

Adjust final solution to volume of

$4 \mathrm{~L}$ with $\mathrm{DI}$ water, and mix thoroughly.

SUM Total chemicals (targe

Total water (target)

$2910 \mathrm{~g}$ Total chemicals (actual)

$4 \mathrm{~L}$ Total water (actual)

2910.091

Target Specific Densit

1.73 Calculated density

Check final solution $\mathrm{pH}$ and recon

$\mathrm{pH}=14_{1} 06$ Readjust if significantly different from target.

Comments: record any difficulties or discrepancies 


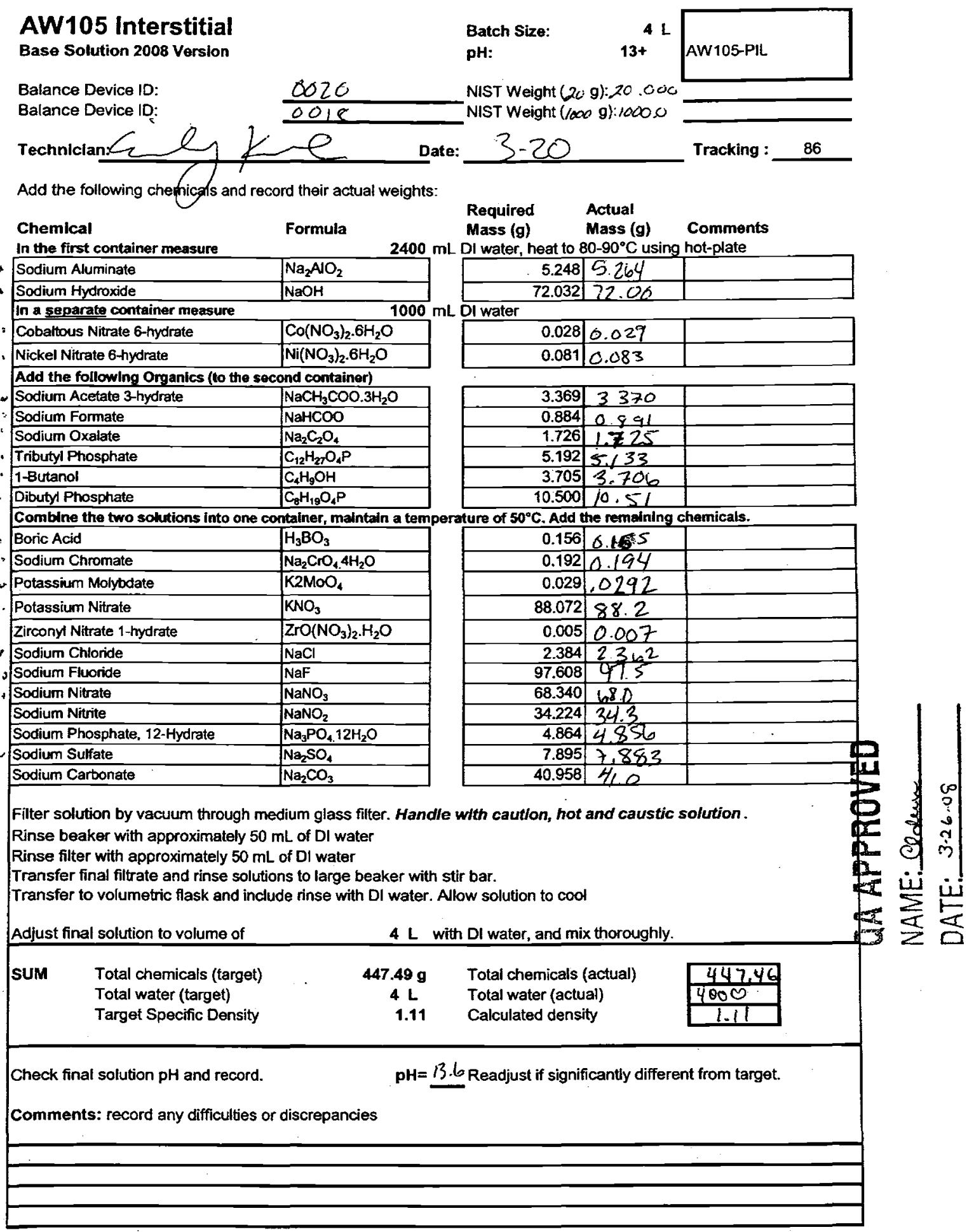




\section{AP105-PSC}

Base Solution 2007 Version

Balance Device ID:

Balance Device ID:
Batch Size:

$\mathrm{pH}$

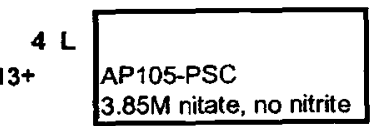

NIST Weight (10 g):10.0000 NIST Weight ( 50 9): $49.9999 \Longrightarrow$

Tochnician: Jesse Rhodes Date: $4 / 1 / 08$ Tracking : 87

Add

2400 L $\mathrm{mL}$ DI water to a beaker.

Insert Teflon stirbar and thermocouple, and place on stirrer / hotplate.

Tum on heater and adjust to $60^{\circ} \mathrm{C}\left( \pm 10^{\circ} \mathrm{C}\right)$.

Add the following chemicals and record their actual weights:

\begin{tabular}{|c|c|c|c|c|}
\hline Chemical & Formula & $\begin{array}{l}\text { Required } \\
\text { Mass (g) }\end{array}$ & $\begin{array}{l}\text { Actual } \\
\text { Mass (g) }\end{array}$ & Comments \\
\hline Sodium Aluminate & $\mathrm{NaAlO}_{2} \cdot 2 \mathrm{H}_{2} \mathrm{O}$ & 70.71 & 70.70 & \\
\hline Sodium Chloride & $\mathrm{NaCl}$ & 7.20 & 7.203 & \\
\hline Sodium Fluoride & $\mathrm{NaF}$ & 1.53 & 1.530 & \\
\hline Sodium Chromate & $\mathrm{Na}_{2} \mathrm{CrO}_{4} 4 \mathrm{H}_{2} \mathrm{O}$ & 9.92 & 9.922 & \\
\hline Sodium Sulfate & $\mathrm{Na}_{2} \mathrm{SO}_{4}$ & 26.82 & 26.80 & \\
\hline Sodium Phosphate, 12-Hydrate & $\mathrm{Na}_{3} \mathrm{PO}_{4} 12 \mathrm{H}_{2} \mathrm{O}$ & 45.77 & 45.80 & \\
\hline Sodium Formate & NaHCOO & 2.72 & 2.719 & \\
\hline Sodium Acetate Trihydrate & $\mathrm{NaCH}_{3} \mathrm{COO} .3 \mathrm{H}_{2} \mathrm{O}$ & 4.08 & 4.081 & \\
\hline Sodium Oxalate & $\mathrm{Na}_{2} \mathrm{C}_{2} \mathrm{O}_{4}$ & 4.02 & 4.022 & \\
\hline Sodium Carbonate & $\mathrm{Na}_{2} \mathrm{CO}_{3}$ & 138.21 & 138.20 & \\
\hline Sodium Nitrate & $\mathrm{NaNO}_{3}$ & 1211.75 & 1211.80 & \\
\hline Potassium Nitrate & $\mathrm{KNO}_{3}$ & 114.57 & 114.60 & \\
\hline Sodium Nitrite & $\mathrm{NaNO}_{2}$ & 0.00 & & \\
\hline Gycolic Acid & $\mathrm{C}_{2} \mathrm{H}_{4} \mathrm{O}_{3}$ & 3.23 & 3.241 & \\
\hline Sodium Hydroxide & $\mathrm{NaOH}$ & 28.18 & 28.20 & \\
\hline
\end{tabular}

* Sodium fluoride is highly toxic. Handle with caution.

Adjust total solution volume to $\quad 3400 \mathrm{~mL}$ by adding $\mathrm{DI}$ water.

Adjust solution temperature to $50^{\circ} \mathrm{C}$ to $60^{\circ} \mathrm{C}$.

Filter solution by vacuum through medium glass filter. Handle with caution, hot and caustic solution.

Rinse beaker with approximately $50 \mathrm{~mL}$ of DI water

Rinse filter with approximately $50 \mathrm{~mL}$ of DI water

Transfer final filtrate and rinse solutions to large beaker with stir bar.

Measure and record initial pH

Check the $\mathrm{pH}$ to make sure it is 14.04

Transfer to volumetric flask and include rinse with DI water. Allow solution to cool

Adjust final solution to volume of $4 \mathrm{~L}$ with DI water, and mix thoroughly.

\begin{tabular}{ccclc|} 
SUM & Total chemicals (target) & $1668.70 \mathrm{~g}$ & Total chemicals (actual) & T6.68.8. \\
Total water (target) & $4 \mathrm{~L}$ & Total water (actual) & 41 \\
& Target Specific Density & 1.42 & Calculated density & 1.42 \\
\hline
\end{tabular}

Check final solution $\mathrm{pH}$ and record

$\mathrm{pH}=13,95$ Readjust if significantly different from target.

Comments: record any difficulties or discrepancies $-573.9,5609.8 \mathrm{~g}, \mathrm{R}$

QAAPPROVED

NANE.

DATE: -14.08 


\section{AP105-PSC}

Base Solution 2007 Version

Balance Device ID

Balance Device ID

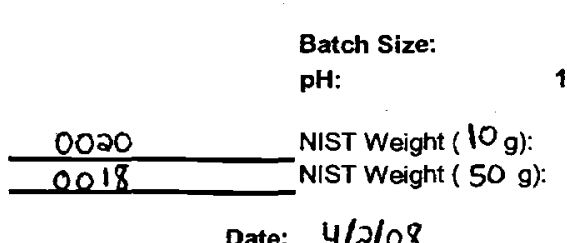

Date: $4 / 2 / 08$
${ }_{13+4}^{4} \frac{}{10.0000}$

Tracking : $\quad 88$

Tochnician: Jesse Rhodes

2400 L $\mathrm{mL}$ DI water to a beaker.

Insert Teflon stirbar and thermocouple, and place on stirrer / hotplate.

Tum on heater and adjust to $60^{\circ} \mathrm{C}\left( \pm 10^{\circ} \mathrm{C}\right)$.

Add the following chemicals and record their actual weights:

\begin{tabular}{|c|c|c|c|c|}
\hline Chemical & Formula & $\begin{array}{l}\text { Required } \\
\text { Mass (g) }\end{array}$ & $\begin{array}{l}\text { Actual } \\
\text { Mass (g) }\end{array}$ & Comments \\
\hline Sodium Aluminate & $\mathrm{NaAlO}_{2} \cdot 2 \mathrm{H}_{2} \mathrm{O}$ & 70.71 & 70.70 & \\
\hline Sodium Chloride & $\mathrm{NaCl}$ & 7.20 & 7.201 & \\
\hline Sodium Fluoride & $\mathrm{NaF}$ & 1.53 & 1.530 & \\
\hline Sodium Chromate & $\mathrm{Na}_{2} \mathrm{CrO}_{4} 4 \mathrm{H}_{2} \mathrm{O}$ & 9.92 & 9.919 & \\
\hline Sodium Sulfate & $\mathrm{Na}_{2} \mathrm{SO}_{4}$ & 26.82 & 26.80 & \\
\hline Sodium Phosphate, 12-Hydrate & $\mathrm{Na}_{3} \mathrm{PO}_{4} 12 \mathrm{H}_{2} \mathrm{O}$ & 45.77 & 45.80 & \\
\hline Sodium Formate & $\mathrm{NaHCOO}$ & 2.72 & 2.721 & \\
\hline Sodium Acotate Trihydrate & $\mathrm{NaCH}_{3} \mathrm{COO} .3 \mathrm{H}_{2} \mathrm{O}$ & 4.08 & 4.078 & \\
\hline Sodium Oxafate & $\mathrm{Na}_{2} \mathrm{C}_{2} \mathrm{O}_{4}$ & 4.02 & 4.019 & \\
\hline Sodium Carbonate & $\mathrm{Na}_{2} \mathrm{CO}_{3}$ & 138.21 & 138.20 & \\
\hline Sodium Nitrate & $\mathrm{NaNO}_{3}$ & 1211.75 & 1211.80 & \\
\hline Potassium Nitrate & $\mathrm{KNO}_{3}$ & 5.38 & 5.378 & \\
\hline Sodium Nitrite & $\mathrm{NaNO}_{2}$ & 74.52 & 7450 & \\
\hline Glycolic Acid & $\mathrm{C}_{2} \mathrm{H}_{4} \mathrm{O}_{3}$ & 3.23 & 3.233 & \\
\hline Sodium Hydroxide & $\mathrm{NaOH}$ & 28.18 & 2810 & \\
\hline
\end{tabular}

Sodium Hydroxide

$\mathrm{NaOH}$

$28.18,2910$

Sodium fluoride is highly toxic. Handle with caution.

Adjust total solution volume to

Adjust solution temperature to $50^{\circ} \mathrm{C}$ to $60^{\circ} \mathrm{C}$.

$3400 \mathrm{~mL}$ by adding DI water.

Filter solution by vacuum through medium glass filter. Handle with caution, hot and caustic solution.

Rinse beaker with approximately $50 \mathrm{~mL}$ of Di water

Rinse filter with approximately $50 \mathrm{~mL}$ of DI water

Transfer final filtrate and rinse solutions to large beaker with stir bar.

Measure and record initial pH 14,40

Check the $\mathrm{pH}$ to make sure it is

Transfer to volumetric flask and include rinse with DI water. Allow solution to coo

Adjust final solution to volume of

$4 \mathrm{~L}$ with DI water, and mix thoroughly.

SUM Total chemicals (target)

Total water (target)

$1634.03 \mathrm{~g}$ Total chemicals (actual)

$4 \mathrm{~L} \quad$ Total.water (actual)

Target Specific Density

1.41 Calculated density

$\left.g_{\frac{1133.98}{4 L}}^{\frac{4 L}{4}}\right|_{1.41}$

Check final solution $\mathrm{pH}$ and record.

$\mathrm{pH}=14.19$ Readjust if significantly different from target.

Comments: record any difficulties or discrepancies

$573954+g R$

(1)

QAAFrnoves

NAIVIE: एक्षणn

DATE: $\quad 4-14-00$ 


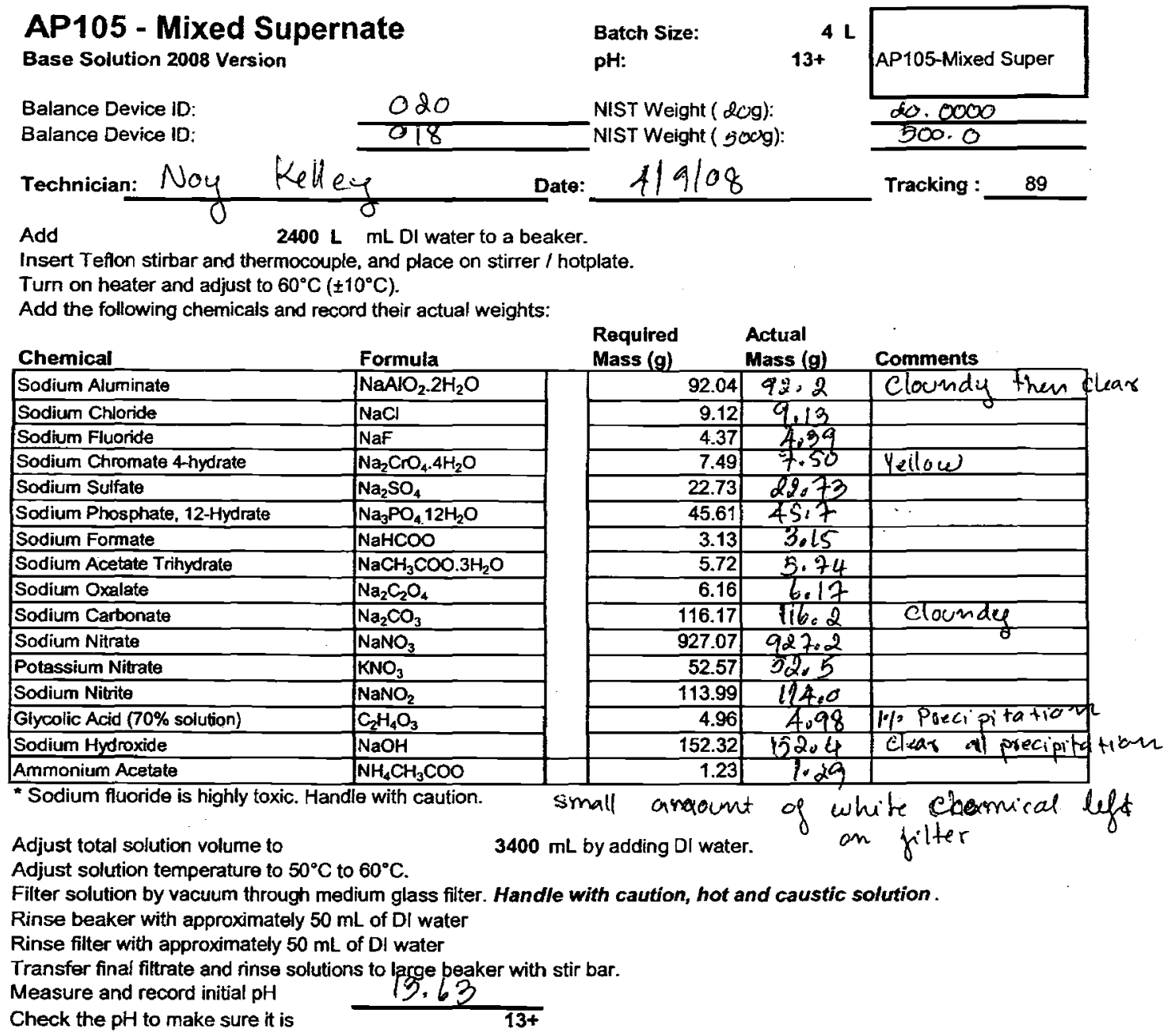

Transfer to volumetric flask and include rinse with DI water. Allow solution to cool

Adjust final solution to volume of

$4 \mathrm{~L}$ with $\mathrm{DI}$ water, and mix thoroughly.

\begin{tabular}{|c|c|c|c|c|c|}
\hline Sum & $\begin{array}{l}\text { Total chemicals (target) } \\
\text { Total water (target) } \\
\text { Target Specific Density }\end{array}$ & $\begin{array}{c}1564.67 \mathrm{~g} \\
4 \mathrm{~L} \\
1.39\end{array}$ & $\begin{array}{l}\text { Total chemicals (actual) } \\
\text { Total water (actual) } \\
\text { Calculated density }\end{array}$ & $\frac{\frac{1565.28}{4000}}{1.39}$ & $g$ \\
\hline
\end{tabular}

Comments: record any difficulties or discrepancies

NAME: QQdun

DATE: $4-14-08$ 
$+1$

AP105-PSC

Base Solution 2007 Version

Balance Device 10:

Balance Device ID:

Technician:

Add

rermocouple, and place on stirrer / hotplate.

Turn on heater and adjust to $60^{\circ} \mathrm{C}\left( \pm 10^{\circ} \mathrm{C}\right)$.

Add the following chemicals and record their actual weights:

Chemical
\begin{tabular}{|l|l|}
\hline Sodium Aluminate & Formula \\
\hline Sodium Chloride & $\mathrm{NaAlO}_{2} \cdot 2 \mathrm{H}_{2} \mathrm{O}$ \\
\hline Sodium Fluoride & $\mathrm{NaCl}$ \\
\hline Sodium Chromate & $\mathrm{NaF}$ \\
\hline Sodium Sulfale & $\mathrm{Na}_{2} \mathrm{CrO}_{4} 4 \mathrm{H}_{2} \mathrm{O}$ \\
\hline Sodium Phosphate, 12-Hydrate & $\mathrm{Na}_{2} \mathrm{SO}_{4}$ \\
\hline Sodium Formate & $\mathrm{Na}_{3} \mathrm{PO}_{4} 12 \mathrm{H}_{2} \mathrm{O}$ \\
\hline Sodium Acetate Trihydrate & $\mathrm{NaHCOO}^{-} \mathrm{NaCH}_{3} \mathrm{COO} 3 \mathrm{H}_{2} \mathrm{O}$ \\
\hline Sodium Oxalate & $\mathrm{Na}_{2} \mathrm{C}_{2} \mathrm{O}_{4}$ \\
\hline Sodium Carbonate & $\mathrm{Na}_{2} \mathrm{CO}_{3}$ \\
\hline Sodium Nitrate & $\mathrm{NaNO}_{3}$ \\
\hline Potassium Nitrate & $\mathrm{KNO}_{3}$ \\
\hline Sodium Nitrite & $\mathrm{NaNO}_{2}$ \\
\hline Glycolic.Acid & $\mathrm{C}_{2} \mathrm{H}_{4} \mathrm{O}_{3}$ \\
\hline Sodium Hydroxide & $\mathrm{NaOH}$ \\
\hline
\end{tabular}

"Sodium fivoride is highly toxic. Handle with caution.

Adjust total solution volume to

Adjust solution temperature to $50^{\circ} \mathrm{C}$ to $60^{\circ} \mathrm{C}$

Filter solution by vacuum through medium glass fiter. Handie with caution, hot and caustic solution

Rinse beaker with approximately $50 \mathrm{~mL}$ of DI water

Rinse filter with approximately $50 \mathrm{~mL}$ of DI water

Transfer final filtrate and rinse solutions to /arga geaker with stir bar.
Measure and record initial pH

Check the $\mathrm{pH}$ to make sure it is

13.18

$13+$

Transfer to volumetric flask and include rinse with DI water. Allow solution to cool

Adjust final solution to volume of

$4 \mathrm{~L}$ with $\mathrm{DI}$ water, and mix thoroughly.

SUM Total chemicals (target)

Total water (target)

Target Specific Density
$4 \mathrm{~L}$

$13+$

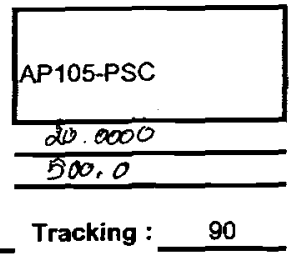

Actual

Mass (g) Mas) Comments

\begin{tabular}{|r|c|c|}
\hline 70.71 & 70.70 & Clondy \\
\hline 7.20 & 9.22 & $*$ \\
\hline 1.53 & 1.56 & $n$ \\
\hline 9.92 & 9.96 & 1 \\
\hline 26.82 & 26.84 & $n$ \\
\hline 45.77 & 46.0 & $n$ \\
\hline 2.72 & 2.84 & $n$ \\
\hline 4.08 & 4.09 & $n$ \\
\hline 4.02 & 1.02 & $n$ \\
\hline 138.21 & 138.4 & $n$ \\
\hline 1211.75 & 1211.8 & $n$ \\
\hline 5.38 & 5.40 & 4 \\
\hline 74.52 & 74.5 & $n$ \\
\hline 3.23 & 3.24 & 4 \\
\hline 28.18 & 28.23 & $n$ \\
\hline
\end{tabular}

solution cliar when fithe

QA APPROVED

NAME:Cldew

DATE: $\quad 4-18.08$

Check final solution $\mathrm{pH}$ and record.

Comments: record any difficulties or discrepancies

solution cloundy but dear when

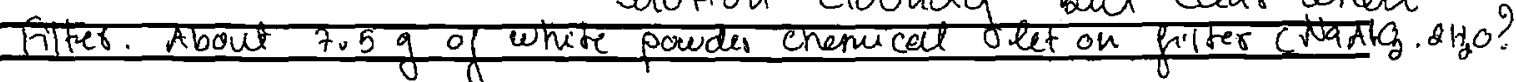




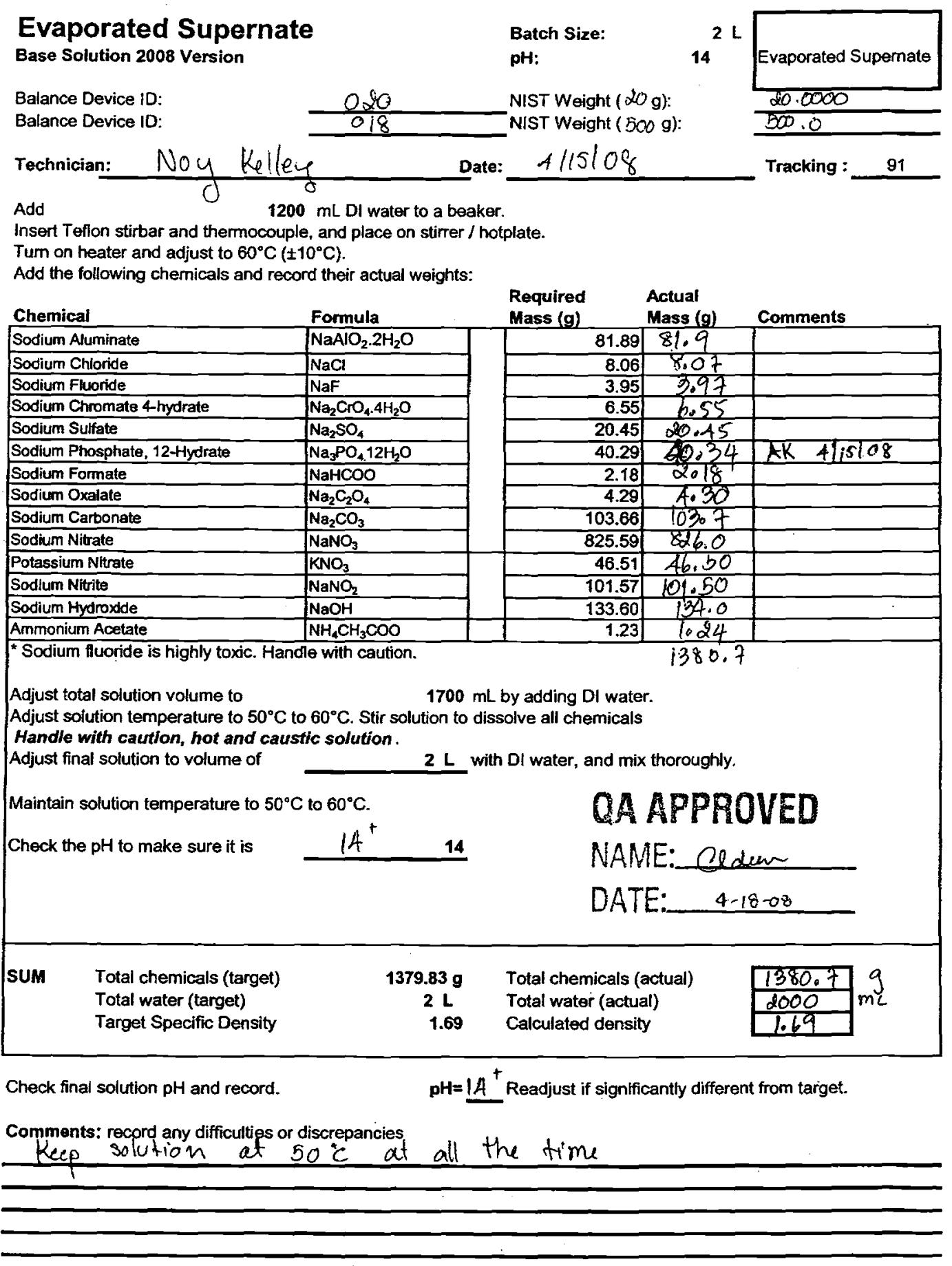




AYY 101-PSC
Base Solution 2007 Version
Balance Device ID:

*Sodium flecride is highly toxic. Handle with caution.

Adjust total solution volume to

Adjust solution temperature to $50^{\circ} \mathrm{C}$ to $60^{\circ} \mathrm{C}$

$1700 \mathrm{~mL}$ by adding DI water.

Filter solution by vacuum through medium glass filter. Handle with caution, hot and caustic solution.

Rinse beaker with approximately $50 \mathrm{~mL}$ of DI water

Rinse filter with approximately $50 \mathrm{~mL}$ of DI water

Transfer final filtrate and rinse solutions to large beaker with stir bar.

Measure and record initial pH

Check the $\mathrm{pH}$ to make sure it is $>13$

$$
>13
$$

non-standard pH

Transfer to volumetric flask and include rinse with DI water. Allow solution to cool

Adjust final solution to volume of

$2 \mathrm{~L}$ with $\mathrm{Dl}$ water, and mix thoroughly.

\begin{tabular}{c|ccl|c|} 
SuM & Total chemicals (target) & $\mathbf{4 3 5 . 1 5} \mathrm{g}$ & Total chemicals (actual) & 4.35 .24 \\
& Total water (target) & $2 \mathrm{~L}$ & Total water (actual) & 2000 \\
& Target Specific Density & 1.22 & Calculated density & 1.22 \\
\hline
\end{tabular}

Check final solution $\mathrm{pH}$ and record.

$\mathrm{pH}=\mathrm{y} / 3$ Readjust if significantly different from target.

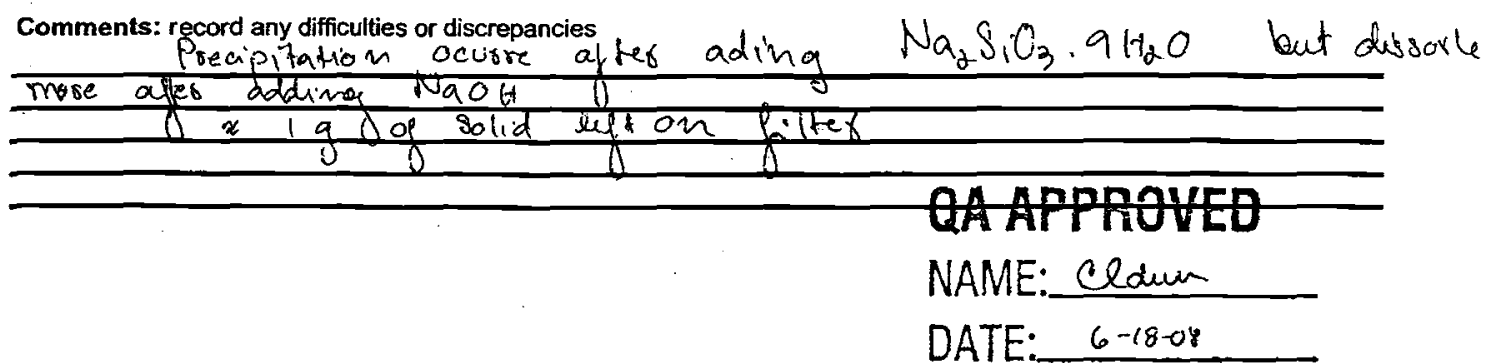


AZ102

Base Solution 2008 Version

Balance Device ID:

Balance Device ID:

Technician: Noy Kelleg

Insert Teflon stimar and thermocouple ditd

Tum on heater and adjust to $60^{\circ} \mathrm{C}\left( \pm 10^{\circ} \mathrm{C}\right)$.

Add

$2400 \mathrm{~mL}$ DI water to a beaker or carboy as appropriate
Batch Size:

pH:

NIST Weight $(20 \mathrm{~g})$ : NIST Weight $(500 \mathrm{~g})$

$6 / 6108$

Add the following chemicals and record their actual weights:

\begin{tabular}{l} 
Chemical \\
\begin{tabular}{|l|l|}
\hline Sodium Aluminate & Formula \\
\hline Sodium Chromate 4-Hydrate & $\mathrm{NaAlO}_{2}$ \\
\hline Potassium Molytdate & $\mathrm{Na}_{2} \mathrm{CrO}_{4} 4 \mathrm{H}_{2} \mathrm{O}$ \\
\hline Potassium Nitrate & $\mathrm{K}_{2} \mathrm{MOO}_{4}$ \\
\hline Sodium Fluoride & $\mathrm{KNO}_{3}$ \\
\hline Sodium Hydroxide & $\mathrm{NaF}$ \\
\hline Sodium Nitrate & $\mathrm{NaOH}^{2}$ \\
\hline Sodium Nitrite & $\mathrm{NaNO}_{3}$ \\
\hline Sodium Sulfate & $\mathrm{NaNO}_{2}$ \\
\hline Sodium Carbonate & $\mathrm{Na}_{2} \mathrm{SO}_{4}$ \\
\hline Sodium bicarbonate & $\mathrm{Na}_{2} \mathrm{CO}_{3}$ \\
\hline Organics & $\mathrm{NaHCO}_{3}$ \\
\hline Sodium Oxalate & \\
\hline & $\mathrm{Na}_{2} \mathrm{C}_{2} \mathrm{O}_{4}$ \\
\hline
\end{tabular} \\
\hline
\end{tabular}

41

12

AZ102

$\frac{20.0000}{000.0}$
Tracking :

volume to

Adjust solution temperature to $50^{\circ} \mathrm{C}$ to $60^{\circ} \mathrm{C}$

Filter solution by vacuum through medium glass filter. Handle with caution, hot and caustic solution.

Rinse beaker with approximately $50 \mathrm{~mL}$ of DI water

Rinse fitter with approximately $50 \mathrm{~mL}$ of DI water

$\begin{array}{ll}\text { Required } & \text { Actual } \\ \text { Mass (g) } & \text { Mass (g) } \quad \text { Comments }\end{array}$

\begin{tabular}{|l|l|l|}
\hline 2.296 & 2.313 & \\
\hline
\end{tabular}

$12.168) \quad 12.176$

$0.476-0.481$

\begin{tabular}{|r|c|l|}
\hline 0.476 & 0.481 & \\
\hline 28.684 & 28.696 & \\
\hline 8.736 & 8.756 & \\
\hline 0.000 & 0.00 & \\
\hline 11.560 & 11.571 & \\
\hline 243.708 & 243.70 & \\
\hline 105.648 & 106.0 & \\
\hline 257.368 & 257.4 & \\
\hline 4.032 & 4.08 & \\
\hline
\end{tabular}

\begin{tabular}{r|r|r|}
\hline 9.112 & 9.122 \\
\hline
\end{tabular}

$3400 \mathrm{~mL}$ by adding DI water.

Transfer final filtrate and rinse solutions to large beaker with stir bar.

Transfer to volumetric flask and include rinse with DI water. Allow solution to cool

Adjust final solution to volume of

$4 \mathrm{~L}$ with $\mathrm{DI}$ water, and mix thoroughly.

\begin{tabular}{|c|c|c|c|c|}
\hline sum & $\begin{array}{l}\text { Total chemicals (target) } \\
\text { Total water (target) } \\
\text { Target Specific Density }\end{array}$ & $\begin{array}{c}683.79 \mathrm{~g} \\
4 \mathrm{~L} \\
1.17\end{array}$ & $\begin{array}{l}\text { Total chemicals (actual) } \\
\text { Total water (actual) } \\
\text { Calculated density }\end{array}$ & $\frac{1694.295}{\frac{4000}{617}}$ \\
\hline
\end{tabular}

Check final solution $\mathrm{pH}$ and record.

$\mathrm{pH}=\mid 2 \cdot d-3$ Adjust to required $\mathrm{pH}$ using $\mathrm{NaOH}$

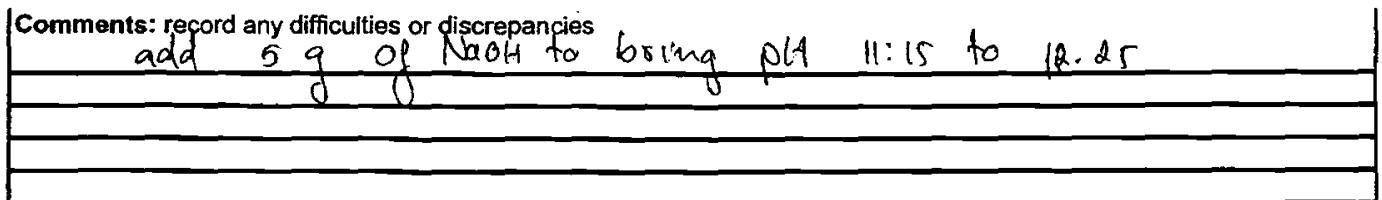

OCP 18 ho

CPP

QA APPROVED

NAME: Cldum

DATE: $\quad 6-1800$ 


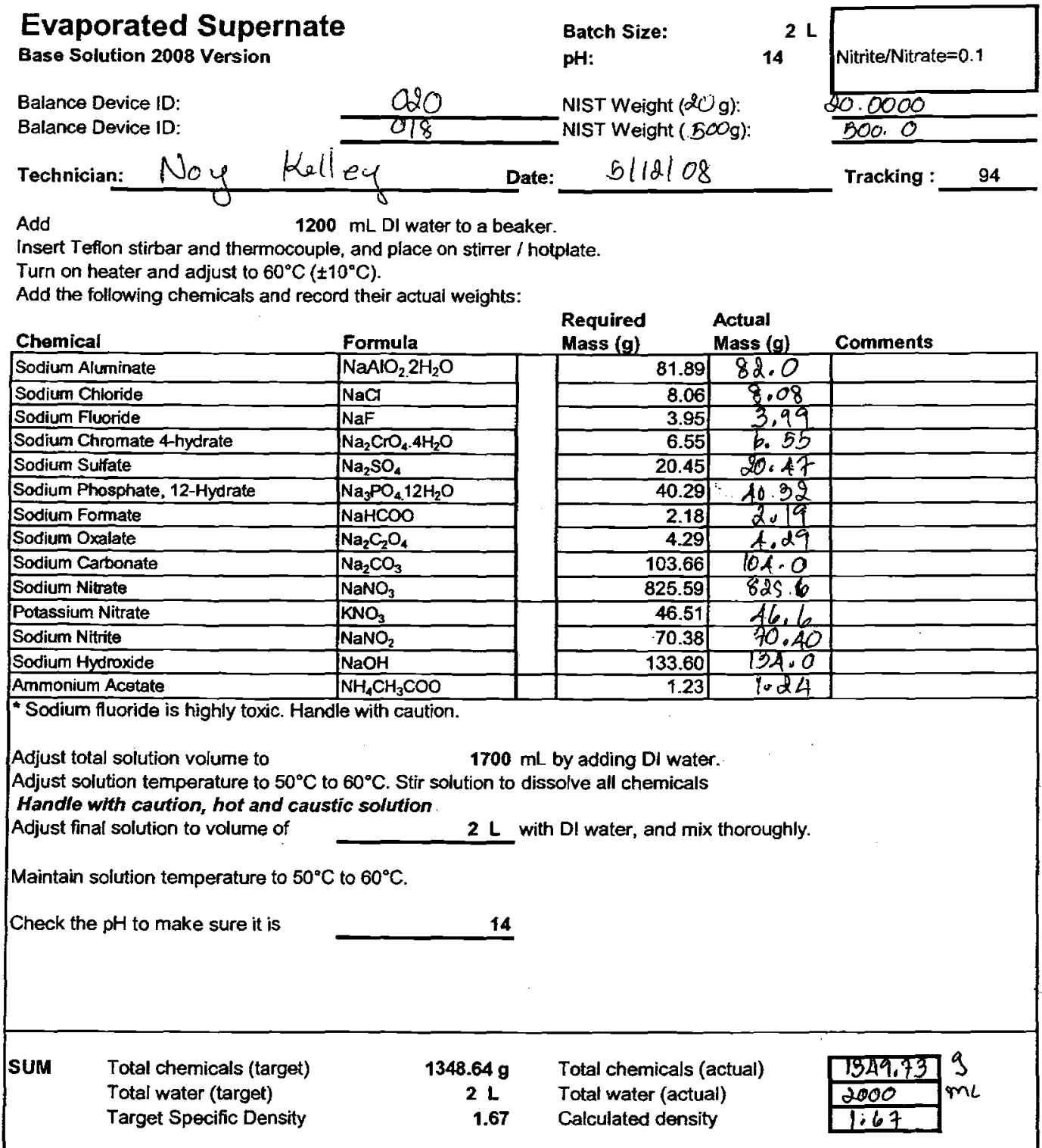

Check final solution $\mathrm{pH}$ and record.

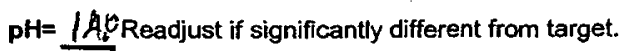

Comments: record any difficulties or discrepancies

QA APPROVED

NAME: Sedum

DATE: $\quad 6-1808$ 


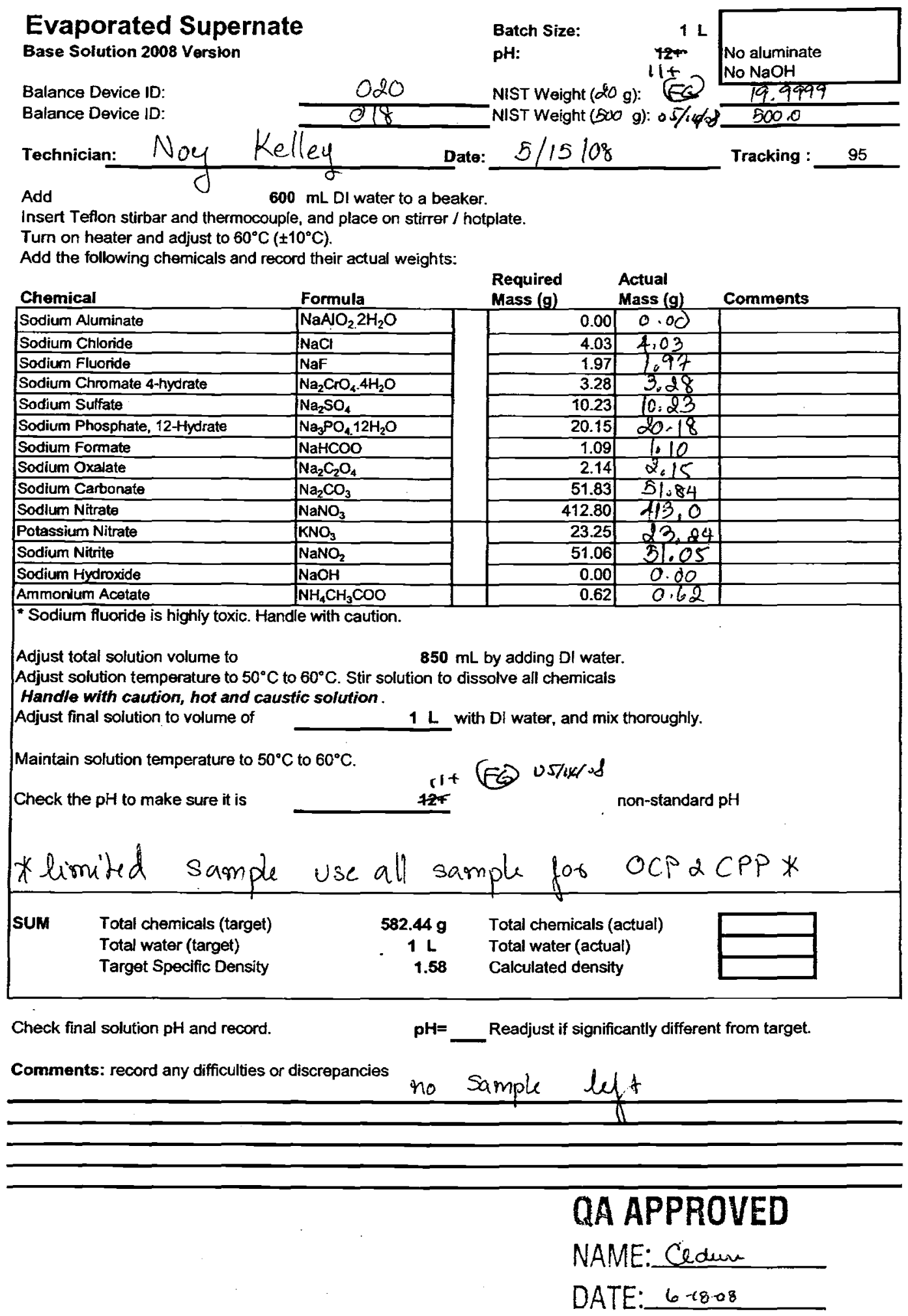




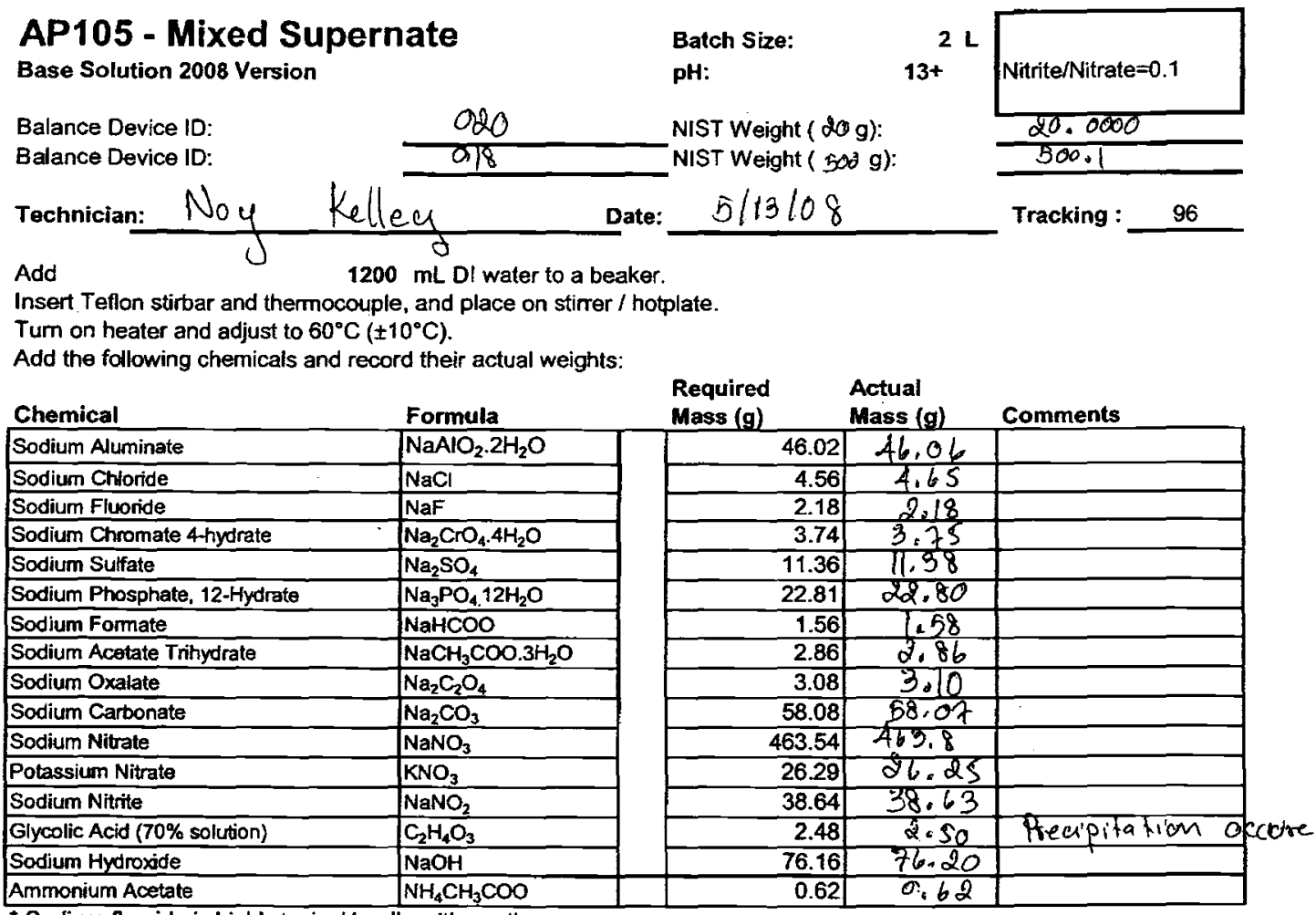

"Sodium fluoride is highly toxic. Handle with caution.

Adjust total solution volume to

Adjust solution temperature to $50^{\circ} \mathrm{C}$ to $60^{\circ} \mathrm{C}$.

$1700 \mathrm{~mL}$ by adding DI water.

Filter solution by vacuum through medium glass filter. Handle with caution, hot and caustic solution

Rinse beaker with approximately $50 \mathrm{~mL}$ of DI water

Rinse filter with approximately $50 \mathrm{~mL}$ of DI water

Transfer final filtrate and rinse solutions to large beaker with stir bar.

Measure and record initial $\mathrm{pH}$

Check the $\mathrm{pH}$ to make sure it is

$\frac{13.50}{14}$

Transfer to volumetric flask and include rinse with $\mathrm{D}$ I water. Allow solution to cool

Adjust final solution to volume of

2 L with Dl water, and mix thoroughly.

\begin{tabular}{cccl|c|} 
SUM & Total chemicals (target) & $763.98 \mathrm{~g}$ & Total chemicals (actual) & 764.439 \\
\hline Total water (target) & $2 \mathrm{~L}$ & Total water (actual) & 2000 \\
\hline & Target Specific Density & 1.38 & Calculated density & 1.38 \\
\hline
\end{tabular}

Check final solution $\mathrm{pH}$ and record.

$\mathrm{pH}=128 \mathrm{R}$ Radjust if significantly different from target.

Comments: record any difficulties or discrepancies

NAME: Cldiw

ก $\triangle T F \cdot \quad 6-1808$ 


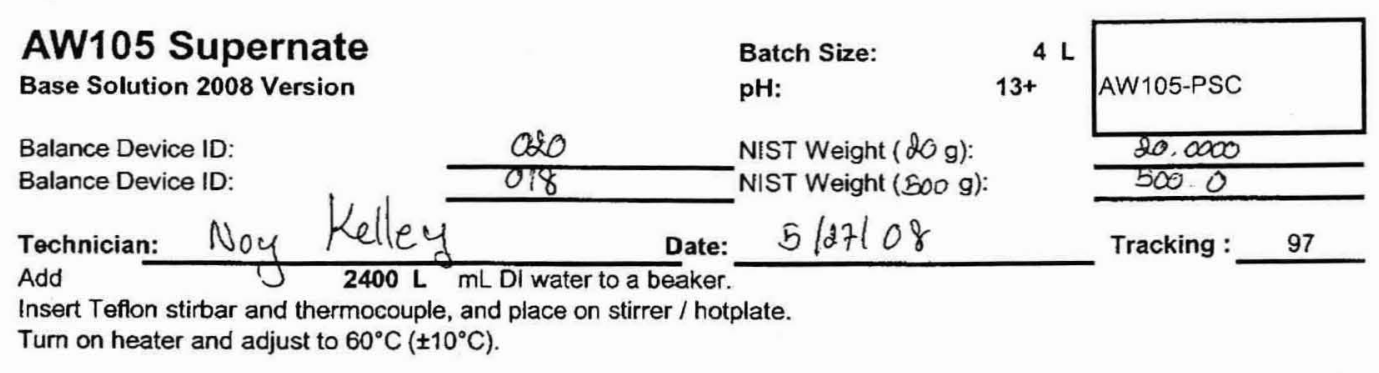

Add the following chemicals and record their actual weights:

\begin{tabular}{|c|c|}
\hline Chemical & Formula \\
\hline Sodium Aluminate & $\mathrm{Na}_{2} \mathrm{AlO}_{2}$ \\
\hline \begin{tabular}{|l|} 
Sodium Hydroxide \\
\end{tabular} & $\mathrm{NaOH}$ \\
\hline Boric Acid & $\mathrm{H}_{3} \mathrm{BO}_{3}$ \\
\hline Sodium Chromate & $\mathrm{Na}_{2} \mathrm{CrO}_{4} 4 \mathrm{H}_{2} \mathrm{O}$ \\
\hline Potassium Molybdate. & $\mathrm{K} 2 \mathrm{MoO} 4$ \\
\hline Potassium Nitrate & $\mathrm{KNO}_{3}$ \\
\hline Zinc Nitrate 6-hydrate & $\mathrm{Zn}\left(\mathrm{NO}_{3}\right)_{2} 6 \mathrm{H}_{2} \mathrm{O}$ \\
\hline Sodium Chloride & $\mathrm{NaCl}$ \\
\hline \begin{tabular}{|l|} 
Sodium Fluoride \\
\end{tabular} & $\mathrm{NaF}$ \\
\hline Sodium Nitrate & $\mathrm{NaNO}_{3}$ \\
\hline Sodium Nitrite & $\mathrm{NaNO}_{2}$ \\
\hline Sodium Phosphate, 12-Hydrate & $\mathrm{Na}_{3} \mathrm{PO}_{4} 12 \mathrm{H}_{2} \mathrm{O}$ \\
\hline Sodium Sulfate & $\mathrm{Na}_{2} \mathrm{SO}_{4}$ \\
\hline Sodium Carbonate & $\mathrm{Na}_{2} \mathrm{CO}_{3}$ \\
\hline Glycolic Acid & $\mathrm{C}_{2} \mathrm{H}_{4} \mathrm{O}_{3}$ \\
\hline Sodium Acetate 3-hydrate & $\mathrm{NaCH}_{3} \mathrm{COO} .3 \mathrm{H}_{2} \mathrm{O}$ \\
\hline Sodium Formate & $\mathrm{NaHCOO}$ \\
\hline Sodium Oxalate & $\mathrm{Na}_{2} \mathrm{C}_{2} \mathrm{O}_{4}$ \\
\hline
\end{tabular}

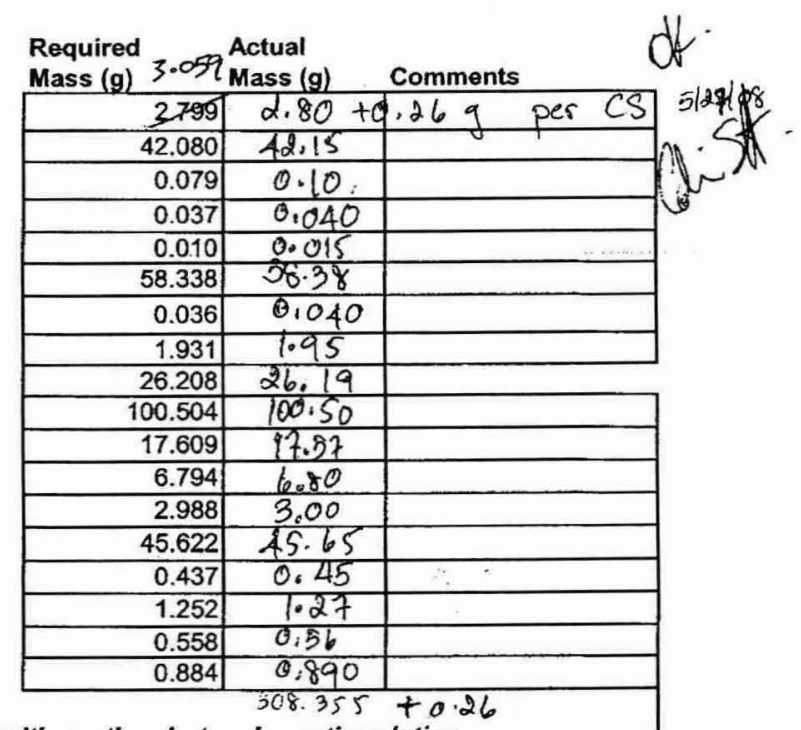

Filter solution by vacuum through medium glass filter. Handle with caution, hot and caustic solution.

Rinse beaker with approximately $50 \mathrm{~mL}$ of DI water

Rinse filter with approximately $50 \mathrm{~mL}$ of DI water

Transfer final filtrate and rinse solutions to large beaker with stir bar.

Transfer to volumetric flask and include rinse with DI water. Allow solution to cool

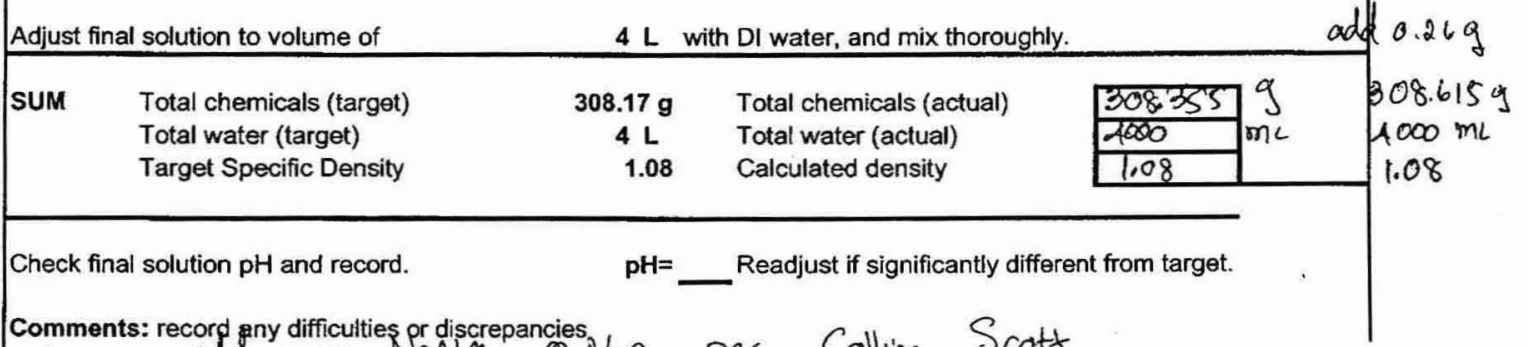

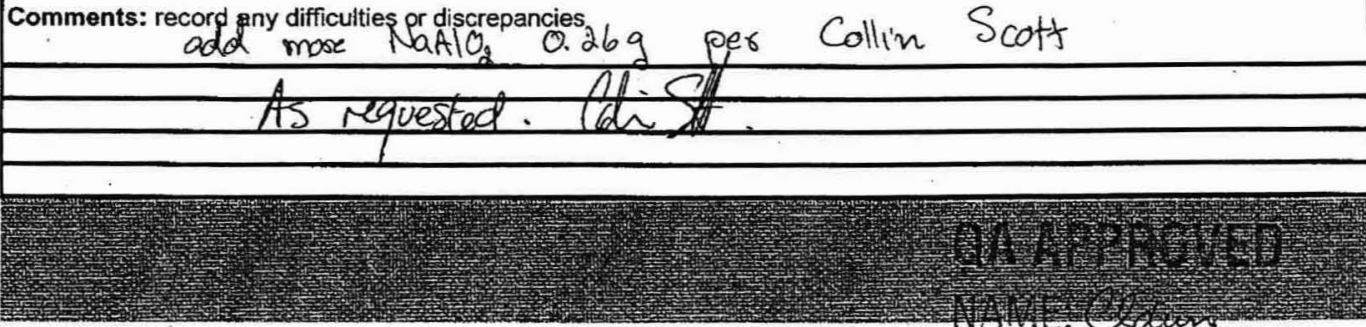

DATE: $\quad 6-24$ ar 


\section{SY101}

Base Solution 2008 Version

Balance Device ID:

Batance Device ID:

Technician: Noy Kelle

Add

$\mathbf{2 4 0 0} \mathrm{mL}$ DI water to a beaker.

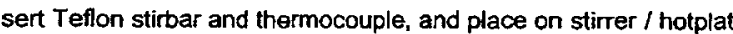

Turn on heater and adjust to $60^{\circ} \mathrm{C}\left( \pm 10^{\circ} \mathrm{C}\right)$.

Add the following chemicals and record their actual weights:

\begin{tabular}{|c|c|}
\hline Chemical & Formula \\
\hline Sodium Aluminate & $\mathrm{NaAlO}_{2} .2 \mathrm{H}_{2} \mathrm{O}$ \\
\hline Sodium Chloride & $\mathrm{NaCl}$ \\
\hline Sodium Fluoride ${ }^{*}$ & $\mathrm{NaF}$ \\
\hline Sodium Chromate & $\mathrm{Na}_{2} \mathrm{CrO}_{4}, 4 \mathrm{H}_{2} \mathrm{O}$ \\
\hline Sodium Sulfate & $\mathrm{Na}_{2} \mathrm{SO}_{4}$ \\
\hline Sodium Phosphate, 12-Hydrate & $\mathrm{Na}_{3} \mathrm{PO}_{4} 12 \mathrm{H}_{2} \mathrm{O}$ \\
\hline Sodium Oxalate & $\mathrm{Na}_{2} \mathrm{C}_{2} \mathrm{O}_{4}$ \\
\hline Sodium Carbonate & $\mathrm{Na}_{2} \mathrm{CO}_{3}$ \\
\hline Iron Nitrate, 9-hydrate & $\mathrm{Fe}\left(\mathrm{NO}_{3}\right)_{2} \cdot 9 \mathrm{H}_{2} \mathrm{O}$ \\
\hline Zinc Nitrate, 6-hydrate & $\mathrm{Zn}\left(\mathrm{NO}_{3}\right)_{2}, 6 \mathrm{H}_{2} \mathrm{O}$ \\
\hline Calcium Nitrate & $\mathrm{Ca}\left(\mathrm{NO}_{3}\right)_{2} \cdot 4 \mathrm{H}_{2} \mathrm{O}$ \\
\hline Sodium Nitrate & $\mathrm{NaNO}_{3}$ \\
\hline Potassium Nitrate & $\mathrm{KNO}_{3}$ \\
\hline Sodium Nitrite & $\mathrm{NaNO}_{2}$ \\
\hline Sodium Hydroxide & $\mathrm{NaOH}$ \\
\hline Boric Acid & $\mathrm{H}_{3} \mathrm{BO}_{3}$ \\
\hline
\end{tabular}

" Sodium fluoride is highly toxic. Handle with caution.

$\begin{aligned} & \text { Required } \\
& \text { Mass (g) }\end{aligned}$
\begin{tabular}{|r|c|l|} 
Mass (g) & Comments \\
\hline 66.41 & 66.42 & \\
\hline 5.32 & 5.32 & \\
\hline 4.65 & 4.66 & \\
\hline 1.92 & 1.92 & \\
\hline 11.16 & 11.16 & \\
\hline 149.54 & 199.6 & \\
\hline 13.08 & 13.11 & \\
\hline 56.30 & 56.31 & \\
\hline 0.04 & 0.05 & \\
\hline 0.08 & 0.08 & \\
\hline 0.50 & 0.55 & \\
\hline 314.26 & 314.3 & \\
\hline 2.79 & 2.80 & \\
\hline 55.95 & 55.95 & \\
\hline 104.88 & 105.0 & \\
\hline 0.21 & 0.22 & \\
\hline & .787 .45 & \\
\hline
\end{tabular}

Adjust total solution volume to

Adjust solution temperature to $50^{\circ} \mathrm{C}$ to $60^{\circ} \mathrm{C}$.

$3400 \mathrm{~mL}$ by adding Dl water.

Batch Size:

pH:

NIST Weight $(20 \mathrm{~g})$ :

NIST Weight ( $500 \mathrm{~g})$

$5 / 28 / 08$
$4 \mathrm{~L}$ $13+$

SY101

$\frac{\frac{20 \cdot 0000}{300.0}}{\text { Tracking : } \quad 98}$

Filter solution by vacuum through medium glass filter. Handle with caution, hot and caustic solution.

Rinse beaker with approximately $50 \mathrm{~mL}$ of DI water

Rinse filter with approximately $50 \mathrm{~mL}$ of DI water

Transfer final filtrate and rinse solutions to large beaker with stir bar.

Measure and record initial pH

Check the pH to make sure it is 13.30

Transfer to volumetric flask and include rinse with DI water. Allow solution to cool

Adjust final solution to volume of

$4 L$ with DI water, and mix thoroughly.

SuM Total chemicals (target)

Total water (target)

Target Specific Density

$786.88 \mathrm{~g}$ Total chemicals (actual)

$4 \mathrm{~L}$ Total water (actual)

1.20 Calculated density

$\frac{787.45}{1000} \frac{9}{1.20}$

Check final solution $\mathrm{pH}$ and record.

$\mathbf{p H}=3,30$ Readjust if significantly different from target.

Comments: record any difficulties or discrepancies

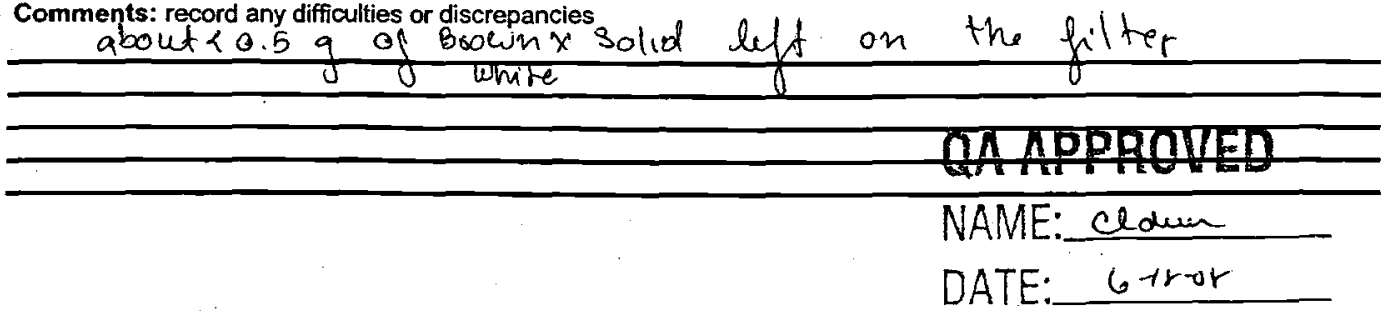




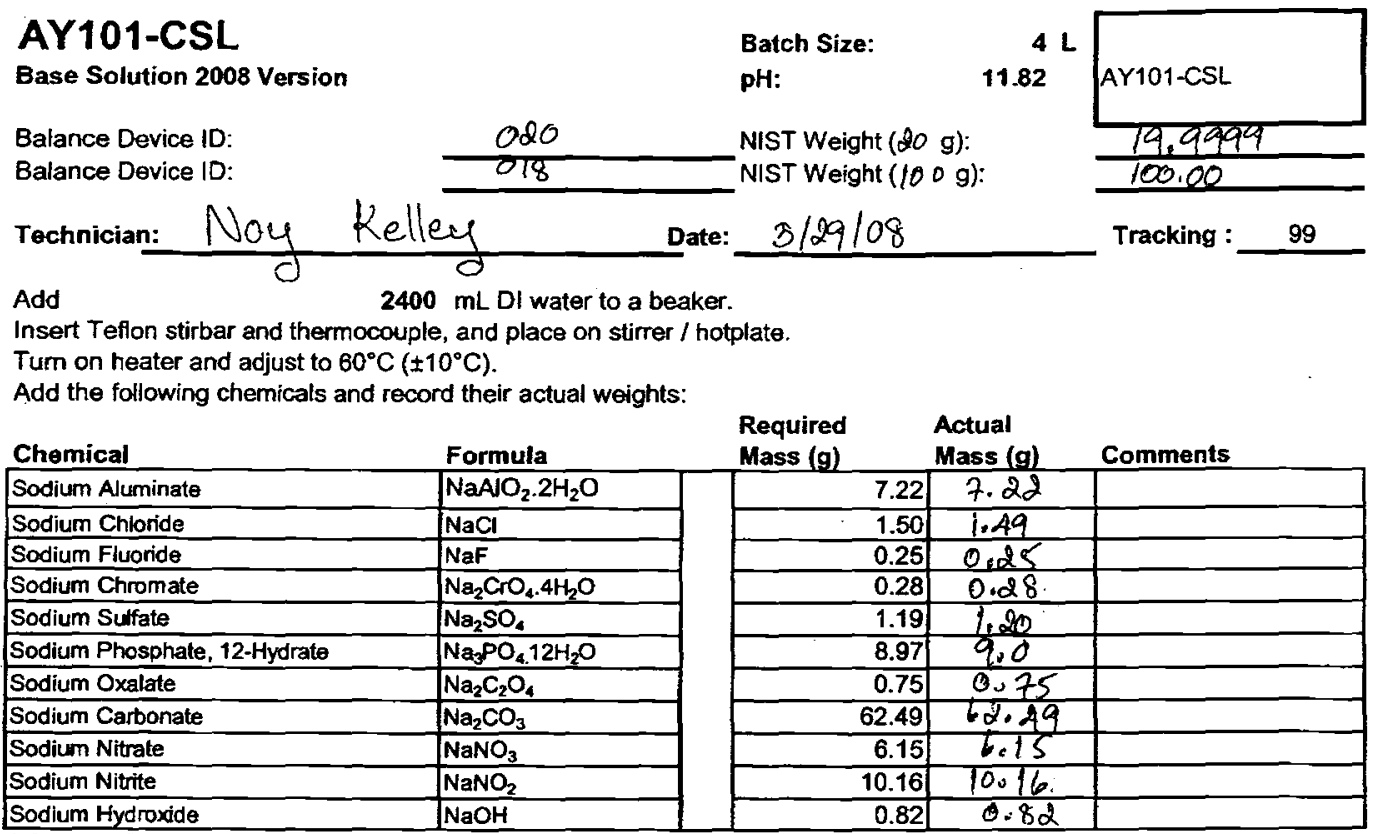

* Sodium fluoride is highly toxic. Handle with caution.

Adjust total solution volume to

Adjust solution temperature to $50^{\circ} \mathrm{C}$ to $60^{\circ} \mathrm{C}$

$3400 \mathrm{~mL}$ by adding DI water.

Filter solution by vacuum through medium glass filter. Handle with caution, hot and caustic solution.

Rinse beaker with approximately $50 \mathrm{~mL}$ of $\mathrm{DI}$ water

Rinse filter with approximately $50 \mathrm{~mL}$ of DI water

Transfer final filtrate and rinse solutions to large beaker with stir bar.

Transfer to volumetric flask and include rinse with DI water. Allow solution to cool

Adjust final solution to volume of $4 \mathrm{~L}$ with DI water, and mix thoroughly.

\begin{tabular}{clcll|} 
Sum & Total chemicals (target) & $99.78 \mathrm{~g}$ & Total chemicals (actual) & 99.81 \\
\cline { 2 - 4 } & Total water (target) & $4 \mathrm{~L}$ & Total water (actual) & 4000 \\
\hline & Target Specific Density & 1.02 & Calculated density & 1.07 \\
\hline
\end{tabular}

Check final solution $\mathrm{pH}$ and record.

$\mathrm{pH}=1,85$ Readjust if significantly different from target.

Comments: record any difficulties or discrepancies

QA APPROVED

NAME: Cldme

DATE: $6-1608$ 


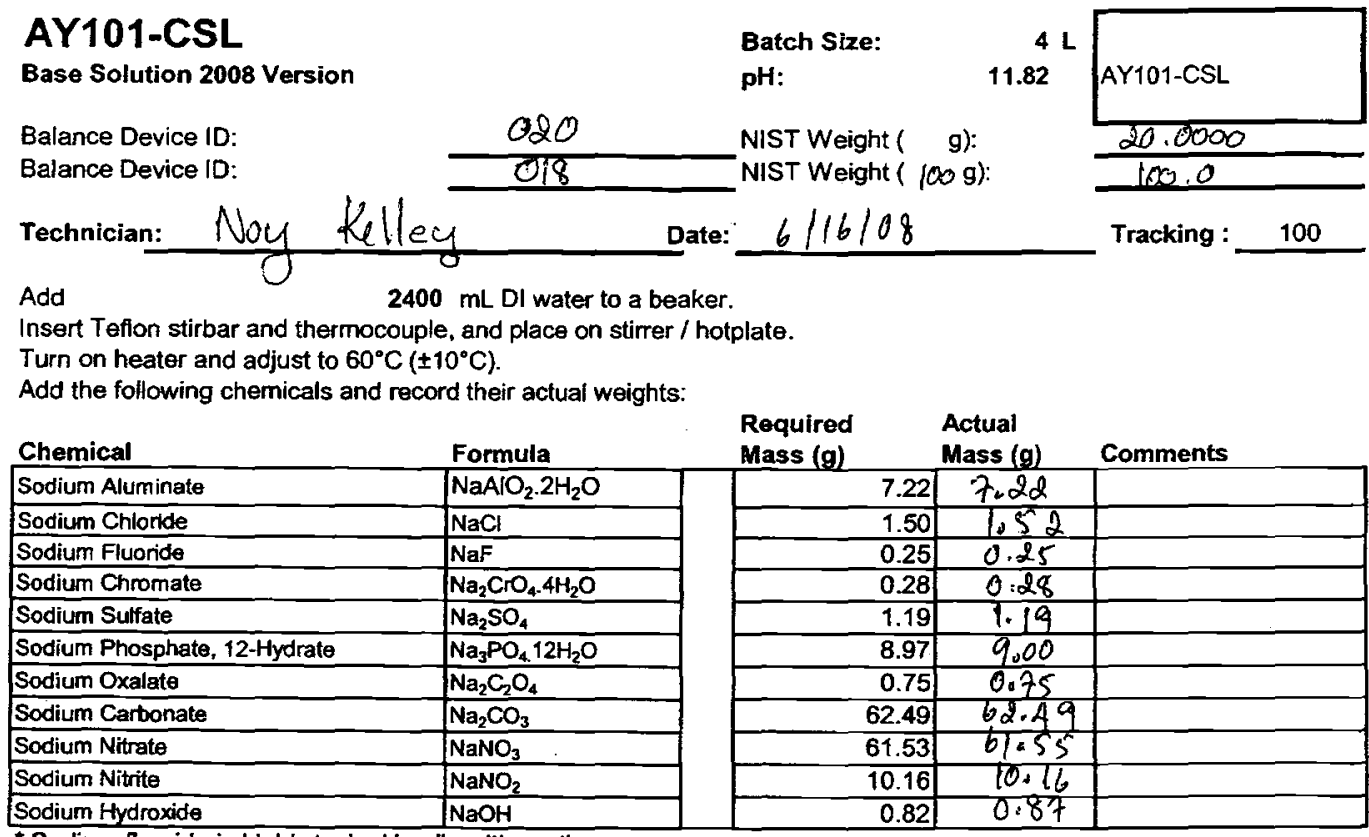

* Sodium fluoride is highly toxic. Handle with caution.

Adjust total solution volume to

Adjust solution temperature to $50^{\circ} \mathrm{C}$ to $60^{\circ} \mathrm{C}$.

$3400 \mathrm{~mL}$ by adding DI water.

Filter solution by vacuum through medium glass filter. Handle with caution, hot and caustic solution.

Rinse beaker with approximately $50 \mathrm{~mL}$ of DI water

Rinse filter with approximately $50 \mathrm{~mL}$ of DI water

Transfer final filtrate and rinse solutions to large beaker with stir bar.

Transfer to volumetric flask and include rinse with DI water. Allow solution to cool

Adjust final solution to volume of

$4 \mathrm{~L}$ with Dl water, añd mix thoroughly.

SUM Total chemicals (target)

Total water (target)

Target Specific Density

$\begin{array}{cl}155.16 \mathrm{~g} & \text { Total chemicals (actual) } \\ 4 \mathrm{~L} & \text { Total water (actual) } \\ 1.04 & \text { Calculated density }\end{array}$

155.289

4000

1.04

Check final solution pH and record.

$\mathrm{pH}=\underline{W} 8 \mathrm{R}$ Readjust if significantly different from target.

Comments: record any difficulties or discrepancies

QA APPROVED

NAME: dedum

DATE: 6 -or-or 


\section{AW105 Supernate \\ Base Solution 2008 Version}

Balance Device ID:

Balance Device ID:
Batch Size:

pH:

NIST Weight $(20 \mathrm{~g})$

NIST Weight $(1 \infty 0 \mathrm{~g})$

Technician: Noy kelley ? 18108

$2 \mathrm{~L}$ $13+$

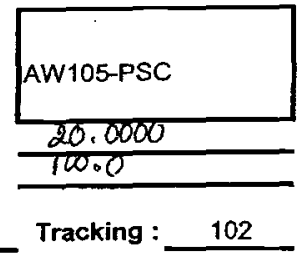

Insert Teflon stirbar and thermocouple, and place on stirrer / hotplate.

Turn on heater and adjust to $60^{\circ} \mathrm{C}\left( \pm 10^{\circ} \mathrm{C}\right)$.

Add the following chemicals and record their actual weights:

\begin{tabular}{|c|c|}
\hline Chemical & Formula \\
\hline Sodium Aluminate & $\mathrm{Na}_{2} \mathrm{AlO}_{2} 2 \mathrm{H}_{2} \mathrm{O}$ \\
\hline Sodium Hydroxide & $\mathrm{NaOH}$ \\
\hline Boric Acid & $\mathrm{H}_{3} \mathrm{BO}_{3}$ \\
\hline Sodium Chromate & $\mathrm{Na}_{2} \mathrm{CrO}_{4} 4 \mathrm{H}_{2} \mathrm{O}$ \\
\hline Potassium Molybdate & $\mathrm{K} 2 \mathrm{MoO4}$ \\
\hline Potassium Nitrate & $\mathrm{KNO}_{3}$ \\
\hline Zinc Nitrate 6-hydrate & $\mathrm{Zn}\left(\mathrm{NO}_{3}\right)_{2} 6 \mathrm{H}_{2} \mathrm{O}$ \\
\hline Sodium Chloride & $\mathrm{NaCl}$ \\
\hline Sodium Fluoride & NaF \\
\hline Sodium Nitrate & $\mathrm{NaNO}_{3}$ \\
\hline Sodium Nitrife & $\mathrm{NaNO}_{2}$ \\
\hline Sodium Phosphate, 12-Hydrate & $\mathrm{Na}_{3} \mathrm{PO}_{4} 12 \mathrm{H}_{2} \mathrm{O}$ \\
\hline Sodium Sulfate & $\mathrm{Na}_{2} \mathrm{SO}_{4}$ \\
\hline Sodium Carbonate & $\mathrm{Na}_{2} \mathrm{CO}_{3}$ \\
\hline Glycolic Acid & $\mathrm{C}_{2} \mathrm{H}_{4} \mathrm{O}_{3}$ \\
\hline Sodium Acetate 3-hydrate & $\mathrm{NaCH}_{3} \mathrm{COO} .3 \mathrm{H}_{2} \mathrm{O}$ \\
\hline Sodium Formate & $\mathrm{NaHCOO}$ \\
\hline Sodium Oxalate & $\mathrm{Na}_{2} \mathrm{C}_{2} \mathrm{O}_{4}$ \\
\hline
\end{tabular}

\begin{tabular}{|c|c|c|}
\hline $\begin{array}{l}\text { Required } \\
\text { Mass (g) }\end{array}$ & $\begin{array}{l}\text { Actual } \\
\text { Mass (g) }\end{array}$ & Comments \\
\hline 1.529 & 1.56. & \\
\hline 21.040 & 21.06. & \\
\hline 0.040 & $0.05 \mathrm{r}$ & \\
\hline 0.019 & $0.03=$ & \\
\hline 0.005 & 0.0087 & \\
\hline 29.169 & ga. $169:$ & \\
\hline$\overline{0.018}$ & 0.022 & \\
\hline 0.965 & 8.967 & \\
\hline 13.104 & $13013 r$ & \\
\hline 50.252 & 30,25 & \\
\hline 8.804 & 8.88 & \\
\hline 3.397 & $9,39 \times$ & \\
\hline 1.494 & 1.50. & \\
\hline 22.811 & 22.83 & \\
\hline 0.219 & 0.287 & \\
\hline 0.626 & 0.629 & \\
\hline $0 . \overline{279}$ & 0.281 & \\
\hline 0.442 & 0.455 & \\
\hline
\end{tabular}

Filter solution by vacuum through medium glass filter. Handle with caution, hot and caus

Rinse beaker with approximately $50 \mathrm{~mL}$ of DI water

Rinse filter with approximately $50 \mathrm{~mL}$ of DI water

Transfer final filtrate and rinse solutions to large beaker with stir bar.

Transfer to volumetric flask and include rinse with DI water. Allow solution to cool

Adjust finat solution to volume of

$2 \mathrm{~L}$ with DI water, and mix thoroughly.

NAME: Clduen

DATE: $8-20.08$

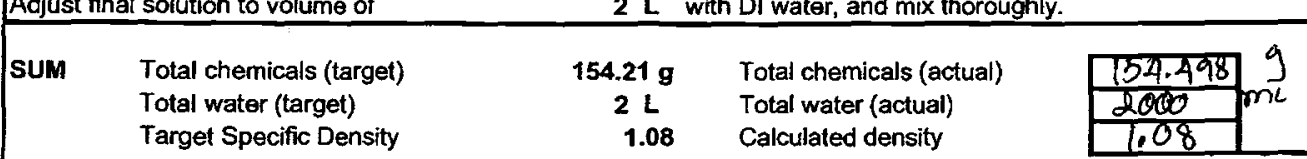

Check final solution $\mathrm{pH}$ and record.

$\mathrm{pH}=\left\{\mathcal{Z}_{i} \backslash\right.$ Readjust if significantly different from target.

Comments: record any difficulties or discrepancies' 
AY101-CSL

Base Solution 2008 Version

Balance Device ID:

Balance Device ID:
Batch Size:

pH:

NIST Weight ( $20 \mathrm{~g})$ NIST Weight ( $100 \mathrm{~g}$ ):

Technician: Noy kellec $7 \longdiv { 8 1 0 8 }$

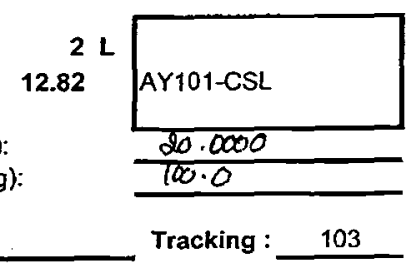

Tracking :

103

Insert Teflon stirbar and thermocouple, and place on stirrer / hotplate.

Turn on heater and adjust to $60^{\circ} \mathrm{C}\left( \pm 10^{\circ} \mathrm{C}\right)$.

Add the following chemicals and record their actual weights:

\begin{tabular}{|c|c|c|c|c|}
\hline Chemical & Formula & $\begin{array}{l}\text { Required } \\
\text { Mass (g) }\end{array}$ & $\begin{array}{l}\text { Actual } \\
\text { Mass (g) }\end{array}$ & Comments \\
\hline Sodium Aluminate & $\mathrm{NaAlO}_{2} \cdot 2 \mathrm{H}_{2} \mathrm{O}$ & 3.61 & 3.66 .1 & \\
\hline Sodium Chloride & $\mathrm{NaCl}$ & 0.75 & $0.75=$ & \\
\hline Sodium Fluoride & NaF & 0.13 & 0.13. & \\
\hline Sodium Chromate & $\mathrm{Na}_{2} \mathrm{CrO}_{4} \cdot 4 \mathrm{H}_{2} \mathrm{O}$ & 0.14 & $0.14:$ & \\
\hline Sodium Sulfate & $\mathrm{Na}_{2} \mathrm{SO}_{4}$ & 0.60 & 0.62. & \\
\hline Sodium Phosphate, 12-Hydrate & $\mathrm{Na}_{3} \mathrm{PO}_{4} 12 \mathrm{H}_{2} \mathrm{O}$ & 4.49 & 4.501 & \\
\hline Sodium Oxalate & $\mathrm{Na}_{2} \mathrm{C}_{2} \mathrm{O}_{4}$ & 0.38 & $0.3 \%$ & \\
\hline Sodium Carbonate & $\mathrm{Na}_{2} \mathrm{CO}_{3}$ & 31.25 & 310271 & \\
\hline Sodium Nitrate & $\mathrm{NaNO}_{3}$ & 30.77 & 30.80, & \\
\hline Sodium Nitrite & $\mathrm{NaNO}_{2}$ & 5.08 & 9.09 & \\
\hline Sodium Hydroxide & $\mathrm{NaOH}$ & 0.41 & 0.46 & \\
\hline
\end{tabular}

"Sodium fluoride is highly toxic. Handle with caution.

Adjust total solution volume to

$1700 \mathrm{~mL}$ by adding DI water.

Adjust solution temperature to $50^{\circ} \mathrm{C}$ to $60^{\circ} \mathrm{C}$.

Filter solution by vacuum through medium glass filter. Handle with caution, hot and caustic solution.

Rinse beaker with approximately $50 \mathrm{~mL}$ of DI water

Rinse filter with approximately $50 \mathrm{~mL}$ of DI water

Transfer final filtrate and rinse solutions to large beaker with stir bar.

\section{intial 11.84QA APPROVED}

NAME: Cedum

Transfer to volumetric flask and indude rinse with DI water. Allow solution to cool

Adjust final solution to volume of

$2 \mathrm{~L}$ with DI water, and mix thoroughly.

DATE: $8-20$ - 2

$\begin{aligned} \text { SuM } \quad & \text { Total chemicals (target) } \\ & \because \text { Total water (target) } \\ & \text { Target Specific Density }\end{aligned}$

Check final solution $\mathrm{pH}$ and record.

Comments: record any difficulties or discrepancies

$\begin{array}{cl}77.58 \mathrm{~g} & \text { Total chemicals (actual) } \\ 2 \mathrm{~L} & \text { Total water (actual) } \\ 1.04 & \text { Calculated density }\end{array}$

$\mathrm{pH}=1.82$ Readjust if significantly different from target.

Aad $\approx 4$ a of NaOl to

adjus PH to $12.8 \mathrm{~d}$




\section{AW105 Supernate \\ Base Solution 2008 Version}

Balance Device ID: 0020

Balance Device ID: 0018

Technician: Noy \& Enr

Add

Insert Teflon stirbar and thermocouple, and place on stirrer / hotplate

Turn on heater and adjust to $60^{\circ} \mathrm{C}\left( \pm 10^{\circ} \mathrm{C}\right)$

Add the following chemicals and record their actual weights:

\begin{tabular}{|c|c|}
\hline Chemical & Formula \\
\hline Sodium Aluminate & $\mathrm{Na}_{2} \mathrm{AlO}_{2} 2 \mathrm{H}_{2} \mathrm{O}$ \\
\hline Sodium Hydroxide & $\mathrm{NaOH}$ \\
\hline Boric Acid & $\mathrm{H}_{3} \mathrm{BO}_{3}$ \\
\hline Sodium Chromate & $\mathrm{Na}_{2} \mathrm{CrO}_{4} 4 \mathrm{H}_{2} \mathrm{O}$ \\
\hline Potassium Molybdate & $\mathrm{K} 2 \mathrm{MoO} 4$ \\
\hline Potassium Nitrate & $\mathrm{KNO}_{3}$ \\
\hline Zinc Nitrate 6-hydrate & $\mathrm{Zn}\left(\mathrm{NO}_{3}\right)_{2} 6 \mathrm{H}_{2} \mathrm{O}$ \\
\hline Sodium Chloride & $\mathrm{NaCl}$ \\
\hline Sodium Fluoride & $\mathrm{NaF}$ \\
\hline Sodium Nitrate & $\mathrm{NaNO}_{3}$ \\
\hline Sodium Nitrite & $\mathrm{NaNO}_{2}$ \\
\hline Sodium Phosphate, 12-Hydrate & $\mathrm{Na}_{3} \mathrm{PO}_{4} 12 \mathrm{H}_{2} \mathrm{O}$ \\
\hline Sodium Sulfate & $\mathrm{Na}_{2} \mathrm{SO}_{4}$ \\
\hline Sodium Cartonate & $\mathrm{Na}_{2} \mathrm{CO}_{3}$ \\
\hline Glycolic Acid & $\mathrm{C}_{2} \mathrm{H}_{4} \mathrm{O}_{3}$ \\
\hline Sodium Acetate 3-hydrate & $\mathrm{NaCH}_{3} \mathrm{COO} .3 \mathrm{H}_{2} \mathrm{O}$ \\
\hline Sodium Formate & $\mathrm{NaHCOO}$ \\
\hline Sodium Oxalate & $\mathrm{Na}_{2} \mathrm{C}_{2} \mathrm{O}_{4}$ \\
\hline
\end{tabular}

\begin{tabular}{|c|c|c|}
\hline $\begin{array}{l}\text { Required } \\
\text { Mass (g) }\end{array}$ & $\begin{array}{l}\text { Actual } \\
\text { Mass (g) }\end{array}$ & Comments \\
\hline 1.529 & 1.5299 & \\
\hline 21.040 & 558 & \\
\hline 0.040 & 0.0397 & \\
\hline 0.019 & 0 & \\
\hline 0.005 & & \\
\hline 29.169 & & \\
\hline 0.018 & 19 & \\
\hline 0.965 & 105 & \\
\hline 13.104 & 152 & \\
\hline 50.252 & 2649 & \\
\hline 4.416 & 4202 & \\
\hline 3.397 & 995 & \\
\hline 1.494 & 2171 & \\
\hline 22.811 & 22.8224 & \\
\hline 0.219 & 0.2906 & \\
\hline 0.626 & 0.6439 & \\
\hline 0.279 & $\theta .2000$ & 02606 \&40 $723 / 00$ \\
\hline 0.442 & 0.4571 & \\
\hline
\end{tabular}

Filter solution by vacuum through medium glass filter. Handle with caution, hot and caustic so/ution

Rinse beaker with approximately $50 \mathrm{~mL}$ of DI water

Rinse filter with approximately $50 \mathrm{~mL}$ of DI water

Transfer final filtrate and rinse solutions to large beaker with stir bar.

Transfer to volumetric flask and include rinse with DI water. Allow solution to cool

Adjust final solution to volume of

2 L. with DI water, and mix thoroughly.

NAME: Cldew

DATE: 8.20 .08

\begin{tabular}{|c|c|c|c|c|}
\hline SUM & $\begin{array}{l}\text { Total chemicais (target) } \\
\text { Total water (target) } \\
\text { Target Specific Density }\end{array}$ & $\begin{array}{c}149.82 \mathrm{~g} \\
2 \mathrm{~L} \\
1.07\end{array}$ & $\begin{array}{l}\text { Total chemicals (actual) } \\
\text { Total water (actual) } \\
\text { Calculated density }\end{array}$ & $\begin{array}{l}150.6721 \\
2000 \\
1.0753 \\
\end{array}$ \\
\hline he & olution $\mathrm{pH}$ and record. & \multicolumn{3}{|c|}{$\mathrm{pH}=13.32$ Readjust if significantly different from target. } \\
\hline
\end{tabular}




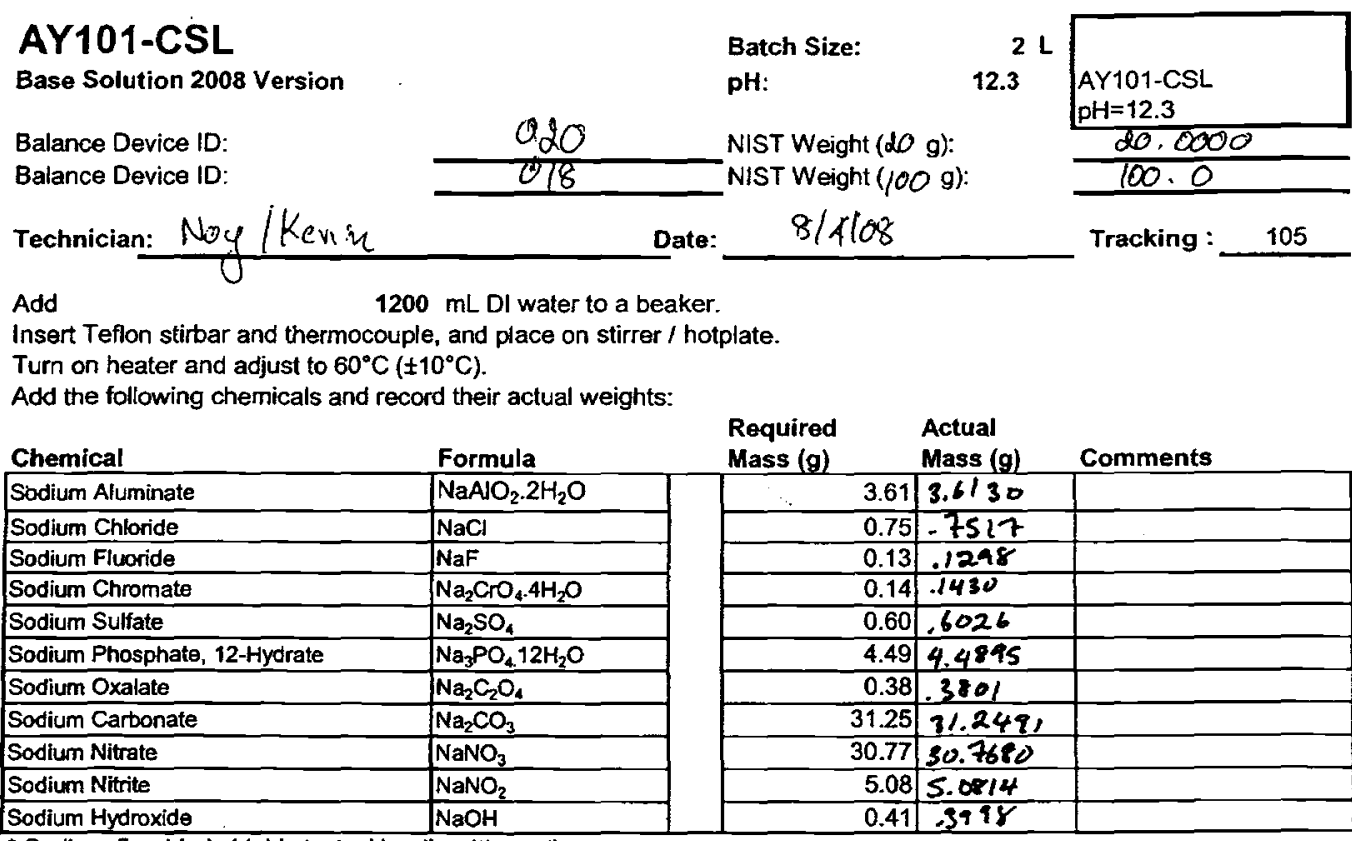

* Sodium fluoride is highly toxic. Handle with caution.

Adjust total solution volume to

$1700 \mathrm{~mL}$ by adding DI water.

Adjust solution temperature to $50^{\circ} \mathrm{C}$ to $60^{\circ} \mathrm{C}$

Filter solution by vacuum through medium glass filter. Handle with caution, hot and caustic solution

Rinse beaker with approximately $50 \mathrm{~mL}$. of DI water

$\begin{array}{ll}\text { Rinse filter with approximately } 50 \mathrm{~mL} \text { of } \mathrm{Dl} \text { water } & \text { initial PH } 11.76 \\ \text { Transfer final filtrate and rinse solutions to large beaker with stir bar. } & \text { Finel APROVED }\end{array}$

Final $\mathrm{pH}$ 12.30 AA APPROV
NAME: Codur

Transfer to volumetric flask and include rinse with DI water. Allow solution to cool

Adjust final solution to volume of

$2 \mathrm{~L}$ with $\mathrm{DI}$ water, and mix thoroughly.

DATE: $\quad 8-2008$

\begin{tabular}{|c|c|c|c|c|}
\hline SUM & $\begin{array}{l}\text { Total chemicals (target) } \\
\text { Total water (target) } \\
\text { Tarcet Specific Density }\end{array}$ & $\begin{array}{c}77.58 \mathrm{~g} \\
2 \mathrm{~L} \\
1.04\end{array}$ & $\begin{array}{l}\text { Total chemicals (actual } \\
\text { Total water (actual) } \\
\text { Calculated density }\end{array}$ & $\frac{7000}{\frac{700}{1.04}}$ \\
\hline
\end{tabular}

Check final solution $\mathrm{pH}$ and record.

$\mathrm{pH}=12.3$ Readjust if significantly different from target.

Comments: record any difficulties or discrepancies

adjusting $\mathrm{pH}$ from 11.76 fo $\mathrm{PH} 12.30$ with $\mathrm{NaOH}$

adysting $\mathrm{pH}$ from 11.76 to $\mathrm{PH} 12.30$ with




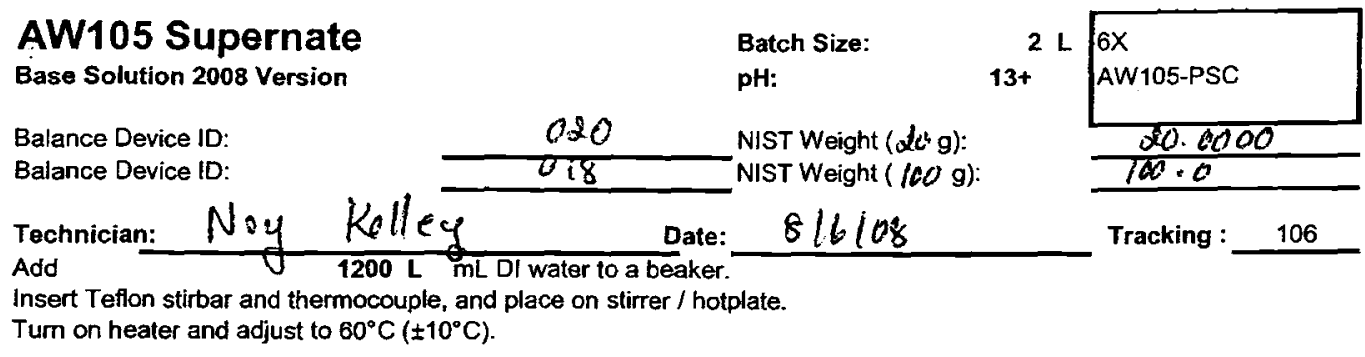

Add the following chemicals and record their actual weights:

\begin{tabular}{|c|c|}
\hline Chemical & Formula \\
\hline Sodium Aluminate & $\mathrm{Na}_{2} \mathrm{AlO}_{2} 2 \mathrm{H}_{2} \mathrm{O}$ \\
\hline Sodium Hydroxide & $\mathrm{NaOH}$ \\
\hline Boric Acid & $\mathrm{H}_{3} \mathrm{BO}_{3}$ \\
\hline Sodium Chromate & $\mathrm{Na}_{2} \mathrm{CrO}_{4} 4 \mathrm{H}_{2} \mathrm{O}$ \\
\hline Potassium Molybdate & $\mathrm{K} 2 \mathrm{MOO4}$ \\
\hline Potassium Nitrate & $\mathrm{KNO}_{3}$ \\
\hline Zinc Nitrate 6-hydrate & $\mathrm{Zn}\left(\mathrm{NO}_{3}\right)_{2} 6 \mathrm{H}_{2} \mathrm{O}$ \\
\hline Sodium Chloride & $\mathrm{NaCl}$ \\
\hline Sodium Fluoride & $\mathrm{NaF}$ \\
\hline Sodium Nitrate & $\mathrm{NaNO}_{3}$ \\
\hline Sodium Nitrite & $\mathrm{NaNO}_{2}$ \\
\hline Sodium Phosphate, 12-Hydrate & $\mathrm{Na}_{3} \mathrm{PO}_{4} 12 \mathrm{H}_{2} \mathrm{O}$ \\
\hline Sodium Sulfate & $\mathrm{Na}_{2} \mathrm{SO}_{4}$ \\
\hline Sodium Carbonate & $\mathrm{Na}_{2} \mathrm{CO}_{3}$ \\
\hline Glycolic Acid & $\mathrm{C}_{2} \mathrm{H}_{4} \mathrm{O}_{3}$ \\
\hline Sodium Acetate 3-hydrate & $\mathrm{NaCH}_{3} \mathrm{COO} .3 \mathrm{H}_{2} \mathrm{O}$ \\
\hline Sodium Formate & $\mathrm{NaHCOO}$ \\
\hline Sodium Oxalate & $\mathrm{Na}_{2} \mathrm{C}_{2} \mathrm{O}_{4}$ \\
\hline
\end{tabular}

$\begin{aligned} & \text { Required } \\
& \text { Mass (g) }\end{aligned}$
\begin{tabular}{|r|l|l|}
\hline 1.529 & \multicolumn{1}{l}{$\begin{array}{l}\text { Actual } \\
\text { Mass (g) }\end{array}$} & Comments \\
\hline 21.040 & 21.079 & \\
\hline 0.040 & .0402 & \\
\hline 0.019 & .0192 & \\
\hline 0.005 & .0064 & \\
\hline 29.169 & 29.1690 & \\
\hline 0.018 & -0180 & \\
\hline 0.965 & .9651 & \\
\hline 13.104 & 18.1062 & \\
\hline 424.252 & 424.3 & \\
\hline 26.496 & 26.4957 & \\
\hline 3.397 & 3.3169 & \\
\hline 1.494 & 1.4931 & \\
\hline 22.811 & 22.8106 & \\
\hline 0.219 & .2189 & \\
\hline 0.626 & .6264 & \\
\hline 0.279 & .2786 & \\
\hline 0.442 & .4420 & \\
\hline & \\
\hline
\end{tabular}
Filter solution by vacuum through medium glass filter. Handle with caution, hot and caustic G/Fio APPROVED
Rinse beaker with approximately $50 \mathrm{~mL}$ of DI water

Rinse filter with approximately $50 \mathrm{~mL}$ of DI water

Transfer final filtrate and rinse solutions to large beaker with stir bar.

Transfer to volumetric flask and include rinse with DI water. Allow solution to cool

Adjust final solution to volume of

$2 \mathrm{~L}$ with $\mathrm{DI}$ water, and mix thoroughly.

\begin{tabular}{|c|c|c|c|c|}
\hline Sum & $\begin{array}{l}\text { Total chemicals (target) } \\
\text { Total water (target) } \\
\text { Target Specific Density }\end{array}$ & $\begin{array}{c}545.90 \mathrm{~g} \\
2 \mathrm{~L} \\
1.27\end{array}$ & $\begin{array}{l}\text { Total chemicals (actual) } \\
\text { Total water (actual) } \\
\text { Calculated density }\end{array}$ & $\frac{545.97}{\frac{2000, L}{2.27}}$ \\
\hline her & olution $\mathrm{pH}$ and record. & \multicolumn{3}{|c|}{$\begin{array}{l}\mathrm{AK} \quad \mathrm{s} / 7108 \\
\mathrm{pH}=\frac{13.4 .4 \text { Readjust if significantly different from target }}{13.15}\end{array}$} \\
\hline
\end{tabular}

NAME: Cedurw

DATE: 8.2008 
RPP-RPT-37505, Rev. 0

GFS Chemicals, Inc.

Columbus, Ohio 43223

LOT ANALYSIS

ITEM: 1099 SODIUM OXALATE, REAGENT (ACS)

LOT\#: P568829

\begin{tabular}{|l|c|c|}
\hline TEST & PASSIFAIL & $\begin{array}{l}\text { NUMERICAL } \\
\text { RESULT }\end{array}$ \\
\hline 1. Assay $99.5 \% \min$ & PASS & $101.8 \%$ \\
\hline 2. Insoluble $0.005 \%$ & PASS & $<0.005 \%$ \\
\hline 3. Loss on drying @ $105 \mathrm{C} 0.01 \%$ & PASS & $0.004 \%$ \\
\hline 4. Neutrality - Pass Test & PASS & Passes Test \\
\hline 5. Chloride $0.002 \%$ & PASS & $<0.002 \%$ \\
\hline 6. Sulfate $0.002 \%$ & PASS & $<0.002 \%$ \\
\hline 7. Ammonium $0.002 \%$ & PASS & $<0.002 \%$ \\
\hline 8. Heavy metals (Pb) $0.002 \%$ & PASS & $<0.002 \%$ \\
\hline 9. Iron $0.001 \%$ & PASS & $<0.0001 \%$ \\
\hline 10. Potassium $0.005 \%$ & PASS & $<0.002 \%$ \\
\hline 11. Substances darkened by H2SO4 pass test & PASS & Passes Test \\
\hline
\end{tabular}

TRACEABLE TON.IST.T. $(Y / N) ? Y$

Comment:

Reported by: Kenneth L. Shafer

Date: 9/15/2005

QC Supervisor: Joan Plowman

Retest Date: 9/15/2010 
RPP-RPT-37505, Rev. 0

GFS Chemicals, Inc.

Columbus, Ohio 43223

LOT ANALYSIS

ITEM: 705 SODIUM CARBONATE, ANHYDROUS, POWDER, REAGENT (ACS)

LOT\#: P675164

\begin{tabular}{|c|c|c|}
\hline TEST & PASSFAIL & $\begin{array}{l}\text { NUNERICAL } \\
\text { RESULT }\end{array}$ \\
\hline 1. Assay $99.5 \% \min$ & PASS & $100.00 \%$ \\
\hline 2. Insoluble $0.01 \%$ & PASS & $0.004 \%$ \\
\hline 3. Loss on heating at $285 \mathrm{C} 1.0 \% \max$ & PASS & $0.4 \%$ \\
\hline 4. Chloride $0.001 \%$ & PASS & $0.0006 \%$ \\
\hline 5. Phosphate $0.001 \%$ & PASS & $0.0003 \%$ \\
\hline 6. Silica $0.005 \%$ & PASS & $0.001 \%$ \\
\hline 7. Sulfur compounds (as SO4) $0.003 \%$ & PASS & $0.001 \%$ \\
\hline 8. Heavy metals $(\mathrm{Pb}) 0.0005 \%$ & PASS & $0.0002 \%$ \\
\hline 9. Iron $0.0005 \%$ & PASS & $0.0002 \%$ \\
\hline 10. Calcium $0.03 \%$ & PASS & $0.005 \%$ \\
\hline 11. Magnesium $0.005 \%$ & PASS & $0.002 \%$ \\
\hline 12. Potassium $0.005 \%$ & PASS & $0.002 \%$ \\
\hline
\end{tabular}

TRACEABLE TON.IS.T. (Y/N)? Y

Comment:

Reported by: Joan E Plowman

Date: 5/3/2006

QC Supervisor: Joan Plowman

Retest Date: 5/3/2011 
GFS Chemicals, Inc.

Columbus, Ohio 43223

LOT ANALYSIS

ITEM: 1099 SODIUM OXALATE, REAGENT (ACS)

LOT\#: P453301

\begin{tabular}{|l|c|c|}
\hline TEST & PASSIFAIL & $\begin{array}{l}\text { NUMERICAL } \\
\text { RESULT }\end{array}$ \\
\hline 1. Assay $99.5 \% \min$ & PASS & $102.7 \%$ \\
\hline 2. Insoluble $0.005 \%$ & PASS & $<0.005 \%$ \\
\hline 3. Loss on drying @ $105 \mathrm{C} 0.01 \%$ & PASS & $<0.01 \%$ \\
\hline 4. Neutrality - Pass Test & PASS & passes test \\
\hline 5. Chloride $0.002 \%$ & PASS & $<0.002 \%$ \\
\hline 6. Sulfate $0.002 \%$ & PASS & $<0.002 \%$ \\
\hline 7. Ammonium $0.002 \%$ & PASS & $<0.002 \%$ \\
\hline 8. Heavy metals $(\mathrm{Pb}) 0.002 \%$ & PASS & $<0.002 \%$ \\
\hline 9. Iron $0.001 \%$ & PASS & $<0.001 \%$ \\
\hline 10. Potassium $0.005 \%$ & PASS & $<0.005 \%$ \\
\hline 11. Substances darkened by $\mathrm{H} 2 S 04$ pass test & PASS & passes test \\
\hline
\end{tabular}

TRACEABLE TON.I.S.T. (Y/N)?Y

Comment:

Reported by: Daniel Merkoziaj

Date: $2 / 17 / 2004$

QC Supervisor: Joan Plowman

Retest Date: 2/17/2006 
RPP-RPT-37505, Rev. 0

GFS Chemicals, Inc.

Columbus, Ohio 43223

LOT ANALYSIS

ITEM: 656 SODIUM ACETATE, TRIHYDRATE, REAGENT (ACS)

LOT\#: L350643

\begin{tabular}{|l|c|c|}
\hline TEST & PASSIFAIL & $\begin{array}{l}\text { NUMERICAL } \\
\text { RESULT }\end{array}$ \\
\hline 1. Assay $99.0-101 \%$ & PASS & $99.99 \%$ \\
\hline 2. Insoluble $0.005 \%$ & PASS & $<0.005 \%$ \\
\hline 3. pH of $5 \%$ solution $7.5-9.2 @ 25 \mathrm{C}$ & PASS & 8.0 \\
\hline 4. Chloride $0.001 \%$ & PASS & $<0.001 \%$ \\
\hline 5. Phosphate $0.0005 \%$ & PASS & $<0.0005 \%$ \\
\hline 6. Sulfate $0.002 \%$ & PASS & $<0.002 \%$ \\
\hline 7. Calcium $0.005 \%$ & PASS & $<0.0005 \%$ \\
\hline 8. Magnesium $0.002 \%$ & PASS & $<0.0001 \%$ \\
\hline 9. Heavy metals (as Pb) 0.0005\% & PASS & $<0.0005 \%$ \\
\hline 10. Iron $0.0005 \%$ & PASS & $<0.0001 \%$ \\
\hline 11. Substances reducing permanganate - Pass Test & PASS & passes test \\
\hline 12. Potassium $0.005 \%$ & PASS & $<0.0016 \%$ \\
\hline
\end{tabular}

TRACEABLE TO N.I.S.T. (Y/N)? Y

Comment:

Reported by: Daniel Merkoziaj

Date: $10 / 1 / 2003$

QC Supervisor: Joan Plowman

Retest Date: 24 Month after shipment 
RPP-RPT-37505, Rev. 0

GFS Chemicals, Inc.

Columbus, Ohio 43223

LOT ANALYSIS

ITEM: 658 SODIUM NITRATE, REAGENT (ACS)

LOT\#: L136875

\begin{tabular}{|l|c|c|}
\hline TEST & PASSIFAIL & $\begin{array}{l}\text { NUMERICAL } \\
\text { RESULT }\end{array}$ \\
\hline 1. Assay $99.0 \%$ min. & PASS & $99.7 \%$ \\
\hline 2. pH of $5 \%$ solution $5.5-8.3 @ 25 \mathrm{C}$ & PASS & 5.9 \\
\hline 3. Insoluble $0.005 \%$ & PASS & $<0.005 \%$ \\
\hline 4. Chloride $0.001 \%$ & PASS & $<0.001 \%$ \\
\hline 5. lodate $0.0005 \%$ & PASS & $<0.0005 \%$ \\
\hline 6. Nitrite $0.001 \%$ & PASS & $<0.001 \%$ \\
\hline 7. Phosphate $0.0005 \%$ & PASS & $<0.0005 \%$ \\
\hline 8. Sulfate $0.003 \%$ & PASS & $<0.003 \%$ \\
\hline 9. Calcium $0.005 \%$ & PASS & $<0.005 \%$ \\
\hline 10. Magnesium $0.002 \%$ & PASS & $<0.002 \%$ \\
\hline 11. Heavy metals $(\mathrm{Pb}) 0.0005 \%$ & PASS & $<0.0005 \%$ \\
\hline 12. Iron $0.0003 \%$ & PASS & $<0.0003 \%$ \\
\hline
\end{tabular}

TRACEABLE TON.I.S.T. (Y/N)?Y

Comment:

Reported by: Kenneth L. Shafer

Date: $9 / 24 / 2001$

QC Supervisor: Joan Plowman

Retest Date: 24 Month after shipment 
RPP-RPT-37505, Rev. 0

GFS Chemicals, Inc.

Columbus, Ohio 43223

\section{LOT ANALYSIS}

ITEM: 658 SODIUM NITRATE, REAGENT (ACS)

LOT\#: L137057

\begin{tabular}{|c|c|c|}
\hline MEST. & PASSIFAIL & Wumarichl \\
\hline 1. Assay $99.0 \% \mathrm{~min}$. & PASS & $100.1 \%$ \\
\hline 2. $\mathrm{pH}$ of $5 \%$ solution $5.5-8.3 @ 25 \mathrm{C}$ & PASS & 5.9 \\
\hline 3. Insoluble $0.005 \%$ & PASS & $<0.005 \%$ \\
\hline 4. Chloride $0.001 \%$ & PASS & $<0.001 \%$ \\
\hline 5. lodate $0.0005 \%$ & PASS & $<0.0005 \%$ \\
\hline 6. Nitrite $0.001 \%$ & PASS & $<0.001 \%$ \\
\hline 7. Phosphate $0.0005 \%$ & PASS & $<0.0005 \%$ \\
\hline 8. Sulfate $0.003 \%$ & PASS & $<0.003 \%$ \\
\hline 9. Calcium $0.005 \%$ & PASS & $<0.0005 \%$ \\
\hline 10. Magnesium $0.002 \%$ & PASS & $<0.0005 \%$ \\
\hline 11. Heavy metals (Pb) $0.0005 \%$ & PASS & $<0.0005 \%$ \\
\hline 12. Iron $0.0003 \%$ & PASS & $<0.0003 \%$ \\
\hline
\end{tabular}

TRACEABLE TON.I.S.T. (Y/N)? Y

\section{Comment:}

Reported by: Kenneth L. Shafer

QC Supervisor: Joan Plowman
Date: $9 / 26 / 2001$

Retest Date: 24 Month after shipment 
RPP-RPT-37505, Rev. 0

GFS Chemicals, Inc.

Columbus, Ohio 43223

ITEM: 559 SODIUM NITRITE, REAGENT (ACS)

\section{LOT ANALYSIS}

\begin{tabular}{|l|c|c|}
\hline TEST & PASSIFAIL & $\begin{array}{l}\text { NUIEERICAL } \\
\text { RESULT }\end{array}$ \\
\hline 1. Assay $97.0 \% \mathrm{~min}$. & PASS & $98.6 \%$ \\
\hline 2. Chloride $0.005 \%$ & PASS & $<0.005 \%$ \\
\hline 3. Sulfate $0.01 \%$ & PASS & $<0.01 \%$ \\
\hline 4. Calcium $0.01 \%$ & PASS & $<0.01 \%$ \\
\hline 5. Heavy metals (as Pb) $0.001 \%$ & PASS & $<0.001 \%$ \\
\hline 6. Iron $0.001 \%$ & PASS & $<0.001 \%$ \\
\hline 7. Potassium $0.005 \%$ & PASS & $<0.005 \%$ \\
\hline 8. Insoluble $0.01 \%$ & PASS & $<0.01 \%$ \\
\hline 9. pH of $5 \%$ solution $5.5-8.3$ @ $25 \mathrm{C}$ & PASS & 7.2 \\
\hline 10. Appearance - White to pale yellow & PASS & Pale Yellow \\
\hline
\end{tabular}

TRACEABLE TON.IS.T. (YIN)?Y

Comment:

Reported by: Robert Kramer

Date: $2 / 28 / 2006$

QC Supervisor: Joan Plowman

Retest Date: 2/28/2011 
RPP-RPT-37505, Rev. 0

GFS Chemicals, Inc.

Columbus, Ohio 43223

ITEM: 559 SODIUM NITRITE, REAGENT (ACS)

LOT ANALYSIS

\begin{tabular}{|l|c|c|}
\hline TEST & PASSFAIL & NUMERICAL \\
RESULT
\end{tabular}

TRACEABLE TO N.I.S.T. (Y/N)? Y

Comment:

Reported by: Kenneth L. Shafer

Date: $6 / 14 / 2006$

QC Supervisor: Joan Plowman

Retest Date: 6/14/2011 
GFS Chemicals, Inc.

Columbus, Ohio 43223

ITEM: 559 SODIUM NITRITE, REAGENT (ACS)

\section{LOT ANALYSIS}

\begin{tabular}{|l|c|c|}
\hline TEST & PASSIFAIL & $\begin{array}{l}\text { NUMERICAL } \\
\text { RESULT }\end{array}$ \\
\hline 1. Assay $97.0 \%$ min. & PASS & $97.9 \%$ \\
\hline 2. Chloride $0.005 \%$ & PASS & $<0.005 \%$ \\
\hline 3. Sulfate $0.01 \%$ & PASS & $<0.01 \%$ \\
\hline 4. Calcium $0.01 \%$ & PASS & $<0.001 \%$ \\
\hline 5. Heavy metals (as Pb) $0.001 \%$ & PASS & $<0.001 \%$ \\
\hline 6. Iron $0.001 \%$ & PASS & $<0.0005 \%$ \\
\hline 7. Potassium $0.005 \%$ & PASS & $<0.001 \%$ \\
\hline 8. Insoluble $0.01 \%$ & PASS & $<0.01 \%$ \\
\hline 9. pH of $5 \%$ solution $5.5-8.3$ @ 25 C & PASS & 7.6 \\
\hline 10. Appearance - White to pale yellow & PASS & pale yellow \\
\hline
\end{tabular}

TRACEABLE TON.I.S.T. (Y/N)? Y

Comment:

Reported by: Kenneth L. Shafer

QC Supervisor: Joan Plowman
Date: $8 / 17 / 2005$

Retest Date: 8/17/2010 
RPP-RH T-37505, Rev. 0

GFS Chemicals, Inc.

Columbus, Ohio 43223

LOT ANALYSIS

ITEM: 2454 SODIUM SULFATE, ANHYDROUS, POWDER, REAGENT (ACS)

LOT\#: P675142

\begin{tabular}{|l|c|c|}
\hline TEST & PASSIFAIL & $\begin{array}{l}\text { MUMERICAL } \\
\text { RESULT }\end{array}$ \\
\hline 1. Assay $99.0 \%$ min. & PASS & $99.75 \%$ \\
\hline 2. pH of $5 \%$ solution @ 25C 5.2-9.2 & PASS & 5.92 \\
\hline 3. Insoluble matter $0.01 \%$ & PASS & $0.003 \%$ \\
\hline 4. Loss on ignition $0.5 \%$ & PASS & $0.22 \%$ \\
\hline 5. Chloride $0.001 \%$ & PASS & $<0.0005 \%$ \\
\hline 6. Nitrogen compounds (as $\mathrm{N}$ ) $0.0005 \%$ & PASS & $<0.0003 \%$ \\
\hline 7. Phosphate $0.001 \%$ & PASS & $<0.0005 \%$ \\
\hline 8. Calcium $0.01 \%$ & PASS & $0.001 \%$ \\
\hline 9. Magnesium $0.005 \%$ & PASS & $0.0005 \%$ \\
\hline 10. Heavy metals (as Pb) $0.0005 \%$ & PASS & $<0.0003 \%$ \\
\hline 11. Iron $0.001 \%$ & PASS & $<0.0005 \%$ \\
\hline 12. Potassium $0.01 \%$ & PASS & $0.0015 \%$ \\
\hline
\end{tabular}

TRACEABLE TON.I.S.T. (Y/N)? Y

Comment:

Reported by: Nicholas E. Dangler

Date: $5 / 5 / 2006$

QC Supervisor: Joan Plowman

Retest Date: 5/5/2011 
GFS Chemicals, Inc.

Columbus, Ohio 43223

LOT ANALYSIS

ITEM: 2454 SODIUM SULFATE, ANHYDROUS, POWDER, REAGENT (ACS)

LOT\#: P571317

\begin{tabular}{|l|c|c|}
\hline TEST & PASSIFAIL & $\begin{array}{l}\text { NUMERICAL } \\
\text { RESULT }\end{array}$ \\
\hline 1. Assay $99.0 \%$ min & PASS & $100.3 \%$ \\
\hline 2. pH of $5 \%$ solution @ 25C 5.2-9.2 & PASS & 5.4 \\
\hline 3. Insoluble matter $0.01 \%$ & PASS & $<0.01 \%$ \\
\hline 4. Loss on ignition $0.5 \%$ & PASS & $<0.5 \%$ \\
\hline 5. Chloride $0.001 \%$ & PASS & $<0.001 \%$ \\
\hline 6. Nitrogen compounds (as N) $0.0005 \%$ & PASS & $<0.0005 \%$ \\
\hline 7. Phosphate $0.001 \%$ & PASS & $<0.001 \%$ \\
\hline 8. Calcium $0.01 \%$ & PASS & $<0.01 \%$ \\
\hline 9. Magnesium $0.005 \%$ & PASS & $<0.005 \%$ \\
\hline 10. Heavy metals (as Pb) $0.0005 \%$ & PASS & $<0.0005 \%$ \\
\hline 11. Iron $0.001 \%$ & PASS & $<0.001 \%$ \\
\hline 12. Potassium $0.01 \%$ & PASS & $<0.01 \%$ \\
\hline
\end{tabular}

TRACEABLE TON.I.S.T. (Y/N)?Y

Comment:

Reported by: Robert Kramer

Date: $12 / 14 / 2005$

QC Supervisor: Joan Plowman

Retest Date: 12/14/2010 
RPP-RPT-37505, Rev. 0

GFS Chemicals, Inc.

Columbus, Ohio 43223

LOT ANALYSIS

ITEM: 1035 SODIUM PHOSPHATE, TRIBASIC, DODECAHYDRATE, REAGENT (ACS)

LOT\#: P562445

\begin{tabular}{|l|c|c|}
\hline TEST & $\begin{array}{c}\text { NUMERICAL } \\
\text { RESULT }\end{array}$ \\
\hline 1. Assay $98.0-102.0 \%$ & PASS & $99.2 \%$ \\
\hline 2. Excess alkali $(\mathrm{NaOH}) 2.5 \%$ & PASS & $1.8 \%$ \\
\hline 3. Insoluble $0.01 \%$ & PASS & $0.005 \%$ \\
\hline 4. Chloride $0.001 \%$ & PASS & $0.0008 \%$ \\
\hline 5. Sulfate $0.01 \%$ & PASS & $0.002 \%$ \\
\hline 6. Heavy metals (as Pb) $0.001 \%$ & PASS & $0.0005 \%$ \\
\hline 7. Iron $0.001 \%$ & PASS & $0.0003 \%$ \\
\hline
\end{tabular}

TRACEABLE TO N.I.S.T. (YNN)? Y

Comment:

Reported by:

Date: $1 / 27 / 2005$

QC Supervisor: Joan Plowman

Retest Date: 1/27/2010 
GFS Chemicals, Inc.

Columbus, Ohio 43223

LOT ANALYSIS

ITEM: 657 SODIUM CHLORIDE, REAGENT (ACS)

\section{LOT\#: P569640}

\begin{tabular}{|c|c|c|}
\hline TEST V. & PASSIFAIL & $\begin{array}{l}\text { NUMERICAL } \\
\text { RESULT }\end{array}$ \\
\hline 1. Assay $99.0 \% \mathrm{~min}$. & PASS & $100.0 \%$ \\
\hline 2. Insoluble $0.005 \%$ & PASS & $<0.005 \%$ \\
\hline 3. pH of $5 \%$ solution $5.0-9.0 @ 25 \mathrm{C}$ & PASS & 5.8 \\
\hline 4. lodide $0.002 \%$ & PASS & $<0.002 \%$ \\
\hline 5. Bromide $0.01 \%$ & PASS & $<0.01 \%$ \\
\hline 6 Chlorate and nitrate (as NO3) $0.003 \%$ & PASS & $<0.003 \%$ \\
\hline 7. Phosphate $0.0005 \%$ & PASS & $<0.0005 \%$ \\
\hline 8 Sulfate $0.004 \%$ & PASS & $0.004 \%$ \\
\hline 9. Barium - pass test & PASS & pass test \\
\hline 10. Heawy Metals (as Pb) $0.0005 \%$ & PASS & $<0.0005 \%$ \\
\hline 11. Iron $0.0002 \%$ & PASS & $<0.0002 \%$ \\
\hline 12. Calcium $0.002 \%$ & PASS & $0.0003 \%$ \\
\hline 13. Magnesium $0.001 \%$ & PASS & $<0.0001 \%$ \\
\hline 14. Potassium $0.005 \%$ & PASS & $<0.005 \%$ \\
\hline
\end{tabular}

TRACEABLE TON.IS.T. (Y/N)? Y

Comment:

Reported by: Daniel Merkoziaj

Date: $10 / 9 / 2005$

QC Supervisor: Joan Plowman

Retest Date: 10/9/2010 
GFS Chemicals, Inc.

Columbus, Ohio 43223

LOT ANALYSIS

ITEM: 630 SODIUM HYDROXIDE, REAGENT (ACS)

LOT\#: P569567

\begin{tabular}{|l|c|c|}
\hline TEST & PASSIFAIL & $\begin{array}{l}\text { NuMERICAL } \\
\text { RESULT }\end{array}$ \\
\hline 1. Assay $97.0 \%$ min & PASS & $99.0 \%$ \\
\hline 2. Sodium carbonate $1.0 \%$ max & PASS & $0.4 \%$ \\
\hline 3. Chloride $0.005 \%$ & PASS & $<0.001 \%$ \\
\hline 4. Nitrogen compounds $(\mathrm{N}) 0.001 \%$ & PASS & $<0.0003 \%$ \\
\hline 5. Phosphate $0.001 \%$ & PASS & $<0.0002 \%$ \\
\hline 6. Sulfate $0.003 \%$ & PASS & $0.0005 \%$ \\
\hline 7. Heavy metals (as Ag) $0.002 \%$ & PASS & $<0.001 \%$ \\
\hline 8. Iron $0.001 \%$ & PASS & $<0.0003 \%$ \\
\hline 9. Mercury $0.00001 \%$ & PASS & $0.00001 \%$ \\
\hline 10. Nickel $0.001 \%$ & PASS & $0.0001 \%$ \\
\hline 11. Calcium $0.005 \%$ & PASS & $0.0003 \%$ \\
\hline 12. Magnesium $0.002 \%$ & PASS & $0.002 \%$ \\
\hline 13. Potassium $0.02 \%$ & PASS & $<0.01 \%$ \\
\hline
\end{tabular}

TRACEABLE TO N.IS.T. (Y/N)? Y

Comment

Reported by: Joan E Plowman

Date: $10 / 5 / 2005$

QC Supervisor: Joan Plowman

Retest Date: 10/5/2010 
RPP-RPT-375U5, Rev. 0

GFS Chemicals, Inc.

Columbus, Ohio 43223

LOT ANALYSIS

ITEM: 656 SODIUM ACETATE, TRIHYDRATE, REAGENT (ACS)

LOT\#: L350643

\begin{tabular}{|l|c|c|}
\hline TEST & PASSIFAL & $\begin{array}{l}\text { NUMERICAL } \\
\text { RESULT }\end{array}$ \\
\hline 1. Assay $99.0-101 \%$ & PASS & $99.99 \%$ \\
\hline 2. Insoluble $0.005 \%$ & PASS & $<0.005 \%$ \\
\hline 3. pH of $5 \%$ solution $7.5-9.2$ @ $25 \mathrm{C}$ & PASS & 8.0 \\
\hline 4. Chloride $0.001 \%$ & PASS & $<0.001 \%$ \\
\hline 5. Phosphate $0.0005 \%$ & PASS & $<0.0005 \%$ \\
\hline 6. Sulfate $0.002 \%$ & PASS & $<0.002 \%$ \\
\hline 7. Ca!cium $0.005 \%$ & PASS & $<0.0005 \%$ \\
\hline 8. Magnesium 0.002\% & PASS & $<0.0001 \%$ \\
\hline 9. Heavy metals (as Pb) 0.0005\% & PASS & $<0.0005 \%$ \\
\hline 10. Iron $0.0005 \%$ & PASS & $<0.0001 \%$ \\
\hline 11. Substances reducing permanganate - Pass Test & PASS & Passes test \\
\hline 12. Potassium 0.005\% & PASS & $<0.0016 \%$ \\
\hline
\end{tabular}

TRACEABLE TO N.I.S.T. (Y/N)?Y

Comment:

Reported by: Daniel Merkoziaj

Date: $10 / 1 / 2003$

QC Supervisor: Joan Plowman

Retest Date: 24 Month after shipment 
RPP-RPT-37505, Rev. 0

GFS Chemicals, Inc.

Columbus, Ohio 43223

LOT ANALYSIS

ITEM: 1935 SODIUM ACETATE, TRIHYDRATE, BIO-REFINED

LOT\#: P677274

\begin{tabular}{|l|c|c|}
\hline TEST & PASSIFAIL & $\begin{array}{l}\text { NUMERICAL } \\
\text { RESULT }\end{array}$ \\
\hline 1. Assay $99.5 \%$ min. & PASS & $99.7 \%$ \\
\hline 2. Substances reducing $\mathrm{KMnO} 40.005 \%$ & PASS & $<0.005 \%$ \\
\hline 3. $\mathrm{pH}(0.5 \mathrm{M}$ in water @ $20 \mathrm{deg}$. $) 7.5-9.0$ & PASS & 8.3 \\
\hline 4. Insoluble matter $0.005 \%$ & PASS & $<0.005 \%$ \\
\hline 5. Chloride (Cl) $0.0005 \%$ & PASS & $<0.0005 \%$ \\
\hline 6. Phosphate (PO4) $0.0005 \%$ & PASS & $<0.0005 \%$ \\
\hline 7. Sulfate (SO4) $0.002 \%$ & PASS & $<0.0001 \%$ \\
\hline 8. Absorbance $(0.50 \mathrm{M}$ in $\mathrm{H} 2 \mathrm{O})$ @ $260 \mathrm{~nm}<0.004$ & PASS & $<0.004$ \\
\hline 9. Absorbance $(0.50 \mathrm{M}$ in $\mathrm{H} 2 \mathrm{O})$ @ $280 \mathrm{~nm}<0.003$ & PASS & $<0.003$ \\
\hline
\end{tabular}

TRACEABLE TON.IS.T. (Y/N)? Y

Comment:

Reported by: Joan E Plowman

Date: $7 / 26 / 2006$

QC Supervisor: Joan Plowman

Retest Date: 7/26/2011 
RPP-RPT-37505, Rev. 0

GFS Chemicals, Inc.

Columbus, Ohio 43223

LOT ANALYSIS

ITEM: 1935 SODIUM ACETATE, TRIHYDRATE, BIO-REFINED

LOT\#: P460400

\begin{tabular}{|l|c|c|}
\hline TEST & PASSIFAIL & $\begin{array}{l}\text { NUMERICAL } \\
\text { RESULT }\end{array}$ \\
\hline 1. Assay $99.5 \%$ min. & PASS & $100.6 \%$ \\
\hline 2. Substances reducing KMnO4 0.005\% & PASS & $<0.005 \%$ \\
\hline 3. pH (0.5M in water @ 20 deg. C) $7.5-9.0$ & PASS & 8.5 \\
\hline 4. Insoluble matter $0.005 \%$ & PASS & $<0.005 \%$ \\
\hline 5. Chloride (Cl) $0.0005 \%$ & PASS & $<0.0005 \%$ \\
\hline 6. Phosphate (PO4) $0.0005 \%$ & PASS & $<0.0005 \%$ \\
\hline 7. Sulfate (SO4) $0.002 \%$ & PASS & $0.0003 \%$ \\
\hline 8. Absorbance @ 260nm/280nm (.5M in H2O) $<0.004 /<0.003$ & PASS & $<0.001 /<0.001$ \\
\hline
\end{tabular}

TRACEABLE TO N.I.S.T. (YNN)? Y

\section{Comment:}

Reported by: Kenneth L. Shafer

QC Supervisor: Joan Plowman
Date: $10 / 27 / 2004$

Retest Date: 10/27/2009 
RPP-RPT-37505, Rev. 0

GFS Chemicals, Inc.

Columbus, Ohio 43223

\section{LOT ANALYSIS}

ITEM: 655 POTASSIUM NITRATE, REAGENT (ACS)

\section{LOT\#: L346711}

\begin{tabular}{|c|c|c|}
\hline 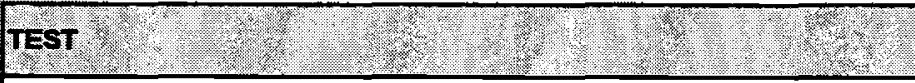 & IPASSIFAIL & $\begin{array}{l}\text { MUTERTCAL } \\
\text { RESULT }\end{array}$ \\
\hline 1. Assay $99.0 \% \mathrm{~min}$ & PASS & $99.7 \%$ \\
\hline 2. Insoluble $0.005 \%$ & PASS & $<0.005 \%$ \\
\hline 3. $\mathrm{pH}$ of $5 \%$ solution $4.5-8.5 @ 25 \mathrm{C}$ & PASS & 5.8 \\
\hline 4. Chloride $0.002 \%$ & PASS & $<0.002 \%$ \\
\hline 5. lodate $0.0005 \%$ & PASS & $<0.0005 \%$ \\
\hline 6. Nitrite $0.001 \%$ & PASS & $<0.001 \%$ \\
\hline 7. Phosphate $0.0005 \%$ & PASS & $<0.0005 \%$ \\
\hline 8 . Sulfate $0.003 \%$ & PASS & $<0.003 \%$ \\
\hline 9. Calcium $0.005 \%$ & PASS & $<0.005 \%$ \\
\hline 10. Magnesium $0.002 \%$ & PASS & $<0.002 \%$ \\
\hline 11. Heavy metals (as Pb) $0.0005 \%$ & PASS & $<0.0005 \%$ \\
\hline 12. Iron $0.0003 \%$ & PASS & $<0.0003 \%$ \\
\hline 13. Sodium $0.005 \%$ & PASS & $<0.005 \%$ \\
\hline
\end{tabular}

TRACEABLE TON.I.S.T. (Y/N)?Y

Comment:

Reported by

Date: $3 / 28 / 2003$

QC Supervisor: Joan Plowman

Retest Date: 24 Month after shipment 


\begin{tabular}{|c|c|c|c|c|}
\hline \multirow{2}{*}{\multicolumn{2}{|c|}{$\begin{array}{l}\text { Fisher Scientific Company } \\
\text { Chomical Manufacturing Division }\end{array}$}} & \multicolumn{3}{|c|}{ Certificate of Analysis } \\
\hline & & \multirow{2}{*}{\multicolumn{3}{|c|}{ 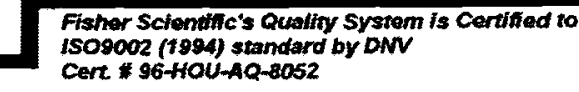 }} \\
\hline \multirow{2}{*}{\multicolumn{4}{|c|}{ Cert $* 96+10 U-A Q-8052$}} & \\
\hline \multicolumn{3}{|l|}{ Fairlawn, NJ 07410} & & \\
\hline \multicolumn{5}{|c|}{ Phone: (201) 796-7100 Fax (201) 796-1329 } \\
\hline Catalog Number 5392 & & Report Date & Mfg. Date & $7 / 23 / 03$ \\
\hline Lot Number & & Sample id & $\$ 392.035270 .00 S$ & \\
\hline Description & DROXIOE NF/FC & CIEP/BP/JP & & \\
\hline \multicolumn{5}{|c|}{ 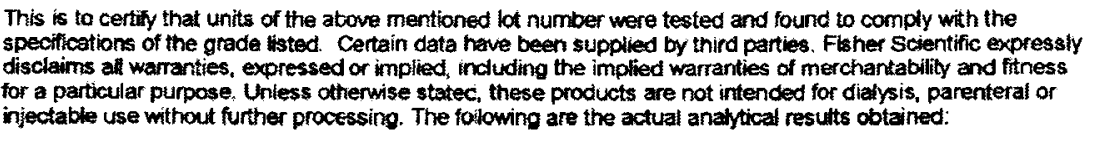 } \\
\hline Result Name & Specifications & & Units & Test value \\
\hline APPEARANCE & White Pellets & & REPORT & WHITE PELLETS \\
\hline \multicolumn{5}{|c|}{ National Formulary Requirements: } \\
\hline ASSAY & $95.0-100.5$ & & $\%$ & 99.6000 \\
\hline ENDOTOXIN TESTING & Report & & EU/g & $<0.4$ \\
\hline HEAWY METALS(AS Pb) & 0.003 Maxmun & & $\%$ & 0.0020 \\
\hline IDENTIFICATION & Pass test & & PASSFALL & PASS \\
\hline $\begin{array}{l}\text { INSOLUBLE SUBSTANCES \& } \\
\text { ORGANIC MATTER }\end{array}$ & Pass test & & PASSAFAIL & PASS \\
\hline POTASSIUM & Pass test & & PASSIFAIL & PASS \\
\hline SODIUM CARBONATE & 3.0 Maximum & & $\%$ & 0.100 \\
\hline \multicolumn{5}{|l|}{ FCC Requirements: } \\
\hline ARSENIC (AS) & 3 Maximum & & mgikg & 3 \\
\hline ASSAY - FCC & $95.0 \cdot 100.5$ & & $\%$ & 99.6 \\
\hline CARBONATE (as Na2CO3) & 30 Maximum & & $\%$ & 0.1 \\
\hline HEAW METALS.FCC & 0.002 Maximur & & $\%$ & 0.002 \\
\hline IDENTIFICATION - FCC & Pass test & & PASSFALL & PASS \\
\hline INSOL SUBT \& ORG MAT & Pass test & & PASSFALL & PASS \\
\hline LEAD & 10 Maximum & & $m g / k g$ & 1 \\
\hline MERCURY $(+g)$ & 0.1 Maximum & & mo/kg & 0.1 \\
\hline
\end{tabular}

CERTHED BY

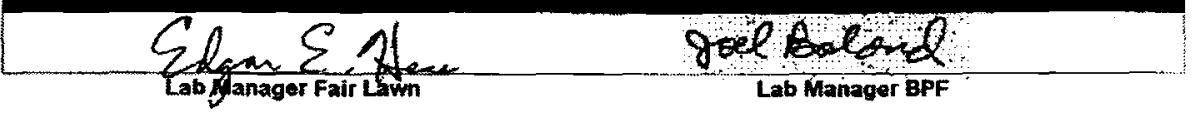

Note: The data listed is valid for all package sizes of this lot of product, expressed as a extension of the cataiog number Histed above. If there are any questions with this centificate, please call Chemical Services at (800) $227-6701$ 


\section{Fisher Scientific Company Chemical Manufacturing Division

\begin{tabular}{|l|}
\hline Certificate of Analysis \\
\hline Fisher Scientific's Queliny System is Certined to \\
(So9002 (1994) standard by DWV \\
Cort
\end{tabular} \\ 1 Reagent Lane \\ Cert. : 96-HOU-AQ-8052 \\ Fairlawn, NJ 07410 \\ Phone: (201) 796-7100 Fax: (201) 796-1329}

\begin{tabular}{|c|c|c|c|c|}
\hline Catalog Number 5392 & & Report Date & Mfg. Date & $7 / 2303$ \\
\hline Lot Number & & Sample ID & $\$ 392.035270 .00 S$ & \\
\hline Description & DROXIDE NFAC & CC/EP/BP/JP & & \\
\hline \multicolumn{5}{|c|}{ 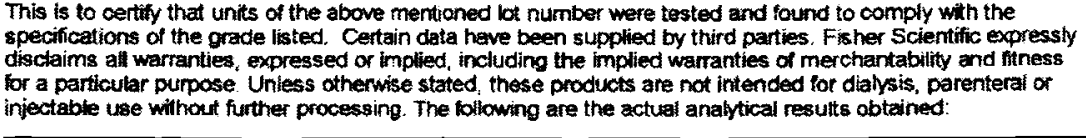 } \\
\hline Result Name & Specifications & & Units & Value \\
\hline \multicolumn{5}{|c|}{ European Pharmacopoeia Requirements: } \\
\hline APPEARANCE OF SOLN & Pass test & & PASS/FAIL & PASS \\
\hline ASSAY & $97.0-100.5$ & & $\%$ & 98.8 \\
\hline CARBONATE & 2.0 Maximum & & $\%$ & 0.6 \\
\hline CHLORIDE & 50 Maximum & & PPM & 17 \\
\hline Bacterial Endotoxins & Report & & Eurg & $\$ 0.4$ \\
\hline HEAW METALS & 20 Maximum & & PPM & 7 \\
\hline IDENTIFICATION & Pass test & & PASSFALL & PASS \\
\hline IRON & 10 Maximum & & PPM & 3 \\
\hline SULFATE & 50 Maximum & & PPM & 13 \\
\hline \multicolumn{5}{|c|}{ British Pharmacopooia Requirements: } \\
\hline APPEARANCE OF SOLN & Pass test & & PASSIFALL & PASS \\
\hline ASSAY & $97.0 \cdot 100.5$ & & $\%$ & 98.8 \\
\hline CARBONATE & 2.0 Maximum & & $\%$ & 0.6 \\
\hline CHLORIDE & 50 Maximum & & PPM & 17 \\
\hline HEAW METALS & 20 Maximum & & PPM & 7 \\
\hline IDENTIFICATION & Pass test: & & PASSIFAlL & PASS \\
\hline IRON & 10 Maximum & & PPM & 3 \\
\hline SULFATE & 50 Maximum & & PPM & 13 \\
\hline
\end{tabular}

CERTFHED BY

Note: The data listed is valid for all package sizes of this lot of product, expressed as a extension of the cetalog number Isted above. If there are any questions with this certificate, please call Chemical Services at (800) $227-6701$ 


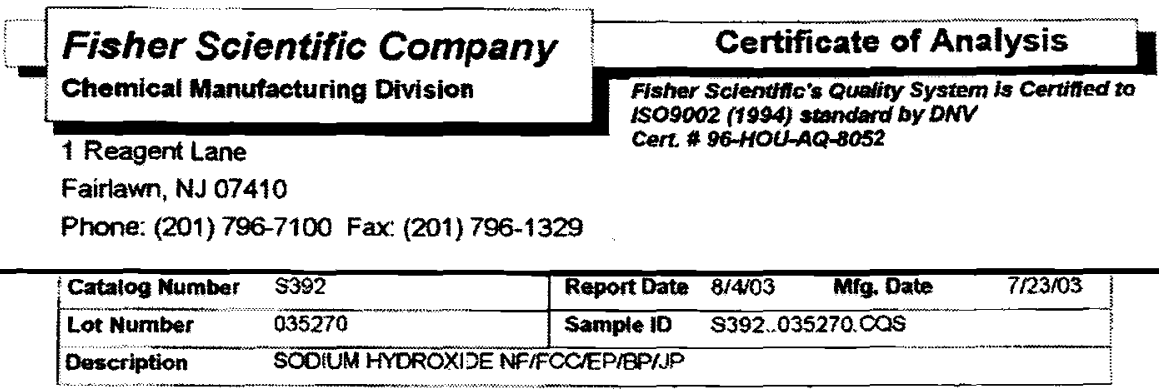

This is to certify that units of the atove mentioned lot number were tested and found to comply with the specifications of the grade listed. Certain data have been supptied by thirc parties. Fisher Scientific expressily disclains all wartanties, expressed of impled, including the moled warrantes of merchantability and mes for a particutar purpose. Untess ohermse stated, these products are not intended for dialysis, parenteral or injectable use without further processing. The following are the actual analytical results obtained:

\begin{tabular}{lllr}
\hline Result Name & Spectications & Units & Test Value \\
appearance of solution & Pass test & PASSIFAlL & PASS \\
ASSAY & 95.0 Minimum & $\%$ & 97.8 \\
SODIUM CARBONATE & 2.0 Maximum & $\%$ & 1.6 \\
CHLORIDE & 0.050 Maxmum & $\%$ & 0.004 \\
HEAW METALS & 30 Maximum & PPM & 8 \\
IDENTIFICATION & Pass test & PASSIFAIL & PASS \\
MERCURY & Pass test & PASS/FAIL & PASS \\
POTASSIUM & Pass test & PASSFALL & PASS
\end{tabular}

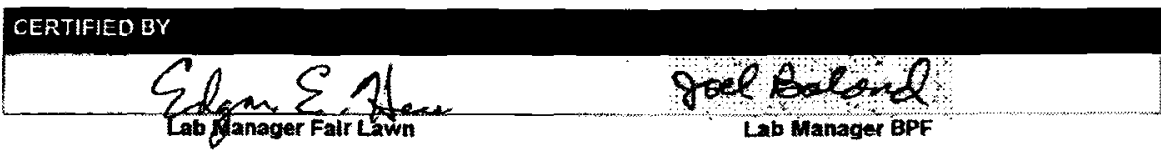

Note: The data listed is valid for all package sizes of this lot of product, expressed as a extension of the catatog number listed above. If there are eny questions with this certificate, please call Chemical Services at (800) 2276701 
RPP-RPT-37505, Rev. 0

GFS Chemicals, Inc.

Columbus, Ohio 43223

\section{LOT ANALYSIS}

ITEM: 1031 SODIUM FLUORIDE, REAGENT (ACS)

\section{LOT\#: L239673}

\begin{tabular}{|l|c|c|}
\hline TEST & PASSFAIL & $\begin{array}{l}\text { NUMERICAL } \\
\text { RESULT }\end{array}$ \\
\hline 1. Assay $99 \% \mathrm{~min}$. & PASS & $101.5 \%$ \\
\hline 2. Insoluble $0.02 \%$ & PASS & $<0.02 \%$ \\
\hline 3. Loss on drying @ $150 \mathrm{C} 0.3 \%$ & PASS & $0.2 \%$ \\
\hline 4. Chloride $0.005 \%$ & PASS & $<0.005 \%$ \\
\hline 5. Titrabie acid $0.03 \mathrm{meq} / \mathrm{g}$ & PASS & $<0.03 \mathrm{meq} / \mathrm{g}$ \\
\hline 6. Titrable base $0.01 \mathrm{meq} / \mathrm{g}$ & PASS & $<0.01 \mathrm{me} / \mathrm{g}$ \\
\hline 7. Sodium fluosilicate $0.1 \%$ & PASS & $<0.1 \%$ \\
\hline 8. Sulfate $0.03 \%$ & PASS & $<0.03 \%$ \\
\hline 9. Sulfite $0.005 \%$ & PASS & $<0.005 \%$ \\
\hline 10. Heavy metals (as Pb) $0.003 \%$ & PASS & $<0.003 \%$ \\
\hline 11. Iron $0.003 \%$ & PASS & $<0.003 \%$ \\
\hline 12. Potassium $0.02 \%$ & PASS & $<0.02 \%$ \\
\hline
\end{tabular}

TRACEABLE TON.I.S.T. (Y/N)?Y

Comment:

Reported by:

Date: $3 / 13 / 2002$

QC Supervisor: Joan Plowman

Retest Date: 24 Month after shipment 
RPP-RPT-37505, Rev. 0

GFS Chemicals, Inc.

Columbus, Ohio 43223

ITEM: 682 BUFFER SOLUTION, pH 10.00

LOT ANALYSIS

LOT\#: P676271

\begin{tabular}{|c|c|c|c|}
\hline 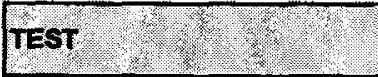 & (lo & PASSIFAIL & $\begin{array}{l}\text { WUMERICAL } \\
\text { RESULT }\end{array}$ \\
\hline 1. $\mathrm{pH}(@ 25 \mathrm{C}) 10.00+/ .0 .01$ & & PASS & 10.01 \\
\hline 2. NIST Traceable & & PASS & As Statec \\
\hline
\end{tabular}

TRACEABLE TON.I.S.T. (Y/N)? Y

\section{Comment:}

Reported by: Nicholas E. Dangler

QC Supervisor: Joan Plowman
Date: $6 / 20 / 2006$

Retest Date: 6/20/2008

GFS Chemicals, Inc.

Columbus, Ohio 43223

ITEM: 681 BUFFER SOLUTION, PH 7.00

LOT ANALYSIS

LOT\#: P678527

\begin{tabular}{|l|c|c|}
\hline TEST & PASSIFAIL & NUMERICAL \\
\hline RESULT
\end{tabular}

TRACEABLE TO N.I.S.T. (Y/N)? Y

Comment:

Reported by: Robert Kramer

Date: $10 / 3 / 2006$

QC Supervisor: Joan Hlowman

Retest Date: 10/3/2008 
RPP-RPT-37505, Rev. 0

GFS Chemicals, Inc.

Columbus, Ohio 43223

LOT ANALYSIS

ITEM: 1031 SODIUM FLUORIDE, REAGENT (ACS)

LOT\#: P676464

\begin{tabular}{|c|c|c|}
\hline TEST & PASSIFAIL & $\begin{array}{l}\text { NUMERICAL } \\
\text { RESULT }\end{array}$ \\
\hline 1. Assay $99 \% \mathrm{~min}$. & PASS & $99.24 \%$ \\
\hline 2. Insoluble $0.02 \%$ & PASS & $0.0057 \%$ \\
\hline 3. Loss on drying @ $150 \mathrm{C} 0.3 \%$ & PASS & $0.042 \%$ \\
\hline 4. Chloride $0.005 \%$ & PASS & $0.003 \%$ \\
\hline 5. Titrable acid $0.03 \mathrm{meq} / \mathrm{g}$ & PASS & $<0.03 \mathrm{meg} / \mathrm{g}$ \\
\hline 6. Titrable base $0.01 \mathrm{meq} / \mathrm{g}$ & PASS & $0.004 \mathrm{meg} / \mathrm{g}$ \\
\hline 7. Sodium fluosilicate $0.1 \%$ & PASS & NIL \\
\hline 8. Sulfate $0.03 \%$ & PASS & $0.02 \%$ \\
\hline 9. Sulfite $0.005 \%$ & PASS & $0.0035 \%$ \\
\hline 10. Heavy metals (as Pb) $0.003 \%$ & PASS & $0.0025 \%$ \\
\hline 11. Iron $0.003 \%$ & PASS & $0.0024 \%$ \\
\hline 12. Potassium $0.02 \%$ & PASS & $0.0049 \%$ \\
\hline
\end{tabular}


RPP-RPT-37505, Rev. 0

GFS Chemicals, Inc.

Columbus, Ohio 43223

LOT ANALYSIS

ITEM: 630 SODIUM HYDROXIDE, REAGENT (ACS)

LOT\#: P780673

\begin{tabular}{|c|c|c|}
\hline $\operatorname{mst}$ & PassfFAl & 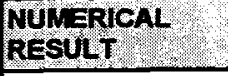 \\
\hline 1. Assay $97.0 \% \min$ & PASS & $99.4 \%$ \\
\hline 2. Sodium carbonate $1.0 \% \max$ & PASS & $0.93 \%$ \\
\hline 3. Chloride $0.005 \%$ & PASS & $<0.005 \%$ \\
\hline 4. Nitrogen compounds (N) $0.001 \%$ & PASS & $<0.001 \%$ \\
\hline 5. Phosphate $0.001 \%$ & PASS & $<0.001 \%$ \\
\hline 6. Sulfate $0.003 \%$ & PASS & $<0.003 \%$ \\
\hline 7. Heavy metals (as Ag) $0.002 \%$ & PASS & $<0.002 \%$ \\
\hline 8. Iron $0.001 \%$ & PASS & $<0.0005 \%$ \\
\hline 9. Mercury $0.00001 \%$ & PASS & $<0.00001 \%$ \\
\hline 10. Nickel $0.001 \%$ & PASS & $<0.0002 \%$ \\
\hline 11. Calcium $0.005 \%$ & PASS & $<0.0005 \%$ \\
\hline 12. Magnesium $0.002 \%$ & PASS & $<0.0002 \%$ \\
\hline 13. Potassium $0.02 \%$ & PASS & $<0.02 \%$ \\
\hline
\end{tabular}

TRACEABLE TO N.I.S.T. (Y/N)? Y

Comment:

Reported by: Robert Kramer

QC Supervisor: Joan Plowman
Date: $1 / 31 / 2007$

Retest Date: $1 / 31 / 2012$ 
GFS Chemicals, Inc

Columbus, Ohio 43223

LOT ANALYSIS

ITEM: 705 SODIUM CARBONATE, ANHYDROUS, POWDER, REAGENT (ACS)

LOT\#: P781010

\begin{tabular}{|l|c|c|}
\hline TEST & PASSFAL & $\begin{array}{c}\text { NUMERICAL } \\
\text { RESULT }\end{array}$ \\
\hline 1. Assay $99.5 \% \mathrm{~min}$ & PASS & $99.99 \%$ \\
\hline 2. Insoluble $0.01 \%$ & PASS & $0.004 \%$ \\
\hline 3. Loss on heating at $285 \mathrm{C} 1.0 \% \max$ & PASS & $0.2 \%$ \\
\hline 4. Chloride $0.001 \%$ & PASS & $0.0004 \%$ \\
\hline 5. Phosphate $0.001 \%$ & PASS & $0.0003 \%$ \\
\hline 6. Silica $0.005 \%$ & PASS & $0.001 \%$ \\
\hline 7. Sulfur compounds (as SO4) $0.003 \%$ & PASS & $0.0009 \%$ \\
\hline 8. Heavy metals $(\mathrm{Pb}) 0.0005 \%$ & PASS & $0.0003 \%$ \\
\hline 9. Iron $0.0005 \%$ & PASS & $0.0003 \%$ \\
\hline 10. Calcium $0.03 \%$ & PASS & $0.005 \%$ \\
\hline 11. Magnesium $0.005 \%$ & PASS & $0.002 \%$ \\
\hline 12. Potassium $0.005 \%$ & PASS & $0.002 \%$ \\
\hline
\end{tabular}

TRACEABLE TON.I.S.T. (Y/N)?Y

Comment:

Reported by: Joan E Plowman

Date: $2 / 20 / 2007$

QC Supervisor: Joan Plowman

Retest Date: 2/20/2012 
RPP-RPT-37505, Rev. 0

GFS Chermicals, Inc.

Columbus, Ohio 43223

LOT ANALYSIS

ITEM: 1099 SODIUM OXALATE, REAGENT (ACS)

LOT\#: P568829

\begin{tabular}{|c|c|c|}
\hline TEST VP & PASSIFAIL: & $\begin{array}{l}\text { NUMERICAL } \\
\text { RESULT }\end{array}$ \\
\hline 1. Assay $99.5 \% \min$ & PASS & $101.8 \%$ \\
\hline 2. Insoluble $0.005 \%$ & PASS & $<0.005 \%$ \\
\hline 3. Loss on drying @ $105 \mathrm{C} 0.01 \%$ & PASS & $0.004 \%$ \\
\hline 4. Neutrality - Pass Test & PASS & Passes Test \\
\hline 5. Chloride $0.002 \%$ & PASS & $<0.002 \%$ \\
\hline 6. Sulfate $0.002 \%$ & PASS & $<0.002 \%$ \\
\hline 7. Ammonium $0.002 \%$ & PASS & $<0.002 \%$ \\
\hline 8. Heavy metals $(\mathrm{Pb}) 0.002 \%$ & PASS & $<0.002 \%$ \\
\hline 9. Iron $0.001 \%$ & PASS & $<0.0001 \%$ \\
\hline 10. Potassium $0.005 \%$ & PASS & $<0.002 \%$ \\
\hline 11. Substances darkened by $\mathrm{H} 2 \mathrm{SO} 4$ pass test & PASS & Passes Test \\
\hline
\end{tabular}

TRACEABLE TO N.IS.T. (Y/N)? Y

Comment:

Reported by: Kenneth L. Shafer

Date: 9/15/2005

QC Supervisor: Joan Plowman

Retest Date: 9/15/2010 
RPP-RPT-37505, Rev. 0

GFS Chemicals, Inc.

Columbus, Ohio 43223

LOT ANALYSIS

ITEM: 658 SODIUM NITRATE, REAGENT (ACS)

LOT\#: L136875

\begin{tabular}{|l|c|c|}
\hline TEST & $\begin{array}{c}\text { PASSIFAIL } \\
\text { PUNERICAL }\end{array}$ \\
\hline RESULT
\end{tabular}

TRACEABLE TO N.I.S.T. (Y/N)? Y

\section{Comment:}

Reported by: Kenneth L. Shafer

QC Supervisor: Joan Plowman
Date: $9 / 24 / 2001$

Retest Date: 24 Month after shipment 
RPP-RPT-37505, Rev. 0

GFS Chemicals, Inc.

Columbus, Ohio 43223

\section{LOT ANALYSIS}

ITEM: 655 POTASSIUM NITRATE, REAGENT (ACS)

LOT\#: L346711

\begin{tabular}{|l|c|c|}
\hline TEST & PASSIFAIL & $\begin{array}{l}\text { NUN } \\
\text { RESULT }\end{array}$ \\
\hline 1. Assay $99.0 \% \mathrm{~min}$ & PASS & $99.7 \%$ \\
\hline 2. Insoluble $0.005 \%$ & PASS & $<0.005 \%$ \\
\hline 3. pH of $5 \%$ solution $4.5-8.5$ @ 25C & PASS & 5.8 \\
\hline 4. Chloride $0.002 \%$ & PASS & $<0.002 \%$ \\
\hline 5. lodate $0.0005 \%$ & PASS & $<0.0005 \%$ \\
\hline 6. Nitrite $0.001 \%$ & PASS & $<0.001 \%$ \\
\hline 7. Phosphate $0.0005 \%$ & PASS & $<0.0005 \%$ \\
\hline 8. Sulfate $0.003 \%$ & PASS & $<0.003 \%$ \\
\hline 9. Calcium $0.005 \%$ & PASS & $<0.005 \%$ \\
\hline 10. Magnesium $0.002 \%$ & PASS & $<0.002 \%$ \\
\hline 11. Heavy metals (as Pb) $0.0005 \%$ & PASS & $<0.0005 \%$ \\
\hline 12. Iron $0.0003 \%$ & PASS & $<0.0003 \%$ \\
\hline 13. Sodium $0.005 \%$ & PASS & $<0.005 \%$ \\
\hline
\end{tabular}

TRACEABLE TON.I.S.T. (Y/N)? Y

Comment:

Reported by:

Date: $3 / 28 / 2003$

QC Supervisor: Joan Plowman

Retest Date: 24 Month after shipment 
RPP-RPT-37505, Rev. 0

GFS Chemicals, Inc.

Columbus, Ohio 43223

LOT ANALYSIS

ITEM: 704 SODIUM BICARBONATE, REAGENT (ACS)

LOT\#: P459685

\begin{tabular}{|l|c|c|}
\hline TEST: & PASSIFAIL & $\begin{array}{l}\text { NUIERICAL } \\
\text { RESULT }\end{array}$ \\
\hline 1. Assay (dried basis) $99.7-100.3 \%$ & PASS & $99.9 \%$ \\
\hline 2. Insoluble $0.015 \%$ & PASS & $<0.015 \%$ \\
\hline 3. Chloride $0.003 \%$ & PASS & $<0.003 \%$ \\
\hline 4. Phosphate $0.001 \%$ & PASS & $<0.001 \%$ \\
\hline 5. Sulfur compounds (as SO4) $0.003 \%$ & PASS & $<0.003 \%$ \\
\hline 6. Ammonium $0.0005 \%$ & PASS & $<0.0005 \%$ \\
\hline 7. Calcium $0.02 \%$ & PASS & $0.004 \%$ \\
\hline 8. Magnesium $0.005 \%$ & PASS & $<0.001 \%$ \\
\hline 9. Heavy metals (as Pb) $0.0005 \%$ & PASS & $<0.0005 \%$ \\
\hline 10. Iron $0.001 \%$ & PASS & $0.0001 \%$ \\
\hline 11. Potassium $0.005 \%$ & PASS & $<0.003 \%$ \\
\hline
\end{tabular}

TRACEABLE TON.I.S.T. (Y/N)?Y

Comment:

Reported by: Kenneth L. Shafer

Date: $9 / 29 / 2004$

QC Supervisor: Joan Plowman

Retest Date: 9/29/2009 
RPP-RPT-37505, Rev. 0

GFS Chemicals, Inc.

Columbus, Ohio 43223

LOT ANALYSIS

ITEM: 559 SODIUM NITRITE, REAGENT (ACS)

LOT\#: P677335

\begin{tabular}{|l|c|c|}
\hline TEST & PASSIFAI & $\begin{array}{l}\text { NUNERICAL } \\
\text { RESULT }\end{array}$ \\
\hline 1. Assay $97.0 \%$ min. & PASS & $98.2 \%$ \\
\hline 2. Chloride $0.005 \%$ & PASS & $<0.005 \%$ \\
\hline 3. Sulfate $0.01 \%$ & PASS & $<0.01 \%$ \\
\hline 4. Calcium $0.01 \%$ & PASS & $<0.001 \%$ \\
\hline 5. Heavy metals (as Pb) $0.001 \%$ & PASS & $<0.001 \%$ \\
\hline 6. Iron $0.001 \%$ & PASS & $<0.001 \%$ \\
\hline 7. Potassium $0.005 \%$ & PASS & $<0.001 \%$ \\
\hline 8. Insoluble $0.01 \%$ & PASS & $<0.01 \%$ \\
\hline 9. pH of $5 \%$ solution $5.5-8.3$ @ 25 C & PASS & 8.0 \\
\hline 10. Appearance - White to pale yellow & PASS & pale yellow \\
\hline
\end{tabular}

TRACEABLE TO N.I.S.T. (Y/N)? Y

Comment:

Reported by: Jon Brandon Kennedy

Date: $7 / 31 / 2007$

QC Supervisor: Joan Plowman

Retest Date: 8/2/2011 
RPP-RPT-37505, Rev. 0

GFS Chemicals, Inc.

Columbus, Ohio 43223

LOT ANALYSIS

ITEM: 2454 SODIUM SULFATE, ANHYDROUS, POWDER, REAGENT (ACS)

LOT\#: P785319

\begin{tabular}{|l|c|c|}
\hline TEST & PASSFAIL & $\begin{array}{l}\text { NUMERICAL } \\
\text { RESULT }\end{array}$ \\
\hline 1. Assay $99.0 \%$ min. & PASS & $99.1 \%$ \\
\hline 2. pH of $5 \%$ solution @ 25C 5.2-9.2 & PASS & 6.0 \\
\hline 3. Insoluble matter $0.01 \%$ & PASS & $<0.01 \%$ \\
\hline 4. Loss on ignition $0.5 \%$ & PASS & $<0.5 \%$ \\
\hline 5. Chloride $0.001 \%$ & PASS & $<0.001 \%$ \\
\hline 6. Nitrogen compounds (as N) $0.0005 \%$ & PASS & $<0.0005 \%$ \\
\hline 7. Phosphate $0.001 \%$ & PASS & $<0.001 \%$ \\
\hline 8. Calcium $0.01 \%$ & PASS & $<0.001 \%$ \\
\hline 9. Magnesium $0.005 \%$ & PASS & $<0.0005 \%$ \\
\hline 10. Heavy metals (as Pb) $0.0005 \%$ & PASS & $<0.0005 \%$ \\
\hline 11. Iron $0.001 \%$ & PASS & $<0.0001 \%$ \\
\hline 12. Potassium $0.01 \%$ & PASS & $0.001 \%$ \\
\hline
\end{tabular}

TRACEABLE TO N.IS.T. (Y/N)? Y

Comment:

Reported by: Robert Kramer

Date: $1 / 31 / 2008$

QC Supervisor: Joan Plowman

Retest Date: 9/17/2012 
RPP-RPT-37505, Rev. 0

GFS Chemicals, Inc.

Columbus, Ohio 43223

LOT ANALYSIS

ITEM: 107§̊ SODIUM CHROMATE, TETRAHYDRATE, REAGENT

LOT\#: P568182

\begin{tabular}{|l|c|c|}
\hline TEST & PASSIFAIL & $\begin{array}{c}\text { MUNERICAL } \\
\text { RESULT }\end{array}$ \\
\hline 1. Assay $99.0-102.0 \%$ & PASS & $100.9 \%$ \\
\hline 2. Insoluble $0.005 \%$ & PASS & $<0.005 \%$ \\
\hline 3. pH of $5 \%$ solution $8.0-9.5$ & PASS & 9.1 \\
\hline 4. Chloride $0.005 \%$ & PASS & $<0.005 \%$ \\
\hline 5. Sulfate $0.01 \%$ & PASS & $<0.01 \%$ \\
\hline 6. Aluminum $0.002 \%$ & PASS & $<0.002 \%$ \\
\hline 7. Calcium $0.005 \%$ & PASS & $<0.005 \%$ \\
\hline
\end{tabular}

TRACEABLE TO N.I.S.T. (YN)?Y

Comment:

Reported by: Nicholas E. Dangler

Date: $1 / 31 / 2008$

QC Supervisor: Joan Plowman

Retest Date: 8/16/2010 
GFS Chemicals, Inc.

Columbus, Ohio 43223

\section{LOT ANALYSIS}

ITEM: 1035 SODIUM PHOSPHATE, TRIBASIC, DODECAHYDRATE, REAGENT (ACS)

LOT\#: P678823

\begin{tabular}{|l|c|c|}
\hline TEST. & PASSIFAIL & $\begin{array}{l}\text { NuM } \\
\text { RESICAL }\end{array}$ \\
\hline 1. Assay $98.0-102.0 \%$ & PASS & $101.4 \%$ \\
\hline 2. Excess alkali $(\mathrm{NaOH}) 2.5 \%$ & PASS & $1.0 \%$ \\
\hline 3. Insoluble $0.01 \%$ & PASS & $<0.01 \%$ \\
\hline 4. Chloride $0.001 \%$ & PASS & $<0.001 \%$ \\
\hline 5. Sulfate $0.01 \%$ & PASS & $<0.01 \%$ \\
\hline 6. Heavy metals (as Pb) $0.001 \%$ & PASS & $<0.001 \%$ \\
\hline 7. Iron $0.001 \%$ & PASS & $<0.001 \%$ \\
\hline
\end{tabular}

TRACEABLE TO N.I.S.T. (YIN)?Y

Comment:

Reported by: Kenneth L. Shafer

Date: $1 / 31 / 2008$

QC Supervisor: Joan Plowman

Retest Date: 10/22/2011 
GFS Chemicals, Inc.

Columbus, Ohio 43223

LOT ANALYSIS

ITEM: 705 SODIUM CARBONATE, ANHYDROUS, POWDER, REAGENT (ACS)

LOT\#: P784287

\begin{tabular}{|c|c|c|}
\hline TEST & PASSIFAIL & $\begin{array}{l}\text { MUNE ERTOAL } \\
\text { RESULT? }\end{array}$ \\
\hline 1. Assay $99.5 \% \min$ & PASS & $99.99 \%$ \\
\hline 2. Insoluble $0.01 \%$ & PASS & $<0.01 \%$ \\
\hline 3. Loss on heating at $285 \mathrm{C} 1.0 \% \max$ & PASS & $<1.0 \%$ \\
\hline 4. Chloride $0.001 \%$ & PASS & $<0.001 \%$ \\
\hline 5. Phosphate $0.001 \%$ & PASS & $<0.001 \%$ \\
\hline 6. Silica $0.005 \%$ & PASS & $<0.005 \%$ \\
\hline 7. Sulfur compounds (as SO4) $0.003 \%$ & PASS & $<0.003 \%$ \\
\hline 8. Heavy metals (Pb) $0.0005 \%$ & PASS & $<0.0005 \%$ \\
\hline 9. Iron $0.0005 \%$ & PASS & $<0.0005 \%$ \\
\hline 10. Calcium $0.03 \%$ & PASS & $<0.03 \%$ \\
\hline 11. Magnesium $0.005 \%$ & PASS & $0.005 \%$ \\
\hline 12. Potassium $0.005 \%$ & PASS & $<0.005 \%$ \\
\hline
\end{tabular}

TRACEABLE TON.I.S.T. (Y/N)? Y

Comment:

Reported by: Joan Plowman

QC Supervisor: Joan Plowman
Date: $2 / 1 / 2008$

Retest Date: 7/24/2012 
RPP-RPT-37505, Rev. 0

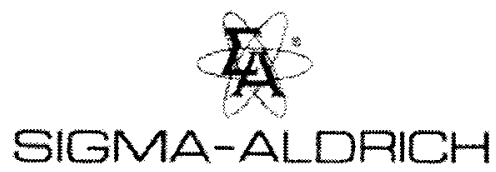

\section{Certificate Analysis}

Product Name
Product Number
Product Brand
CAS Number
Molecular Formula
Molecular Weight

TEST

APPEARANCE

TITRATION

TRACE ANAL YSIS, ICP

ICP ASSAY

SOLUBILITY

PURITY

QUALITY CONTROL ACCEPT ANCE DATE

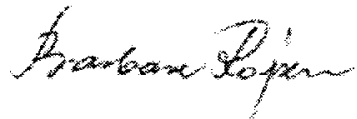

Barbara Rajzer, Supenisor Quality Control

Milwaukee, Wisconsin USA
}

\author{
Cerium (III) nitrate hexahydrate, \\ 99\% (metals basis) \\ 238538 \\ Aldrich \\ 10294-41-4 \\ $\mathrm{Ce}\left(\mathrm{NO}_{3}\right)_{3} \cdot 6 \mathrm{H}_{2} \mathrm{O}$ \\ 434.22 \\ SPECIFICATION \\ LOT 06703CO RESUL TS \\ MOIST WHITE TO OFF- \\ WHITE CRYSTALS MOIST WHITE CRYSTALS \\ AND/OR \\ $96.5 \%-103.5 \%$ (OR $31.1 \%-32.2 \%$ CE \\ $33.4 \% \mathrm{CE})$ \\ (COMPLEXOMETRIC) \\ B 192 PPM; \\ MG 11.4 PPM; \\ CA 6.5 PPM \\ CONFIRMS CERIUM CONFIRMS CERIUM \\ COMPONENT. \\ COMPONENT \\ $5 \%$ IN H2O; CLEAR, $5 \%$ IN H2O; CLEAR, \\ COLORLESS SOLUTION COLORLESS SOLUTION \\ PURITY BASED ON TRACE $>99 \%$ BASED ON TRACE \\ METAIS ANALYSIS METAL ANALYSIS \\ MARCH, 2004
}


RPP-RPT-37505, Rev. 0

GFS Chemicals, Inc.

Columbus, Ohio 43223

\section{LOT ANALYSIS}

ITEM: 619 SODIUM FORMATE, REAGENT (ACS)

LOT\#: P673902

\begin{tabular}{|c|c|c|}
\hline TEST & PASSIFAIL & $\begin{array}{l}\text { NUVERICAL } \\
\text { RESULT }\end{array}$ \\
\hline 1. Assay $99.0 \% \mathrm{~min}$. & PASS & $99.6 \%$ \\
\hline 2. Insoluble $0.005 \%$ & PASS & $<0.005 \%$ \\
\hline 3. Chloride $0.001 \%$ & PASS & $<0.001 \%$ \\
\hline 4. Sulfate $0.001 \%$ & PASS & $<0.001 \%$ \\
\hline 5. Calcium $0.005 \%$ & PASS & $<0.0005 \%$ \\
\hline 6. Heavy Metals (as Pb) $0.0005 \%$ & PASS & $<0.0005 \%$ \\
\hline 7. Iron $0.0005 \%$ & PASS & $<0.0005 \%$ \\
\hline
\end{tabular}

TRACEABLE TON.IS.T. (Y/N)? Y

Comment:

Reported by: Joan Plowman

Date: $2 / 4 / 2008$

QC Supervisor: Joan Plowman

Retest Date: 3/24/2011 
RPP-RPT-37505, Rev. 0

EMD

Certificate of Analysis

Emo Chemicals inc.

80 \$. Democrat Road

Gibbstown, NJ 08027

Fax 356-423-4389

Name:

Sodium Aluminate, Hydrated

Technical

Formula: $\mathrm{NaAlO}_{2} \mathrm{x+} \mathrm{H}_{2} \mathrm{O}$

hem Number: Sx0275/5

Formula nt: $81.97^{*}$

Lot Number: $\quad$ 4428154

Deta Order No: 000089318

\begin{tabular}{|c|c|c|c|c|}
\hline CHARACTERISTIC & RE & ENT & RESULTS & UNITS \\
\hline & Min. & Max. & & \\
\hline Assay (cont plexom stric) & 65.0 & & 78.5 & $\%$ \\
\hline Color & & & White & \\
\hline Fom & & & Granular powder & \\
\hline
\end{tabular}

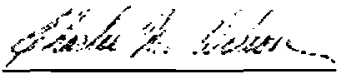

Charles M. Wilson.

Quality Assurance Manager

Release Date: 10/:32004

EMD Chemicals inc

(Formery EM Science, $A$ Division of $E M$ industries. Inc.)

An Affsidte of Metek KG *A, Darmstadt, Gerrn ari 
RPP-RPT-37505, Rev. 0

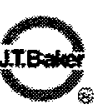

Certificate of Analysis

Product No. 3868 Sodium meta-Silicate, 9-Hydrate, Crystal 'BAKER ANALYZED' Reagent

Formula $\mathrm{NaSO}_{3} 9 \mathrm{H}_{2} \mathrm{O} \quad$ F.W. 28420

Relea se Date $09 / 28 / 2001$

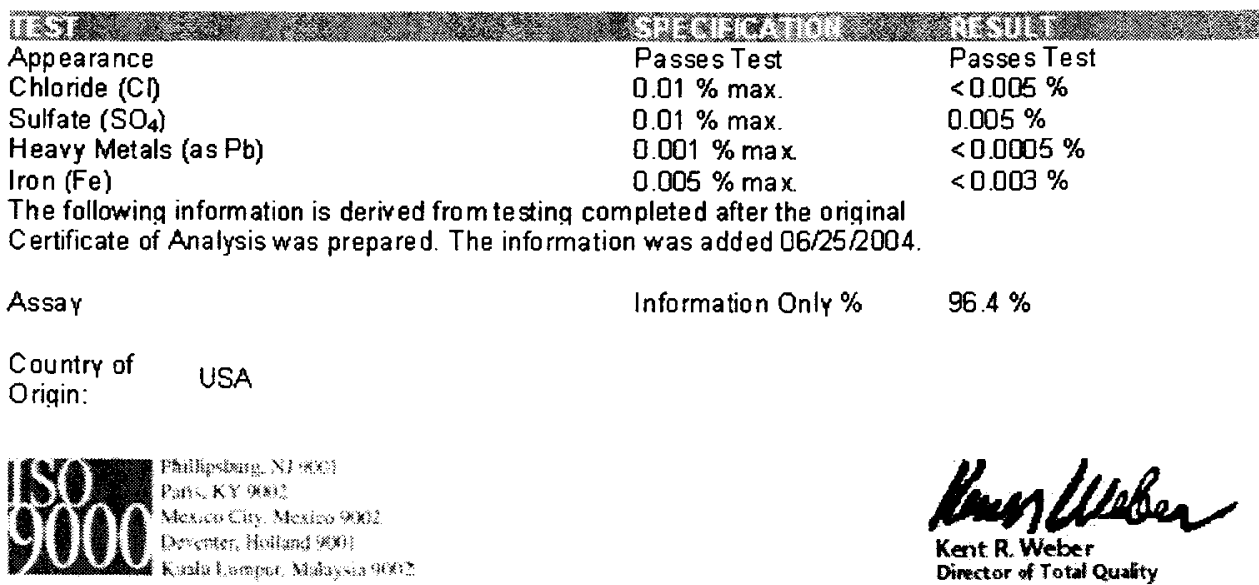

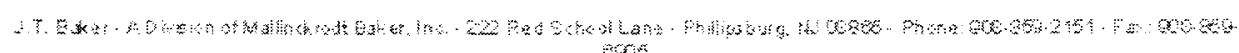
कs 
RPP-RPT-37505, Rev. 0

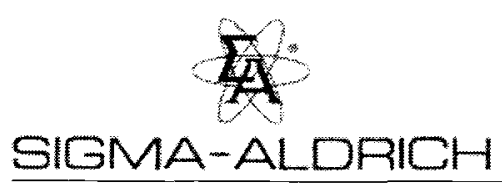

Certificate ofAnalysis

\begin{tabular}{|c|c|c|}
\hline Product Name & \multicolumn{2}{|l|}{$\begin{array}{l}\text { Glycolic acid solution, } \\
\text { technical grade, } 70 \text { wt. } \% \text { in } \mathrm{H}_{2} \mathrm{O}\end{array}$} \\
\hline Product Number & \multicolumn{2}{|l|}{420603} \\
\hline Product Brand & \multicolumn{2}{|l|}{ Aldrich } \\
\hline CAS Number & \multicolumn{2}{|l|}{$79-14-1$} \\
\hline Molecular Formula & \multicolumn{2}{|l|}{$\mathrm{HOCH}_{2} \mathrm{COOH}$} \\
\hline Molecular Weight & \multicolumn{2}{|l|}{76.05} \\
\hline TEST & SPECIFICATION & LOT 10915KD RESULTS \\
\hline APPEARANCE & $\begin{array}{l}\text { COLORLESS TO AMBER } \\
\text { LIQUD }\end{array}$ & COLORLESS LIQUID \\
\hline PROTON NMR SPECTRUM & $\begin{array}{l}\text { CONFORMS TO } \\
\text { STRUCTURE. }\end{array}$ & $\begin{array}{l}\text { CONFORMS TO } \\
\text { STRUCTURE. }\end{array}$ \\
\hline \multirow[t]{9}{*}{ VENDOR INFORMATION } & $\begin{array}{l}70.0 \%-72.0 \% \text { TOTAL ACID } \\
\text { AS GLYCOLIC ACD * }\end{array}$ & $\begin{array}{l}70.80 \% \text { TOTAL ACD AS } \\
\text { GLYCOLIC ACD * }\end{array}$ \\
\hline & $\begin{array}{l}3 \text { GARDNER COLOR } \\
\text { (MAXMMUM) * }\end{array}$ & $0.798 \%$ FORMIC ACD * \\
\hline & $<1 \%$ FORMIC ACID * & 1 GARDNER (COLOR) * \\
\hline & $\begin{array}{l}800 \text { PPM SO4 (MAXIMUM) } \\
\text { * }\end{array}$ & 111.2 PPM SULFATES * \\
\hline & 6.0 NTU (MAXIMUM) * & TURBIDITY: 0.55 NTU * \\
\hline & $\begin{array}{l}\text { *DUPONT } \\
\text { SPECIFICATION }\end{array}$ & PRODUCT OF DUPONT \\
\hline & $\begin{array}{l}\text { REVISED FEBRUARY } 15 . \\
2005 \text { RMM }\end{array}$ & PRODUCT OF DUPONT \\
\hline & $\begin{array}{l}\text { * DUPONT } \\
\text { SPECIFICATION }\end{array}$ & *SUPPLIER DATA \\
\hline & $\begin{array}{l}\text { REVISED FEBRUARY } 15 \text {, } \\
2005 \text { RMM }\end{array}$ & *SUPPLIER DATA \\
\hline CONTROL & & SEPTEMBER 2005 \\
\hline
\end{tabular}


RPP-RPT-37505, Rev. 0

$\not 2+6+2 y$

Barbara Rajzer, Supervisor Quality Control

Milwaukee, Wisconsin USA 
GFS Chemicals, Inc.

Columbus, Ohio 43223

LOT ANALYSIS

ITEM: 624 ACETIC ACID, GLACIAL, REAGENT (ACS)

LOT\#: P780790

\begin{tabular}{|c|c|c|}
\hline $\mathrm{TEST}$ & PASSIFALL & WUIVERICAL \\
\hline 1. Assay $99.7 \% \mathrm{~min}$. & PASS & $101.3 \%$ \\
\hline 2. Color (APHA) 10 max & PASS & $<10$ \\
\hline 3. Dilution Test Pass test & PASS & Passed Test \\
\hline 4. Residue after evaporation $0.001 \%$ & PASS & $0.0002 \%$ \\
\hline 5. Acetic Anhydride $0.01 \%$ & PASS & $<0.01 \%$ \\
\hline 6. Chloride $0.0001 \%$ & PASS & $<0.0001 \%$ \\
\hline 7. Sulfate $0.0001 \%$ & PASS & $<0.0001 \%$ \\
\hline 8. Heavy metals $0.00005 \%$ & PASS & $<0.00005 \%$ \\
\hline 9. Iron $0.00002 \%$ & PASS & $<0.00002 \%$ \\
\hline 10. Substances reducing dichromate-Pass test & PASS & Passed Test \\
\hline 11. Substances reducing permanganate-Pass test & PASS & Passed Test \\
\hline 12. Titrable base $0.0004 \mathrm{meq} / \mathrm{g}$ & PASS & $<0.0004 \mathrm{meq} / \mathrm{g}$ \\
\hline
\end{tabular}

TRACEABLE TO N.IS.T. (Y/N)? Y

Comment:

Reported by: Robert Kramer

QC Supervisor: Joan Plowman
Date: 2/4/2008

Retest Date: 2/12/2012 
RPP-RPT-37505, Rev. 0

GFS Chemicals, Inc.

Columbus, Ohio 43223

ITEM: 681 BUFFER SOLUTION, PH 7.00

LOT ANALYSIS

LOT\#: P678527

\begin{tabular}{|l|c|c|}
\hline TEST & PASSEAIL & $\begin{array}{l}\text { NUNERICAL } \\
\text { RESULT }\end{array}$ \\
\hline 1. $\mathrm{pH}(@ 25 \mathrm{C}) 7.00+1-0.01$ & PASS & 7.01 \\
\hline 2. NIST Traceable & PASS & AS Stated \\
\hline
\end{tabular}

TRACEABLE TON.I.S.T. (Y/N)?Y

Comment:

Reported by: Robert Kramer

Date: $2 / 4 / 2008$

QC Supervisor: Joan Plowman

Retest Date: 10/3/2008 
RPP-RPT-37505, Rev. 0

GFS Chemicals, Inc.

Columbus, Ohio 43223

ITEM: 682 BUFFER SOLUTION, pH 10.00

LOT ANALYSIS

LOT\#: P676271

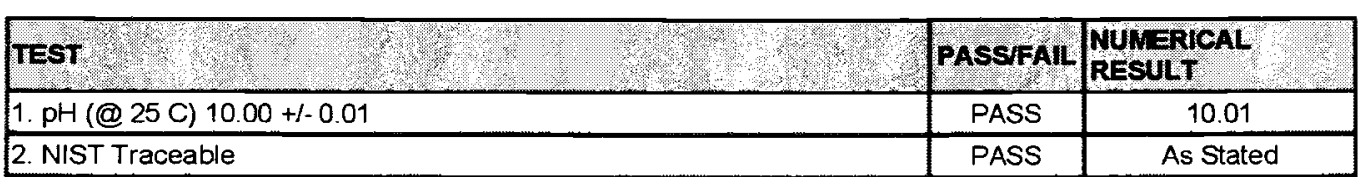

TRACEABLE TON.I.S.T. (Y/N)? Y

Comment:

Reported by: Nicholas E. Dangler

Date: $2 / 4 / 2008$

QC Supervisor: Joan Plowman

Retest Date: 6/20/2008 
RPP-RPT-37505, Rev. 0

\section{ARES Chem}

G F S CHEMICALS, INC.

LOT ANALYSIS

ITEA: 920 ETHYLENE GLYCOL, REAGENT

LOT\#: P783656

\begin{tabular}{|c|c|c|}
\hline TEST & $\begin{array}{l}\text { PASSi } \\
\text { FAIL }\end{array}$ & $\begin{array}{l}\text { NUMERICAL } \\
\text { RESULT }\end{array}$ \\
\hline 1. Boiling range $\overline{194-200 \mathrm{C}}$ & PASS & $194-200 \mathrm{C}$ \\
\hline 2. Specific gravity $20 \mathrm{C} \quad 1.115-1.116 \mathrm{~g} / \mathrm{ml}$ & PASS & 1.1151 \\
\hline 3. Acidity (CH3COOH) 0.018 & PASS & 0.00005 \\
\hline 4. Water 0.28 & RASS & $\overline{0.014}$ \\
\hline 5. Residue 0.0058 & PASS & $<0.005$ \\
\hline 6. Chloride 0.00058 & PASS & 0.00001 \\
\hline 7. Iron 0.000028 & PASS & $<0.00002$ \\
\hline
\end{tabular}

TRACEABLE TO N.I.S.T. $\{Y / N \mid ? N$

Comment:

Reported by: Silaja Nacharaju

C/A Print Date: $3 / 14 / 08$

QC Supervisor: Silaja Nacharajti

Quality Assured to Retest Point: 60 montins

from: shipment

Not for direct use in food, cosmetic or pharmaceuticals.

Consult warranty limitations at www.gfachemicals.con/terms asp.

For resale by GPS authorized distributors only. 
RPP-RPT-37505, Rev. 0

G F s chrmicats, IMC.

Columbus, Ohio 43222

LOT ANALYSIS

ITES: 658 SODTOM NTTRATE, REAGENT (ACS)

LOT\#: P786671

\begin{tabular}{|c|c|c|}
\hline TEST & $\begin{array}{l}\text { PASS/ } \\
\text { FAIL }\end{array}$ & $\begin{array}{l}\text { NUMERICAL } \\
\text { RESUIT }\end{array}$ \\
\hline 1. Assay 99.0 min. & PASS & $100.7 \%$ \\
\hline 2. $\overline{\mathrm{pH}}$ of 58 solution $\overline{5} . \overline{5}-8.3 \cdot \overline{25} \mathrm{C}$ & PASS & 6.2 \\
\hline 3. Insoluble 0.0058 & PASS & $<0.005 \%$ \\
\hline 4. Chloride $0.00 \overline{8}$ & PASS & $<0.001 \%$ \\
\hline 5. Todate 0.0005 & PASS & $<0.00058$ \\
\hline 6. Nitrite $0.001 \%$ & PASS & $<0.0018$ \\
\hline 7. Phosphate 0.0005 : & PASS & $<0.0005$ \\
\hline 8. Sulfate $0.003 \frac{1}{8}$ & PASS & $<0.003 \%$ \\
\hline 9. Calciun 0.0058 & $\overline{\text { DASS }}$ & $<0.0058$ \\
\hline 10. Magnesium $0.002 \%$ & PASS & $<0.0028$ \\
\hline 11. Heavy metals (Pb) 0.00058 & PASS & $<0.00058$ \\
\hline 12. Iron 0.00038 & PASS & $<0.0003 \%$ \\
\hline
\end{tabular}

TRACEABLE TO N.I.S.T, $(Y / N) ? X$

Comment:

Reported by: Robert Kramer

C/A Print Date: $3 / 19 / 08$

oc Supervisor: Joan Plowman

Quality Assured to Retest Foint: 60 months

Not for direct use in food, cosmetic or pharmaceuticals.

consult warranty limitations at ww.geschemicals, com/terms asp.

For resale by GFS authorized distributors only. 
o 5 cemcrcals, INC.

Columbus, Ohio 43222

LOT ANALYSTS

ITEM: 559 SODIUM NITRITE, REAGENT (ACS)

LOT\#: P786739

\begin{tabular}{|c|c|c|}
\hline TEST & $\begin{array}{l}\text { RASS/ } \\
\text { FAIL }\end{array}$ & $\begin{array}{l}\text { NUMERTCAE } \\
\text { RESULT }\end{array}$ \\
\hline 1. Assay $97.0 \%$ min. & PASS & $99.1 \%$ \\
\hline 2. Chloxide 0.005 & PASS & $<0.005$ \\
\hline 3. Sulfate $0.01 \%$ & PASS & $<0.01 \div$ \\
\hline 4. Calcium 0.018 & PASS & $<0.001$ \\
\hline 5. Heavy metals (as Pb) 0.0018 & pASS & $<0.001 \%$ \\
\hline 6. Iron 0.0018 & PASS & $<0.001 \div$ \\
\hline 7. Potassiun $0.005 \%$ & PASS & $<0.001$ \\
\hline 8. Insoluble $0.01 \frac{1}{8}$ & PASS & $<0.01 \$$ \\
\hline 9. pH of $5 \%$ solution $5.5-8.3 \bigcirc 25 \mathrm{C}$ & PASS & 7.4 \\
\hline 10. Appearance White to pale yellow & PASS & As Stated \\
\hline
\end{tabular}

TRACEABLE TO N.T.S.T. (Y/N)? Y

Comment:

Reported by: Kenneth I. Shafer QC Supervisor: Joan plowman
C/A Print Date: 3/19/08

Quality Assured to Retest Point: 60 months from ahipment 
G F s chamcats, INC.

Collumbus, Onio 43222

IOT ANALYSIS

ITEY: 619 SODIOM PORMATE, REAGENT (ACS)

LOT\#2 P673902

\begin{tabular}{|c|c|c|}
\hline TEST & $\begin{array}{l}\text { PASS/ } \\
\text { FAIL }\end{array}$ & $\begin{array}{l}\text { NOMERTCAL } \\
\text { RESULT }\end{array}$ \\
\hline 1. Assay 99.07 min. & $\overline{\text { PASS }}$ & 99.58 \\
\hline 2. Insoluble $0.005 \%$ & PASS & $<0.005$ 娄 \\
\hline 3. Chloride 0.0018 & PASS & $<0.001 \%$ \\
\hline 4. Sulfate 0.001 t & PASS & $<0.0018$ \\
\hline 5. Calciun $0.005 \frac{5}{8}$ & PASS & $<0 . \overline{00058}$ \\
\hline 6. Heavy Metals (as $\mathrm{Pb}$ ) 0.0005 & PASS & $<0.0005$ \\
\hline 7. Iron 0.0005 & PASS & $<0.0005^{\frac{5}{3}}$ \\
\hline
\end{tabular}

TRACEABLE TO N.I.S.T. (Y/N)? X

Comment:

Reported by: Joan Plowman C/A Print Date: 3/19/0B

QC Supervisor: Joan Plowman

Not for direct use in food, cosmetic or pharmaceuticals.

Coneult warranty linitations at ww.gfschemicals.cos/terms.asp.

por resale by GFS authorized distributors only. 
RPP-RPT-37505, Rev. 0

$G$ F $S$ CHEMICALS, INC.

Columbus, Ohio 43222

LOT ANALYSIS

ITEM: 1078 SODIUA CHROMATE, TETRAHYDRATE, REAGENT

LOT* : P568182

\begin{tabular}{|c|c|c|}
\hline TEST & $\begin{array}{l}\text { PASS/ } \\
\text { FAIE }\end{array}$ & $\begin{array}{l}\text { NUMERTCAI. } \\
\text { RESULT }\end{array}$ \\
\hline 1. Assay $99.0-102.08$ & PASS & 100.98 \\
\hline 2. Insoluble 0.005 t & PASS & $<0.005 \%$ \\
\hline 3. $\mathrm{pH}$ of $5 \frac{1}{8}$ solution $8 . \overline{0-9.5}$ & PASS & 9.1 \\
\hline 4. Chloride 0.005 & PASS & $<0.005 \%$ \\
\hline 5. Sulfate 0.018 & PASS & $<0.01 \%$ \\
\hline 6. Aluminum $0.002 \%$ & PASS & $<0.0028$ \\
\hline 7. Calefum 0.005 & PASS & $<0.005 \%$ \\
\hline
\end{tabular}

TRACEABLE TO N.I.S.T. (Y/N)? $Y$

comment:

Reported by: Nicholas E. Dangler C/A Pxint Date: 3/29/08

QC Supervisor: Joan Plownan Quality Assured to Retest Point: 60 months

from shipment

Not for direct use in food, cosmetic or pharmaceuticals.

Consult warranty limitations at ww.gfschewicals.con/terms.asp

For resale by GFs authorized distributors only. 


\section{ARES Chem}

G $F$ S CHEMICALS, INC.

Columbus, Ohio 43222

LOT ANALYSIS

ITEM: 920 ETHYLENE GLYCOL, REAGENT

LOT\# : $\quad$ P783656

\begin{tabular}{|c|c|c|}
\hline TEST & $\begin{array}{l}\text { PASS/ } \\
\text { FAIL }\end{array}$ & $\begin{array}{l}\text { NUMERICAL } \\
\text { RESULT }\end{array}$ \\
\hline I. Boiling range $194-200 \mathrm{C}$ & PASS & $194-200 \mathrm{C}$ \\
\hline 2. Specific gravity @20 C $1.115-1.116 \mathrm{~g} / \mathrm{ml}$ & PASS & 1.1151 \\
\hline 3. Acidity (CH3COOH) $0.01 \%$ & $\overline{\text { PASS }}$ & 0.00005 \\
\hline 4. Water $0.2 \%$ & $\overline{\text { PASS }}$ & 0.014 \\
\hline 5. Residue $0.005 \%$ & PASS & $<0.005$ \\
\hline 6. Chloride $0.0005 \%$ & PASS & 0.00001 \\
\hline 7. Iron $0 . \overline{00002 \%}$ & PASS & $<0.00002$ \\
\hline
\end{tabular}

TRACEABLE TO N.I.S.T. (Y/N)? N

comment:

Reported by: Silaja Nacharaju

C/A Print Date: 3/14/08

QC Supervisor: Silaja Nacharaju

Quality Assured to Retest Point: 60 months

from shipment

Not for direct use in food, cosmetic or pharmaceuticals.

Consuit warranty limitations at www.gfschemicals.com/terms.asp.

For resale by GFS authorized distributors only. 
G F S CHEMICALS, INC.

Columbus, Ohio 43222

LOT ANALYSIS

ITEM: 658 SODIUM NITRATE, REAGENT (ACS)

LOT\# : P786671

\begin{tabular}{|c|c|c|}
\hline TEST & $\begin{array}{l}\text { PASS / } \\
\text { FAIL }\end{array}$ & $\begin{array}{l}\text { NUMERICAL } \\
\text { RESULT }\end{array}$ \\
\hline 1. Assay $99.0 \% \mathrm{~min}$. & PASS & $100.7 \frac{8}{6}$ \\
\hline 2. $\mathrm{pH}$ of 5 \% solution $5.5-8.3$ @ $25 \mathrm{C}$ & PASS & 6.2 \\
\hline 3. Insoluble $0.005 \%$ & PASS & $<0.005 \%$ \\
\hline 4. Chloride 0.0018 & PASS & $<0.001 \%$ \\
\hline 5. Iodate $0.0005 \%$ & PASS & $<0.0005 \%$ \\
\hline 6. Nitrite $0.001 \%$ & PASS & $<0.001 \%$ \\
\hline 7. Phosphate $0.0005 \%$ & PASS & $<0.0005 \%$ \\
\hline 8. Sulfate $0.003 \%$ & PASS & $<0.003 \%$ \\
\hline 9. Calcium $0.005 \%$ & PASS & $<0.005 \%$ \\
\hline$\overline{10 .}$ Magnesium $0.002 \%$ & PASS & $<0.0028$ \\
\hline 11. Heavy metals (Pb) $0.0005 \%$ & PASS & $<0.0005 \%$ \\
\hline 12. Iron $0.0003 \%$ & PASS & $<0.0003 \%$ \\
\hline
\end{tabular}

TRACEABLE TO N.I.S.T. $(Y / N) ? \quad Y$

Comment:

Reported by: Robert Kramer

C/A Print Date: 3/19/08

QC Supervisor: Joan Plowman

Quality Assured to Retest Point: 60 months

Not for direct use in food, cosmetic or pharmaceuticals.

from shipment

Consult warranty limitations at www.gfachemicals.com/terms.asp.

For resale by GFS authorized distributors only. 
RPP-RPT-37505, Rev. 0

G F S CHEMICALS, INC.

Columbus, Ohio 43222

LOT ANALYSIS

ITEM : 559 SODIUM NITRITE, REAGENT (ACS)

LOT\# : $\quad$ P786739

\begin{tabular}{|c|c|c|}
\hline TEST & $\begin{array}{l}\text { PASS } \\
\text { FAIL }\end{array}$ & $\begin{array}{l}\text { NUMERICAL } \\
\text { RESULT }\end{array}$ \\
\hline 1. Assay $97.0 \% \mathrm{~min}$. & PASS & 99.18 \\
\hline 2. Chloride $0.005 \%$ & PASS & $<0.005^{\circ}$ \\
\hline 3. Sulfate $0.01 \%$ & PASS & $<0.01 \frac{9}{6}$ \\
\hline 4. Calcium $0.01 \%$ & PASS & $<0.001 \%$ \\
\hline 5. Heavy metals (as $\mathrm{Pb}) 0.001 \%$ & $\overline{\text { PASS }}$ & $<0.001 \div$ \\
\hline 6. Iron $0.001 \%$ & PASS & $<0.001 \%$ \\
\hline 7. Potassium $0.005 \%$ & PASS & $<0.001 \%$ \\
\hline 8. Insoluble 0.018 & PASS & $<0.01 \frac{9}{b}$ \\
\hline 9. $\mathrm{pH}$ of 5\% solution $5.5-8.3$ (25 C & PASS & 7.4 \\
\hline 10. Appearance - white to pale yellow & PASS & As stated \\
\hline
\end{tabular}

TRACEABLE TO N.I.S.T. (Y/N)? Y

comment :

Reported by: Kenneth L. Shafer

QC Supervisor: Joan PIowman
C/A Print Date: 3/19/08

Quality Assured to Retest Point: 60 months from shipment 


\begin{tabular}{|c|c|c|c|c|}
\hline \multicolumn{5}{|c|}{ Potentiodynamic/Potentiostatic Polarization } \\
\hline \multicolumn{5}{|c|}{ Test Information Form } \\
\hline Project Name: & ARES & Project\#: & \multicolumn{2}{|r|}{81170134} \\
\hline Test Type: & Cyclic Potentiodynamic Polarization & Date Start: & \multicolumn{2}{|c|}{$11 / 14101$} \\
\hline Specimen ID: & ELIIg6-54 & Time Start: & \multicolumn{2}{|c|}{$12=00 \mathrm{pm}$} \\
\hline \multirow{2}{*}{ Data Files: } & \multirow{2}{*}{\multicolumn{4}{|c|}{\begin{tabular}{l|l} 
OCP: & EUIIGb-54-OCP.DTA \\
CPP: & ELIG $G-54-O C P . D T A$ \\
\end{tabular}}} \\
\hline & & \multicolumn{3}{|c|}{ CPP: EUIIG-rL-OCP.DTA } \\
\hline Solution: & APlos-PSr & \multicolumn{2}{|l|}{ Atmosphere: } & Nitrogen purging \\
\hline Temperature: & so & \multicolumn{2}{|c|}{ Reference Electrode: } & SCE \\
\hline Initial pH: & $>13$ & \multicolumn{2}{|c|}{ Final pH: } & $\$ \bar{B}$ \\
\hline Starting Potential: & Vvs. OCP & \multicolumn{2}{|c|}{\begin{tabular}{|l|} 
Reversal Potential: \\
\end{tabular}} & Vvs. SCE \\
\hline Scan Rate: & 0.17 & \multicolumn{2}{|c|}{ Final Potential: } & -0.1 V vs. OCP \\
\hline \multicolumn{5}{|l|}{ Reverse Current } \\
\hline Sample Length: & 3.18 & \multicolumn{2}{|c|}{ Sample Diameter: } & 0.68 \\
\hline \multicolumn{5}{|l|}{ Sample Area: } \\
\hline \multicolumn{5}{|c|}{ ARES AY102 Solution Batch ID: $\quad$ Tracking 68} \\
\hline Potentiostat: & \multicolumn{4}{|l|}{ Bamy Ret GoO } \\
\hline \multicolumn{5}{|l|}{ Potentiostat ID: } \\
\hline \multicolumn{5}{|l|}{ Comments: } \\
\hline Test Performed by: & Feng Gui & \multirow{2}{*}{\multicolumn{2}{|c|}{ Home Phone: }} & $614-777-9599$ \\
\hline Project Manager: & \multirow{2}{*}{ Sean Brossia } & & & \\
\hline Date end: & & \multicolumn{2}{|c|}{ Time end: } & $3: 00$ pm \\
\hline
\end{tabular}

* Set a value such that the reversal current density is $1 \mathrm{~mA} / \mathrm{cm}^{2}$;

\section{QA APPROVED}

NAME: Clowew




\begin{tabular}{|c|c|c|c|c|}
\hline \multicolumn{5}{|c|}{ Potentiodynamic/Potentiostatic Polarization } \\
\hline \multicolumn{5}{|c|}{ Test Information Form } \\
\hline Project Name: & ARES & \multirow{2}{*}{\begin{tabular}{|l|} 
Project\#: \\
Date Start:
\end{tabular}} & \multicolumn{2}{|c|}{81170134} \\
\hline Test Type: & Cyclic Potentiodynamic Polarization & & \multicolumn{2}{|c|}{$12 / 03 / 07$} \\
\hline Specimen ID: & Elig6-60 & Time Start: & \multicolumn{2}{|c|}{$12=00 p m$} \\
\hline \multirow{2}{*}{ Data Files: } & \multicolumn{4}{|l|}{ OCP: $E L 1196-60-O C P$ DTA } \\
\hline & \multicolumn{4}{|l|}{ CPP: $\quad E L 1196-60-C P P-D T A$} \\
\hline Solution: & APp105-PS & \multicolumn{2}{|l|}{ Atmosphere: } & Nitrogen purging \\
\hline Temperature: & $50 \quad{ }^{\circ} \mathrm{C}$ & \multicolumn{2}{|c|}{ Reference Electrode: } & SCE \\
\hline Initial pH: & 213 & \multicolumn{2}{|c|}{ Final $\mathrm{pH}$ : } & 213 \\
\hline Starting Potentlal: & $-0.1 \quad$ Vvs. OCP & \multicolumn{2}{|c|}{ Reversal Potential: } & V vs. SCE \\
\hline Scan Rate: & $0.1] \quad \mathrm{mV} / \mathrm{s}$ & \multicolumn{2}{|c|}{ Final Potential: } & -0.1 V vs. OCP \\
\hline Reverse Current & $4.78 \quad \mathrm{~mA}^{*}$ & \multicolumn{2}{|l|}{ rinar potential: } & \\
\hline & \multirow[b]{2}{*}{$3.17 \mathrm{~cm}$} & \multirow{2}{*}{\multicolumn{2}{|c|}{ Sample Diameter: }} & \\
\hline Sample Length: & & & & 0.8 \\
\hline Sample Area: & 4.78 & & \\
\hline \multicolumn{5}{|c|}{$\begin{array}{l}\text { APlos-PSe } P H \\
\text { Tracking\#. } 68\end{array}$} \\
\hline Potentiostat: & \multicolumn{4}{|l|}{ Gamry Ref 600} \\
\hline Potentiostat ID: & \multicolumn{4}{|l|}{$1(13)$} \\
\hline \multicolumn{5}{|l|}{ Comments: } \\
\hline Test Performed by: & Feng Gui & \multicolumn{2}{|c|}{ Home Phone: } & 614-777-9599 \\
\hline Project Manager: & Sean Brossia & & & \\
\hline Date end: & $12 / 04107$ & Time end: & & $3+10 \mathrm{pm}$ \\
\hline
\end{tabular}

* Set a value such that the reversal current density is $1 \mathrm{~mA} / \mathrm{cm}^{2}$;

QA APPROVED
NAME: Cedien
DATE: 41808


RPP-RPT-37505, Rev. 0

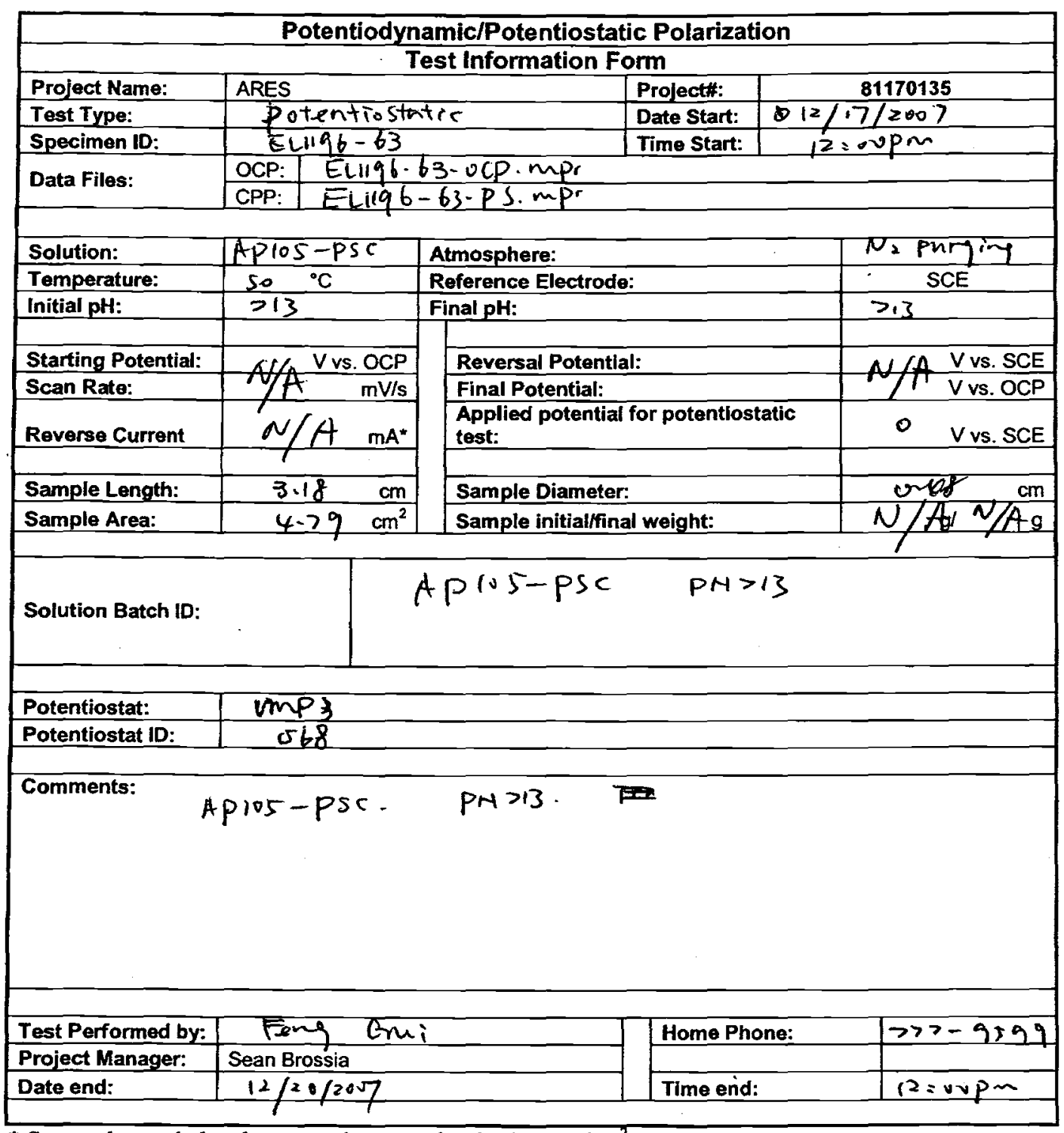

* Set a value such that the reversal current density is $1 \mathrm{~mA} / \mathrm{cm}^{2}$;

\section{QA APPROVED}

NAME:Cldure

DATE: 4-18-08 


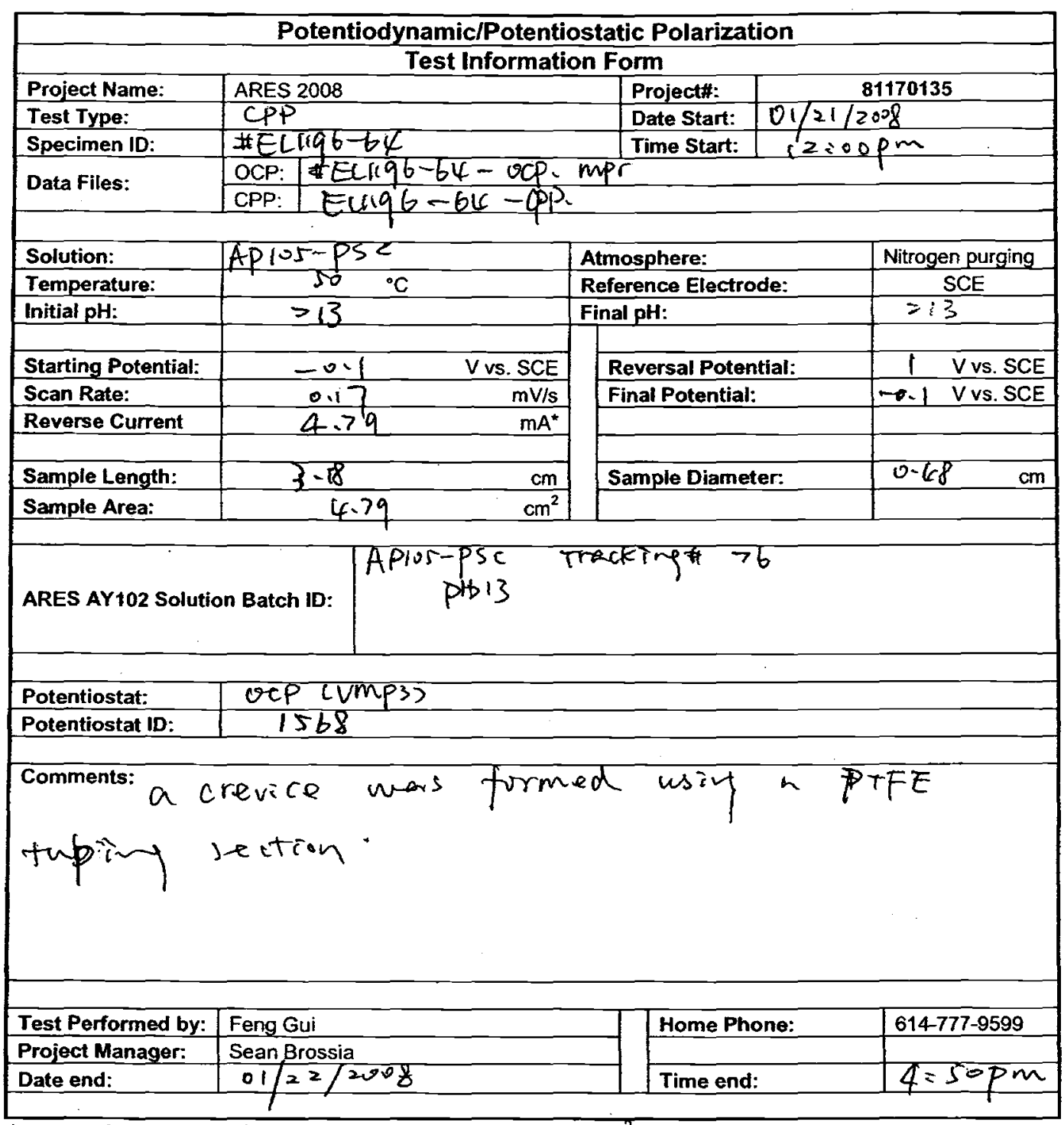

* Set a value such that the reversal current density is $1 \mathrm{~mA} / \mathrm{cm}^{2}$; 


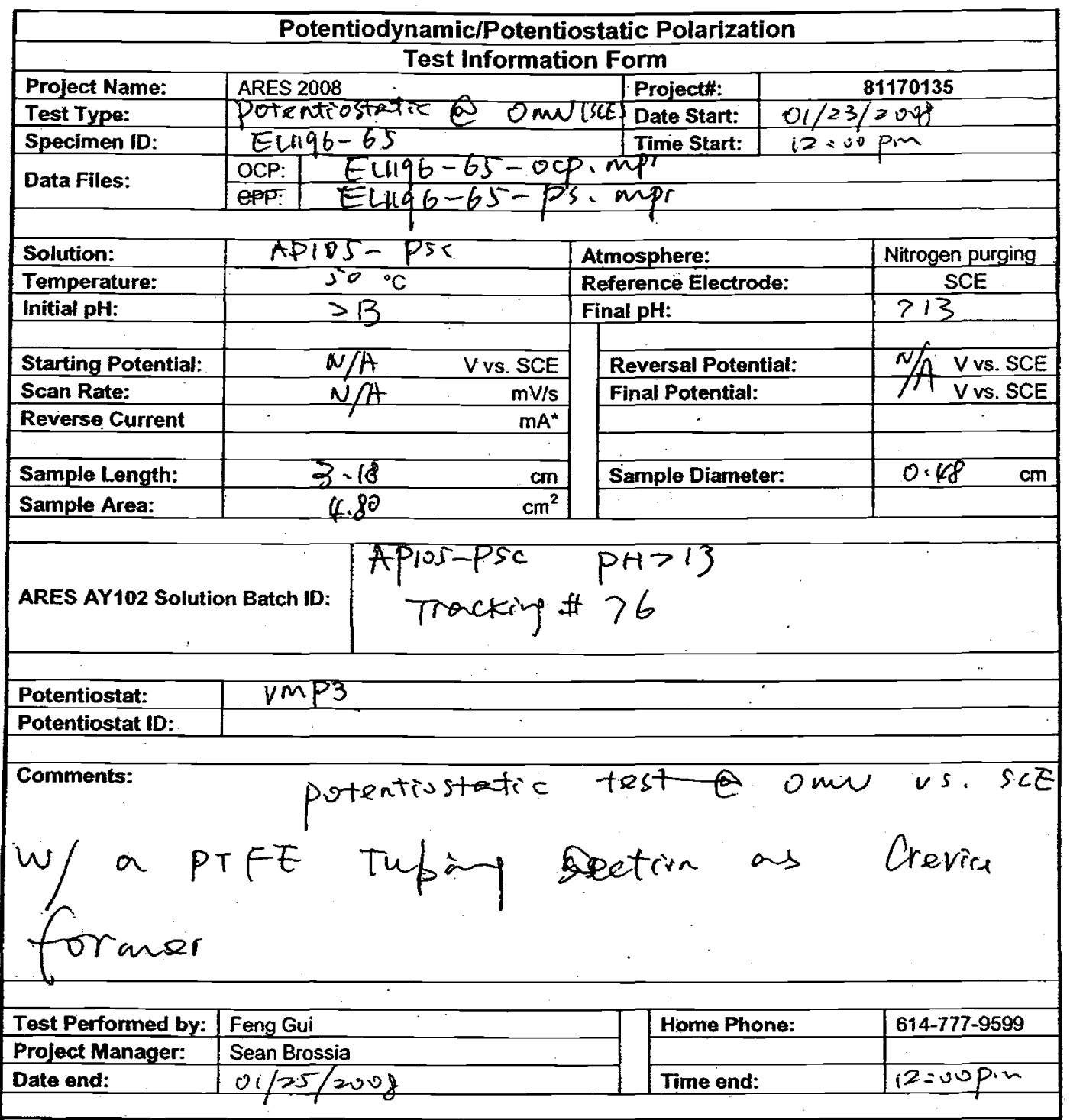

* Set a value such that the reversal current density is $1 \mathrm{~mA} / \mathrm{cm}^{2}$;

\section{AA APPROVED \\ VAME:Cldur \\ JATE: $\quad 4-18008$}




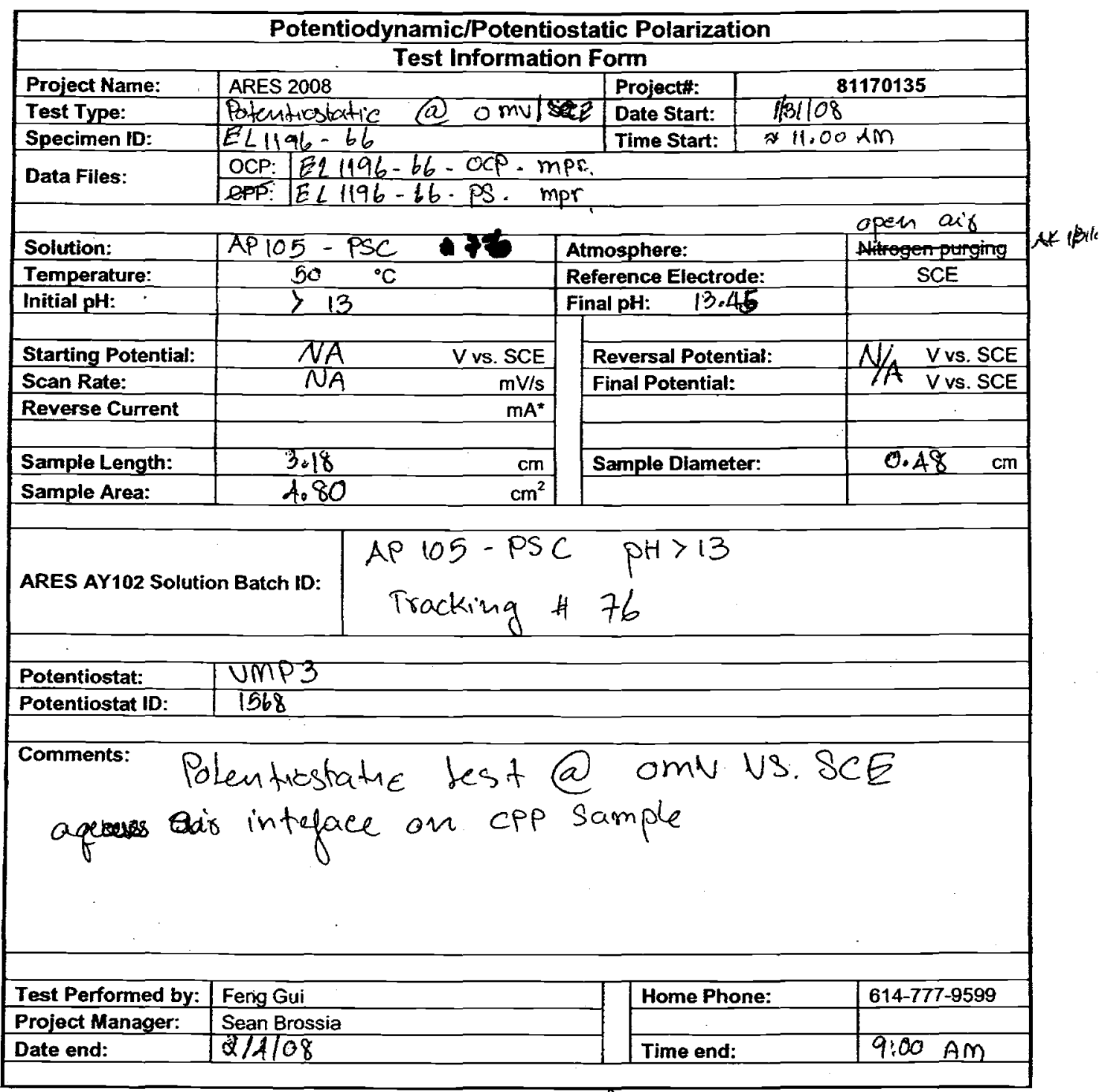

* Set a value such that the reversal current density is $1 \mathrm{~mA} / \mathrm{cm}^{2}$;

QA APPROVED

NAME: clduw

DATE: 4-14-08 


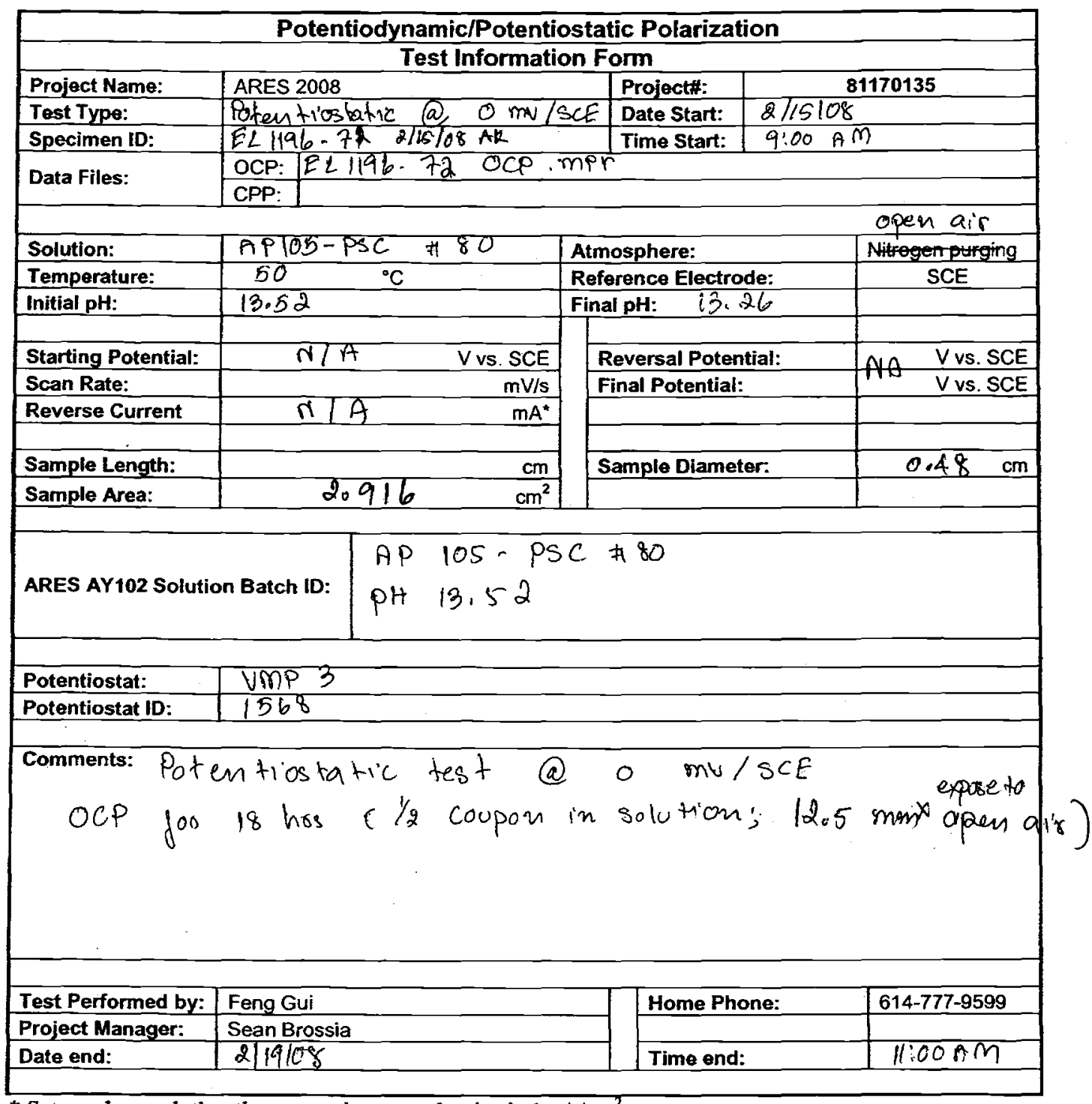

* Set a value such that the reversal current density is $1 \mathrm{~mA} / \mathrm{cm}^{2}$;

NAME: Codur

DATE: $\quad 4-14-08$ 


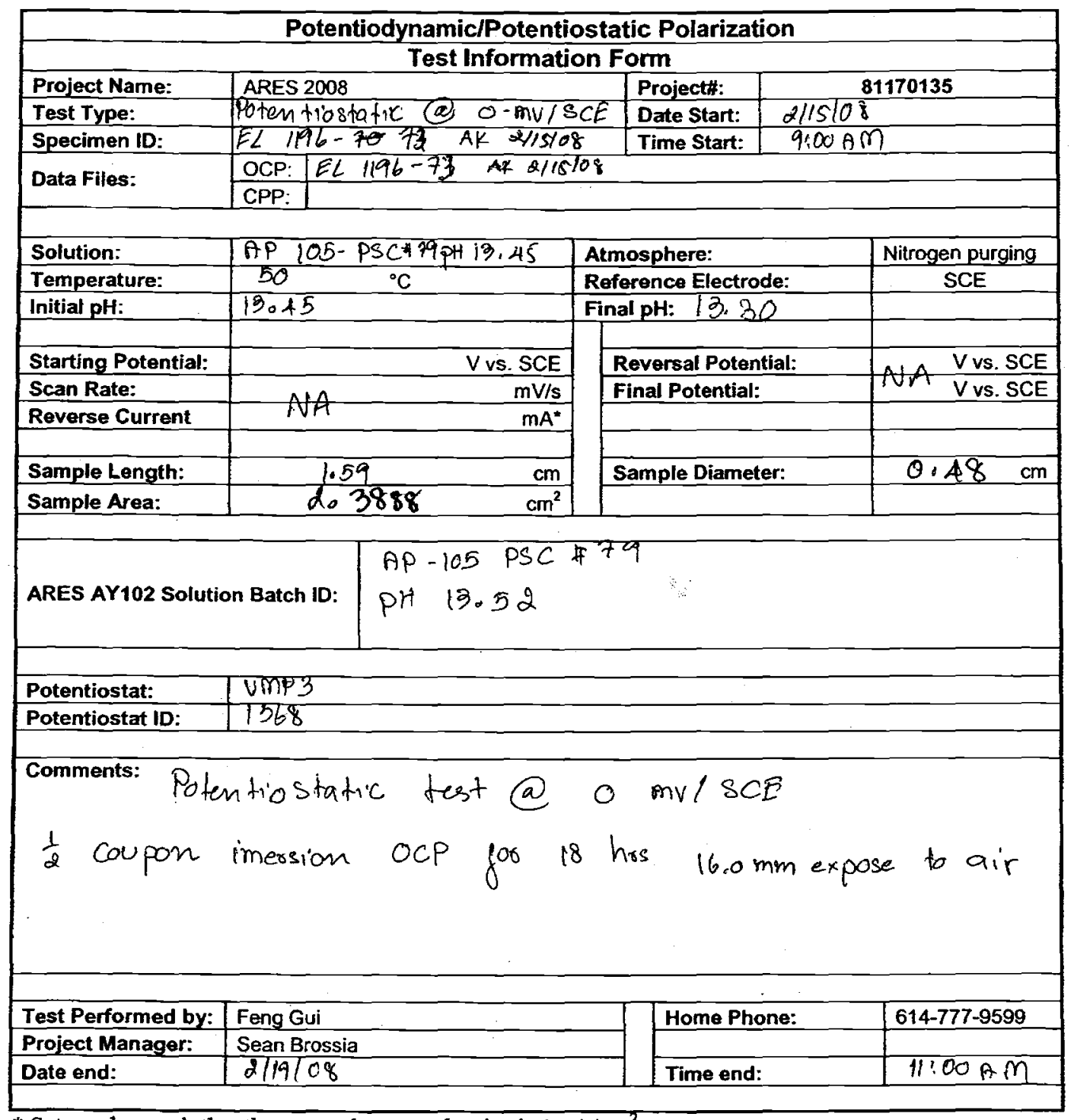

* Set a value such that the reversal current density is $1 \mathrm{~mA} / \mathrm{cm}^{2}$;

\section{QA APPROVED}

NAME: Cedien

DATE: $4-14-08$ 
RPP-RPT-37505, Rev. 0

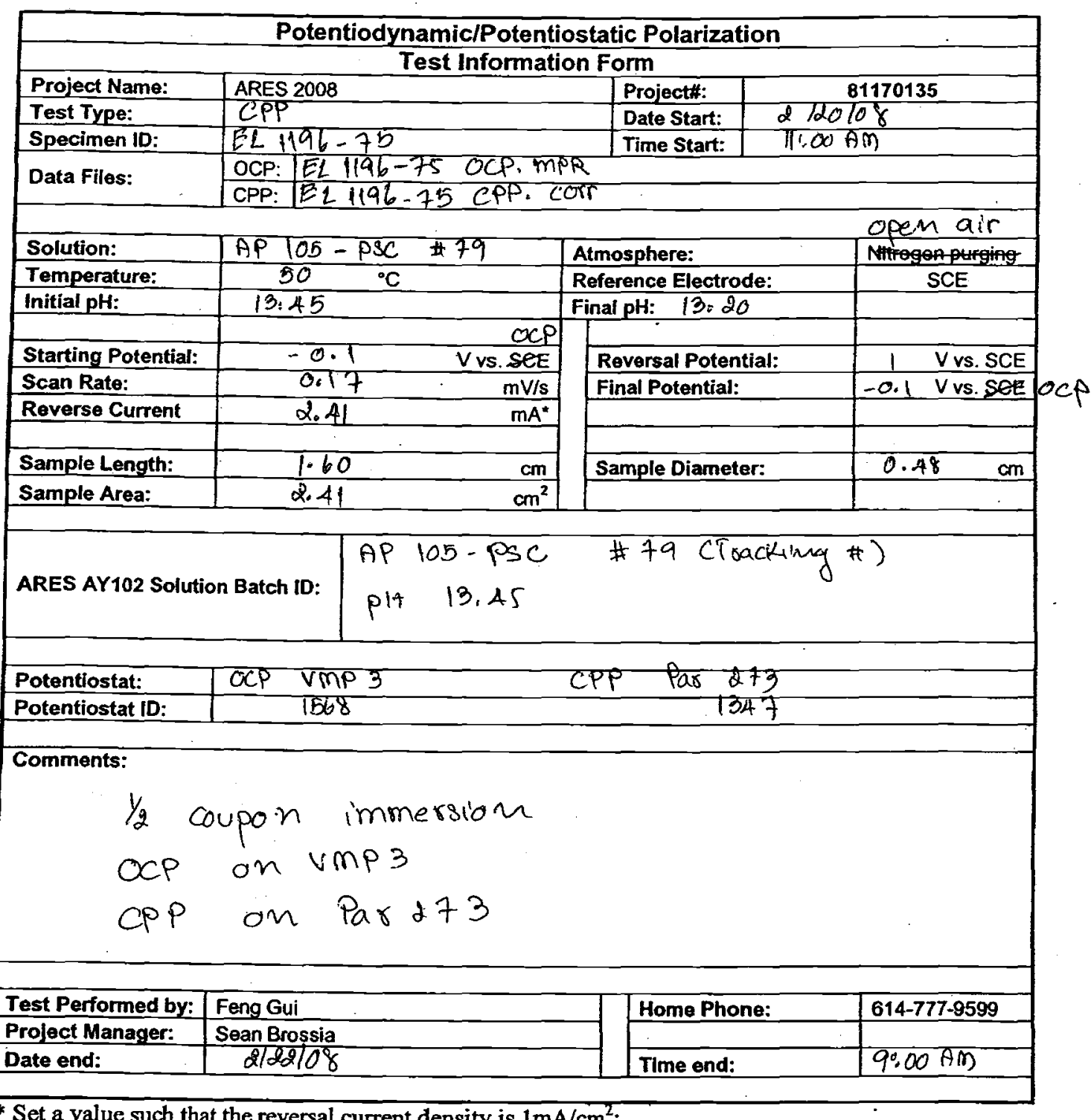

* Set a value such that the reversal current density is $1 \mathrm{~mA} / \mathrm{cm}^{2}$; 
RPP-RPT-37505, Rev. 0

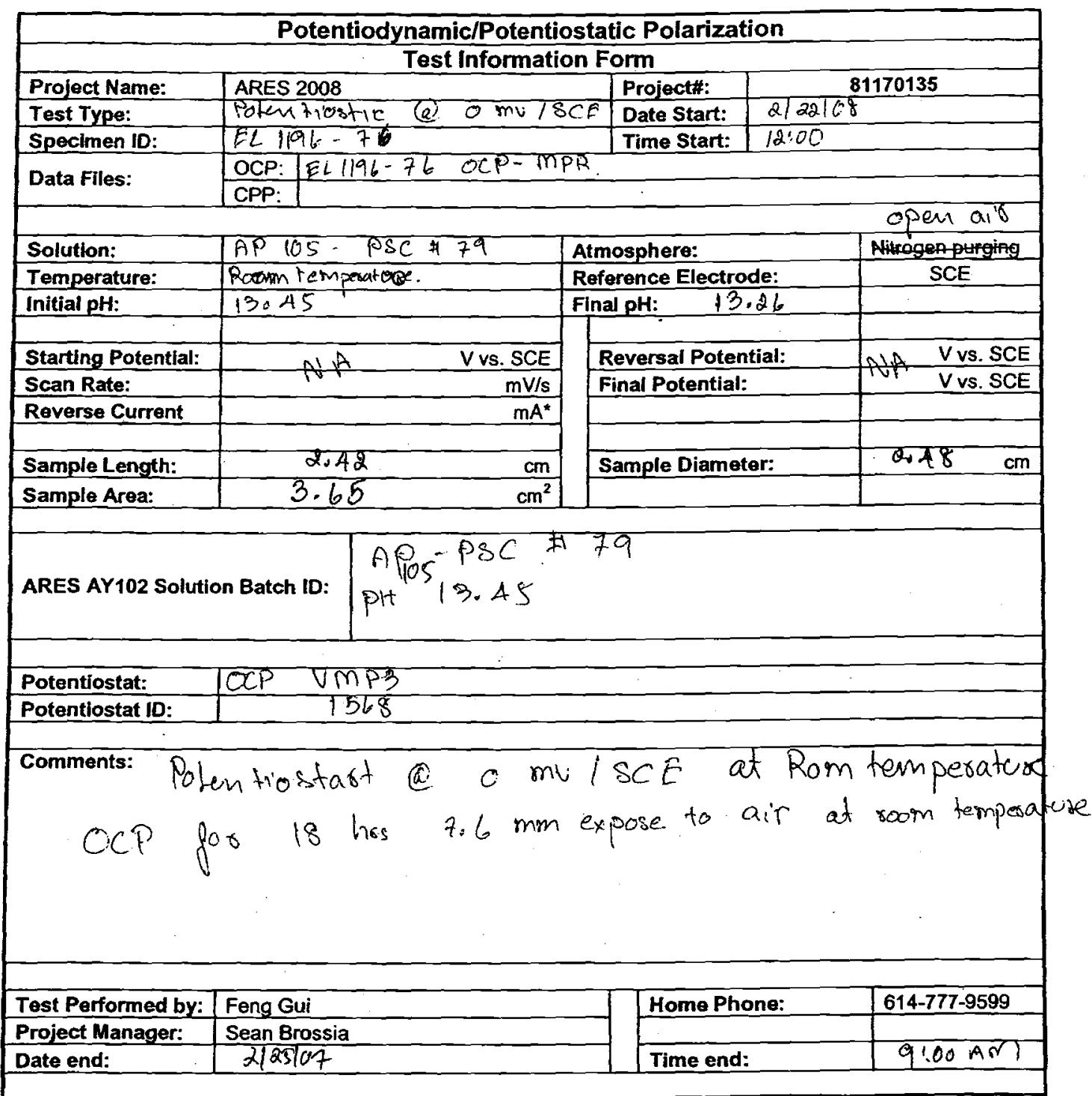

* Set a value such that the reversal current density is $1 \mathrm{~mA} / \mathrm{cm}^{2}$;

QA APPPROVED

NAME: Cedum

DATE: $\quad 4 \cdot 14-08$ 
RPP-RPT-37505, Rev. 0

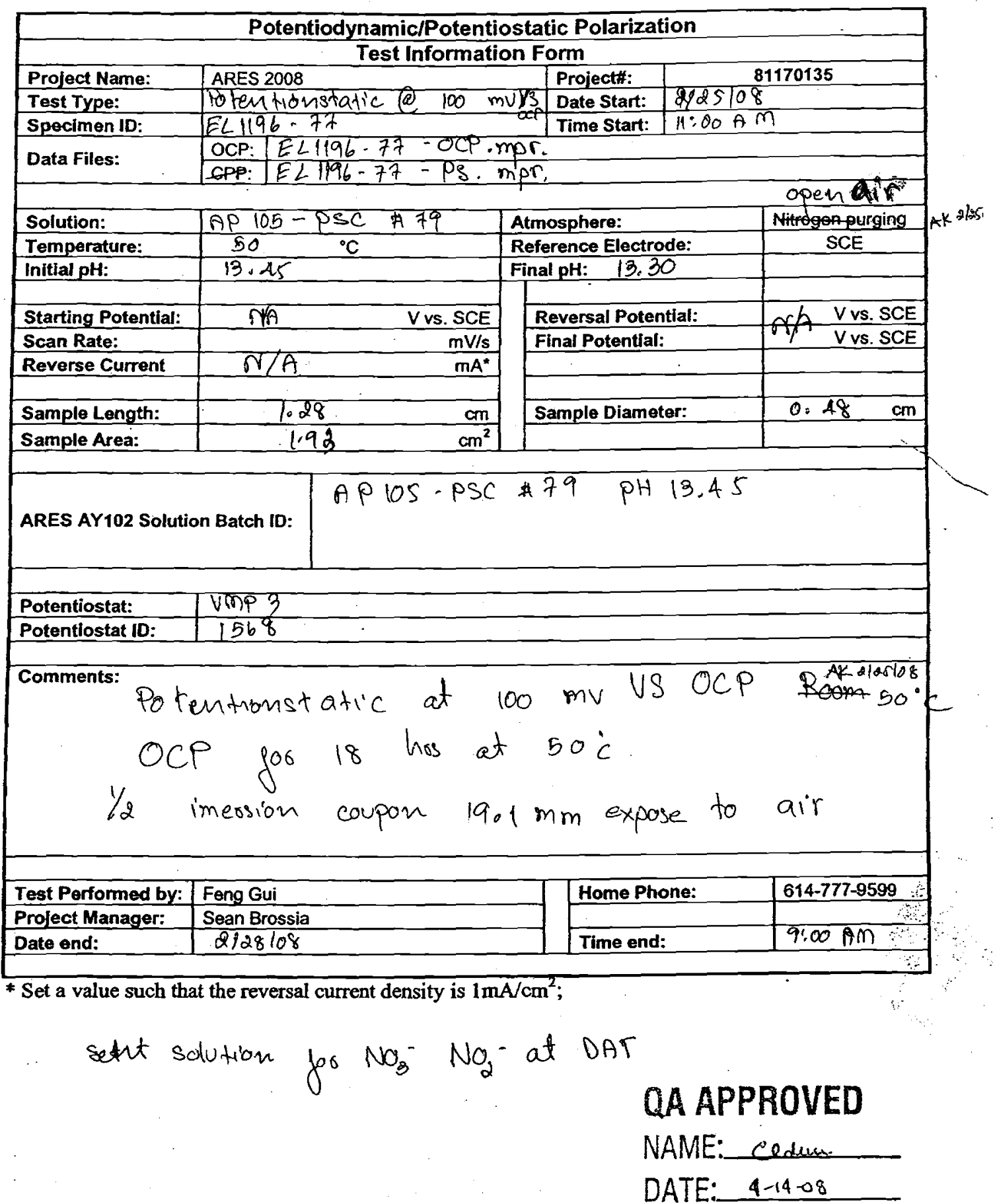




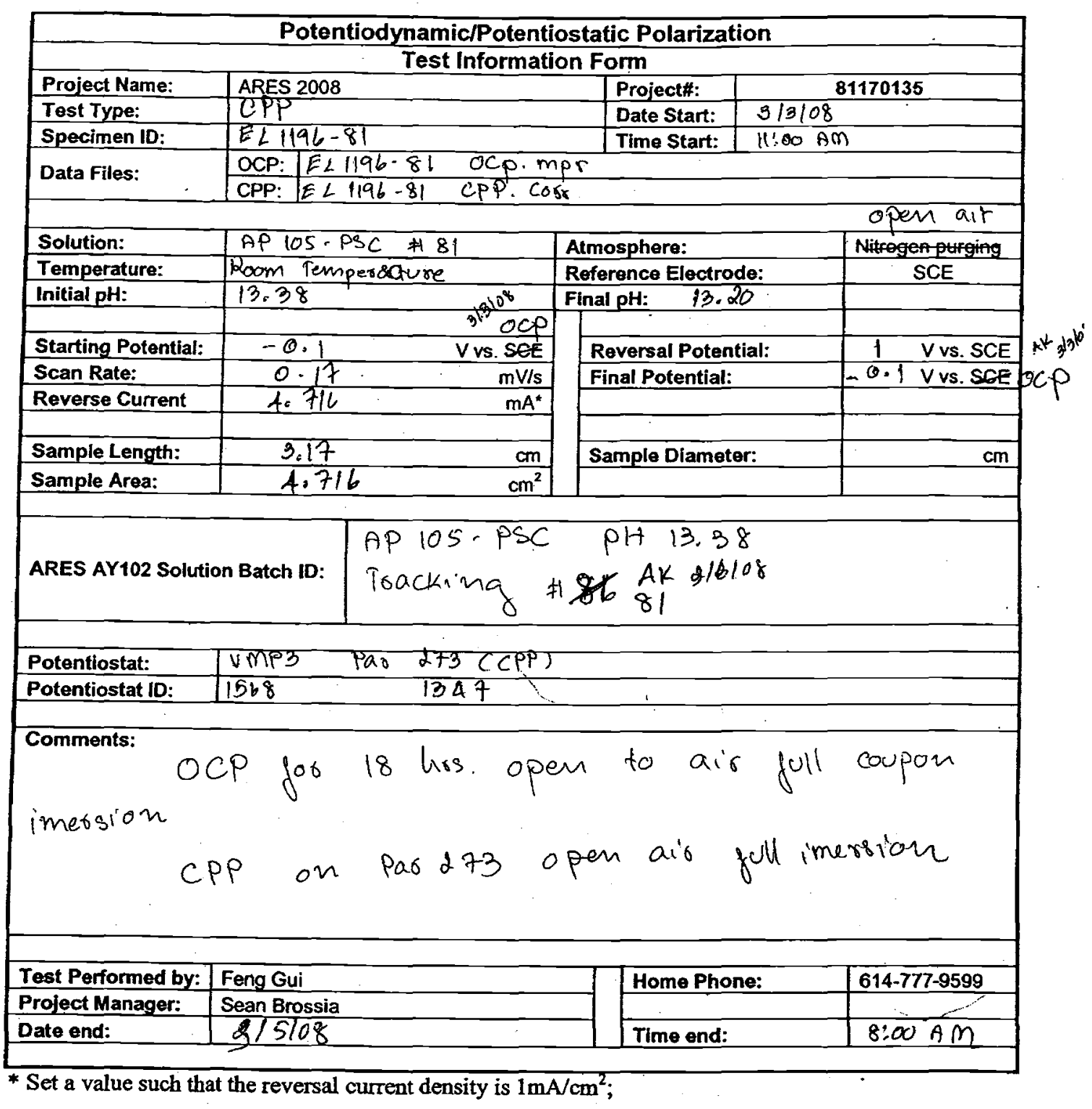

QA APPROVED

NAME: Cedun

DATE: 4-14.08 


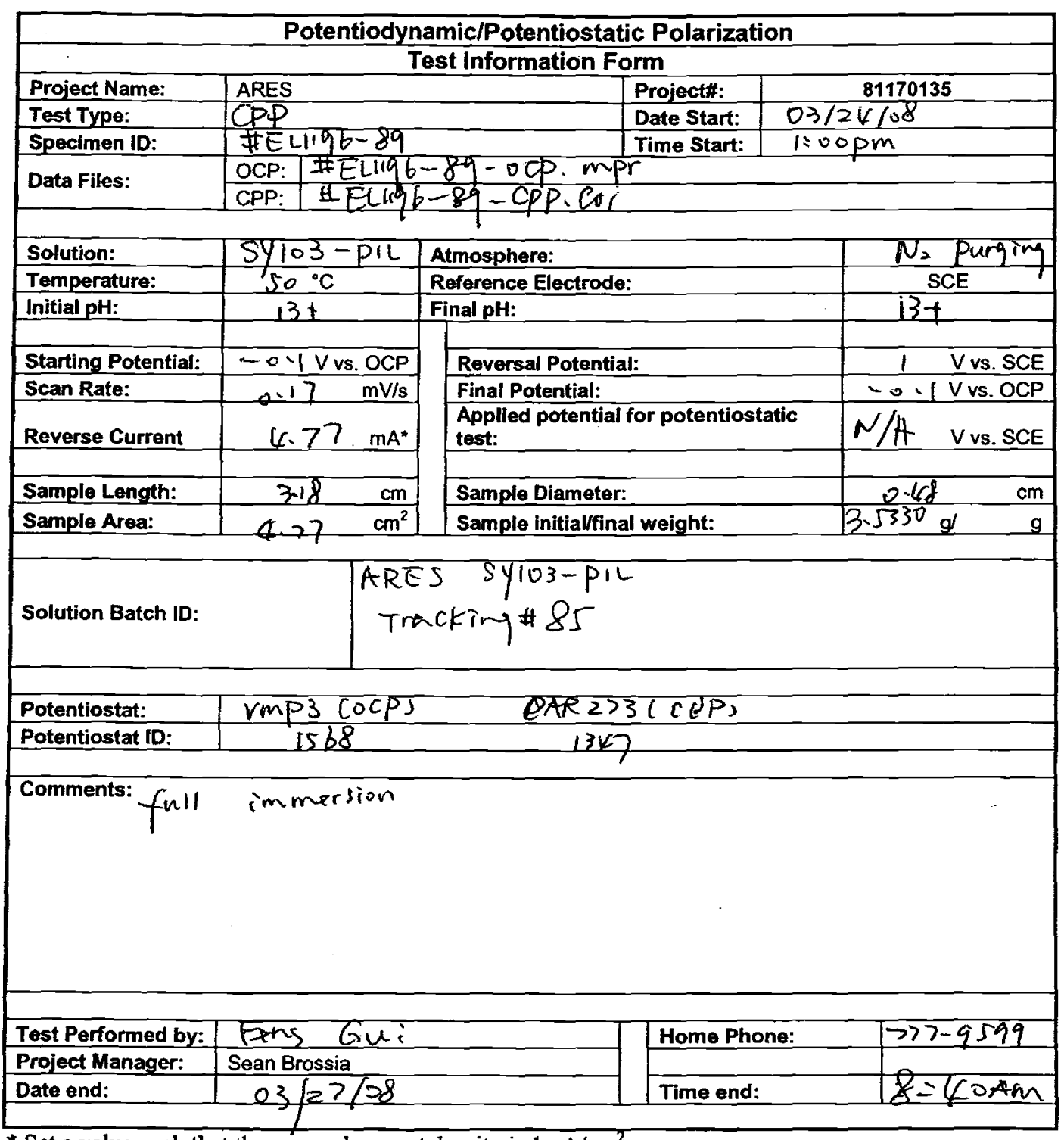

* Set a value such that the reversal current density is $1 \mathrm{~mA} / \mathrm{cm}^{2}$; 


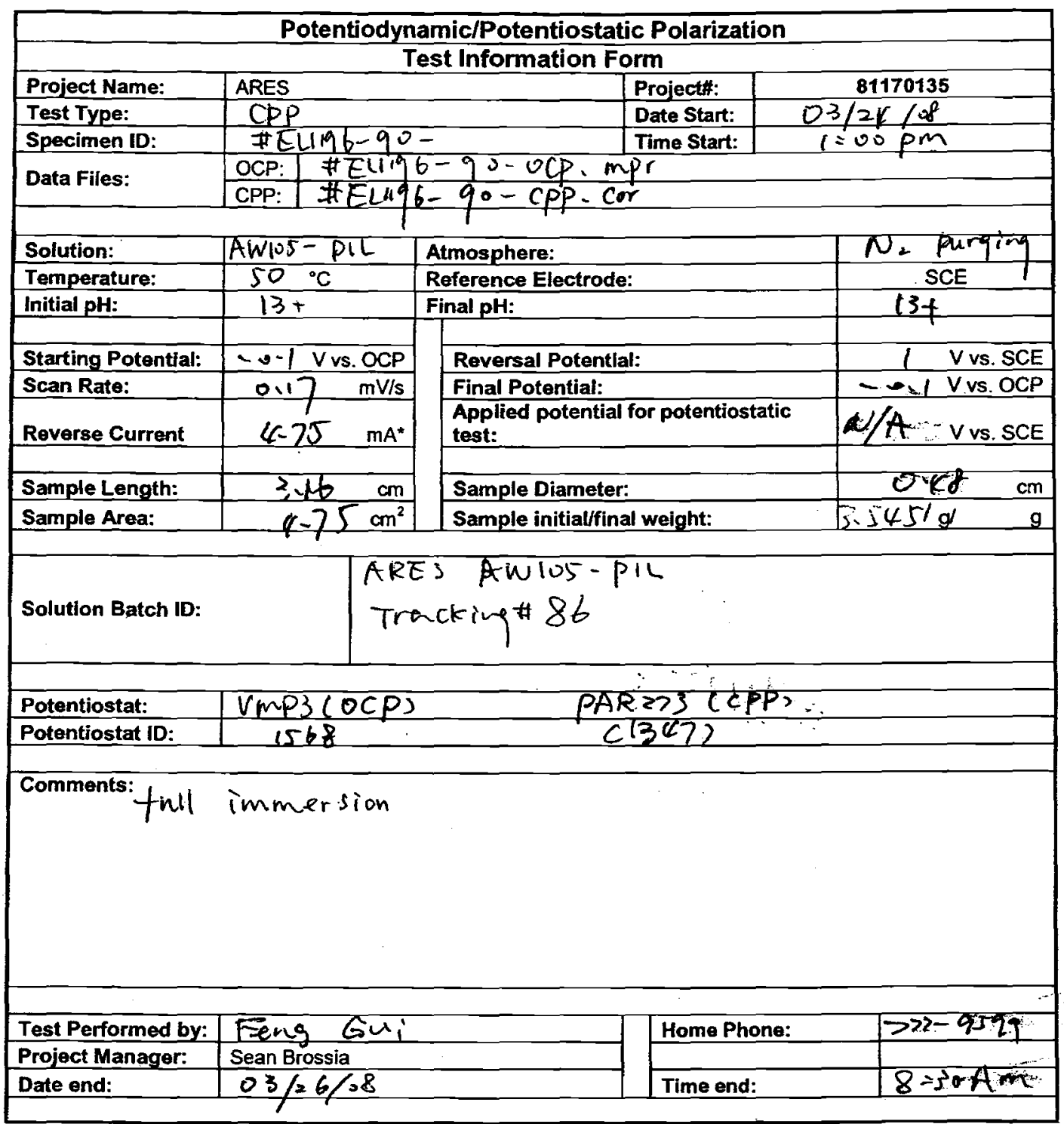

* Set a value such that the reversal current density is $1 \mathrm{~mA} / \mathrm{cm}^{2}$; 


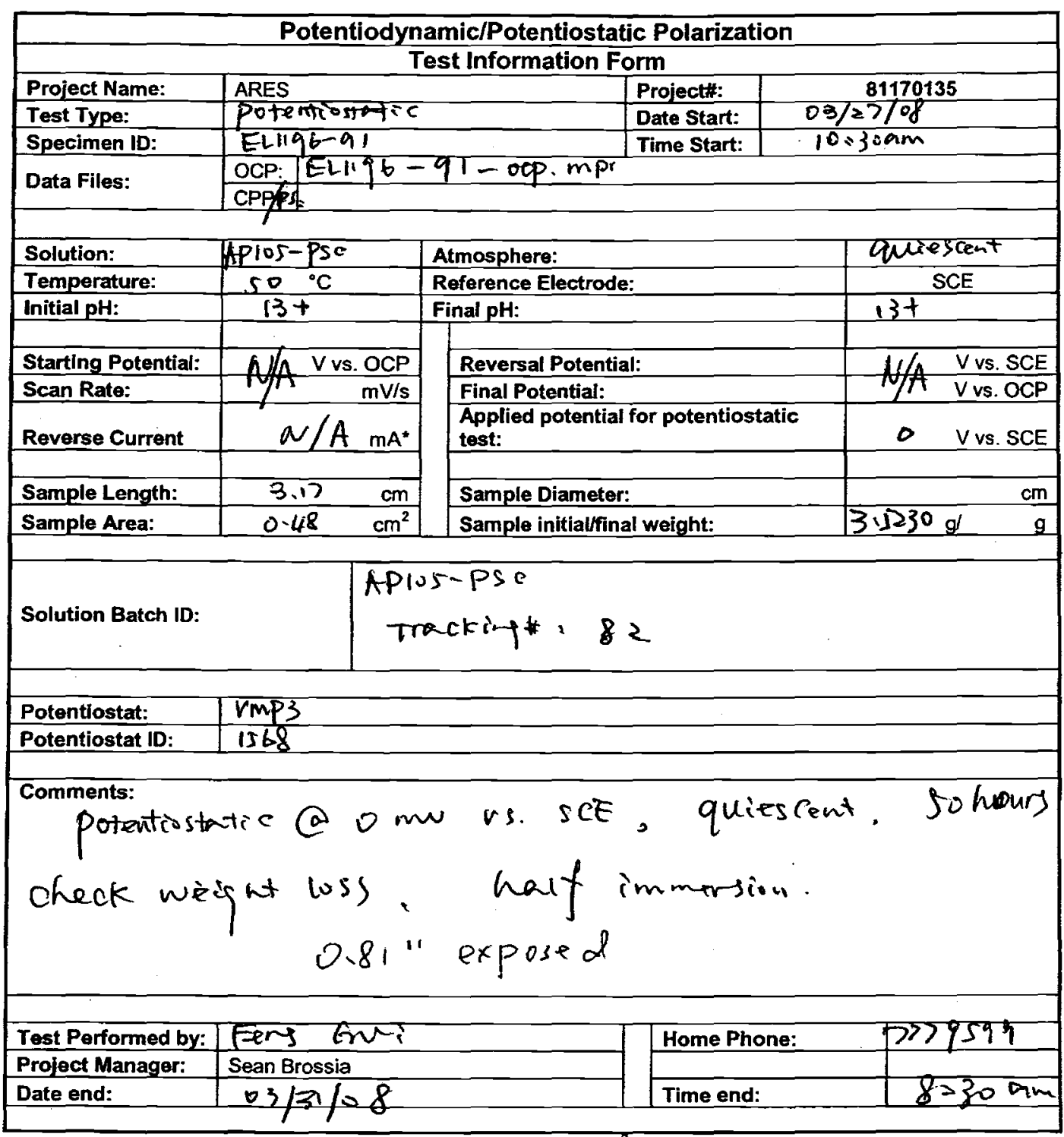

* Set a value such that the reversal current density is $1 \mathrm{~mA} / \mathrm{cm}^{2}$; 


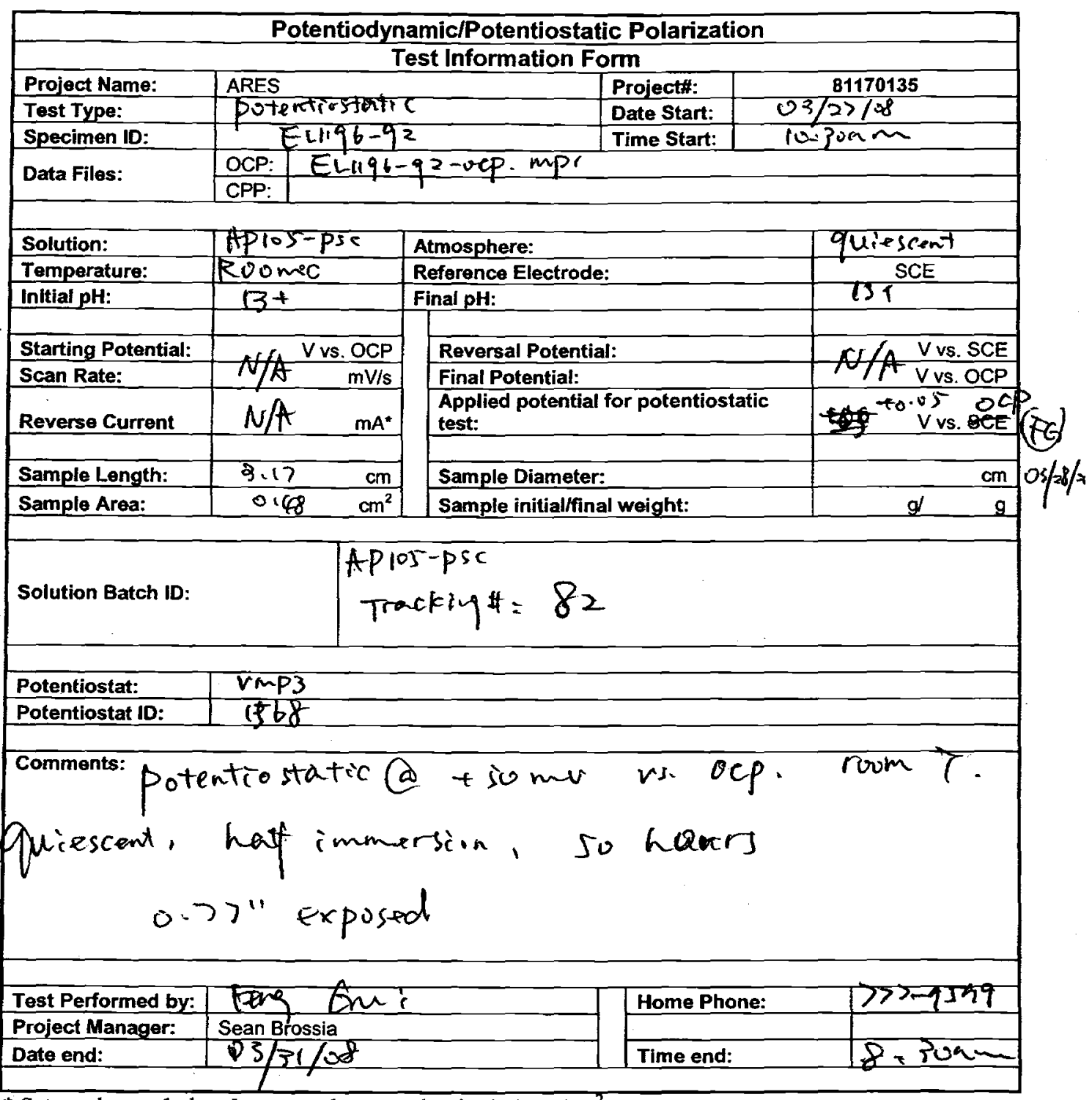

* Set a value such that the reversal current density is $1 \mathrm{~mA} / \mathrm{cm}^{2}$;

MAPPROVED
NAME: Cedum
DATE: 4-14-08




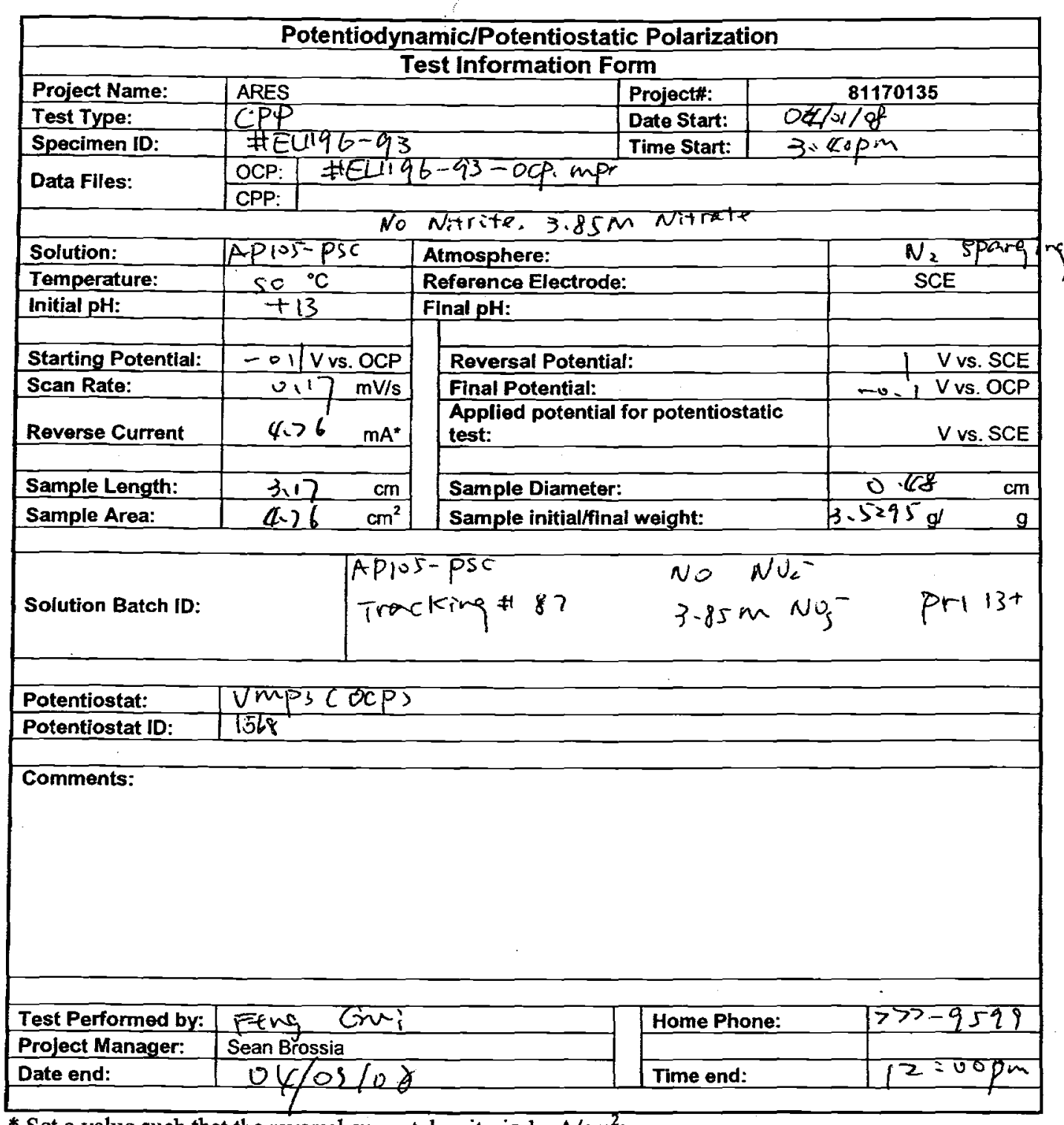

* Set a value such that the reversal current density is $1 \mathrm{~mA} / \mathrm{cm}^{2}$; 


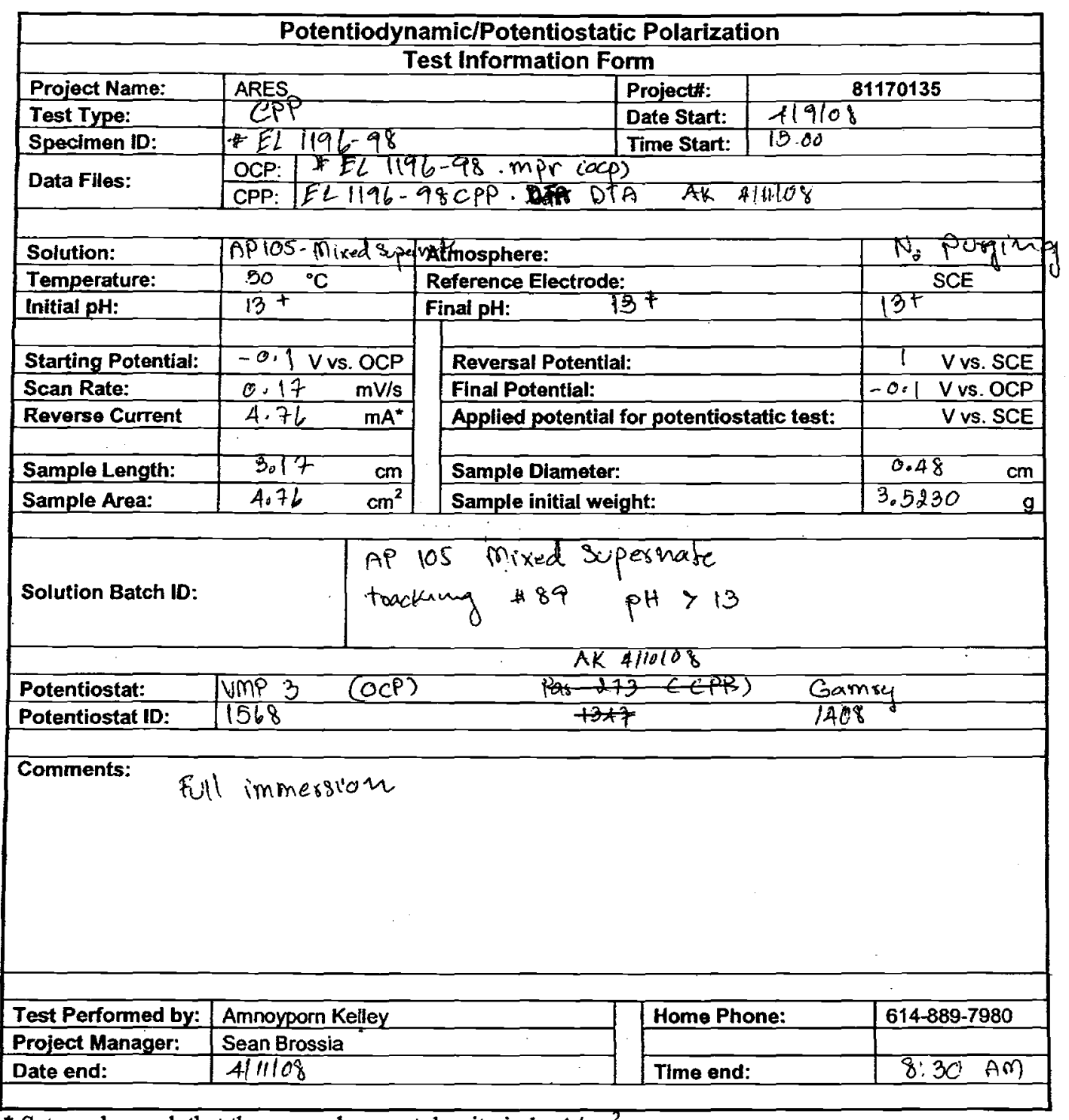

* Set a value such that the reversal current density is $1 \mathrm{~mA} / \mathrm{cm}^{2}$;

\section{QA APPROVED}

NAME: Cedeun

DATE: $8-7-08$ 


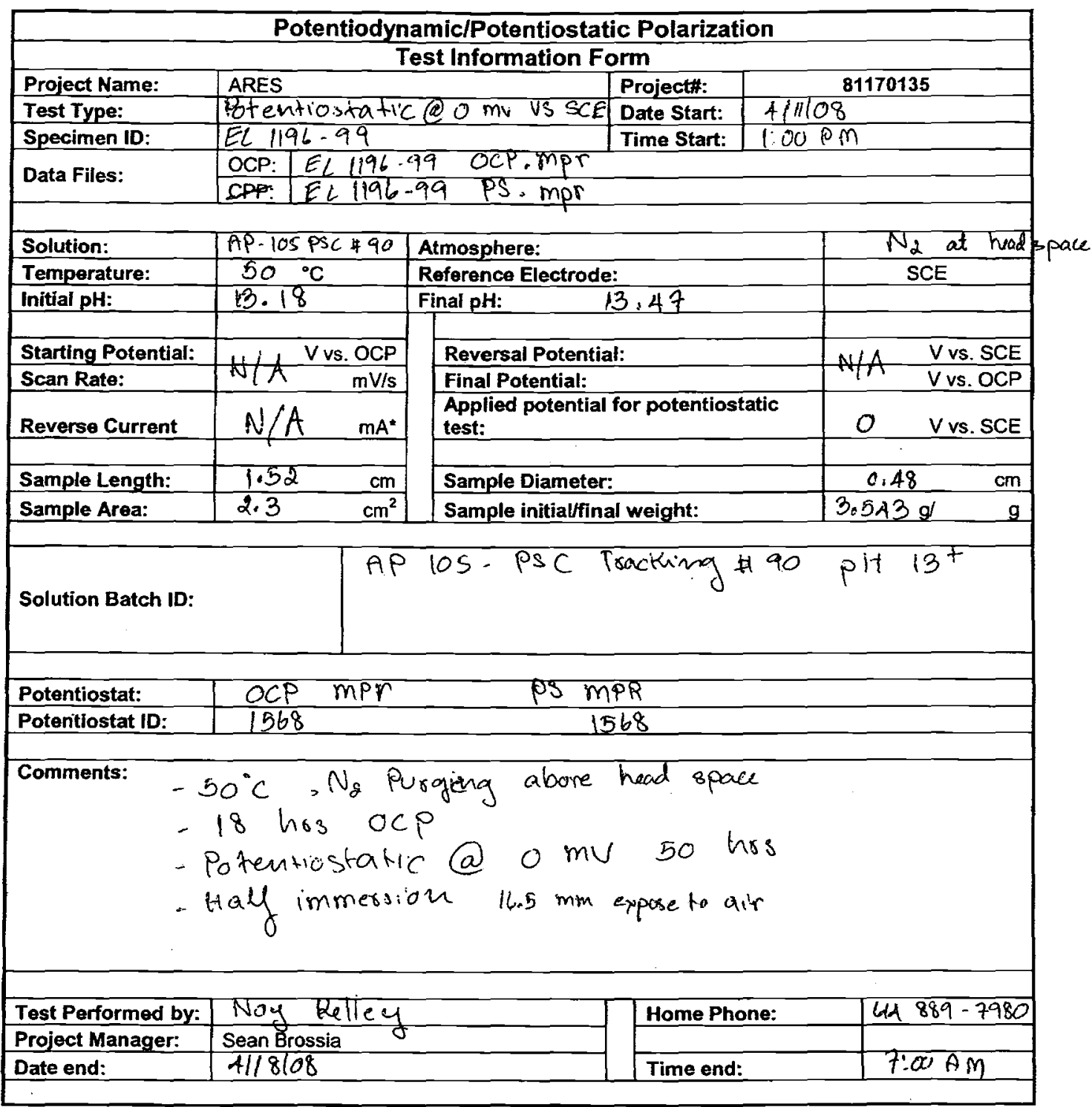

* Set a value such that the reversal current density is $1 \mathrm{~mA} / \mathrm{cm}^{2}$;

* coossion Prodeck Pluck lugging probe when finished

\section{QA APPROVED}

NAME: Cldur

DATE: $\quad 8-200$ 


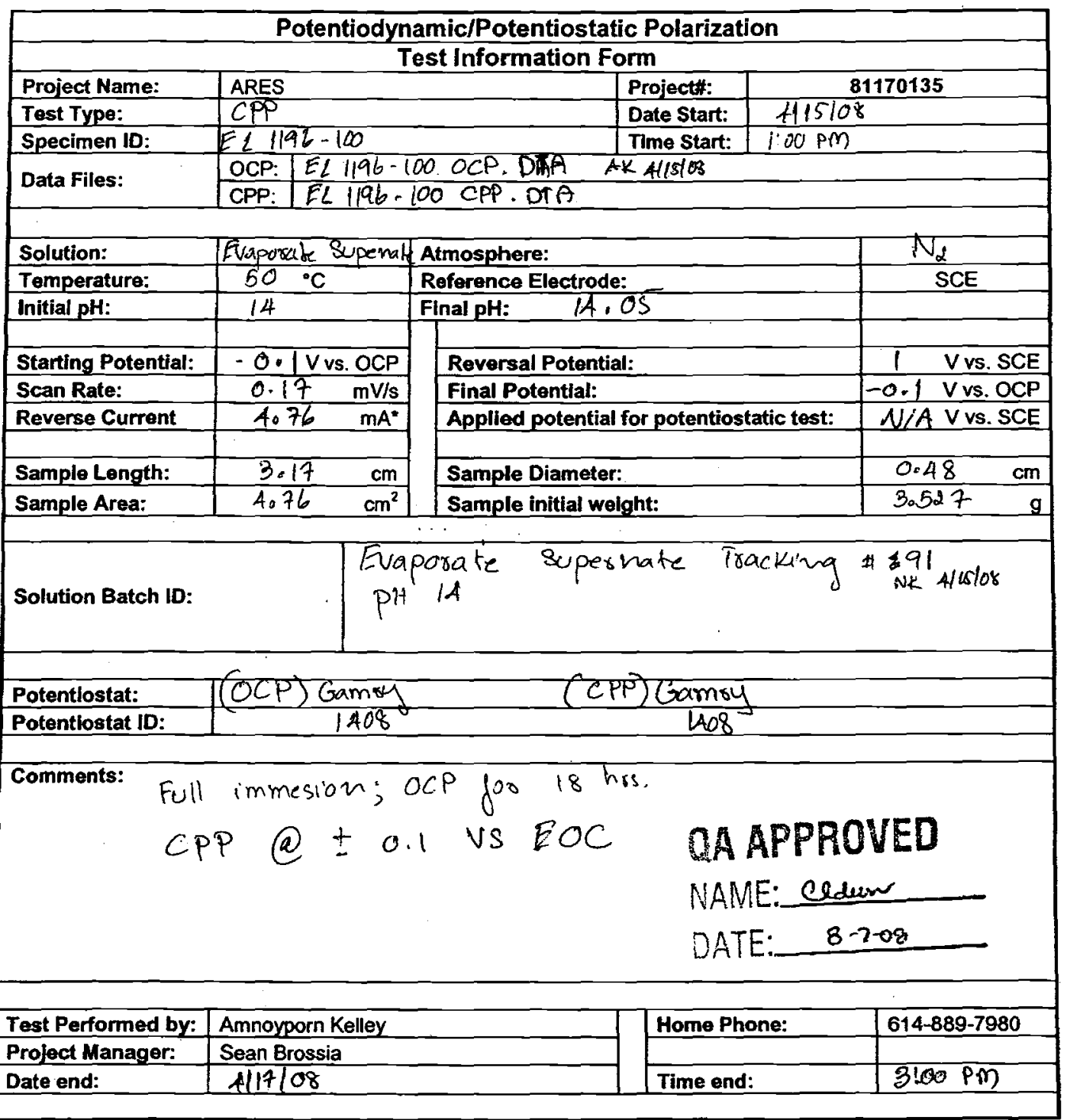

* Set a value such that the reversal current density is $1 \mathrm{~mA} / \mathrm{cm}^{2}$;

- Solution cloundy when start experiment but torn cleas after ron ocp - when jinish run ePp saturated chemical settle droon in the bottom of the cell 


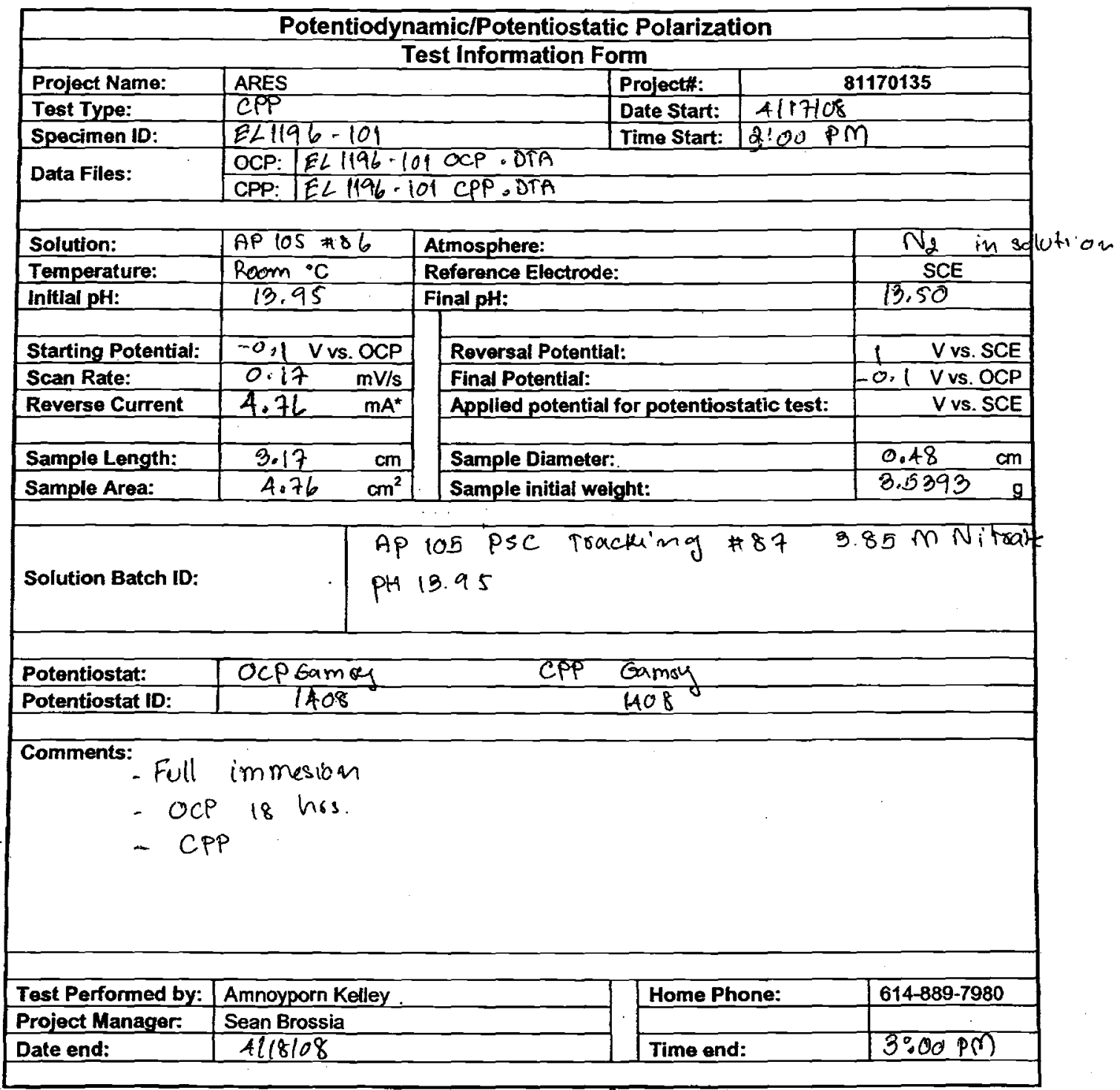

* Set a value such that the reversal current density is $1 \mathrm{~mA} / \mathrm{cm}^{2}$;

No coroosion product

NAME: Cedur

DATE: $8-708$ 


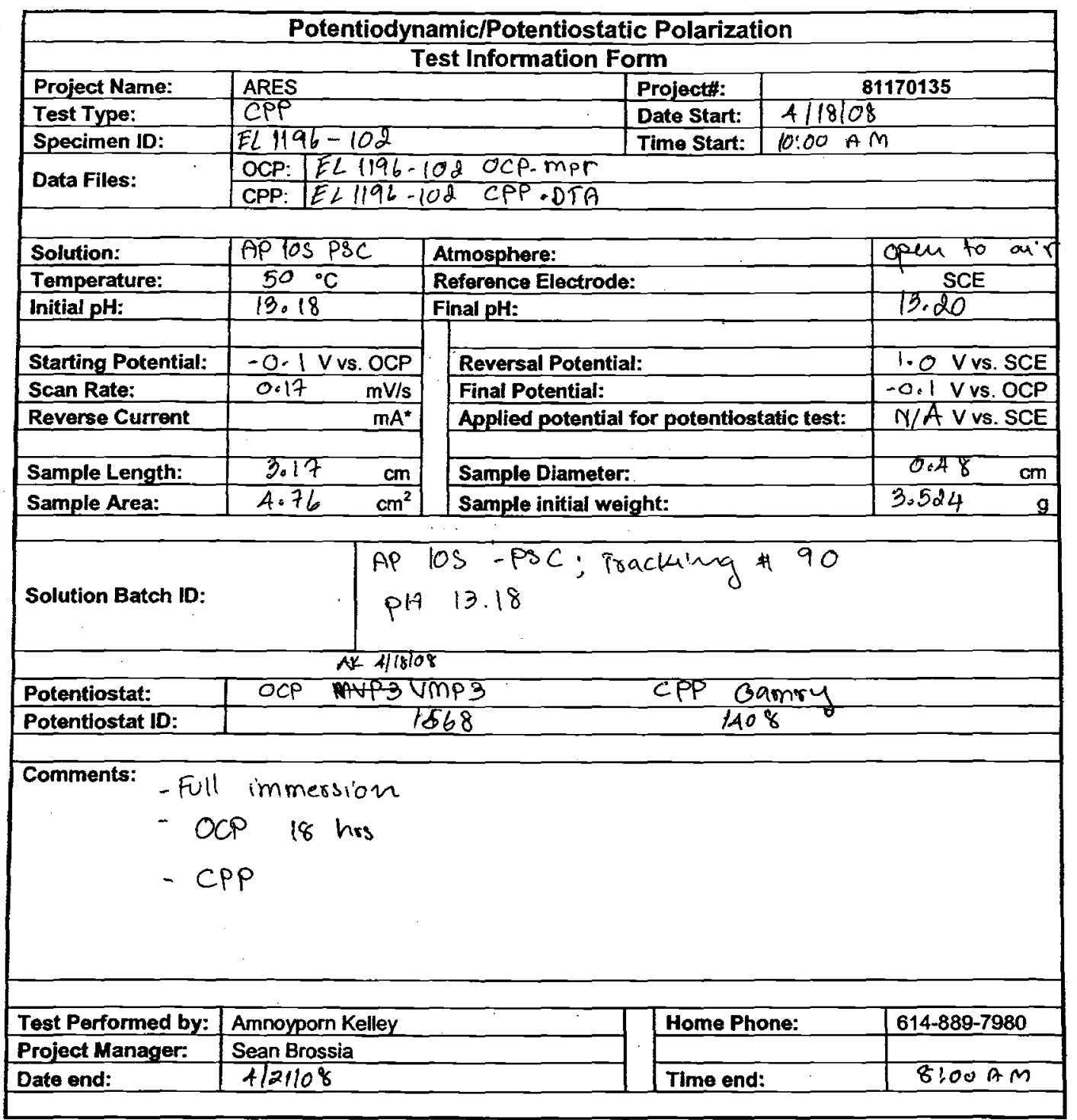

* Set a value such that the reversal current density is $1 \mathrm{~mA} / \mathrm{cm}^{2}$; 


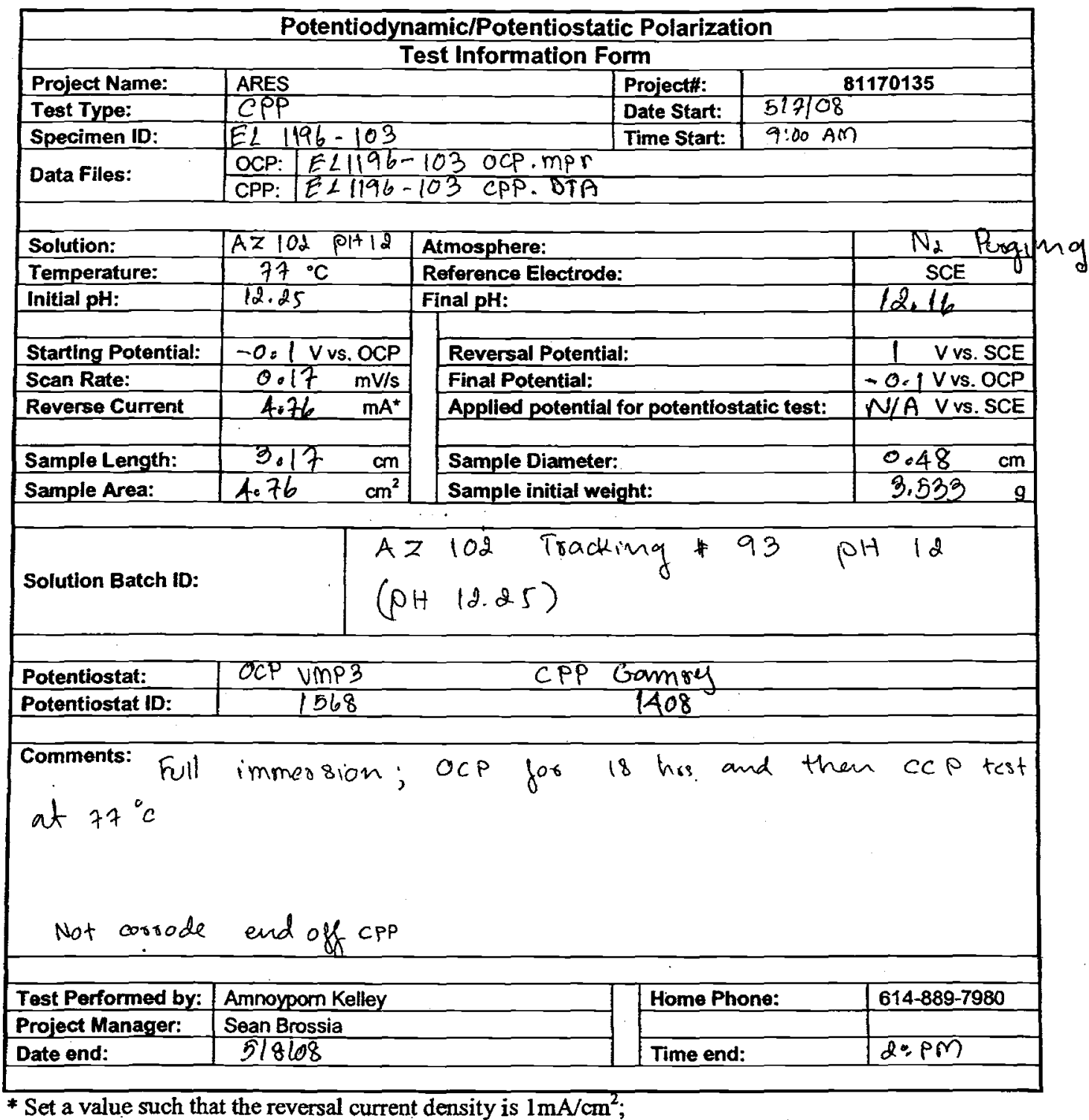

\section{QA APPROVED}

NAME: Clduen

DATE: 8-206 


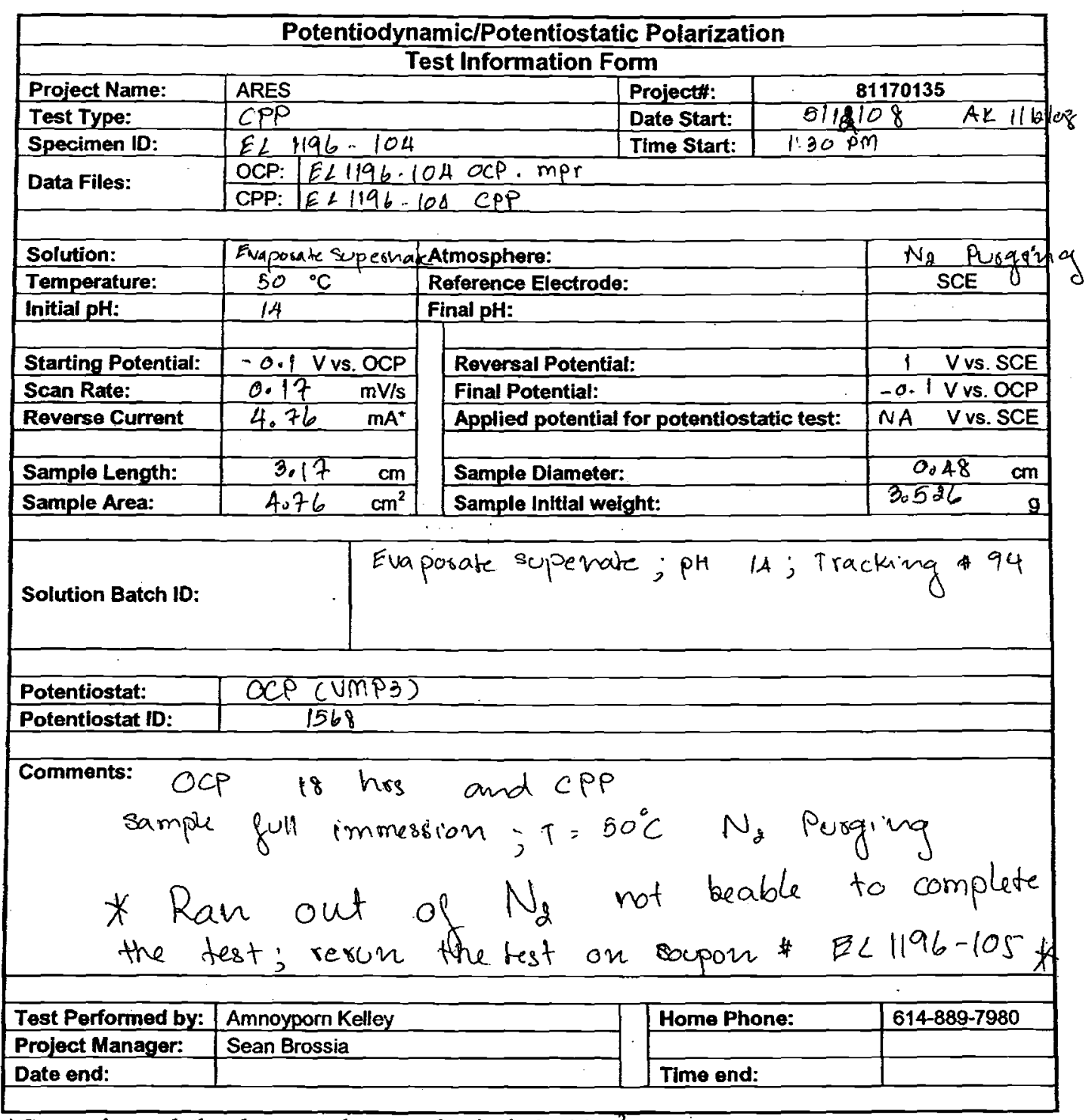

* Set a value such that the reversal current density is $1 \mathrm{~mA} / \mathrm{cm}^{2}$;

DATE: 8.700 


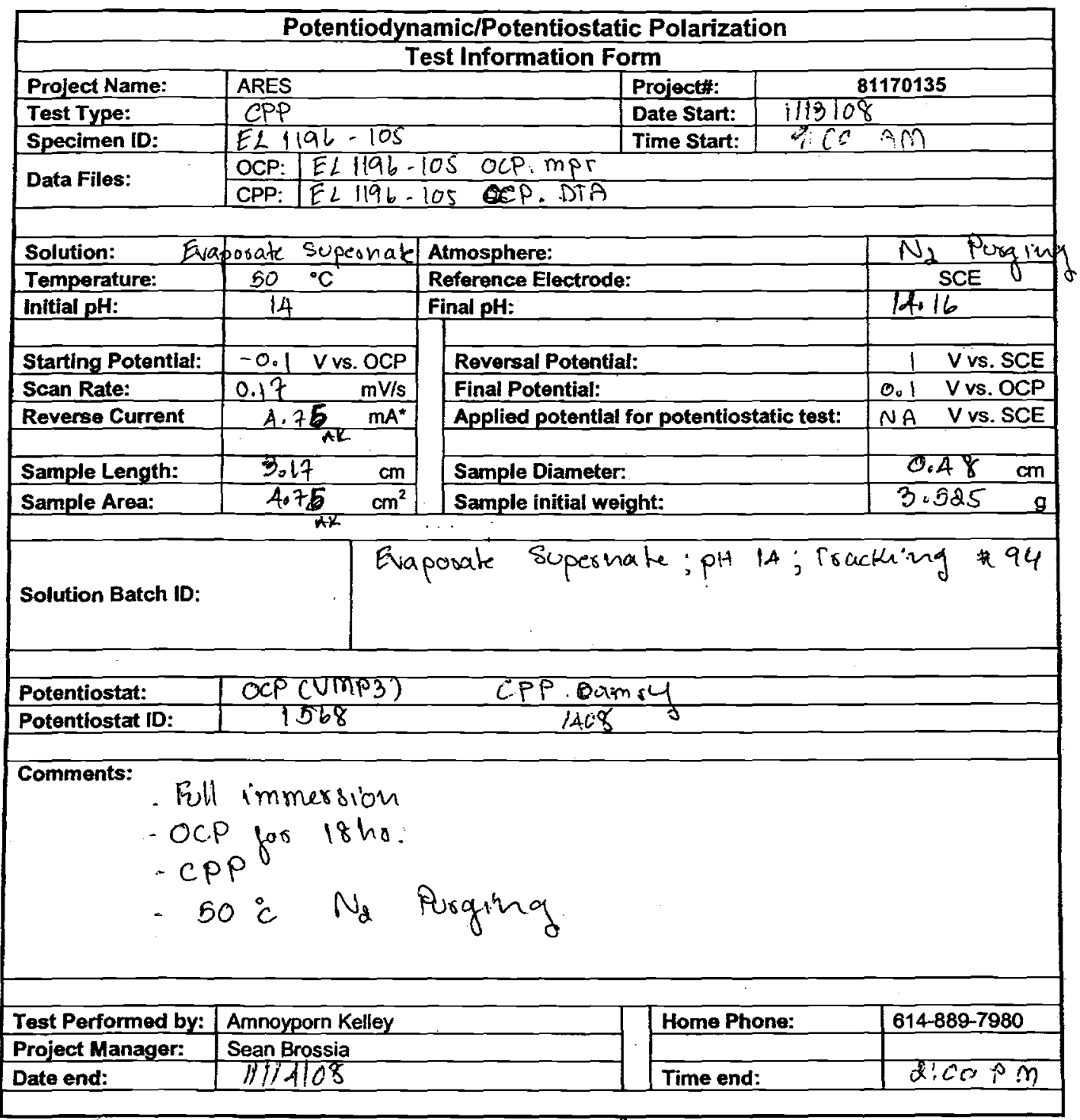

* Set a value such that the reversal current density is $1 \mathrm{~mA} / \mathrm{cm}^{2}$; 


\begin{tabular}{|c|c|c|c|c|c|}
\hline \multicolumn{6}{|c|}{ Potentiodynamic/Potentiostatic Polarization } \\
\hline \multicolumn{6}{|c|}{ Test Information Form } \\
\hline Project Name: & \multicolumn{2}{|l|}{ ARES } & Project\#: & \multicolumn{2}{|r|}{81170135} \\
\hline Test Type: & \multicolumn{2}{|l|}{ CPP } & Date Start: & \multicolumn{2}{|c|}{$5 / 14108$} \\
\hline Specimen ID: & \multicolumn{2}{|l|}{ EL 1196.106} & Time Start: & \multicolumn{2}{|c|}{$9: 00 \mathrm{Am}$} \\
\hline \multirow{2}{*}{ Data Files: } & \multicolumn{5}{|c|}{ OCP: EL $1196-106$ OCP. MPr. } \\
\hline & \multicolumn{5}{|c|}{ CPP: $E L 1196-106$ CPP } \\
\hline \multicolumn{6}{|c|}{ suppernate } \\
\hline Solution: & \multicolumn{2}{|c|}{ TAP 105 Ofixed Atmosphere: } & & & $N_{2}$ purge \\
\hline Temperature: & $50^{\circ}{ }^{\circ} \mathrm{C}$ & \multicolumn{3}{|c|}{$\begin{array}{l}\text { Atmosphere: } \\
\text { Reference Electrode: }\end{array}$} & SCE \\
\hline Initial pH: & $13^{7}$ & \multicolumn{3}{|c|}{$\begin{array}{l}\text { Reference Electrode: } \\
\text { FInal pH: }\end{array}$} & $15+$ \\
\hline Starting Potential: & $-O_{01}$ V vs. OCP & \multicolumn{3}{|c|}{ Reversal Potential: } & 0.1 V vs. SCE \\
\hline Scan Rate: & $0.17 \quad \mathrm{mV} / \mathrm{s}$ & \multicolumn{3}{|c|}{ Final Potential: } & -0.1 Vvs. OCP \\
\hline Reverse Current & $4.75 \quad \mathrm{~mA}^{*}$ & \multicolumn{3}{|c|}{ Applied potential for potentiostatic test: } & NA V vS. SCE \\
\hline Sample Length: & 3.17 & \multicolumn{3}{|c|}{ Sample Diameter: } & 0.48 \\
\hline Sample Area: & 4.75 & \multicolumn{3}{|c|}{ Sample initial weight: } & 3.528 \\
\hline $\begin{array}{l}\text { AP } 105 \text { mixed Supernate tracking } \$ 96 \\
\text { plt } 13^{+}\end{array}$ & \multicolumn{5}{|c|}{$\begin{array}{l}\text { AP } 105 \text { Mixed Supernate tracking } \$ 96 \\
\text { plt } 13^{+}\end{array}$} \\
\hline Potentiostat: & \multicolumn{5}{|c|}{ 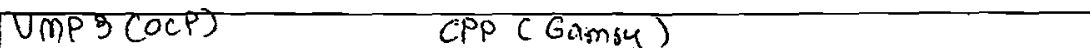 } \\
\hline Potentiostat 1D: & \multicolumn{5}{|c|}{$1568 \quad 1408$} \\
\hline \multicolumn{6}{|c|}{$\begin{array}{l}\text { Comments: Full immersion; } 50{ }^{\circ} \mathrm{C} ; N_{2} \text { Purging } \\
-O C P \text { and CPP }\end{array}$} \\
\hline Test Performed by: & \multicolumn{2}{|l|}{ Amnoyporn Kelley } & \multicolumn{2}{|c|}{ Home Phone: } & $614-889-7980$ \\
\hline Project Manager: & \multicolumn{2}{|l|}{ Sean Brossia } & \multirow{2}{*}{\multicolumn{2}{|c|}{ Time end: }} & \\
\hline Date end: & \multicolumn{2}{|l|}{$3 / 15103$} & & & $13: 00 \mathrm{Pm}$ \\
\hline
\end{tabular}

* Set a value such that the reversal current density is $1 \mathrm{~mA} / \mathrm{cm}^{2}$;

\section{QA APPROVED}

NAME: Clduw

DATE: $8 \rightarrow 2.06$ 


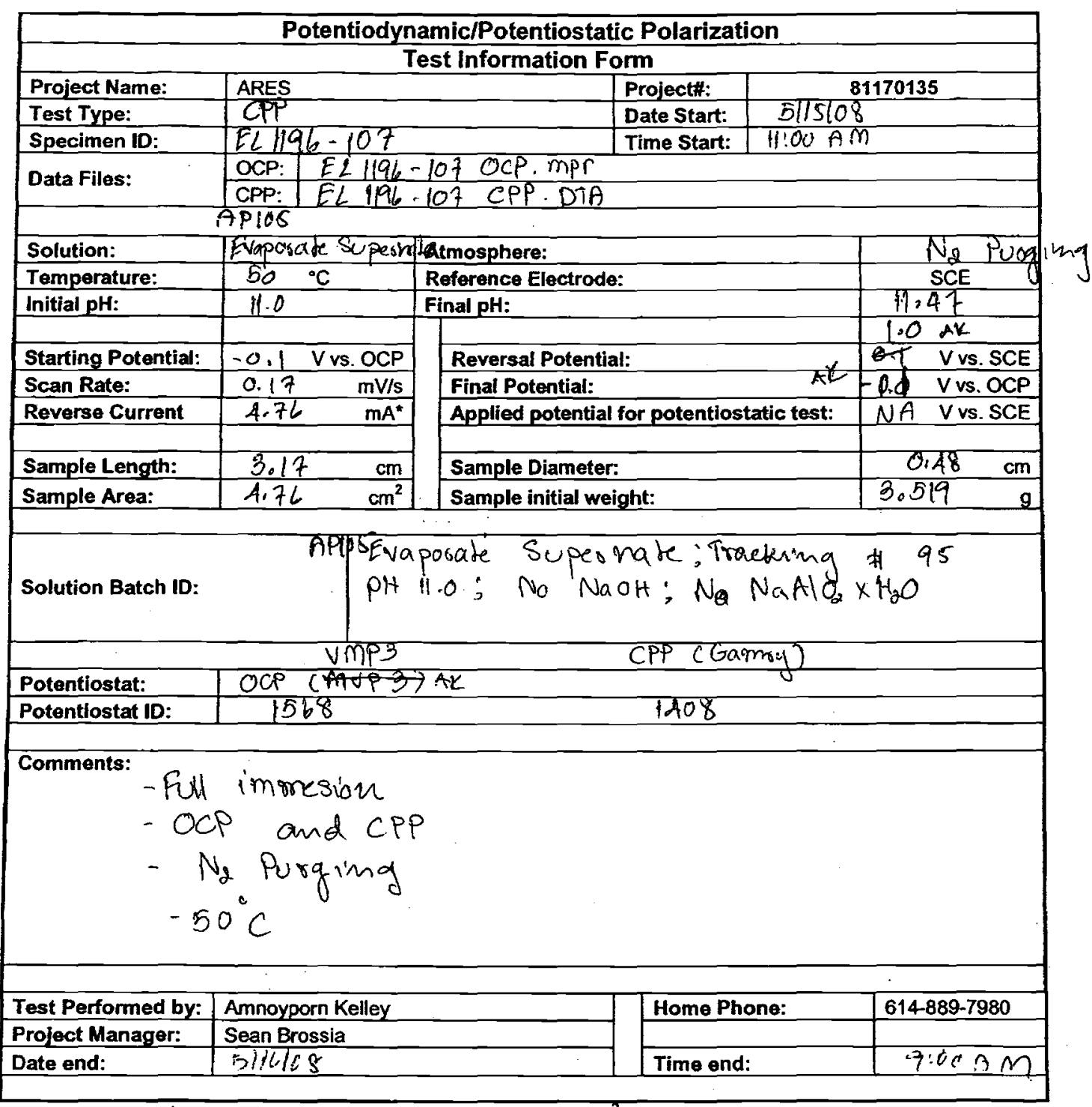

* Set a value such that the reversal current density is $1 \mathrm{~mA} / \mathrm{cm}^{2}$; 


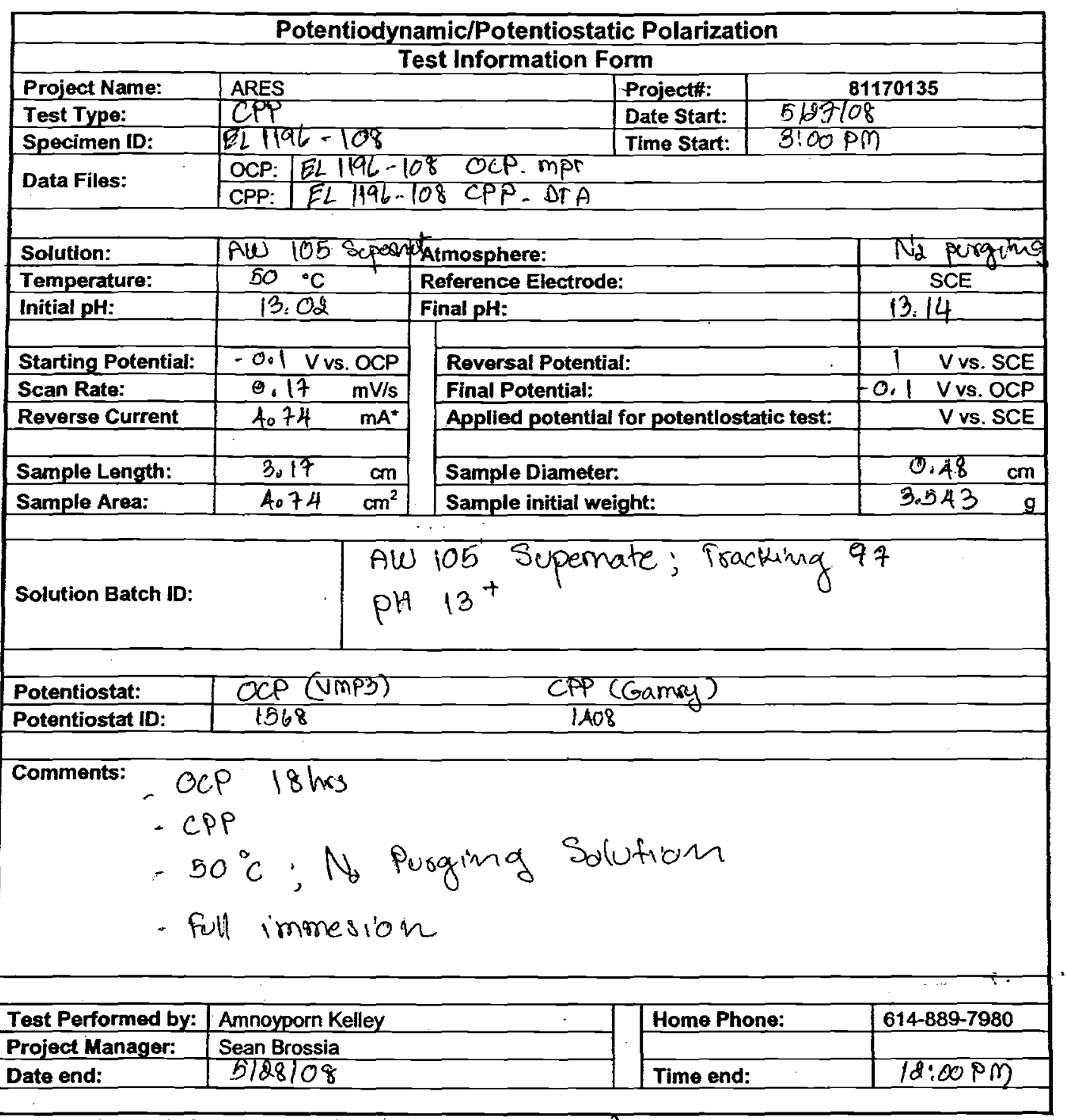

* Set a value such that the reversal current density is $1 \mathrm{~mA} / \mathrm{cm}^{2}$;

$$
\text { No crivican proituct }
$$




\begin{tabular}{|c|c|c|c|c|c|}
\hline \multicolumn{6}{|c|}{ Potentiodynamic/Potentiostatic Polarization } \\
\hline \multicolumn{6}{|c|}{ Test Information Form } \\
\hline Project Name: & \multicolumn{2}{|l|}{ ARES } & Project): & \multicolumn{2}{|r|}{81170135} \\
\hline Test Type: & \multicolumn{2}{|l|}{ CPP } & Date Start: & \multicolumn{2}{|c|}{5128108} \\
\hline Specimen 1D: & \multicolumn{2}{|l|}{$E L 1196-109$} & Time Start: & \multicolumn{2}{|c|}{$18: 00 \mathrm{pm}$} \\
\hline \multirow{2}{*}{ Data Files: } & \\
\hline & \multicolumn{5}{|c|}{ CPP: EL $1196-109$ CPP. DTA } \\
\hline Solution: & sytol & \multicolumn{3}{|l|}{ Atmosphere: } & $N_{3}$ \\
\hline Temperature: & 50 & \multicolumn{3}{|c|}{ Reference Electrode: } & SCE \\
\hline Initial pH: & 1330 & \multirow{2}{*}{\multicolumn{3}{|c|}{ Final pH: }} & 13.50 \\
\hline & & & & & $\Lambda ^ { k } 5 \longdiv { 8 8 }$ \\
\hline Starting Potential: & $-0+1$ V vs. OCP & \multicolumn{3}{|c|}{ Reversal Potential: } & an 1 V V. SCE \\
\hline Scan Rate: & $0.17 \mathrm{mV} / \mathrm{s}$ & \multicolumn{3}{|c|}{ Final Potential: } & RF 0.1 V vs. OCP \\
\hline Reverse Current & 4.76 & \multicolumn{3}{|c|}{ Applied potential for potentiostatic test: } & V vs. SCE \\
\hline Sample Length: & 8.17 & \multicolumn{3}{|c|}{ Sample Diameter: } & 0.18 \\
\hline Sample Area: & 4.76 & \multicolumn{3}{|c|}{ Sample initial weight: } & 3.559 \\
\hline \multicolumn{6}{|l|}{ Solution Batch ID: } \\
\hline Potentiostat: & \multicolumn{5}{|c|}{ OCP (NMPB) $\quad$ CPP (Gamsy) } \\
\hline Potentlostat ID: & \multicolumn{5}{|c|}{1568} \\
\hline \multicolumn{6}{|c|}{$\begin{aligned} \text { Comments: } & - \text { OCP } 18 \text { hrs } \\
& -C P P \quad \mathrm{~N} \text { purging } \\
& - \text { at } 50 \overline{\mathrm{C}} \mathrm{N} \\
& - \text { Fult immession }\end{aligned}$} \\
\hline Test Performed by: & \multicolumn{2}{|l|}{ Amnoyporn Kelley } & \multicolumn{2}{|c|}{ Home Phone: } & $614-889-7980$ \\
\hline Project Manager: & \multicolumn{2}{|l|}{\begin{tabular}{|l} 
Sean Brossia \\
$5 / 2910 \%$ \\
\end{tabular}} & & \\
\hline Date end: & \multicolumn{2}{|l|}{5129108} & \multicolumn{2}{|c|}{ Time end: } & $15: 00 \mathrm{pM}$ \\
\hline
\end{tabular}

* Set a value such that the reversal current density is $1 \mathrm{~mA} / \mathrm{cm}^{2}$;

Not corroded.

\section{QA APPROVED}

NAME: Ceduw

DATE: $8-2-08$ 


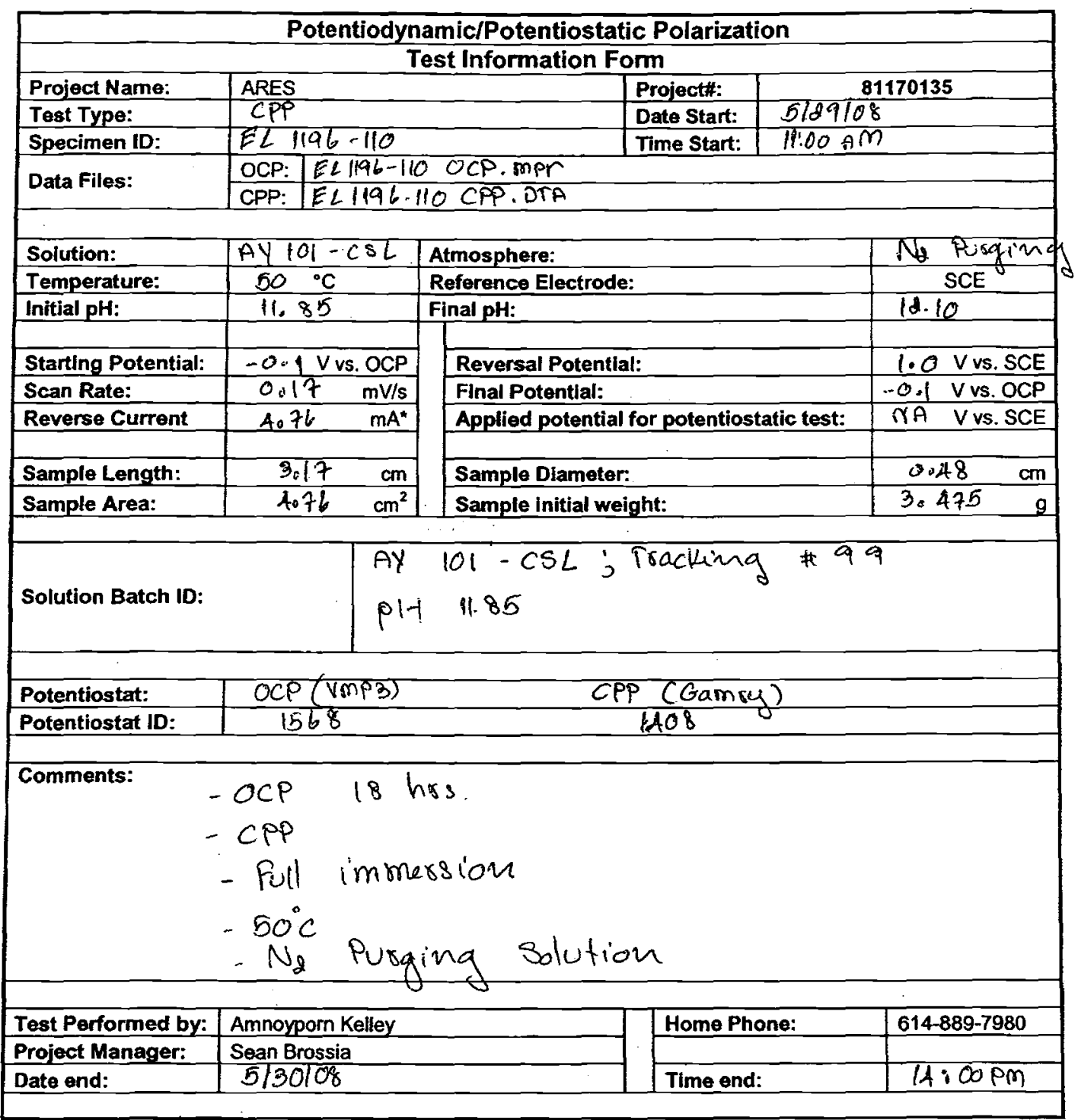

* Set a value such that the reversal current density is $1 \mathrm{~mA} / \mathrm{cm}^{2}$;

\section{QA APPROVED}

NAME: Ceduen

DATE: $8 \rightarrow \rightarrow 0$ 


\begin{tabular}{|c|c|c|c|c|c|}
\hline \multicolumn{6}{|c|}{ Potentiodynamic/Potentiostatic Polarization } \\
\hline \multicolumn{6}{|c|}{ Test Information Form } \\
\hline Project Name: & \multicolumn{2}{|l|}{ ARES } & Project\#: & \multicolumn{2}{|c|}{81170135} \\
\hline Test Type: & \multicolumn{2}{|l|}{ CPP } & Date Start: & \multicolumn{2}{|c|}{6116108} \\
\hline Specimen ID: & \multicolumn{2}{|l|}{ EL $1196-111$} & Time Start: & \multicolumn{2}{|c|}{$4+4 A M$} \\
\hline \multirow{2}{*}{ Data Files: } & \multicolumn{5}{|c|}{\begin{tabular}{|l|lll} 
OCP: & $E L$ & $119 b-111$ OQP. $m P r$ \\
CPP. & $E E, ~ 119 b-111$ CPP \\
\end{tabular}} \\
\hline & \multicolumn{5}{|c|}{ CPP: $E_{L}\|96\| .1 \| C P P_{1}$ DTA } \\
\hline Solution: & AY $101-C S L$ & \multicolumn{3}{|l|}{ Atmosphere: } & No Purging \\
\hline Temperature: & $50{ }^{\circ} \mathrm{C}$ & \multicolumn{3}{|l|}{ Reference Electrode: } & SCE \\
\hline Initial pH: & 11.82 & \multicolumn{3}{|l|}{ Final pH: } & 11.90 \\
\hline Starting Potential: & $-0 .\{$ V vs. OCP & \multicolumn{3}{|c|}{ Reversal Potential: } & 1.0 V vs. SCE \\
\hline Scan Rate: & $0.17 \quad \mathrm{mV} / \mathrm{s}$ & \multicolumn{3}{|l|}{ Final Potential: } & -0.1 V vs. OCP \\
\hline Reverse Current & 4.76 & \multicolumn{3}{|c|}{ Applied potential for potentiostatic test: } & NA V vs. SCE \\
\hline Sample Length: & 3.17 & \multicolumn{3}{|l|}{ Sample Diameter: } & 0.48 \\
\hline Sample Area: & $4076 \quad \mathrm{~cm}^{2}$ & \multicolumn{3}{|c|}{ Sample initial weight: } & $3.518 \quad \mathrm{~g}$ \\
\hline \multicolumn{6}{|l|}{ Solution Batch ID: } \\
\hline Potentiostat: & \multicolumn{3}{|c|}{ OCP UMP3 CPP Gamry } & & \\
\hline Potentiostat ID: & \multicolumn{3}{|c|}{$1568 \quad 1408$} & & \\
\hline \multicolumn{6}{|c|}{ * Cosscsion on coupon } \\
\hline Test Performed by: & \multicolumn{2}{|l|}{ Amnoyporn Kelley } & \multicolumn{2}{|c|}{ Home Phone: } & $614-889-7980$ \\
\hline Project Manager: & \multirow{2}{*}{\multicolumn{2}{|c|}{\begin{tabular}{|l} 
Sean Brossia \\
$6 / 17108$
\end{tabular}}} & & \\
\hline Date end: & & & Time end: & & $12: 00 \mathrm{Pm}$. \\
\hline
\end{tabular}

* Set a value such that the reversal current density is $1 \mathrm{~mA} / \mathrm{cm}^{2}$;

\section{QA APPROVED}

NAME: Qdeur

DATE: $8 \rightarrow \sigma$ 
RPP-RPT-37505, Rev. 0

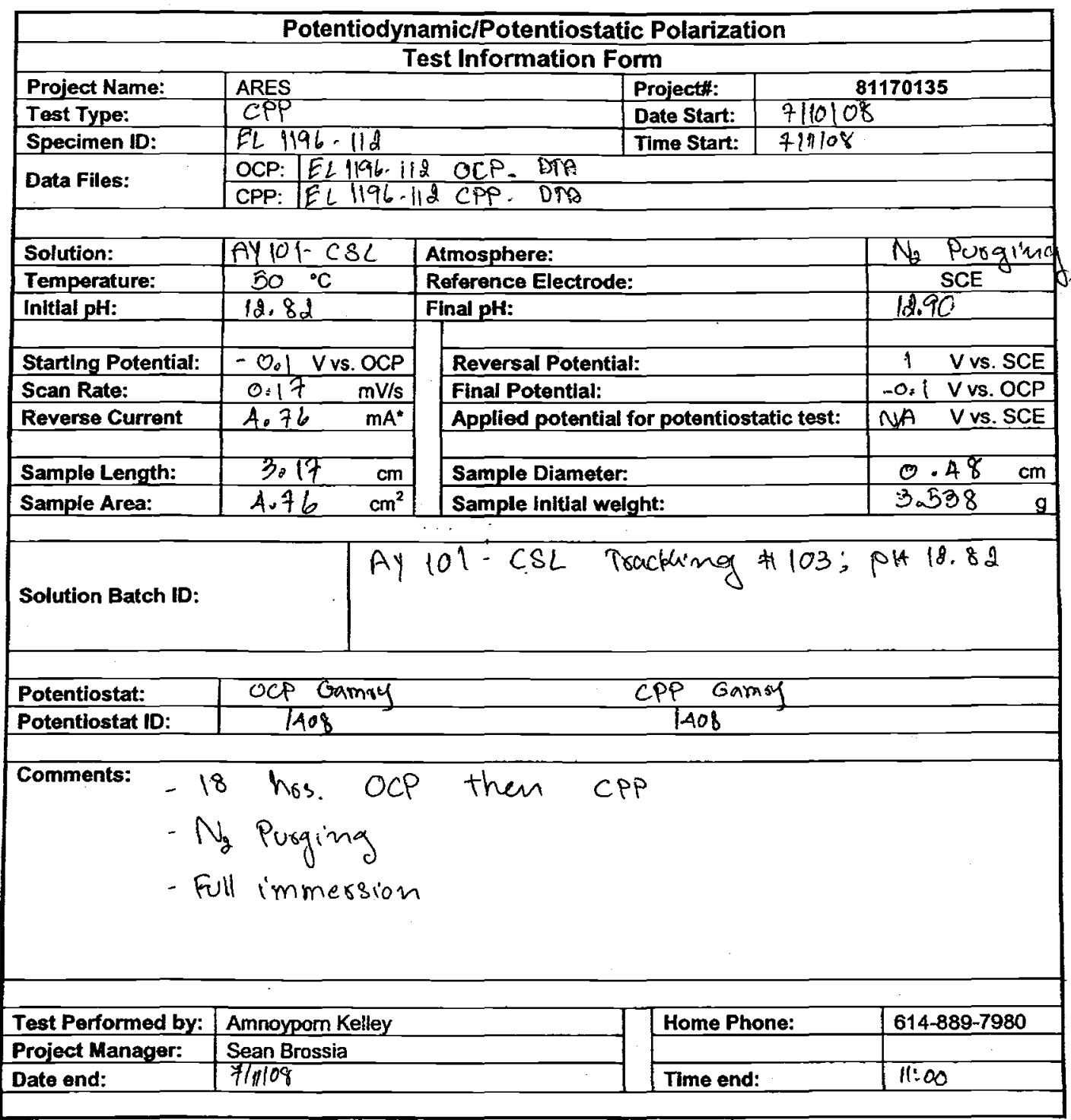

* Set a value such that the reversal current density is $1 \mathrm{~mA} / \mathrm{cm}^{2}$;

$$
\text { coupon not corrode }
$$

QA APPROVED

NAME:Cedur

DATE: $8 \rightarrow-\infty$ 


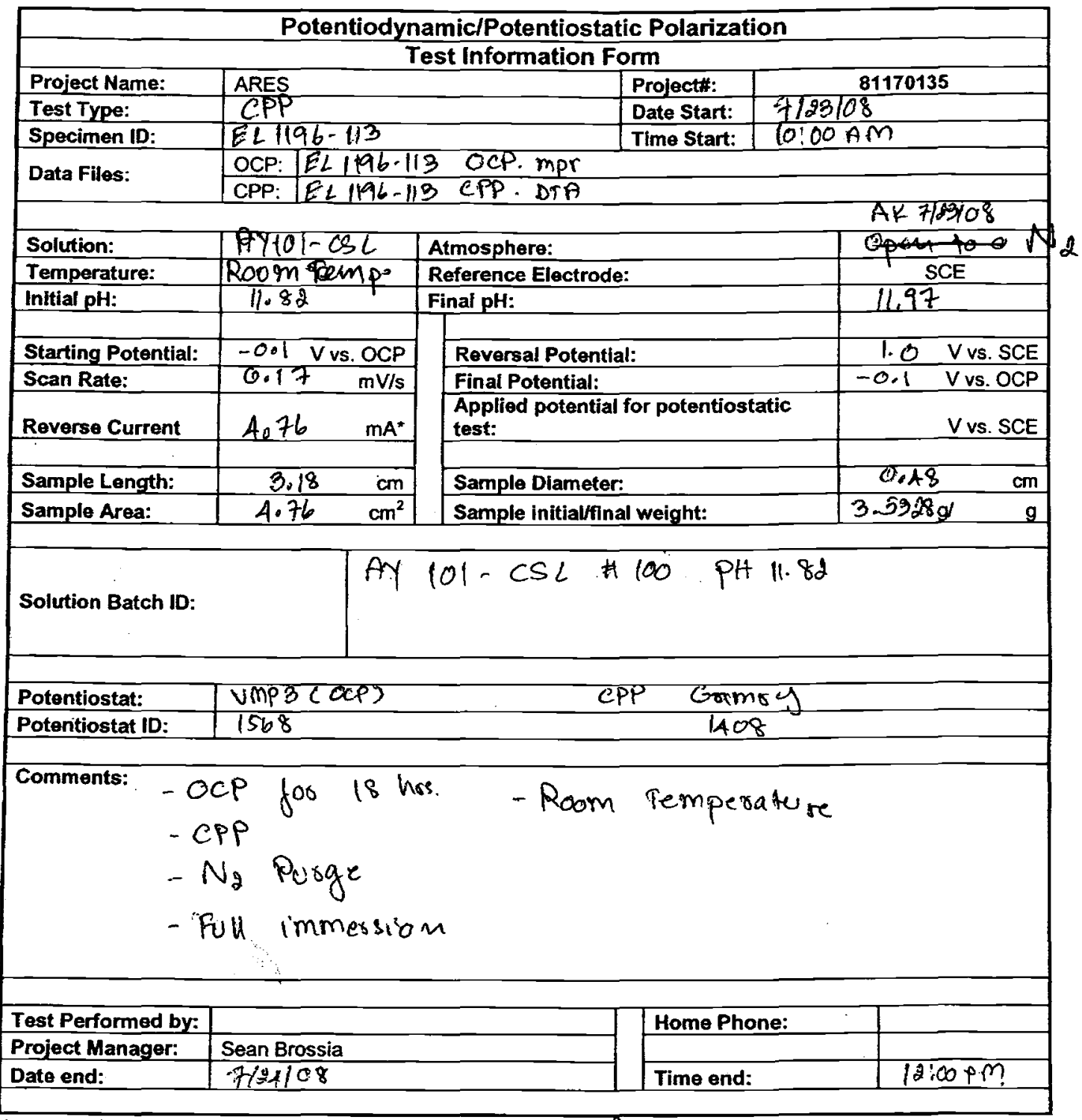

* Set a value such that the reversal current density is $1 \mathrm{~mA} / \mathrm{cm}^{2}$; coupon net cosoode.

NAME: Qdum

DATE: $8 \rightarrow 08$ 


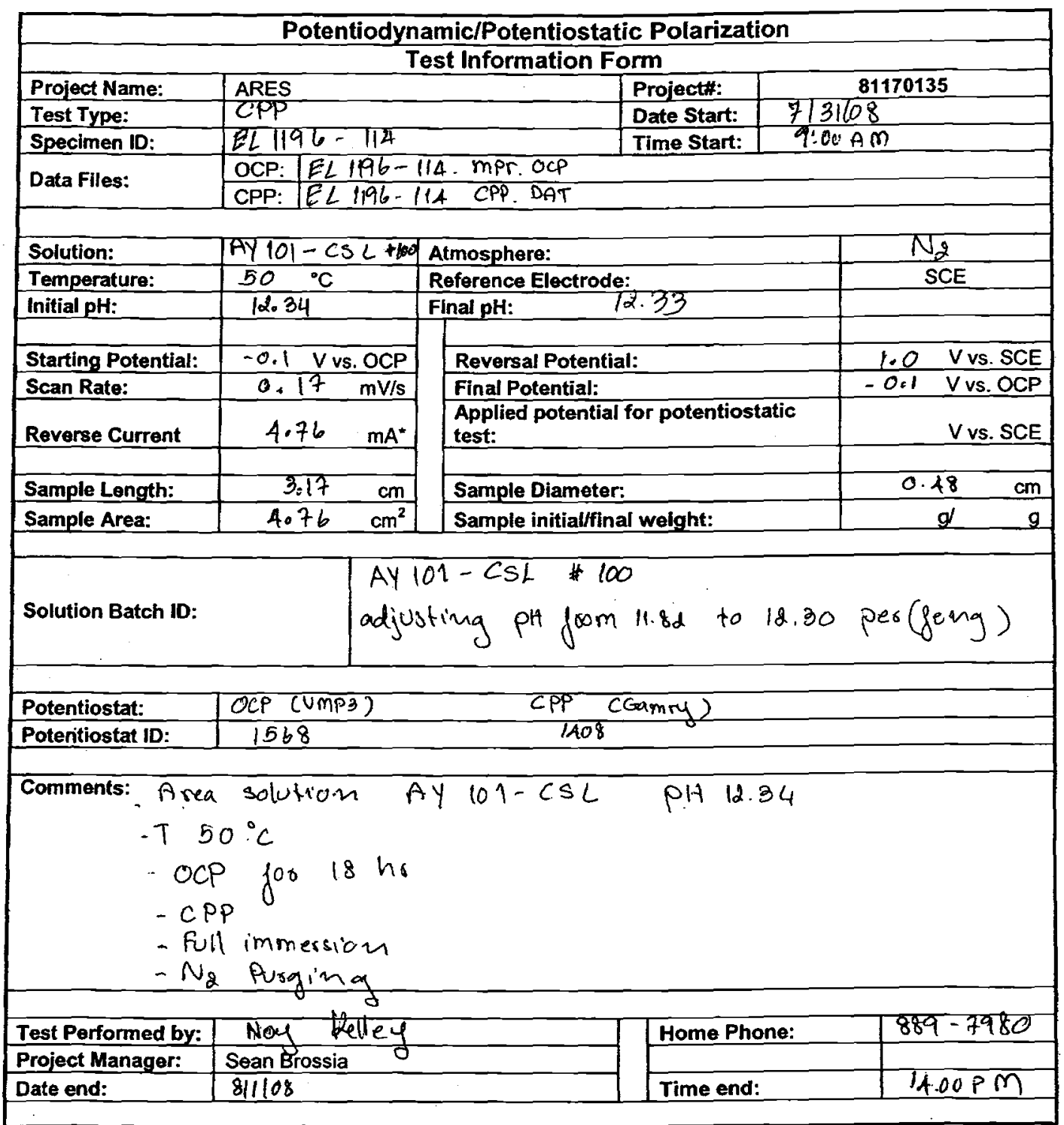

* Set a value such that the reversal current density is $1 \mathrm{~mA} / \mathrm{cm}^{2}$;

\section{QA APPROVED}

NAME: Ceduw

DATE: 8-7-08 
RPP-RPT-37505, Rev. 0

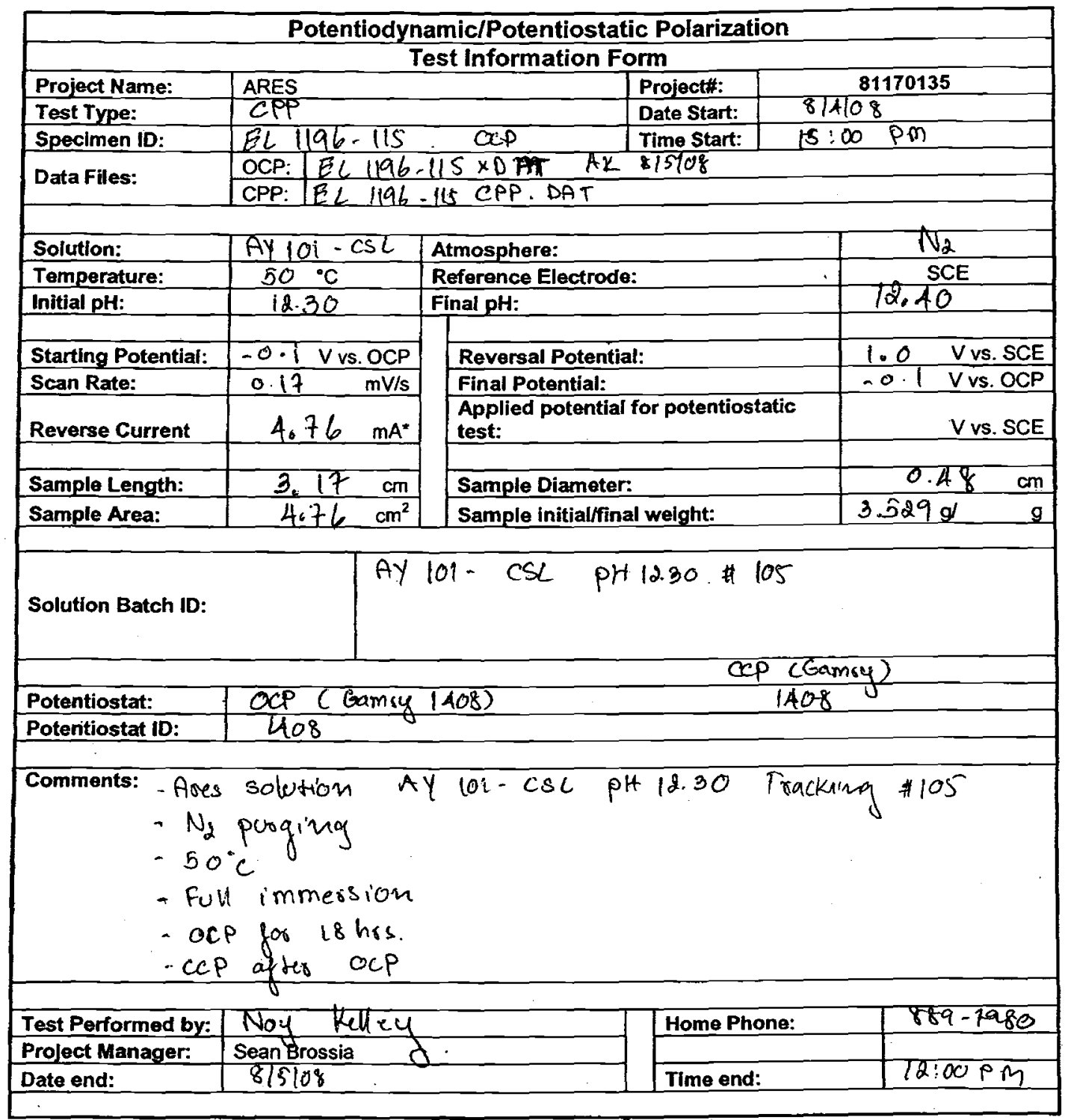

* Set a value such that the reversal current density is $1 \mathrm{~mA} / \mathrm{cm}^{2}$;

$$
\text { sample cooode after CPP }
$$

QA APPROVED

NAME: Cedur

DATE: $\quad 8-7-02$ 
Slow Strain Rate

Work Request/Test Information Form

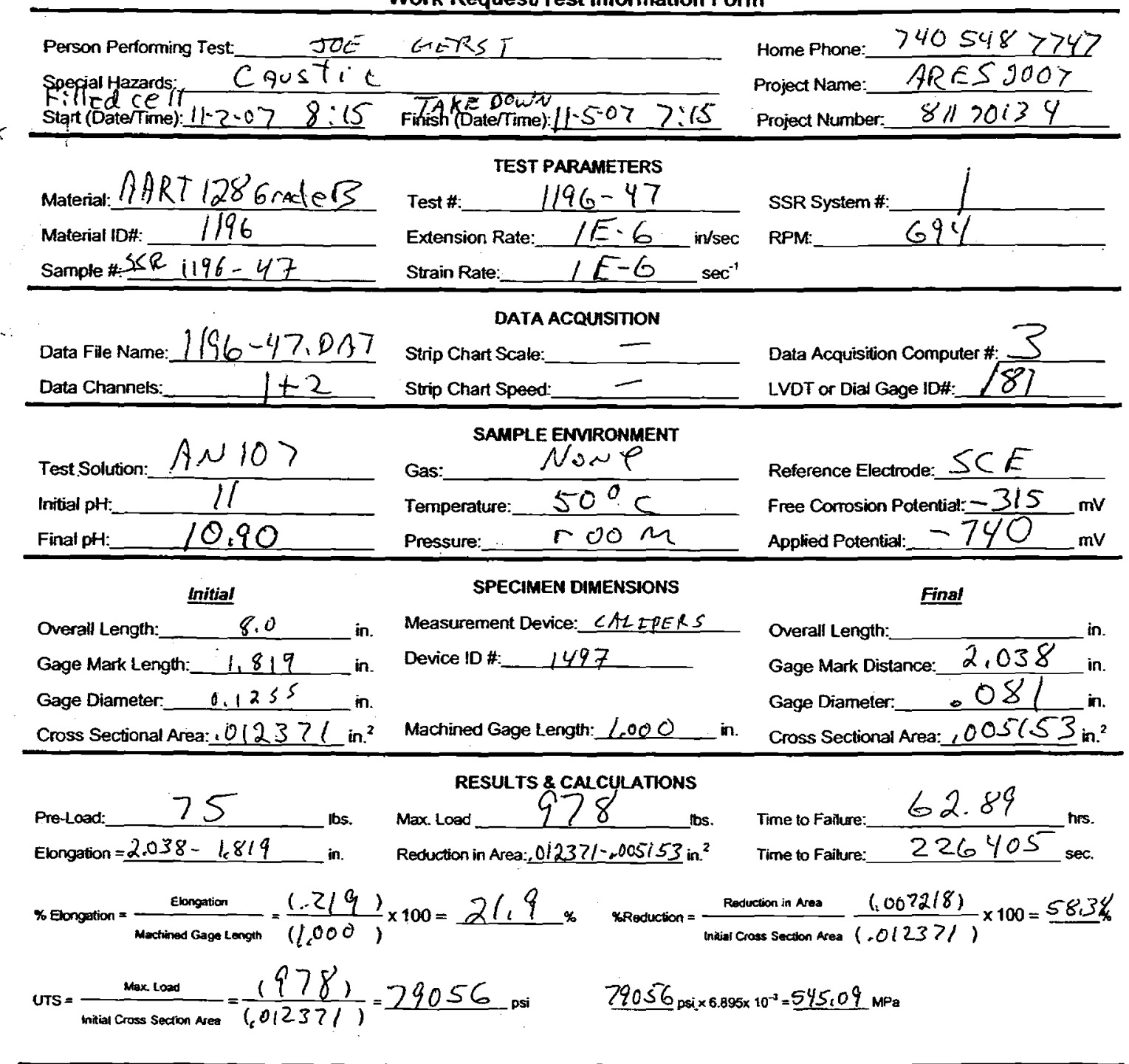

CRACKING

Visual:
Low Power (30X):
Metallographic:
Comments: $100 \Omega$ ResisTor
PSTA 2090 Tcent/aller 1260 TC 1532

Crack Mode:

Max Crack Depth: $\mathrm{mm}$

Crack Velocity: $\mathrm{mm} / \mathrm{sec}$

Project Leader's Signature:
$\begin{aligned} & \text { QA O09-SSR Specimens, Tests, \& Evaluatio } \\ & \text { Revision 2 }\end{aligned}$


RPP-RPT-37505, Rev. 0

\section{Test Sheet Addendum}

\begin{tabular}{|c|c|}
\hline Test \# & $1196-47$ \\
\hline Sample \# & SSR $1196-47$ \\
\hline Filar Eye Piece & CCT\# 0224 \\
\hline Magnification & $30 x$ \\
\hline inches/graduation & .001 \\
\hline
\end{tabular}

\begin{tabular}{|c|c|c|}
\hline \multicolumn{2}{|l|}{$\begin{array}{c}\text { Readings } \\
86 \\
5\end{array}$} & \\
\hline $\begin{array}{c}\text { Avg. } \\
\text { Reading, } \\
\text { graduations }\end{array}$ & * $\begin{array}{c}\text { inches/ } \\
\text { graduation }\end{array}$ & $\begin{array}{l}=\text { Final Diameter, } \\
\text { in. }\end{array}$ \\
\hline 81 & .001 & .081 \\
\hline
\end{tabular}

\section{Comments}


Slow Strain Rate

Work Request/Test Information Form

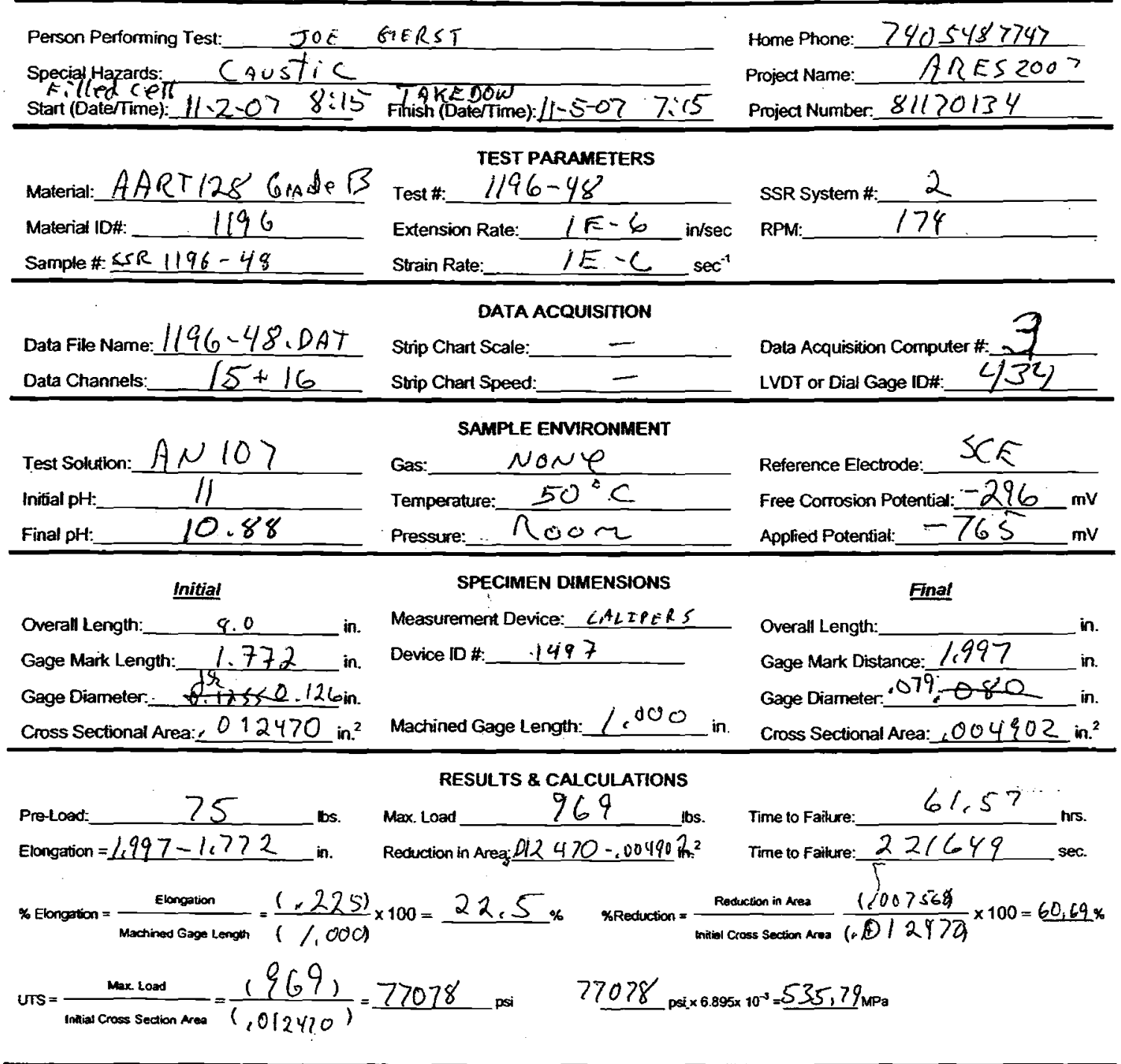

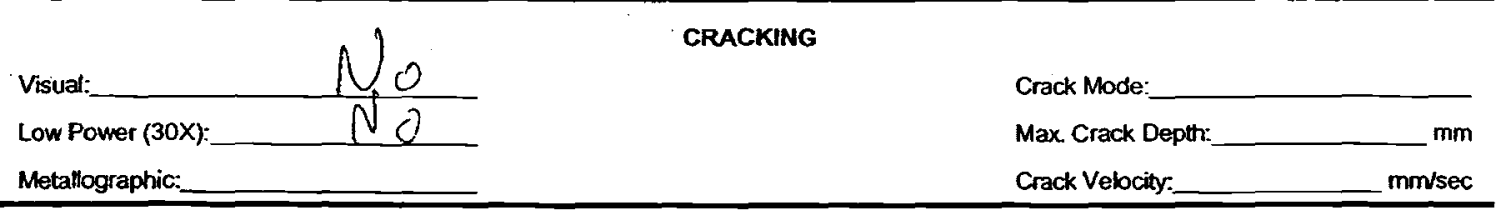

Comments: $100 \mathrm{n}$ Resistor

PSTAT \#2088 Tcontraller \#1269 TC\#1538

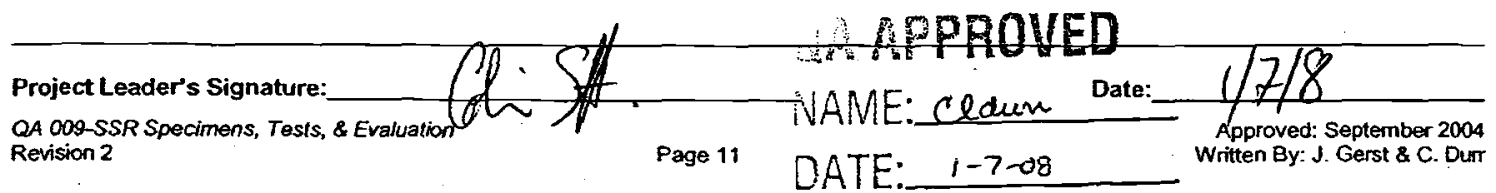


RPP-RPT-37505, Rev. 0

\section{Test Sheet Addendum}

\begin{tabular}{|c|c|}
\hline Test \# & $1196-48$ \\
\hline Sample \# & SSR $1196-48$ \\
\hline Filar Eye Piece & CCT \# 0224 \\
\hline Magnification & 30 \\
\hline inches/graduation & .001 \\
\hline
\end{tabular}

Readings

99

20

Reading, inches/ = Final Diameter, graduations graduation in.

fe.07.79 .001_.079

\section{Comments}


RPP-RPT-37505, Rev. 0

Slow Strain Rate

Work Request/Test Information Form

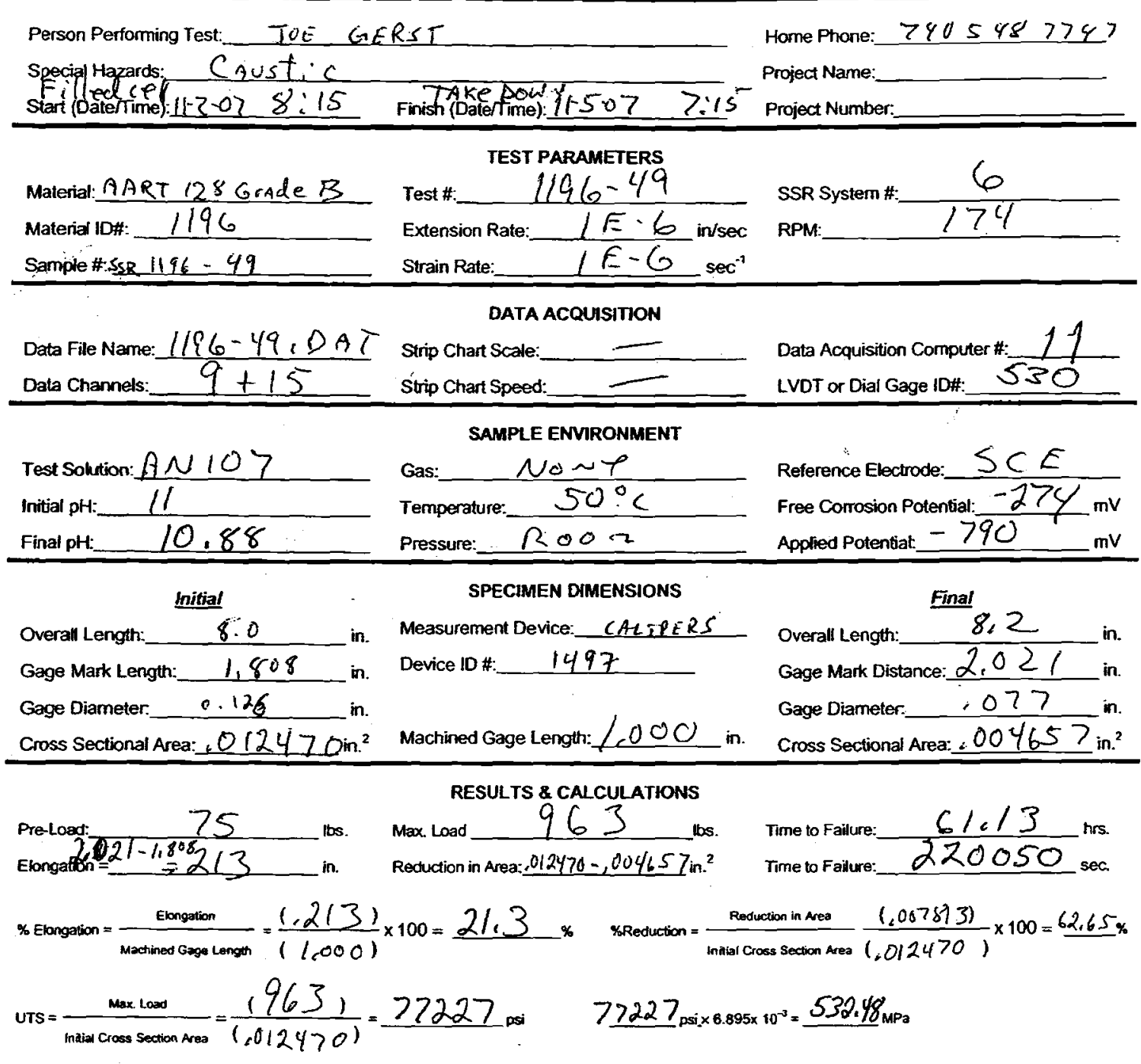

CRACKING

Visual:

Crack Mode

Low Power (30X):

Max. Crack Depth:

mm

Metallographic:

Crack Velocity.

$\mathrm{mm} / \mathrm{sec}$

comments: $\Omega 100$ Resistor

PSTAT \#2115 Tcontroller\#1325 TC 1534

Project Leader's Signature:_f
$\begin{aligned} & \text { A4 0og-SSR Specimens, Tests, \& Evaluation } \\ & \text { Revision 2 }\end{aligned}$ 
RPP-RPT-37505, Rev. 0

\section{Test Sheet Addendum}
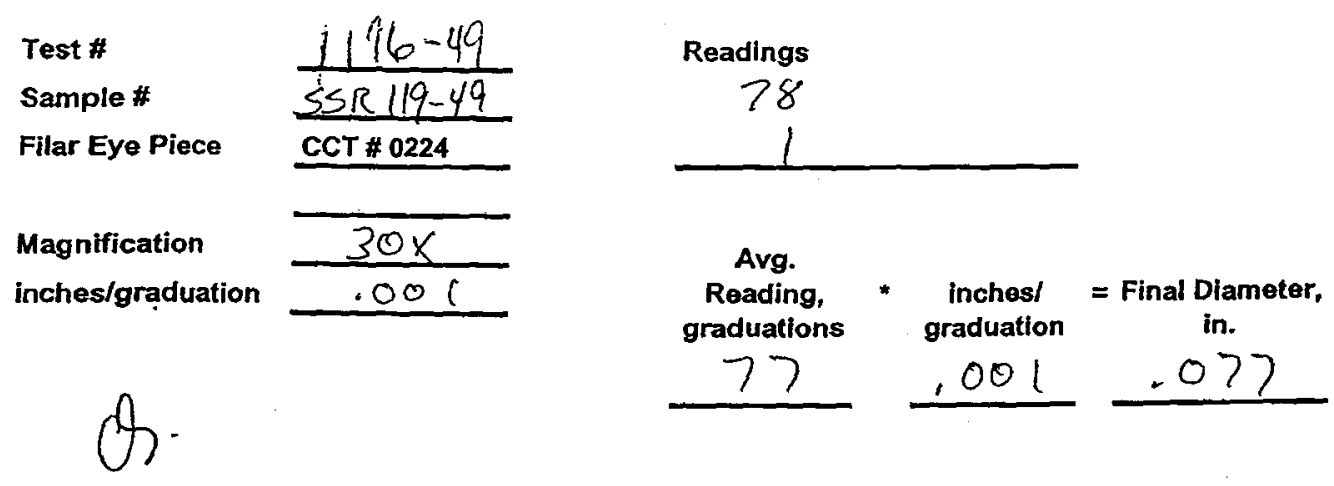

\section{Comments}


Slow Strain Rate

Work RequestTest Information Form

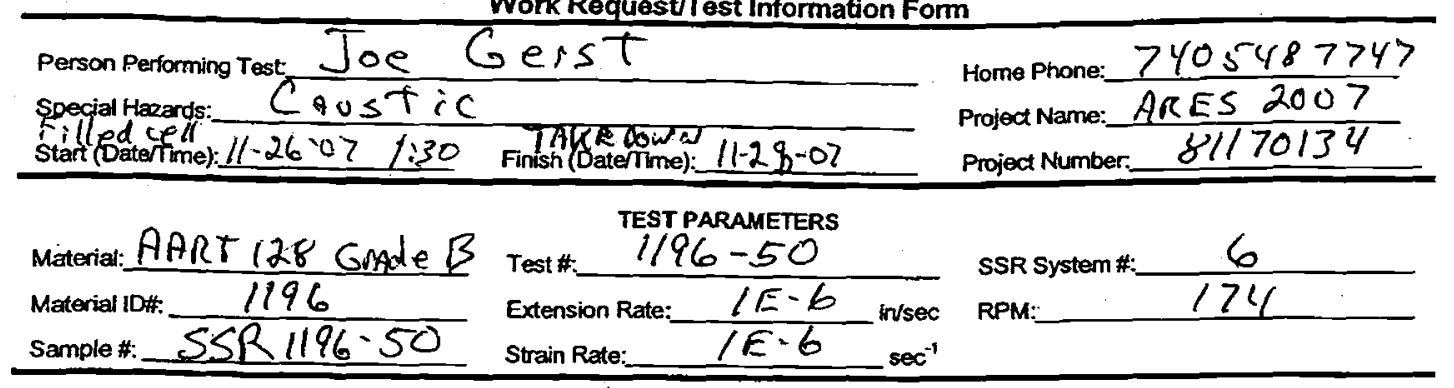

Data File $1 / 96-50$, DAT DATAACQuisition

Data File Name: $\frac{1196-50, \text { DAT Strip Chart Scale:- }}{9+15}$ strip Chart Speed:-

Tracking 68 PSC sample envionment

Test Solution: AP IOS PSC

Final pH: 13.77
Initial pH: 13,14

Gas: No Ne

Temperature: $\frac{50}{\mathrm{R}} \mathrm{Com}$

SPECIMEN DIMENSIONS

Overal Length: $\frac{4.0}{1,681}$ in.

Cross Sectional Area: $0123.71 \mathrm{~m}^{2}$

measurement Device: Calipers

Machined Gauge Length: 1,000 in.
Temperature: $50^{\circ} \mathrm{C}$

Gauge Diameter. 1255 in

Device ID \#: 1497

Data Acquisition Computer \#- 11

LVDT or Dial Gauge ID\# $\quad 530$

Reference Electrode: SCE

Freo Corrosion Potential: $-242 \mathrm{mv}$

Applied Potential: $\mathrm{C} \mathrm{mv}$

Overall Length: $\quad \frac{\text { Final }}{8,2}$

Overall Length: $\quad-\frac{8,2}{T 0}$ corroded

Gauge Mark Distance: 10 coirod in.

Gauge quámeter. To me Asuren.

Cross Sectional Area:

$\mathrm{m}^{2}$

\section{RESULTS \& CALCULATIONS}

Max. Lasd 955 Time to Falure: 41.58 hrs.

Reduction in Area:_ in $^{2}$ Time to Faikre: 149670 sec.

Elongation $=.158$ in. Reduction in Area: in $^{2}$

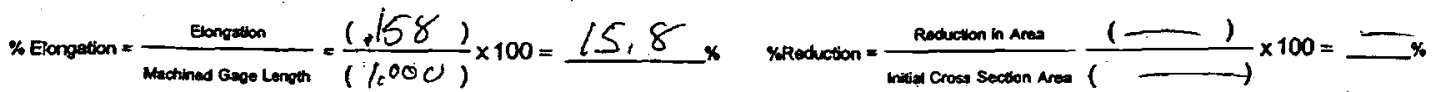

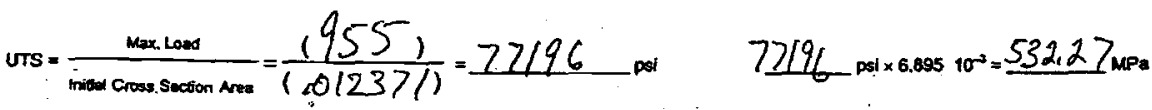

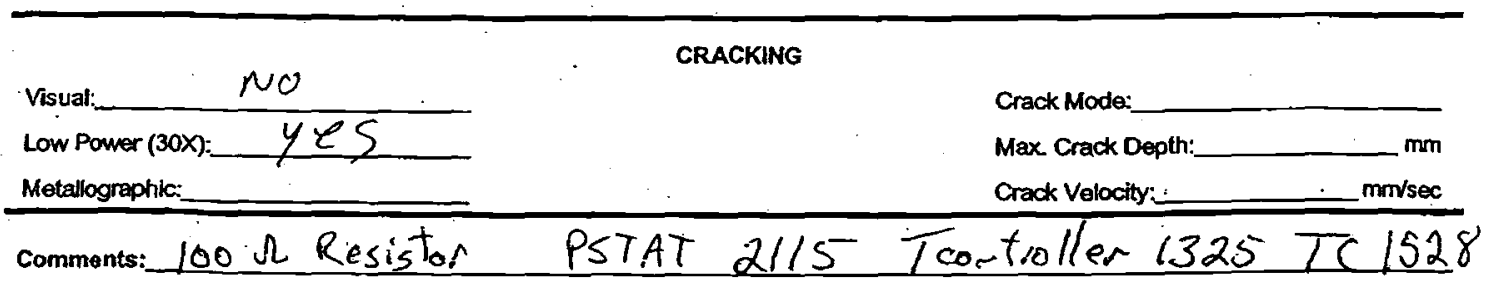


RPP-RPT-37505, Rev. 0

\section{Test Sheet Addendum}

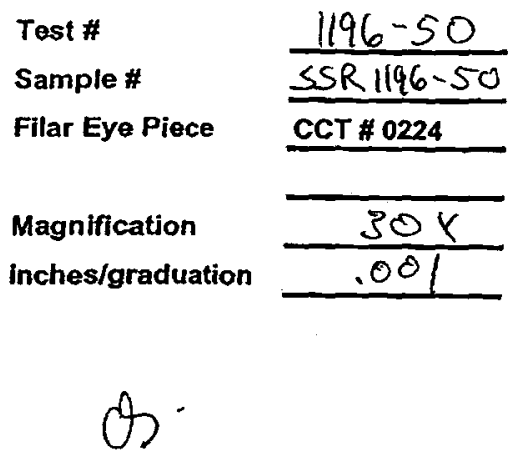

Readings $T_{100} \operatorname{cor} \frac{d e^{d}}{10} e^{s^{s^{f}}}$

Avg.

Reading, * inchesl = Final Diameter, graduations graduation

in.

\section{Comments}


Slow Strain Rate

Work Request/Test information Form

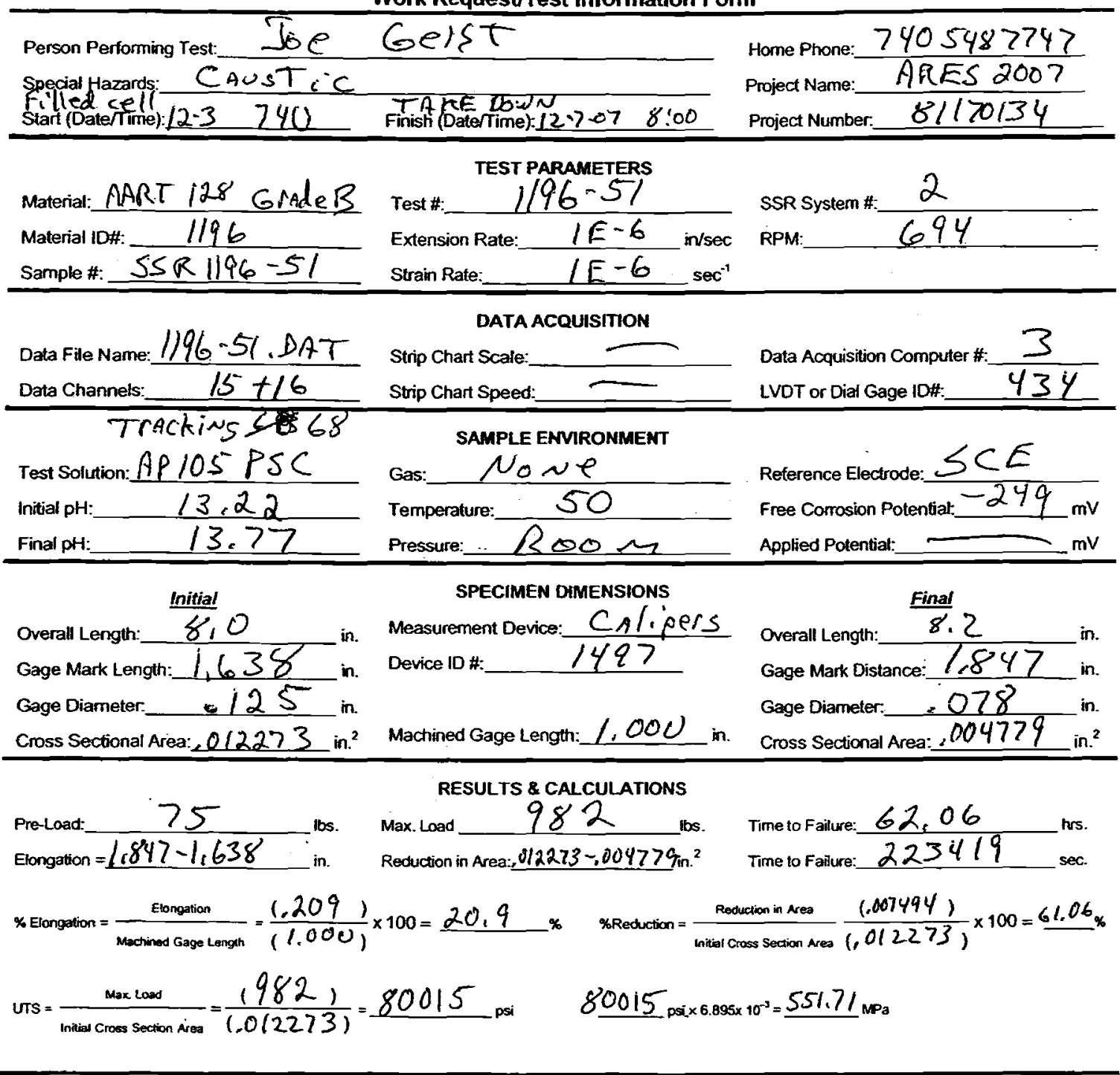

CRACKING

Visual:

Low Power (30x): $\quad y<S$

Metallographic:____ Crack Velocity.

Crack Mode

comments: $\not$ Tcoutudlen \#1325 TC 1528

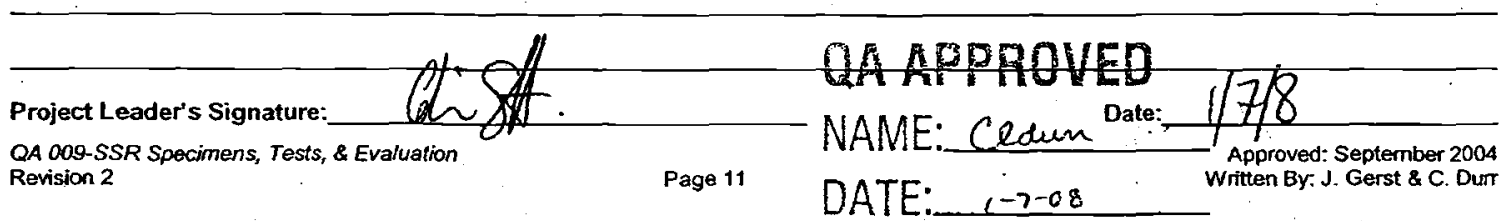


RPP-RPT-37505, Rev. 0

\section{Test Sheet Addendum}

\begin{tabular}{|c|c|}
\hline $\begin{array}{l}\text { Test \# } \\
\text { Sample \# }\end{array}$ & $\frac{1196 \cdot 51}{\operatorname{ssR} 1196-51}$ \\
\hline Fllar Eye Piece & CCT\# 0224 \\
\hline Magnification & $30 x$ \\
\hline Inches/graduation & .001 \\
\hline
\end{tabular}
Readings
78
0

Avg.

Reading, * Inchesl = Final Diameter, graduations graduation

in.

78

$.00 \mathrm{C}$

.078

\section{Comments}


Slow Strain Rate

Work Request/Test Information Form

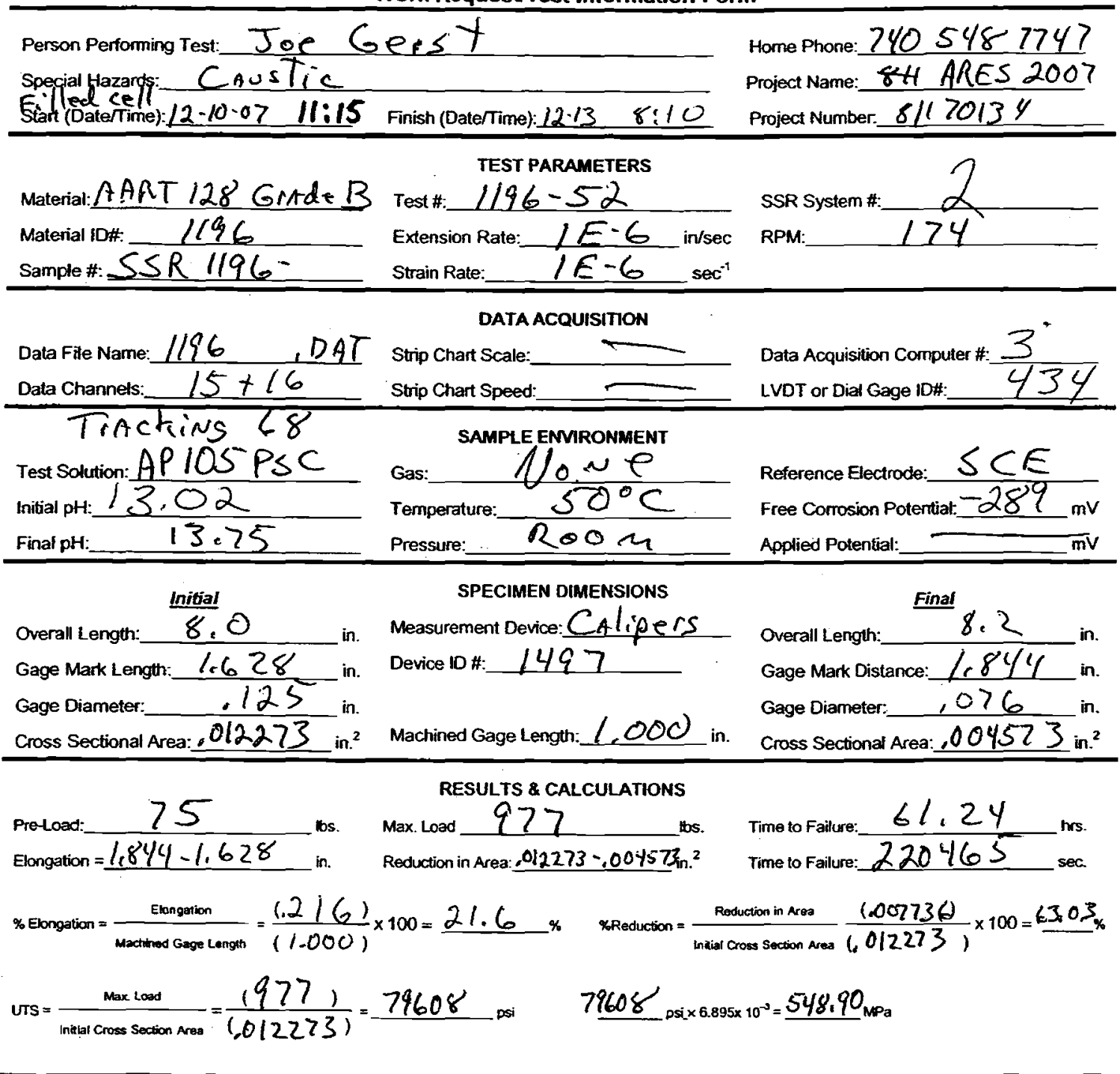

CRACKING

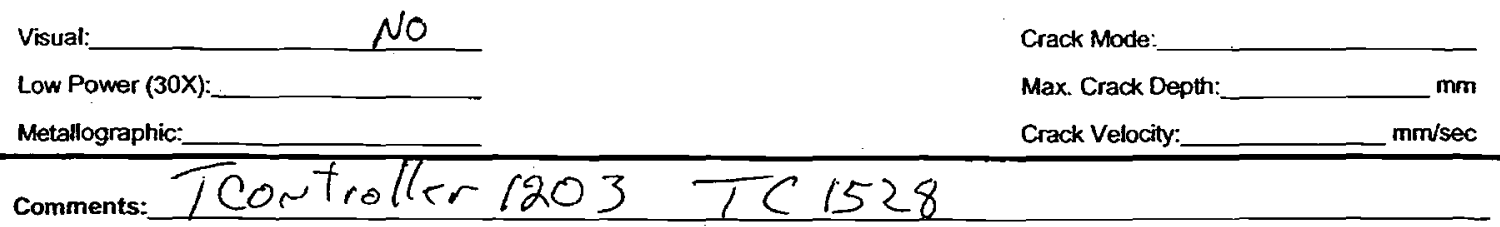

Project Leader's Signature:
$\begin{aligned} & \text { OA OOSSSR Specimens, Tests, \& Evaluation } \\ & \text { Revision 2 }\end{aligned}$


RPP-RPT-37505, Rev. 0

\section{Test Sheet Addendum}
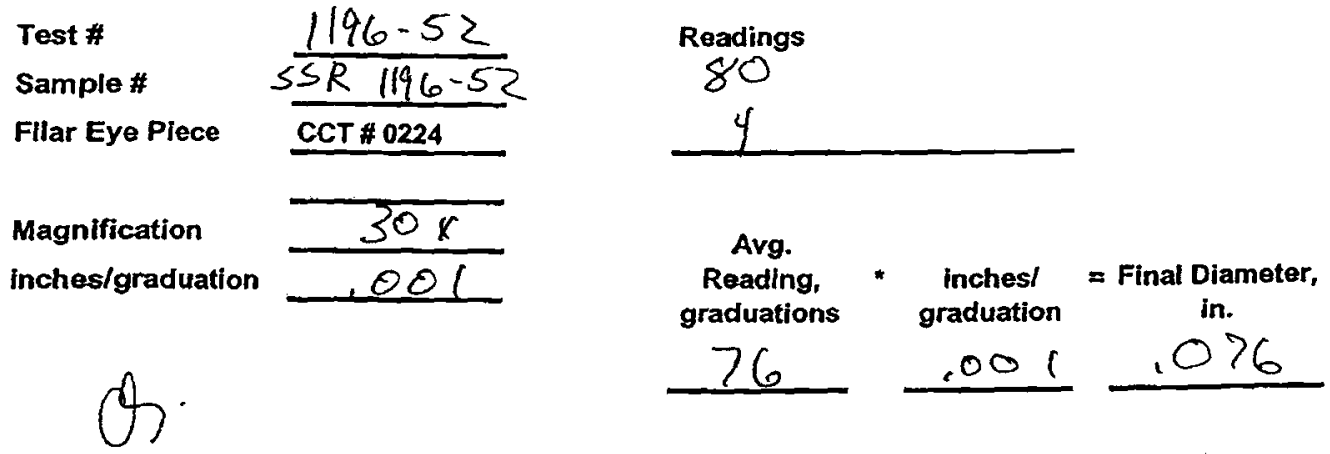

\section{Comments}


Slow Strain Rate

Work Request/Test Information Form

\begin{tabular}{|c|c|c|}
\hline \multicolumn{2}{|c|}{ Person Performing Test: Joe Gefst } & \multirow{2}{*}{ 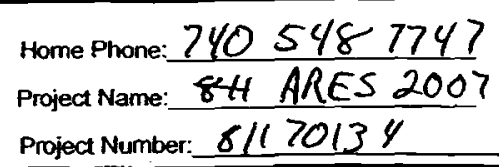 } \\
\hline 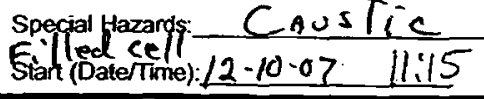 & Finish (DaterTime): $12-13 \quad 8: 00$ & \\
\hline $\begin{array}{l}\text { Material:AART } 128 \text { GrAde B } \\
\text { Material ID\#: } \frac{1196}{\text { Sample \#: SSR } 1196-}\end{array}$ & 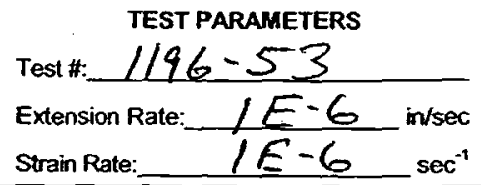 & SSR System \#:- $\frac{6}{174}$ \\
\hline Data File Name: $\frac{1196-5,28}{9+15}$ & $\begin{array}{l}\text { DATA ACQUISITION } \\
\text { Strip Chart Scale: } \\
\text { Strip Chart Speed: }\end{array}$ & $\begin{array}{l}\text { Data Acquisition Computer \#: } \\
\text { LVDT or Dial Gage ID\#: }\end{array}$ \\
\hline 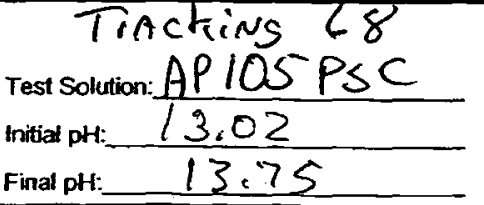 & 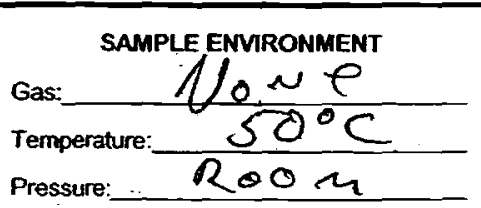 & $\begin{array}{l}\text { Reference Electrode: } \quad S C E \\
\text { Free Corrosion Polential: }-25 q \\
\text { Applied Potertial: } \quad 0 \mathrm{mv}\end{array}$ \\
\hline $\begin{array}{l}\text { Overall Length: } \frac{\frac{\text { mitial }}{8}, 0}{1,720} \text { in. } \\
\text { Gage Mark Length: } \frac{1,125}{\text { Gage Diameter: }} \text { in. } \\
\text { Cross Sectional Area: }, 012273 \text { in. }\end{array}$ & $\begin{array}{l}\text { SPECIMEN DIMENSIONS } \\
\text { Measurement Device:Cal ipers } \\
\text { Device to }=1497\end{array}$ & $\begin{array}{l}\text { Overall Length: } \frac{\text { Final }}{8,2} \text { in. } \\
\text { Gage Mark Distance: } \frac{1,900}{.095} \text { in. } \\
\text { Gage Diameter } \frac{.09}{\text { in. }} \\
\text { Cross Sectional Area: }, 007089 \text { in. }^{2}\end{array}$ \\
\hline
\end{tabular}

\section{RESULTS \& CALCULATIONS}

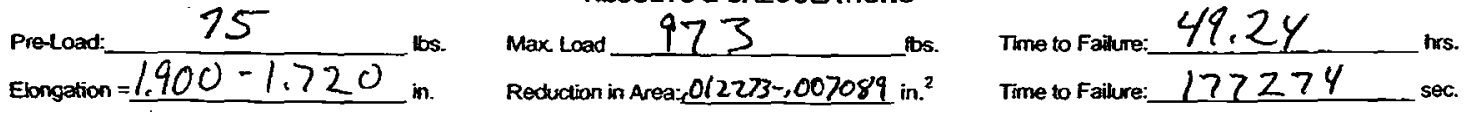

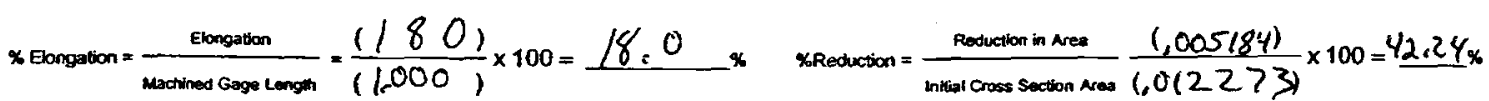

UTS $=\frac{\max \cos }{\text { Inition cross section Area }}=\frac{(973)}{(.012273)}=79282$ psi $\quad 79282$ psix $\times 6.895 \times 10^{\circ}=596.65 \mathrm{mpa}$

CRACKING

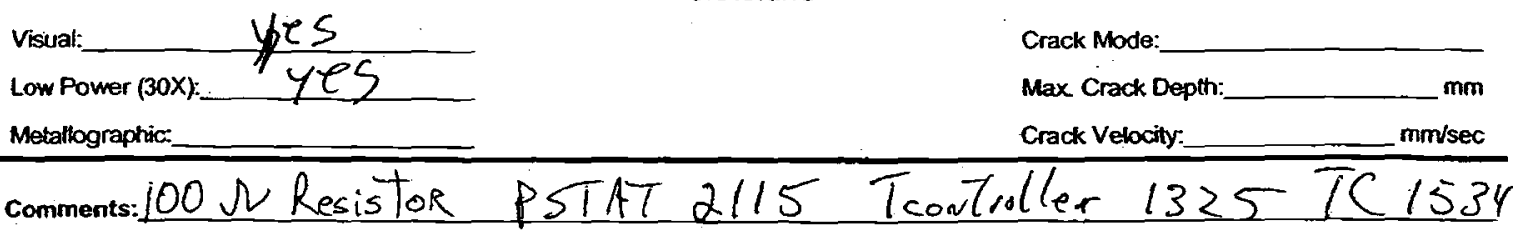

Project Leader's Signature:
$\begin{aligned} & \text { QA Oog-SSR Specimens, Tests, \& Evaluation } \\ & \text { Revision 2 }\end{aligned}$


RPP-RPT-37505, Rev. 0

\section{Test Sheet Addendum}

\begin{tabular}{ll} 
Test \# \\
Sample \# \\
Filar Eye Piece & $\frac{1196-53}{\text { SSR } 1196-53}$ \\
$\begin{array}{l}\text { Magnification } \\
\text { inches/graduation }\end{array}$ & $\frac{30224}{.001}$ \\
\hline
\end{tabular}

\begin{tabular}{|c|c|c|}
\hline $\begin{array}{c}\text { Readings } \\
100 \\
5\end{array}$ & & \\
\hline $\begin{array}{c}\text { Avg. } \\
\text { Reading, } \\
\text { graduations }\end{array}$ & * $\begin{array}{c}\text { Inches/ } \\
\text { graduation }\end{array}$ & $\begin{array}{c}=\text { Final Diameter, } \\
\text { in. }\end{array}$ \\
\hline 95 & .001 & $09 s^{\prime}$ \\
\hline
\end{tabular}

\section{Comments}


Slow Strain Rate

Work Request/Test Information Form.

Persor Performing Test: Joe Coerst

Special Hazargs: CAUSTiC
Filled cell
start (Datertime): 2.1 .08 i2 30 Fisher

Ho7

Finish (Datefime): $2-4-08715$

TEST PARAMETERS

Material: AART 128 Grade B

sample \#: $\leq S R 1196-54$

Test \#: $1196-54$

Extension Rate: $/ E-6$ in $/ \mathrm{sec}$

Straln Rate: $\frac{1 E-6}{1 E-1}$
Home Phone: 7405487747

Project Name: 81170135

Project Number

SSR System \#:

RPM: $\quad 694$

RPM

\begin{tabular}{|c|c|}
\hline & DATAACQUISITION \\
\hline ata File Name: I/ & Strip Chart Scale: \\
\hline Data Channels: $1 \times 2$ & Strip Chart Speed:- - \\
\hline
\end{tabular}

Data Acquisition Computer \#. 3 LVDT or Dial Gauge ID\#.

AP 105 SAMPLEENIRONMENT

Test Solution: AP 105 Initial $\mathrm{pH}: \frac{12.98}{12.10}$

Final $\mathrm{pH}: \frac{12,10}{13,10}$

Gas:

None

Temperature: $50^{\circ} \mathrm{C}$

Pressure: $\quad \mathrm{ROOM}$

Reference Electrode: SCE

Free Corrosion Potential: $-287 \mathrm{mv}$

Applied Potential: $\bigcirc \mu \mathrm{mV}$

Overall Length: $\frac{\text { initial }}{8}, 0$

Gauge Mark Length: 1.208

Gauge Diameter: 0.1245

cross Sectional Area: 012175
SPECIMEN DIMENSIONS

Measurement Device: CAl ipers 1497

Device ID \#: 1497

Machined Gauge Length: 1,000 in.

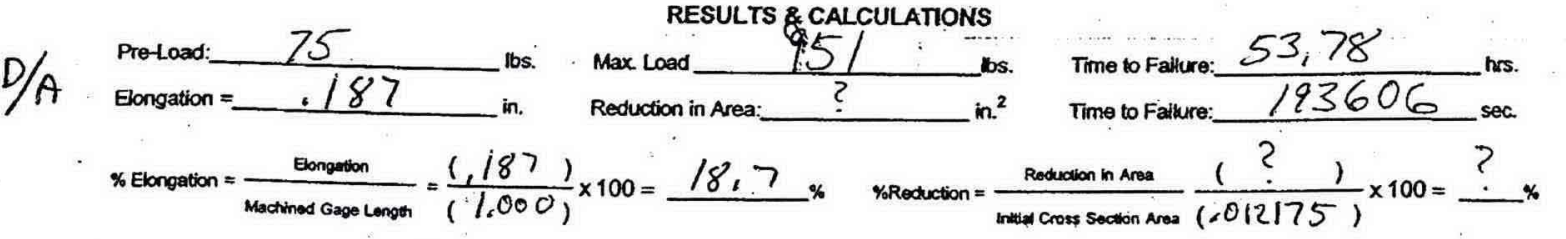

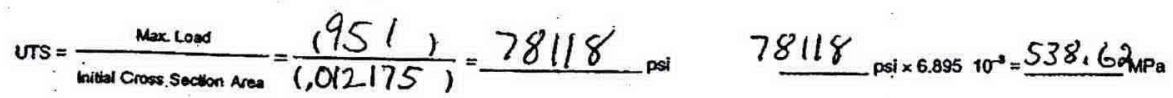

visual:_cornoded.

Low Power (30X):

Metallographic:
CRACKING

comments: $100 \Omega$ Resistor BSTAT2090 Tcontiollen 1260 TC \#/528 scribed $x$ on end of specimen that wil be Top Project Leader's Signature:-20 NAMF. Clduen Date: $2 / 5 / 08$.

\section{QA009}

Revision \#3

SSR Spedimens, Tests, \& Evaluation

Page TATE: 2-5-or
Crack Mode:

Max. Crack Depth: $\mathrm{mm}$

Crack Velocity.

Date Approved: April 2006 Prepared By: C. Soott 
Slow Strain Rate

Work Request/Test Information Form

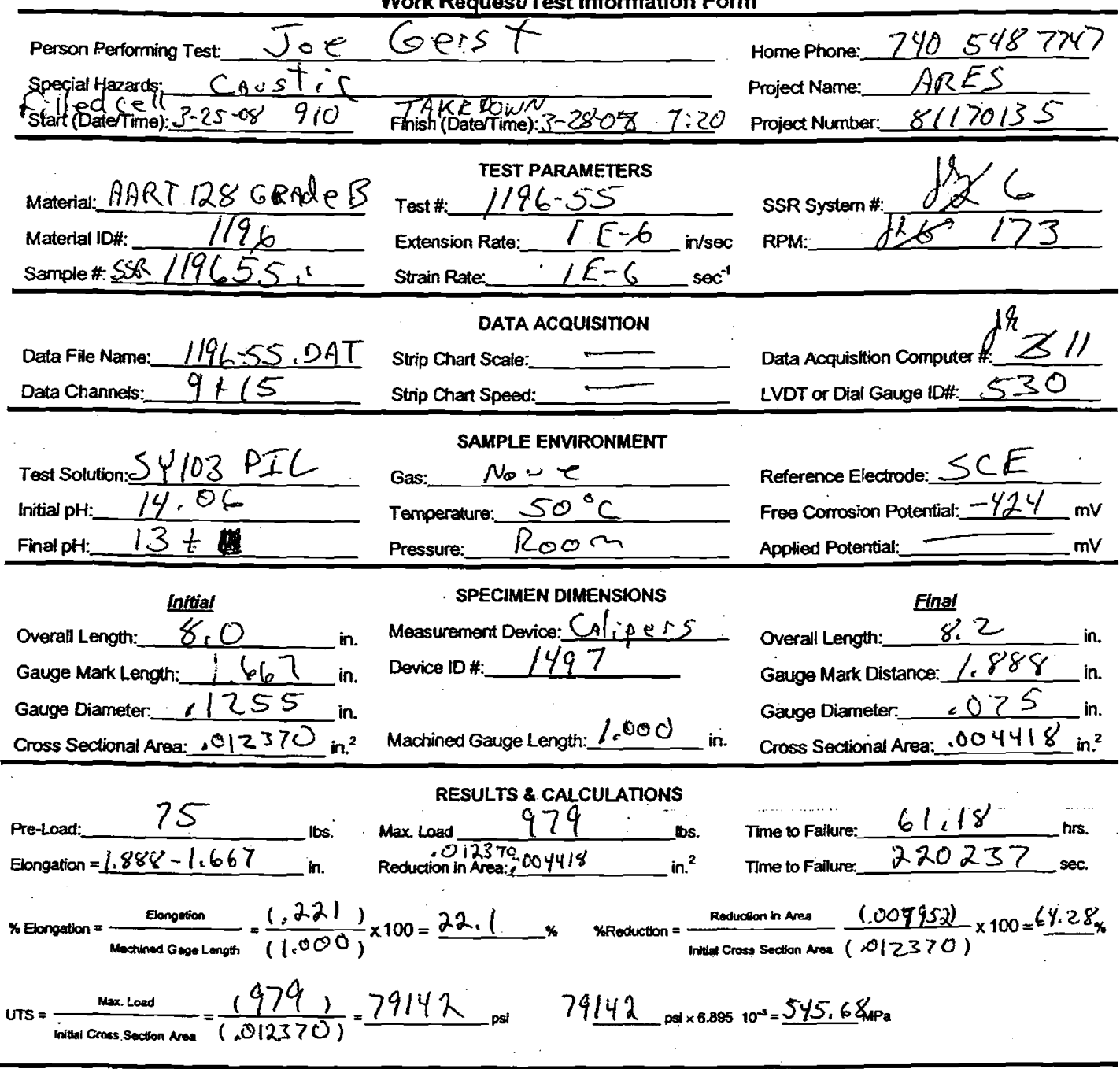

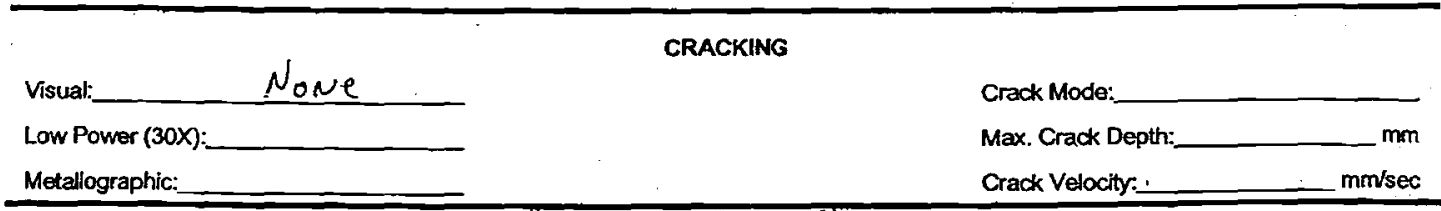

comments: Teup Controller \$203 $/ \mathrm{C} / 620$


RPP-RPT-37505, Rev. 0

Test Sheet Addendum

$\begin{array}{ll}\text { Test \# } \\ \text { Sample \# } \\ \text { Filar Eye Piece } & \frac{1196-55}{S S R 1196.55} \\ \begin{array}{l}\text { Magnification } \\ \text { inches/graduation }\end{array} & \frac{.001}{\text { CCT } 0224}\end{array}$

\begin{tabular}{|c|c|c|}
\hline $\begin{array}{c}\text { Readings } \\
87 \\
12 \\
\end{array}$ & & \\
\hline 25 & & \\
\hline $\begin{array}{l}\text { Avg. } \\
\text { Reading, } \\
\text { graduations }\end{array}$ & $\begin{array}{c}\text { inches/ } \\
\text { graduation }\end{array}$ & $\begin{array}{c}=\text { Final Diameter, } \\
\text { in. }\end{array}$ \\
\hline 75 & .001 & .075 \\
\hline
\end{tabular}

\section{Comments}


Slow Strain Rate

Work Request/Test Information Form

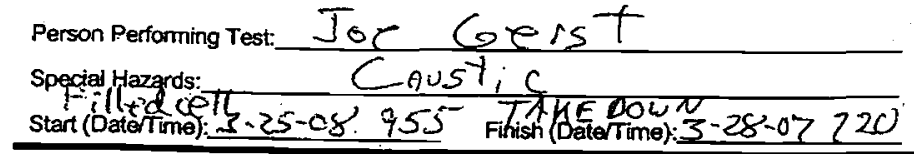

Home Phone: 7405487747

Project Name:ARES

Material:AART 128 Grade B

TEST PARAMETERS

Material ID\#: $\quad 1196$

Test \#: 119656 ,

Sample \#: SSR $1196-56$

Extension Rate: $\quad \angle E-6$ in/sec

Strain Rate: $\quad \angle E-G \sec ^{-1}$

P1170135

Data File Name: $1196.56,0 \mathrm{AT}$

DATA ACQUISTIION

Data Channels: $15+16$

Strip Chart Speed:

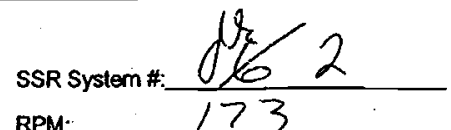

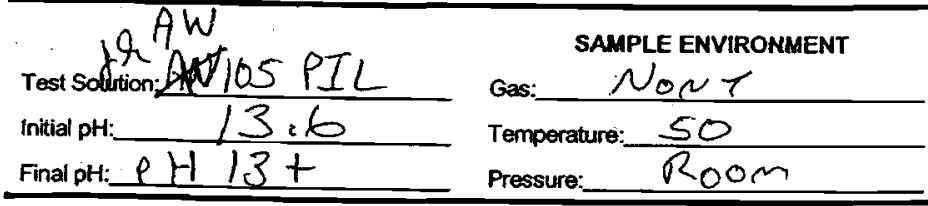

Initial SPECIMEN DIMENSJONS

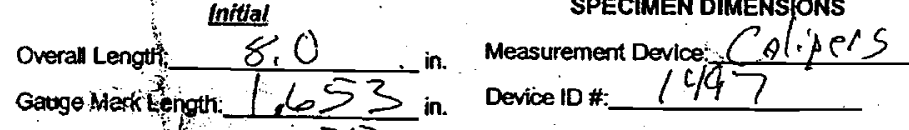

Gauge Diametion 1255 in.

Cross Sectional Area: .012370 in. Machined Gauge Length: $1.00 \mathrm{~d}$

Data Acquisition Computer \#: $\frac{3}{434}$

$75 \quad$ RESULTS \& gaLCULATIONS

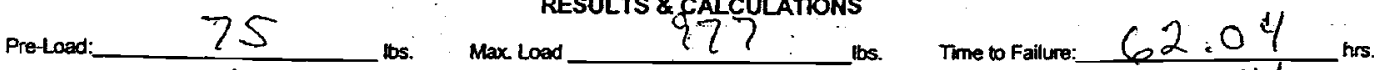

Elongation $=1820-1,653$ in. Reduction in Area: $212370, .004537 \mathrm{~m}^{2}$ Time to Fallure: 223341 sec.

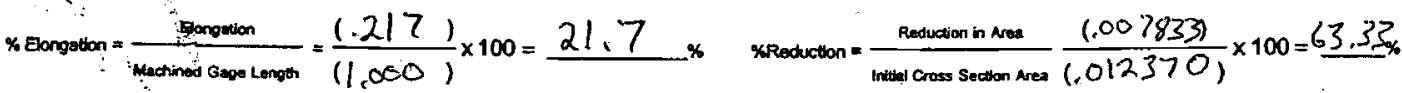

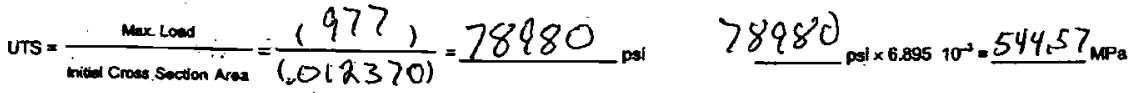

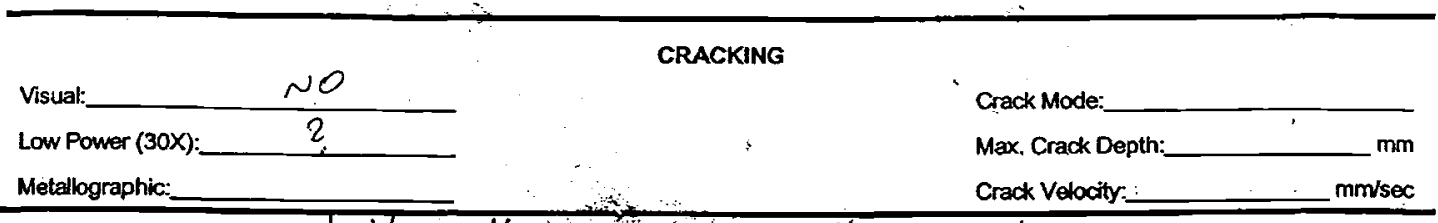

Comments: Temp Controller $\# / 236$ TC\#/668

4 fitting in corrosion in curck like nreas And corrosion product in solution removed from cell

Project Leader's Ŝignatüre:

QA APPROUKED

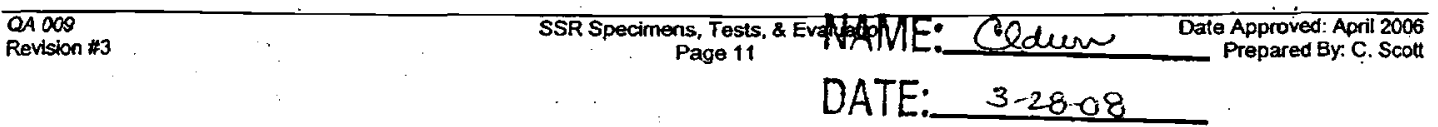


RPP-RPT-37505, Rev. 0

\section{Test Sheet Addendum}

\begin{tabular}{|c|c|}
\hline Test \# & $1196-56$ \\
\hline Sample \# & SSR 1196.56 \\
\hline Filar Eye Piece & CCT \# 0224 \\
\hline icatic & $30 x$ \\
\hline inches/graduation & 1001 \\
\hline
\end{tabular}

$\begin{gathered}\text { Readings } \\ 81 \\ 5\end{gathered}$
$\begin{gathered}\text { Avg. } \\ \text { Reading, } \\ \text { graduations } \\ 76\end{gathered}$ inches/
graduation
.001

\section{Comments}


Slow Strain Rate

Work Request/Test Information Form

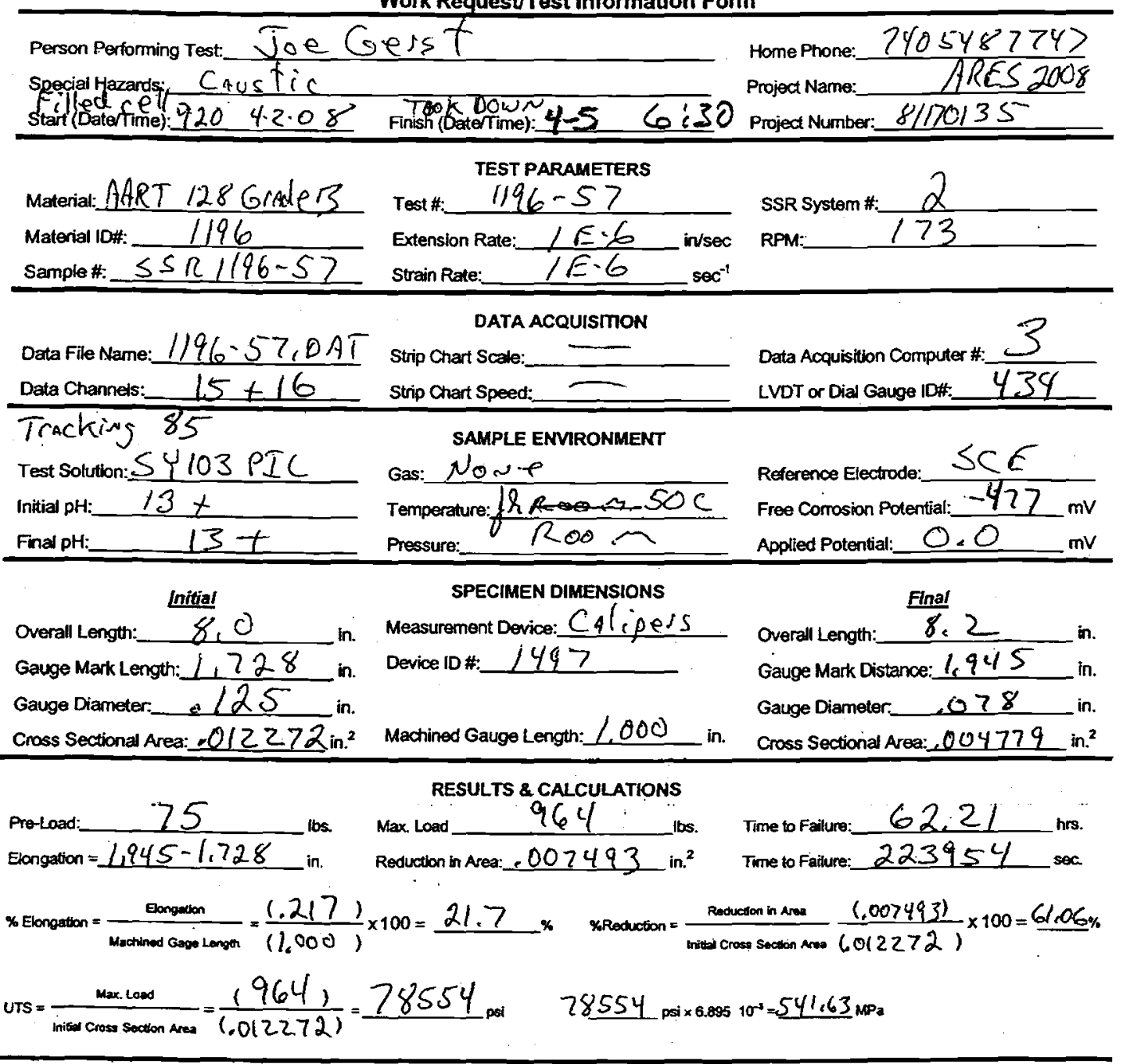

\begin{tabular}{ll}
\hline Visual:__ CRACKING & Crack Mode:__ \\
Low Power (30X): & Max. Crack Depth:__ Crack Velocity:__ $\mathrm{mm}$ \\
Metallographic: & $\mathrm{mm} / \mathrm{mec}$ \\
\hline
\end{tabular}

Comments:

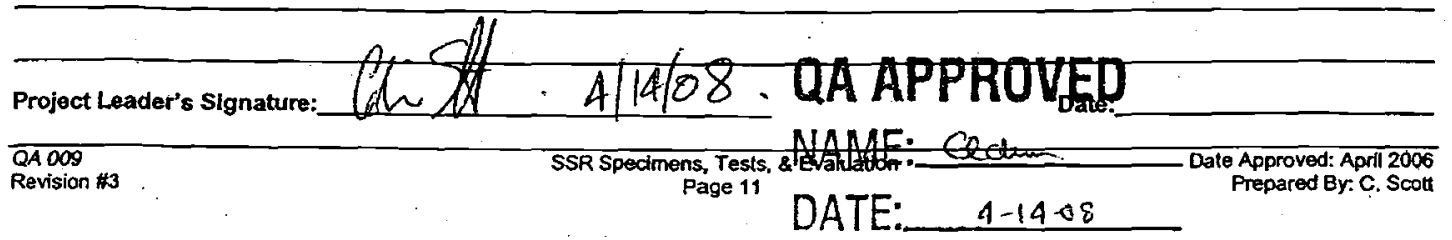


RPP-RPT-37505, Rev. 0

\section{Test Sheet Addendum}

\begin{tabular}{|c|c|}
\hline Test \# & $1196-57$ \\
\hline Sample \# & SSR $1196-S$ \\
\hline Filar Eye Piece & CCT \# 0224 \\
\hline Magnification & $30 x$ \\
\hline inches/graduation & .001 \\
\hline
\end{tabular}

\section{Comments}


Slow Strain Rate

Work Request/Test Information Form

\begin{tabular}{|c|c|c|}
\hline \multicolumn{2}{|c|}{ Person Performing Test Joe Gerst } & \multirow{2}{*}{ Home Phone: $\frac{7405487747}{A R E S 2008}$} \\
\hline 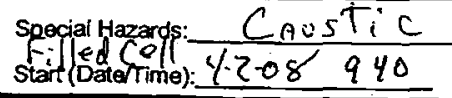 & Finish (Dotek pouth $4-7-08 \quad 7.20$ & \\
\hline Material:ABRT 128 Grade 3 & \multirow{2}{*}{$\begin{array}{l}\text { TEST PARAMETERS } \\
1 / 96-58\end{array}$} & \multirow{2}{*}{ SSR Systern \#: $\frac{6}{173}$} \\
\hline Material ID\#: $\frac{1196}{5 S R 1196-58}$ & & \\
\hline Data File Name: $1196-58, D A T$ & \multirow[t]{2}{*}{ DATA ACQUISITION } & Data Acquisition Computer \#. \\
\hline Data Channels: $\quad 9+15$ & & LVDT or Dial Gauge IDA: \\
\hline
\end{tabular}

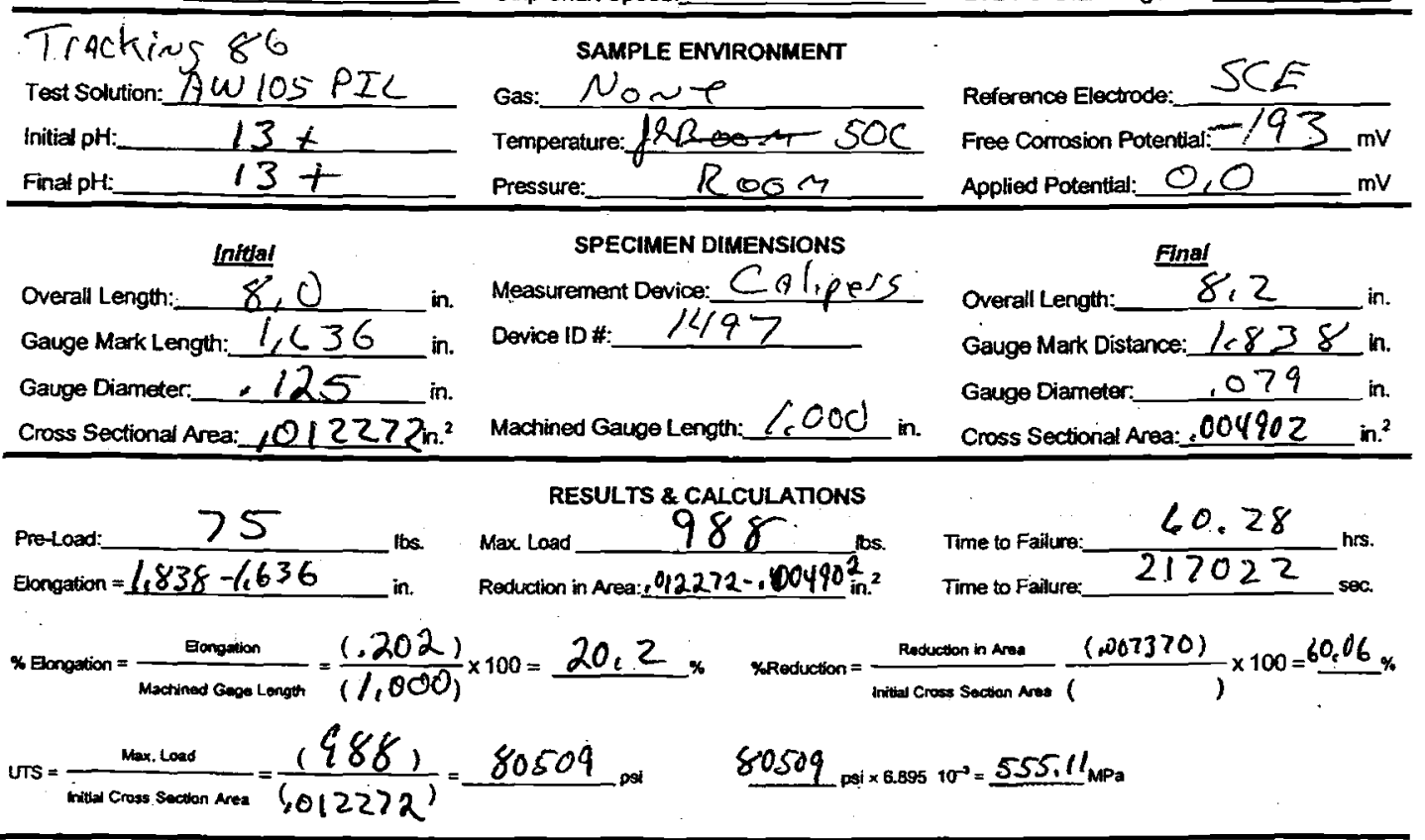

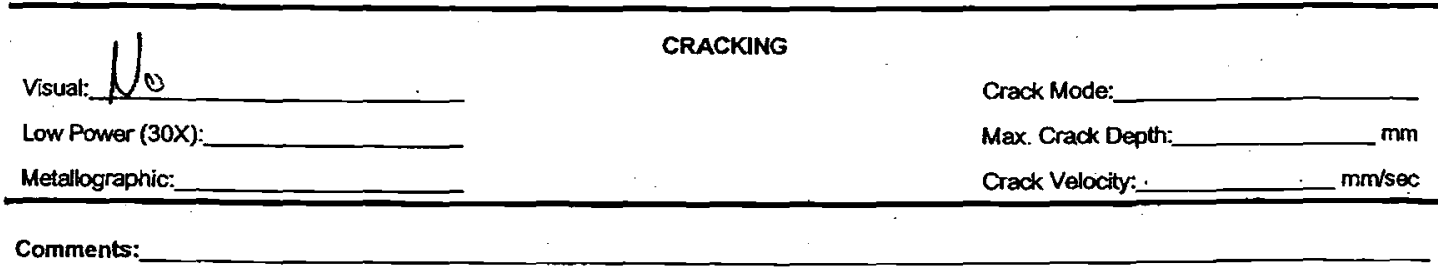

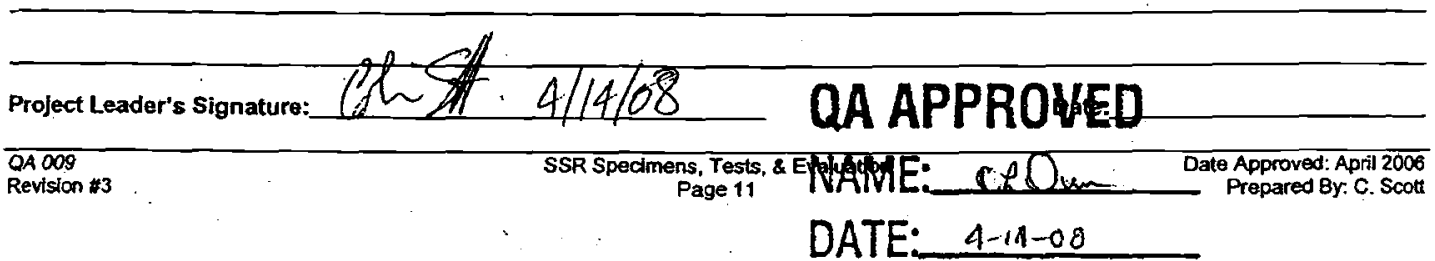


RPP-RPT-37505, Rev. 0

\section{Test Sheet Addendum}

\begin{tabular}{|c|c|}
\hline Sample\# & SSR $1196-5$ \\
\hline Filar Eye Piece & CCT \# 0224 \\
\hline Magnification & $30 x$ \\
\hline inches/graduation & .001 \\
\hline
\end{tabular}

Readings

89

10

Avg.

Reading, graduations

Inches/ = Final Diameter,

79.001 .079

\section{Comments}


Slow Strain Rate

Work Request/Test Information Form

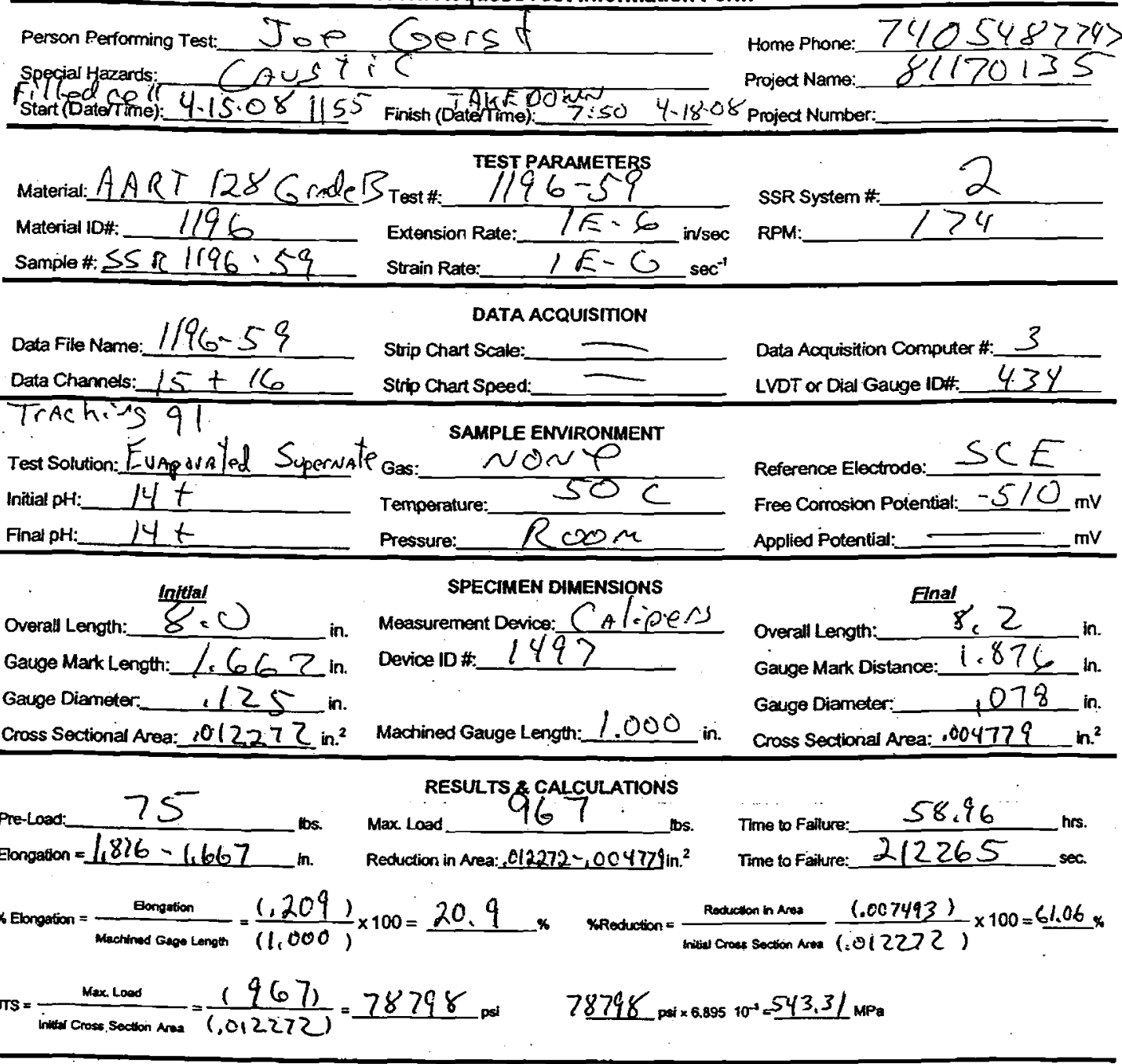

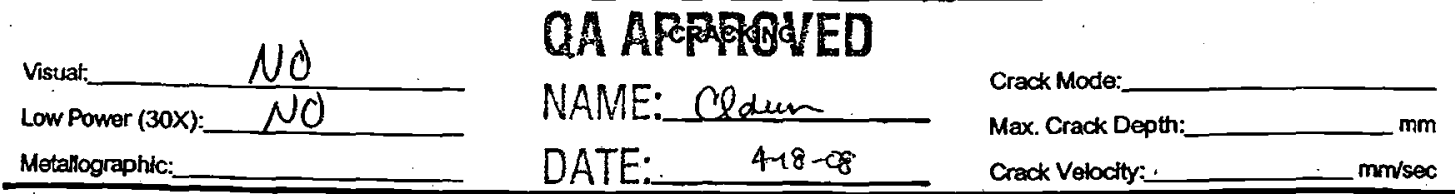

comments: Tcontraller \#1236 TC $\$ 1670$
oue side of Fracture was damaged when I dropped it in The sirt 
Slow Strain Rate

Work Request/Test Information Form

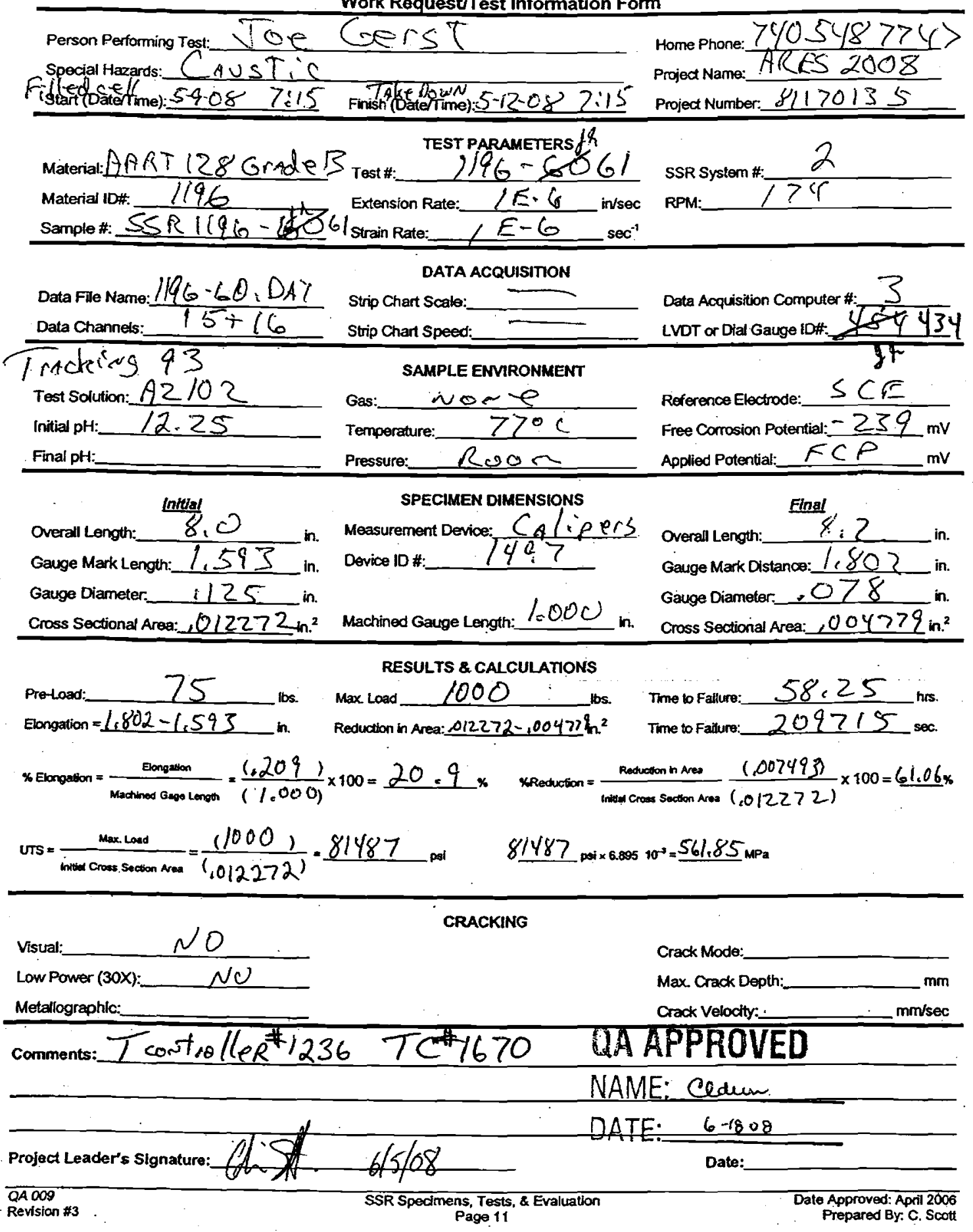


RPP-RPT-37505, Rev. 0

\section{Test Sheet Addendum}

\begin{tabular}{|c|c|}
\hline Test \# & $196-61$ \\
\hline Sample \# & $S S R \| 1196-6$ \\
\hline Filar Eye Piece & CCT \# 0224 \\
\hline Magnification & $30 x$ \\
\hline inches/graduation & .001 \\
\hline
\end{tabular}

Readings

90

$\frac{12}{78}$

Avg.

Reading, * inches/ = Final Diameter graduations graduation in.

$78 \quad .001 \quad .078$

\section{Comments}


Slow Strain Rate

Work Request/Test Information Form

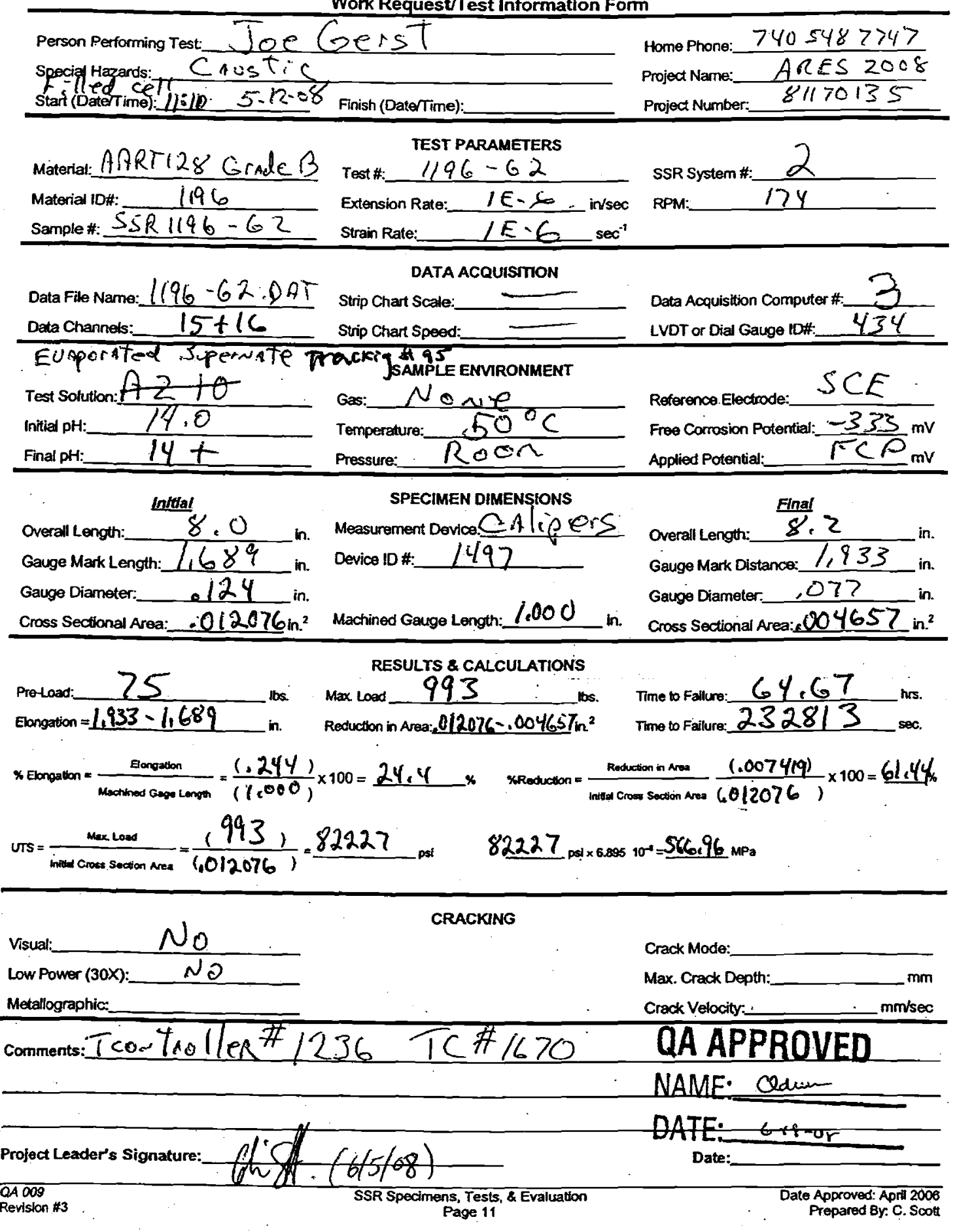


RPP-RPT-37505, Rev. 0

\section{Test Sheet Addendum}

$\begin{array}{ll}\text { Test \# } \\ \text { Sample \# } \\ \text { Filar Eye Piece } & \frac{1196-62}{S S R 1196-62} \\ \begin{array}{l}\text { Magnification } \\ \text { inches/graduation }\end{array} & \frac{\text { CCT } 0224}{30 X} \\ & \frac{.001}{}\end{array}$

\begin{tabular}{c}
$\begin{array}{c}\text { Readings } \\
87 \\
10\end{array}$ \\
$\begin{array}{c}77 \\
\text { Avg. } \\
\text { Reading, } \\
\text { graduations } \\
77\end{array} \quad \begin{array}{c}\text { inchesl } \\
\text { graduation } \\
.001\end{array} \quad \begin{array}{c}\text { Final Diameter, } \\
\text { in. }\end{array}$ \\
\hline
\end{tabular}

\section{Comments}


Slow Strain Rate

Work Request/Test Information Form

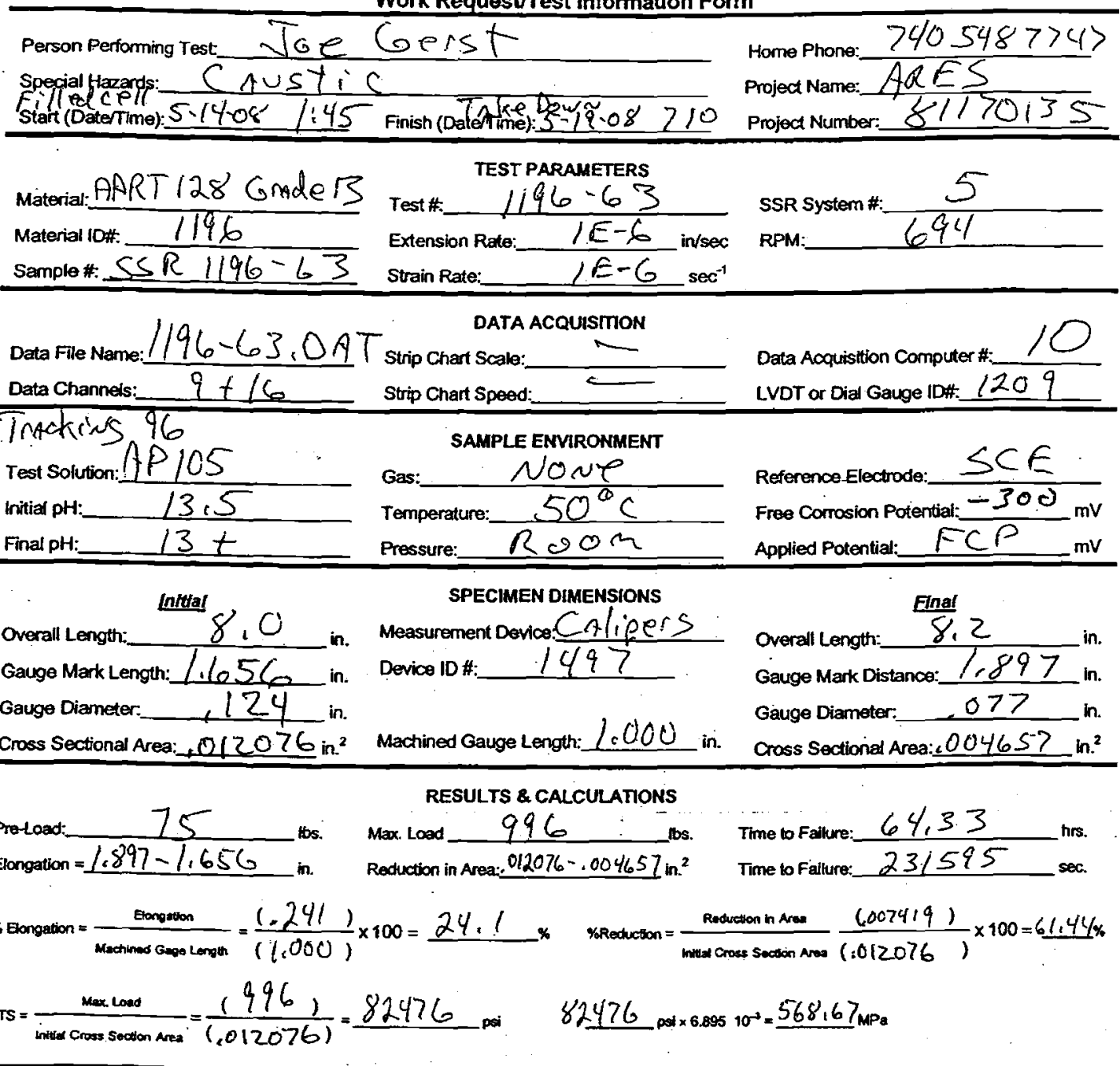

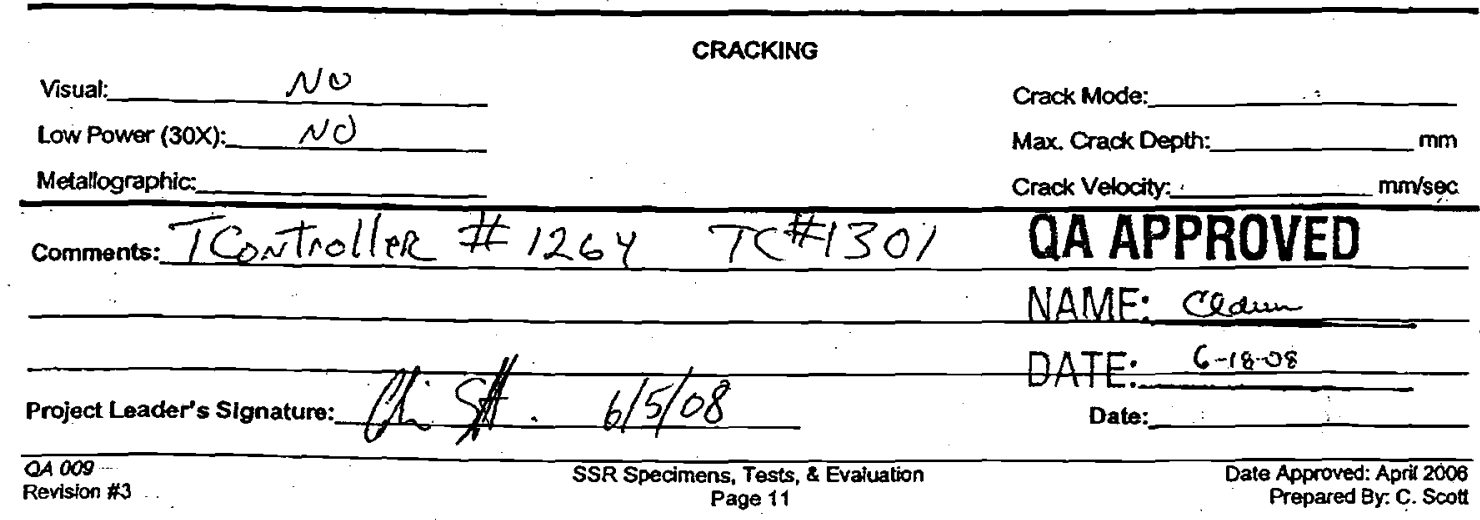


RPP-RPT-37505, Rev. 0

\section{Test Sheet Addendum}

$\begin{array}{ll}\text { Test \# } \\ \text { Sample \# } \\ \text { Filar Eye Piece } & \frac{1196-63}{S S R 1196-63} \\ \begin{array}{l}\text { Magnification } \\ \text { inches/graduation }\end{array} & \frac{30224}{30 \times} \\ { } } & \frac{.00(}{}\end{array}$

Readings

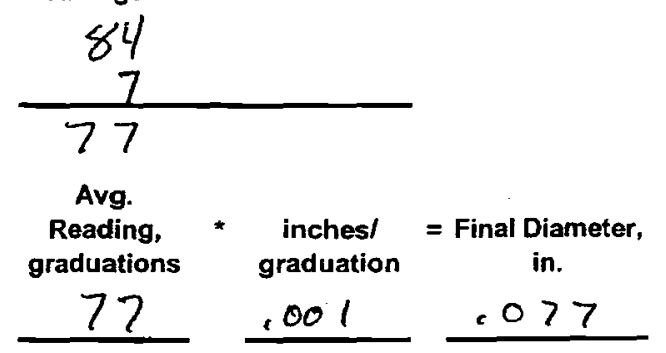

\section{Comments}


Slow Strain Rate

Work Request/Test Information Form

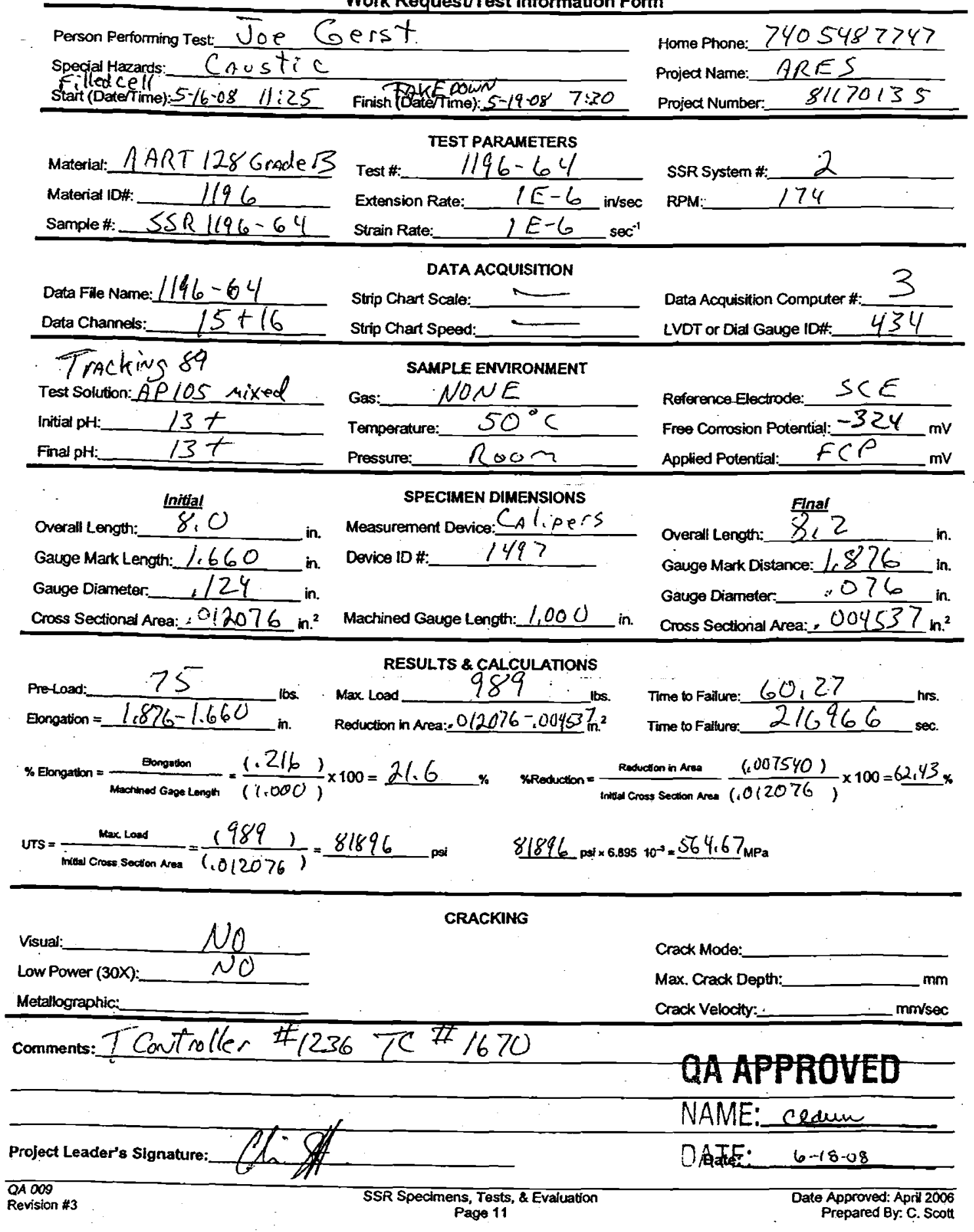


RPP-RPT-37505, Rev. 0

Test Sheet Addendum

$\begin{array}{ll}\text { Test \# } \\ \text { Sample \# } \\ \text { Filar Eye Piece } & \frac{1196-64}{\text { SSR } 1196-6 \%} \\ \begin{array}{l}\text { Magnification } \\ \text { inches/graduation } 0224\end{array} & \frac{30 X}{1001}\end{array}$

\begin{tabular}{|c|c|c|}
\hline $\begin{array}{c}\text { Readings } \\
91 \\
15 \\
\end{array}$ & & \\
\hline 76 & & \\
\hline $\begin{array}{c}\text { Avg. } \\
\text { Reading, } \\
\text { graduations }\end{array}$ & $\begin{array}{c}\text { * } \quad \text { inches/ } \\
\text { graduation }\end{array}$ & $\begin{array}{c}=\text { Final Diameter, } \\
\text { in. }\end{array}$ \\
\hline $2+076$ & Do 1 & .076 \\
\hline
\end{tabular}

\section{Comments}


Slow Strain Rate

Work Request/Test Information Form

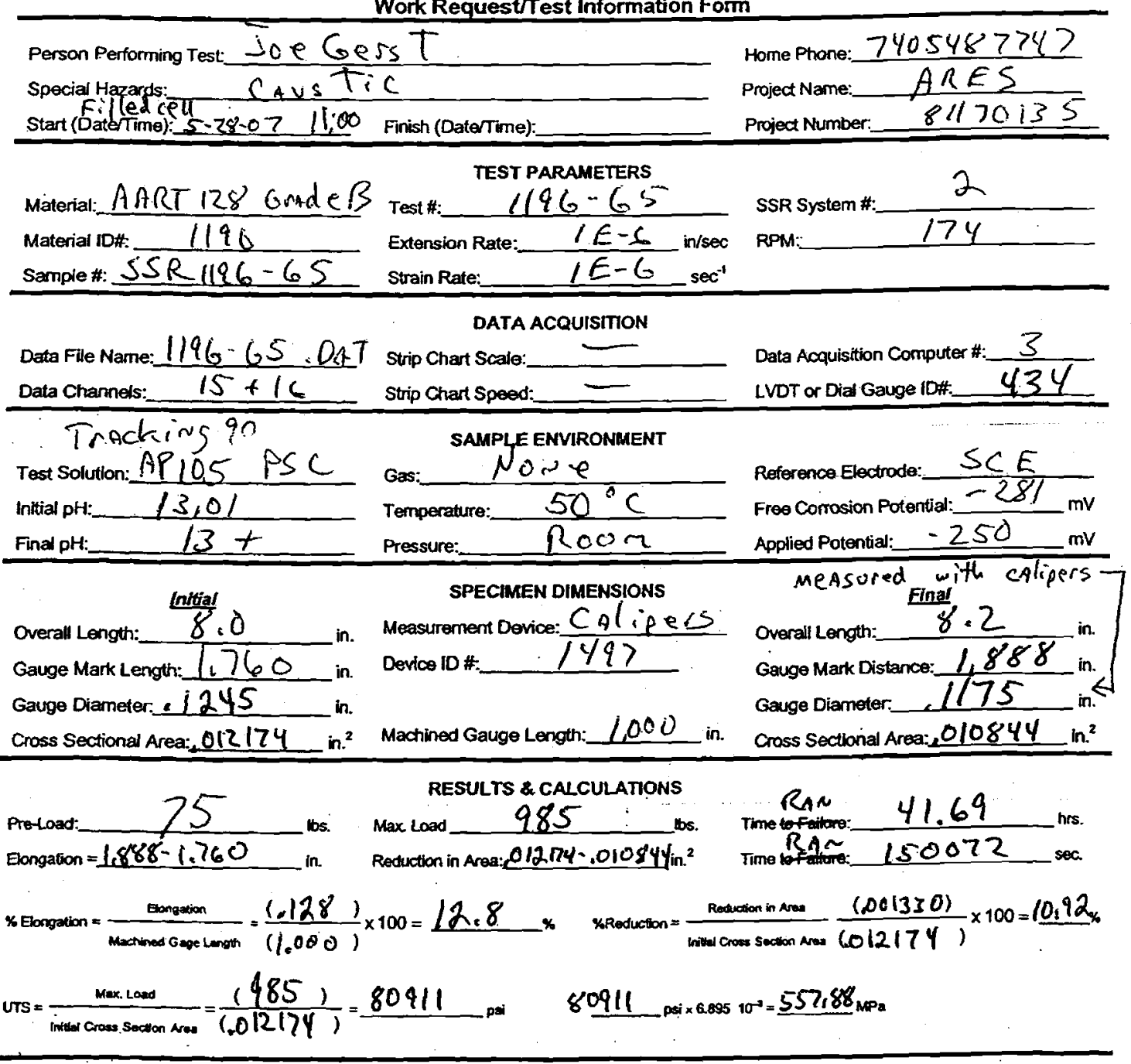

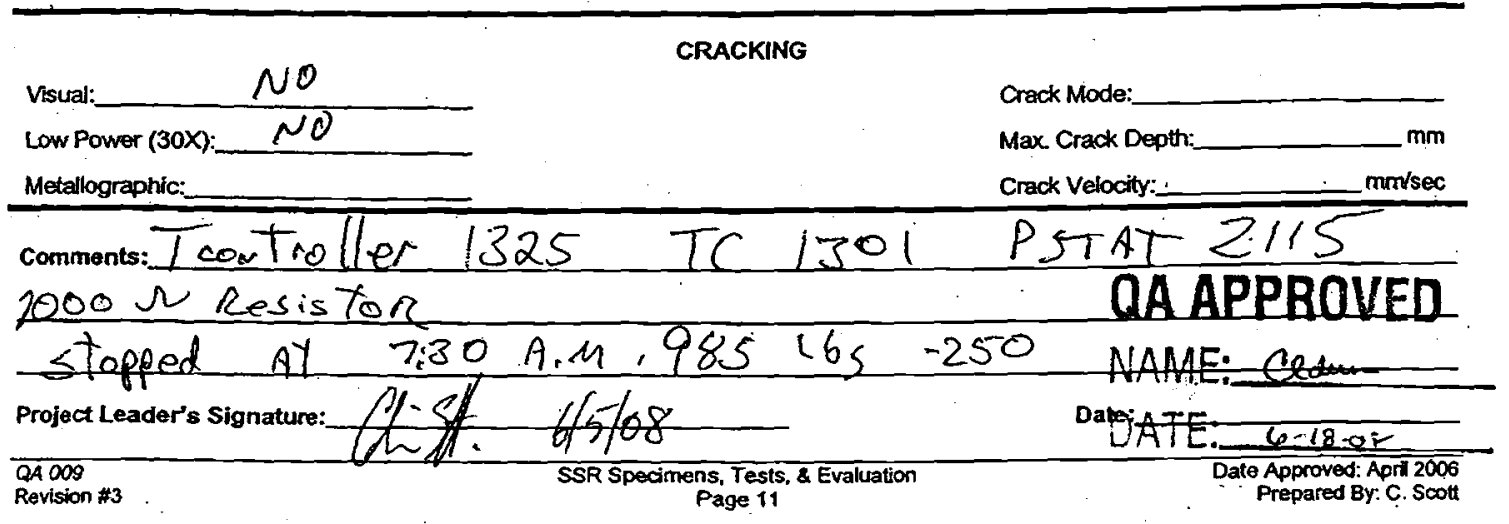


Slow Strain Rate

Work Request/Test Information Form

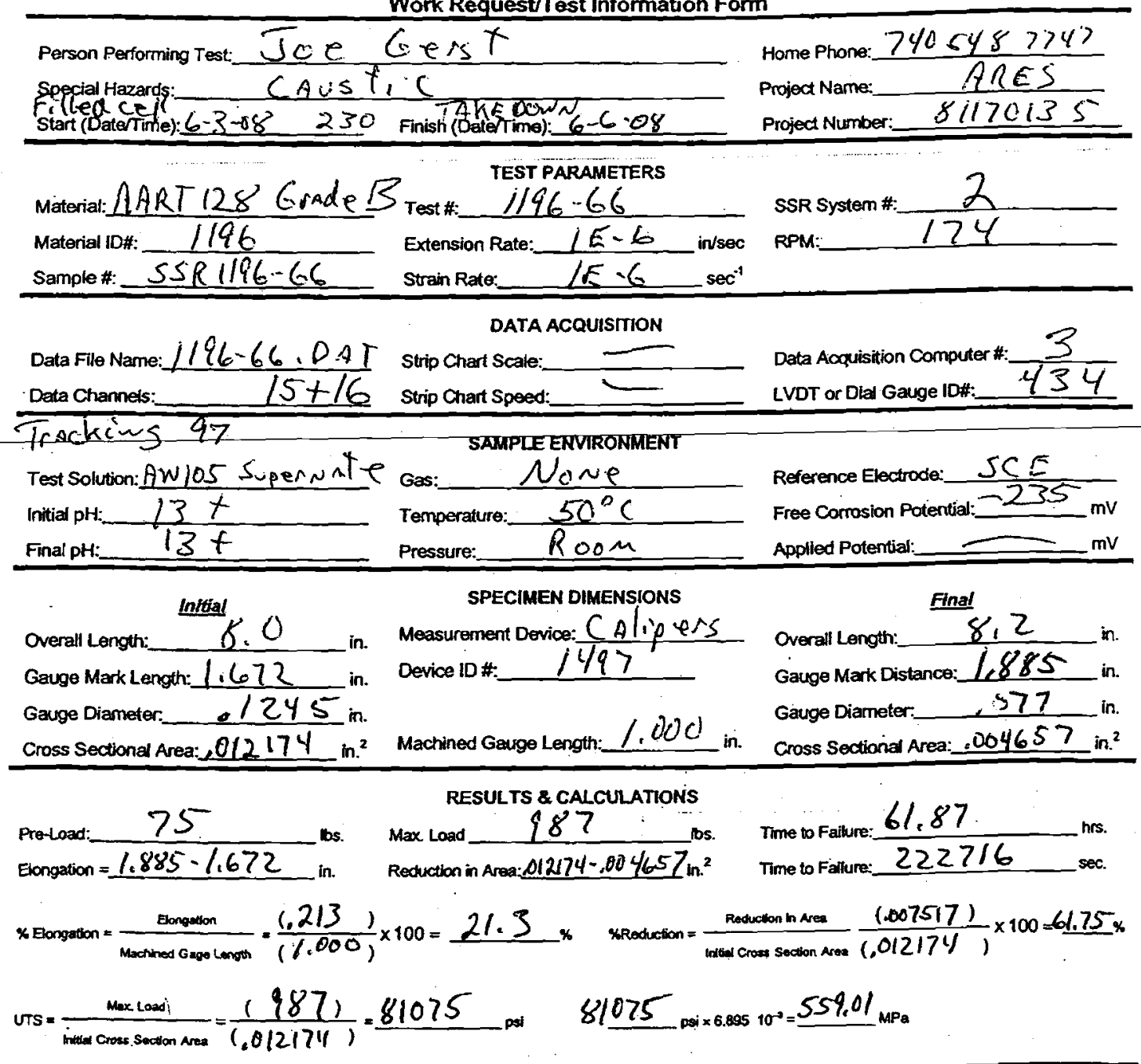

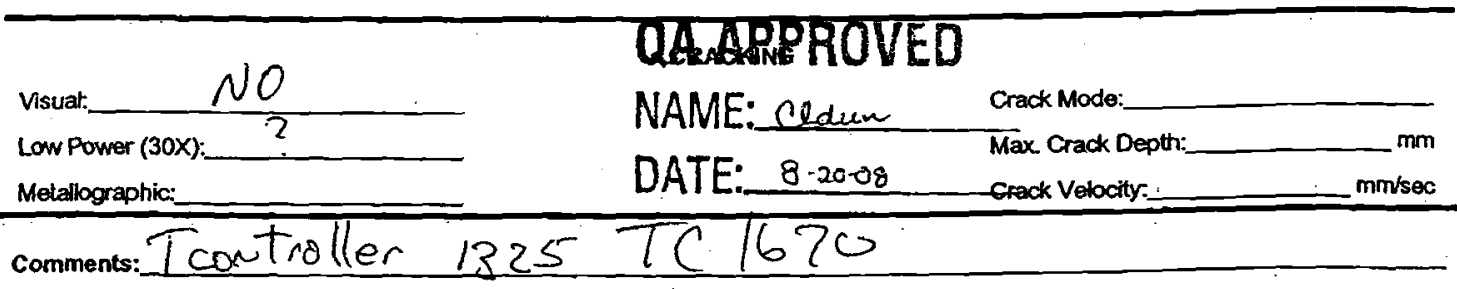

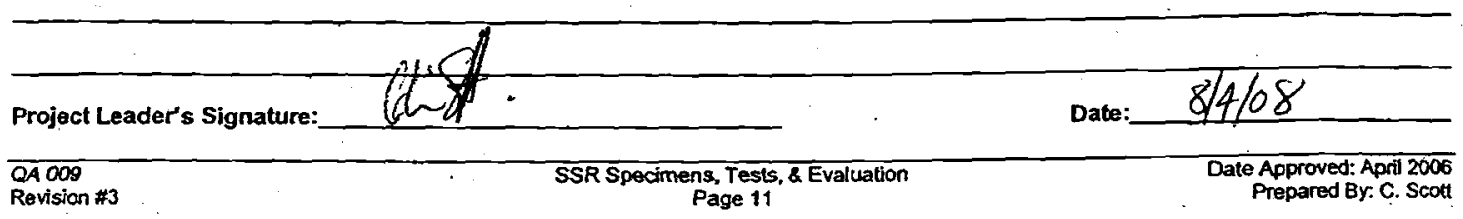


RPP-RPT-37505, Rev. 0

\section{Test Sheet Addendum}

\begin{tabular}{|c|c|}
\hline Test \# & 1196.66 \\
\hline Sample \# & $\operatorname{sSR} 1196-66$ \\
\hline Filar.Eye Piece & CCT \#0224 \\
\hline Magnification & $30 x$ \\
\hline inches/graduation & .001 \\
\hline
\end{tabular}

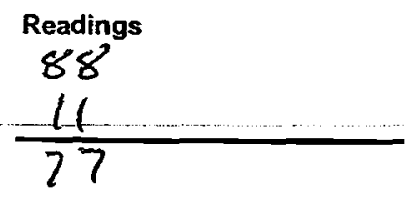

Avg.

Reading, * inches/ = Final Diameter, graduations graduation

In.

77

\section{Comments}


RPP-RPT-37505, Rev. 0

Slow Strain Rate

Work Request/Test Information Form

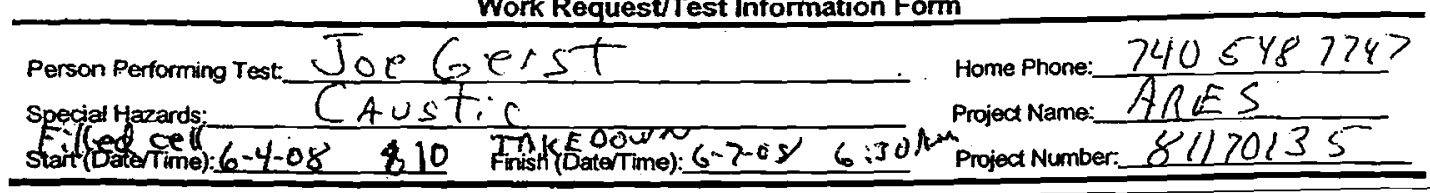

- TEst parameters

Material:AART128 GiadeB Test $\quad 1 / 96.67$

Material ID\#: $\frac{1196}{196}$ Extension Rate: 15.6

Extension Rate: $\frac{1 E-6}{1 E-6}$ in/sec

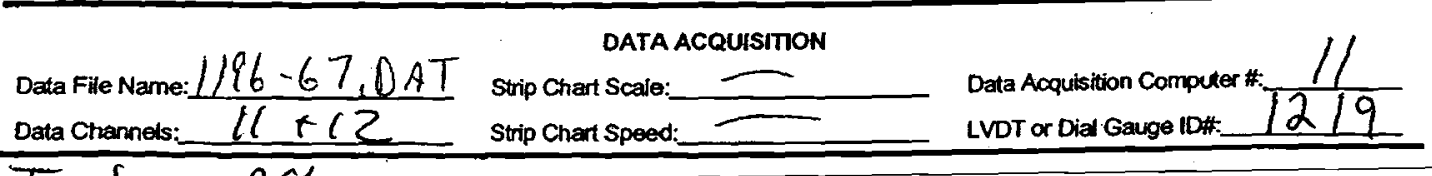

Trackergy 98 SAMPLE ENMRONMENT

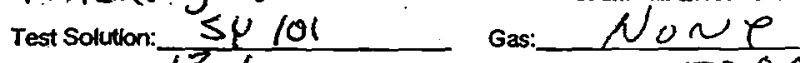

Initial pH: $\frac{\sqrt{3}+}{13+}$

Temperaure: $50^{\circ} \mathrm{C}$

SSR Systern H: $\frac{4}{694}$

Pressure:

noom

Reference Electrode: SCE

Overall Length: $\frac{\text { inflgat }}{8}, 0$

SPECIMEN DIMENSIONS

Gauge Mark Length: 1,676 in.

Measurament Device: $C_{\text {al }}$ ipers

Devico ID \#: $\quad 1497$.

Gauge Diameter. 1245 in.

Cross Sectional Area: 012174 in. $^{2}$ Machined Gauge Length: 1,000 in.

Freo corrosion Potential: $-206 \mathrm{mV}$

Applied Potential: $\longrightarrow \mathrm{mV}$

$75 \quad$ RESULTS \& CALCULATIONS

Pre-Load: $\frac{75}{1.900-1,676}$ ingation $\quad$ Machuction in Area:012174-.004418.in ${ }^{2}$

Time to Faiture: $\quad 63.70$ hrs.

Overall Length: 8.2 in.

Gauge Mark Distance: 1,900 in.

Gauge Diameter $\quad 075$ in.

Cross Sectional Area:, $004 \% 18 \mathrm{~m}^{2}$

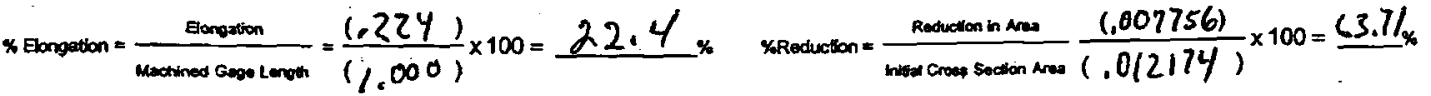

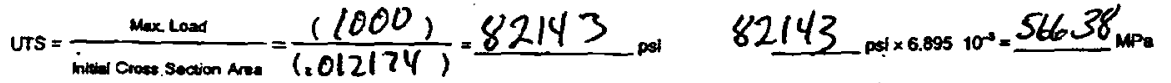

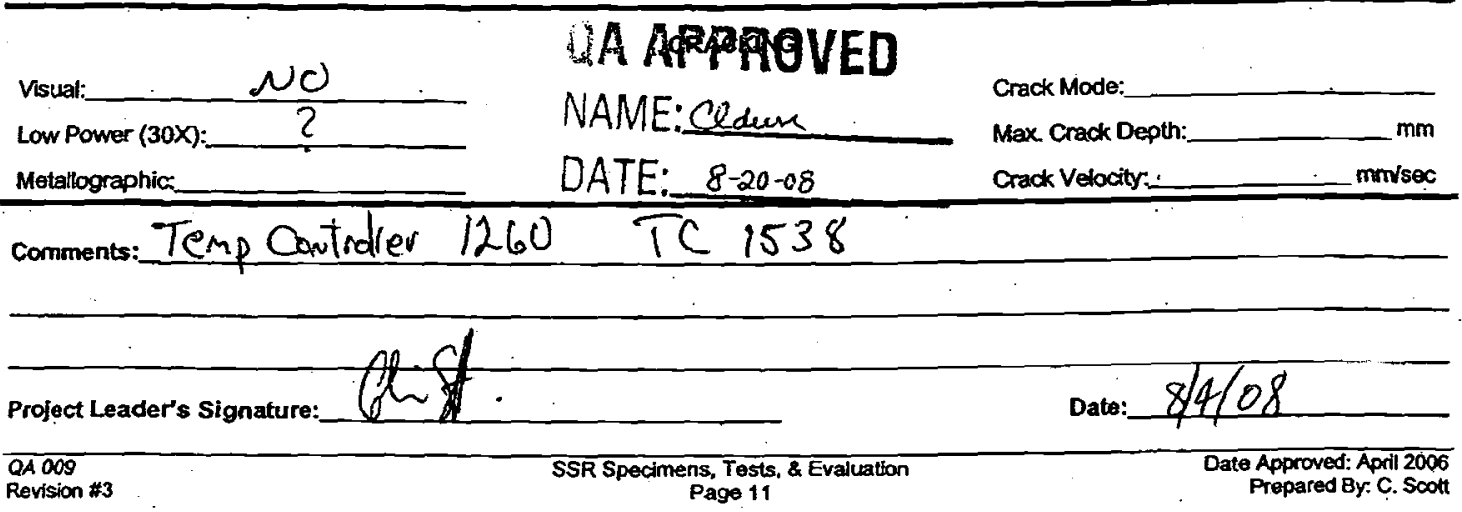


RPP-RPT-37505, Rev. 0

\section{Test Sheet Addendum}

\begin{tabular}{|c|c|c|c|c|}
\hline $\begin{array}{l}\text { Test \# } \\
\text { Sample \# }\end{array}$ & $\frac{1196-67}{S S R 1196-67}$ & $\begin{array}{c}\text { Readings } \\
77\end{array}$ & & \\
\hline Filar Eyo Piece & CCT \#0224 & 2 & & \\
\hline & & 25 & & \\
\hline $\begin{array}{l}\text { Magnification } \\
\text { inches/graduation }\end{array}$ & $\frac{30 x}{.001}$ & $\begin{array}{c}\text { Avg. } \\
\text { Reading, } \\
\text { graduations }\end{array}$ & $\begin{array}{c}\text { inchesl } \\
\text { graduation }\end{array}$ & $\begin{array}{c}=\text { Final Diameter, } \\
\text { in. }\end{array}$ \\
\hline & & 75 & .001 & .075 \\
\hline
\end{tabular}

\section{Comments}


Slow Strain Rate Work Request/Test Information Form

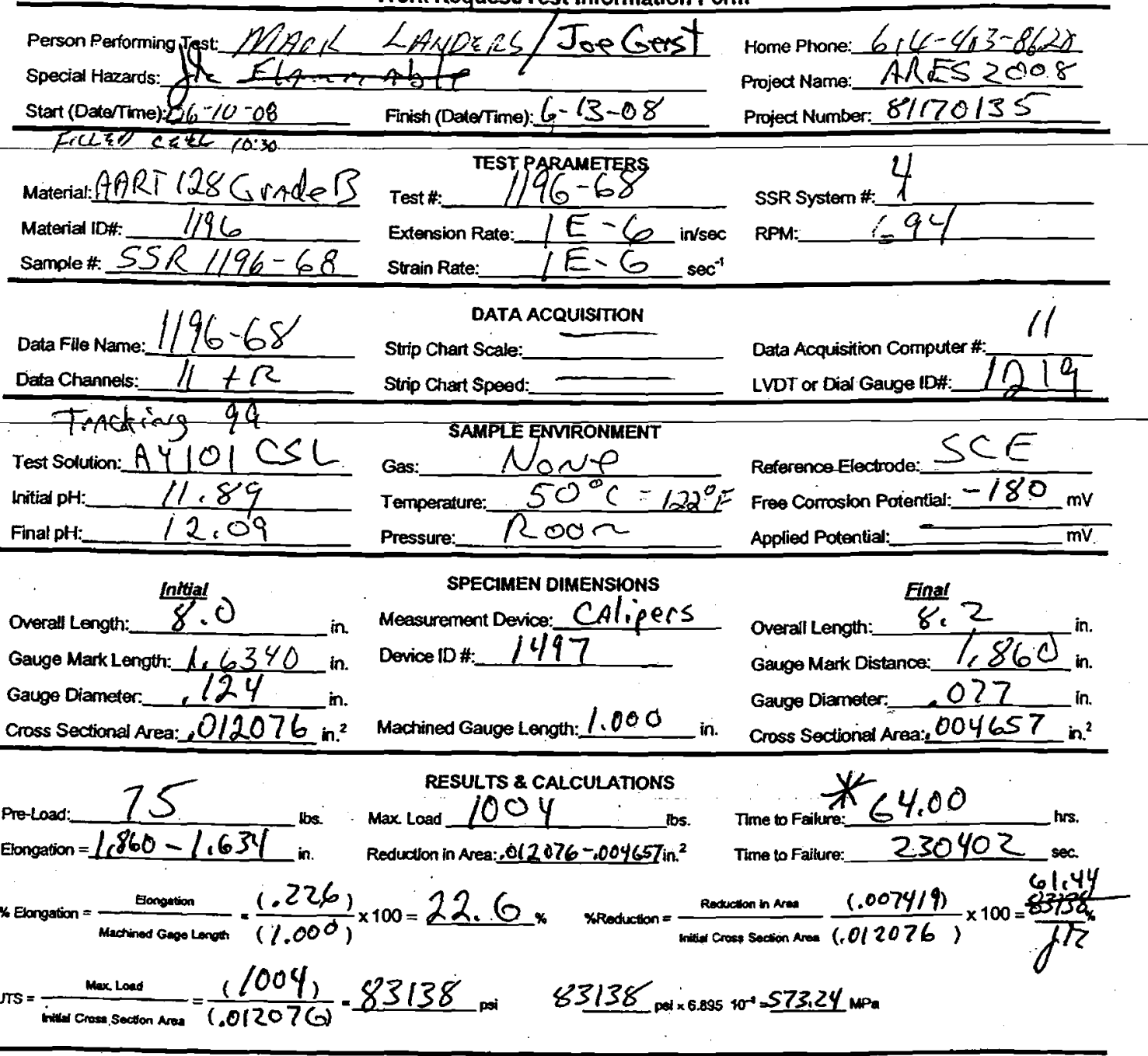
Vsat_- $\quad N_{0}$ QA APPROVED Low Power (30x): $\frac{2}{2}$ NAME: Cldum Crack Mode:

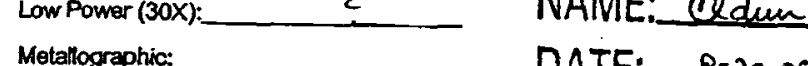
Max. Crack Depth:__

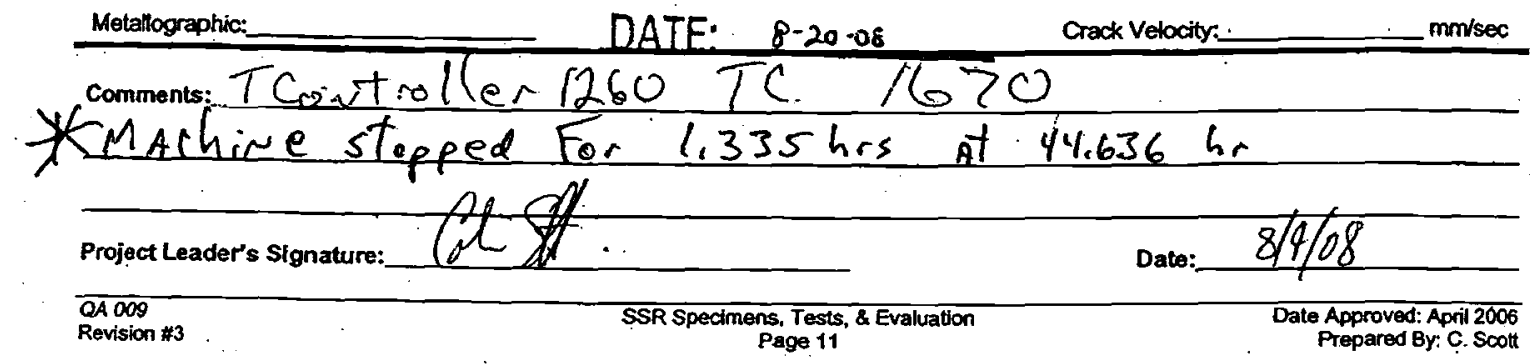


RPP-RPT-37505, Rev. 0

\section{Test Sheet Addendum}

\begin{tabular}{|c|c|c|c|c|}
\hline $\begin{array}{l}\text { Test \# } \\
\text { Sample \# } \\
\text { Filar Eye Pieee- }\end{array}$ & $\frac{\frac{1196-68}{S S R 1196-68}}{\text { CCT } 10224}$ & $\begin{array}{l}\text { Readings } \\
94 \\
17\end{array}$ & & \\
\hline & & 77 & & \\
\hline Magnification & $30 x$ & & & \\
\hline inches/graduation & .001 & $\begin{array}{c}\text { Reading, } \\
\text { graduations } \\
77\end{array}$ & * $\begin{array}{c}\text { inches/ } \\
\text { graduation }\end{array}$ & $\begin{array}{c}=\text { Final Diameter, } \\
\text { in. }\end{array}$ \\
\hline
\end{tabular}

\section{Comments}


Slow Strain Rate

Work Request/Test Information Form

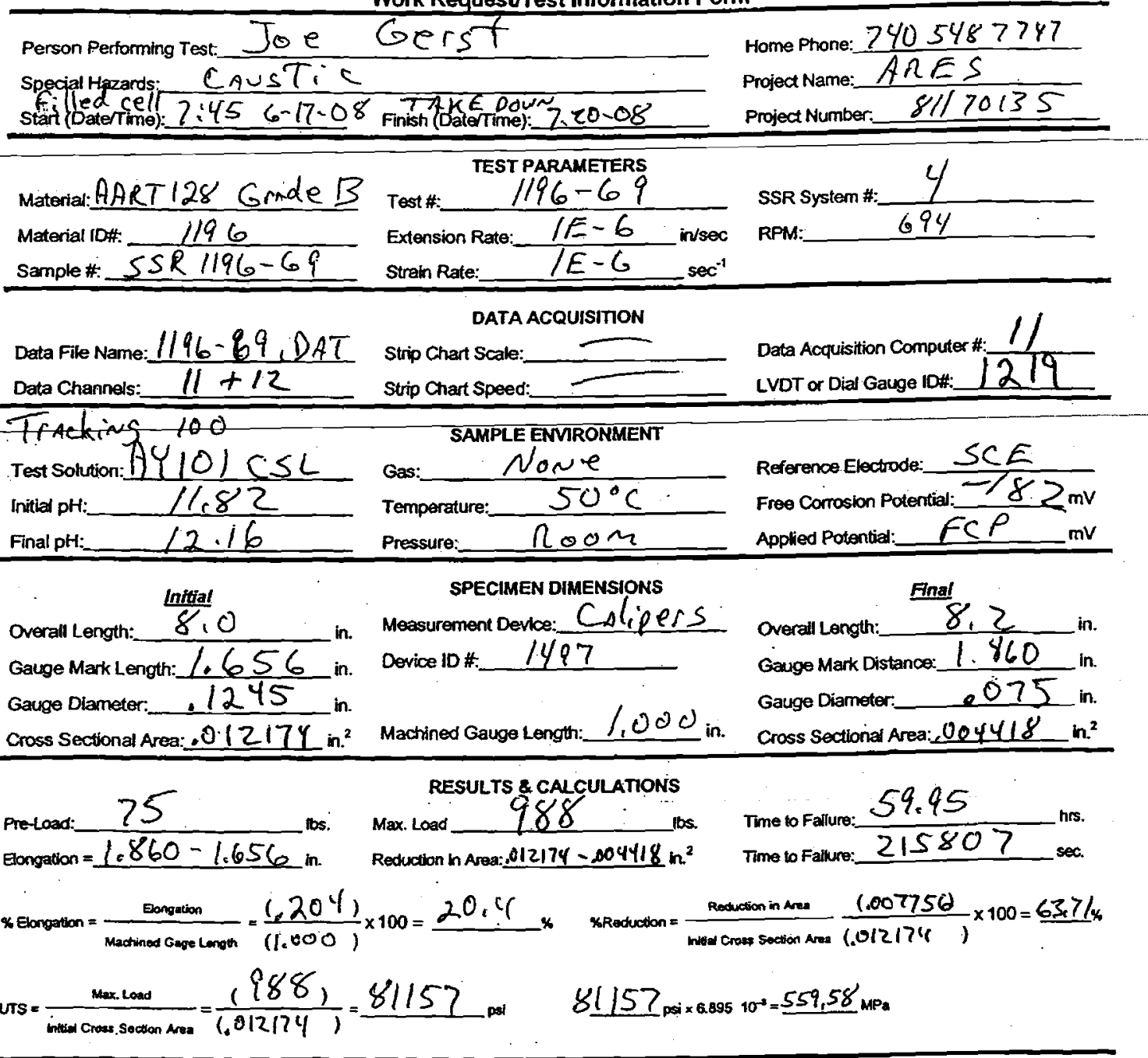

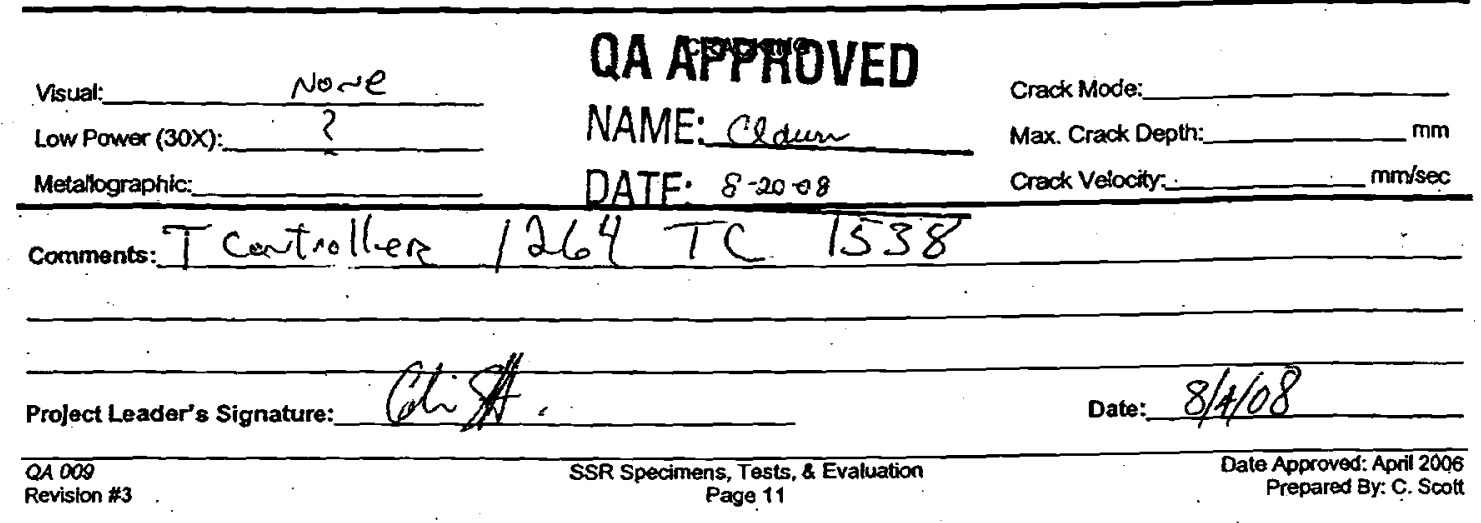


RPP-RPT-37505, Rev. 0

\section{Test Sheet Addendum}

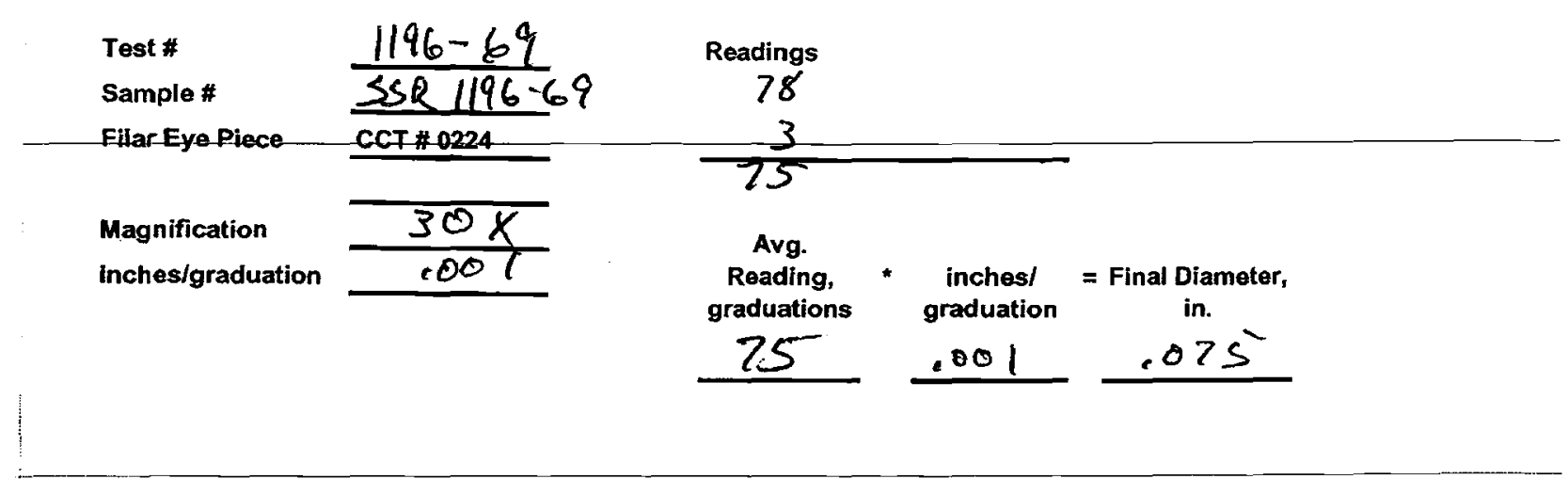

\section{Comments}


Slow Strain Rate

Work Request/Test Information Form



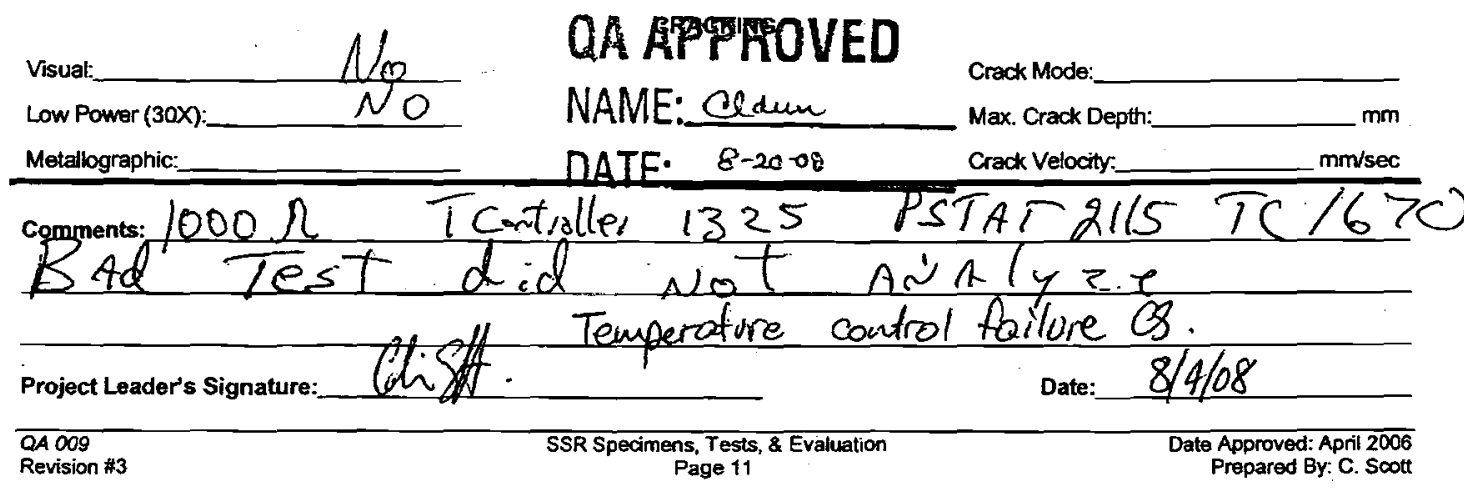


RPP-RPT-37505, Rev. 0

\section{Test Sheet Addendum}

$\begin{array}{ll}\text { Test \# } \\ \text { Sample \# } \\ \text { Filar Eye Piece } & \frac{1196 \cdot 70}{\operatorname{SSR} 1196 \cdot 70} \\ \begin{array}{l}\text { Magnification } \\ \text { inches/graduation }\end{array} & \frac{30224}{30 x} \\ & \end{array}$

\begin{tabular}{|c|c|c|}
\hline \multicolumn{3}{|l|}{ Readings } \\
\hline 77 & & \\
\hline $\begin{array}{l}\text { Avg. } \\
\text { Reading, } \\
\text { graduations }\end{array}$ & $\begin{array}{c}\text { inches/ } \\
\text { graduation }\end{array}$ & $\begin{array}{c}=\text { Final Diameter, } \\
\text { in. }\end{array}$ \\
\hline 77 & .001 & .077 \\
\hline
\end{tabular}

\section{Comments}




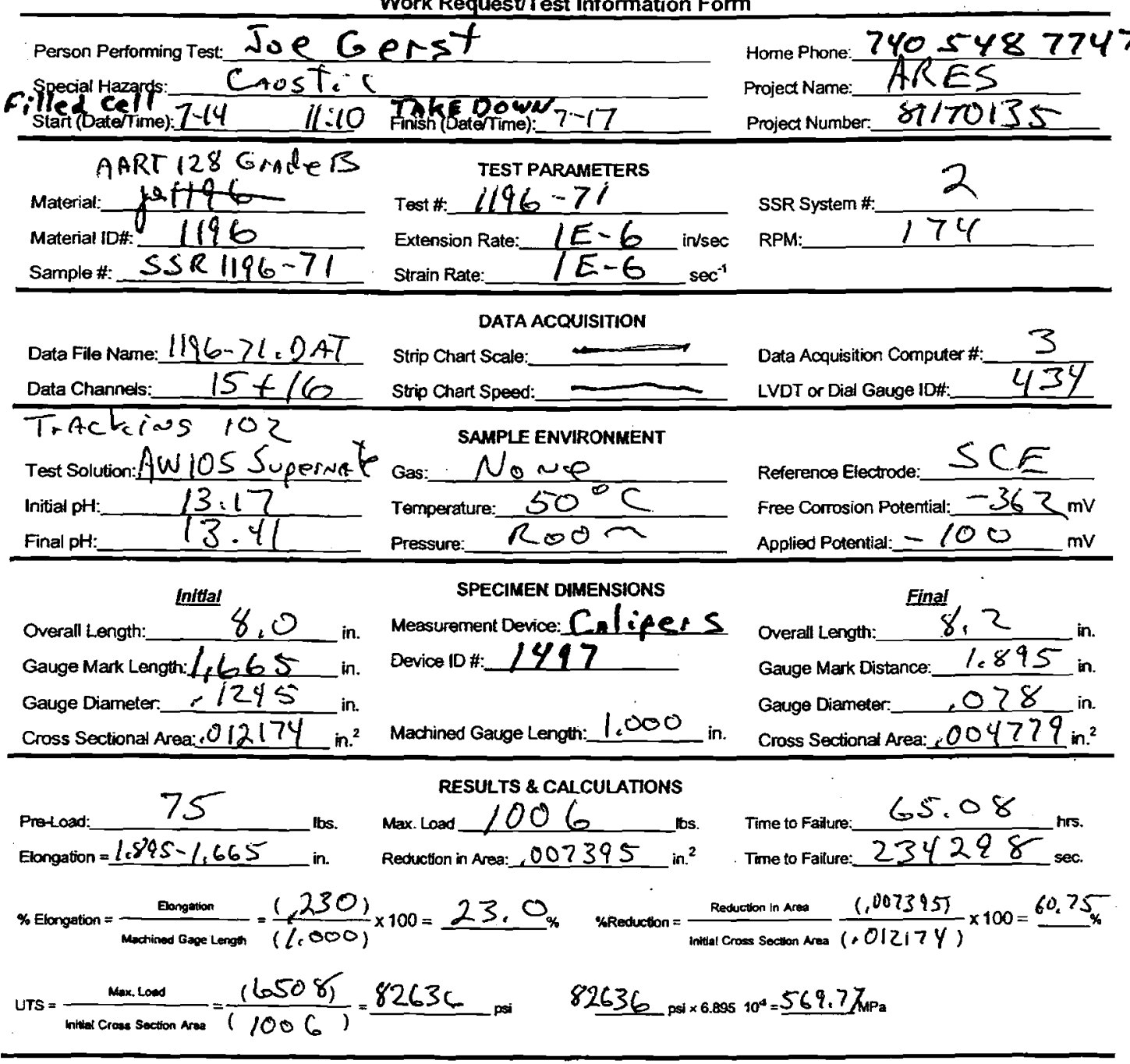

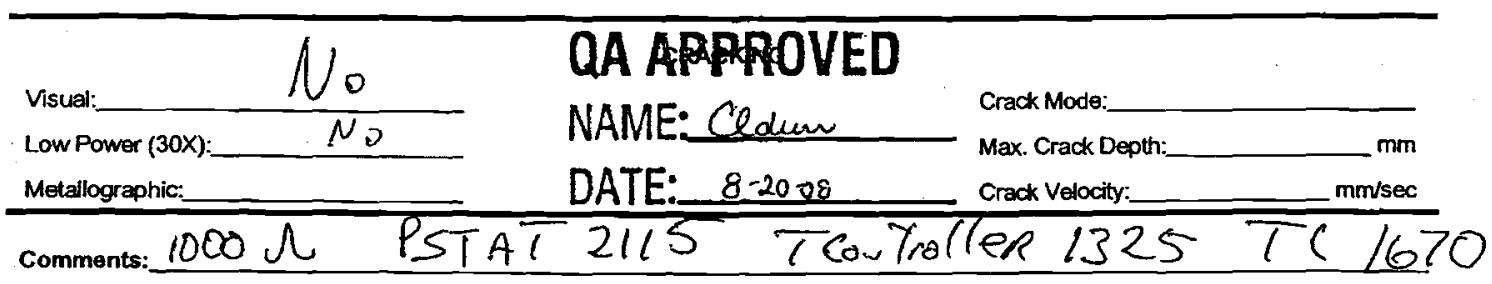

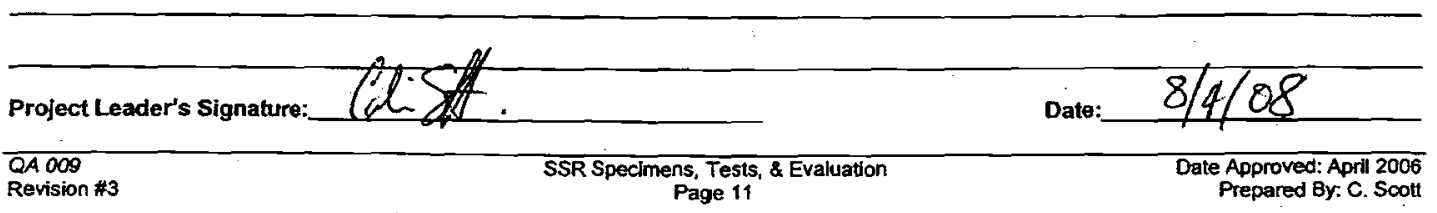


RPP-RPT-37505, Rev. 0

\section{Test Sheet Addendum}

$\begin{array}{ll}\text { Test \# } \\ \text { Sample \# } \\ \text { Filar Eye Piece } & \frac{1196-71}{S S R 196-71} \\ & \frac{C C T \# 0224}{30 X} \\ \begin{array}{l}\text { Magnification } \\ \text { inches/graduation }\end{array} & \frac{301}{.001}\end{array}$

Readings 81

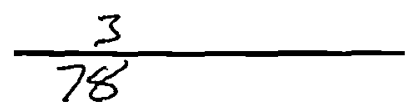

Avg.

Reading, * inches/ = Final Diameter, graduations graduation in.

78

.001 .078

\section{Comments}


Slow Strain Rate

Work Request/Test Information Form

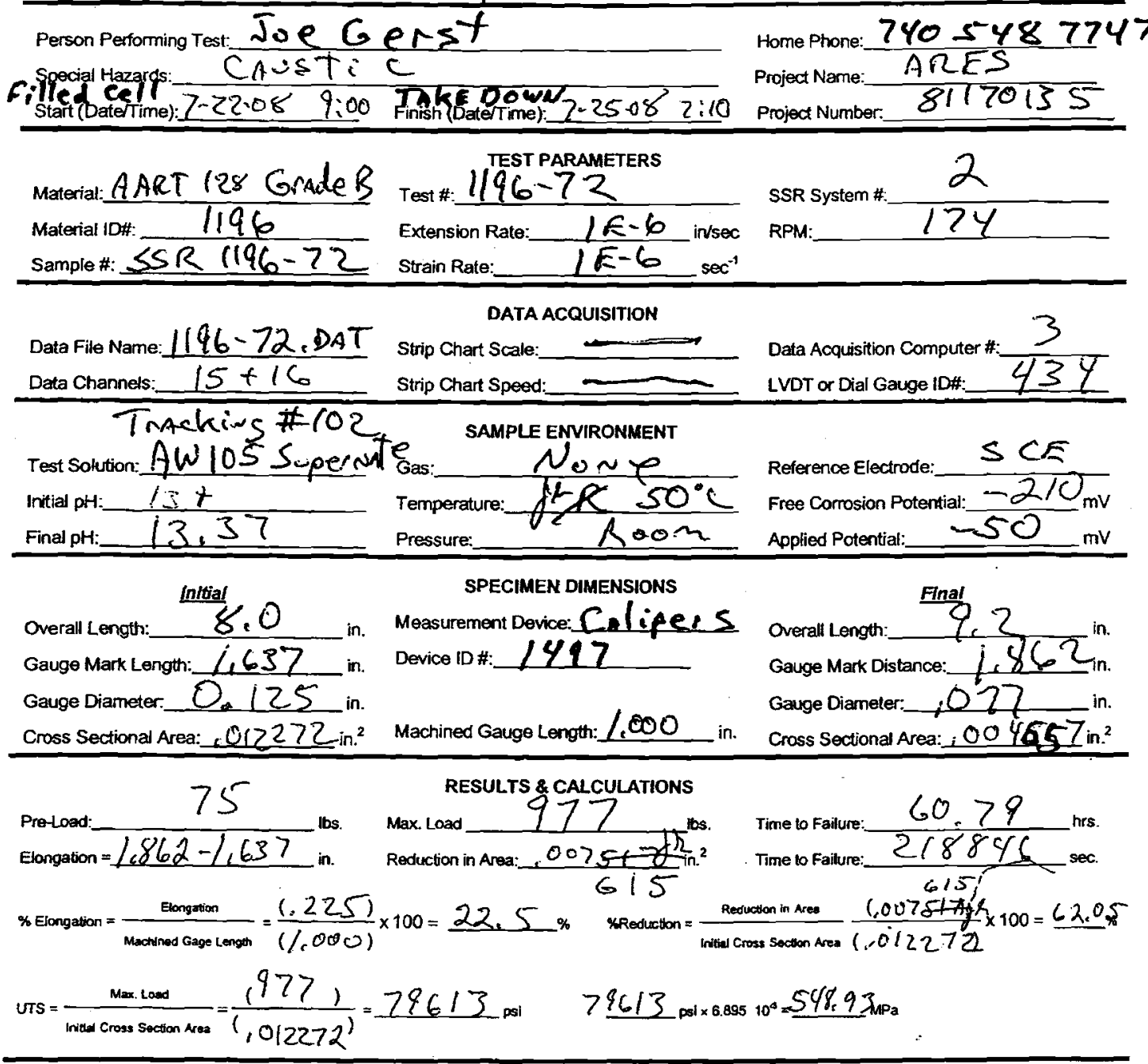

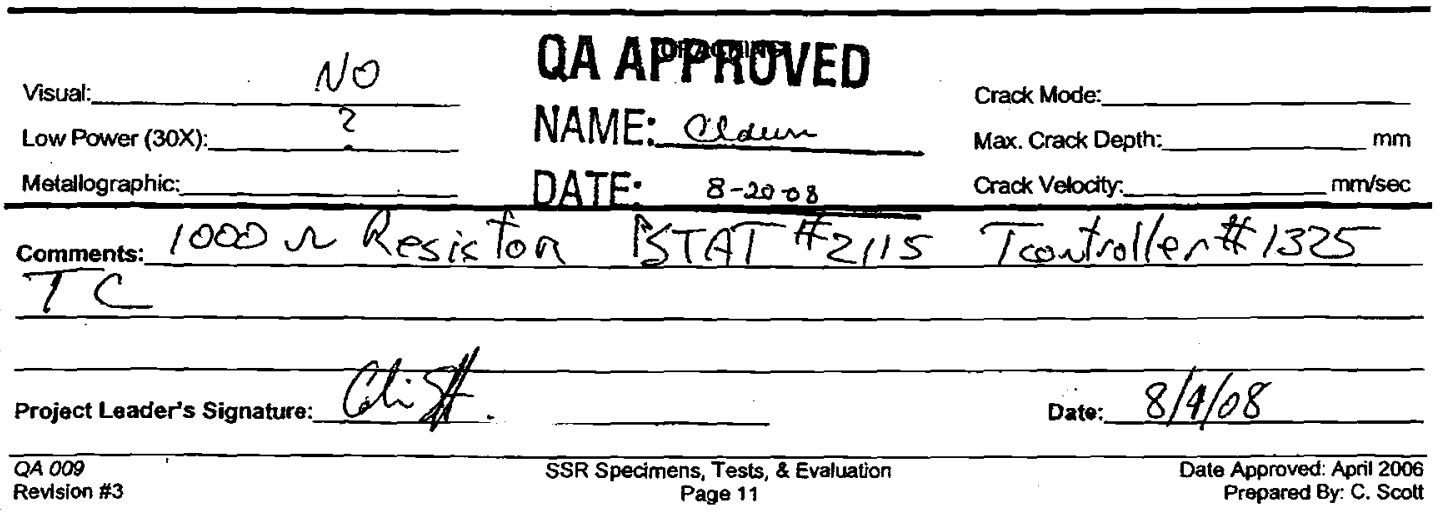


RPP-RPT-37505, Rev. 0

\section{Test Sheet Addendum}

$\begin{array}{ll}\text { Test \# } \\ \begin{array}{l}\text { Sample \# } \\ \text { Filar Eye Piece }\end{array} & \frac{196-72}{\text { SSR } 196-72} \\ \begin{array}{l}\text { Magnification } \\ \text { Inches/graduation }\end{array} & \frac{30224}{.001}\end{array}$

\begin{tabular}{c}
$\begin{array}{c}\text { Readings } \\
82 \\
5\end{array}$ \\
\hline 77 \\
$\begin{array}{c}\text { Avg. } \\
\text { Reading, } \\
\text { graduations } \\
27\end{array}$ inches/ \\
graduation \\
.001
\end{tabular}$\quad \begin{gathered}\text { Final Diameter, } \\
\text { in. }\end{gathered}$

\section{Comments}


RPP-RPT-37505, Rev. 0

Siow Strain Rate

Work RequestTest Information Form

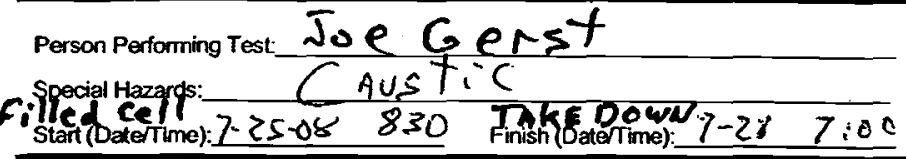

Home Phane: $740 \quad 5487747$

Project Name: ARES 2008

Project Number: 81170135

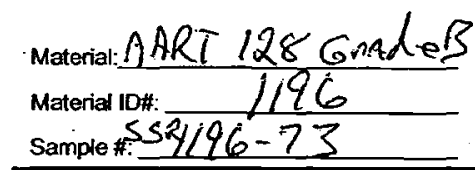

TEST PARAMETERS

Test: $1196-73$

Extension Rate: $1 k-C_{2}$ in'sec

Strain Rate: $\quad / E-6 \quad \sec ^{-1}$

SSR System \#: $\frac{2}{174}$

Data File Name:1 $196-73.09 T$ strip Chart Scale:

Data Channels: $15+16$

Strip Chart Speed:

Data Aoquisition Computer \#: 3

LVDT or Dial Gauge ID\#: $\quad 4 / 34$

TRACKING 103 .032MNI

Tost Solutiongly.3.3 AW 105 supernat Gas: NOUE

Initial pH: 13,32

Final $\mathrm{pH}:-13 \mathrm{t}$

Gas: $\quad \mathrm{SO}^{\circ} \mathrm{C}$

Pressure: RoOn

Reference Electrode: $\mathrm{SCF}$

Free Corrosion Potential: $2717 \mathrm{mv}$

Applied Potential: $-100 \quad \mathrm{mv}$

Overall Length: $\quad 8.0$

SPECIMEN DMMENSIONS

Gauge Mark Length: 1.634 in.

Gauge Diameter: .127 in.

Cross Sectional Area: 012668 in. $^{2}$

Measurement Device:Califers

Dovice 10\#: 1497

Overall Length: $\quad \frac{\text { Final }}{8}, 2$

Gauge Mark Distance: 1,835 in.

Gauge Diameter: $\quad .077$ in.

Machined Gauge Length: 1,000 in

Cross Sectional Area:, $004657 \mathrm{~m}^{2}$

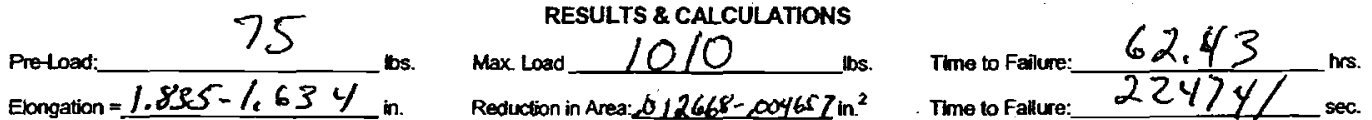

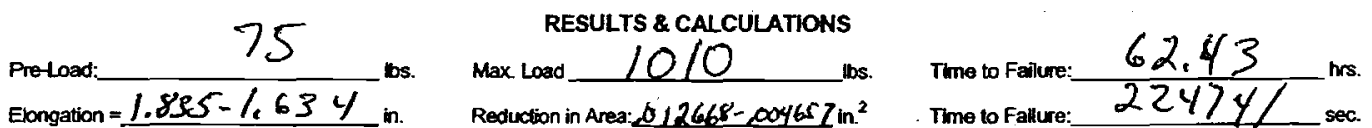

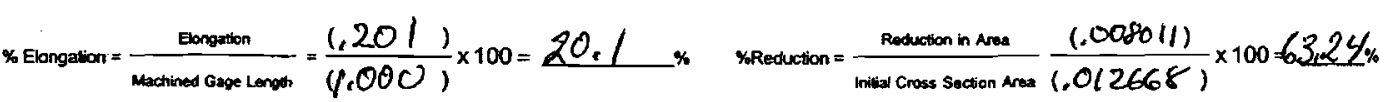

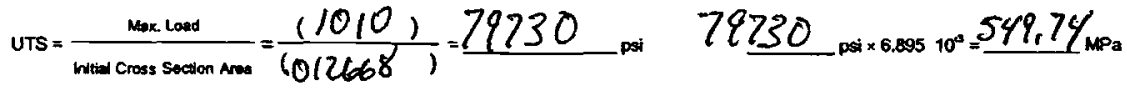

Visual:

Low Power (30X):

Metallographic:

DATE.
QA APPFKOVED
Crack Mode:

Max. Crack Depth:

Crack Velocity: $\mathrm{mm}$ $\mathrm{mm} / \mathrm{sec}$ comments: $1000 \Omega$ Resistor Pstat \#215 /covtroller \#/325 TS 1670

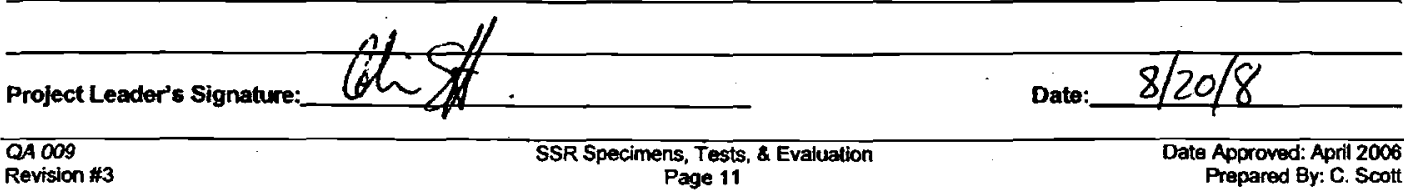


RPP-RPT-37505, Rev. 0

Test Sheet Addendum

\begin{tabular}{|c|c|}
\hline Test \# & $1196-73$ \\
\hline Sample \# & SSR $1196-73$ \\
\hline Filar Eye Piece & CCT \# 0224 \\
\hline Magnification & 30 \\
\hline inches/graduation & .001 \\
\hline
\end{tabular}

\begin{tabular}{c}
$\begin{array}{c}\text { Readings } \\
85 \\
8\end{array}$ \\
$\begin{array}{c}\text { Avg. } \\
\text { Reading, * } \\
\text { graduations } \\
77\end{array}$ inches/ \\
\hline 7 graduation \\
.001
\end{tabular}

\section{Comments}


Slow Strain Rate

Work Request/Test Information Form

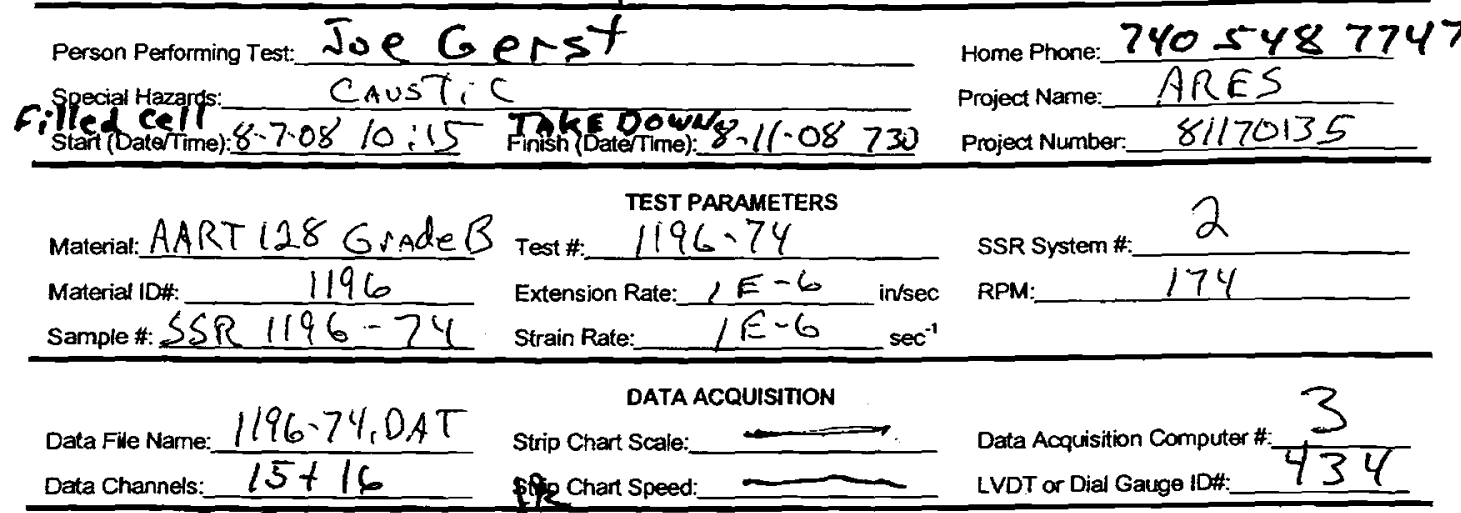
AW 105 foc TRACkis 105

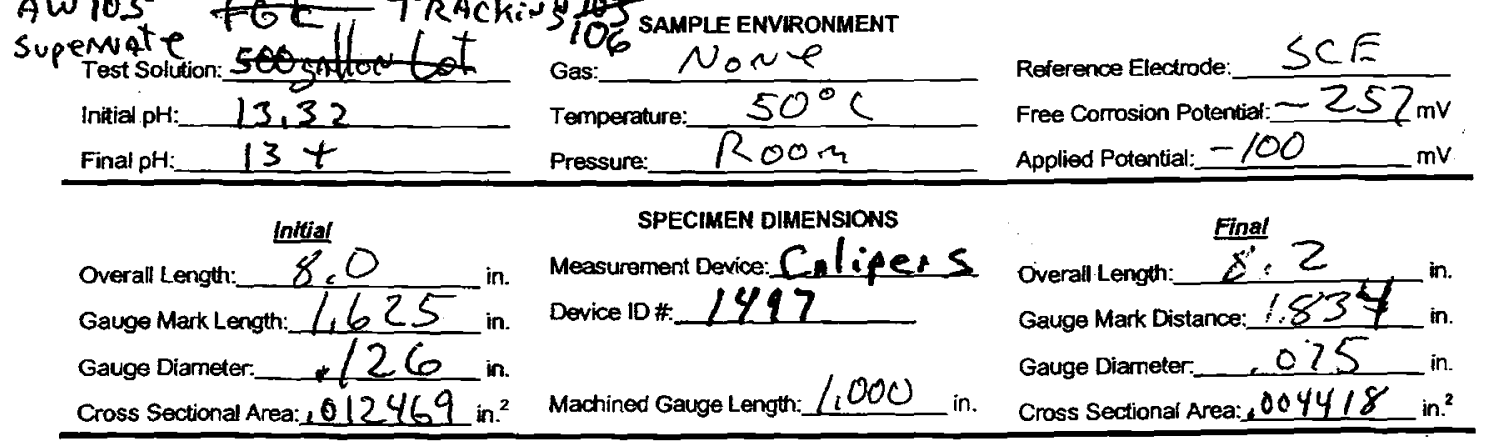

\begin{tabular}{|c|c|c|c|}
\hline 75 & $\begin{array}{l}\text { RESULTS \& CALCULATIONS } \\
101 ?\end{array}$ & & 61.28 \\
\hline Elongation $=4.834-1.625$ & Reduction in Area: $012468 \cdot .004418$ in. ${ }^{2}$ & Time to Failune: & 220620 \\
\hline
\end{tabular}

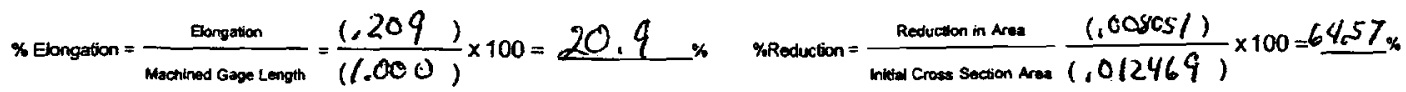

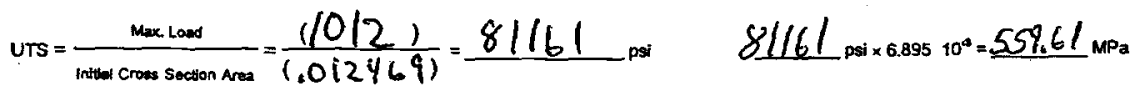

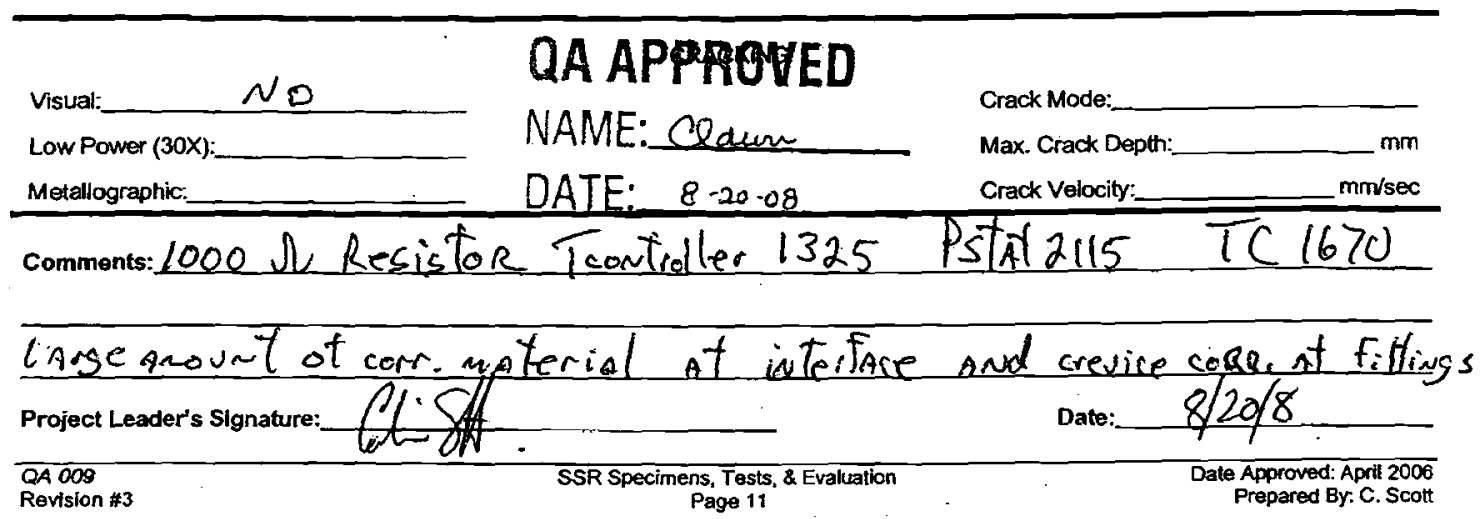


RPP-RPT-37505, Rev. 0

\section{Test Sheet Addendum}

$\begin{array}{ll}\text { Test \# } \\ \begin{array}{l}\text { Sample \# } \\ \text { Filar Eye Piece }\end{array} & \frac{\frac{1196-74}{S S R 1196-74}}{\frac{\text { CCT } 0224}{30 X}} \\ \begin{array}{l}\text { Magnification } \\ \text { inches/graduation }\end{array} & \frac{.006}{100}\end{array}$

Readings

77

$\frac{2}{75}$

Avg.

Reading, * inches/ = Final Diameter, graduations

$.001 \quad .075$

\section{Comments}


Slow Strain Rate

Work Request/Test Information Form

Person Performing Test: $A A R K C$

Fit(edsell 1.00 8-14.08 Finish (DaterTime):5-15.08 4:45

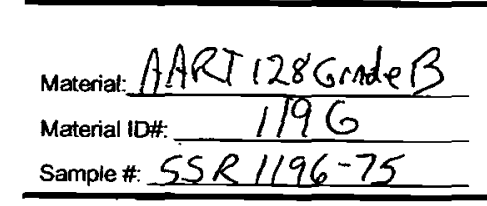

TEST PARAMETERS

Test \#: $\quad 1 / 96-75$

Extension Rate: $\quad 16-6 \quad$ in/sec

Strain Rate: $\quad / E-G \quad \sec ^{-1}$
Home Phone: $6 / 4-403-8620$ Project Name: ARES 2008 Project Number. $\quad \delta 127013 \leqslant 5$ SSR System * fats RPM: 174

\section{DATA ACQUISITION}

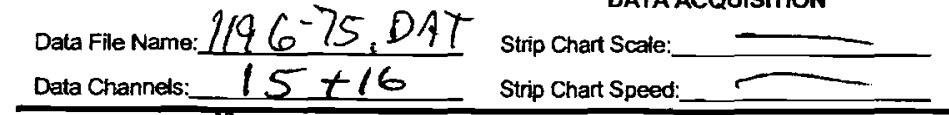

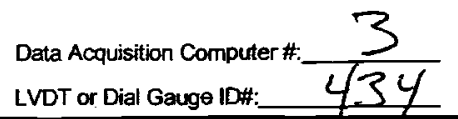

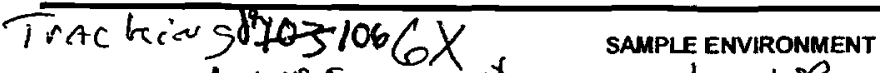

Test Solution: Aw 105 superintegas:_ No

Initial pH: $13+$ Temperature: $50^{\circ} \mathrm{C}$ Final $\mathrm{pH}: \quad 13 t$

Pressure: $/ 20024$ Reference Electrode: $S C E$ Free Corrosion Potential: $-270 \mathrm{mv}$ Applied Potential: $-5 \mathrm{mv}$

$$
\text { Overall Length: } \quad 8,8
$$

SPECIMEN DIMENSIONS

Gauge Mark Length: 1.6445

Measurement Device: $C$ A $c 9$ P

Device ID\#_ $/ 497$

Overall Length: $\quad \frac{\text { Final }}{8}, 1$

Gauge Diameter. .125

Gauge Mark Distance:To cerraded. Gauge Diameter to m ensure in. Cross Sectional Area: $\quad, 012272$ in. $^{2}$ Machined Gauge Length: 1.000 in.

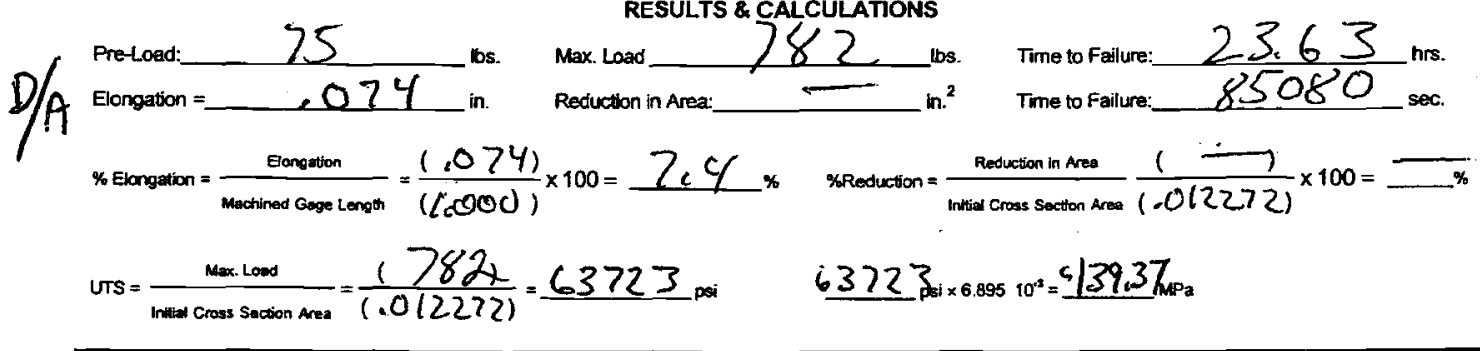

\section{QA APRARQVED}

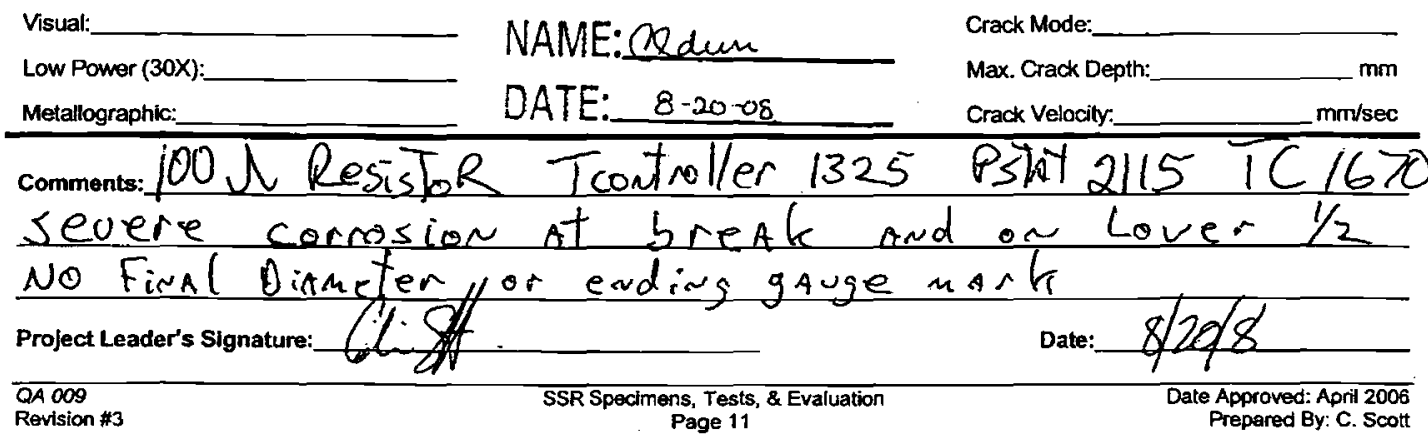




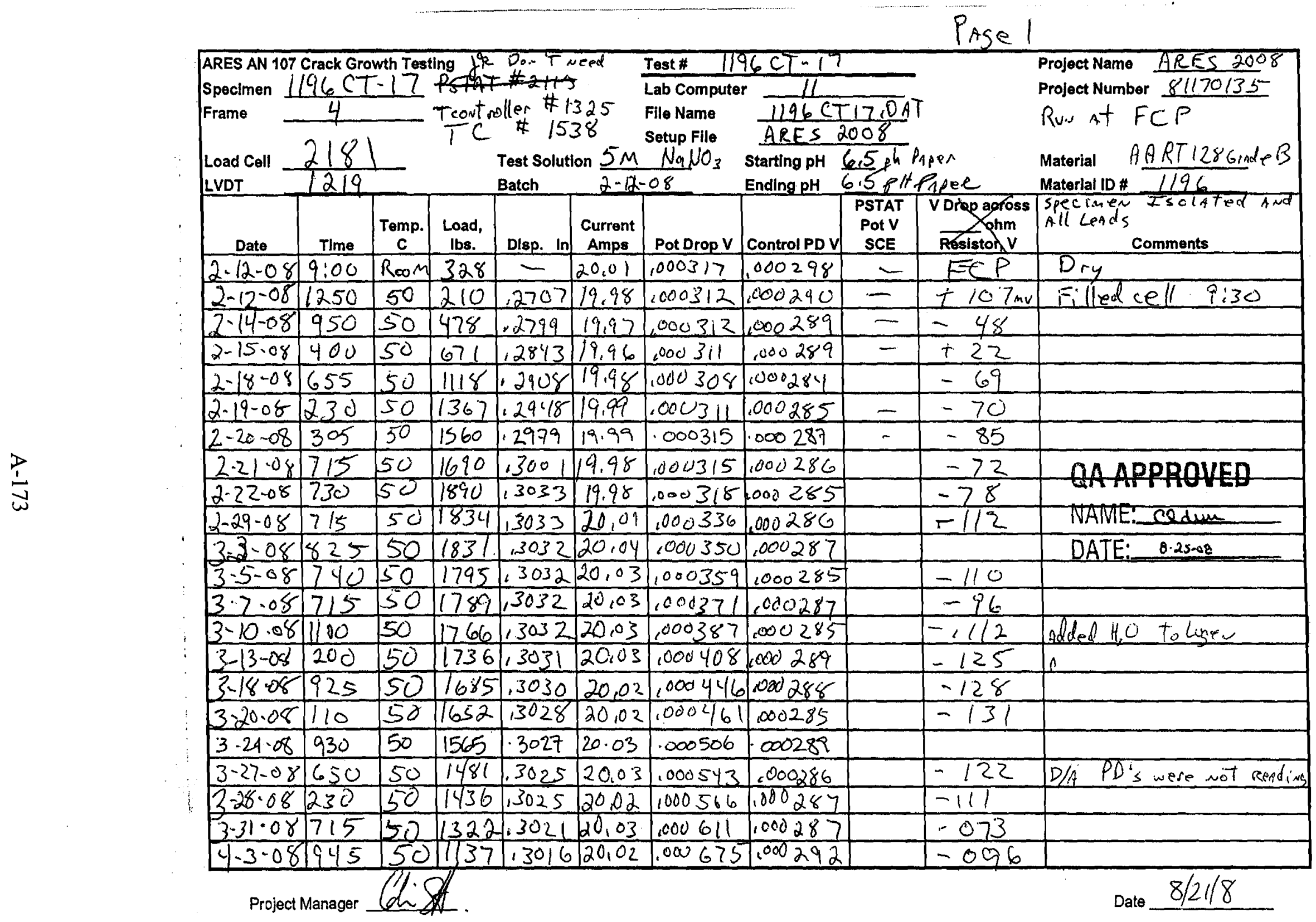




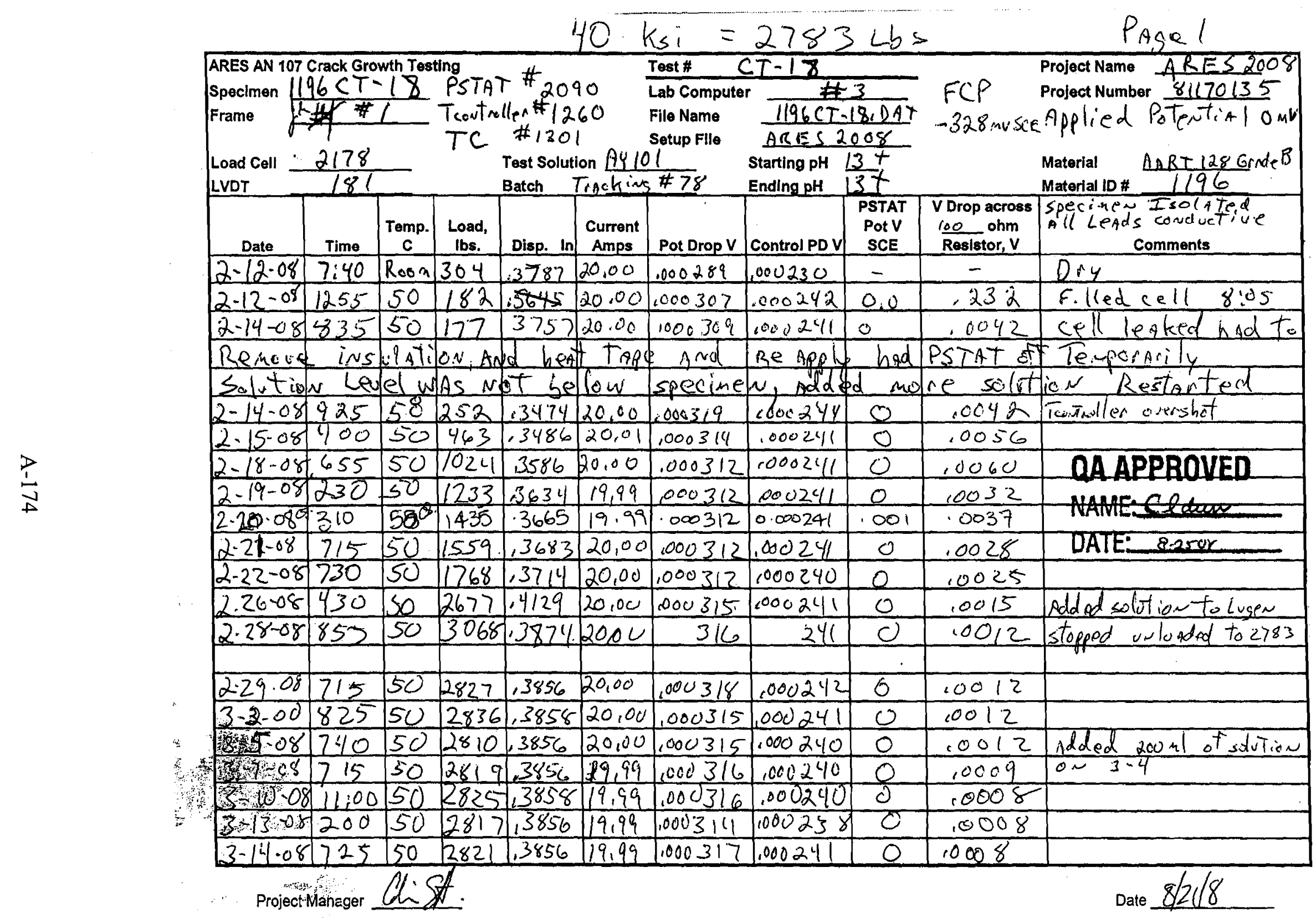


Page 2

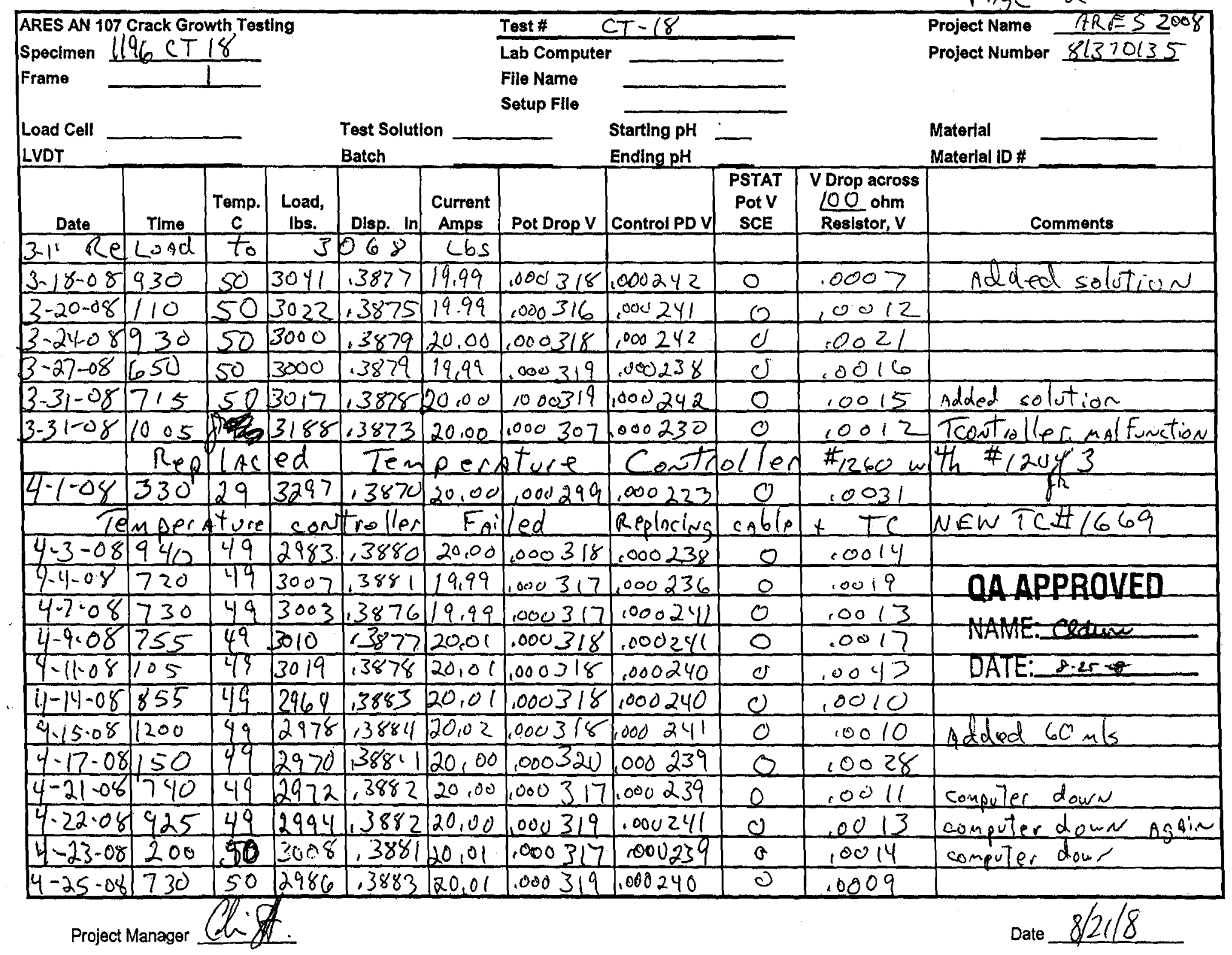




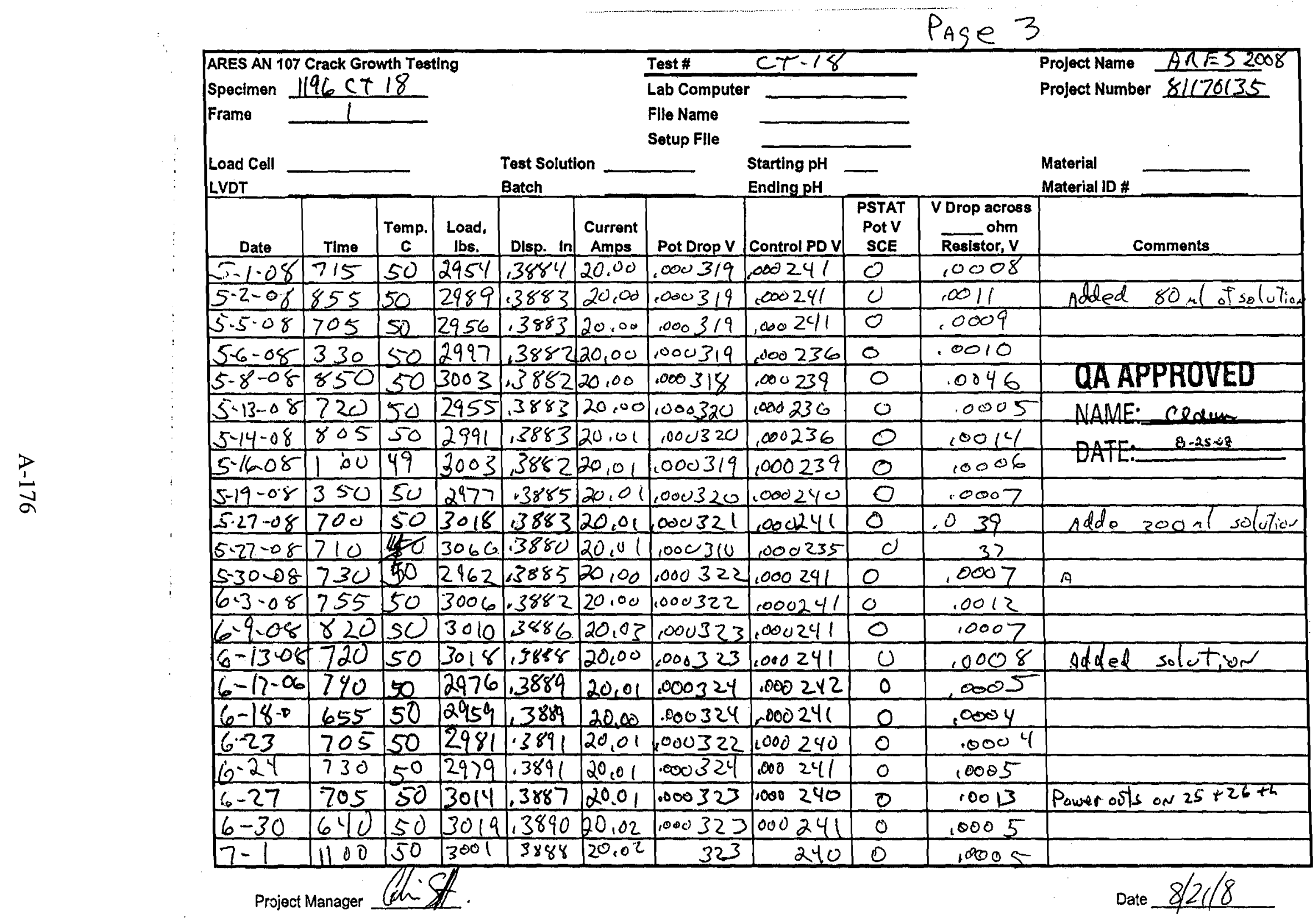




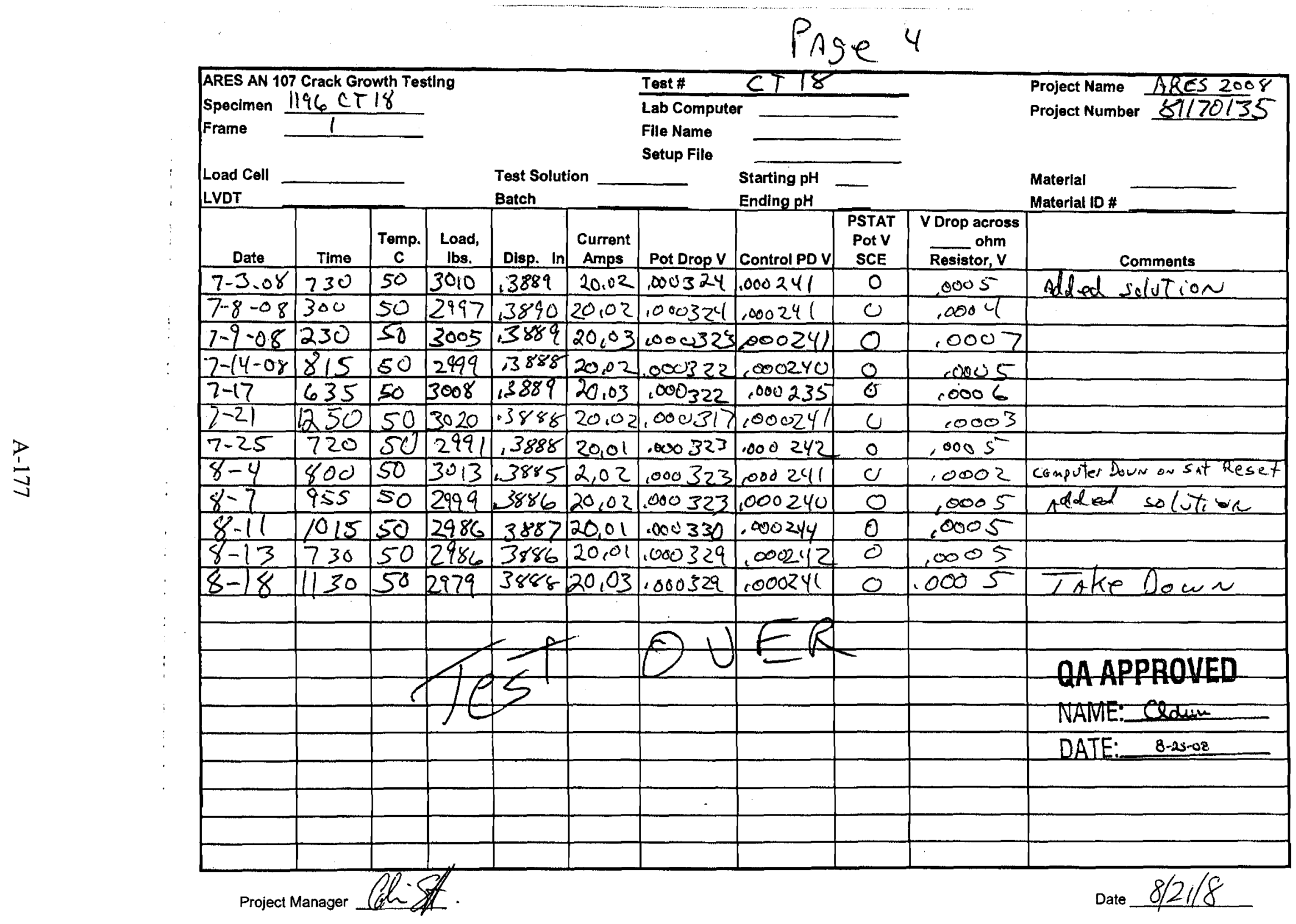


RPP-RPT-3\%弓05, Rev. 0

APPENDIX B

CYCLIC POTENTIODYNAMIC POLARIZATION (CPP) TESTING DATA 
Table B-1. A Summary of Electrochemical Tests Performed in AP105-PSC Based Simulants.

\begin{tabular}{|c|c|c|c|c|c|c|c|c|c|c|c|c|}
\hline $\begin{array}{c}\text { Base } \\
\text { Chemistry }\end{array}$ & pH & $\begin{array}{l}\mathrm{NO}_{2}^{-} \\
(\mathrm{M})\end{array}$ & $\begin{array}{l}\mathrm{NO}_{3}^{-} \\
(\mathrm{M})\end{array}$ & $\begin{array}{l}\text { TIC } \\
(\mathrm{M}) \\
\end{array}$ & $\begin{array}{c}\mathrm{OH}^{-} \\
(\mathbf{M})^{*}\end{array}$ & $\begin{array}{c}\mathrm{Cl}^{-} \\
(\mathrm{M})\end{array}$ & $\begin{array}{c}\mathbf{F}^{-} \\
(\mathbf{M})\end{array}$ & $\begin{array}{c}\mathrm{T} \\
\left({ }^{\circ} \mathrm{C}\right)\end{array}$ & $\begin{array}{l}\text { Aeration } \\
\text { condition }\end{array}$ & Testing type & Visual & $\begin{array}{c}\text { Sample ID } \\
\text { (\#EL1196-) }\end{array}$ \\
\hline AP105-PSC & $>13$ & 0.27 & 3.58 & 0.326 & 0.176 & 0.03 & 0.009 & 50 & $\begin{array}{c}\mathrm{N}_{2} \\
\text { sparging }\end{array}$ & $\begin{array}{c}\text { CPP } \\
\text { Full immersion }\end{array}$ & No pitting & 54 \\
\hline AP105-PSC & $>13$ & 0.27 & 3.58 & 0.326 & 0.176 & 0.03 & 0.009 & 50 & $\stackrel{\mathrm{N}_{2}}{\text { sparging }}$ & $\begin{array}{c}\text { CPP } \\
\text { Full immersion }\end{array}$ & No pitting & 60 \\
\hline AP105-PSC & $>13$ & 0.27 & 3.58 & 0.326 & 0.176 & 0.03 & 0.009 & 50 & $\begin{array}{c}\mathrm{N}_{2} \\
\text { sparging }\end{array}$ & $\begin{array}{c}\text { Potentiostatic at } 0 \\
\mathrm{mV}\end{array}$ & No pitting & 63 \\
\hline AP105-PSC & $>13$ & 0.27 & 3.58 & 0.326 & 0.176 & 0.03 & 0.009 & 50 & $\begin{array}{c}\mathrm{N}_{2} \\
\text { sparging }\end{array}$ & $\begin{array}{c}\text { CPP } \\
\text { Full immersion } \\
\end{array}$ & $\begin{array}{c}\text { Crevice } \\
\text { corrosion }\end{array}$ & 64 \\
\hline AP105-PSC & $>13$ & 0.27 & 3.58 & 0.326 & 0.176 & 0.03 & 0.009 & 50 & $\begin{array}{c}\mathrm{N}_{2} \\
\text { sparging }\end{array}$ & $\begin{array}{c}\text { Potentiostatic at } 0 \\
\mathrm{mV}\end{array}$ & $\begin{array}{l}\text { Crevice } \\
\text { corrosion }\end{array}$ & 65 \\
\hline AP105-PSC & $>13$ & 0.27 & 3.58 & 0.326 & 0.176 & 0.03 & 0.009 & 50 & $\begin{array}{l}\text { Quiescent } \\
\text { air }\end{array}$ & $\begin{array}{c}\text { Potentiostatic at } 0 \\
\mathrm{mV} \text {, half } \\
\text { immersion }\end{array}$ & $\begin{array}{c}\text { Severe attack at } \\
\text { solution/vapor } \\
\text { interface }\end{array}$ & 66 \\
\hline API05-PSC & $>13$ & 0.6 & 3.58 & 0.326 & 0.176 & 0.03 & 0.009 & 50 & $\begin{array}{l}\text { Quiescent } \\
\text { air }\end{array}$ & $\begin{array}{c}\text { Potentiostatic at } 0 \\
\mathrm{mV} \text {, half } \\
\text { immersion }\end{array}$ & Corrosion** & 72 \\
\hline AP105-PSC & $>13$ & 0.27 & 3.58 & 0.326 & 0.176 & 0.03 & 0.009 & 50 & $\begin{array}{c}\mathrm{N}_{2} \\
\text { sparging }\end{array}$ & $\begin{array}{c}\text { Potentiostatic at } 0 \\
\mathrm{mV} \text {, half } \\
\text { immersion }\end{array}$ & Corrosion** & 73 \\
\hline AP105-PSC & $>13$ & 0.27 & 3.58 & 0.326 & 0.176 & 0.03 & 0.009 & 50 & $\begin{array}{l}\text { Quiescent } \\
\text { air }\end{array}$ & $\begin{array}{c}\text { CPP } \\
\text { Half immersion }\end{array}$ & Corrosion & 75 \\
\hline AP105-PSC & $>13$ & 0.27 & 3.58 & 0.326 & 0.176 & 0.03 & 0.009 & Room & $\begin{array}{l}\text { Quiescent } \\
\text { air }\end{array}$ & $\begin{array}{c}\text { Potentiostatic at } 0 \\
\mathrm{mV} \text {, half } \\
\text { immersion }\end{array}$ & Corrosion** & 76 \\
\hline AP105-PSC & $>13$ & 0.27 & 3.58 & 0.326 & 0.176 & 0.03 & 0.009 & 50 & $\begin{array}{l}\text { Quiescent } \\
\text { air }\end{array}$ & $\begin{array}{c}\text { Potentiostatic at } \\
100 \mathrm{mV} \text { vs. OCP, } \\
\text { half immersion }\end{array}$ & Corrosion** & 77 \\
\hline AP105-PSC & $>13$ & 0.27 & 3.58 & 0.326 & 0.176 & 0.03 & 0.009 & Room & $\begin{array}{l}\text { Quiescent } \\
\text { air }\end{array}$ & $\begin{array}{c}\text { CPP } \\
\text { Full immersion }\end{array}$ & No pitting & 81 \\
\hline AP105-PSC & $>13$ & 0.27 & 3.58 & 0.326 & 0.176 & 0.03 & 0.009 & 50 & $\begin{array}{l}\text { Quiescent } \\
\text { air }\end{array}$ & $\begin{array}{c}\text { Potentiostatic at } 0 \\
\mathrm{mV} \\
\text { Half immersion }\end{array}$ & Minor corrosion & 91 \\
\hline AP105-PSC & $>13$ & 0.27 & 3.58 & 0.326 & 0.176 & 0.03 & 0.009 & Room & $\begin{array}{l}\text { Quiescent } \\
\text { air }\end{array}$ & $\begin{array}{c}\text { Potentiostatic at } 50 \\
\text { mV vs. OCP } \\
\text { Half immersion }\end{array}$ & Corrosion & 92 \\
\hline API05-PSC & $>13$ & 0 & 3.85 & 0.326 & 0.176 & 0.03 & 0.009 & 50 & $\begin{array}{c}\mathrm{N}_{2} \\
\text { sparging }\end{array}$ & $\begin{array}{c}\text { CPP } \\
\text { Full immersion }\end{array}$ & Pitting & 93 \\
\hline
\end{tabular}


Figure B-1. The CPP Curve in Deaerated AP105-PSC Simulant $\left(\mathrm{T}=50^{\circ} \mathrm{C}\right.$ and pH>13).

(a)

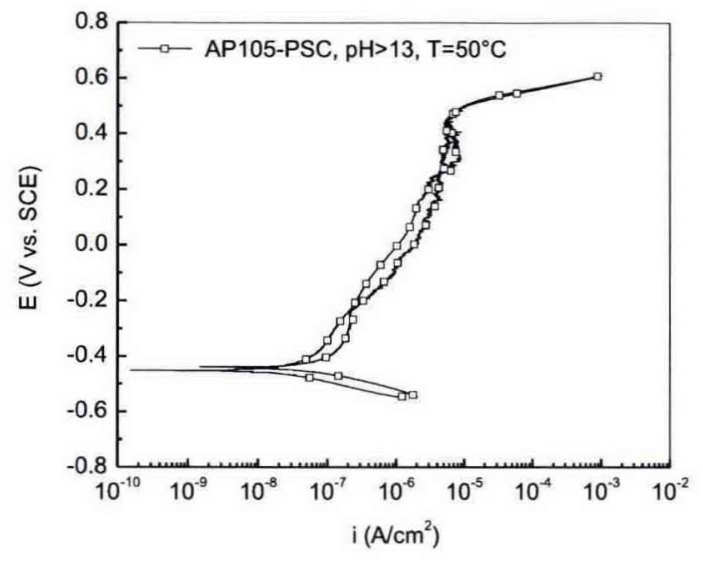

(b)

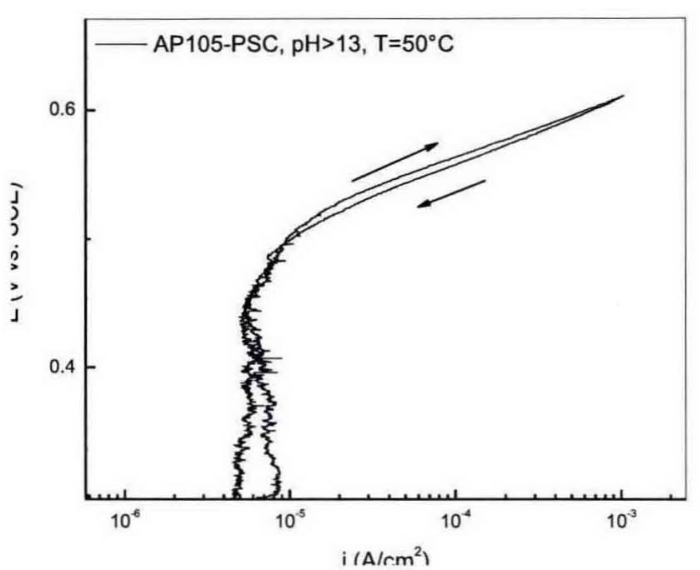

Figure B-2. A Comparison of CPP Curves in Deaerated AP105-PSC Simulant at Different Nitrite and Nitrate Concentrations $\left(\mathrm{pH}=13+, \mathrm{T}=50^{\circ} \mathrm{C}\right)$

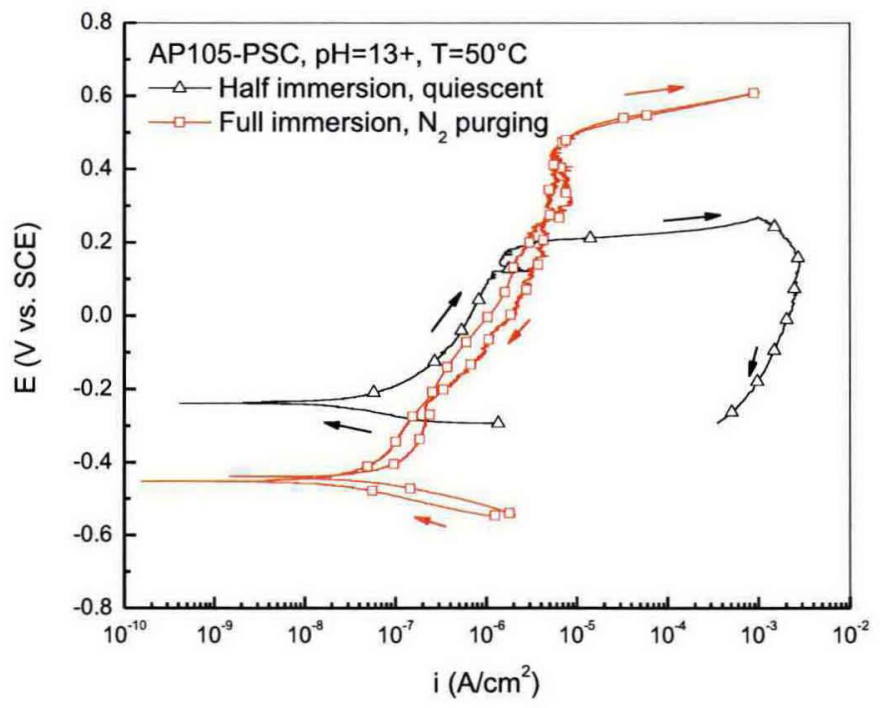


Figure B-3. Sample Appearance after CPP Testing in AP105-PSC Simulant at Quiescent Condition $\left(\mathrm{pH}=13+, \mathrm{T}=50^{\circ} \mathrm{C}\right)$
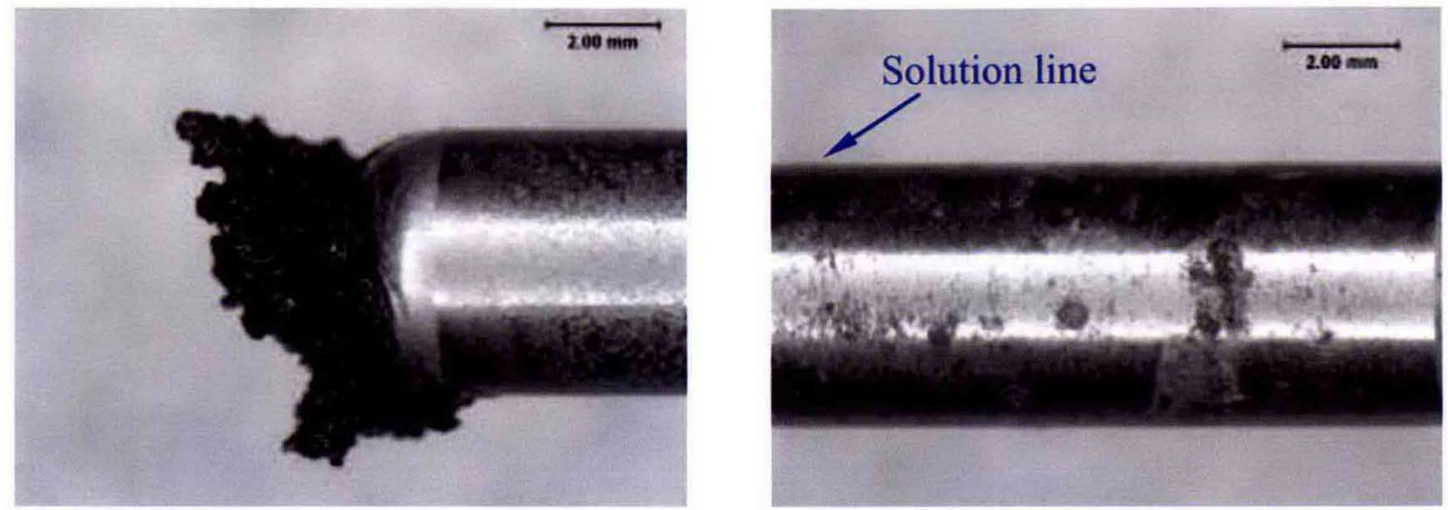

Figure B-4. The Current Density as a Function of Time when the Partially Immersed Sample Was Held at $0 \mathrm{mV}$ vs. SCE (AP105-PSC, pH>13, $\mathbf{T}=5^{\circ}{ }^{\circ} \mathrm{C}$, Quiescent Condition).

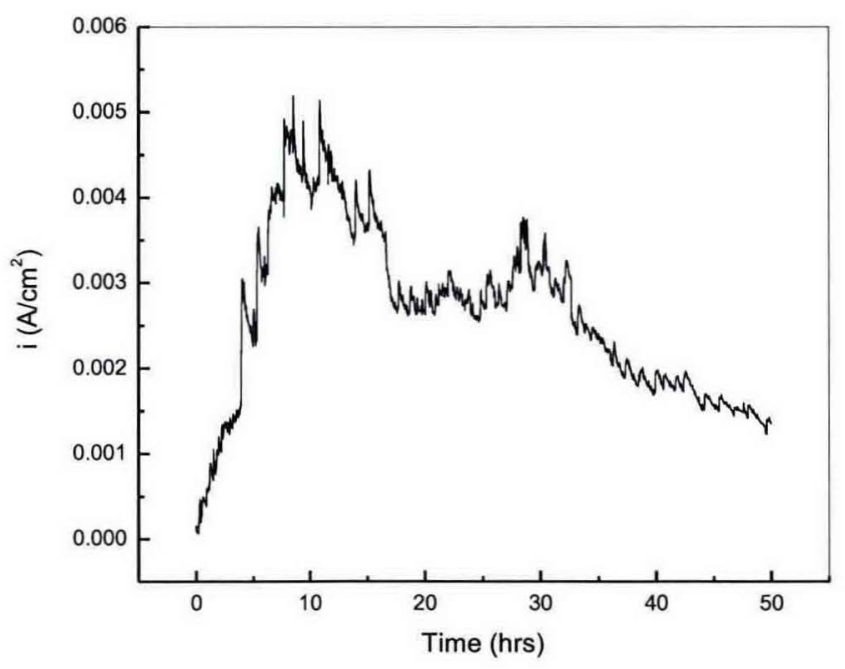


Figure B-5. The Sample Appearance after 50 Hours of Potentiostatic Testing at $0 \mathrm{mV}$ vs. SCE in the AP105-PSC Simulant $\left(\mathrm{pH}>13, \mathrm{~T}=50^{\circ} \mathrm{C}\right.$, Quiescent Condition).

(a) Corrosion at Solution/Vapor Interface;

(b) Corrosion on the Portion above the Solution/vapor Interface.

(a)

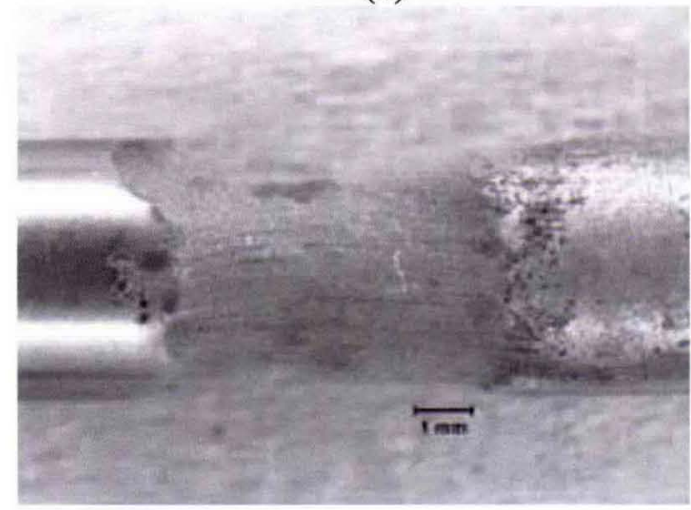

(b)

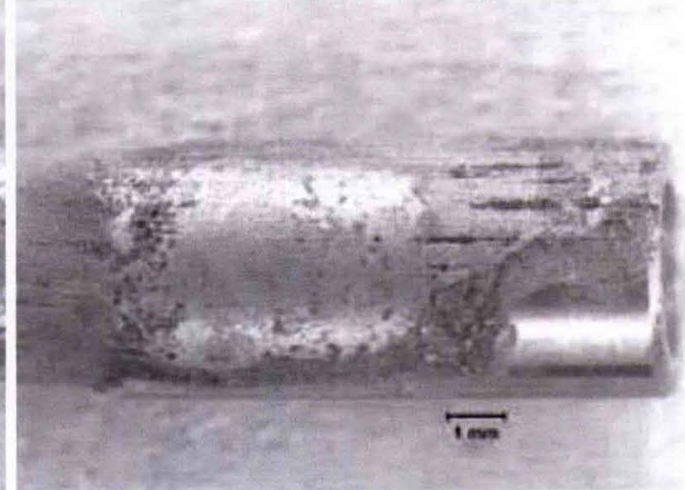

(b)

Figure B-6. The Current Density as a Function of Time When the Fully Immersed Sample Was Held at $0 \mathrm{mV}$ vs. SCE in AP105-PSC Simulant $\left(\mathrm{T}=50^{\circ} \mathrm{C}\right.$, pH>13).

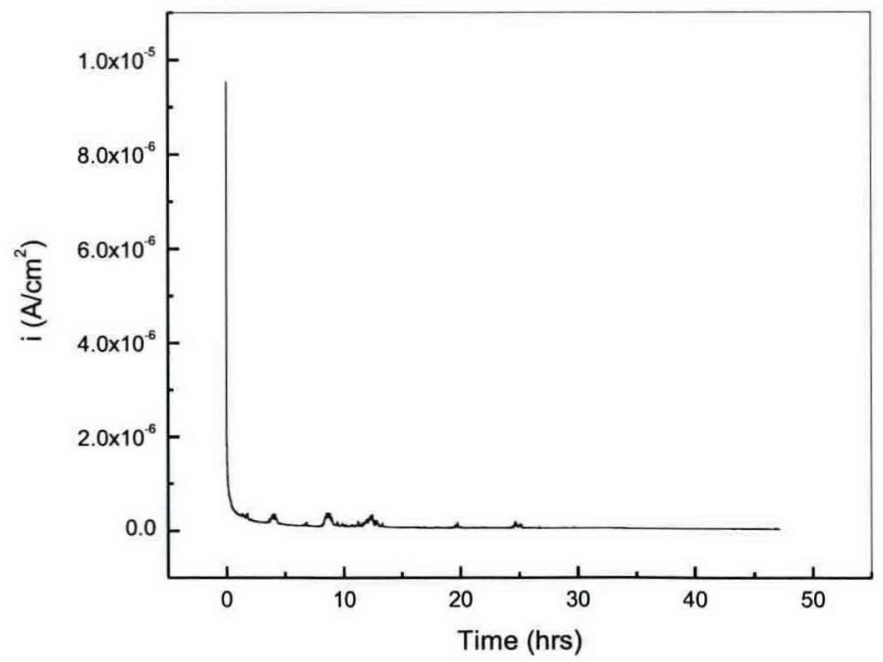


Figure B-7. A Comparison of the Current Density as a Function of Time in the Potentiostatic Tests Conducted in AP105-PSC Simulants with Different Nitrite Concentrations at $5^{\circ} \mathrm{C}$ and Quiescent Conditions.

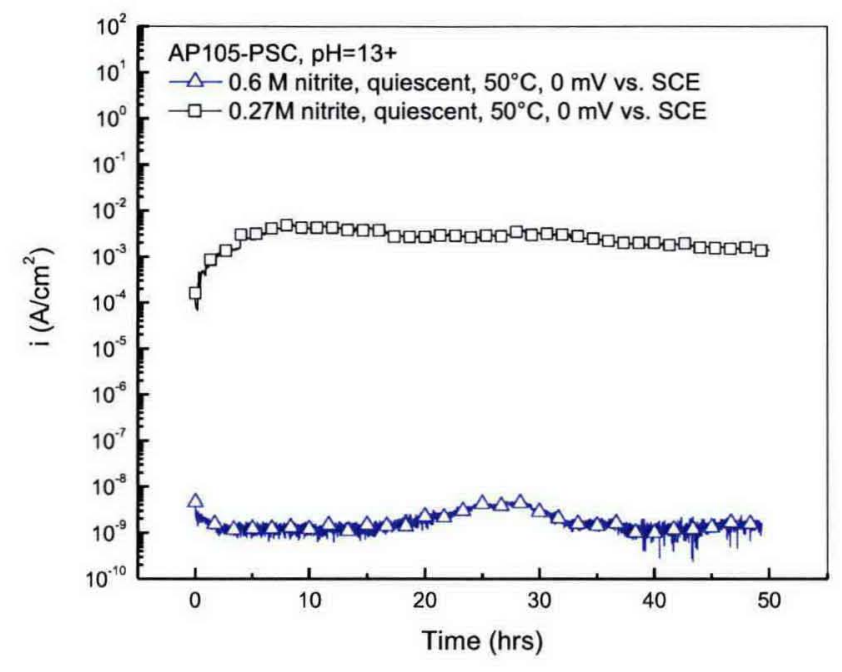

Figure B-8. The Sample Appearance After Potentiostatic Test at $0 \mathrm{mV}$ (vs. SCE) in the AP105-PSC Simulant with 0.6 M Nitrite for 50 hours (Sample Partially Immersed) at $50^{\circ} \mathrm{C}$.
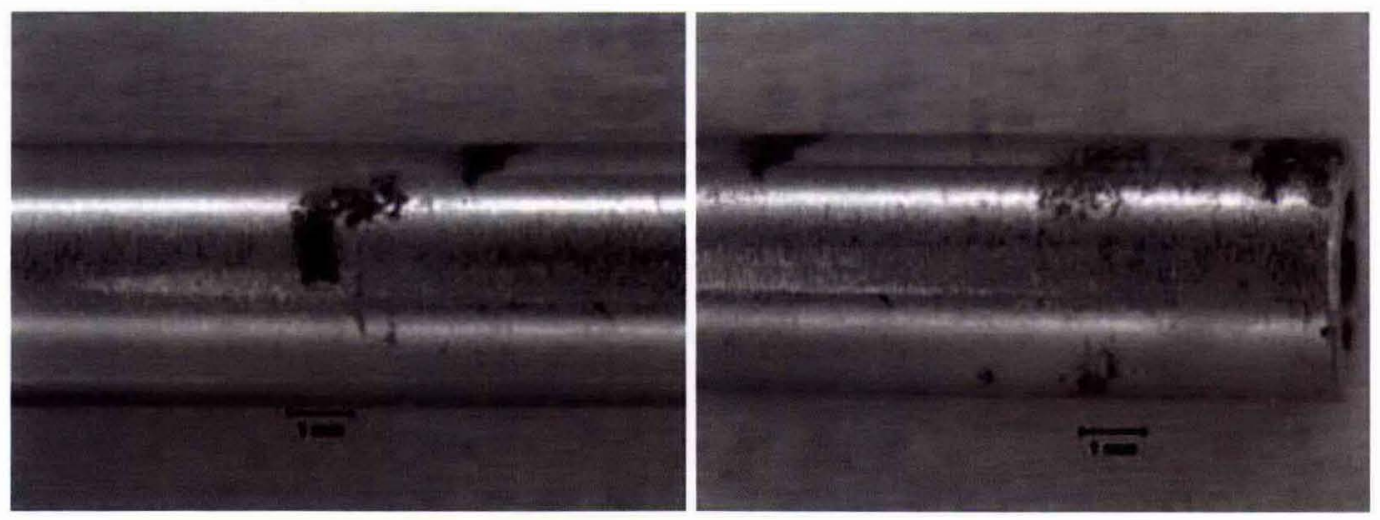
Figure B-9. A Comparison of the Current Density as a Function of Time in the Potentiostatic Tests Conducted at $0 \mathrm{mV}$ (vs. SCE) in Quiescent and Nitrogen Purged AP105-PSC Simulants at $50^{\circ} \mathrm{C}$.

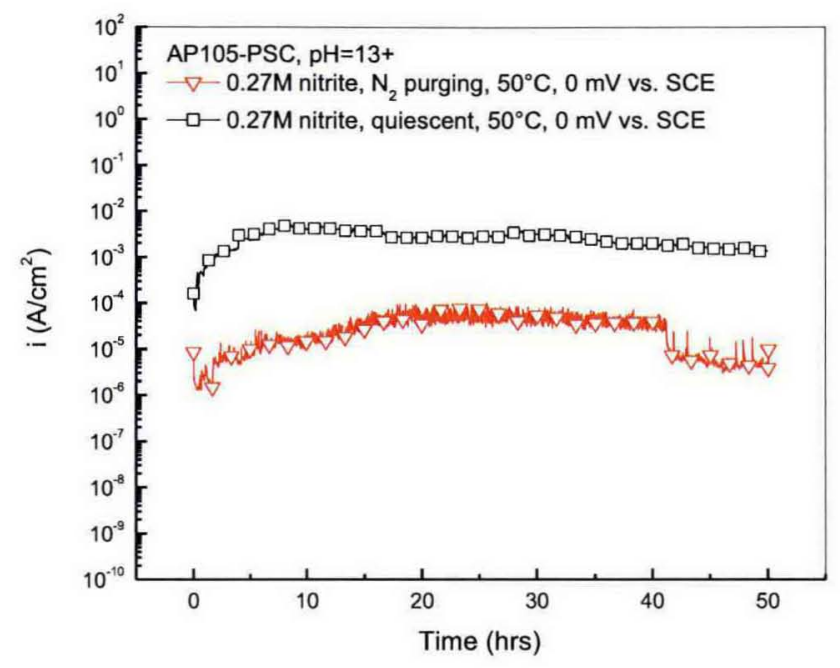

Figure B-10. The Sample Appearance after Potentiostatic Test at $0 \mathrm{mV}$ (vs. SCE) in Deaerated AP105-PSC Simulant for 50 hours (Sample Partially Immersed) at $50^{\circ} \mathrm{C}$.
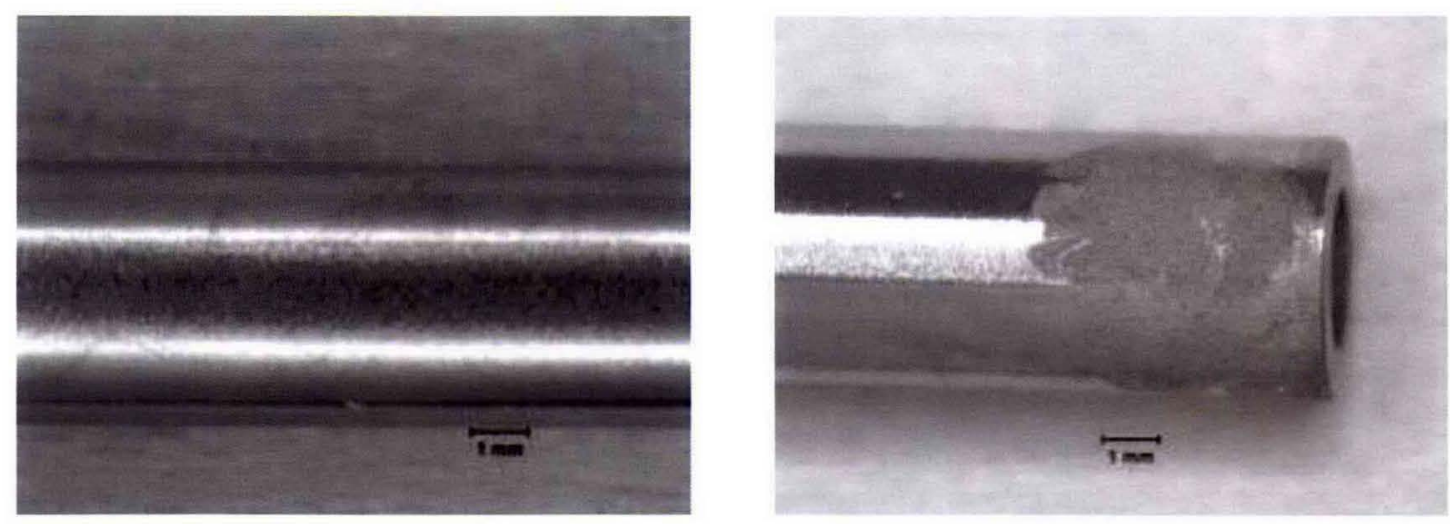
Figure B-11. A Comparison of the Current Density as a Function of Time in the Potentiostatic Tests Conducted in AP105-PSC Simulants at $0 \mathrm{mV}$ (vs. SCE) and $100 \mathrm{mV}$ (vs. OCP) $\left(50^{\circ} \mathrm{C}\right.$, Quiescent Condition).

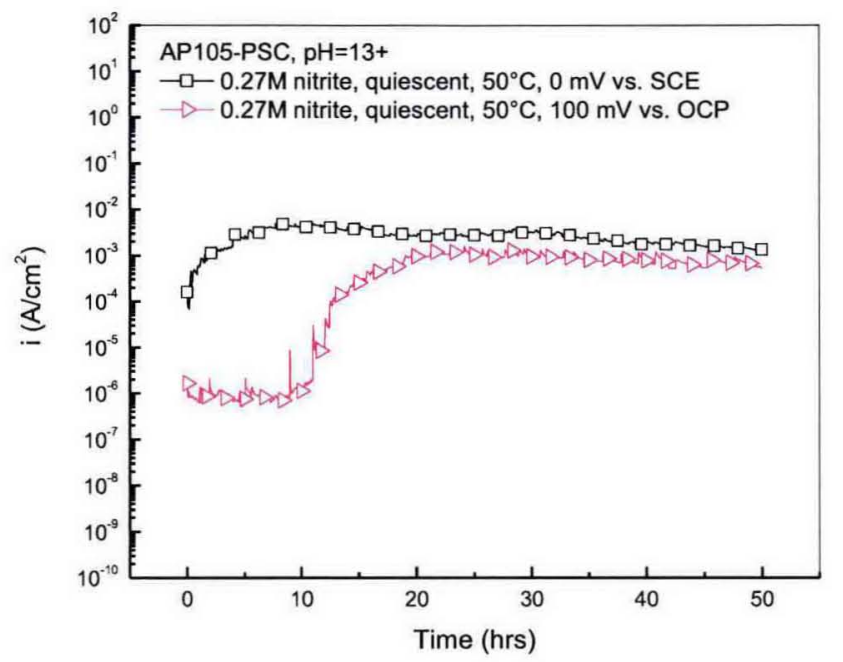

Figure B-12. The Sample Appearance after Potentiostatic Test at $100 \mathbf{~ m V}$ (vs. OCP) in the AP105-PSC Simulant for 50 Hours (Sample Partially Immersed) at $50^{\circ} \mathrm{C}$.

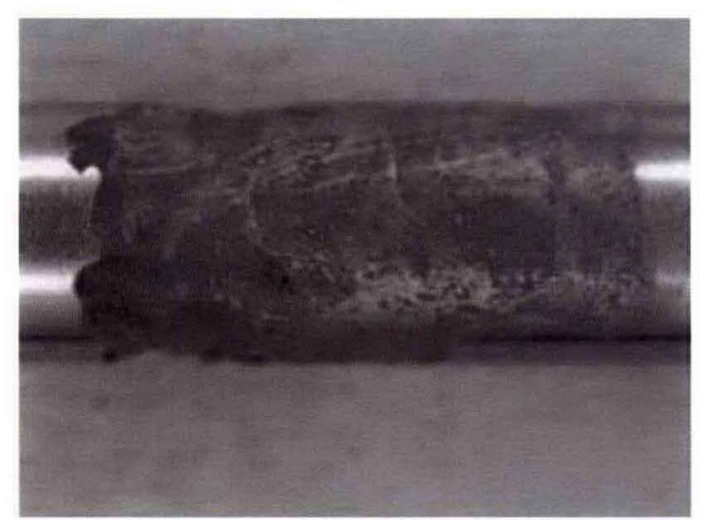


Figure B-13. A Comparison of CPP Curves in Deaerated AP105-PSC Simulant at Different Nitrite and Nitrate Concentrations $\left(\mathrm{pH}=13+, \mathrm{T}=50^{\circ} \mathrm{C}\right)$.

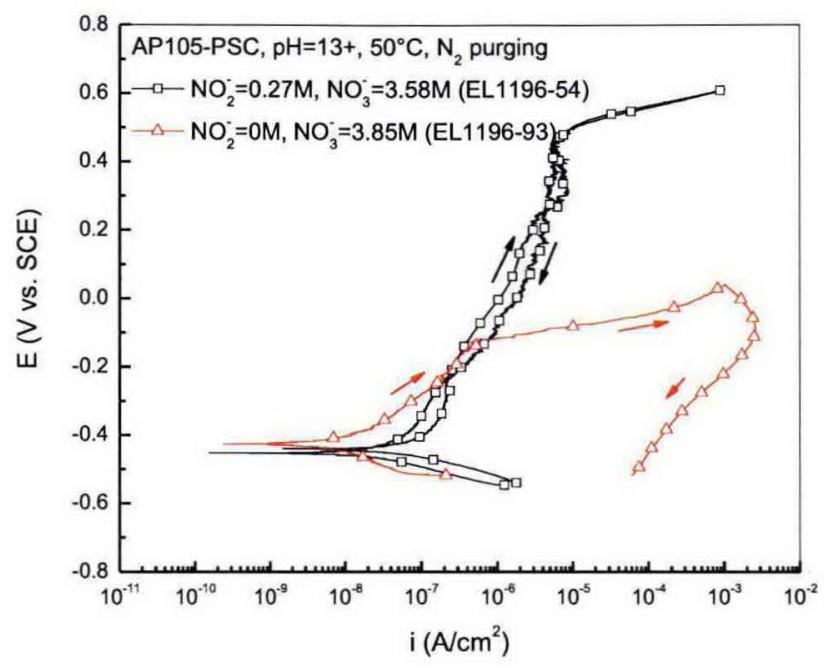

Figure B-14. The Sample Appearance after CPP Testing in Deaerated AP105-PSC with $0 \mathrm{M}$ Nitrite and 3.85 $\mathrm{M}$ Nitrate $\left(\mathrm{pH}=13+, \mathrm{T}=\mathbf{5 0}^{\circ} \mathrm{C}\right)$.

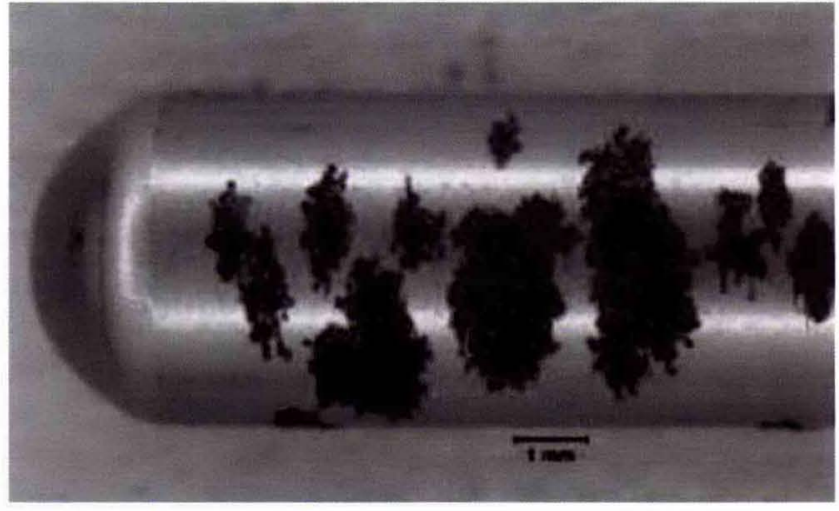


Figure B-15. A Comparison of the Current Density as a Function of Time in the Potentiostatic Tests Conducted in Different Conditions. (a) Room T vs. $50^{\circ} \mathrm{C}$;

(b) $0 \mathrm{mV}$ (vs. SCE) vs. $50 \mathrm{mV}$ (vs. OCP) at Room T.

(a) Temperature effect

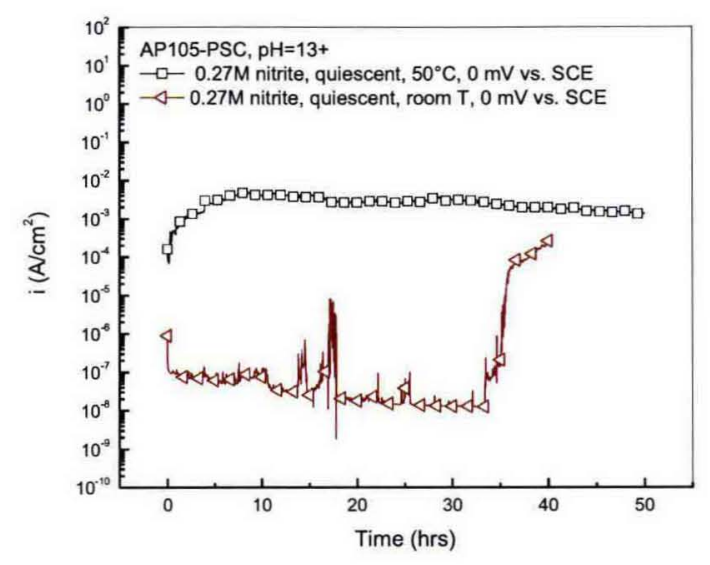

(b) Potential effect
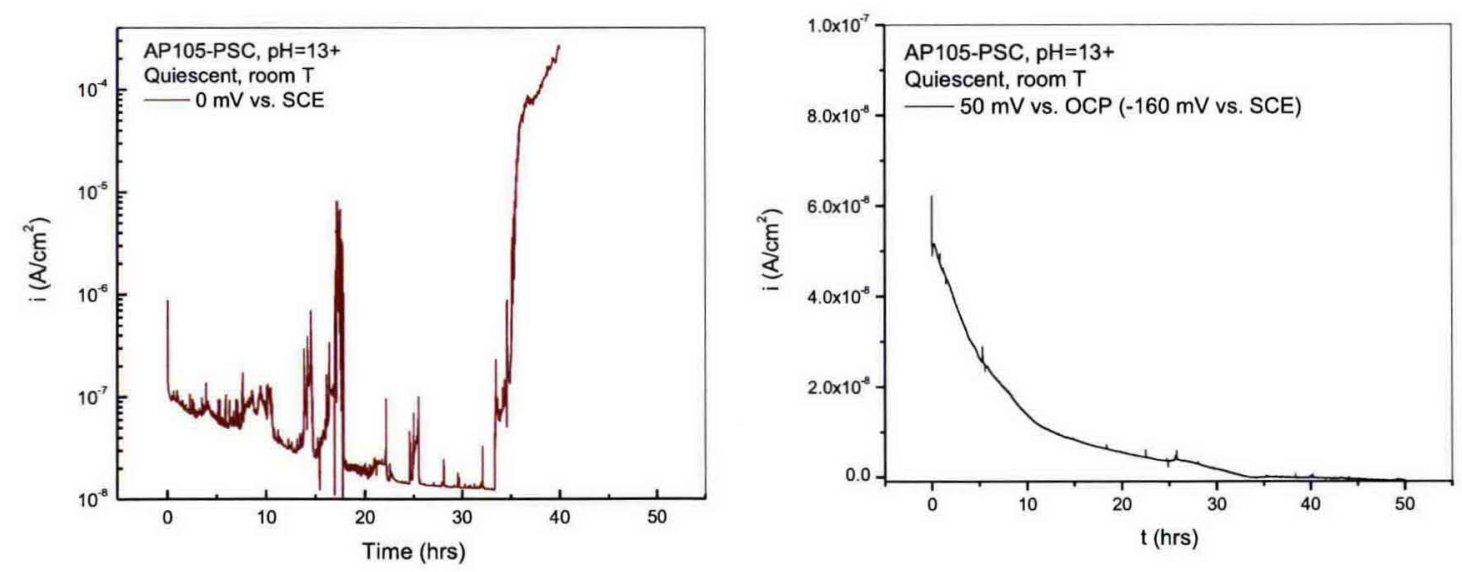
Figure B-16. A Comparison of the Sample Appearance after Potentiostatic Testing in AP105-PSC Simulant at Different Potentials (Under Quiescent Condition, Room Temperature). (a) $0 \mathrm{mV}$ vs. SCE; (b) $50 \mathrm{mV}$ vs. SCE ($160 \mathrm{mV}$ vs. SCE).

(a)

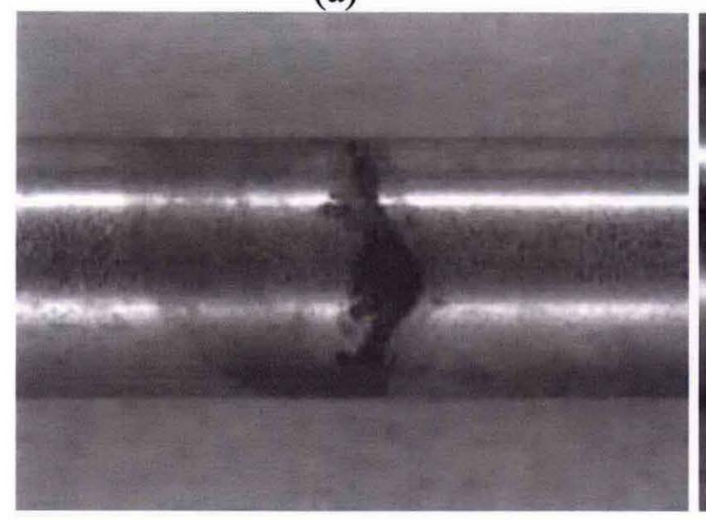

(b)

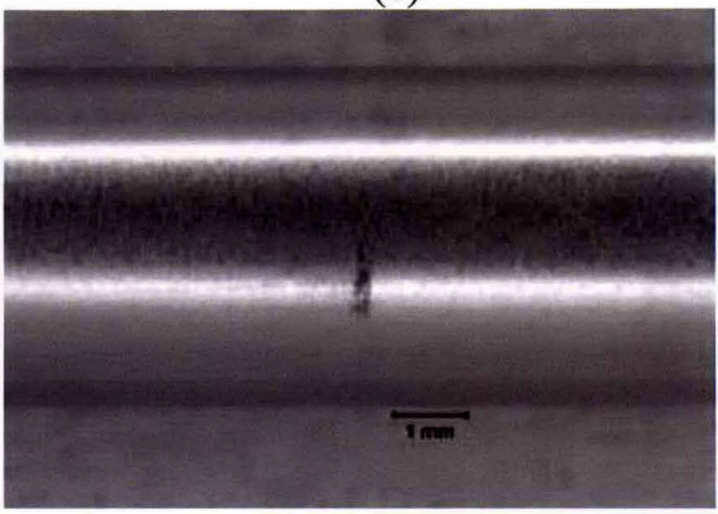

Figure B-17. A Comparison of the CPP Curves Obtained with and without Using a Crevice Former (AP105-PSC, $\mathrm{pH}>13, \mathrm{~T}=5^{\circ} \mathrm{C}$ )

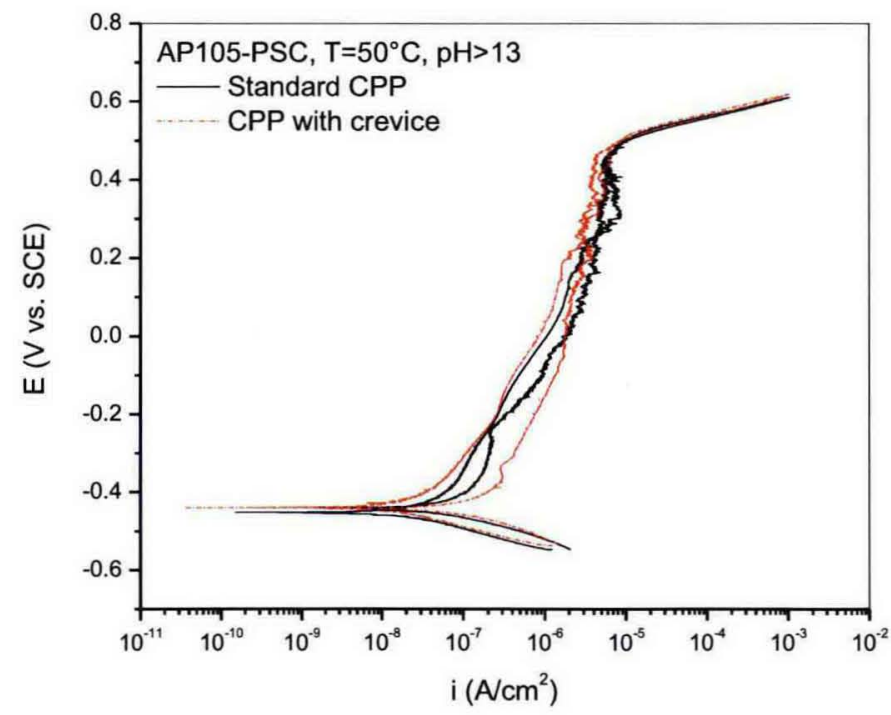


Figure B-18. The Crevice Assembly of the CPP Sample (a) and the Sample Appearance at the Crevice Section after CPP Testing in AP105-PSC Simulant (b) $\left(\mathrm{pH}>13, \mathrm{~T}=50^{\circ} \mathrm{C}\right)$.

(a)

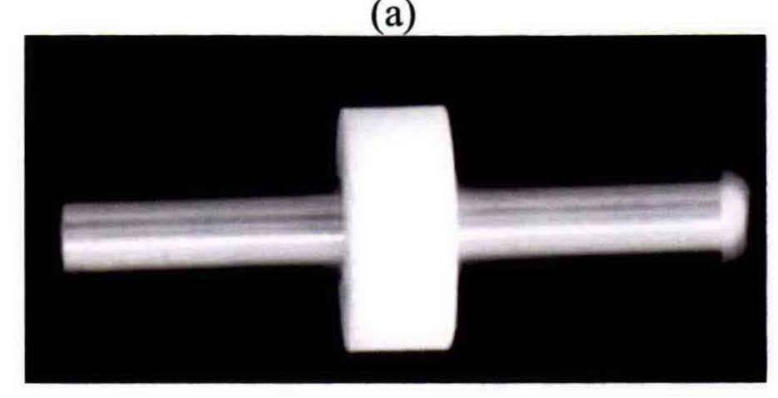

(b)

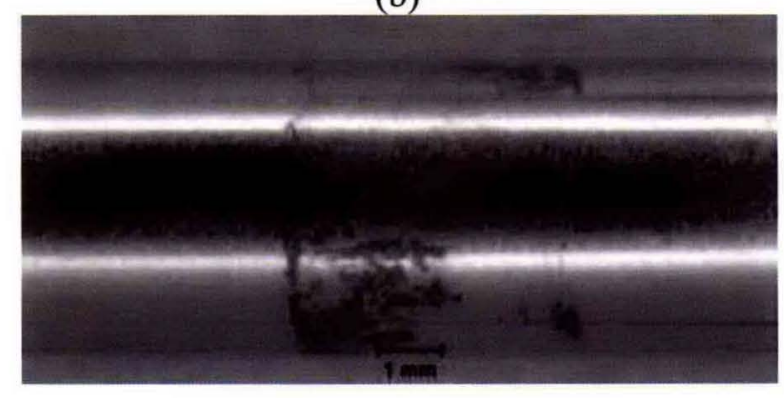


Figure B-19. The Current Density as a Function of Time When the Sample with a Crevice Former Was Polarized to $0 \mathrm{mV}$ vs. SCE (AP105-PSC, $\mathrm{pH}>\mathbf{1 3}, \mathrm{T}=\mathbf{5 0}^{\circ} \mathrm{C}$, Deaerated Condition).

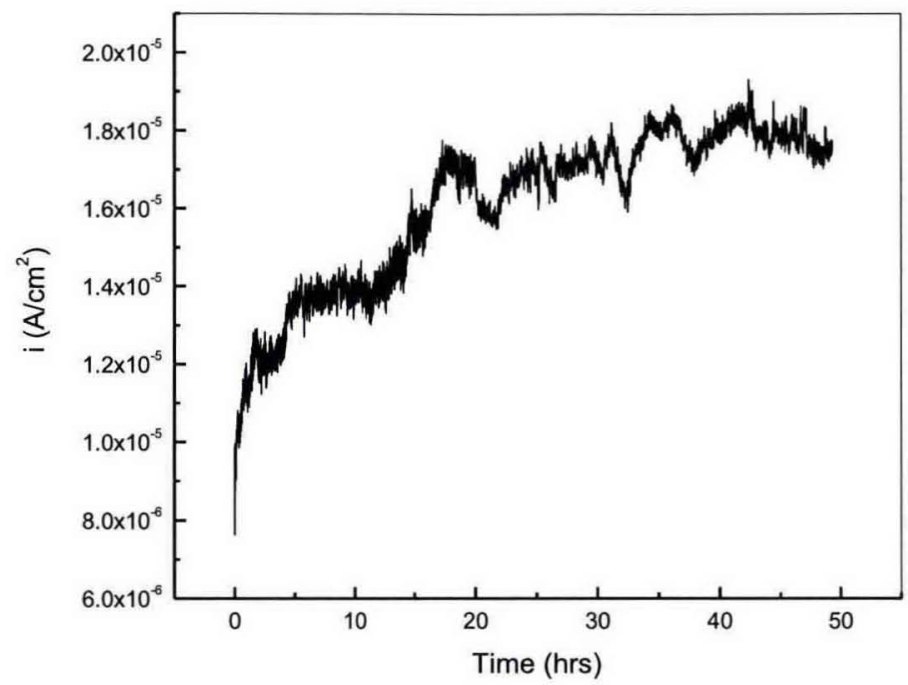

Figure B-20. The Sample Appearance at the Crevice Section after Potentiostatic Test at $0 \mathrm{mV}$ vs. SCE in AP105-PSC Simulant for 50 Hours ( $\mathrm{pH}>13, \mathrm{~T}=50^{\circ} \mathrm{C}$, Deaerated Condition).

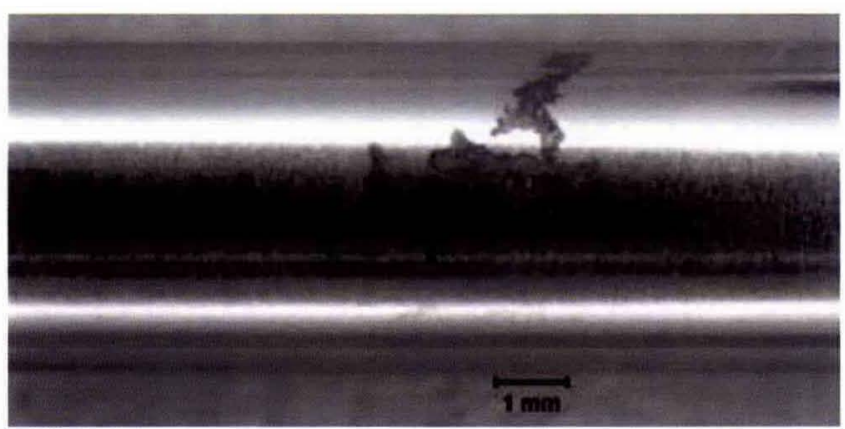


Figure B-21. A Comparison of the CPP Curves Obtained in the AP105-PSC Simulant under Different Aeration Conditions Using Fully Immersed Samples.

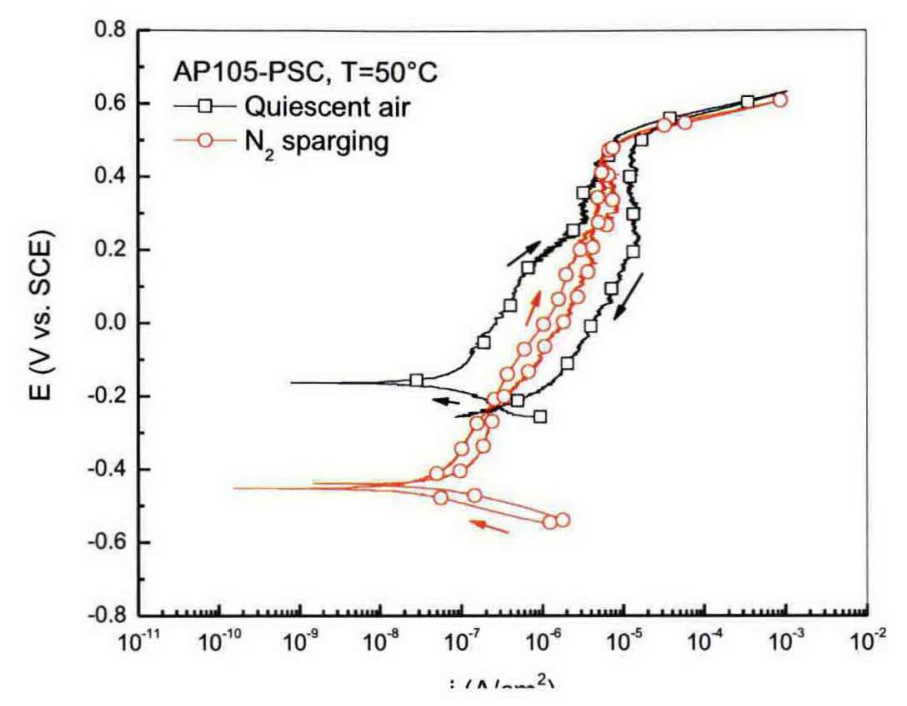

Figure B-22. The Pits on the Samples Tested in the AP105-PSC

Simulant under Quiescent Conditions and at $50^{\circ} \mathrm{C}(\mathrm{Ph}=13+)$.

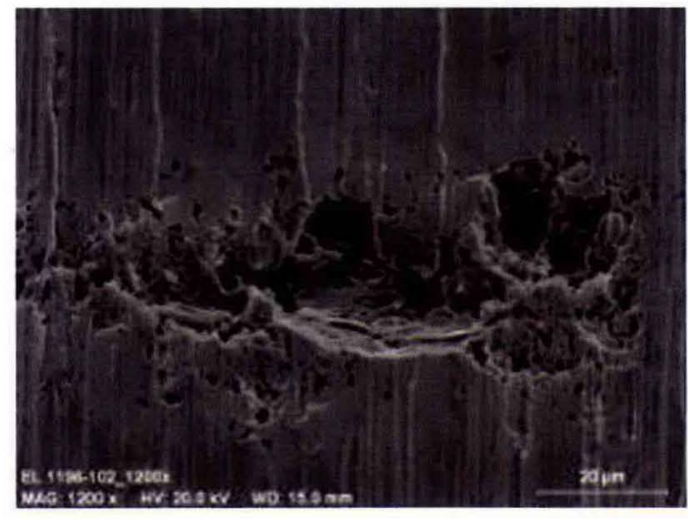


RPP-RPT-37505, Rev. 0

Figure B-23. The Corrosion Rate of the Samples Exposed to AP105-PSC at Different Conditions to Investigate the Interface Corrosion.

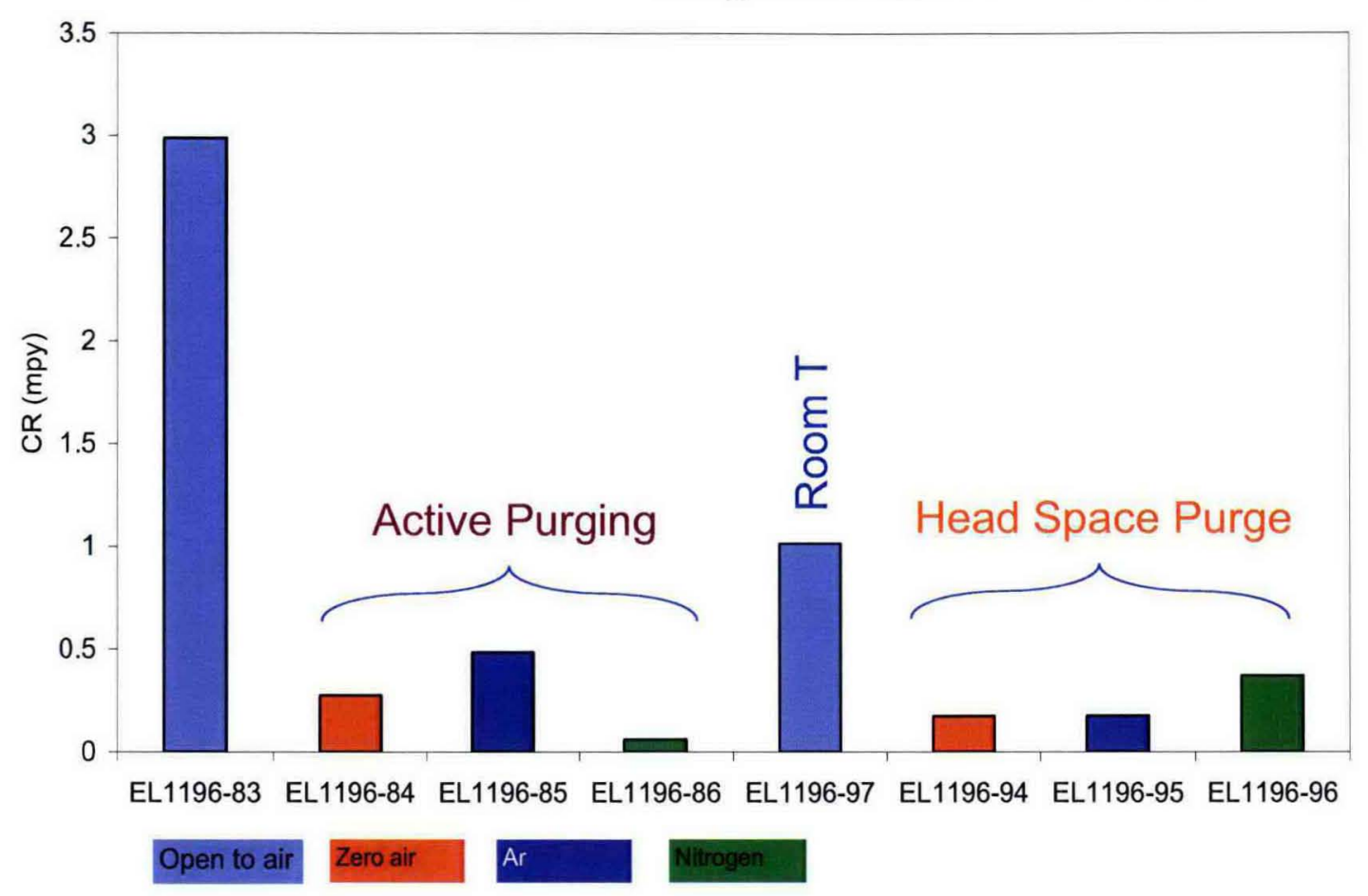


Figure B-24. The Appearance of the Sample (a, b) and the Cross Section of a Corroded Site (c) after Exposed in AP105-PSC at Quiescent Condition (Sample Partially Immersed, $\mathrm{T}=\mathbf{5 0}^{\circ}, \mathrm{EL1196-83}$ ).

(a)

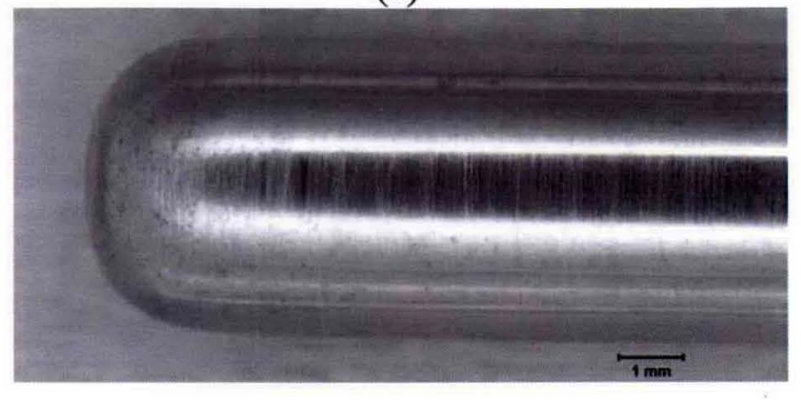

(b)

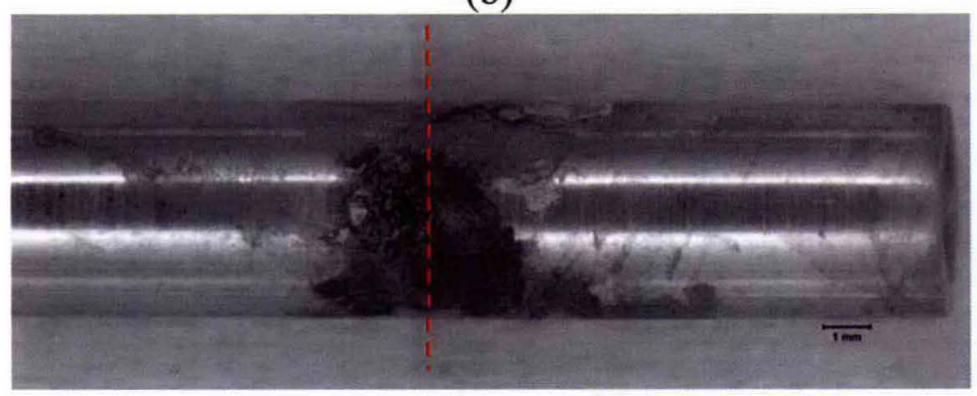

(c)

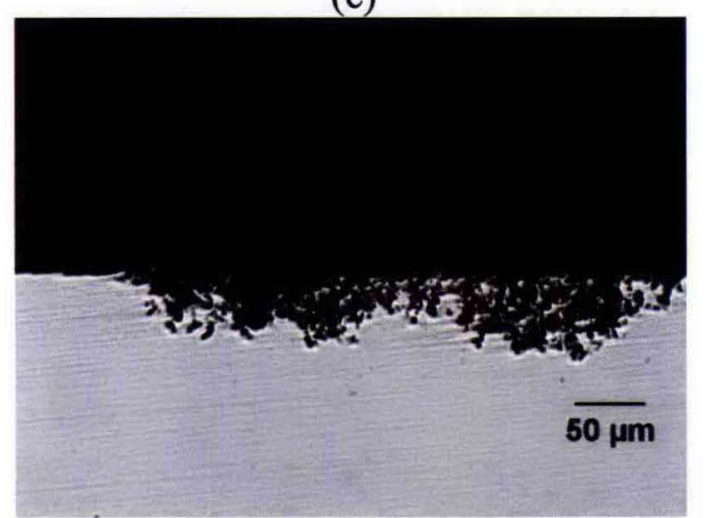


Figure B-25. The Appearance of the Sample after Exposed in AP105-PSC Purged with Zero Air (Sample Partially Immersed, $\mathrm{No} \mathrm{CO}_{2}, \mathrm{~T}=50^{\circ}, \mathbf{E L 1 1 9 6 - 8 4}$ )

(a)

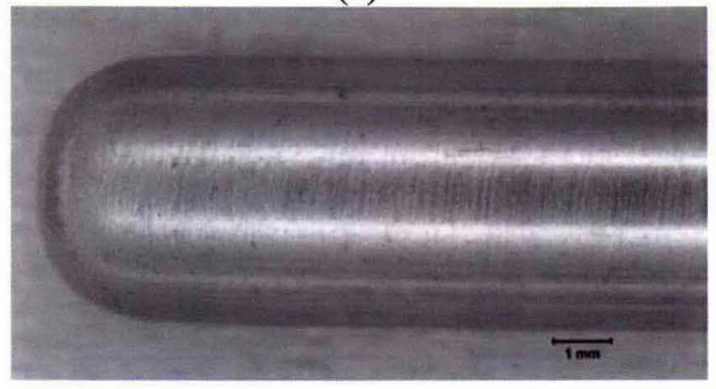

(b)

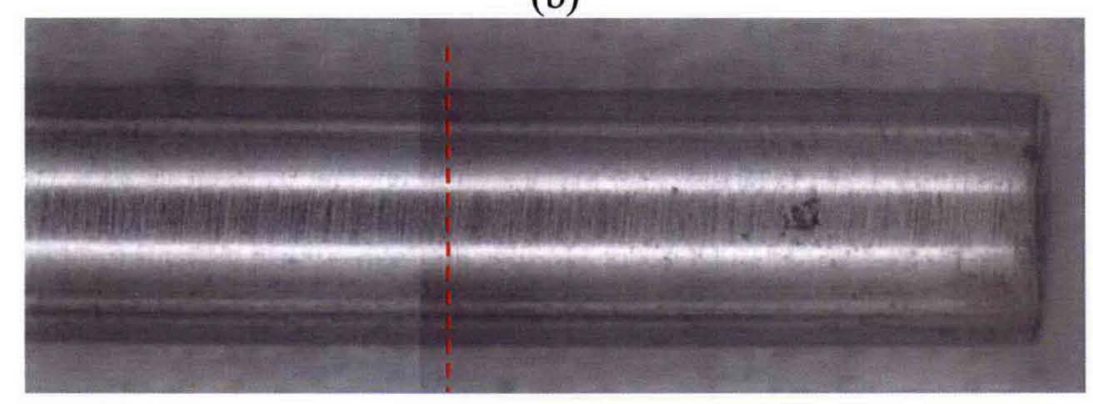

Figure B-26. The Appearance of the Sample after Exposed in AP105-PSC Purged with Ar (Sample Partially Immersed, T=50 ${ }^{\circ}$, EL1196-85).

(a)

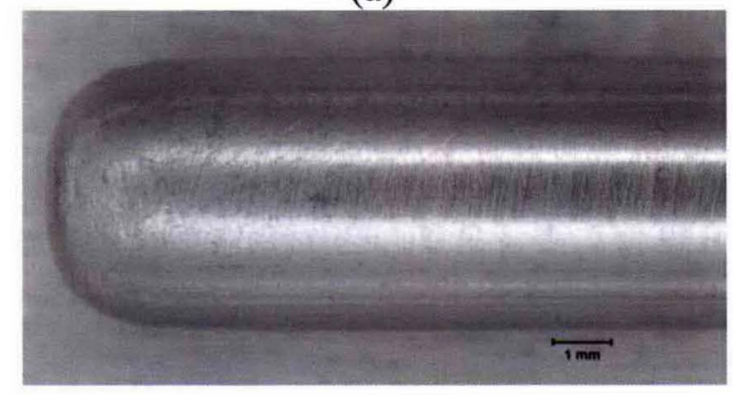

(b)

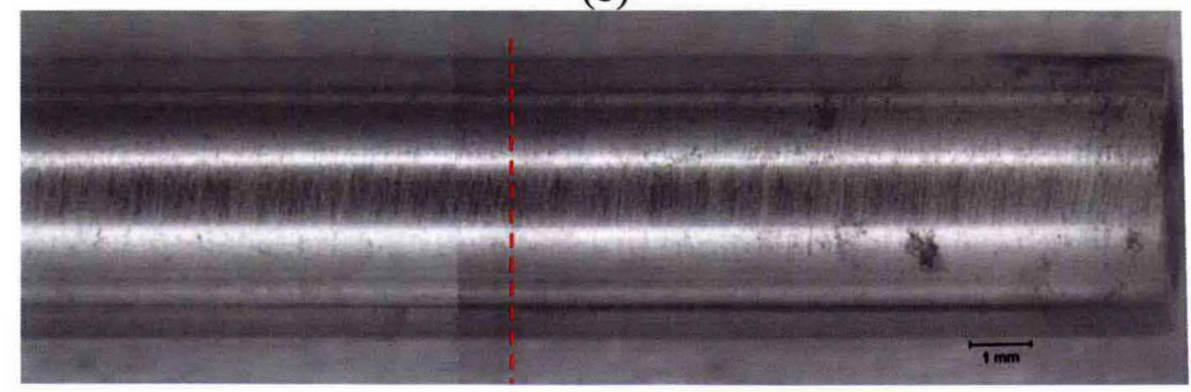


RPP-RPT-37505, Rev. 0

Figure B-27. The Appearance of the Sample after Exposed in AP105-PSC Purged with $\mathrm{N}_{2}$ (Sample Partially Immersed, $\mathrm{T}=\mathbf{5 0}^{\circ}$, EL1196-86).

(a)

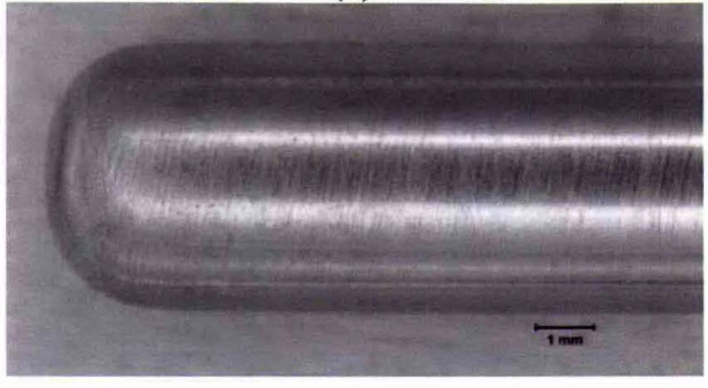

(b)

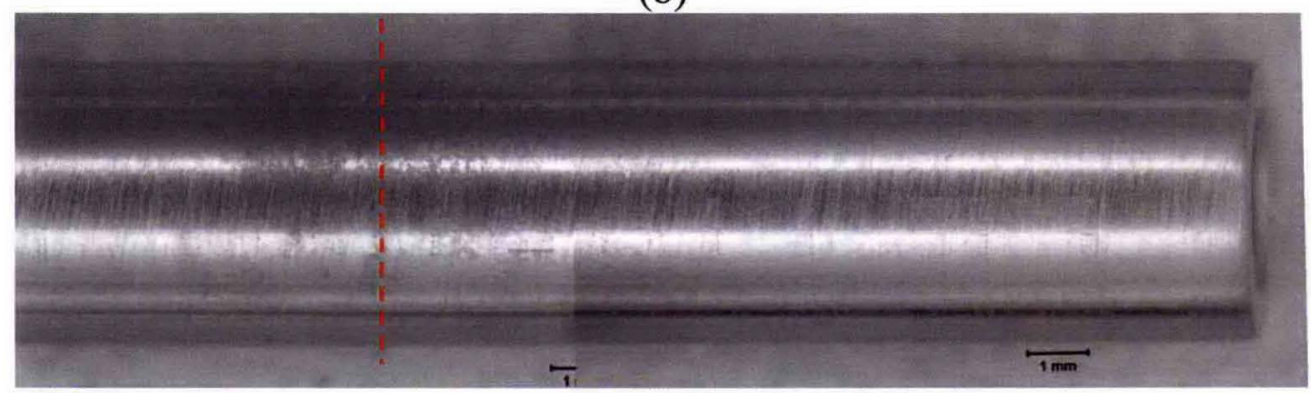


Figure B-28. The Appearance of the Sample (a, b) and the Cross Section of a Corroded Site (c) after Exposed in AP105-PSC at Quiescent Condition (Sample Partially Immersed, Room T, EL1196-97).

(a)

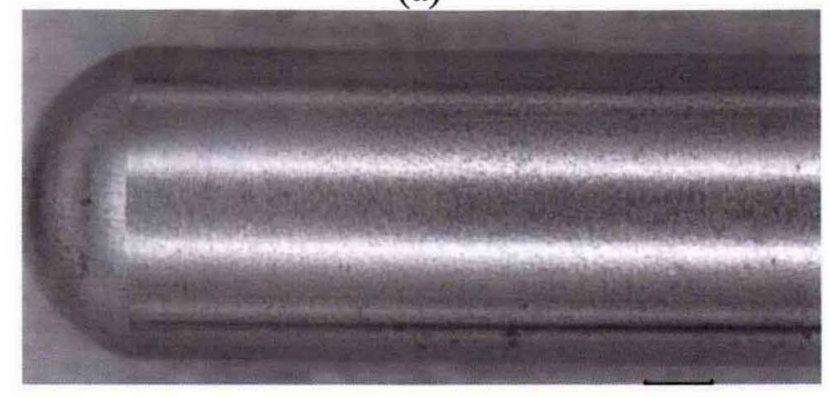

(b)

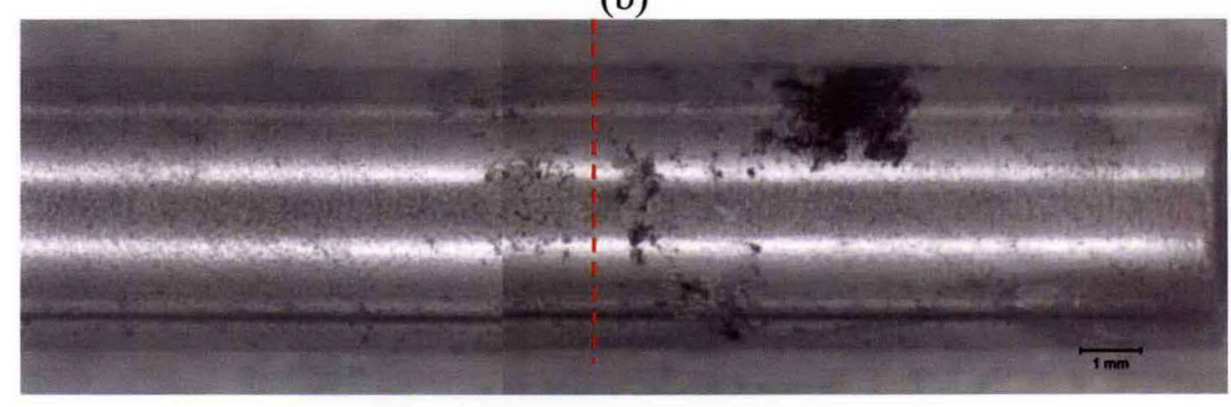

(c)

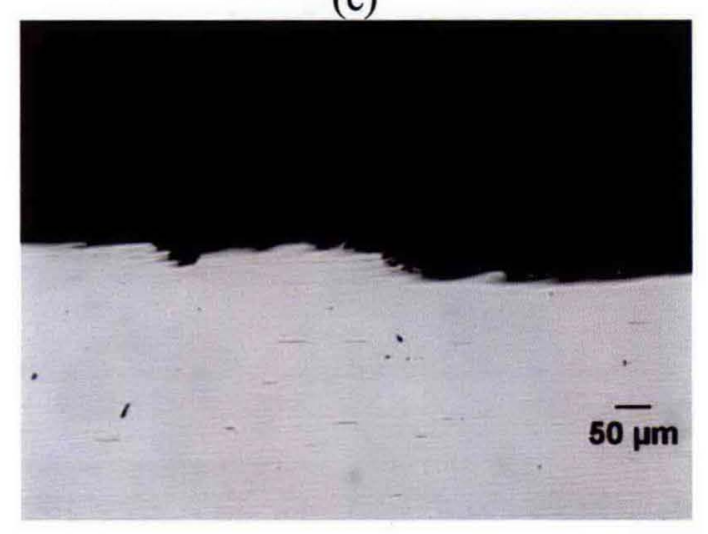


Figure B-29. The Appearance of the Sample after Exposed in AP105-PSC. The Head Space of the Cell Was Purged with Zero Air (No $\mathrm{CO}_{2}$, Sample Partially Immersed, $\mathrm{T}=\mathbf{5 0}^{\circ}$, EL1196-94).

(a)

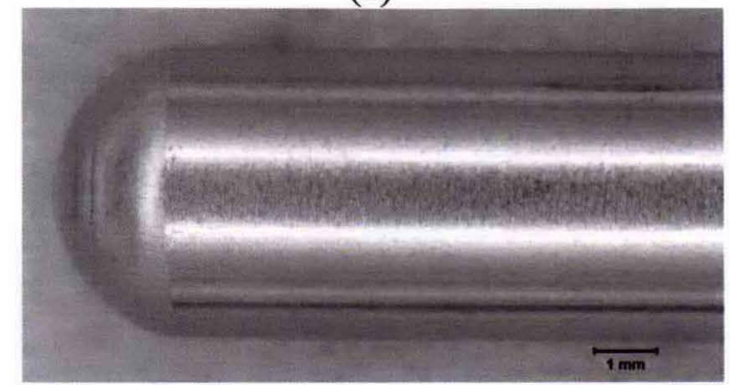

(b)

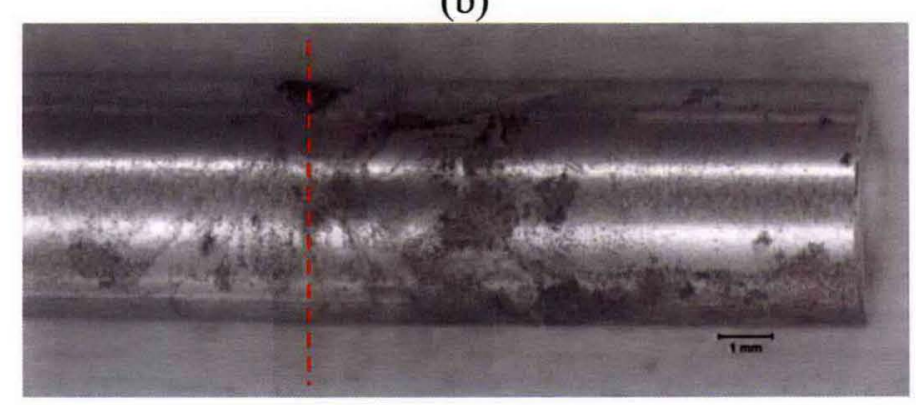

Figure B-30. The Appearance of the Sample after Exposed in AP105-PSC. The Head Space of the Cell Was Purged with Ar (Sample Partially Immersed, $\mathrm{T}=\mathbf{5 0}^{\circ}$, EL1196-95).

(a)

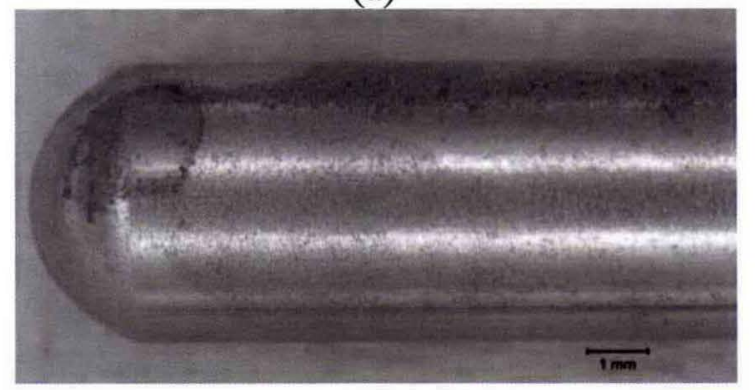

(b)

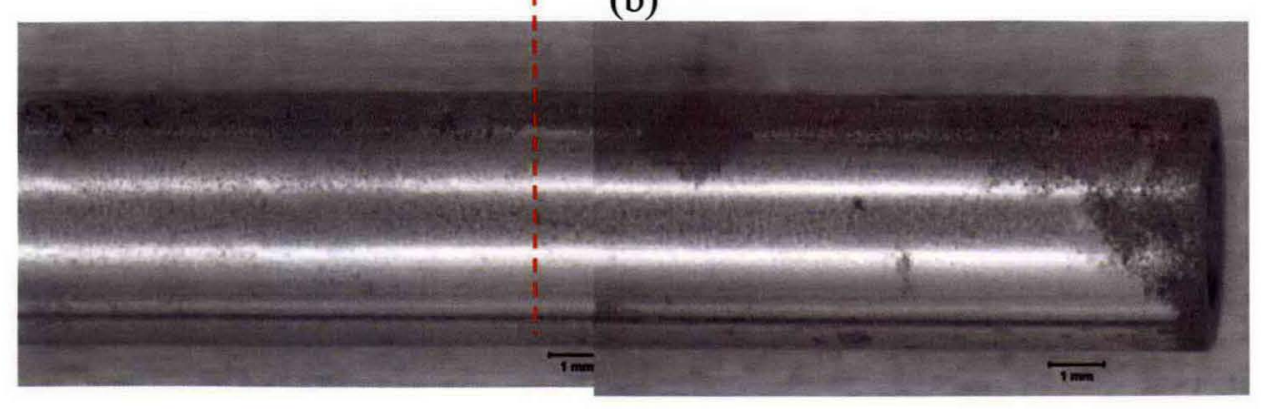


Figure B-31. The Appearance of the Sample after Exposed in AP105-PSC. The Head Space of the Cell Was Purged with $\mathbf{N}_{2}$ (Sample Partially Immersed, $\mathrm{T}=$ 50 $^{\circ}$, EL1196-96).

(a)

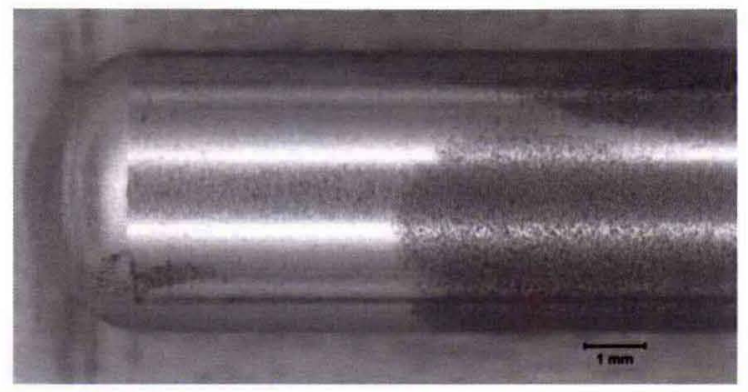

(b)

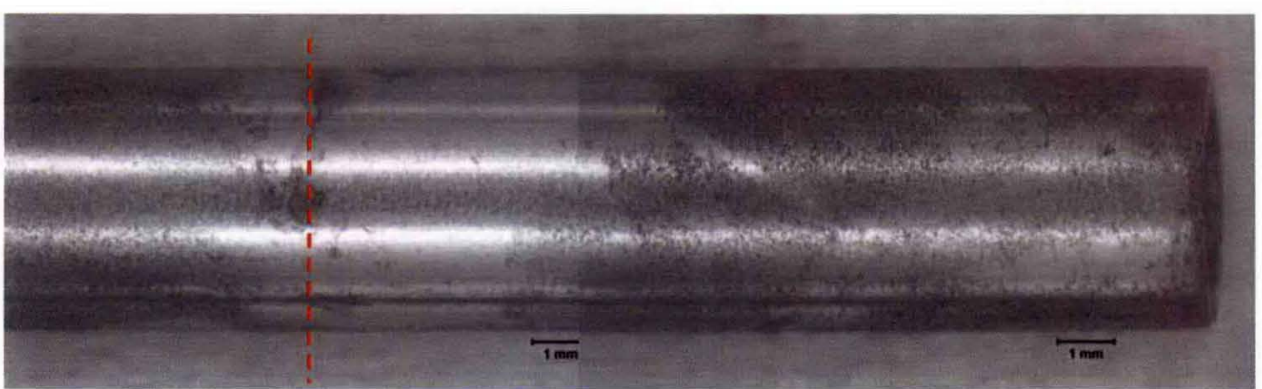

Table B-2. The pH Values of the Simulant after the Long Term Immersion Tests.

\begin{tabular}{|c|c|}
\hline Exposed sample & Solution pH after test \\
\hline EL1196-83 & 13.28 \\
\hline EL1196-84 & 13.23 \\
\hline EL1196-85 & 13.32 \\
\hline EL1196-86 & 13.21 \\
\hline & \\
\hline EL1196-97 & 13.32 \\
\hline EL1196-94 & 13.4 \\
\hline EL1196-95 & 13.44 \\
\hline EL1196-96 & 13.38 \\
\hline
\end{tabular}


Table B-3. A Summary of Electrochemical Test Performed in SY103-PIL Based Simulant.

\begin{tabular}{|c|c|c|c|c|c|c|c|c|c|c|c|}
\hline $\begin{array}{c}\text { Base } \\
\text { Chemistry }\end{array}$ & pH & $\begin{array}{l}\mathrm{NO}_{2}^{-} \\
(\mathrm{M})\end{array}$ & $\begin{array}{l}\mathrm{NO}_{3}{ }^{-} \\
(\mathrm{M})\end{array}$ & $\begin{array}{l}\text { TIC } \\
\text { (M) }\end{array}$ & $\begin{array}{l}\mathrm{OH}^{-} \\
(\mathrm{M})^{*}\end{array}$ & $\begin{array}{l}\mathrm{Cl}^{-} \\
(\mathrm{M})\end{array}$ & $\begin{array}{c}\mathbf{F}^{-} \\
(\mathbf{M})\end{array}$ & $\begin{array}{c}\mathrm{T} \\
\left({ }^{\circ} \mathrm{C}\right)\end{array}$ & $\begin{array}{l}\text { Aeration } \\
\text { condition }\end{array}$ & Visual & $\begin{array}{l}\text { Sample ID } \\
\text { (\#EL1196-) }\end{array}$ \\
\hline SY103-PIL & $>13$ & 2.91 & 1.97 & 0.123 & 2.43 & 0.5 & 0 & 50 & $\mathrm{~N}_{2}$ sparging & No pitting & 89 \\
\hline
\end{tabular}

Figure B-32. A CPP Curve in Deaerated SY103-PIL Simulant $\left(\mathrm{pH}>13\right.$ and $\left.\mathrm{T}=50^{\circ} \mathrm{C}\right)$.

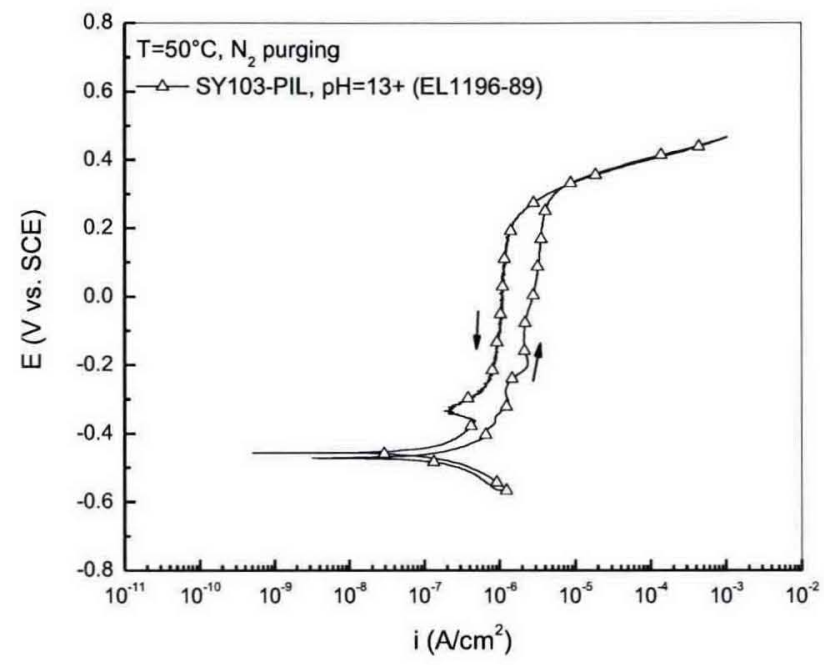

Table B-4. A Summary of Electrochemical Test Performed in AW105 Based Simulant.

\begin{tabular}{|c|c|c|c|c|c|c|c|c|c|c|c|c|}
\hline $\begin{array}{c}\text { Base } \\
\text { Chemistry }\end{array}$ & pH & $\begin{array}{l}\mathrm{NO}_{2}^{-} \\
(\mathrm{M})\end{array}$ & $\begin{array}{l}\mathrm{NO}_{3}{ }^{-} \\
(\mathrm{M})\end{array}$ & $\begin{array}{l}\text { TIC } \\
\text { (M) }\end{array}$ & $\begin{array}{l}\mathbf{O H}^{-} \\
(\mathbf{M})^{*}\end{array}$ & $\begin{array}{l}\mathrm{Cl}^{-} \\
(\mathrm{M})\end{array}$ & $\begin{array}{c}F^{-} \\
(\mathbf{M})\end{array}$ & $\begin{array}{c}\mathbf{T} \\
\left({ }^{\circ} \mathbf{C}\right)\end{array}$ & $\begin{array}{l}\text { Aeration } \\
\text { condition }\end{array}$ & Testing type & Visual & $\begin{array}{l}\text { Sample ID } \\
\text { (\#EL1196-) }\end{array}$ \\
\hline AW105-PIL & $>13$ & 0.124 & 0.419 & 0.097 & 0.4502 & 0.01 & 0.58 & 50 & $\begin{array}{c}\mathrm{N}_{2} \\
\text { sparging }\end{array}$ & $\begin{array}{c}\text { CPP } \\
\text { Full immersion }\end{array}$ & $\begin{array}{c}\text { No } \\
\text { pitting }\end{array}$ & 90 \\
\hline AW105-PSC & $>13$ & 0.0638 & 0.44 & 0.1076 & 0.2630 & 0.0083 & 0.156 & 50 & $\begin{array}{c}\mathrm{N}_{2} \\
\text { sparging }\end{array}$ & $\begin{array}{c}\text { CPP } \\
\text { Full immersion }\end{array}$ & $\begin{array}{c}\text { No } \\
\text { pitting }\end{array}$ & 108 \\
\hline
\end{tabular}


Figure B-33. A CPP Curve in Deaerated AW105-PIL Simulant (pH $>13$ and $\left.\mathrm{T}=50^{\circ} \mathrm{C}\right)$.

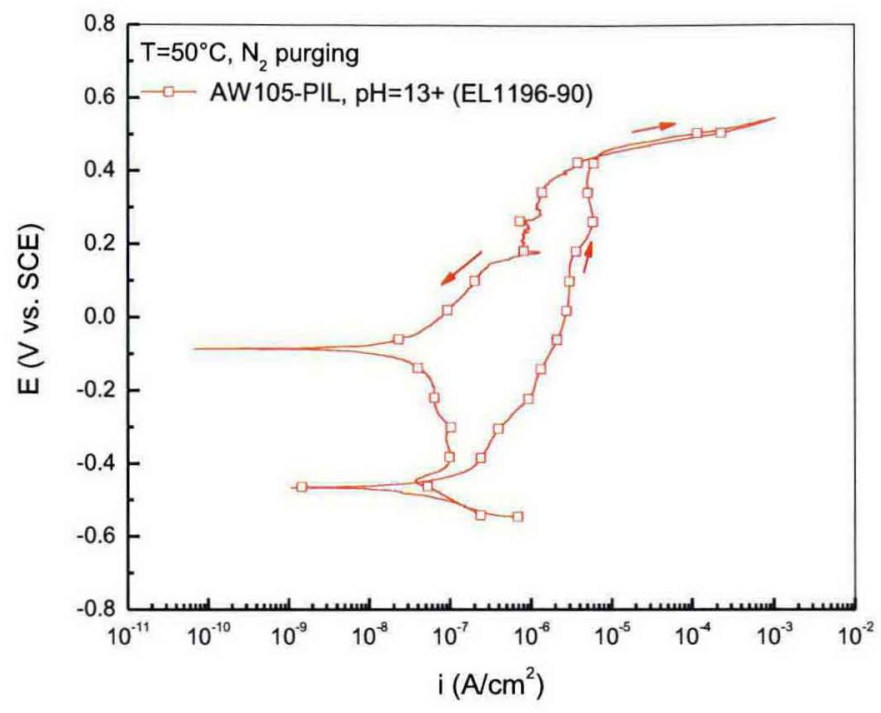

Figure B-34. A CPP Curve in Deaerated AW105-PSC Simulant $\left(\mathrm{pH}>13\right.$ and $\left.\mathrm{T}=50^{\circ} \mathrm{C}\right)$.

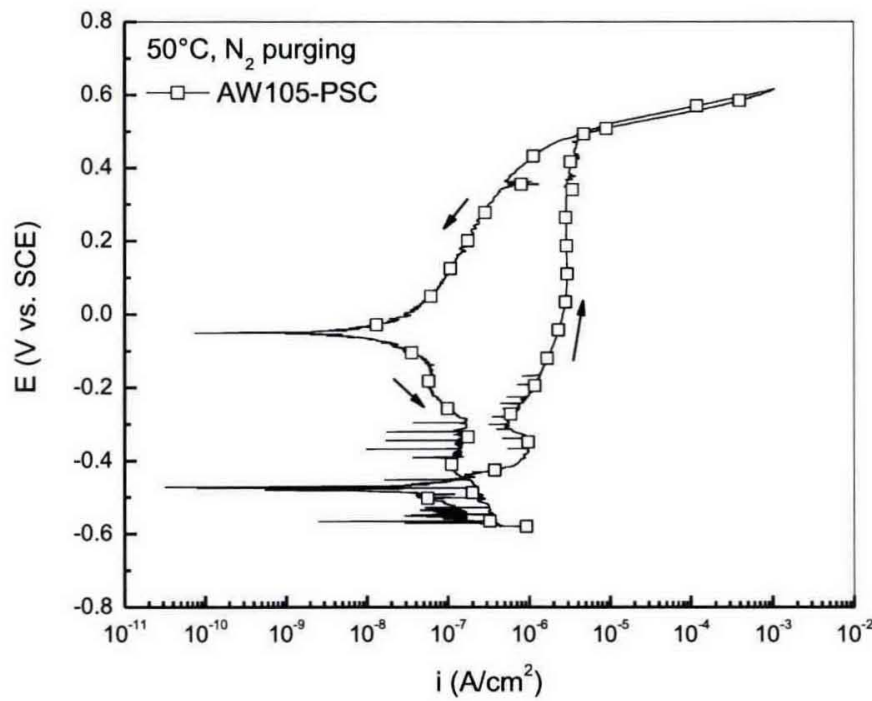

Table B-5. A Summary of Electrochemical Test Performed in AZ102 Based Simulant.

\begin{tabular}{|c|c|c|c|c|c|c|c|c|c|c|c|c|}
\hline $\begin{array}{c}\text { Base } \\
\text { Chemistry }\end{array}$ & $\mathbf{p H}$ & $\begin{array}{c}\mathbf{N O}_{2}^{-} \\
(\mathbf{M})\end{array}$ & $\begin{array}{c}\mathbf{N O}_{3}^{-} \\
(\mathbf{M})\end{array}$ & $\begin{array}{c}\text { TIC } \\
(\mathbf{M})\end{array}$ & $\begin{array}{c}\mathbf{O H}^{-} \\
(\mathbf{M})^{*}\end{array}$ & $\begin{array}{c}\mathbf{C l}^{-} \\
(\mathbf{M})\end{array}$ & $\begin{array}{c}\mathbf{F}^{-} \\
(\mathbf{M})\end{array}$ & $\begin{array}{c}\mathbf{T} \\
\left({ }^{\circ} \mathbf{C}\right)\end{array}$ & $\begin{array}{c}\text { Aeration } \\
\text { condition }\end{array}$ & Testing type & Visual & $\begin{array}{c}\text { Sample ID } \\
(\# \mathbf{E L 1 1 9 6 -})\end{array}$ \\
\hline $\mathrm{AZ102}$ & $>12$ & 0.883 & 0.105 & 0.619 & - & - & 0.052 & 77 & $\begin{array}{c}\mathrm{N}_{2} \\
\text { sparging }\end{array}$ & $\begin{array}{c}\text { CPP } \\
\text { Full immersion }\end{array}$ & $\begin{array}{c}\text { No } \\
\text { pitting }\end{array}$ & 103 \\
\hline
\end{tabular}


Figure B-35. A CPP Curve in Deaerated AZ102 Simulant (pH>12 and $\left.\mathrm{T}=77^{\circ} \mathrm{C}\right)$.

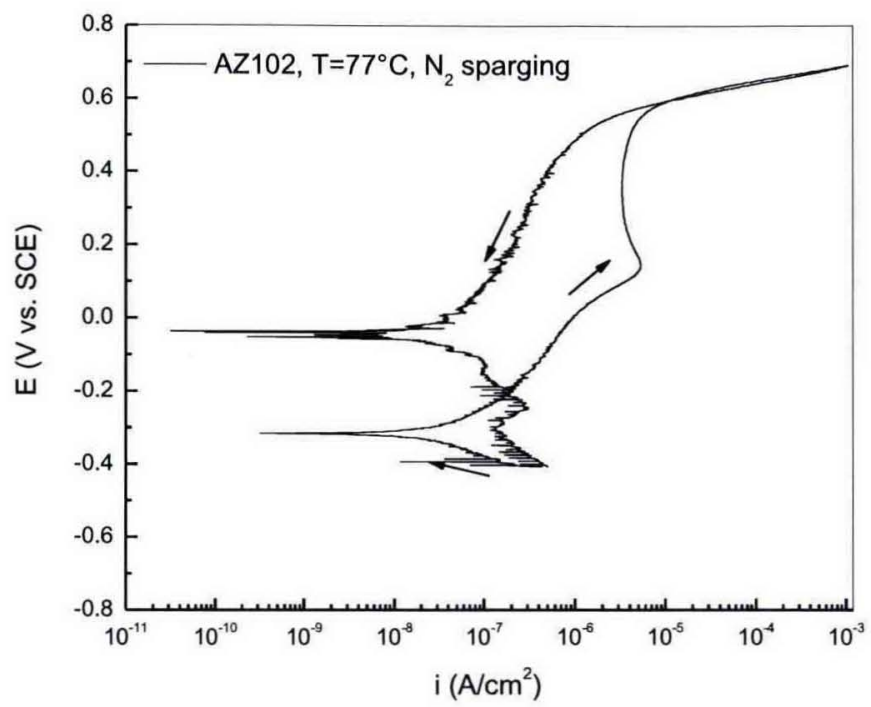

Table B-6. A Summary of Electrochemical Test Performed in SY101 Based Simulant.

\begin{tabular}{|c|c|c|c|c|c|c|c|c|c|c|c|c|}
\hline $\begin{array}{c}\text { Base } \\
\text { Chemistry }\end{array}$ & pH & $\begin{array}{l}\mathrm{NO}_{2}^{-} \\
(\mathrm{M})\end{array}$ & $\begin{array}{l}\mathrm{NO}_{3}{ }^{-} \\
(\mathrm{M})\end{array}$ & $\begin{array}{l}\text { TIC } \\
\text { (M) }\end{array}$ & $\begin{array}{l}\mathrm{OH}^{-} \\
(\mathrm{M})^{*}\end{array}$ & $\begin{array}{c}\mathrm{Cl}^{-} \\
(\mathrm{M})\end{array}$ & $\begin{array}{l}\mathrm{F}^{-} \\
(\mathbf{M})\end{array}$ & $\begin{array}{c}\mathbf{T} \\
\left({ }^{\circ} \mathbf{C}\right)\end{array}$ & $\begin{array}{c}\text { Aeration } \\
\text { condition }\end{array}$ & Testing type & Visual & $\begin{array}{c}\text { Sample ID } \\
\text { (\#EL1196-) }\end{array}$ \\
\hline SY 101 & $>13$ & 0.2027 & 0.9313 & 0.1328 & 0.6555 & 0.0228 & 0.0277 & 50 & $\begin{array}{c}\mathrm{N}_{2} \\
\text { sparging }\end{array}$ & $\begin{array}{c}\text { CPP } \\
\text { Full immersion }\end{array}$ & $\begin{array}{c}\text { No } \\
\text { pitting }\end{array}$ & 109 \\
\hline
\end{tabular}

Figure B-36. A CPP Curve in Deaerated SY101 Simulant at $\mathrm{pH} 13+$ and $50^{\circ} \mathrm{C}$.

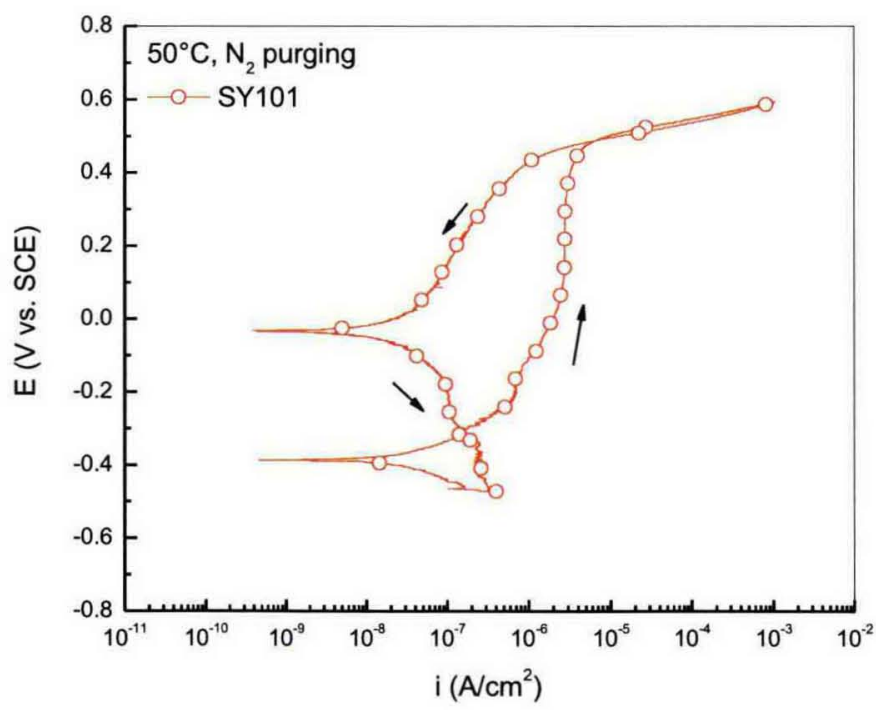


Table B-7. A Summary of Electrochemical Test Performed in AY101-CSL Based Simulant.

\begin{tabular}{|c|c|c|c|c|c|c|c|c|c|c|c|c|}
\hline $\begin{array}{c}\text { Base } \\
\text { Chemistry }\end{array}$ & pH & $\begin{array}{l}\mathrm{NO}_{2}^{-} \\
(\mathrm{M})\end{array}$ & $\begin{array}{l}\mathrm{NO}_{3}^{-} \\
(\mathrm{M}) \\
\end{array}$ & $\begin{array}{l}\text { TIC } \\
\text { (M) } \\
\end{array}$ & $\begin{array}{l}\mathrm{OH}^{-} \\
(\mathrm{M})^{*}\end{array}$ & $\begin{array}{c}\mathrm{Cl}^{-} \\
(\mathrm{M})\end{array}$ & $\begin{array}{c}\mathbf{F}^{-} \\
(\mathbf{M})\end{array}$ & $\begin{array}{c}\mathrm{T} \\
\left({ }^{\circ} \mathrm{C}\right) \\
\end{array}$ & $\begin{array}{c}\text { Aeration } \\
\text { condition }\end{array}$ & Testing type & Visual & $\begin{array}{l}\text { Sample ID } \\
\text { (\#EL1196-) }\end{array}$ \\
\hline AY101-CSL & 11.82 & 0.0368 & 0.181 & 0.1474 & 0.0051 & 0.0064 & 0.0015 & 50 & $\begin{array}{c}\mathrm{N}_{2} \\
\text { sparging }\end{array}$ & $\begin{array}{c}\text { CPP } \\
\text { Full immersion }\end{array}$ & Pitting & 111 \\
\hline AY101-CSL & 12.82 & 0.0368 & 0.181 & 0.1474 & 0.0051 & 0.0064 & 0.0015 & 50 & $\begin{array}{c}\mathrm{N}_{2} \\
\text { sparging }\end{array}$ & $\begin{array}{c}\text { CPP } \\
\text { Full immersion }\end{array}$ & $\begin{array}{c}\text { No } \\
\text { Pitting }\end{array}$ & 112 \\
\hline AY101-CSL & 11.82 & 0.0368 & 0.181 & 0.1474 & 0.0051 & 0.0064 & 0.0015 & Room & $\begin{array}{c}\mathrm{N}_{2} \\
\text { sparging }\end{array}$ & $\begin{array}{c}\text { CPP } \\
\text { Full immersion }\end{array}$ & $\begin{array}{c}\text { No } \\
\text { Pitting }\end{array}$ & 113 \\
\hline AY101-CSL & 12.3 & 0.0368 & 0.181 & 0.1474 & 0.0051 & 0.0064 & 0.0015 & 50 & $\begin{array}{c}\mathrm{N}_{2} \\
\text { sparging }\end{array}$ & $\begin{array}{c}\text { CPP } \\
\text { Full immersion }\end{array}$ & Pitting & 115 \\
\hline
\end{tabular}

Figure B-37. A Comparison of CPP Curves in the Deaerated AY101-CSL Simulant at Different $\mathrm{pH}$ and Temperature Levels.

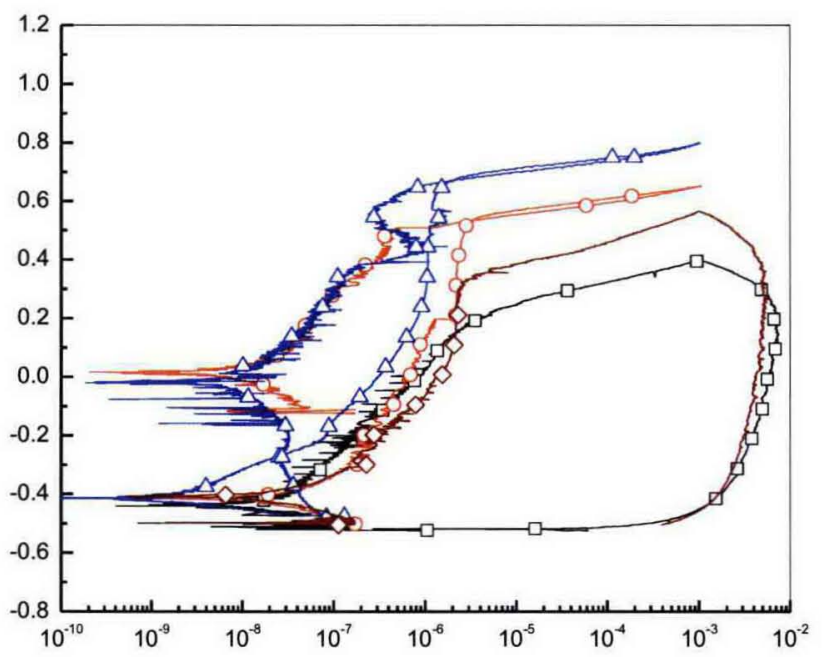


Figure B-38. The appearance of the sample after CPP test in the deaerated AY101CSL simulant at $50^{\circ} \mathrm{C}$ and $\mathrm{pH} 11.82$. (a) before cleaning; (b) after cleaning

(a)

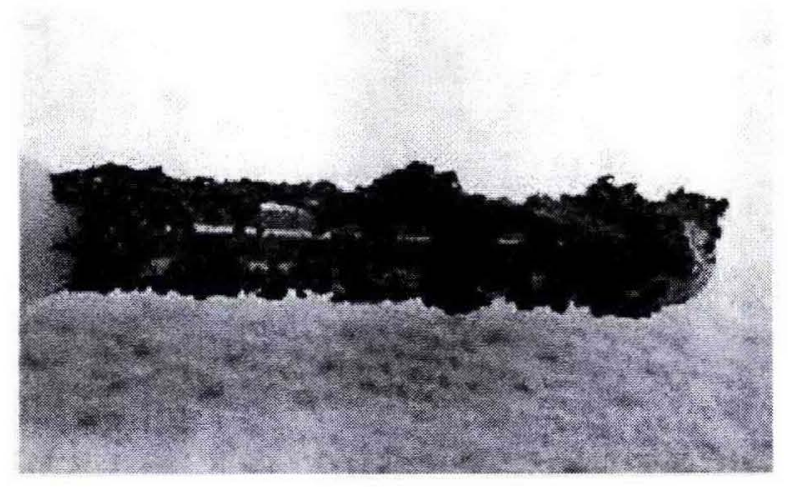

(b)

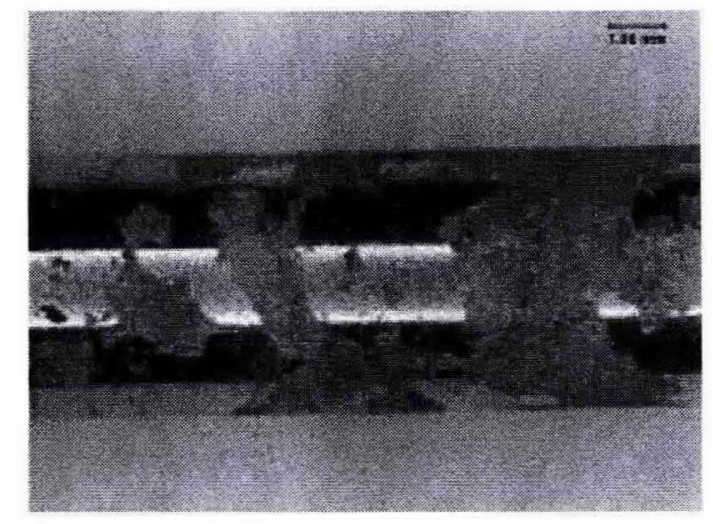

Figure B-39. The appearance of the sample after CPP test in AY101-CSL at $\mathrm{pH} 12.3$ and $50^{\circ} \mathrm{C}$.

(a)

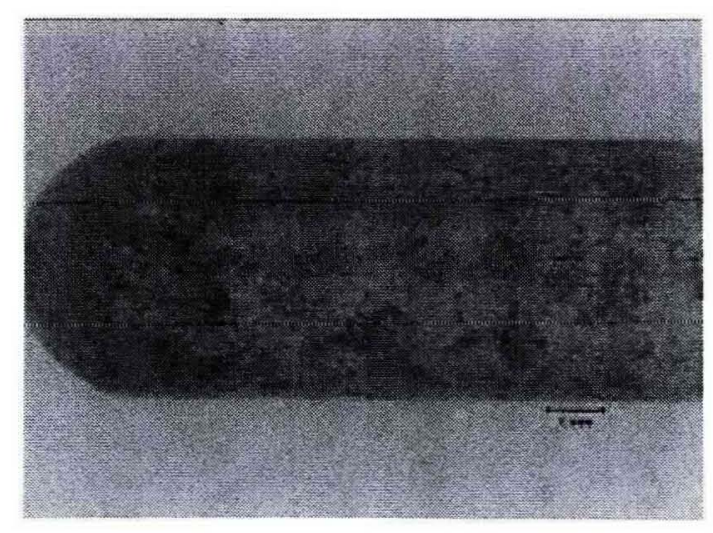

(b)

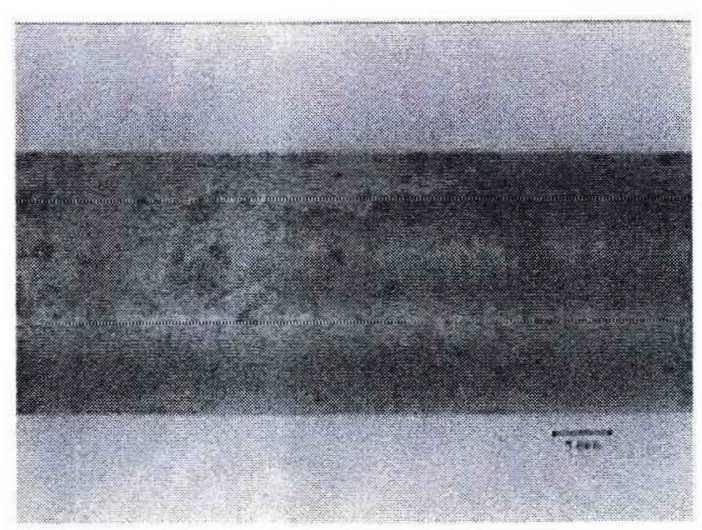


RPP-RPT-37505, Rev. 0

APPENDIX C

SLOW STRAIN RATE TEST DATA AND MICROGRAPHS 
Figure C-1. The Stress-Strain Curve from SSRT 47 Performed in AN107 Standard Simulant at $50^{\circ} \mathrm{C}, \mathrm{pH} 11$ and at $-740 \mathrm{mV}$ vs. SCE.

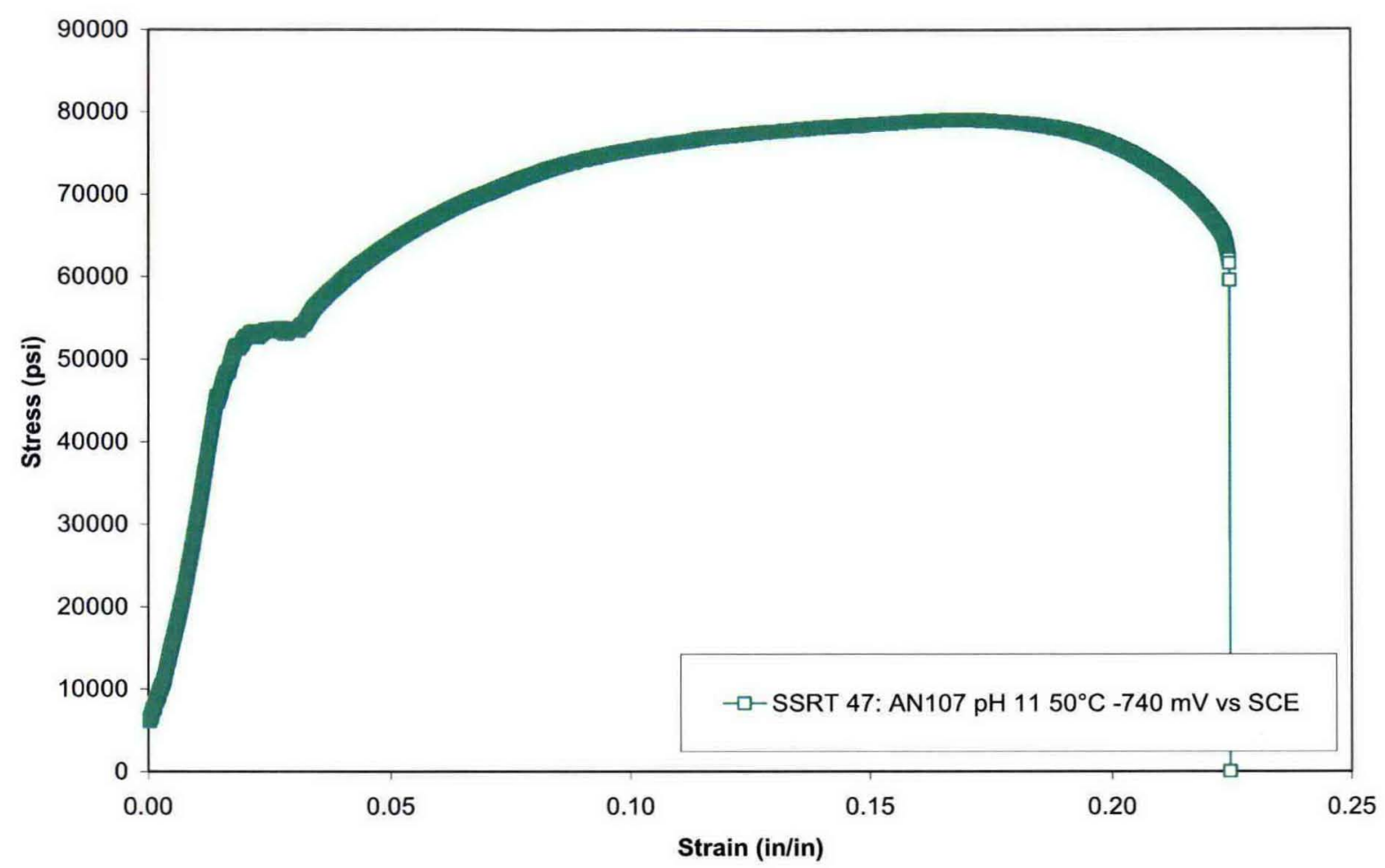

Figure C-2. A Stereo-Micrograph of the Sample from SSRT 47 Performed in AN107 Standard Simulant at $50^{\circ} \mathrm{C}$, pH 11 and at $-740 \mathrm{mV}$ vs. SCE.

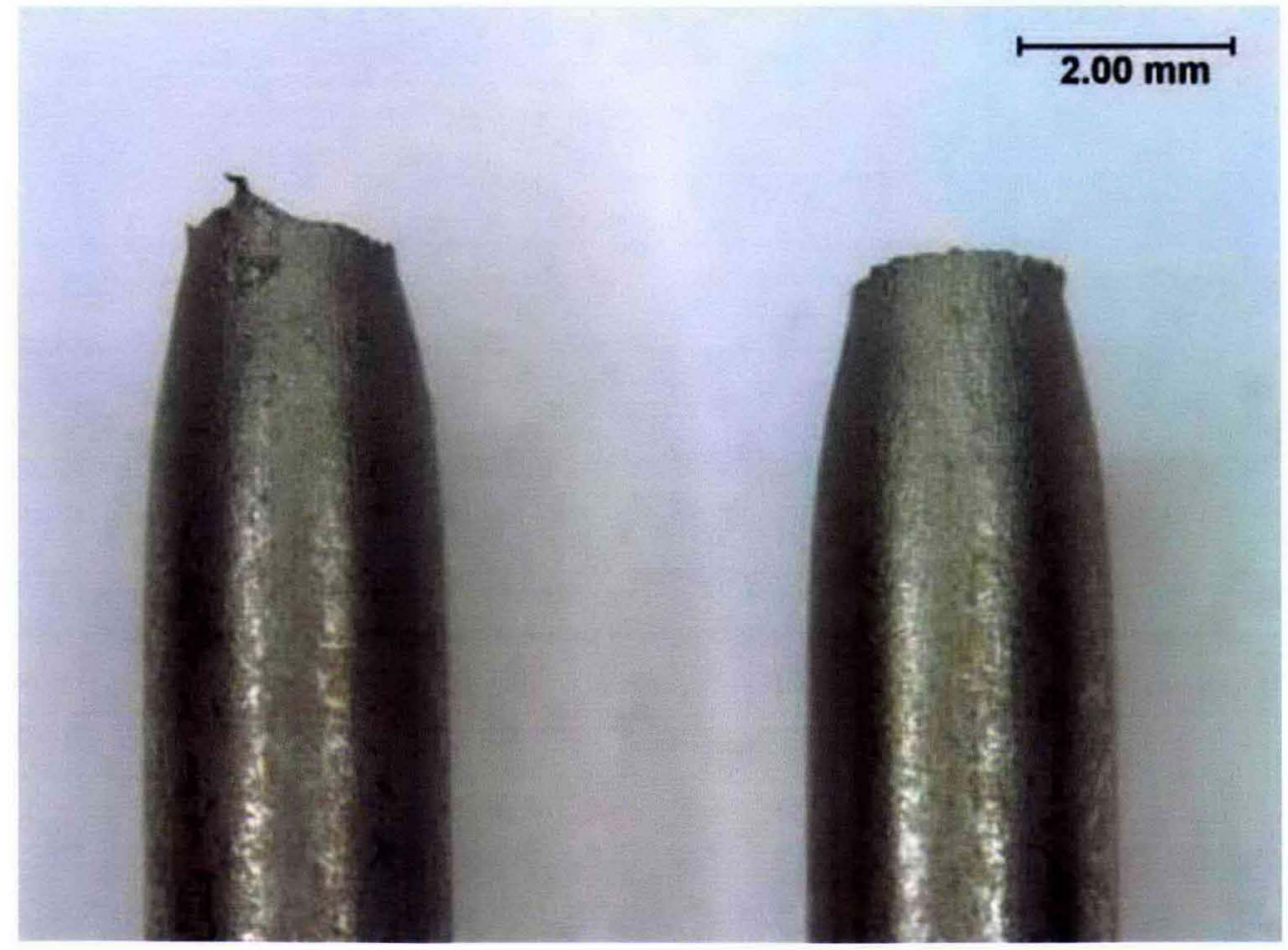




$$
\text { RPP-RPT-37505, Rev. } 0
$$

Figure C-3. An Electron-Micrograph of the Fracture Surface from SSRT 47 Performed in AN107 Standard Simulant at $50^{\circ} \mathrm{C}$, pH 11 and at $-740 \mathrm{mV}$ vs. SCE.

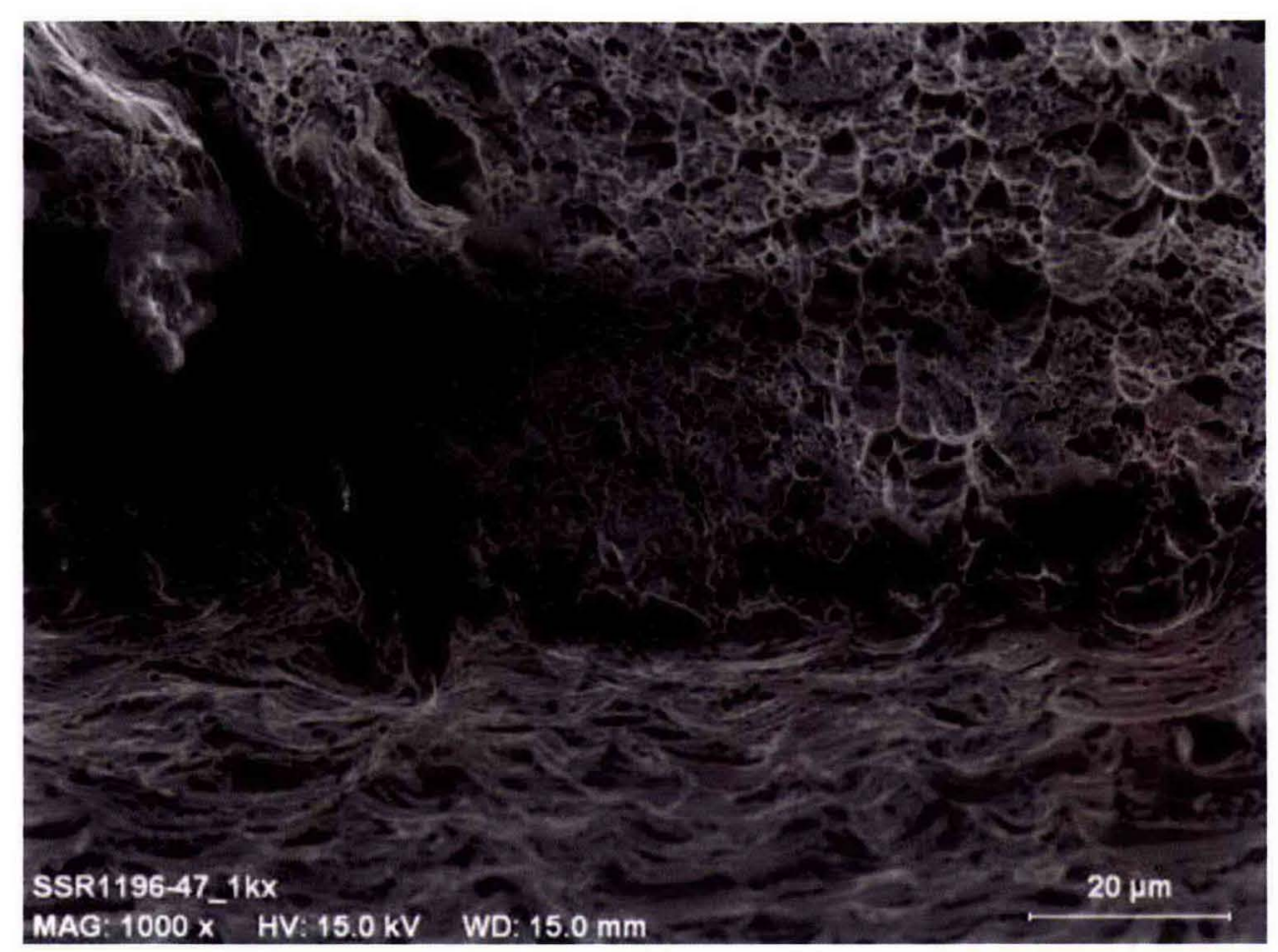


Figure C-4. The Stress-Strain Curve from SSRT 48 Performed in AN107 Standard Simulant at $77^{\circ} \mathrm{C}, \mathrm{pH} 11$ and at $-765 \mathrm{mV}$ vs. SCE.

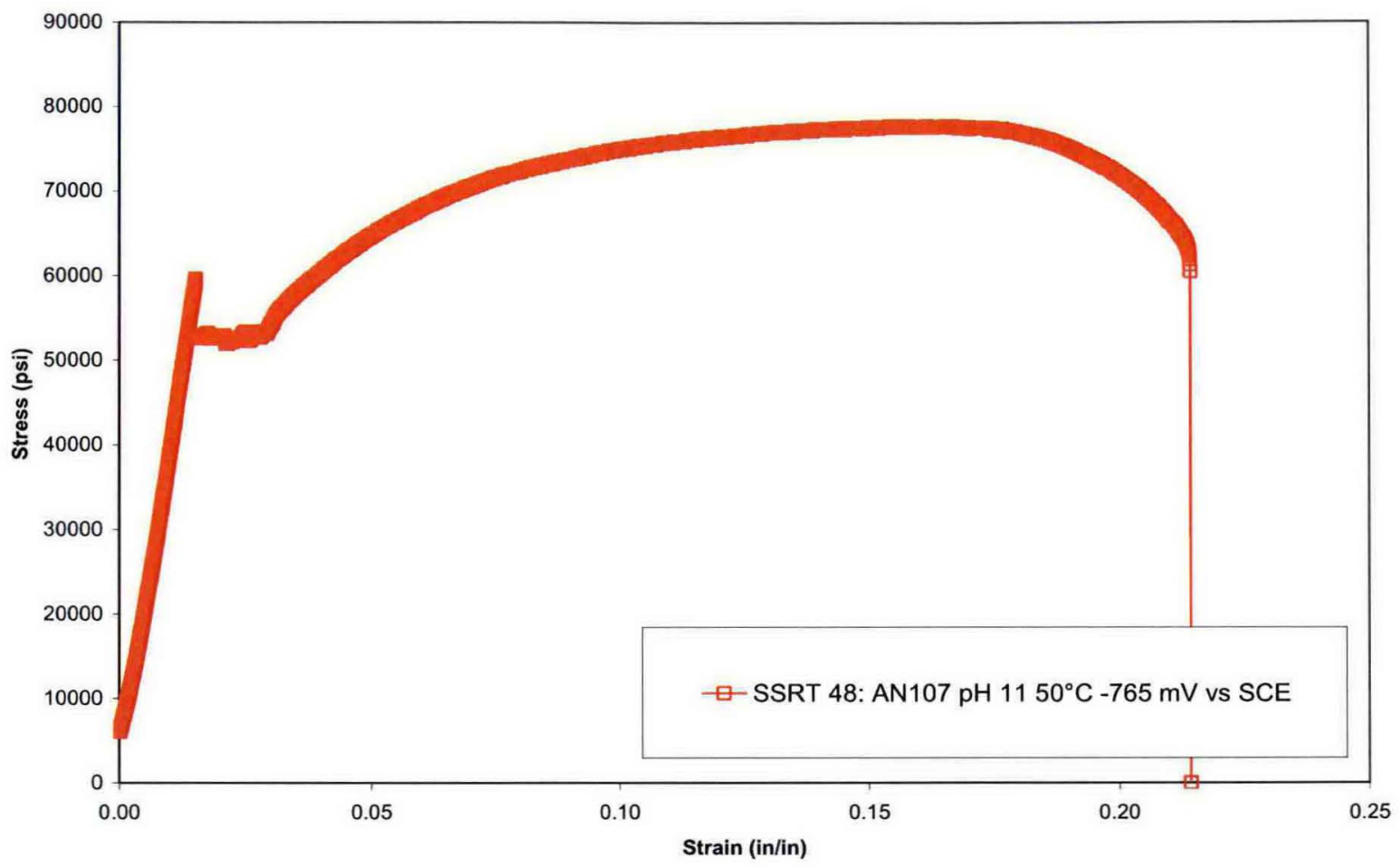

Figure C-5. A Stereo-Micrograph of the Sample from SSRT 48 Performed in AN107 Standard Simulant at $77^{\circ} \mathrm{C}, \mathrm{pH} 11$ and at $-765 \mathrm{mV}$ vs. SCE. 
RPP-RPT-37505, Rev. 0

Figure C-6. An Electron-Micrograph of the Fracture Surface from SSRT 48 Performed in AN107 Standard Simulant at $77^{\circ} \mathrm{C}, \mathrm{pH} 11$ and at $-765 \mathrm{mV}$ vs. SCE.

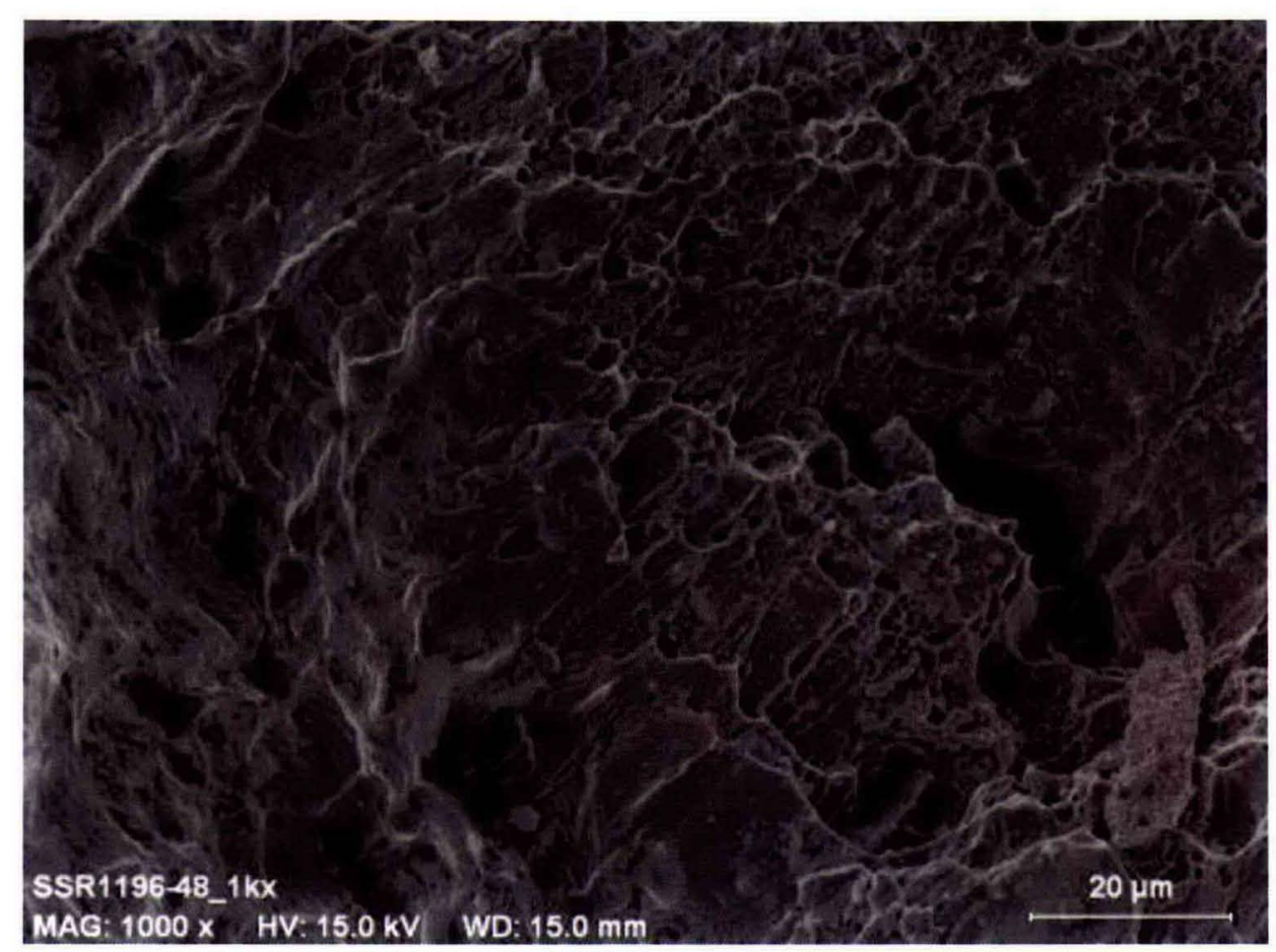


Figure C-7. The Stress-Strain Curve from SSRT 49 Performed in AN107 Standard Simulant at $77^{\circ} \mathrm{C}$, pH $13+$ and at $-790 \mathrm{mV}$ vs. SCE.

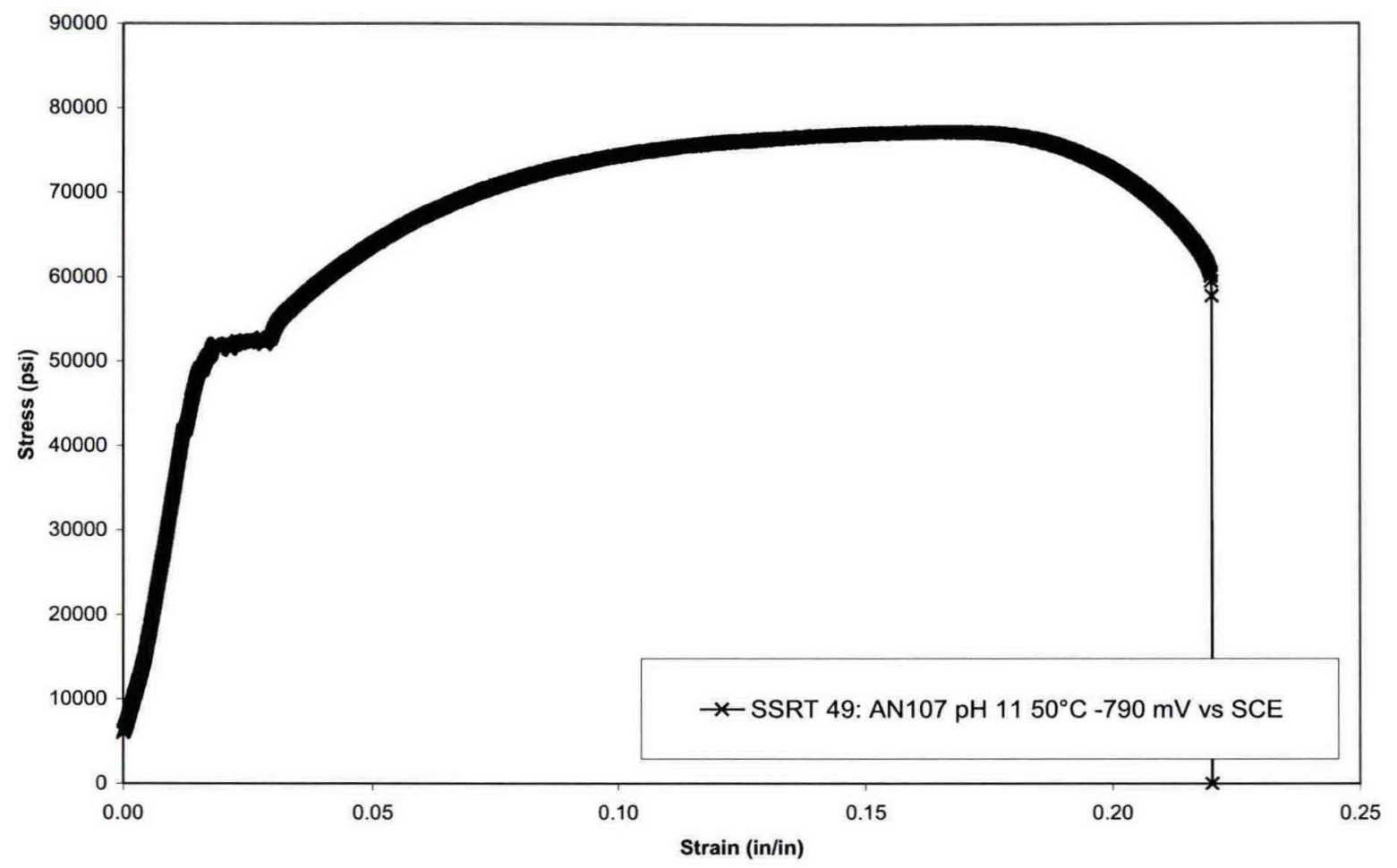

Figure C-8. A Stereo-Micrograph of the Sample from SSRT 49 Performed in AN107 Standard Simulant at $77^{\circ} \mathrm{C}, \mathrm{pH} 13+$ and at $-790 \mathrm{mV}$ vs. SCE. 
RPP-RPT-37505, Rev. 0

Figure C-9. An Electron-Micrograph of the Fracture Surface from SSRT 49 Performed in AN107 Standard Simulant at $77^{\circ} \mathrm{C}$, pH 13+ and at $-790 \mathrm{mV}$ vs. SCE.

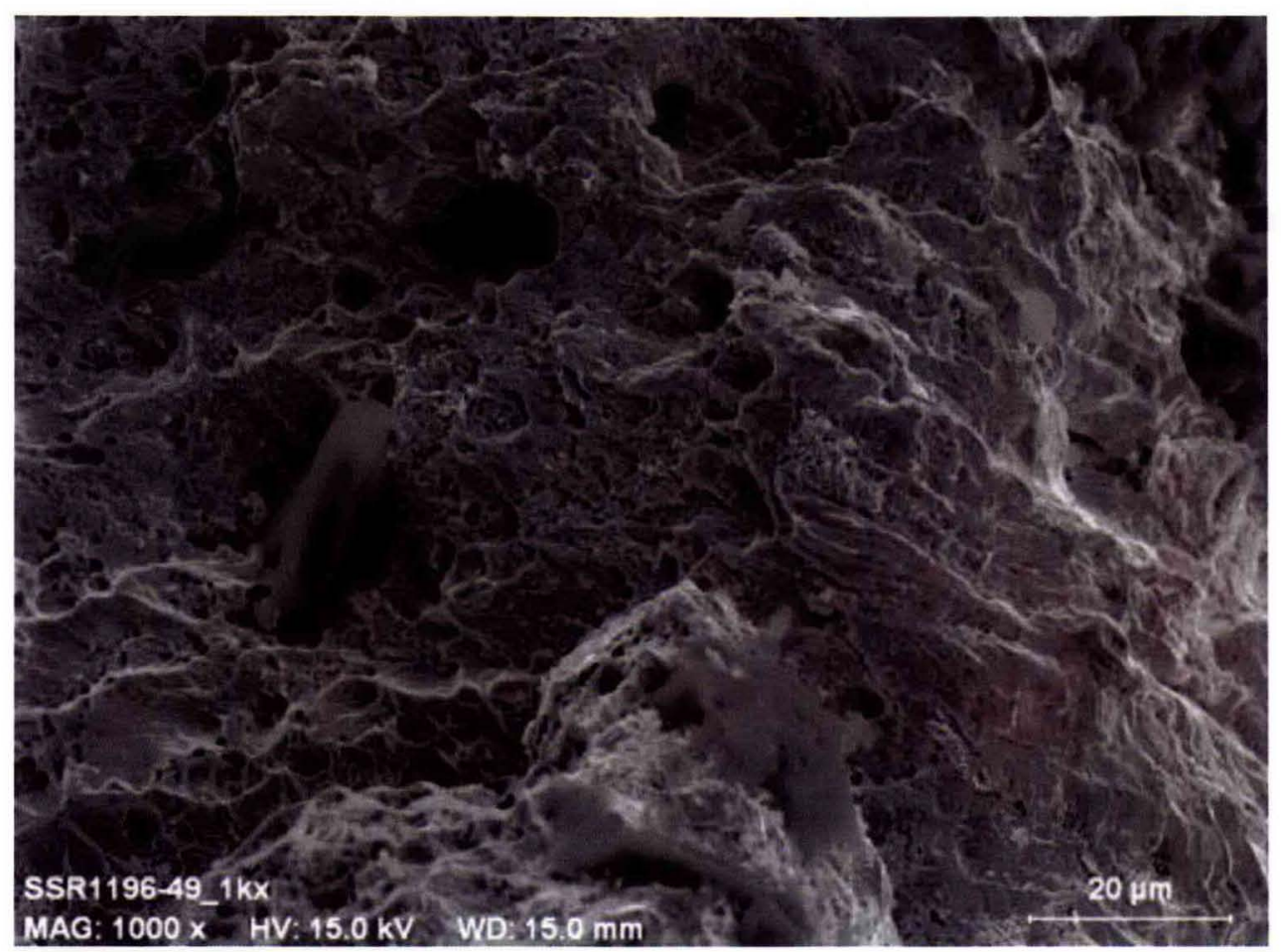


Figure C-10. The Stress-Strain Curve from SSRT 50 Performed in AP105-PSC Standard Simulant at $50^{\circ} \mathrm{C}, \mathrm{pH} 13+$ and at $0 \mathrm{mV}$ vs. SCE.

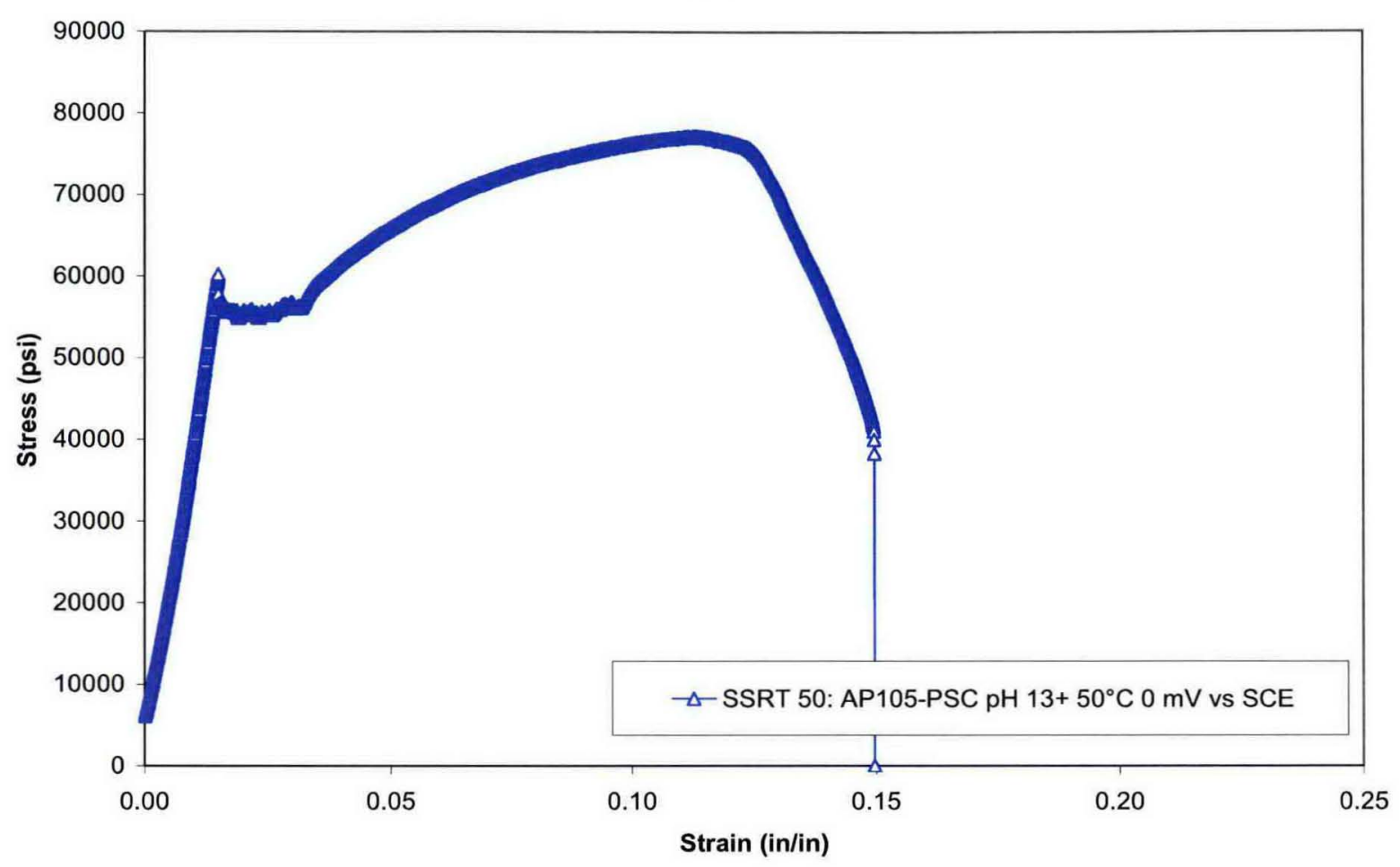

Figure C-11. A Stereo-Micrograph of the Sample from SSRT 50 Performed in AP105-PSC Standard Simulant at $50^{\circ} \mathrm{C}$, $\mathrm{pH} 13+$ and at $0 \mathrm{mV}$ vs. SCE. 
RPP-RPT-37505, Rev. 0

Figure C-12. An Electron-Micrograph of the Fracture Surface from SSRT 50 Performed in AP105-PSC Standard Simulant at $50^{\circ} \mathrm{C}, \mathrm{pH} 13+$ and at $0 \mathrm{mV}$ vs. SCE.

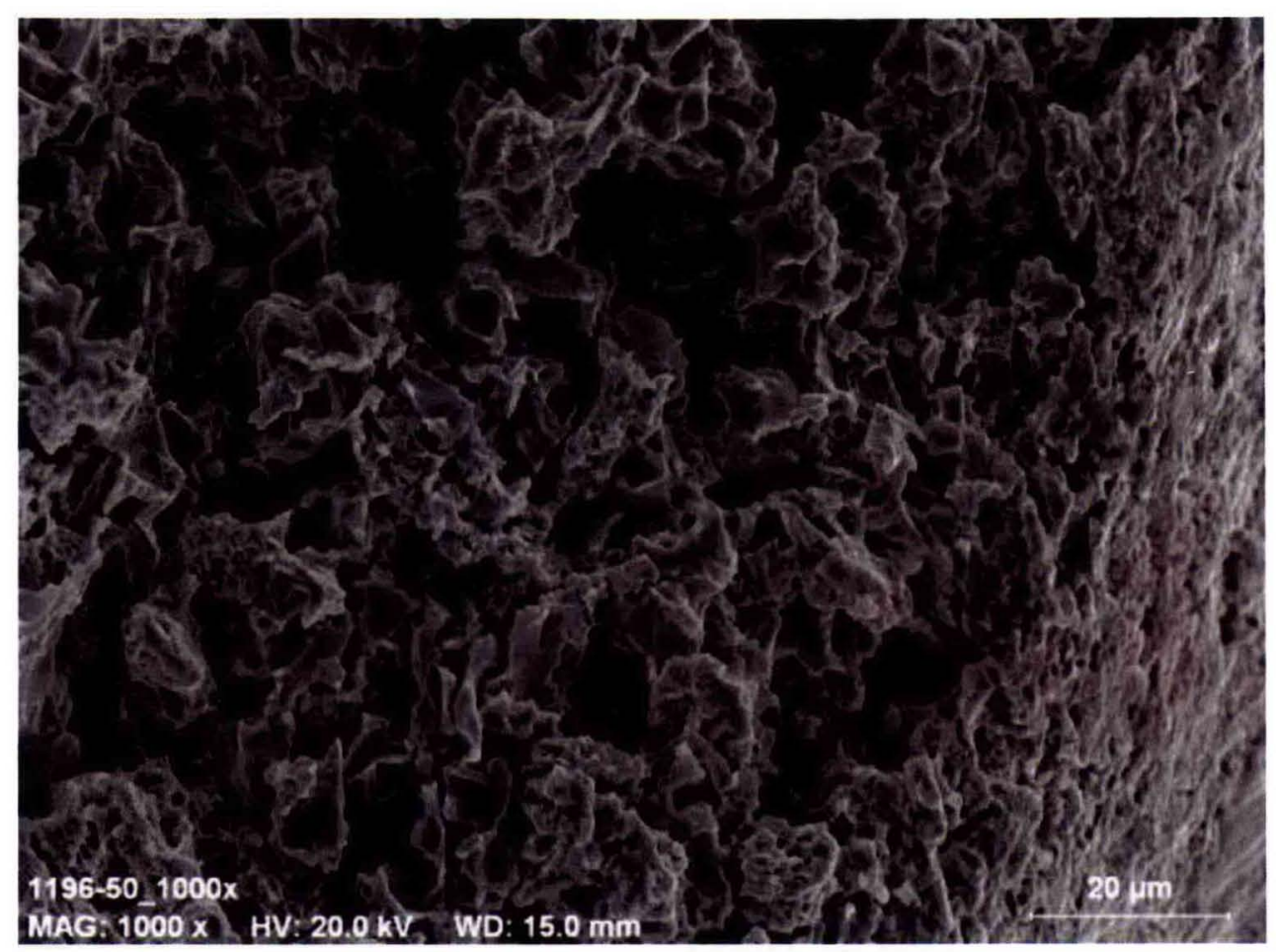


RPP-RPT-37505, Rev. 0

Figure C-43. The Stress-Strain Curve from SSRT 51 Performed in AP105-PSC Standard Simulant at $50^{\circ} \mathrm{C}, \mathrm{pH} 13+$ and at $\mathrm{OCP}(-249 \mathrm{mV}$ vs. SCE).

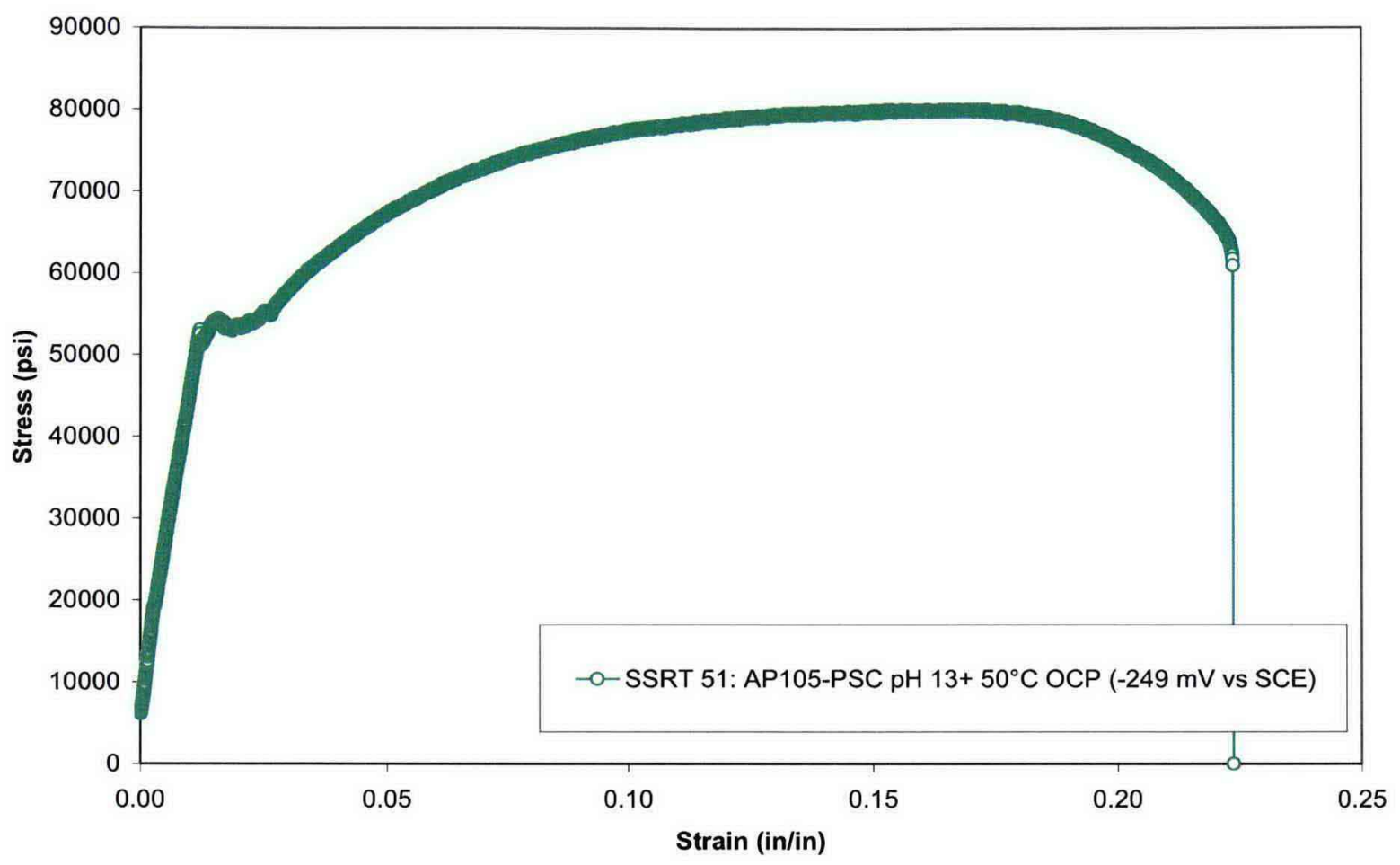

Figure C-14. A Stereo-Micrograph of the Sample from SSRT 51 Performed in AP105-PSC Standard Simulant at $50^{\circ} \mathrm{C}$, pH 13+ and at OCP (-249 $\mathrm{mV}$ vs. SCE).

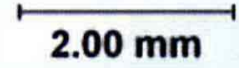

C-10 
Figure C-15. An Electron-Micrograph of a Secondary Crack in the Shaft of SSRT 51 Performed in AP105-PSC Standard Simulant at $50^{\circ} \mathrm{C}, \mathrm{pH} 13+$ and at $\mathrm{OCP}(-249 \mathrm{mV}$ vs. SCE $)$.

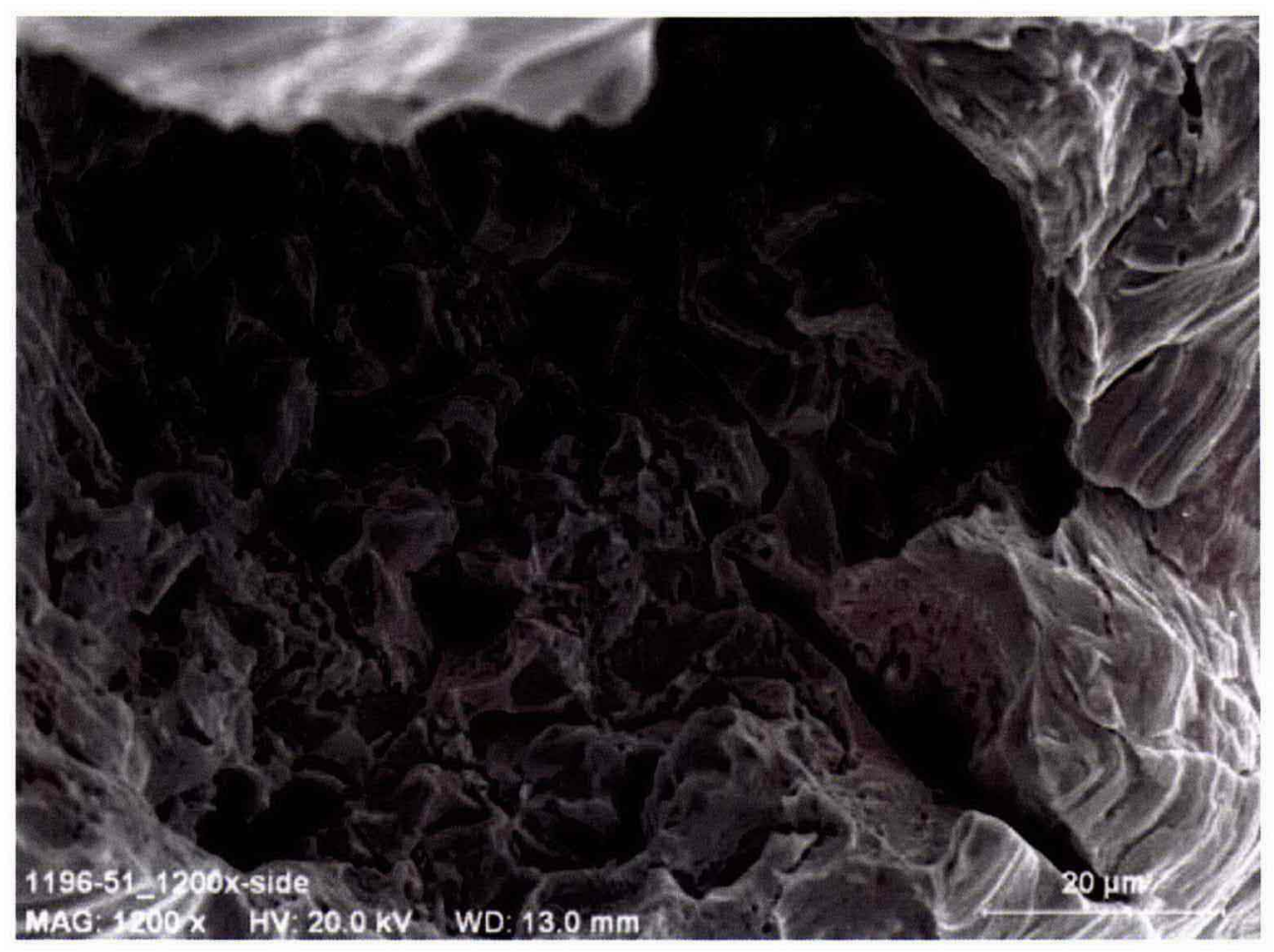




\section{RPP-RPT-37505, Rev. 0}

Figure C-16. The Stress-Strain Curve from SSRT 52 Performed in AP105-PSC Standard Simulant at $50^{\circ} \mathrm{C}, \mathrm{pH} 13+$ and at $\mathrm{OCP}(-289 \mathrm{mV}$ vs. SCE).

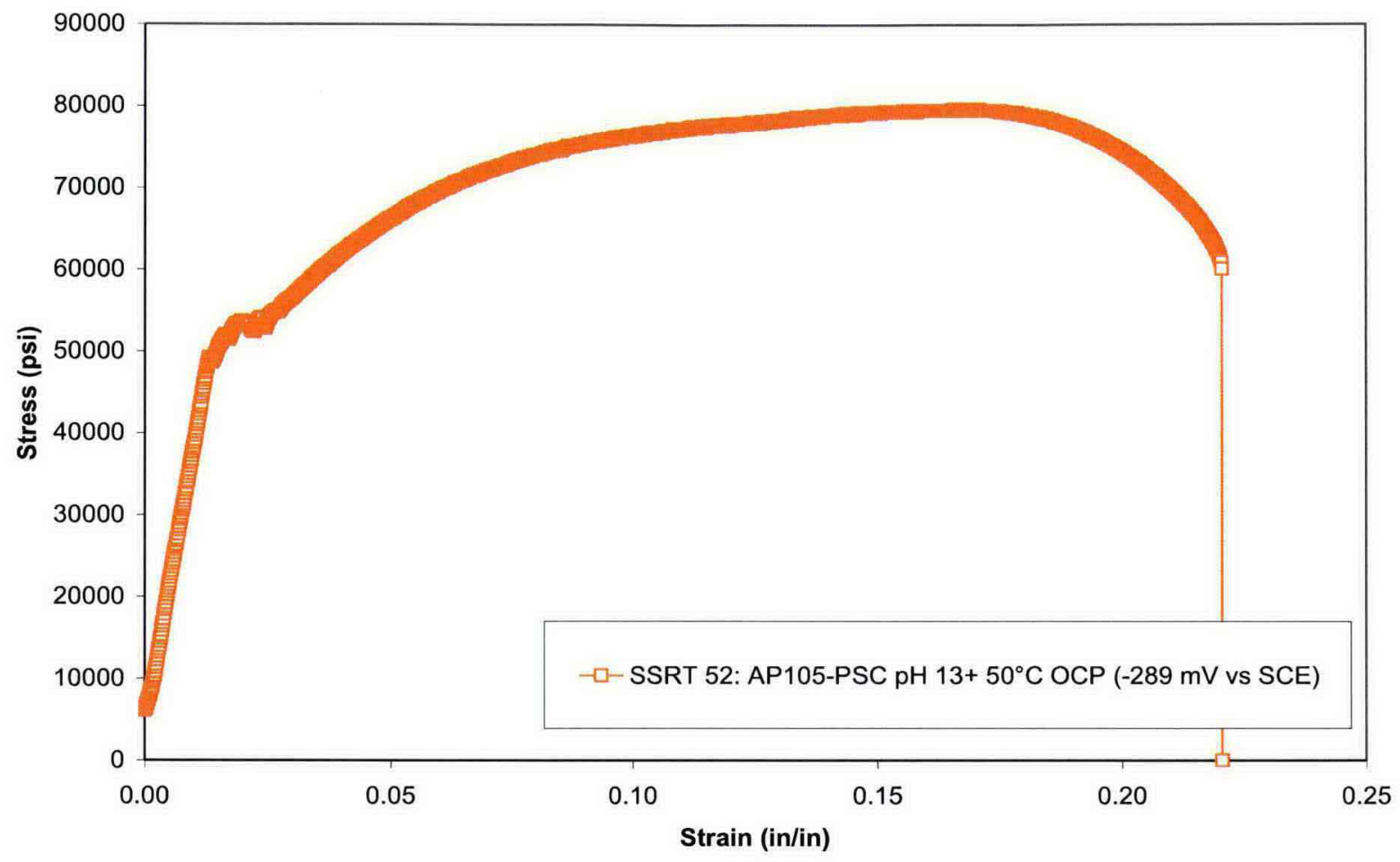

Figure C-17. A Stereo-Micrograph of the Sample from SSRT 52 Performed in AP105-PSC Standard Simulant at $50^{\circ} \mathrm{C}$, pH $13+$ and at $\mathrm{OCP}(-289 \mathrm{mV}$ vs. SCE).

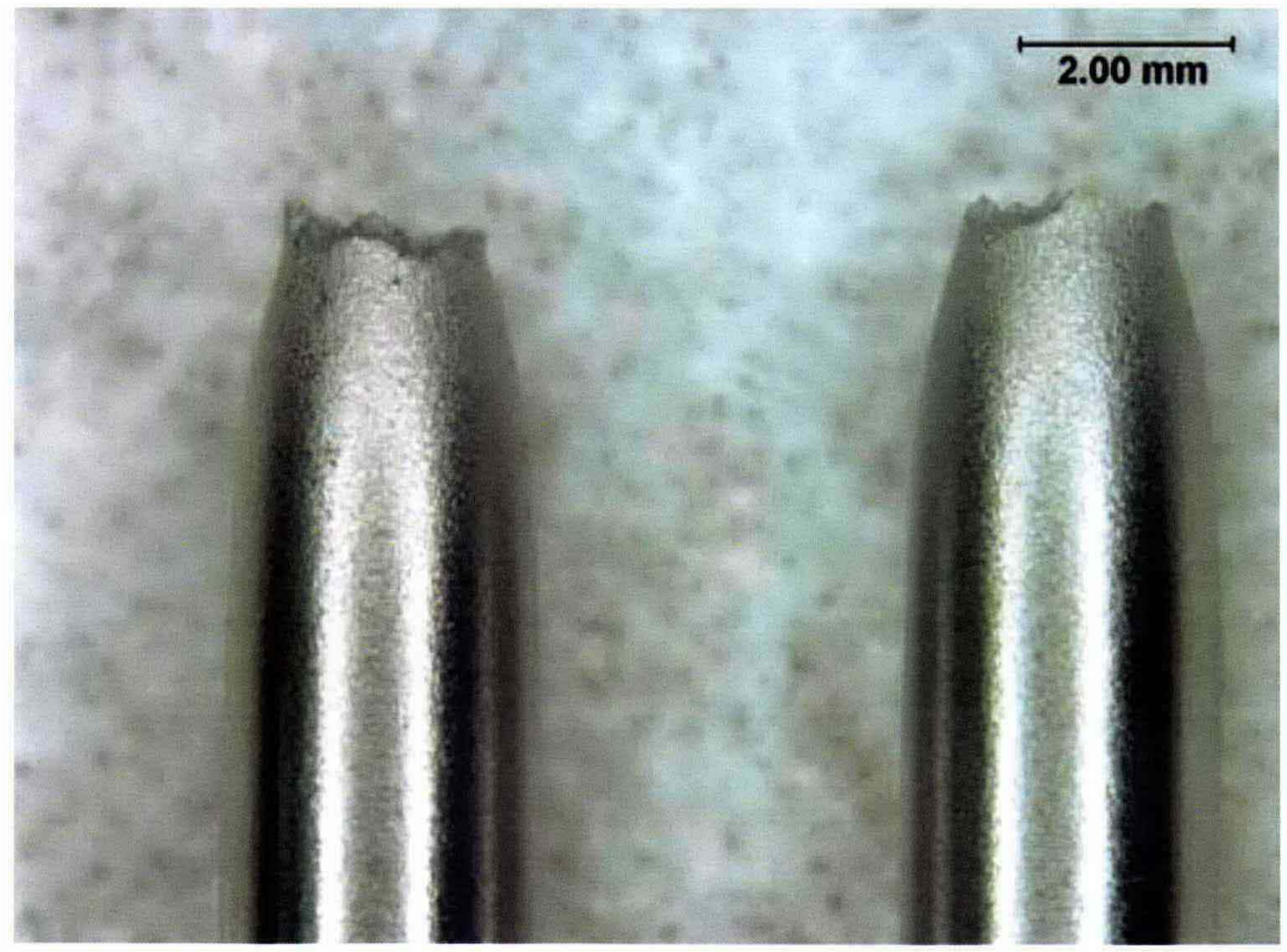


RPP-RPT-37505, Rev. 0

Figure C-18. An Electron-Micrograph of the Fracture Surface from SSRT 52 Performed in AP105-PSC Standard Simulant at $50^{\circ} \mathrm{C}$, pH 13+ and at OCP (-289 $\mathrm{mV}$ vs. SCE).

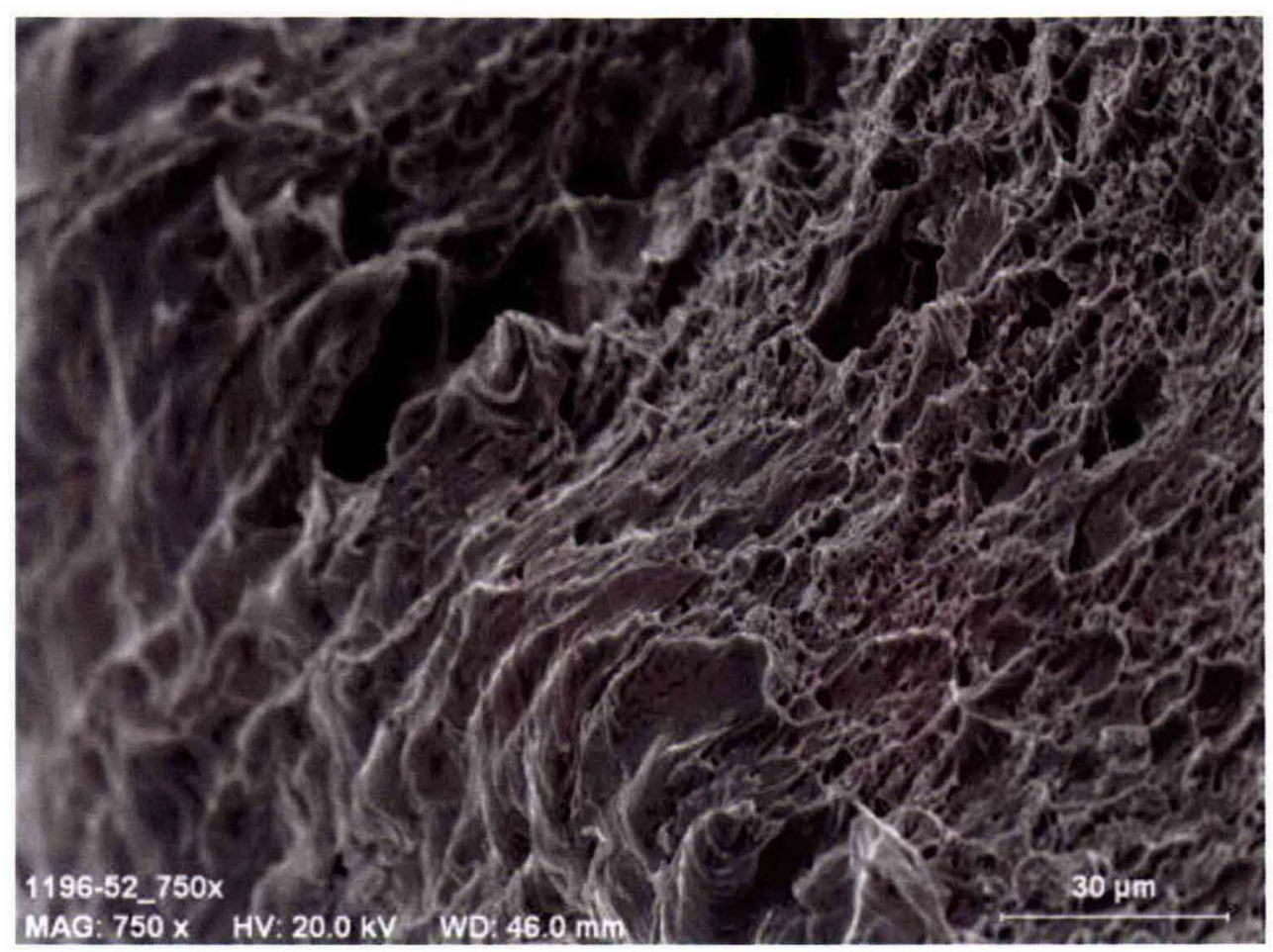


Figure C-19. The Stress-Strain Curve from SSRT 53 Performed in AP105-PSC Standard Simulant at $50^{\circ} \mathrm{C}, \mathrm{pH} 13+$ and at $0 \mathrm{mV}$ vs. SCE.

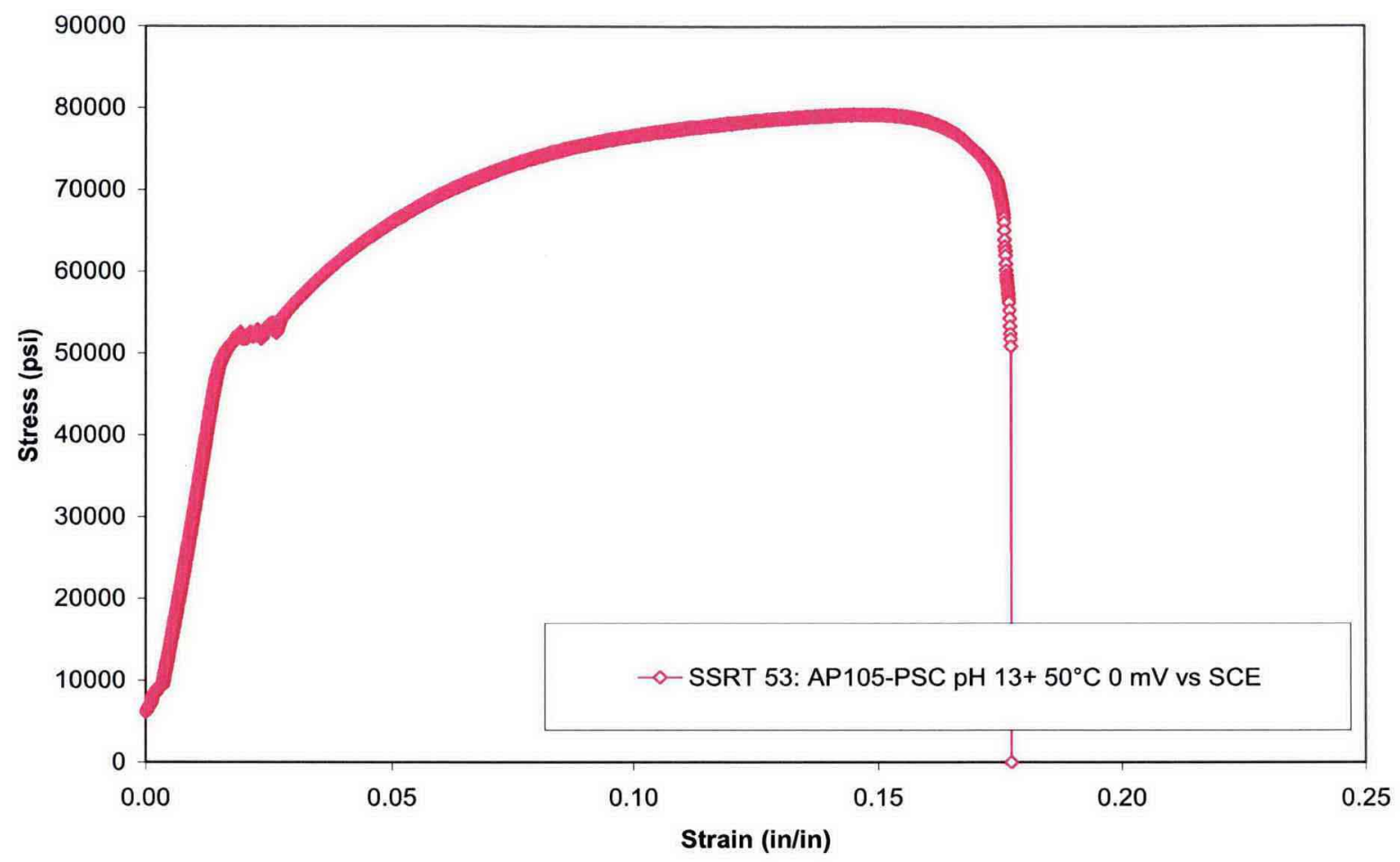

Figure C-20. A Stereo-Micrograph of the Sample from SSRT 53 Performed in AP105-PSC Standard Simulant at $50^{\circ} \mathrm{C}$, pH $13+$ and at $0 \mathrm{mV}$ vs. SCE.

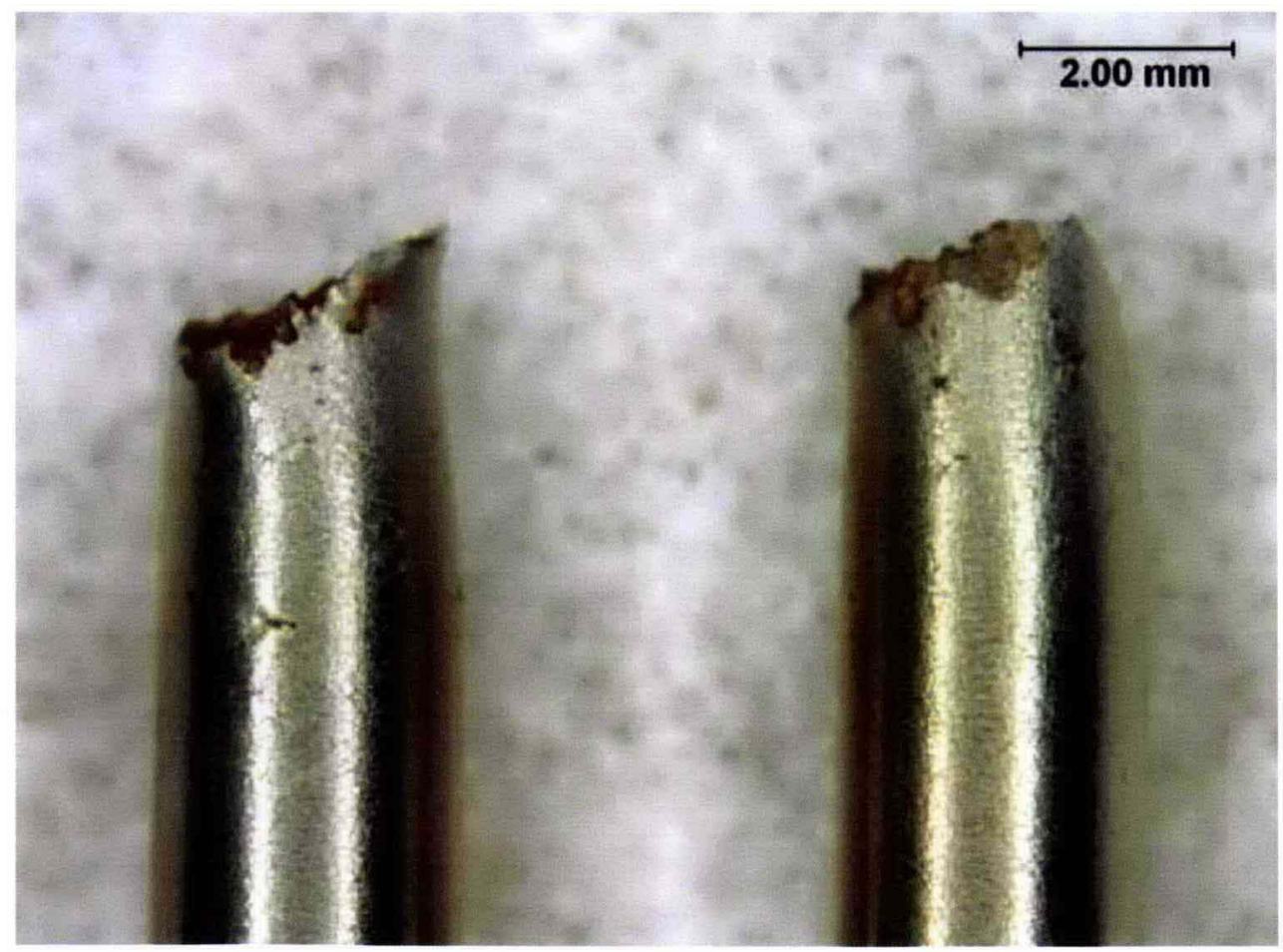


RPP-RPT-37505, Rev. 0

Figure C-21. An Electron-Micrograph of the Fracture Surface from SSRT 53 Performed in AP105-PSC Standard Simulant at $50^{\circ} \mathrm{C}$, pH $13+$ and at $0 \mathrm{mV}$ vs. SCE.

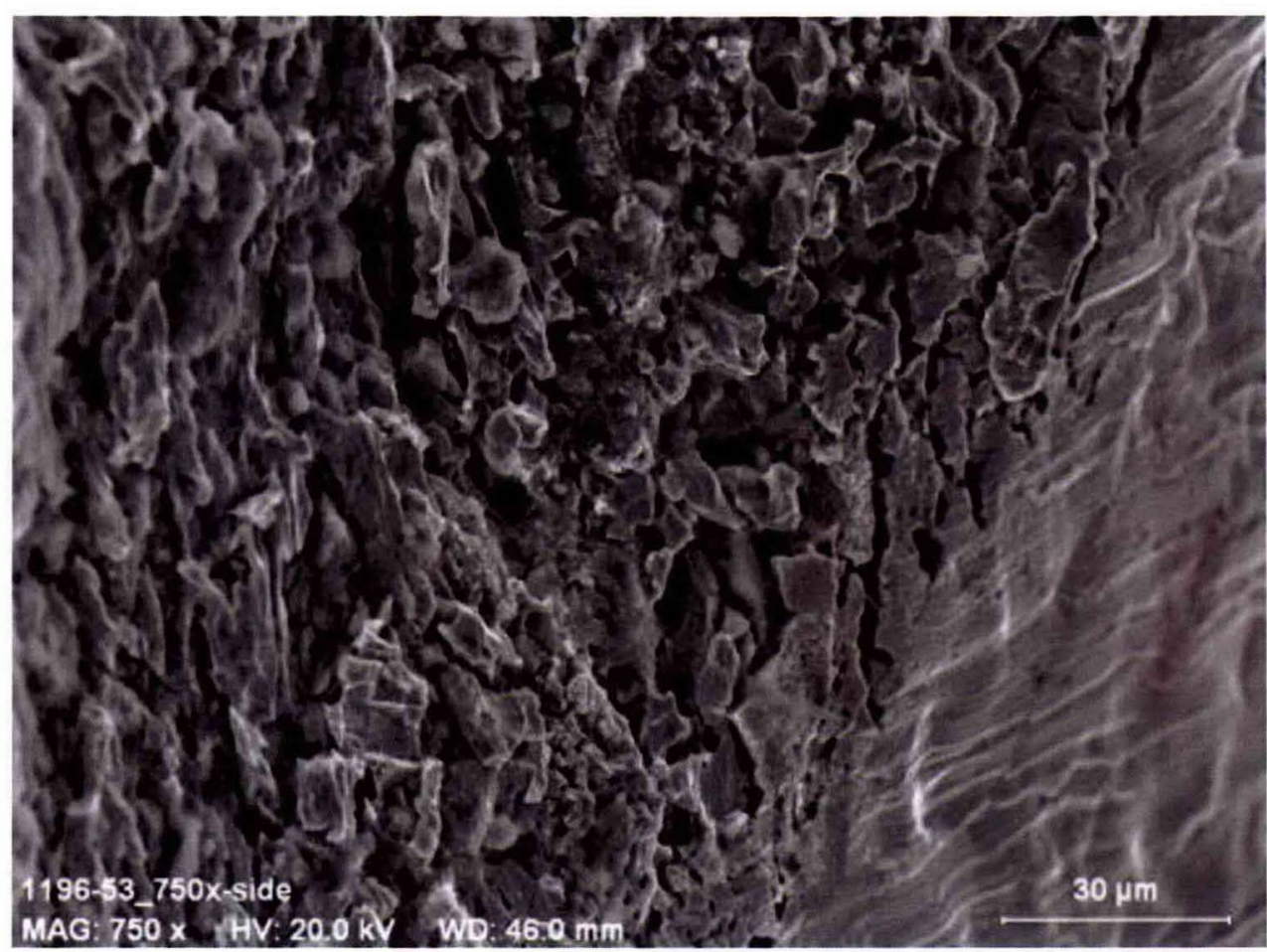

C-15 
Figure C-22. The Stress-Strain Curve from SSRT 54 Performed in AP105-PSC Standard Simulant at $50^{\circ} \mathrm{C}, \mathrm{pH} 13+$ and at $0 \mathrm{mV}$ vs. SCE.

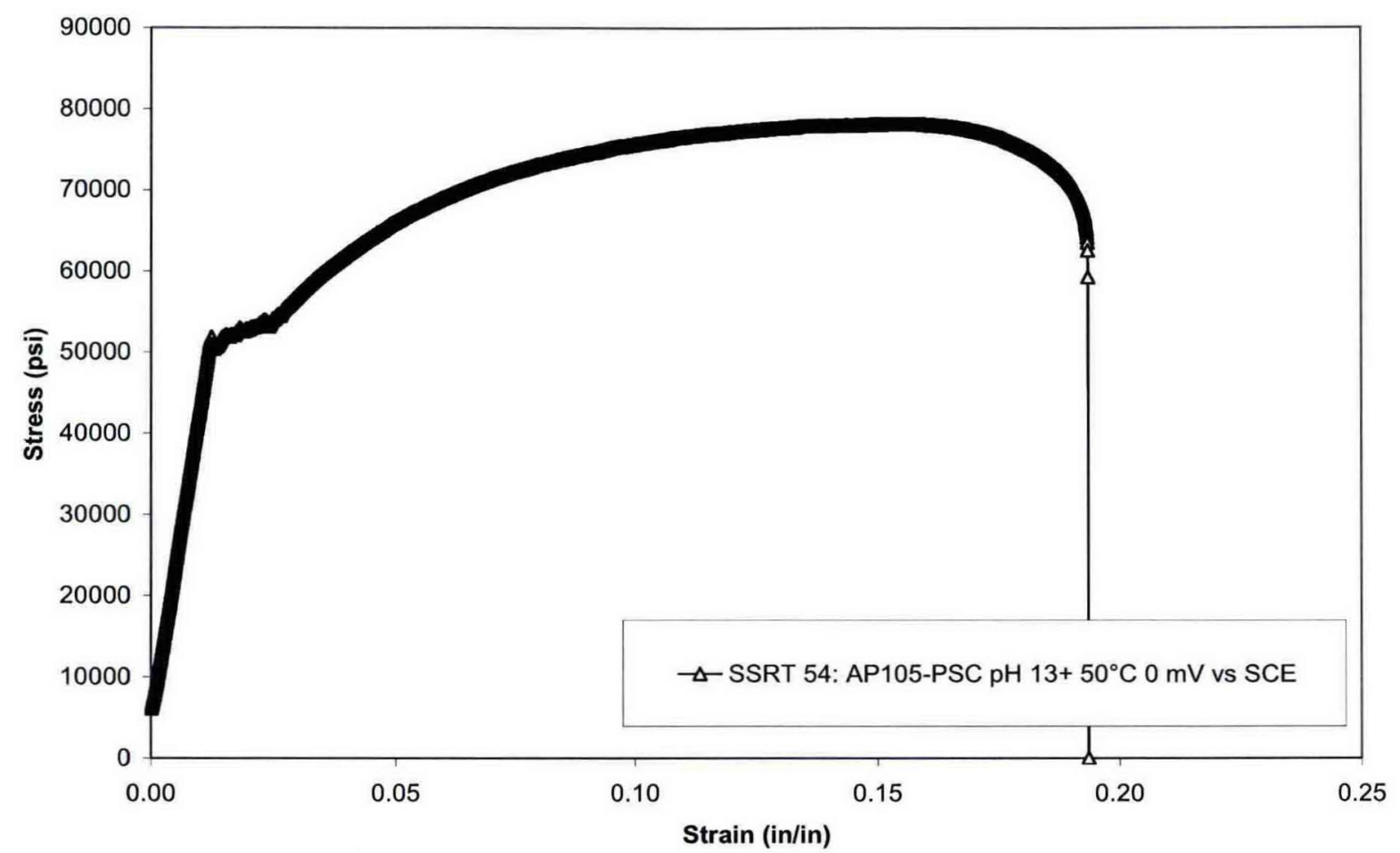

Figure C-23. A Stereo-Micrograph of the Sample from SSRT 54 Performed in AP105-PSC Standard Simulant at $50^{\circ} \mathrm{C}$, $\mathrm{pH} 13+$ and at $0 \mathrm{mV}$ vs. SCE.

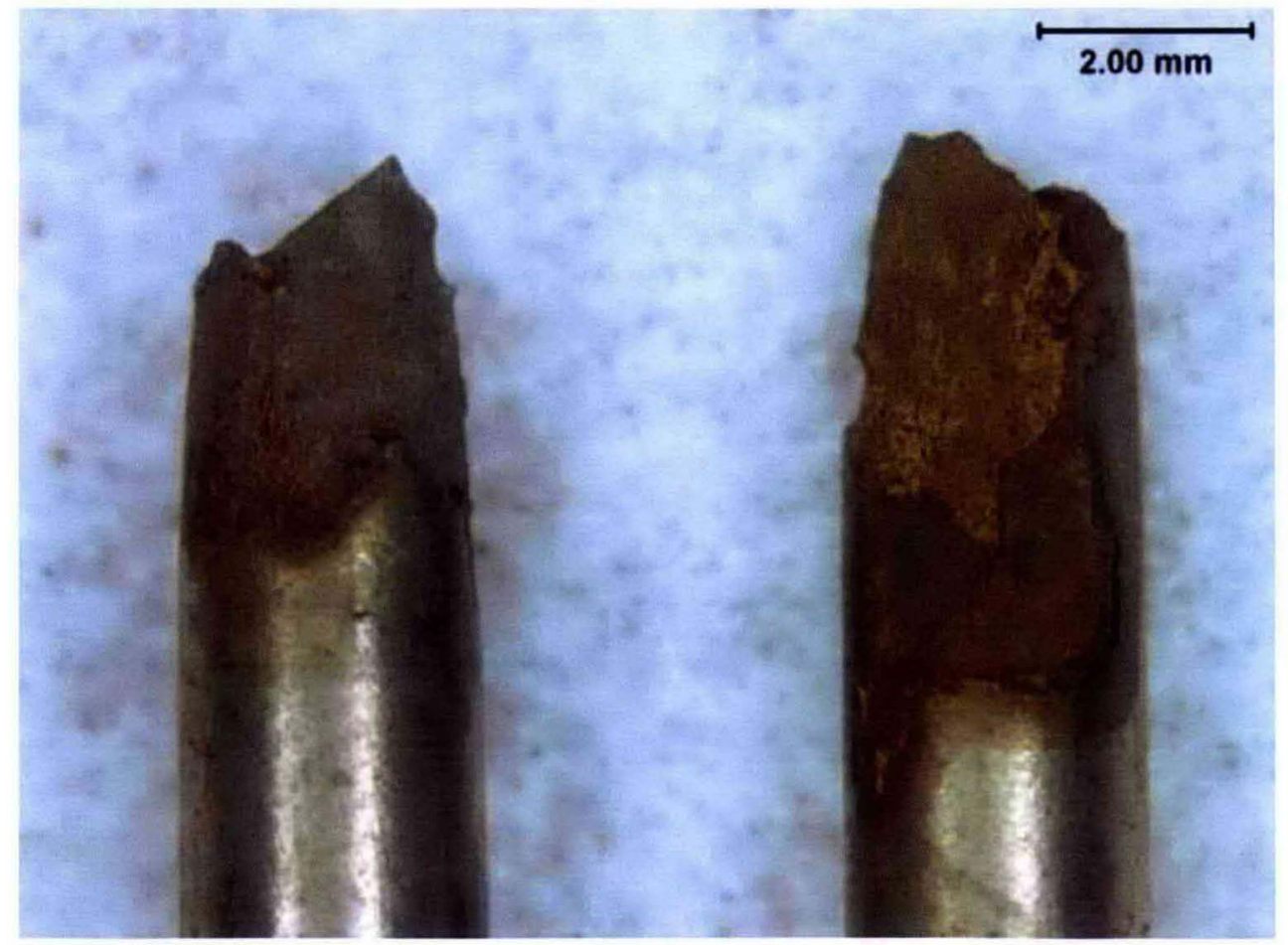


RPP-RPT-37505, Rev. 0

Figure C-24. An Electron-Micrograph of the Fracture Surface from SSRT 54 Performed in AP105-PSC Standard Simulant at $50^{\circ} \mathrm{C}$, pH $13+$ and at $0 \mathrm{mV}$ vs. SCE.

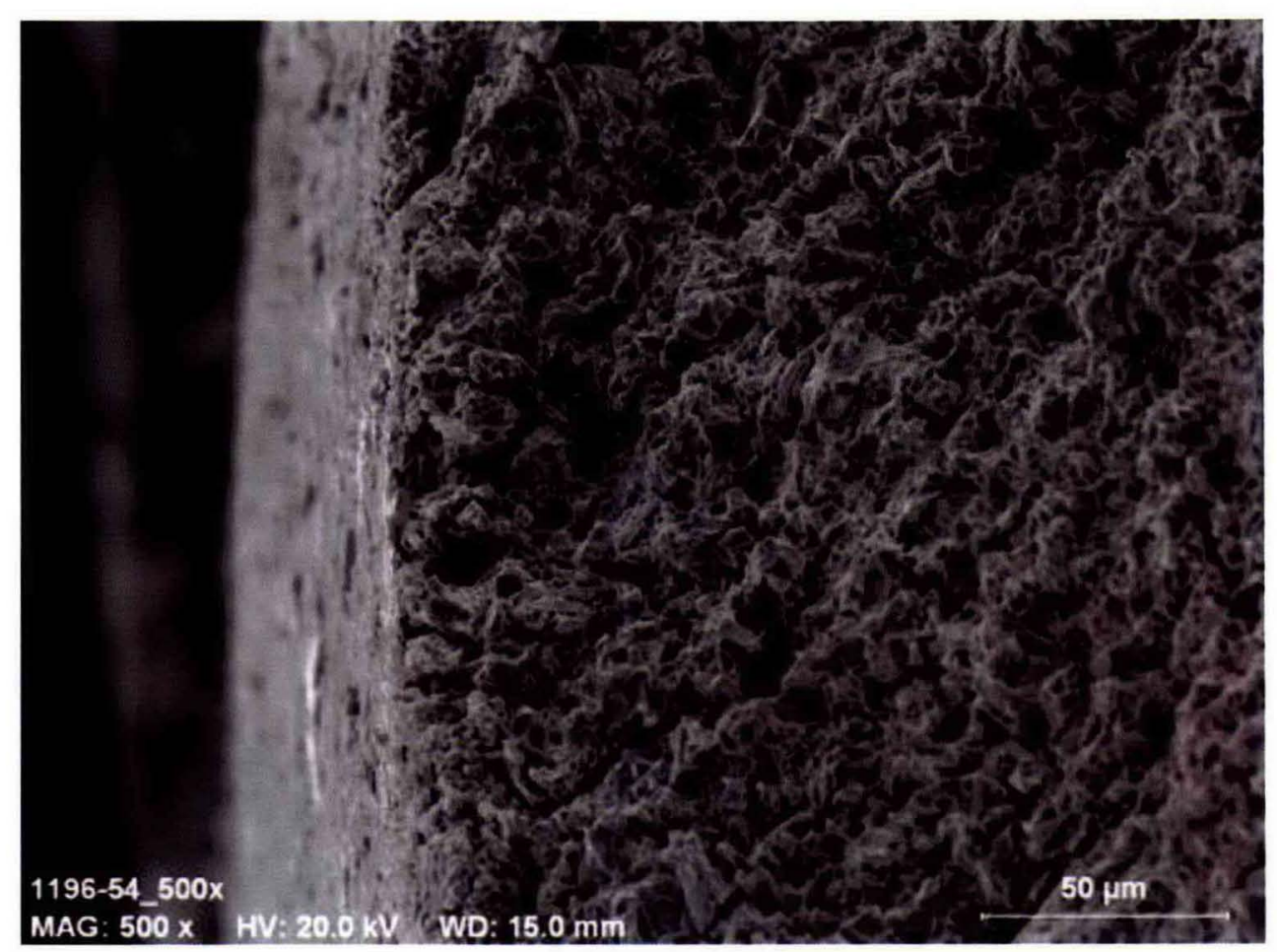


Figure C-25. The Stress-Strain Curve from SSRT 55 Performed in SY103-PIL Standard Simulant at $50^{\circ} \mathrm{C}, \mathrm{pH} 14$ and at $\mathrm{OCP}(-424 \mathrm{mV}$ vs. SCE).

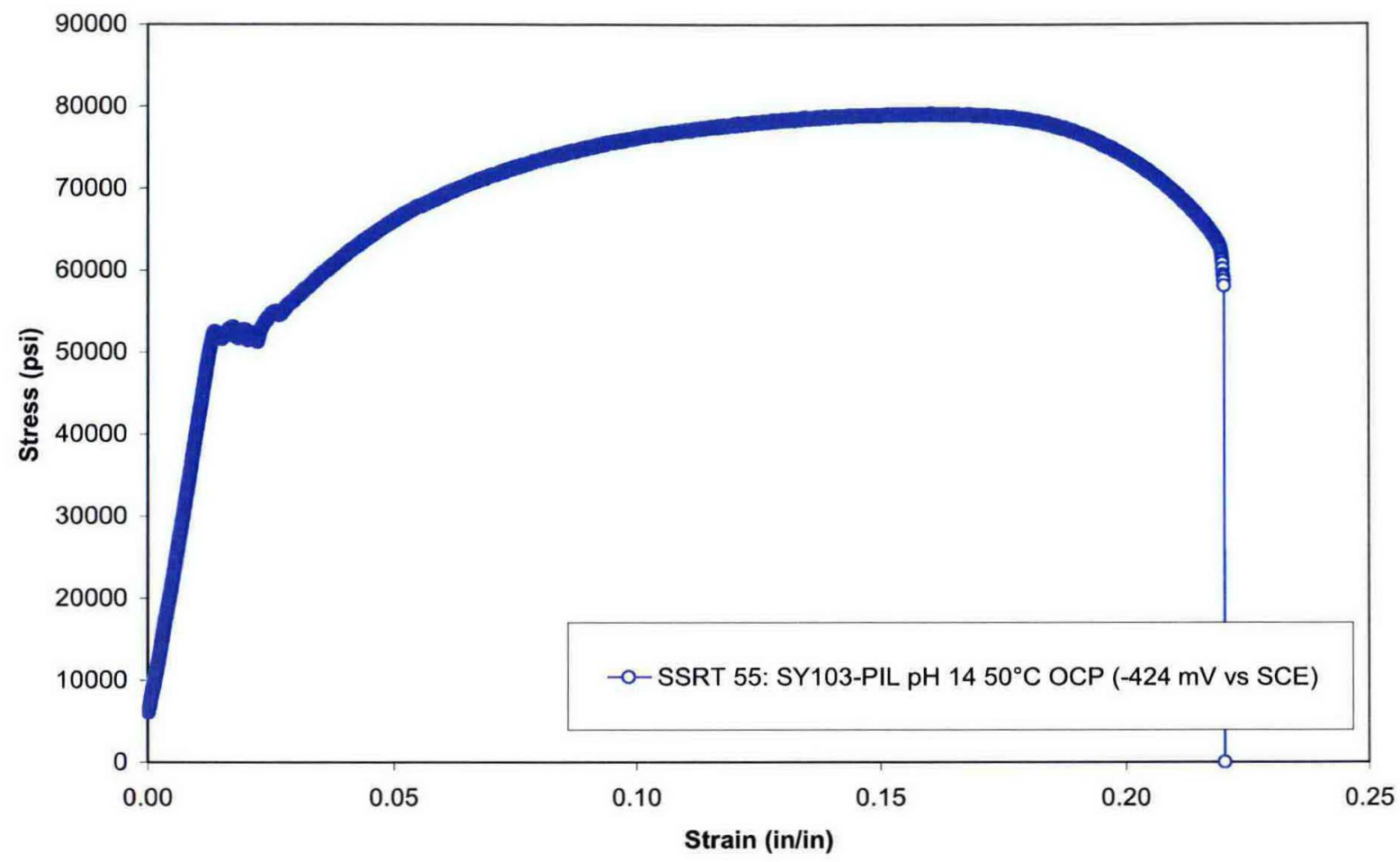

Figure C-26. A Stereo-Micrograph of the Sample from SSRT 55 Performed in SY103-PIL Standard Simulant at $50^{\circ} \mathrm{C}$, pH 14 and at $\mathrm{OCP}(-424 \mathrm{mV}$ vs. SCE).

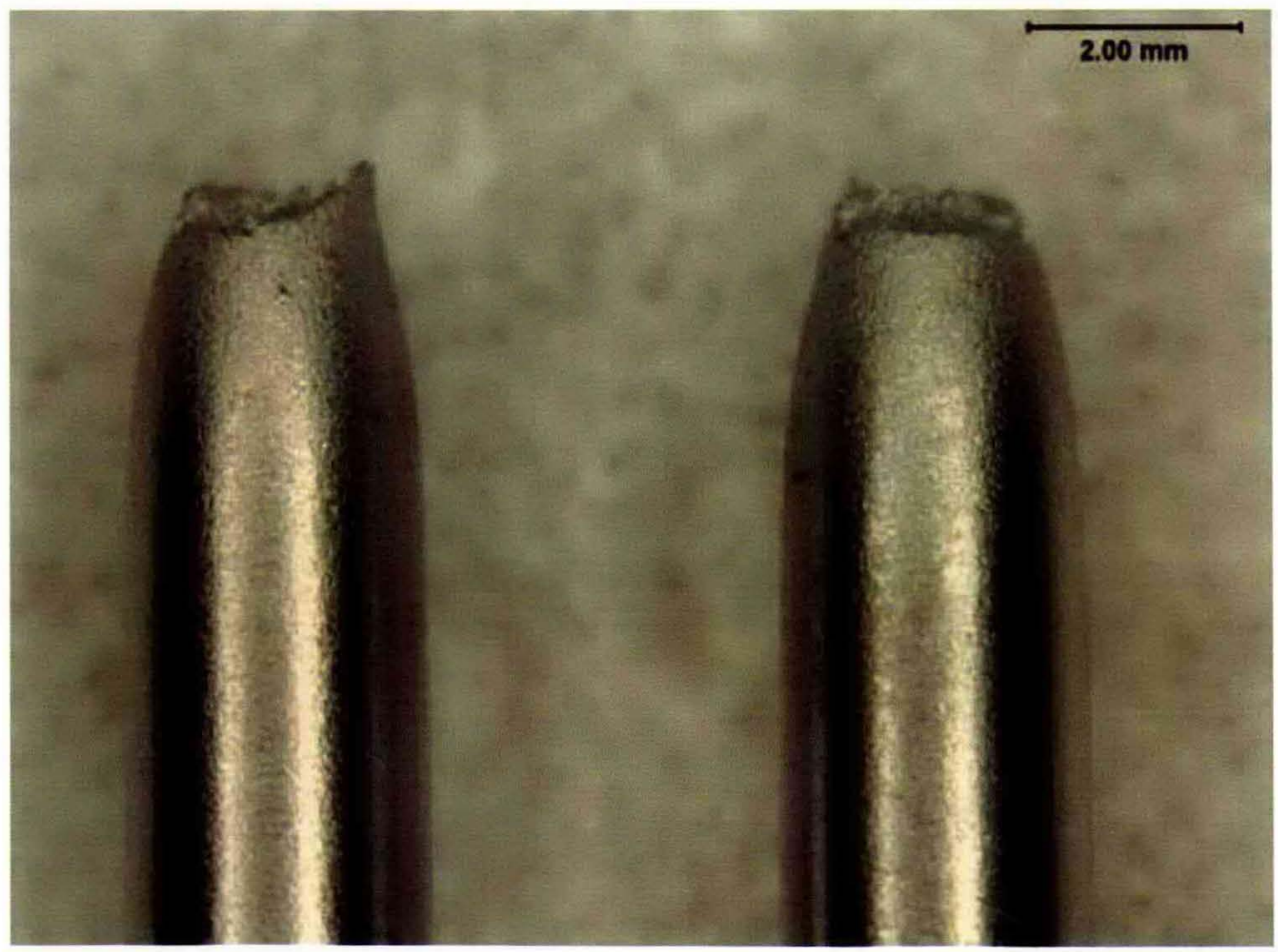


RPP-RPT-37505, Rev. 0

Figure C-27. An Electron-Micrograph of the Fracture Surface from SSRT 55 Performed in SY103-PIL Standard Simulant at $50^{\circ} \mathrm{C}$, pH 14 and at OCP (-424 mV vs. SCE).

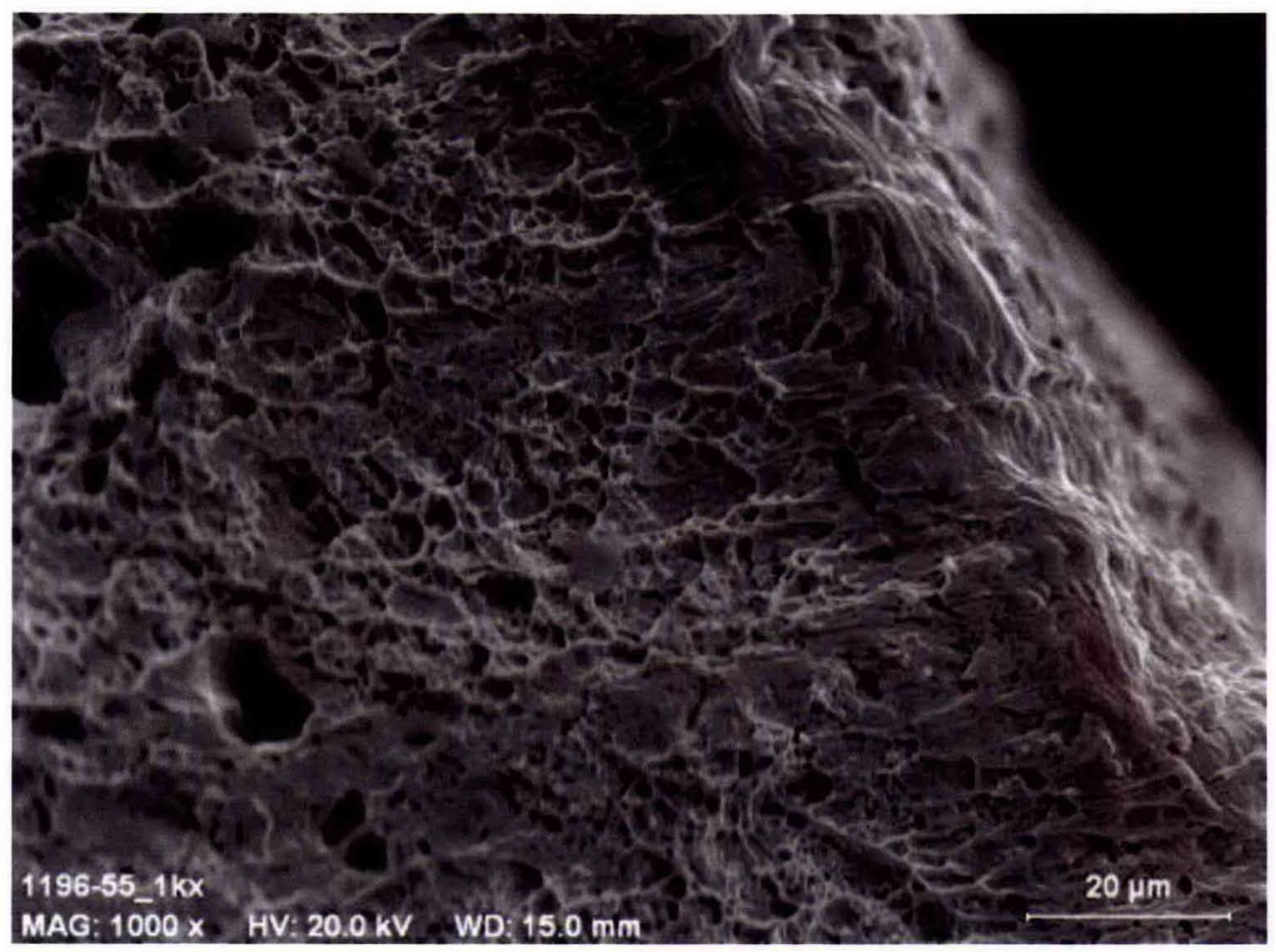


Figure C-28. The Stress-Strain Curve from SSRT 56 Performed in AW105-PIL Standard Simulant at $50^{\circ} \mathrm{C}, \mathrm{pH} 13+$ and at $\mathrm{OCP}(-290 \mathrm{mV}$ vs. SCE $)$.

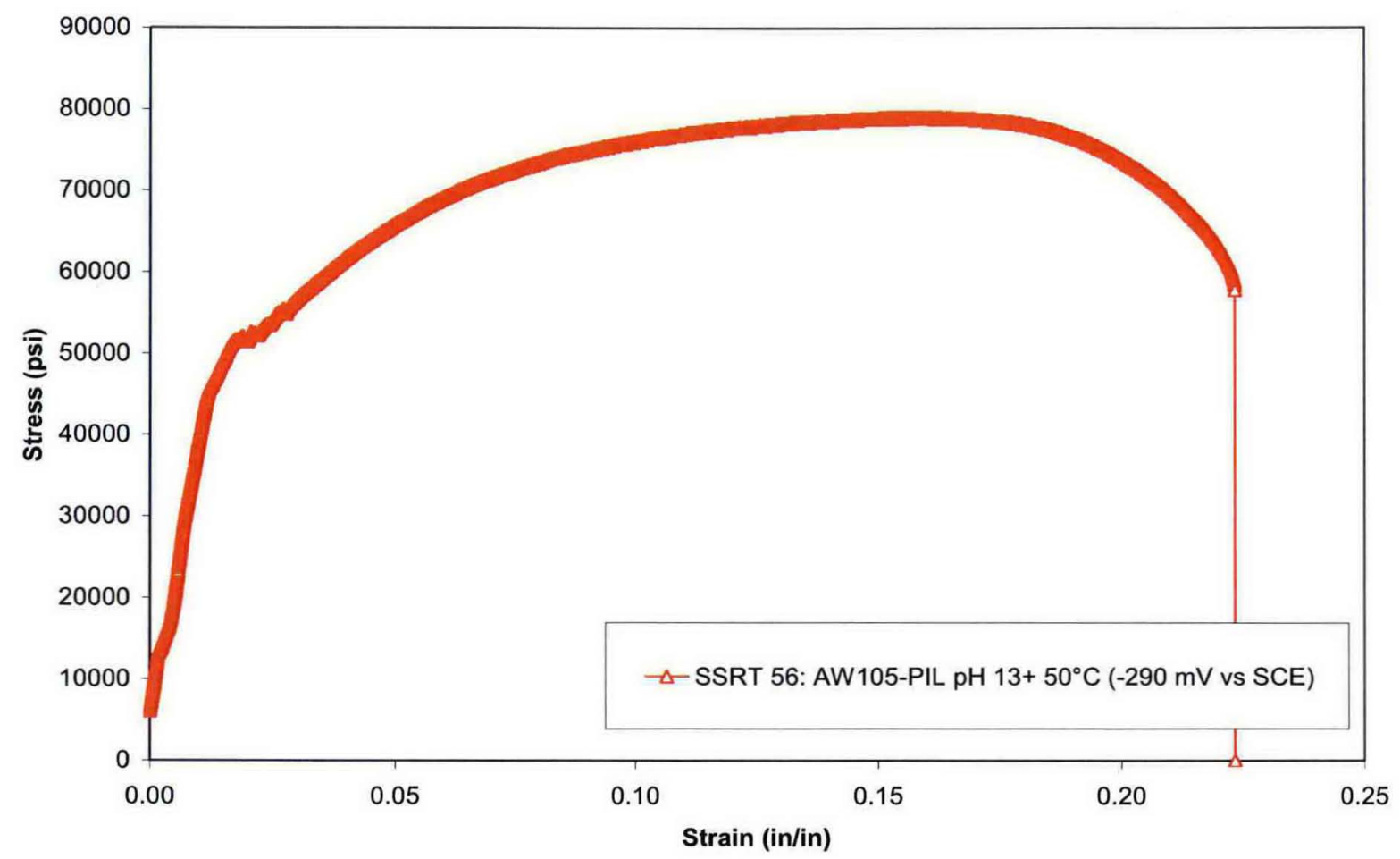

Figure C-29. A Stereo-Micrograph of the Sample from SSRT 56 Performed in AW105-PIL Standard Simulant at $50^{\circ} \mathrm{C}$, pH 13+ and at OCP (-290 mV vs. SCE).

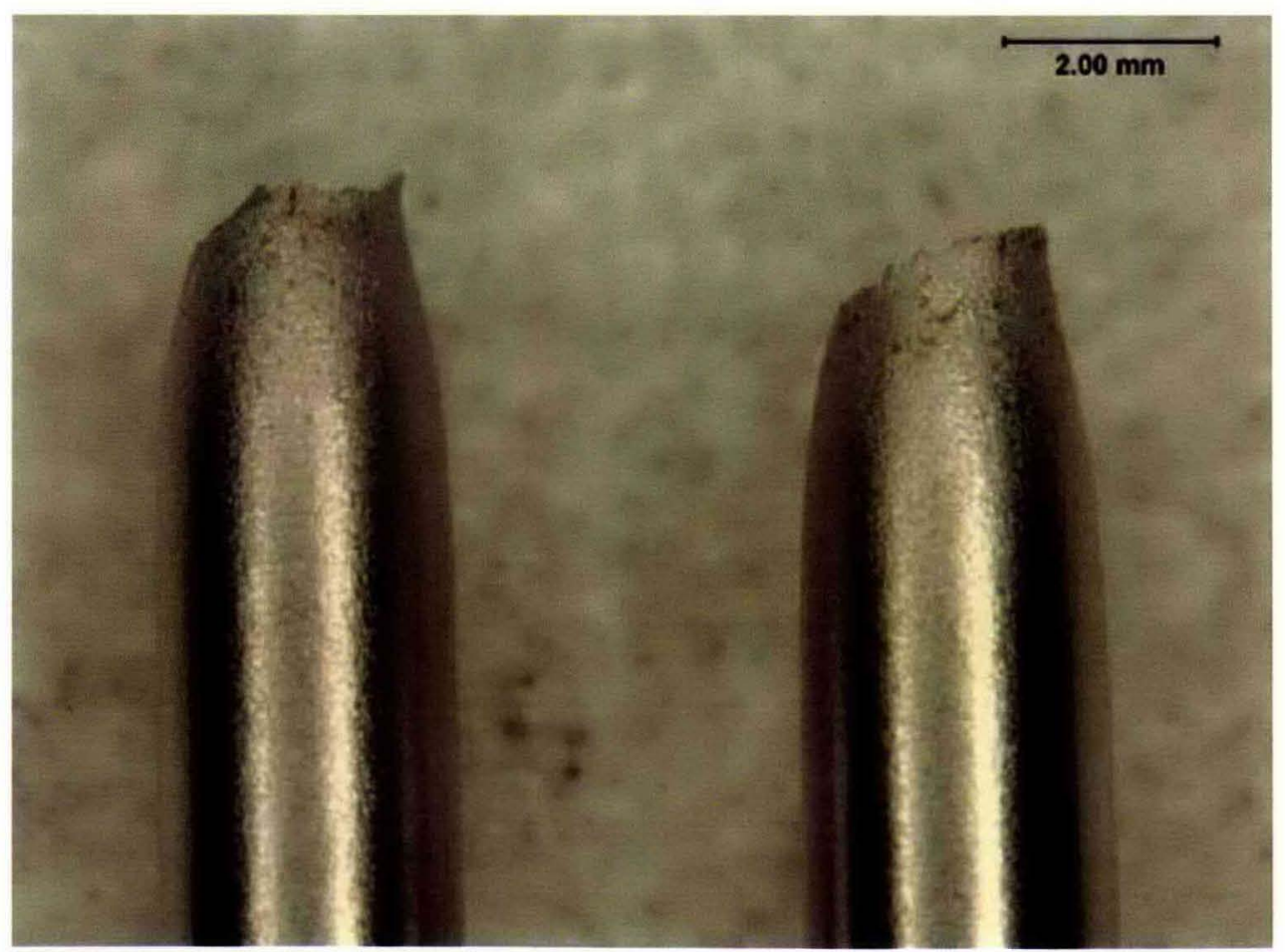


RPP-RPT-37505, Rev. 0

Figure C-30. An Electron-Micrograph of the Fracture Surface from SSRT 56 Performed in AW105-PIL Standard Simulant at $50^{\circ} \mathrm{C}$, pH 13+ and at OCP (-290 mV vs. SCE).

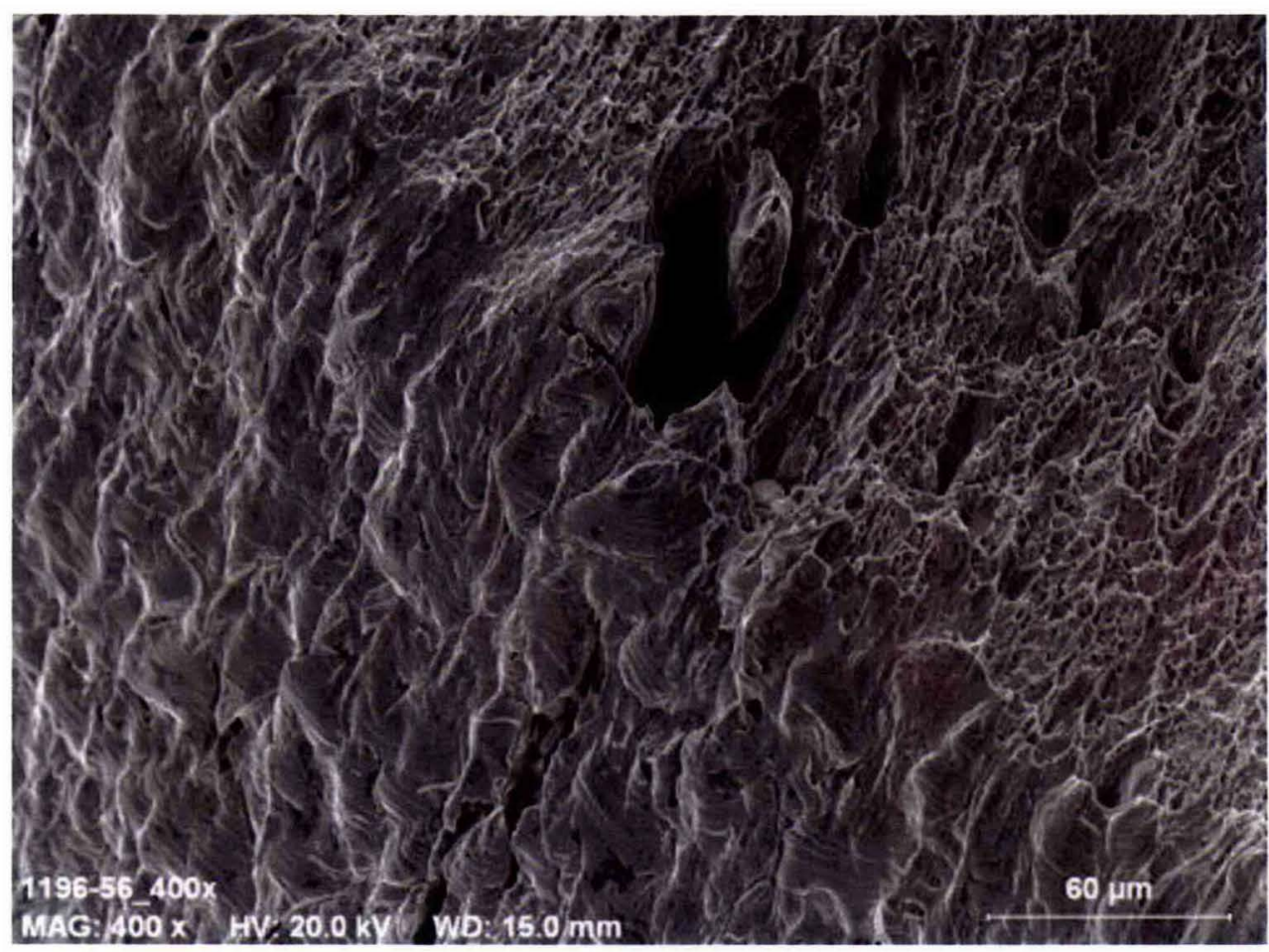


RPP-RPT-37505, Rev. 0

Figure C-31. The Stress-Strain Curve from SSRT 57 Performed in SY103-PIL Standard Simulant at $50^{\circ} \mathrm{C}$, pH 14 and at $0 \mathrm{mV}$ vs. SCE.

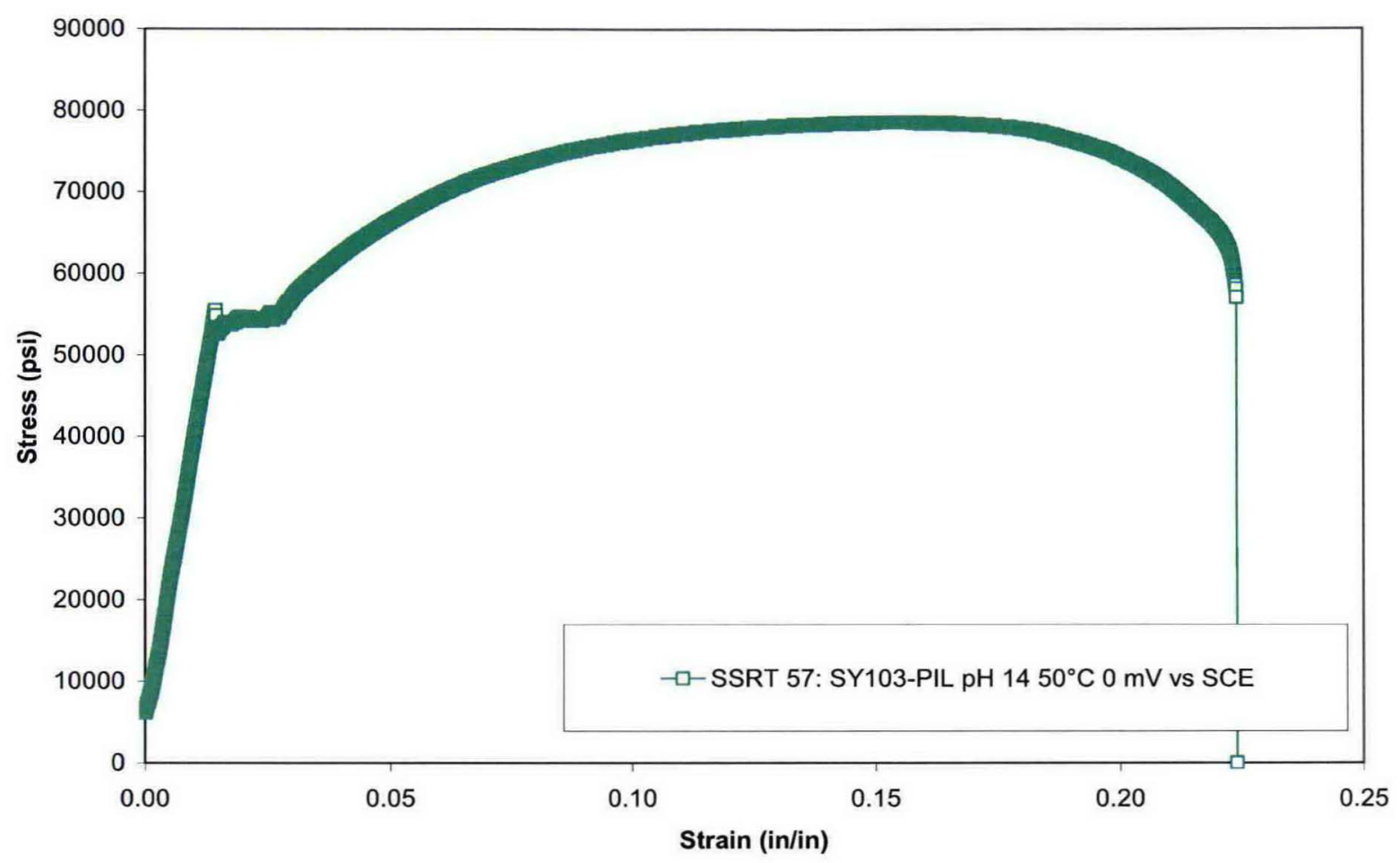

Figure C-32. A Stereo-Micrograph of the Sample from SSRT 57 Performed in SY103-PIL Standard Simulant at $50^{\circ} \mathrm{C}$, pH 14 and at $0 \mathrm{mV}$ vs. SCE.

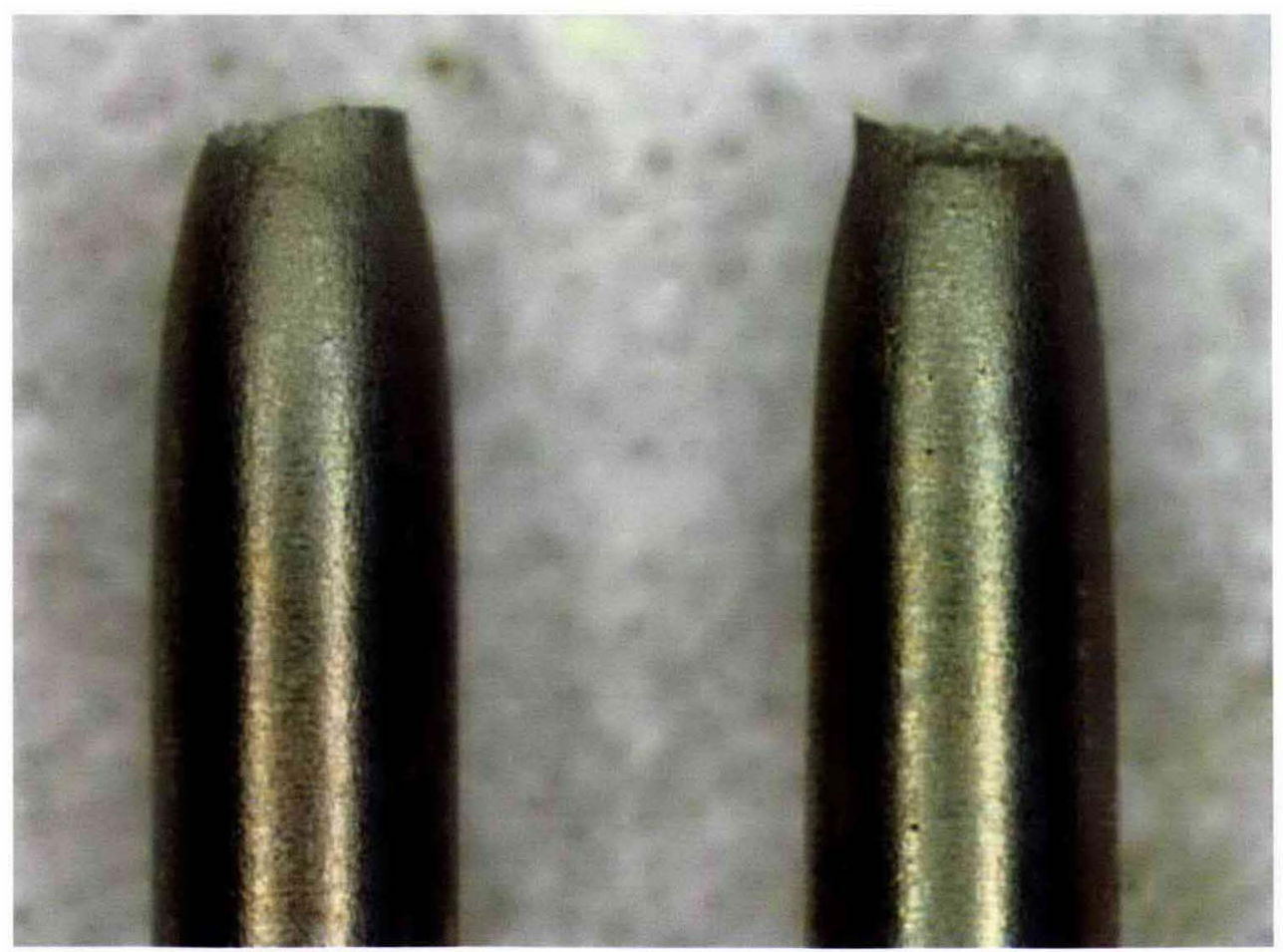


RPP-RPT-37505, Rev. 0

Figure C-33. An Electron-Micrograph of the Fracture Surface from SSRT 57 Performed in SY103-PIL Standard Simulant at $50^{\circ} \mathrm{C}$, pH 14 and at $0 \mathrm{mV}$ vs. SCE.

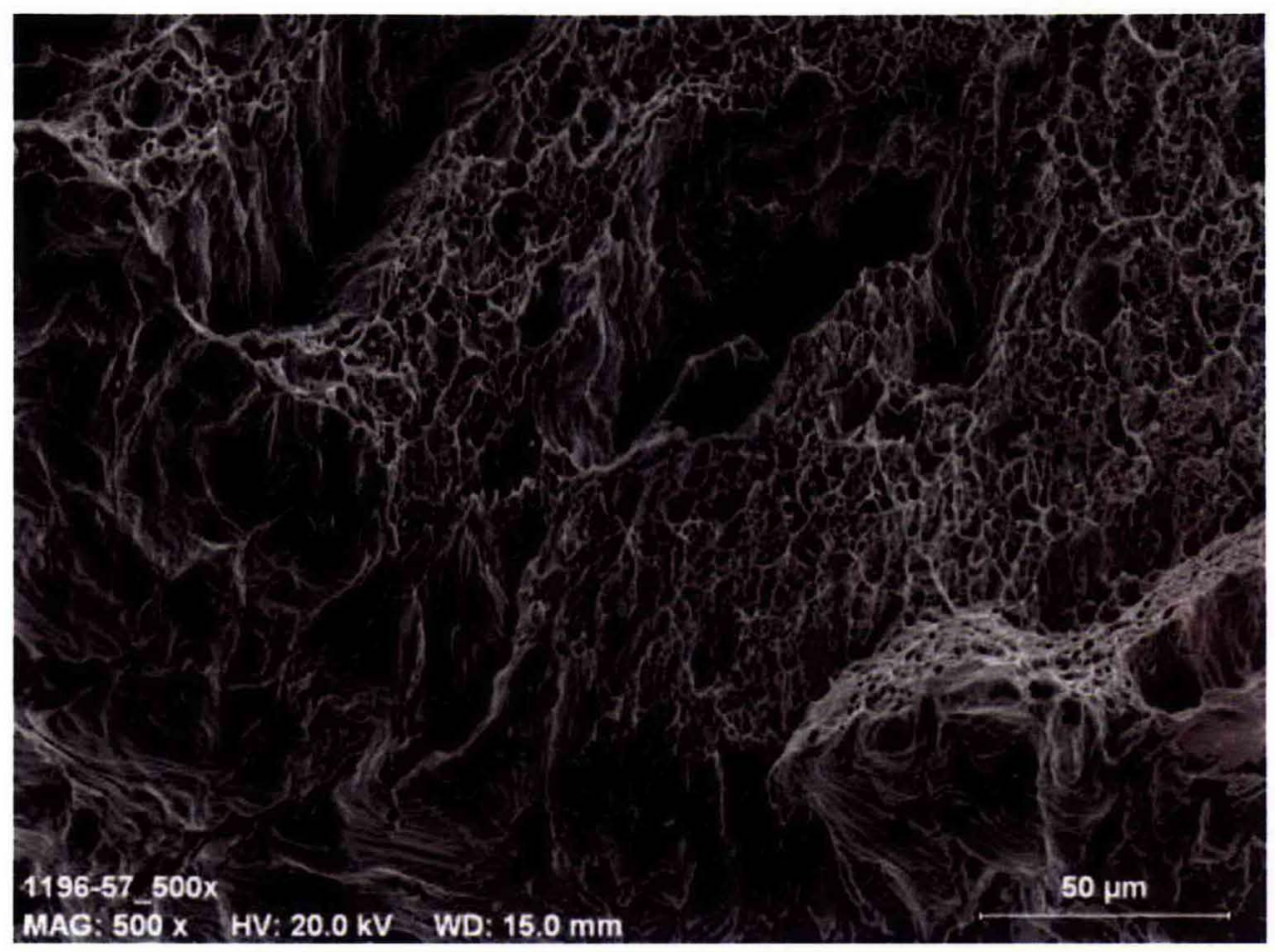




$$
\text { RPP-RPT-37505, Rev. } 0
$$

Figure C-34. The Stress-Strain Curve from SSRT 58 Performed in AW105-PIL Standard Simulant at $50^{\circ} \mathrm{C}, \mathrm{pH} 13+$ and at $0 \mathrm{mV}$ vs. SCE.

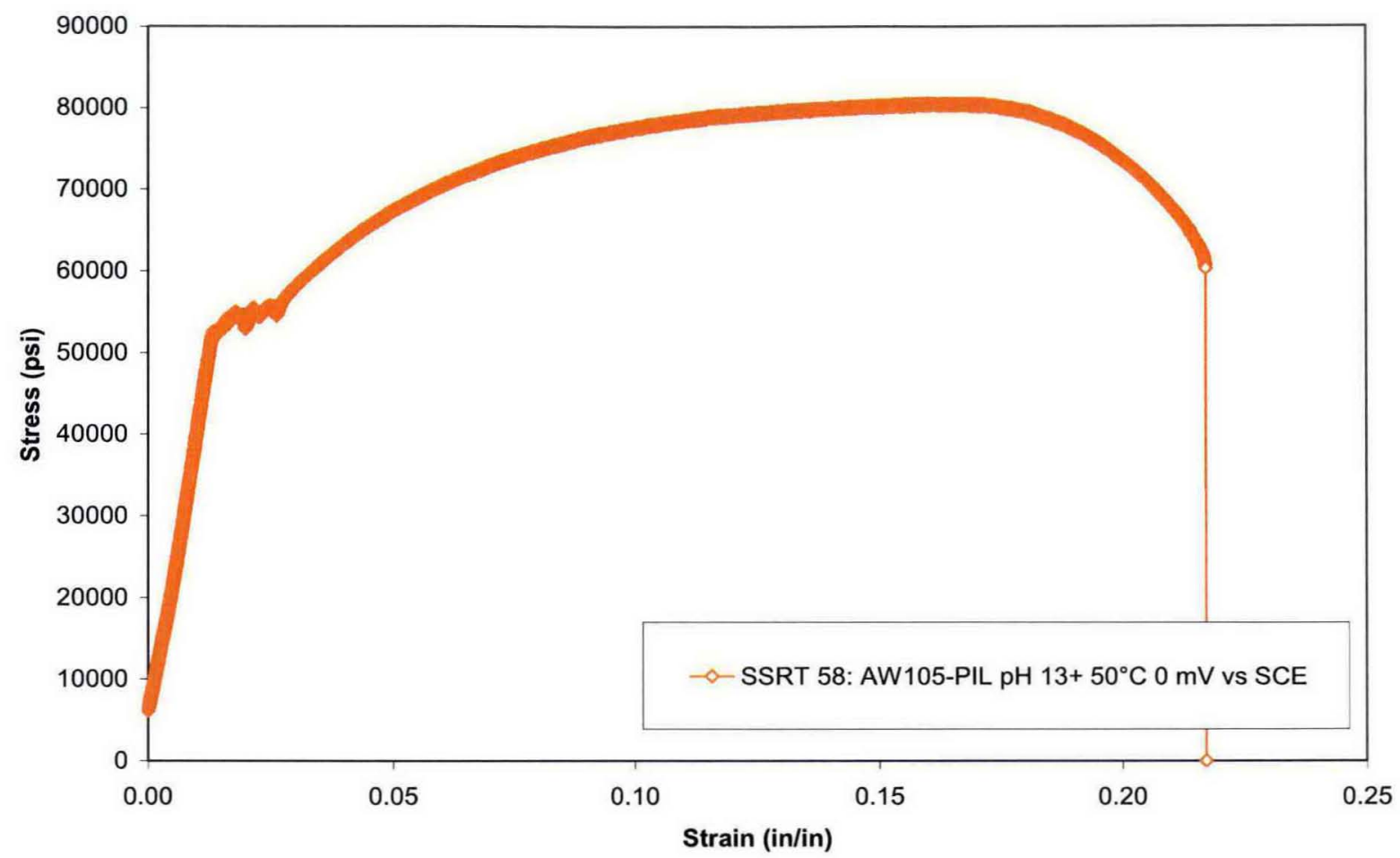

Figure C-35. A Stereo-Micrograph of the Sample from SSRT 58 Performed in AW105-PIL Standard Simulant at $50^{\circ} \mathrm{C}, \mathrm{pH} 13+$ and at $0 \mathrm{mV}$ vs. SCE.

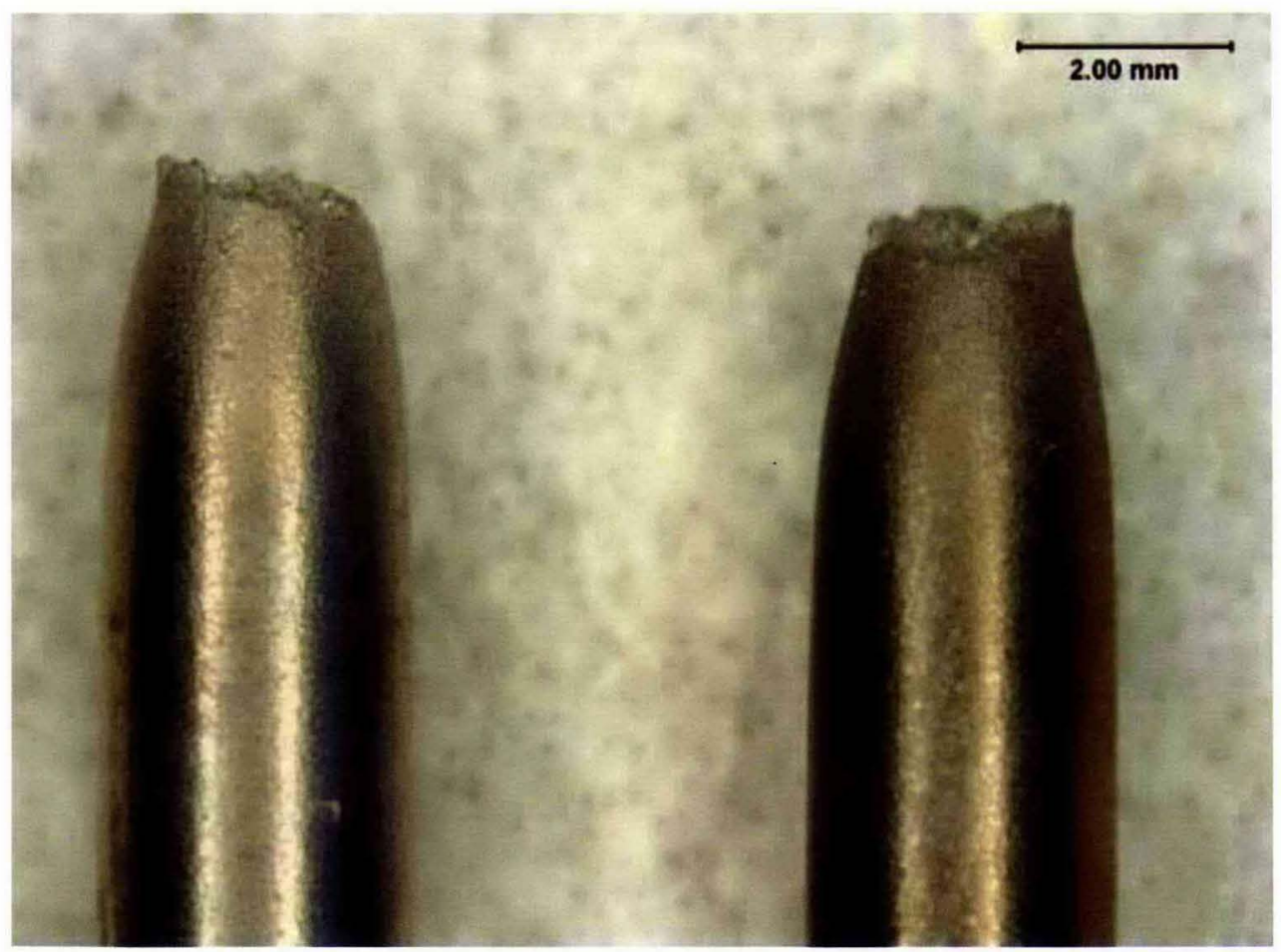




$$
\text { RPP-RPT-37505, Rev. } 0
$$

Figure C-36. An Electron-Micrograph of the Fracture Surface from SSRT 58 Performed in AW105-PIL Standard Simulant at $50^{\circ} \mathrm{C}, \mathrm{pH} 13+$ and at $0 \mathrm{mV}$ vs. SCE.

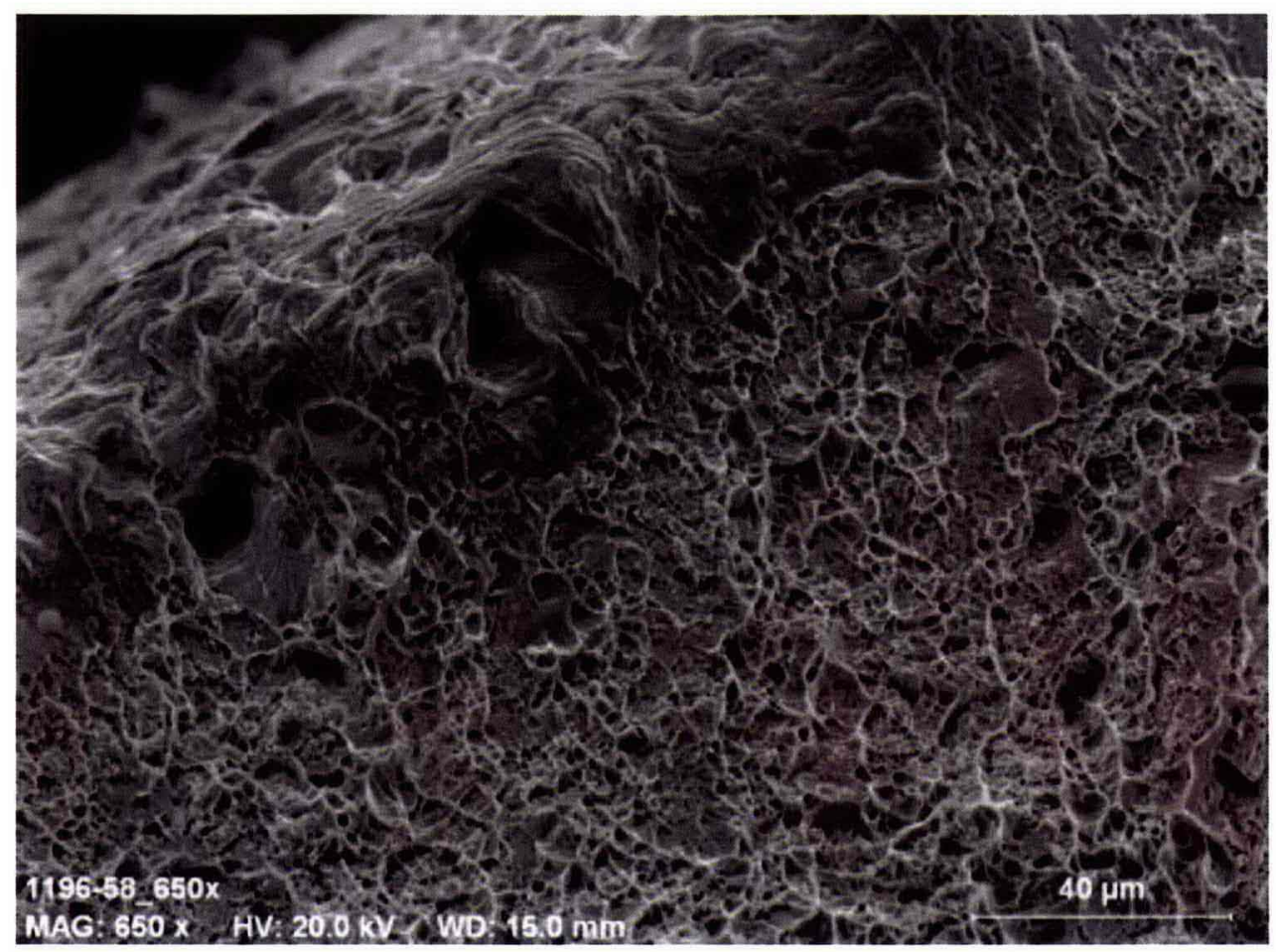


Figure C-37. The Stress-Strain Curve from SSRT 59 Performed in AP105-Evaporated Simulant at $50^{\circ} \mathrm{C}, \mathrm{pH} 13+$ and at $\mathrm{OCP}(-510 \mathrm{mV}$ vs. SCE $)$.

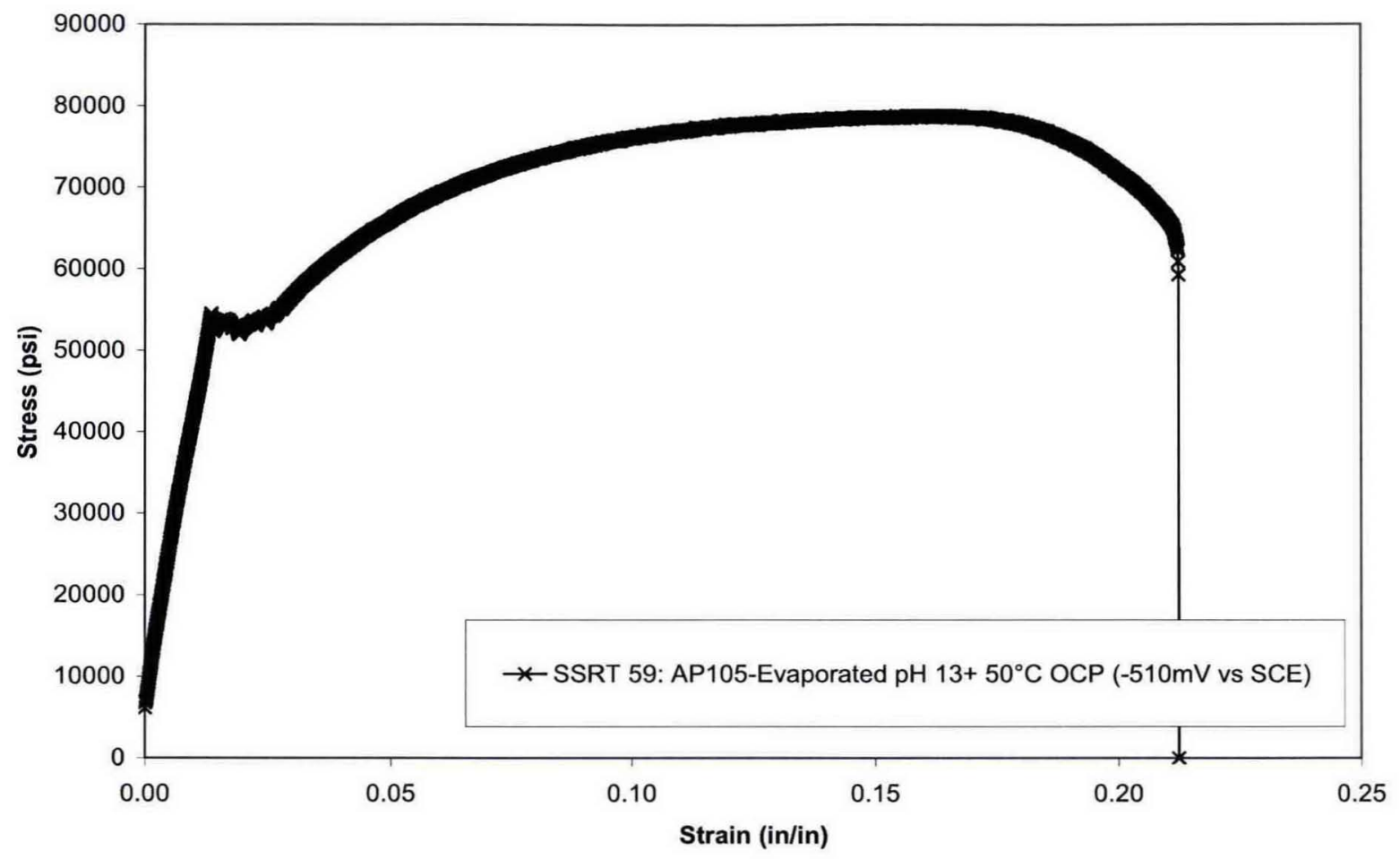

Figure C-38. A Stereo-Micrograph of the Sample from SSRT 59 Performed in AP105Evaporated Simulant at $50^{\circ} \mathrm{C}, \mathrm{pH} 13+$ and at $\mathrm{OCP}(-510 \mathrm{mV}$ vs. SCE).
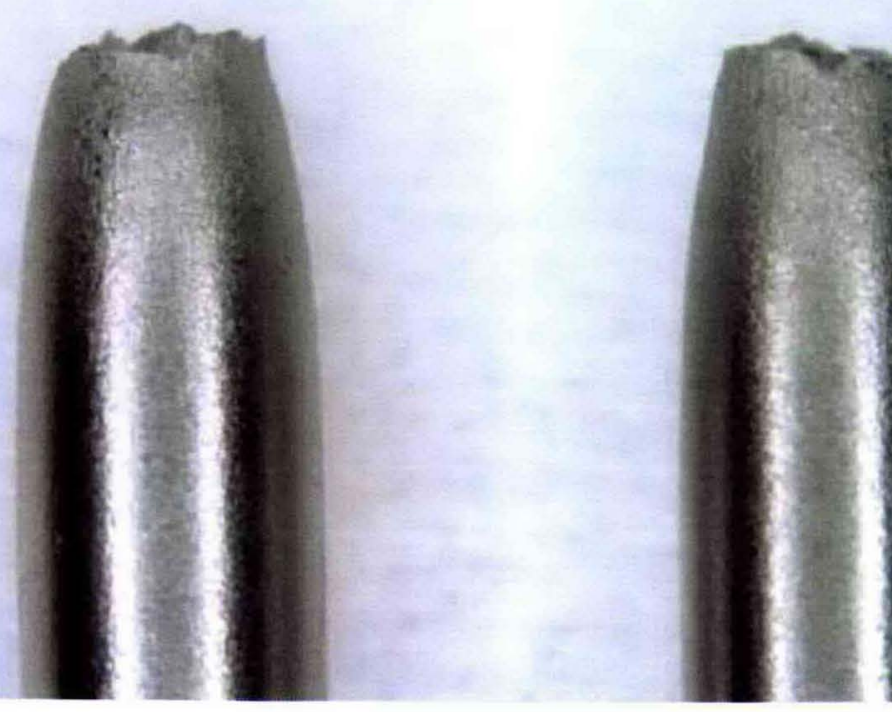
RPP-RPT-37505, Rev. 0

Figure C-39. An Electron-Micrograph of the Fracture Surface from SSRT 59 Performed in AP105-Evaporated Simulant at $50^{\circ} \mathrm{C}, \mathrm{pH} \mathrm{13+}$ and at $\mathrm{OCP}(-510 \mathrm{mV}$ vs. SCE).

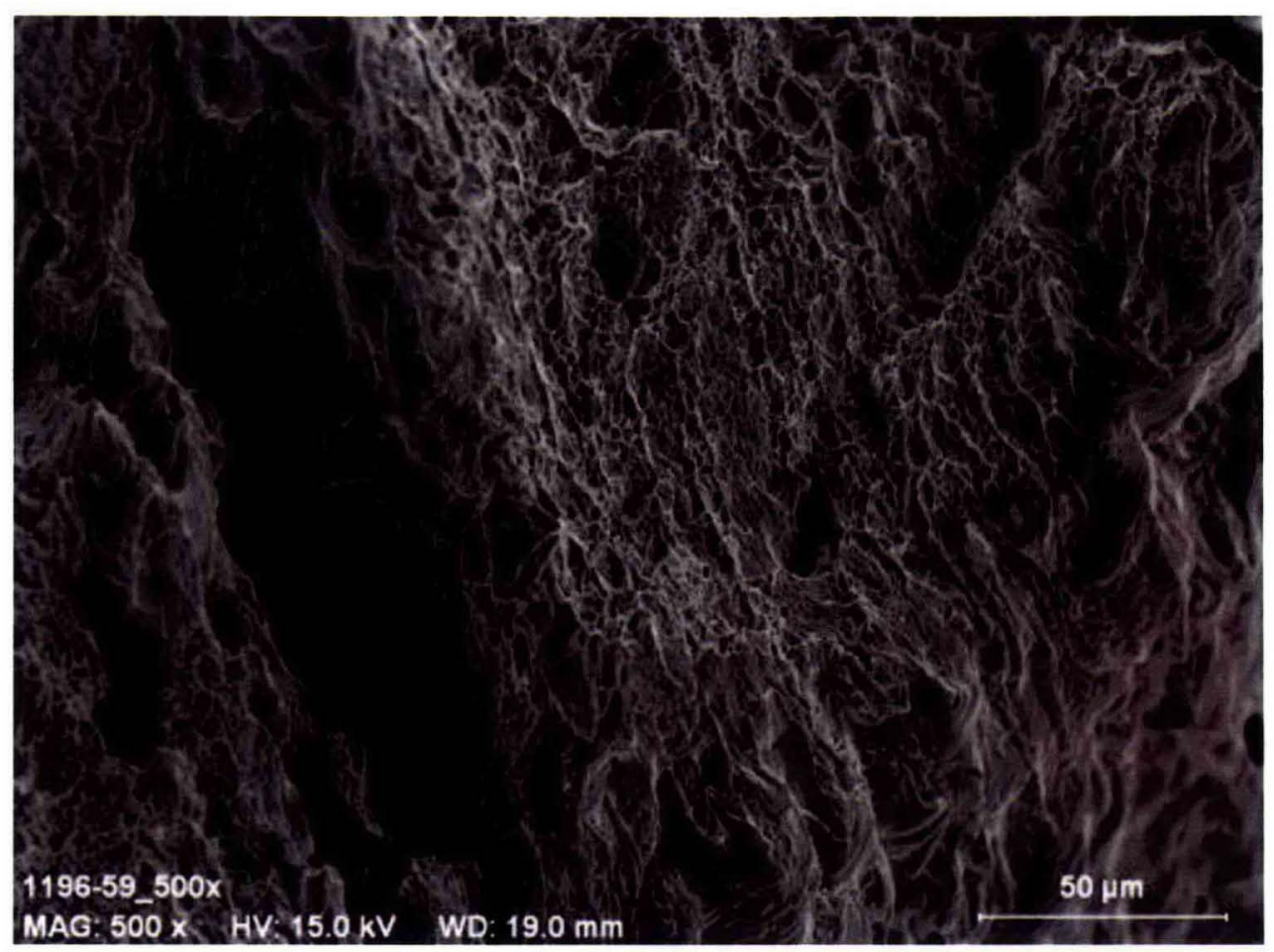


Figure C-40. The Stress-Strain Curve from SSRT 60 Performed in AP105-PSC Simulant at $50^{\circ} \mathrm{C}, \mathrm{pH} 13+$ and at $\mathrm{OCP}(-277 \mathrm{mV}$ vs. SCE). Tested to UTS and stopped.

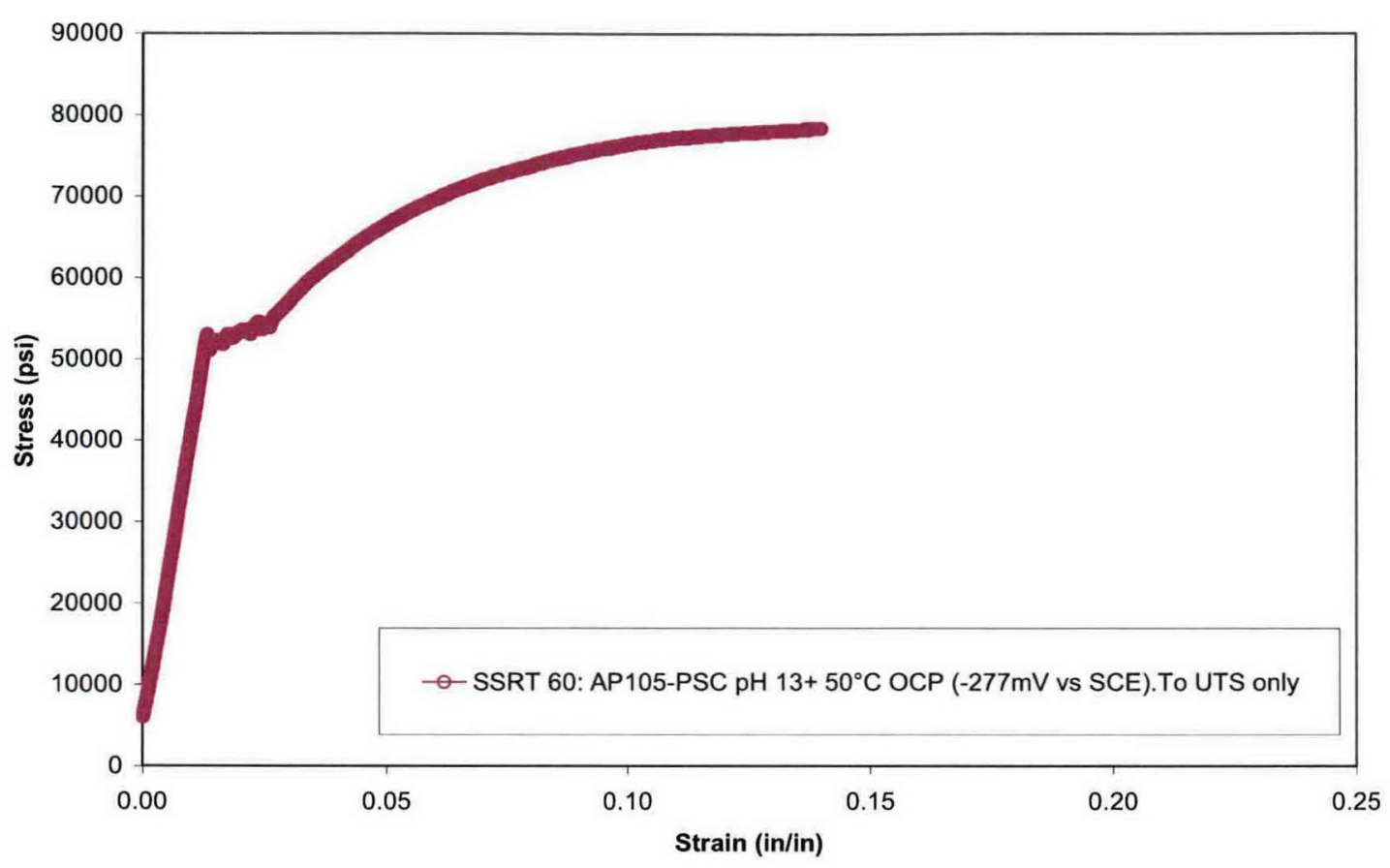

Figure C-41. A Stereo-Micrograph of the Sample from SSRT 60 Performed in AP105-PSC Simulant at $50^{\circ} \mathrm{C}, \mathrm{pH} 13+$ and at $\mathrm{OCP}(-277 \mathrm{mV}$ vs. SCE). Tested to UTS and stopped.

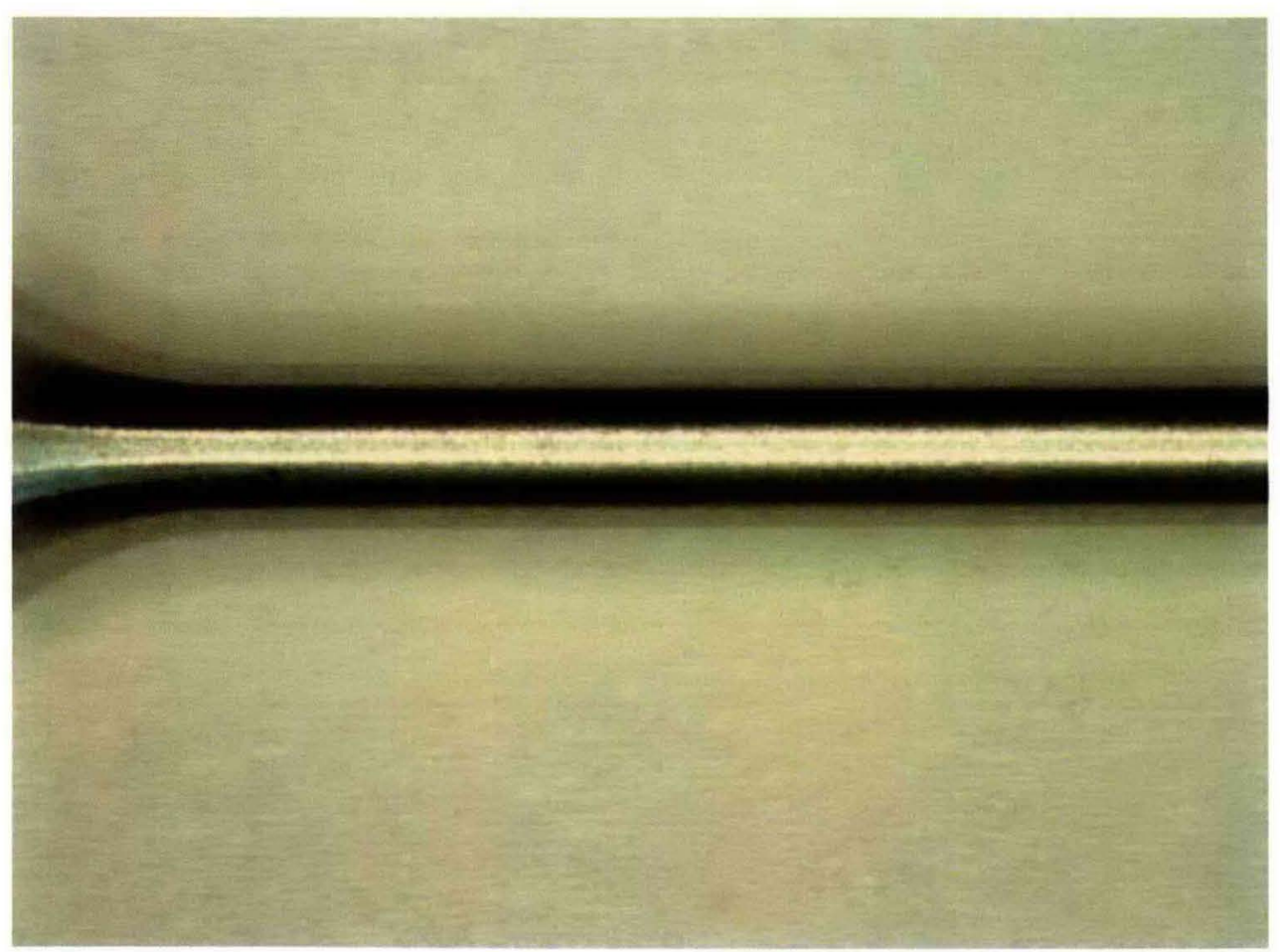


Figure C-42. A Stereo Micrograph of the Liquid / Vapor Interface Region from SSRT 60 Performed in AP105-PSC Simulant at $50^{\circ} \mathrm{C}$, $\mathrm{pH} 13+$ and at OCP (-277 $\mathrm{mV}$ vs. SCE). Tested to UTS and stopped.

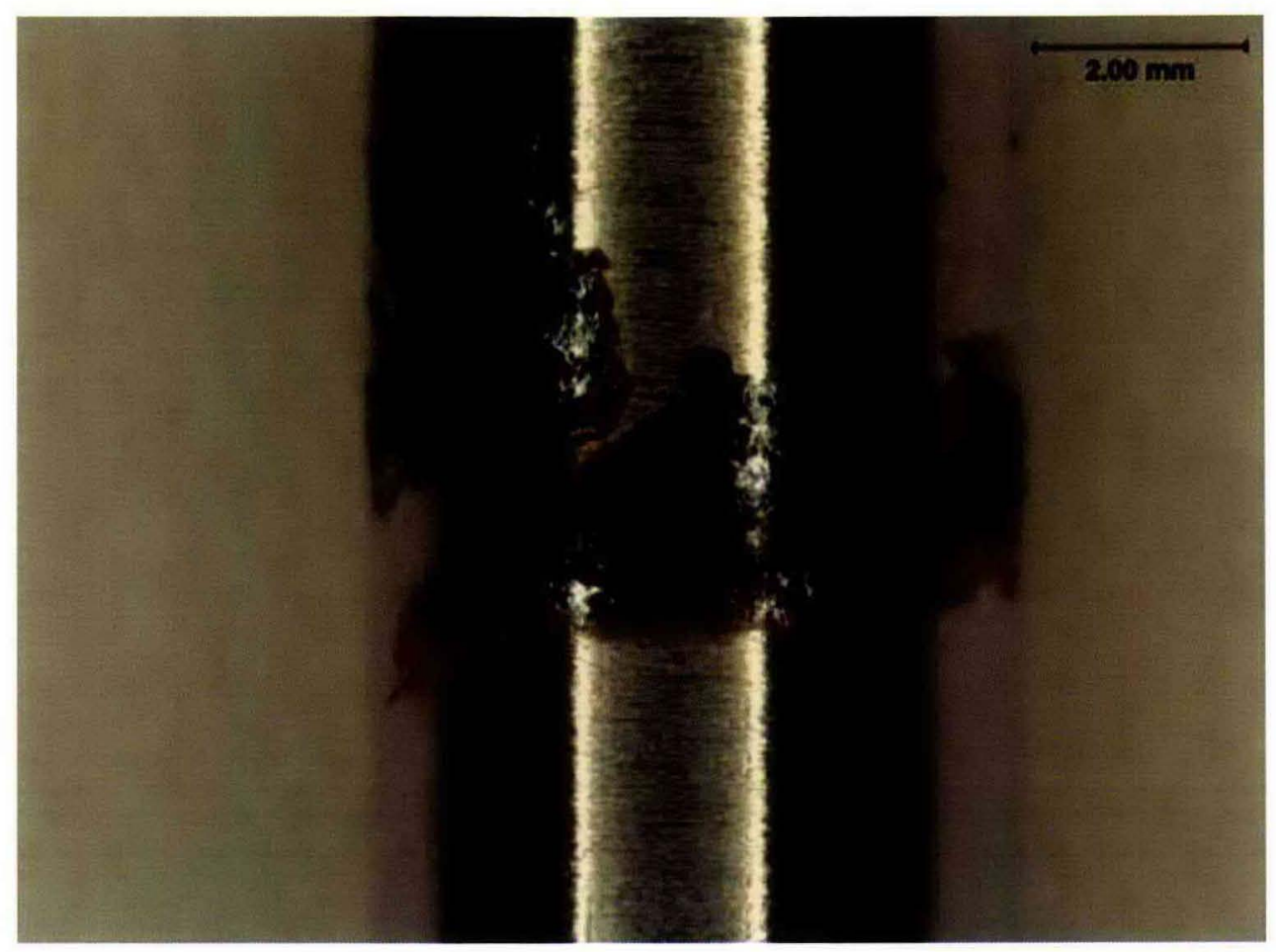


Figure C-43. The Stress-Strain Curve from SSRT 61 Performed in AZ102 Simulant at $77^{\circ} \mathrm{C}, \mathrm{pH} 12+$ and at $\mathrm{OCP}(-239 \mathrm{mV}$ vs. SCE).

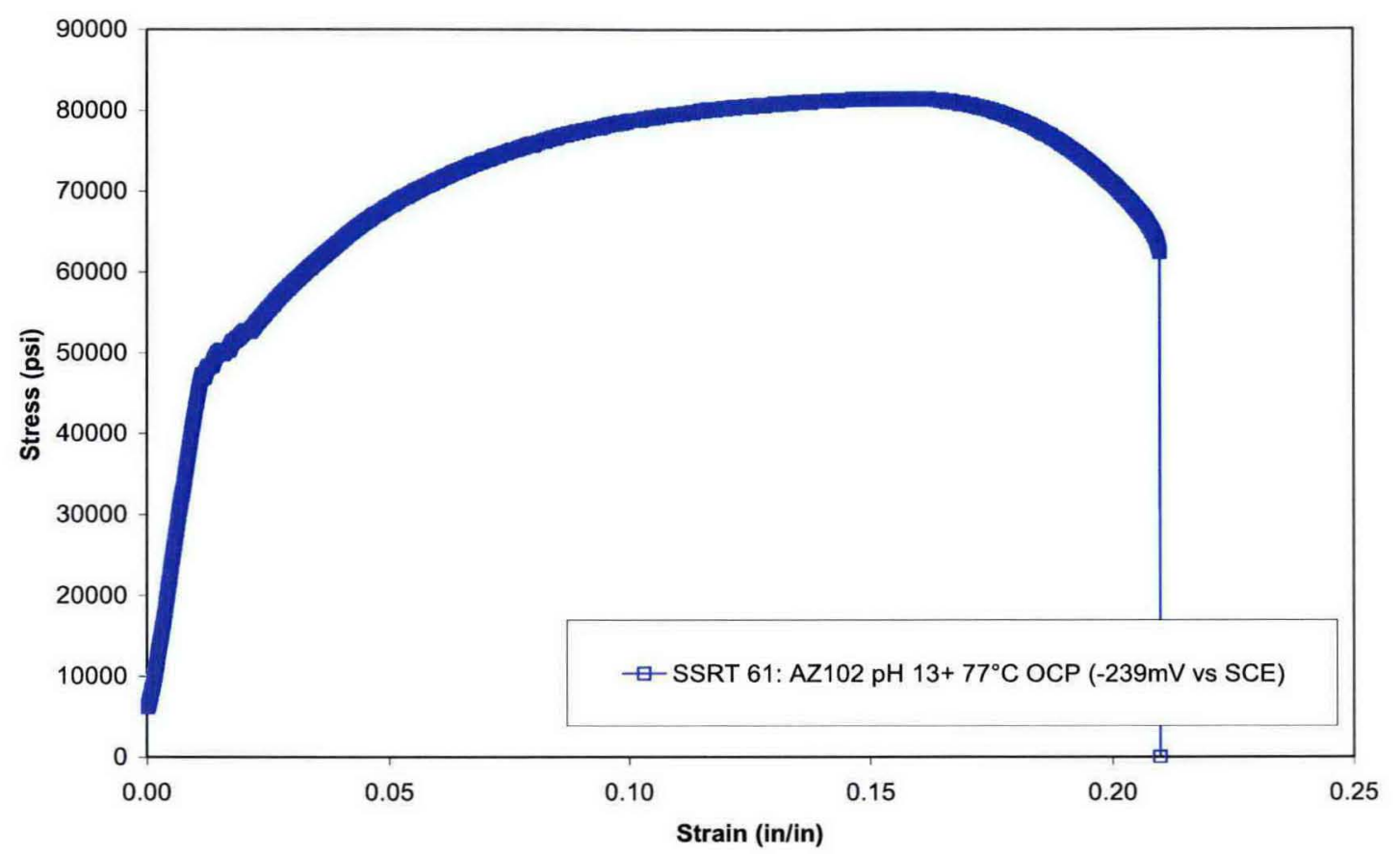

Figure C-44. A Stereo-Micrograph of the Sample from SSRT 61 Performed in AZ102 Simulant at $77^{\circ} \mathrm{C}, \mathrm{pH} 12+$ and at $\mathrm{OCP}(-239 \mathrm{mV}$ vs. SCE).

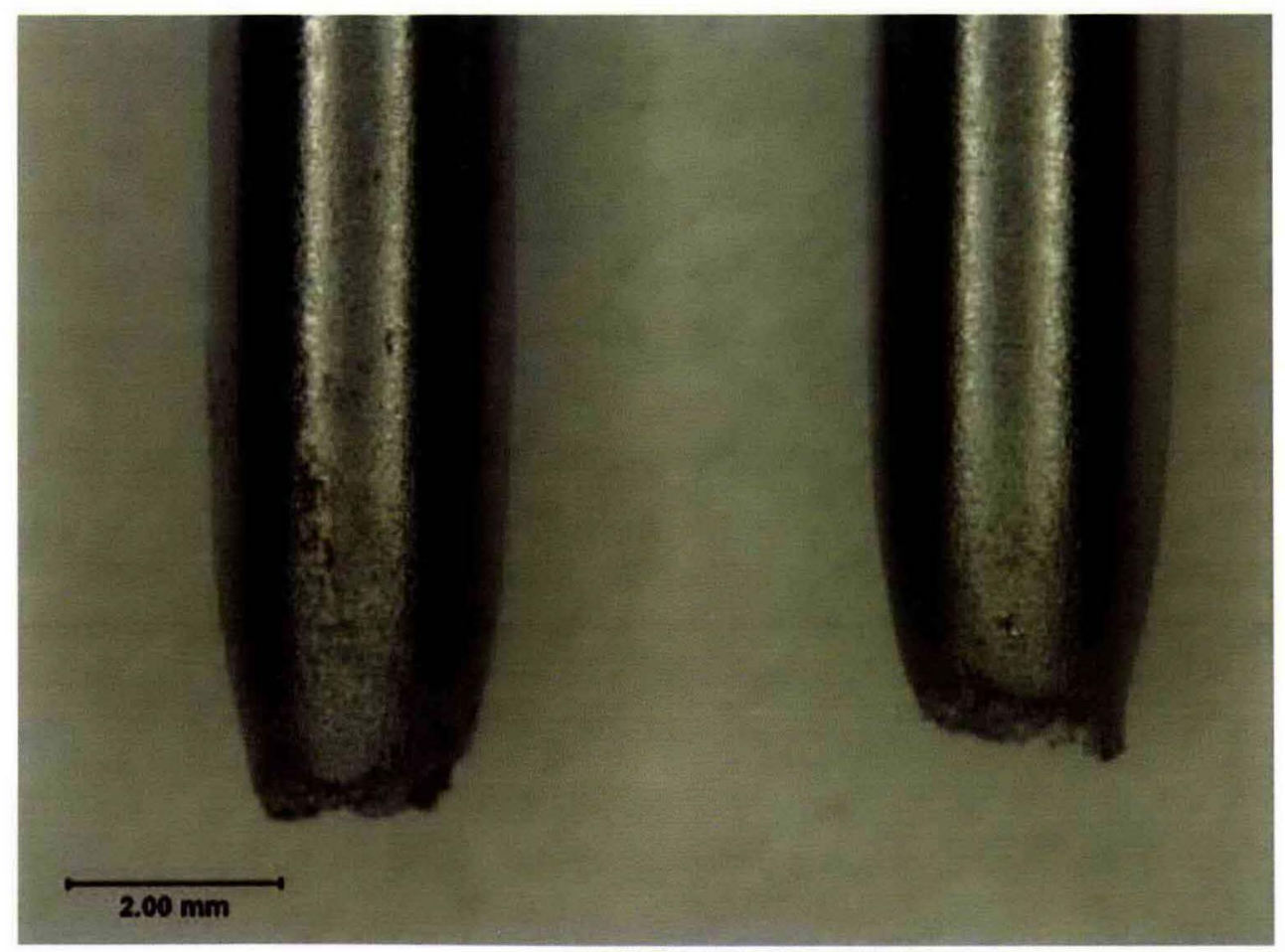


Figure C-45. An Electron-Micrograph of the Fracture Surface from SSRT 61 Performed in AZ102 Simulant at $77^{\circ} \mathrm{C}$, pH 12+ and at $\mathrm{OCP}(-239 \mathrm{mV}$ vs. SCE).

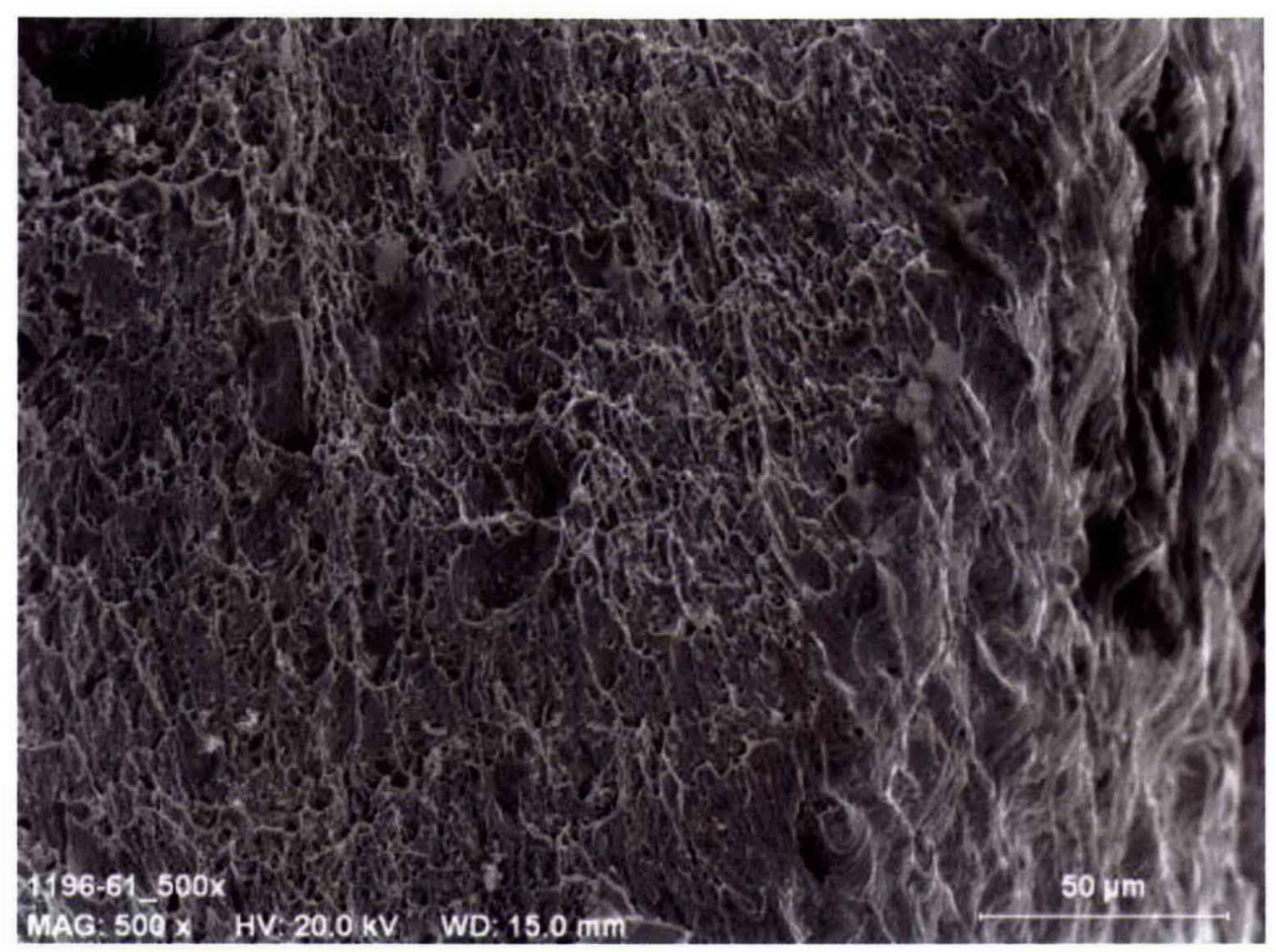


Figure C-46. The Stress-Strain Curve from SSRT 62 Performed in AP105-Evaporated Simulant with Nitrite/Nitrate ratio of 0.1 at $50^{\circ} \mathrm{C}, \mathrm{pH} 13+$ and at $\mathrm{OCP}(-333 \mathrm{mV}$ vs. SCE).

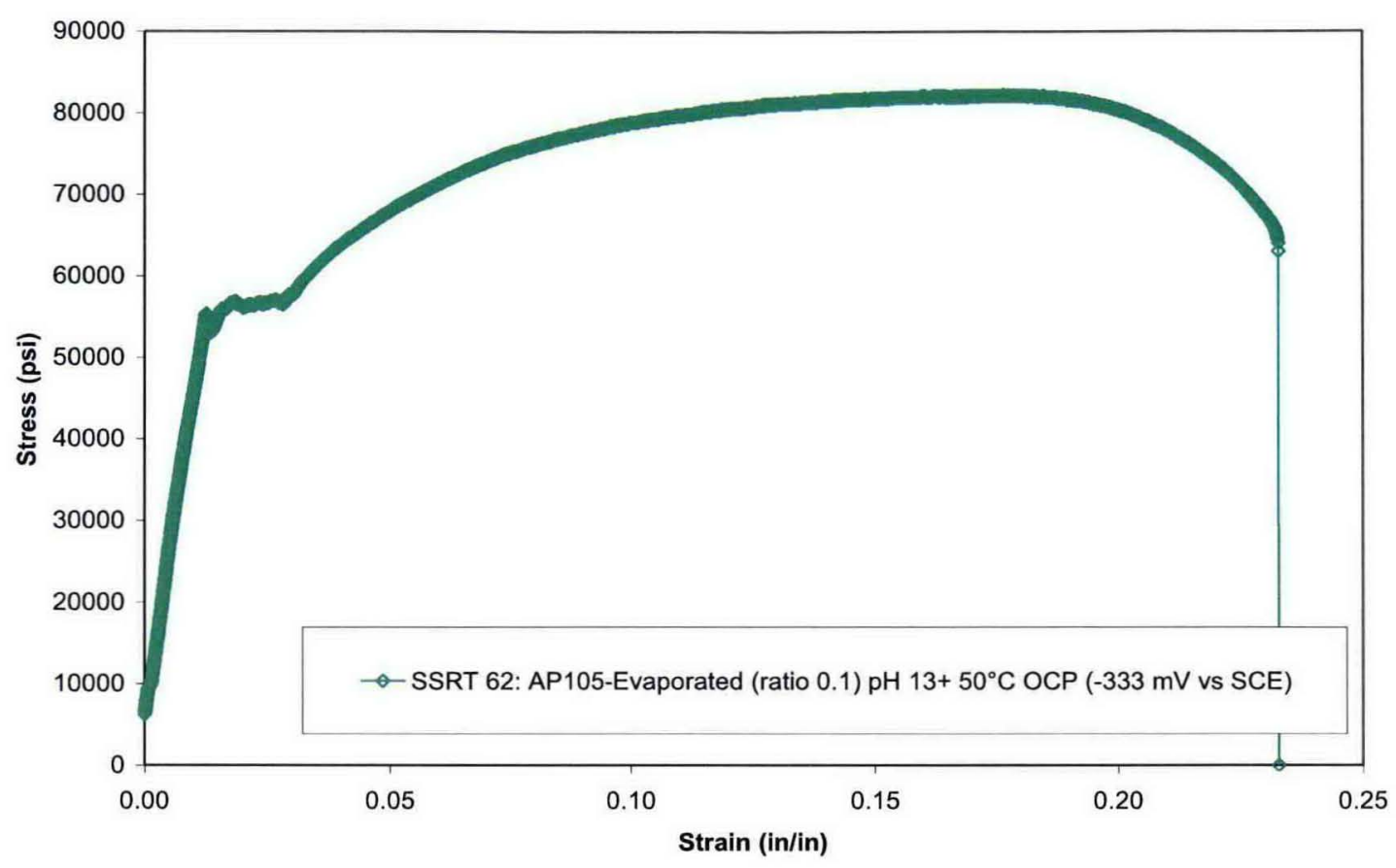

Figure C-47. A Stereo-Micrograph of the Sample from SSRT 62 Performed in AP105-Evaporated Simulant with Nitrite/Nitrate ratio of 0.1 at $50^{\circ} \mathrm{C}, \mathrm{pH} 13+$ and at $\mathrm{OCP}(-333 \mathrm{mV}$ vs. SCE).

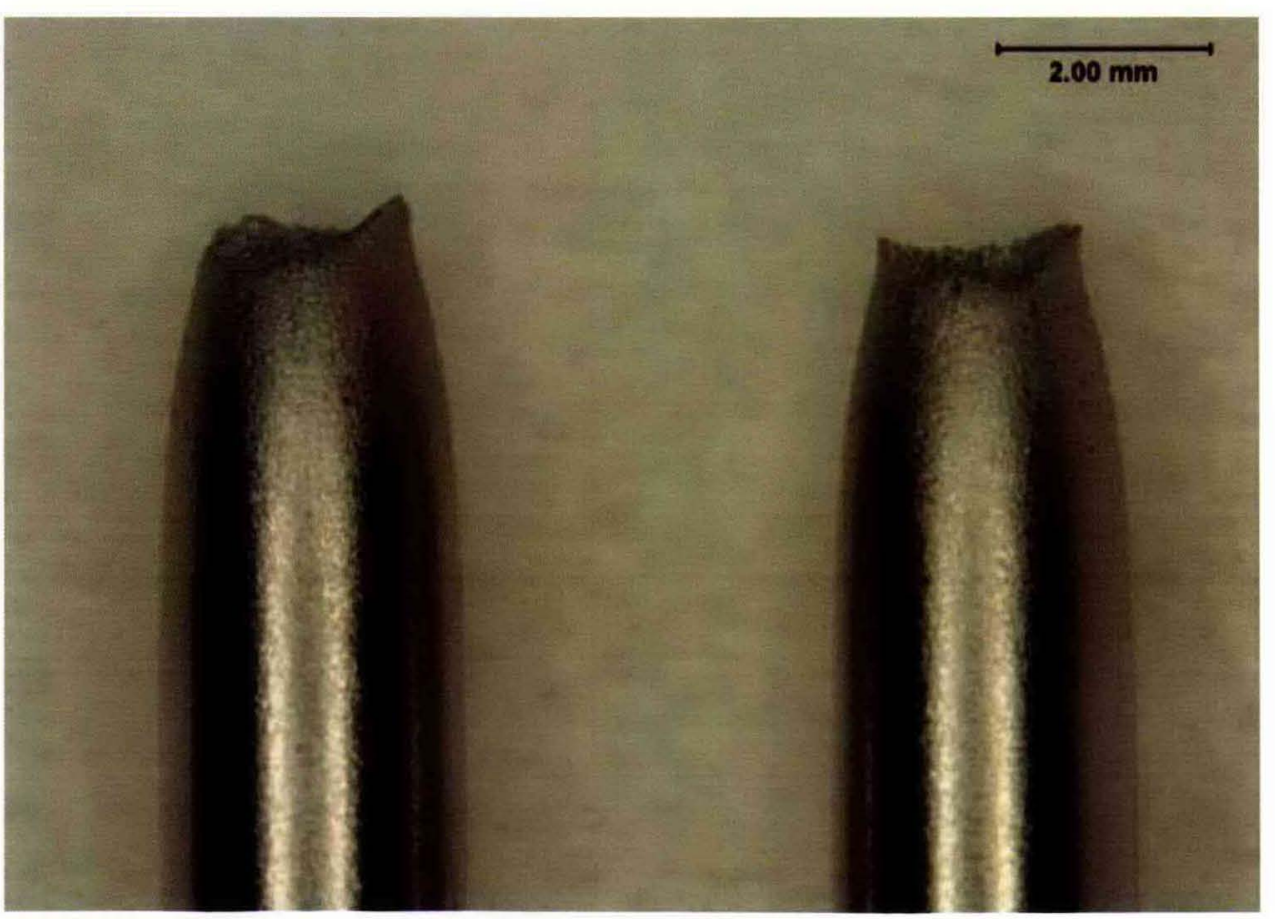


Figure C-48. An Electron-Micrograph of the Fracture Surface from SSRT 62 Performed in AP105-Evaporated Simulant with Nitrite/Nitrate ratio of 0.1 at $50^{\circ} \mathrm{C}$, $\mathrm{pH} 13+$ and at $\mathrm{OCP}(-333 \mathrm{mV}$ vs. SCE).

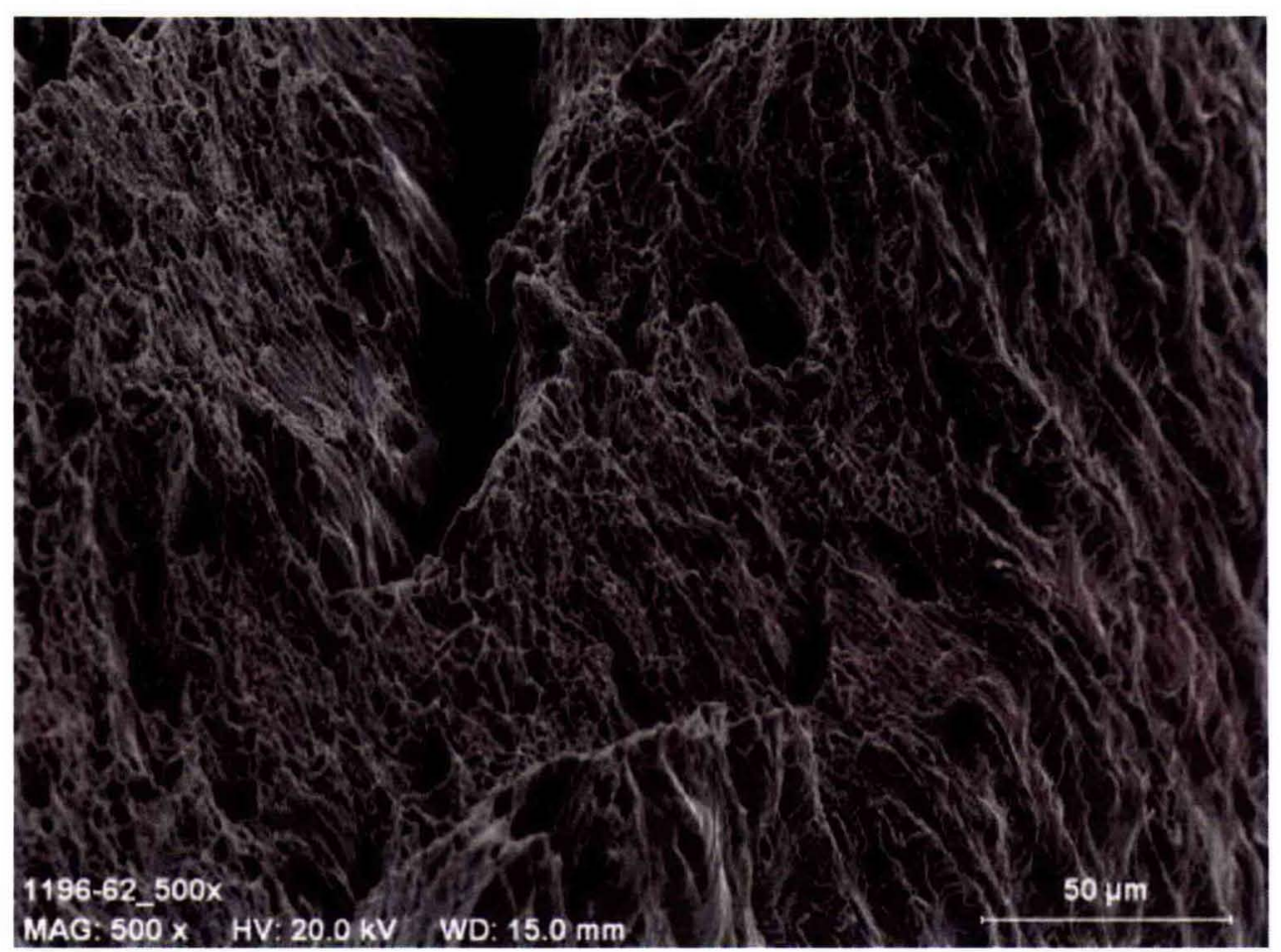


Figure C-49. The Stress-Strain Curve from SSRT 63 Performed in AP105-Mixed Simulant with Nitrite/Nitrate ratio of 0.1 at $50^{\circ} \mathrm{C}$, $\mathrm{pH} 13+$ and at $\mathrm{OCP}(-259 \mathrm{mV}$ vs. SCE).

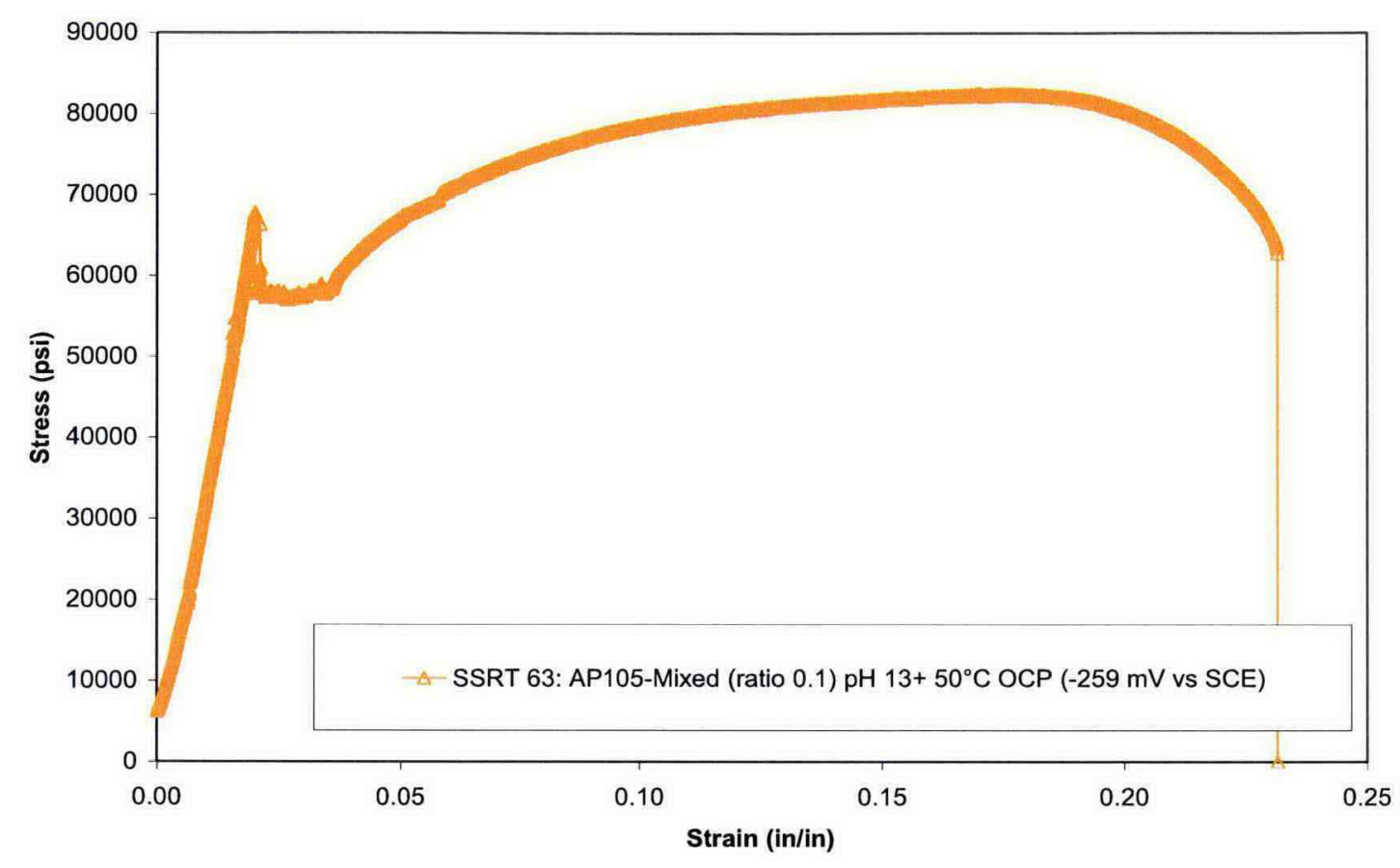

Figure C-50. A Stereo-Micrograph of the Sample from SSRT 63 Performed in AP105-Mixed Simulant with Nitrite/Nitrate ratio of 0.1 at $50^{\circ} \mathrm{C}$, pH $13+$ and at OCP (-259 $\mathrm{mV}$ vs. SCE).

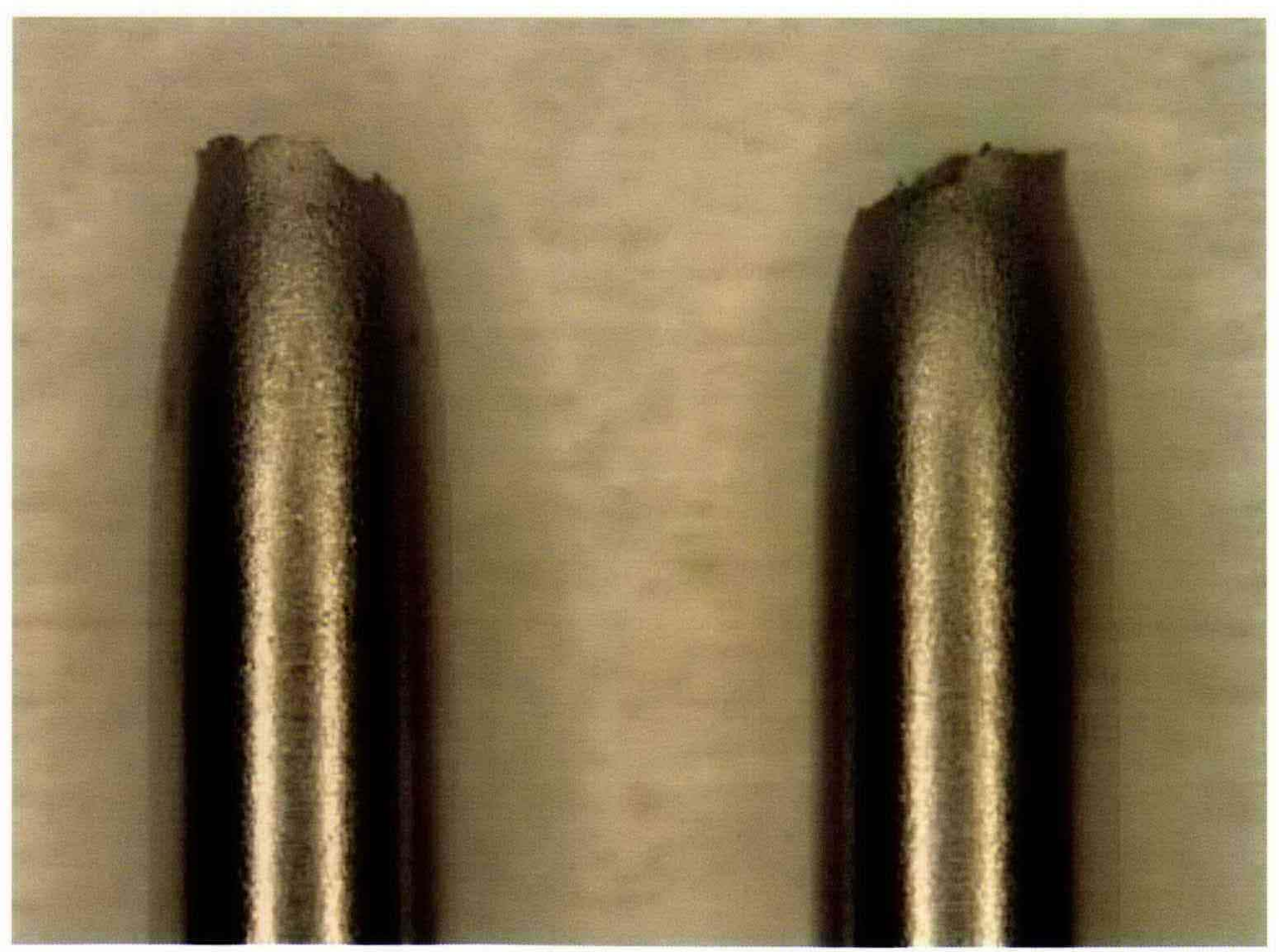


Figure C-51. An Electron-Micrograph of the Fracture Surface from SSRT 63 Performed in AP105-Mixed Simulant with Nitrite/Nitrate ratio of 0.1 at $50^{\circ} \mathrm{C}, \mathrm{pH} 13+$ and at $\mathrm{OCP}(-259 \mathrm{mV}$ vs. SCE).

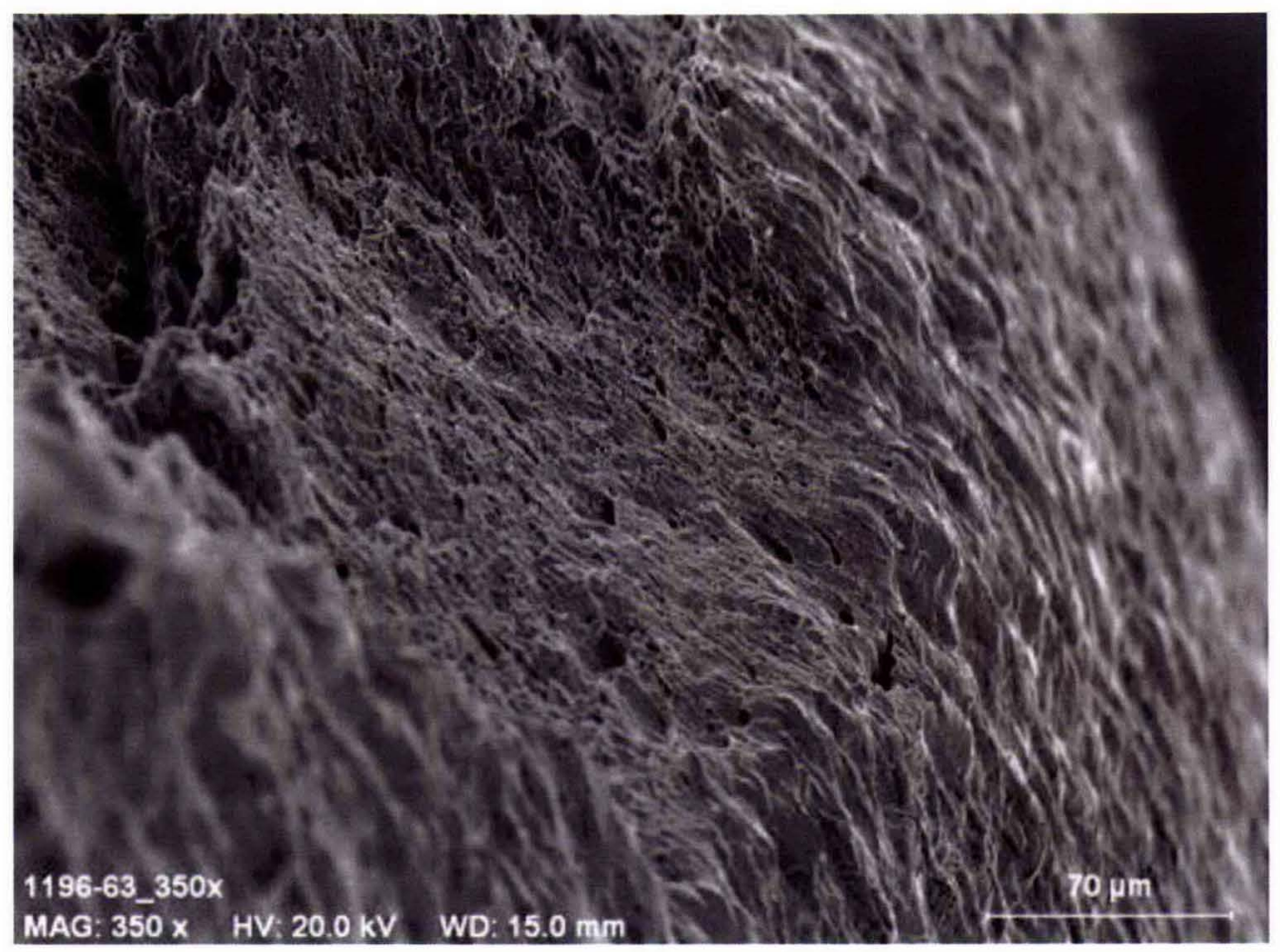


Figure C-52. The Stress-Strain Curve from SSRT 64 Performed in AP105-Mixed Simulant at $50^{\circ} \mathrm{C}$, pH 13+ and at OCP (-312 mV vs. SCE).

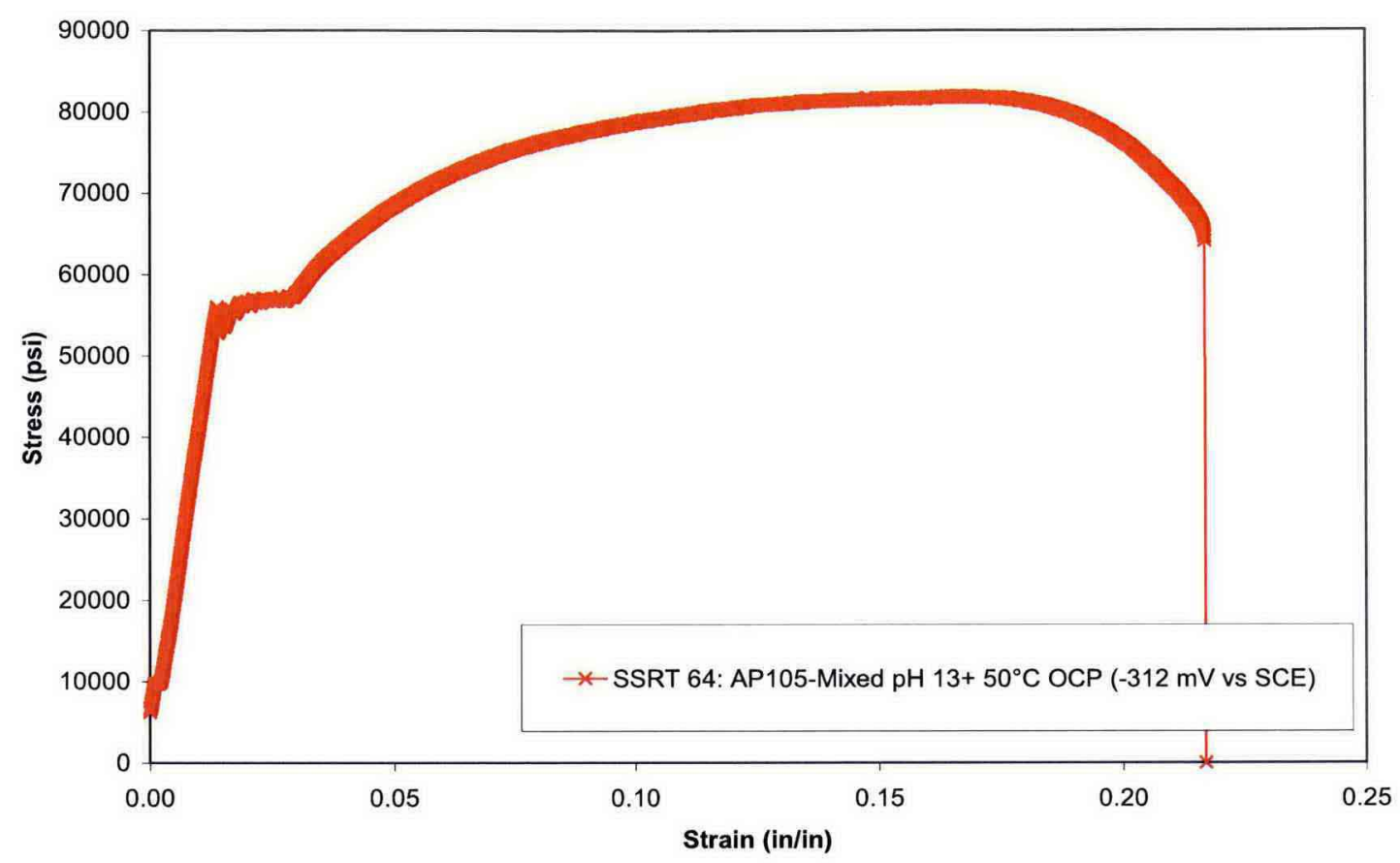

Figure C-53. A Stereo-Micrograph of the Sample from SSRT 64 Performed in AP105-Mixed Simulant at $50^{\circ} \mathrm{C}$, pH 13+ and at OCP (-312 mV vs. SCE).

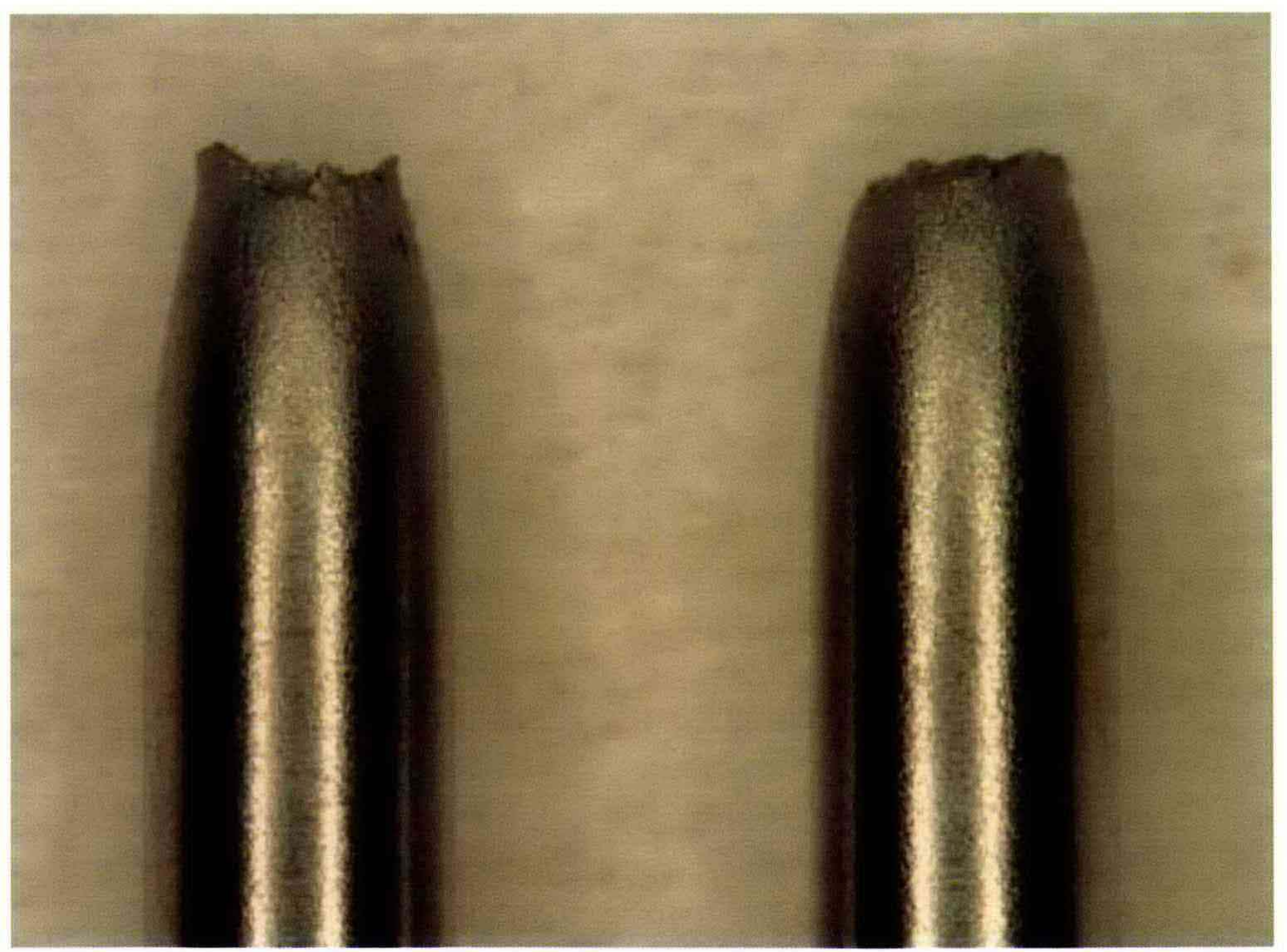


Figure C-54. An Electron-Micrograph of the Fracture Surface from SSRT 64 Performed in AP105-Mixed Simulant at $50^{\circ} \mathrm{C}, \mathrm{pH} 13+$ and at $\mathrm{OCP}(-312 \mathrm{mV}$ vs. SCE).

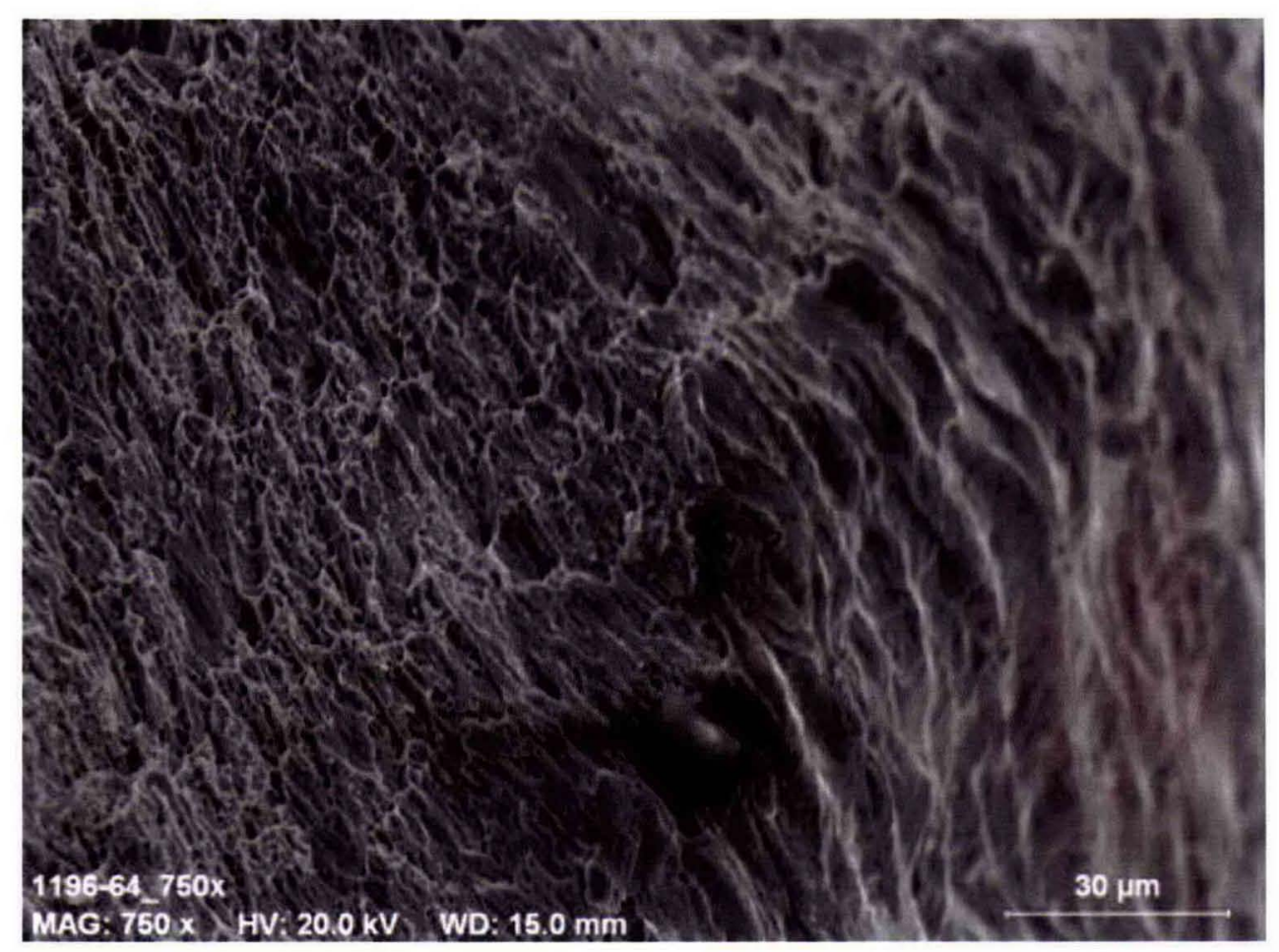


Figure C-55. The Stress-Strain Curve from SSRT 65 Performed in AP105-PSC Simulant at $50^{\circ} \mathrm{C}$, pH $13+$ and at $-250 \mathrm{mV}$ vs. SCE. Test stopped at UTS.

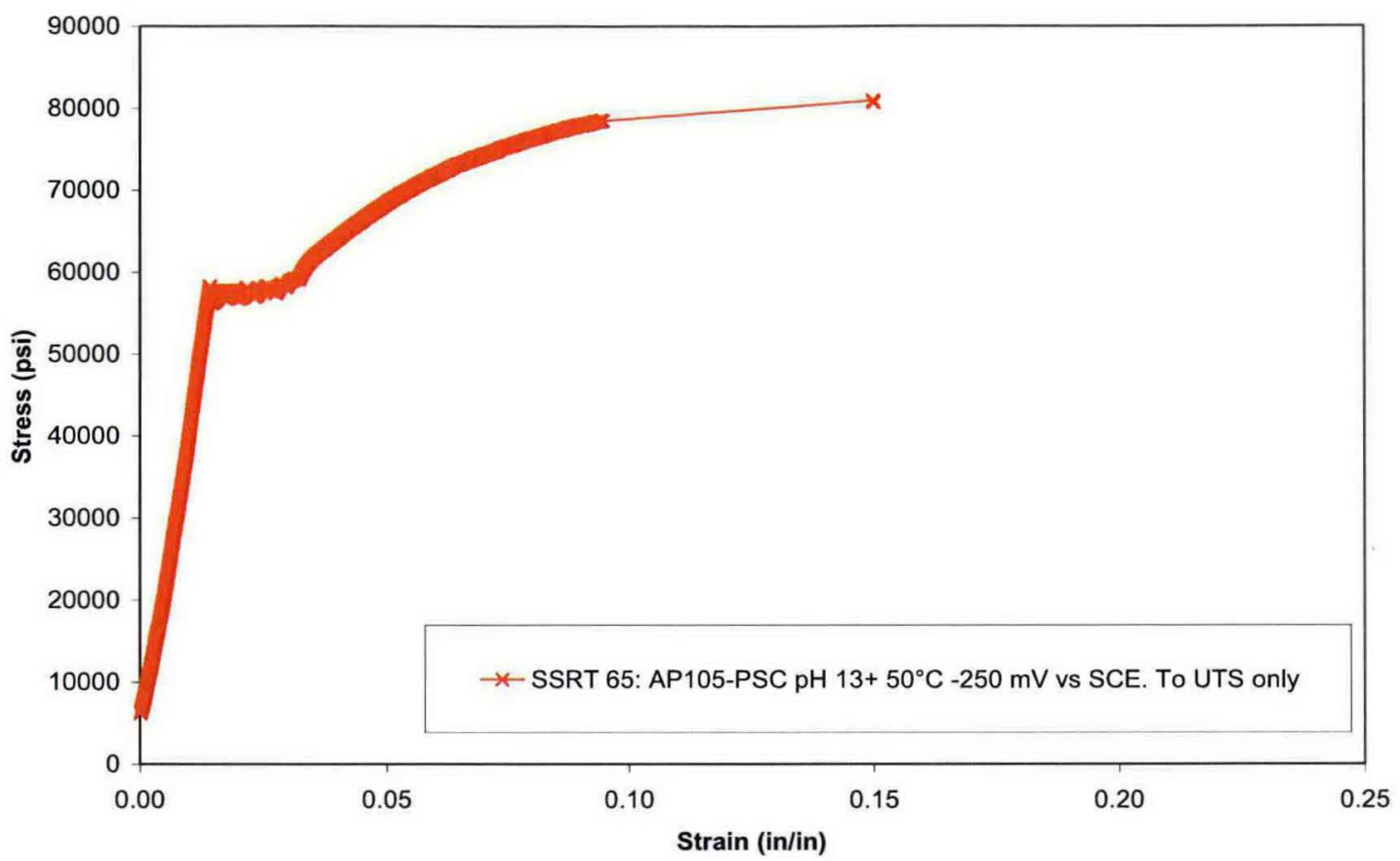

Figure C-56. A Stereo-Micrograph of the Sample from SSRT 65 Performed in AP105-PSC Simulant at $50^{\circ} \mathrm{C}, \mathrm{pH} 13+$ and at $-250 \mathrm{mV}$ vs. SCE. Test stopped at UTS.

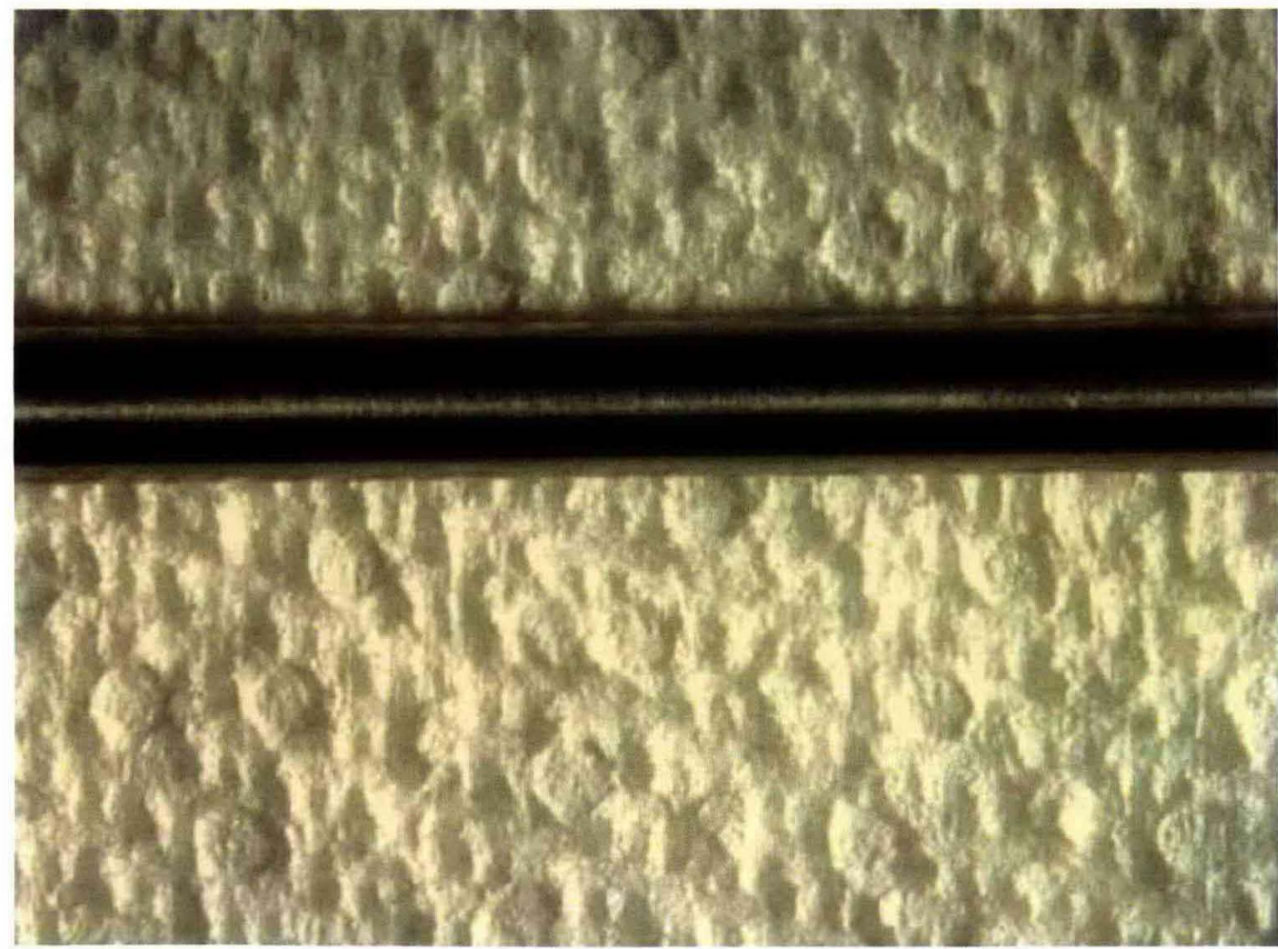


Figure C-57. The Stress-Strain Curve from SSRT 66 Performed in AW105-PSC Simulant at $50^{\circ} \mathrm{C}, \mathrm{pH} 13+$ and at $\mathrm{OCP}(-235 \mathrm{mV}$ vs. SCE).

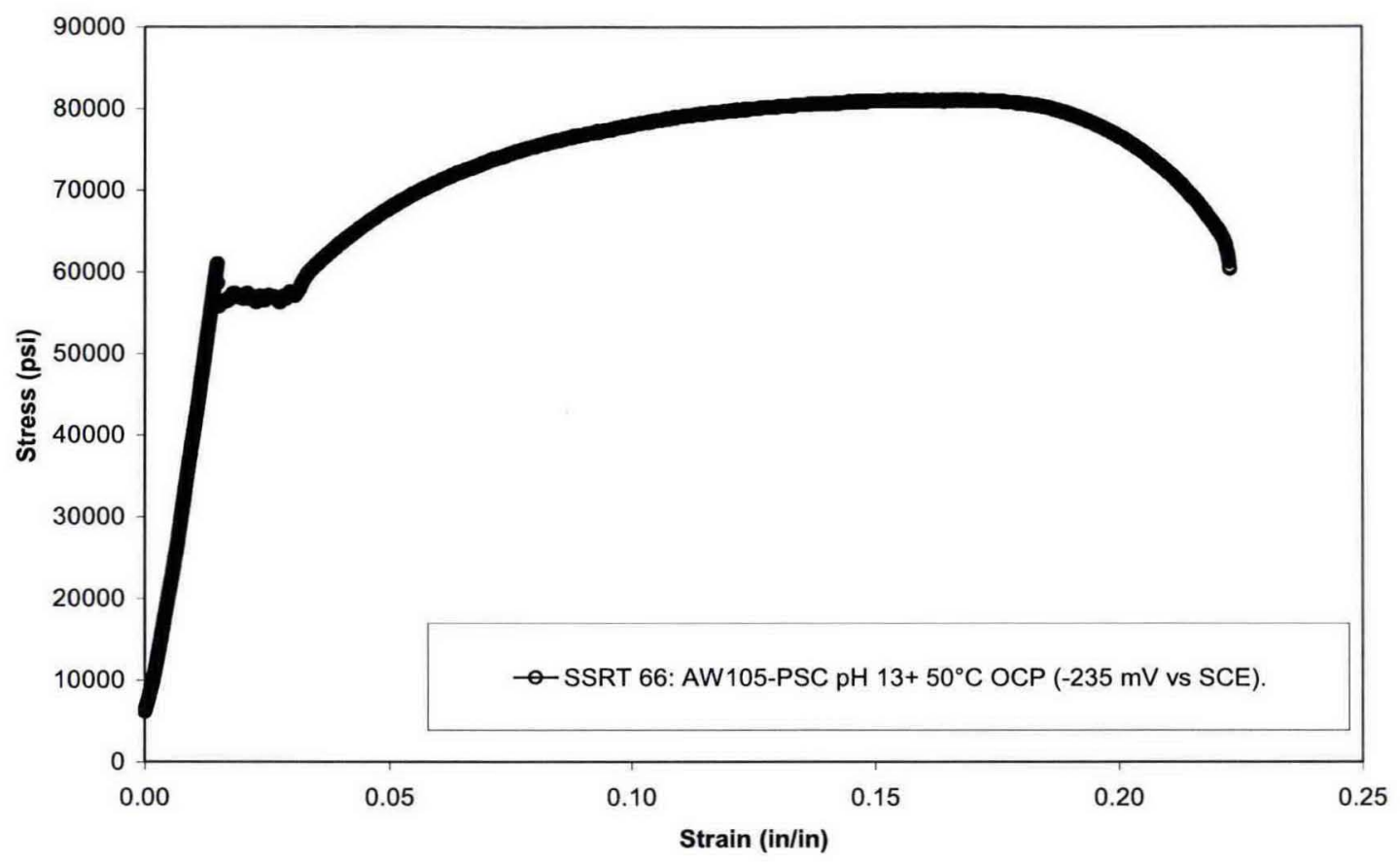

Figure C-58. A Stereo-Micrograph of the Sample from SSRT 66 Performed in AW105-PSC Simulant at $50^{\circ} \mathrm{C}$, pH 13+ and at OCP (-235 mV vs. SCE).

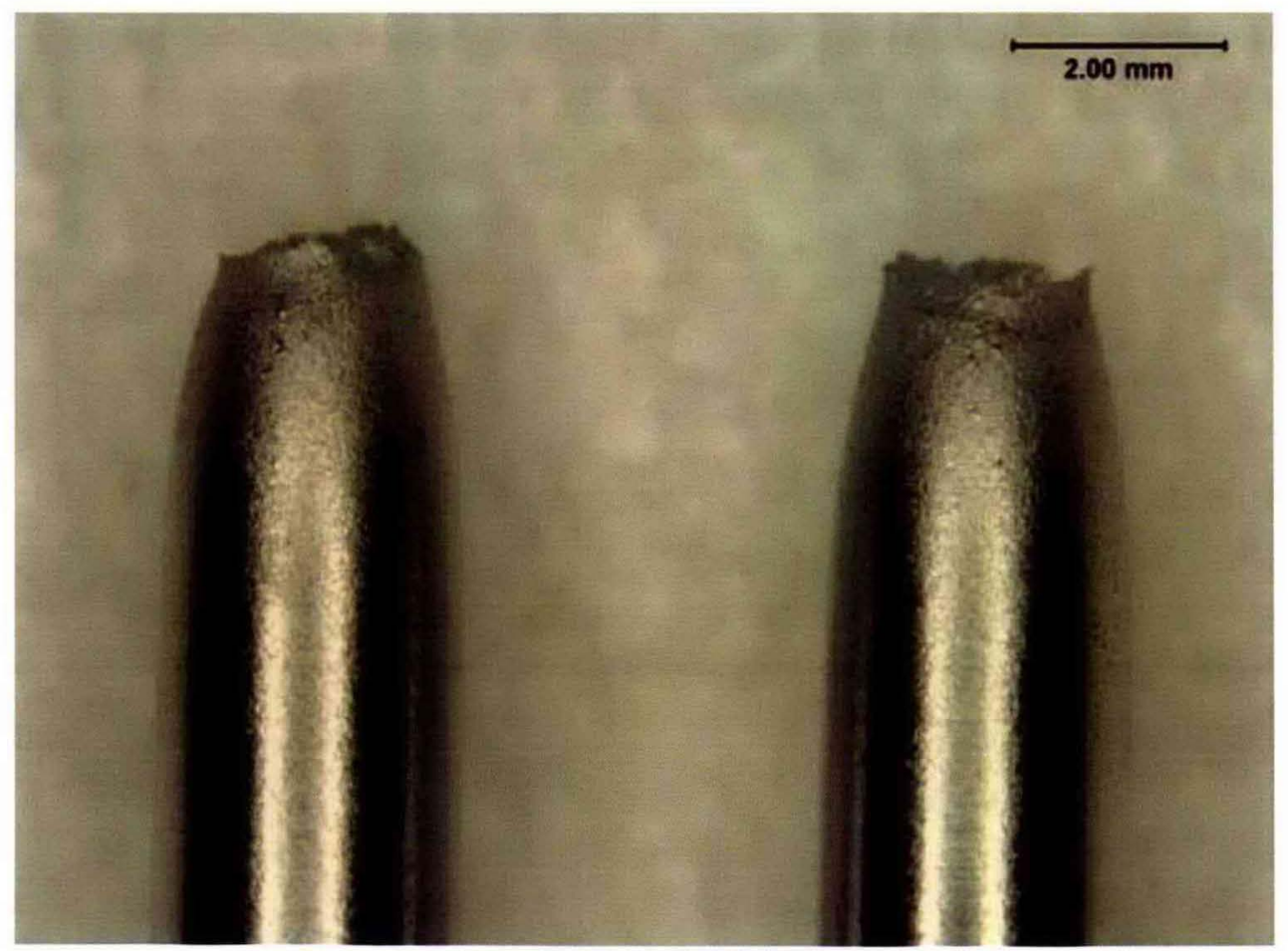


Figure C-59. An Electron-Micrograph of the Fracture Surface from SSRT 66 Performed in AW105-PSC Simulant at $50^{\circ} \mathrm{C}$, pH 13+ and at OCP (-235 mV vs. SCE).

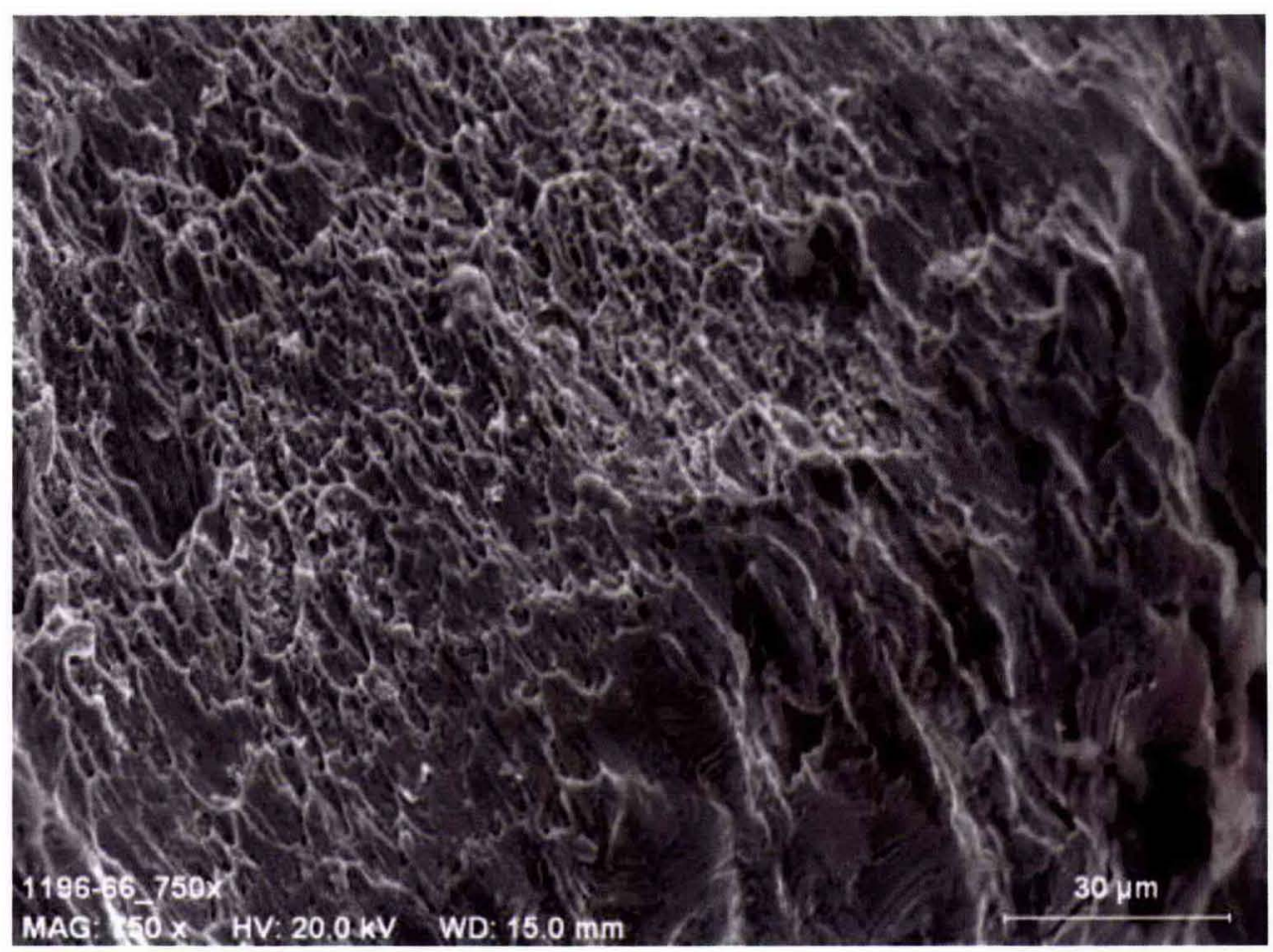


Figure C-60. The Stress-Strain Curve from SSRT 67 Performed in SY101 Simulant at $50^{\circ} \mathrm{C}, \mathrm{pH} 13+$ and at $\mathrm{OCP}(-206 \mathrm{mV}$ vs. SCE).

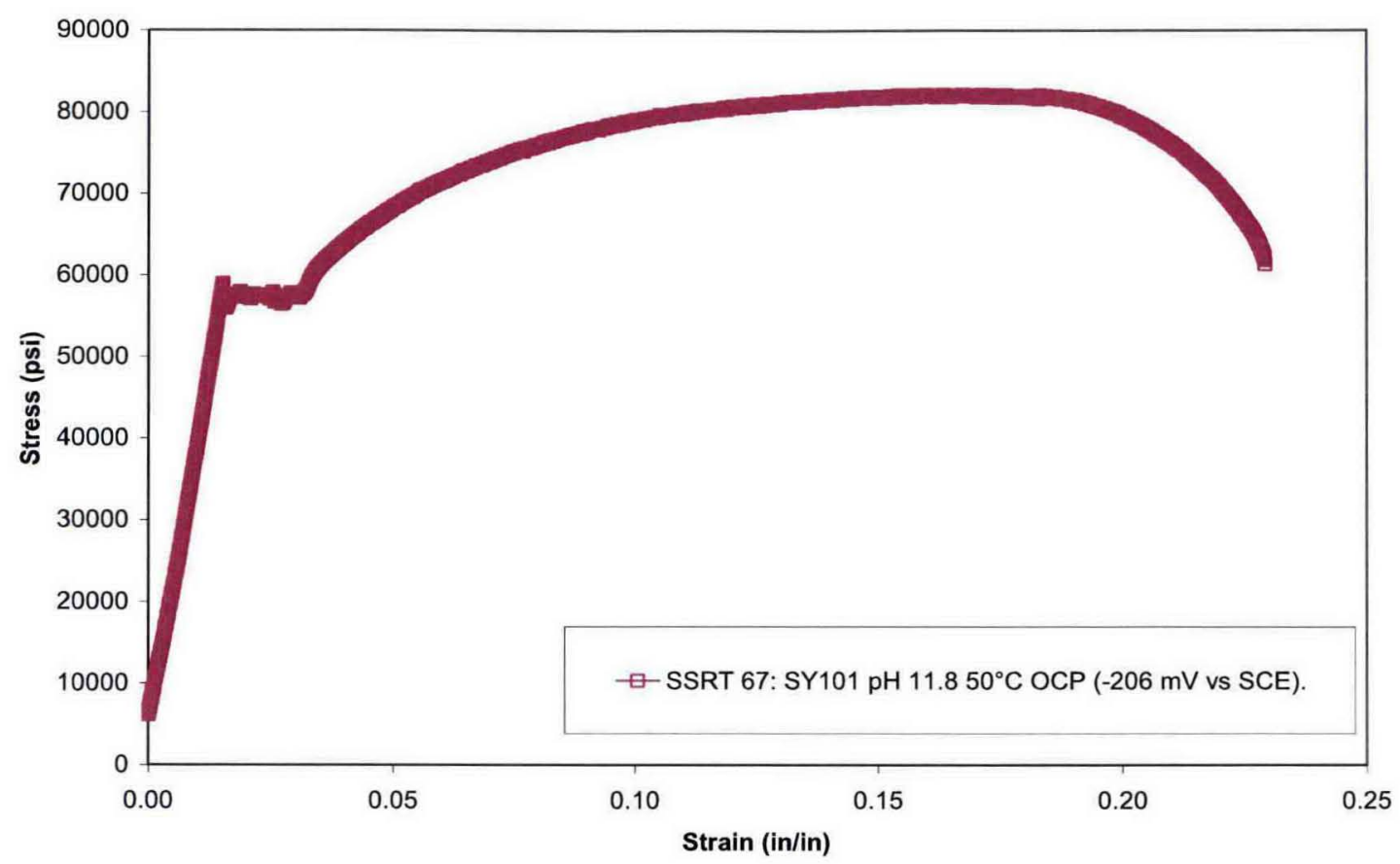

Figure C-61. A Stereo-Micrograph of the Sample from SSRT 67 Performed in SY101 Simulant at $50^{\circ} \mathrm{C}, \mathrm{pH} 13+$ and at OCP (-206 mV vs. SCE).

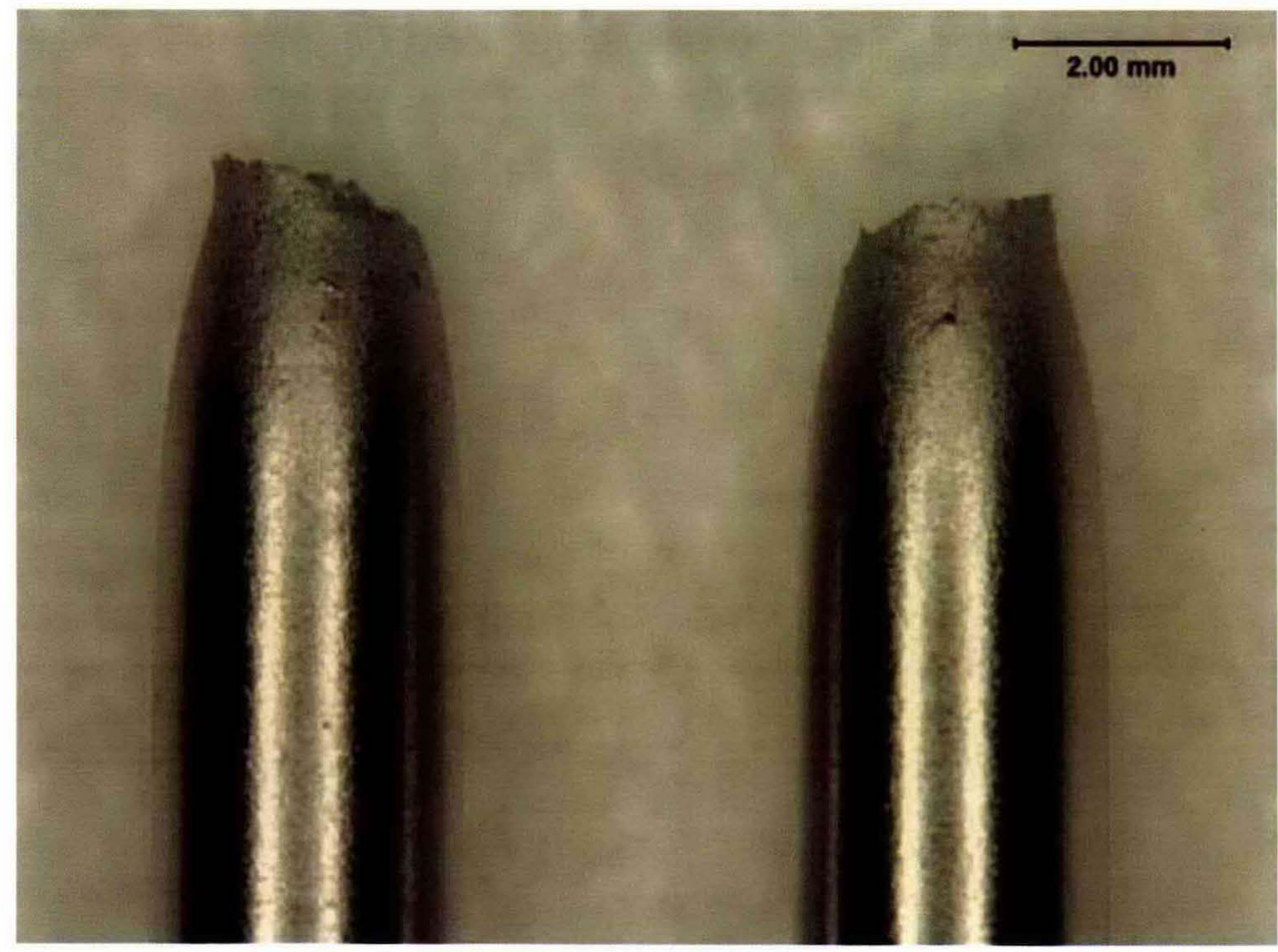


Figure C-62. An Electron-Micrograph of the Fracture Surface from SSRT 67 Performed in SY101 Simulant at $50^{\circ} \mathrm{C}$, pH 13+ and at OCP (-206 $\mathrm{mV}$ vs. SCE).

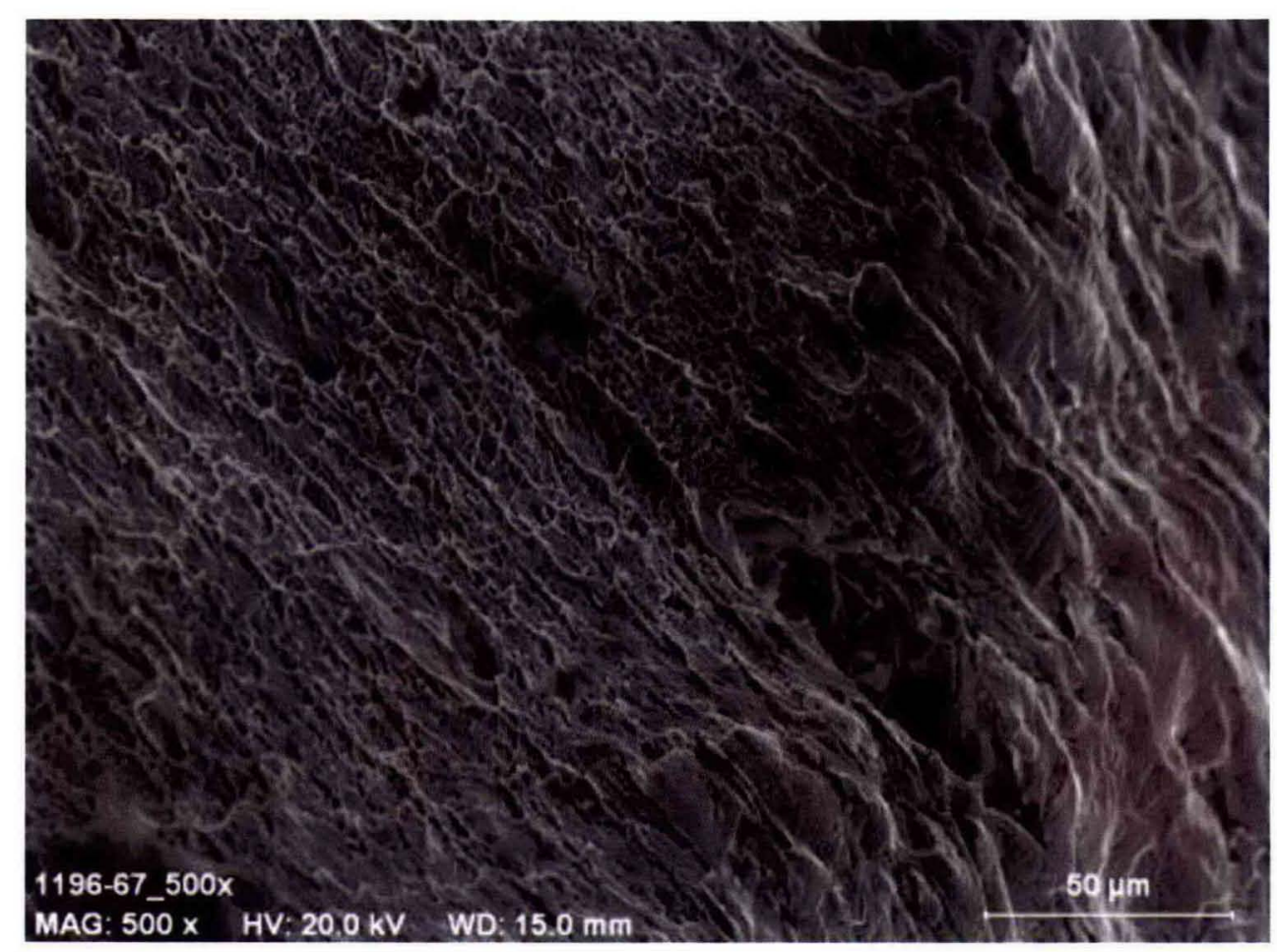


Figure C-63. The Stress-Strain Curve from SSRT 69 Performed in AY101-CSL Simulant at $50^{\circ} \mathrm{C}, \mathrm{pH} 11.8$ and at $\mathrm{OCP}(-181 \mathrm{mV}$ vs. SCE).

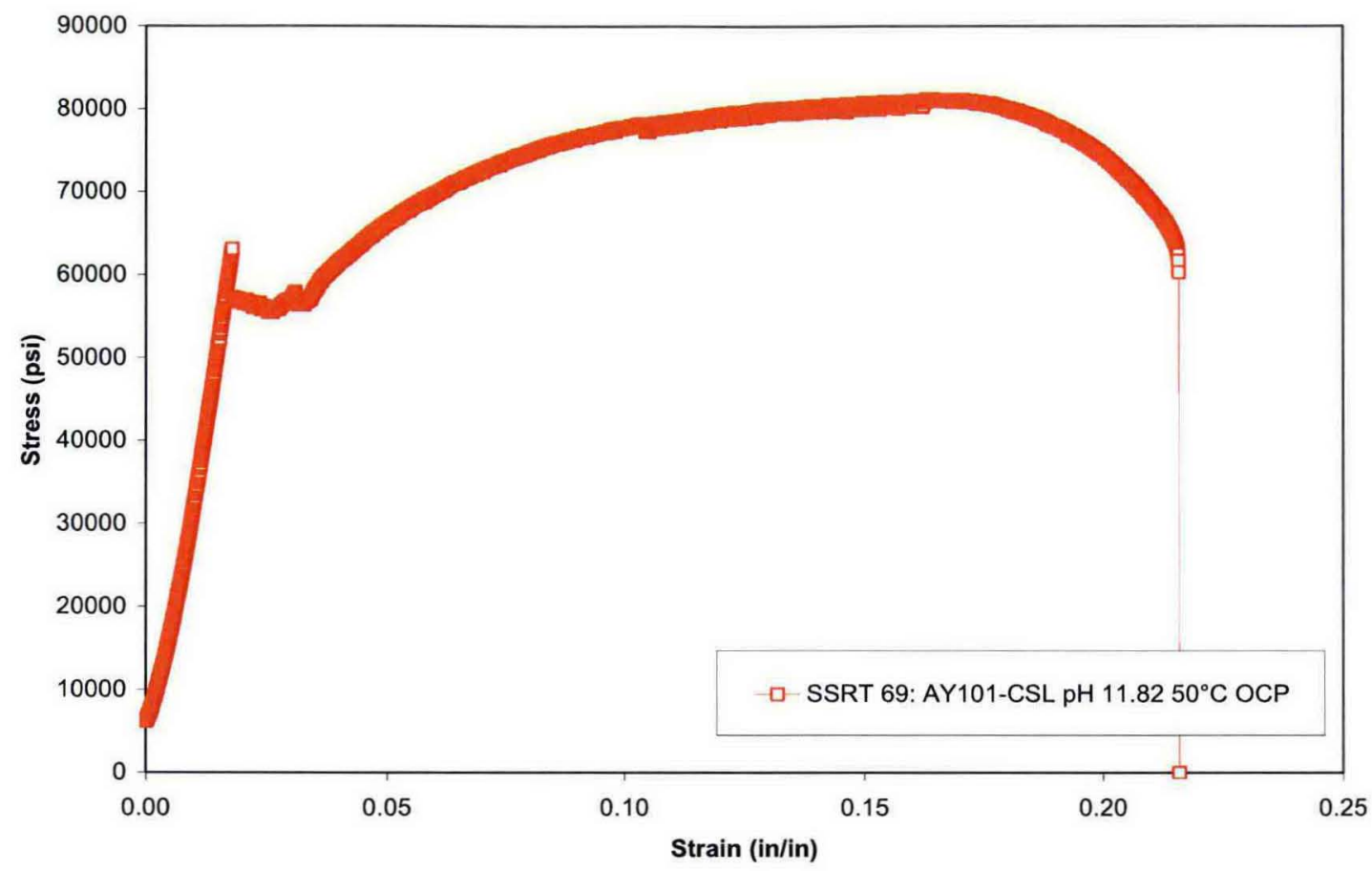

Figure C-64. A Stereo-Micrograph of the Sample from SSRT 69 Performed in AY101-CSL Simulant at $50^{\circ} \mathrm{C}$, pH 11.8 and at $\mathrm{OCP}(-181 \mathrm{mV}$ vs. SCE).

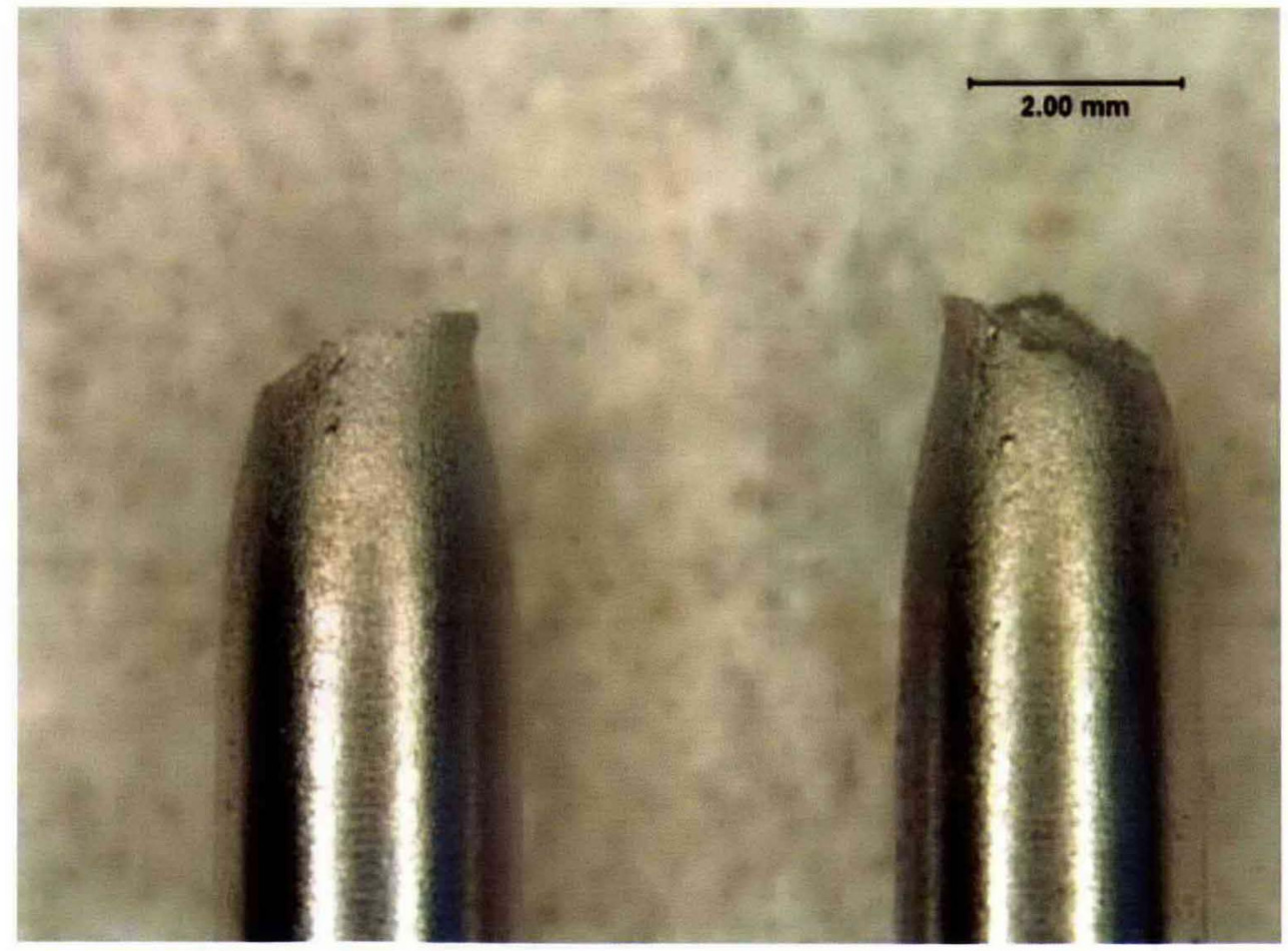


Figure C-65. An Electron-Micrograph of the Fracture Surface from SSRT 69 Performed in AY101-CSL Simulant at $50^{\circ} \mathrm{C}$, pH 11.8 and at $\mathrm{OCP}(-181 \mathrm{mV}$ vs. SCE).

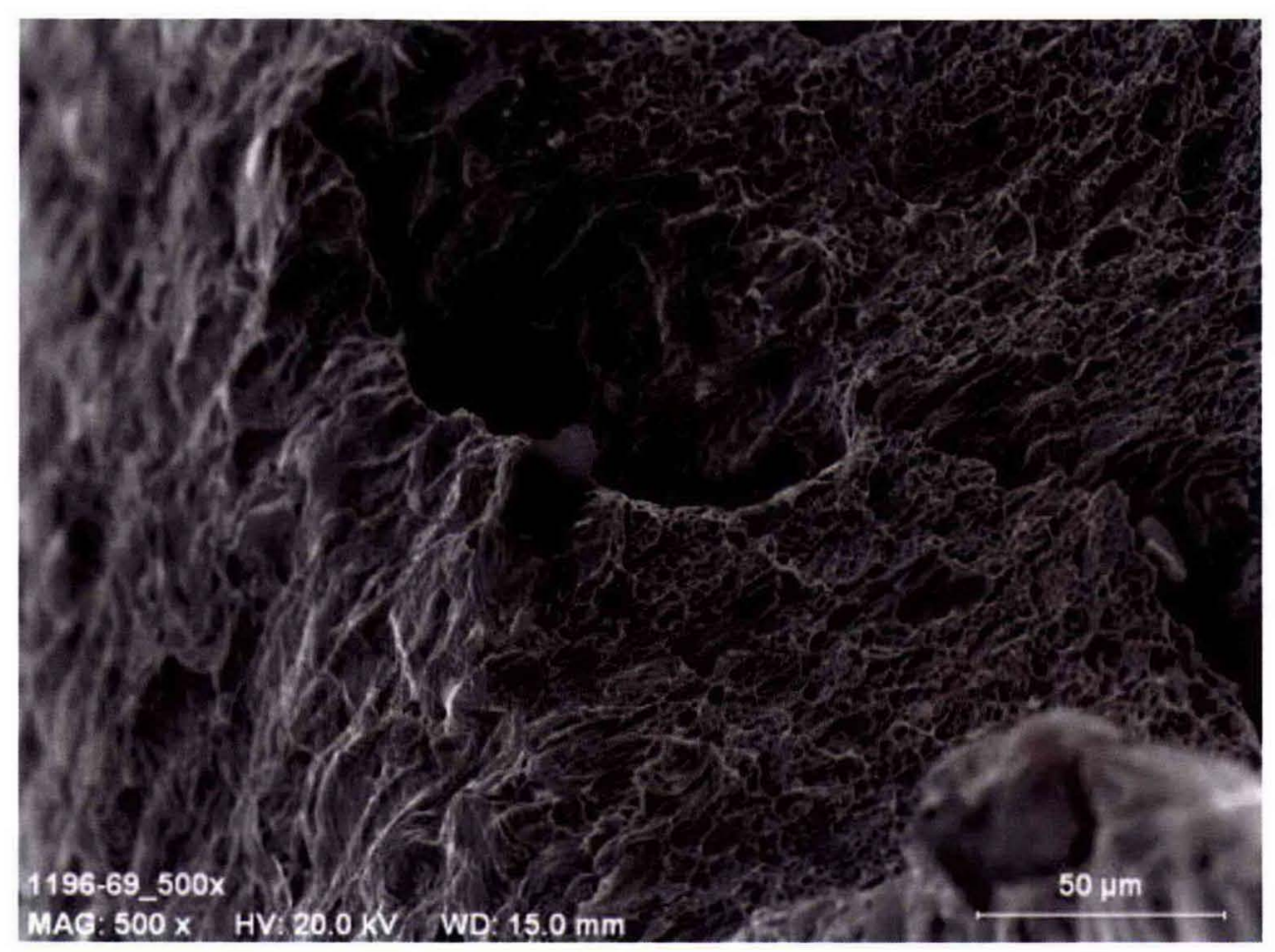


Figure C-66. The Stress-Strain Curve from SSRT 71 Performed in AW105-PSC Simulant at $50^{\circ} \mathrm{C}$, pH 13+ and at $-100 \mathrm{mV}$ vs. SCE.

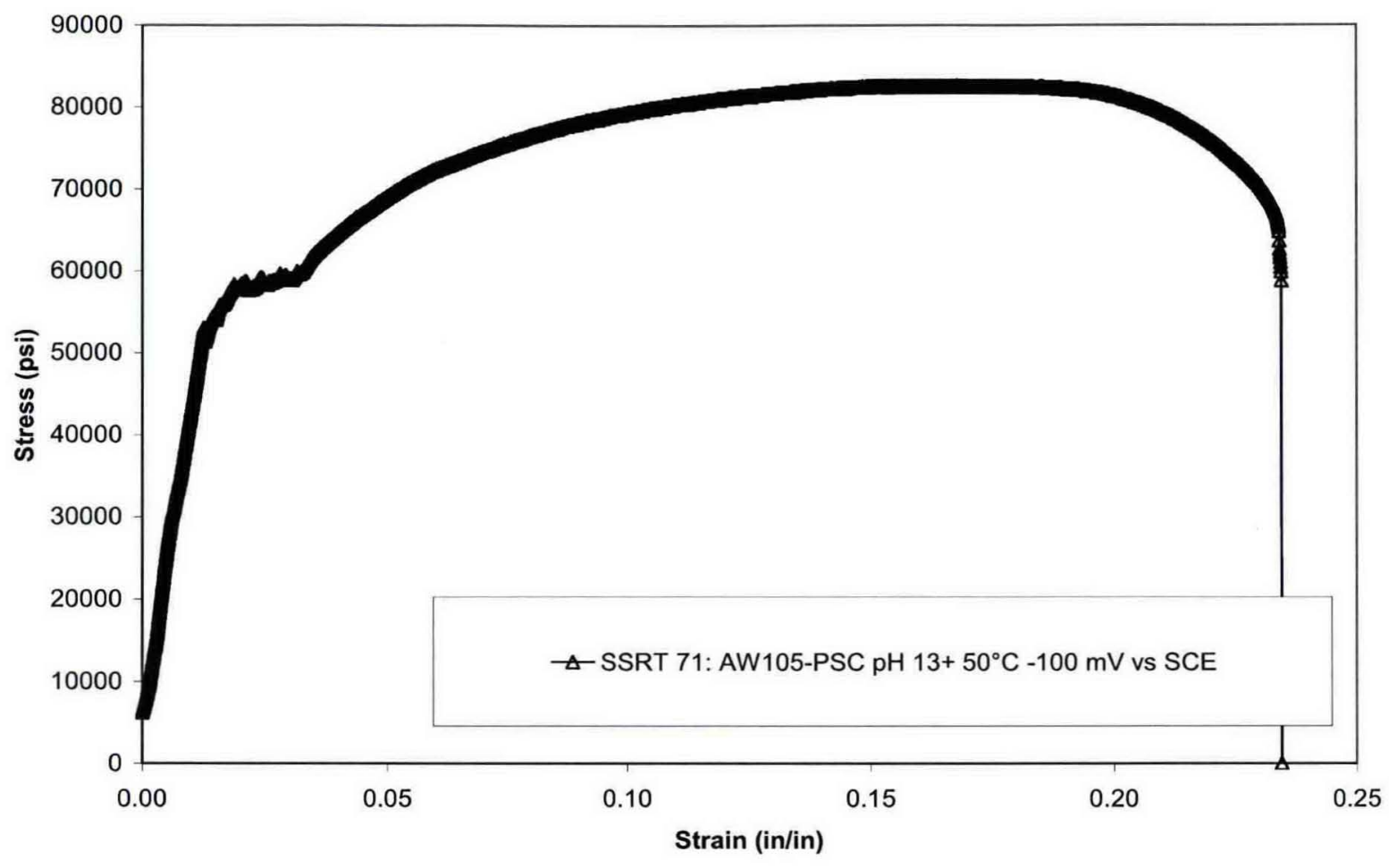

Figure C-67. A Stereo-Micrograph of the Sample from SSRT 71 Performed in AW105-PSC Simulant at $50^{\circ} \mathrm{C}$, pH $13+$ and at $-100 \mathrm{mV}$ vs. SCE.

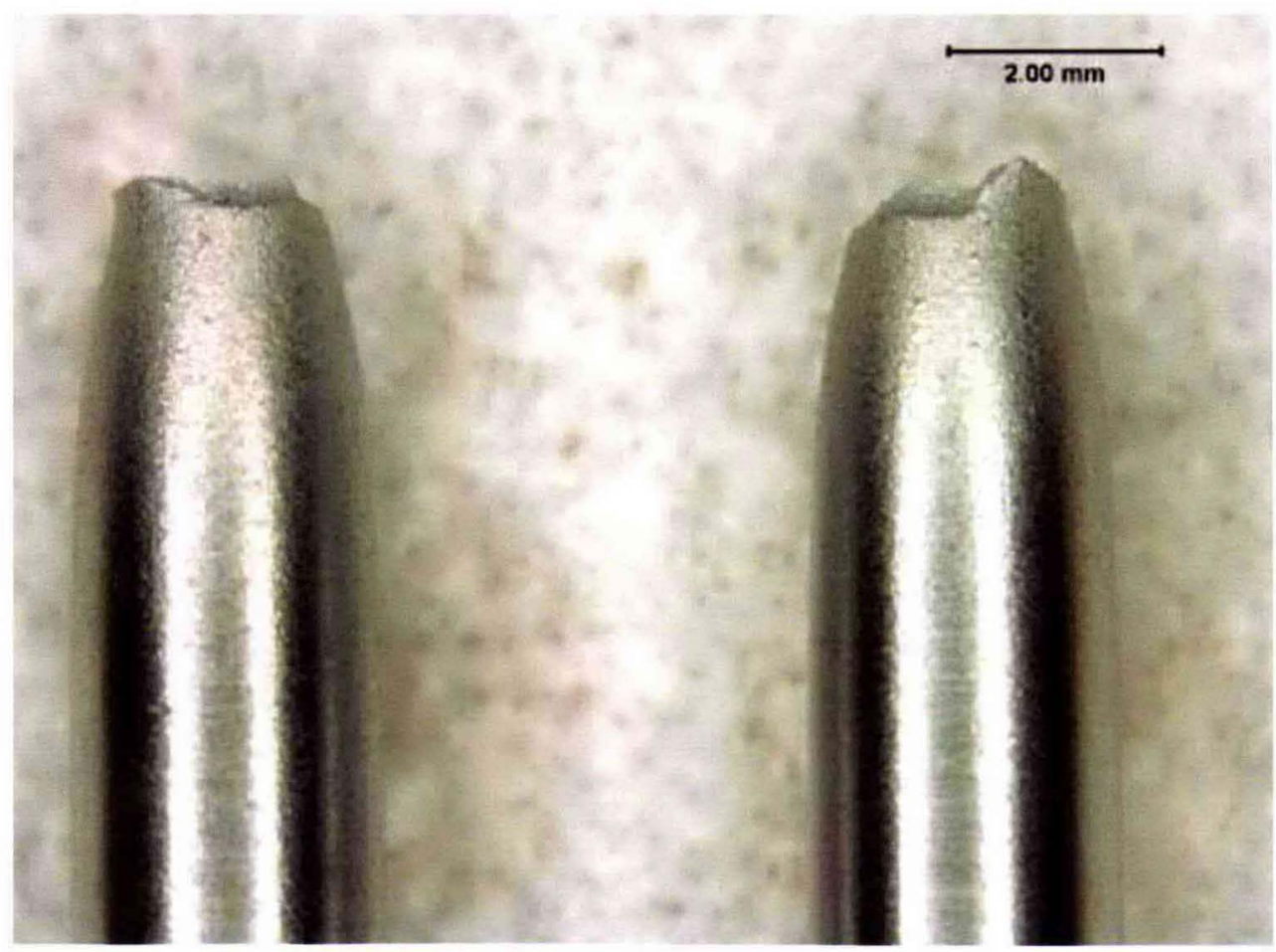


Figure C-68. An Electron-Micrograph of the Fracture Surface from SSRT 71 Performed in AW105-PSC Simulant at $50^{\circ} \mathrm{C}$, $\mathrm{pH} 13+$ and at $-100 \mathrm{mV}$ vs. SCE.

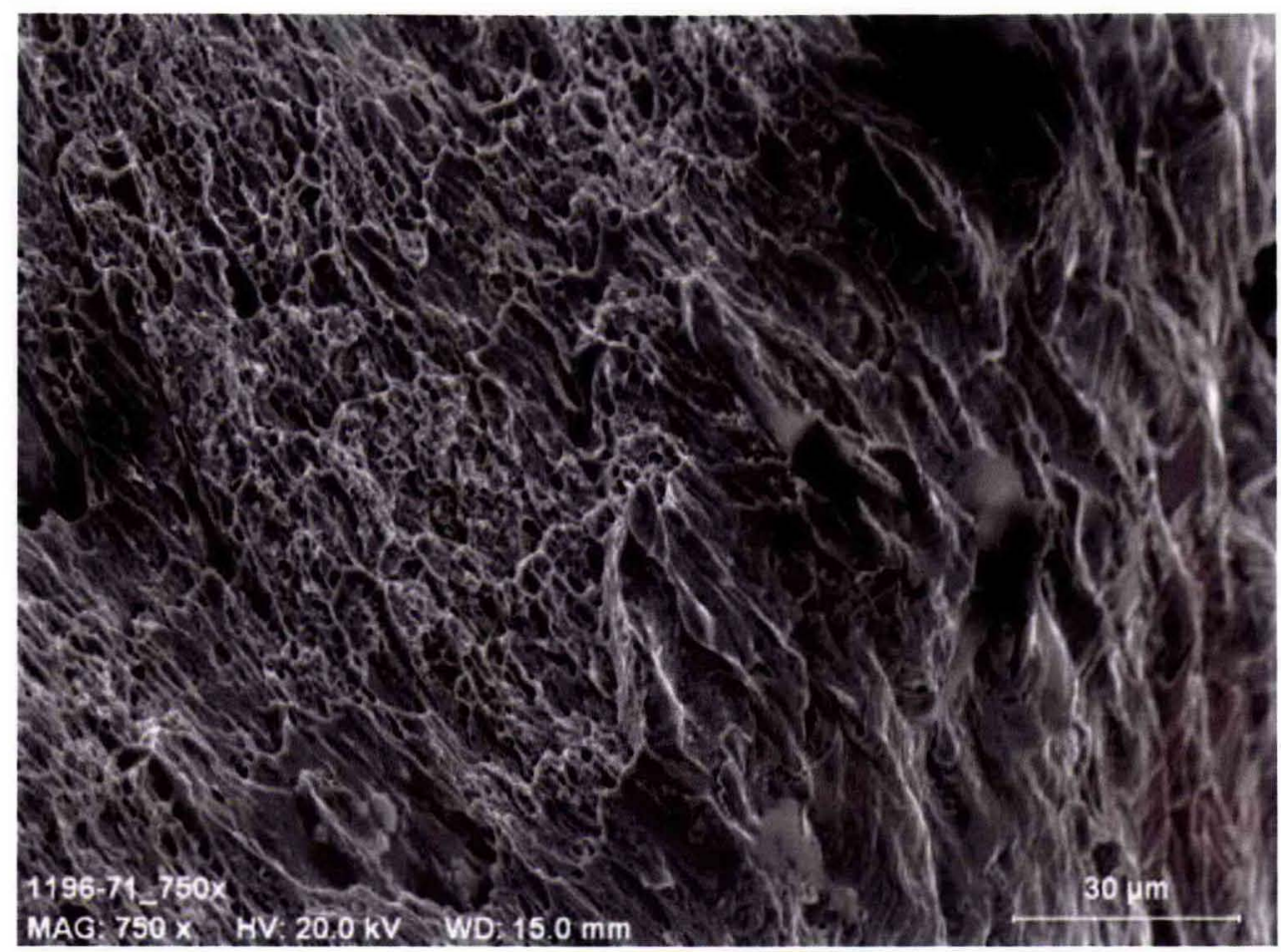


RPP-RPT-37505, Rev. 0

Figure C-69. The Stress-Strain Curve from SSRT 72 Performed in AW105-PSC Simulant at $50^{\circ} \mathrm{C}$, pH 13+ and at $-50 \mathrm{mV}$ vs. SCE.

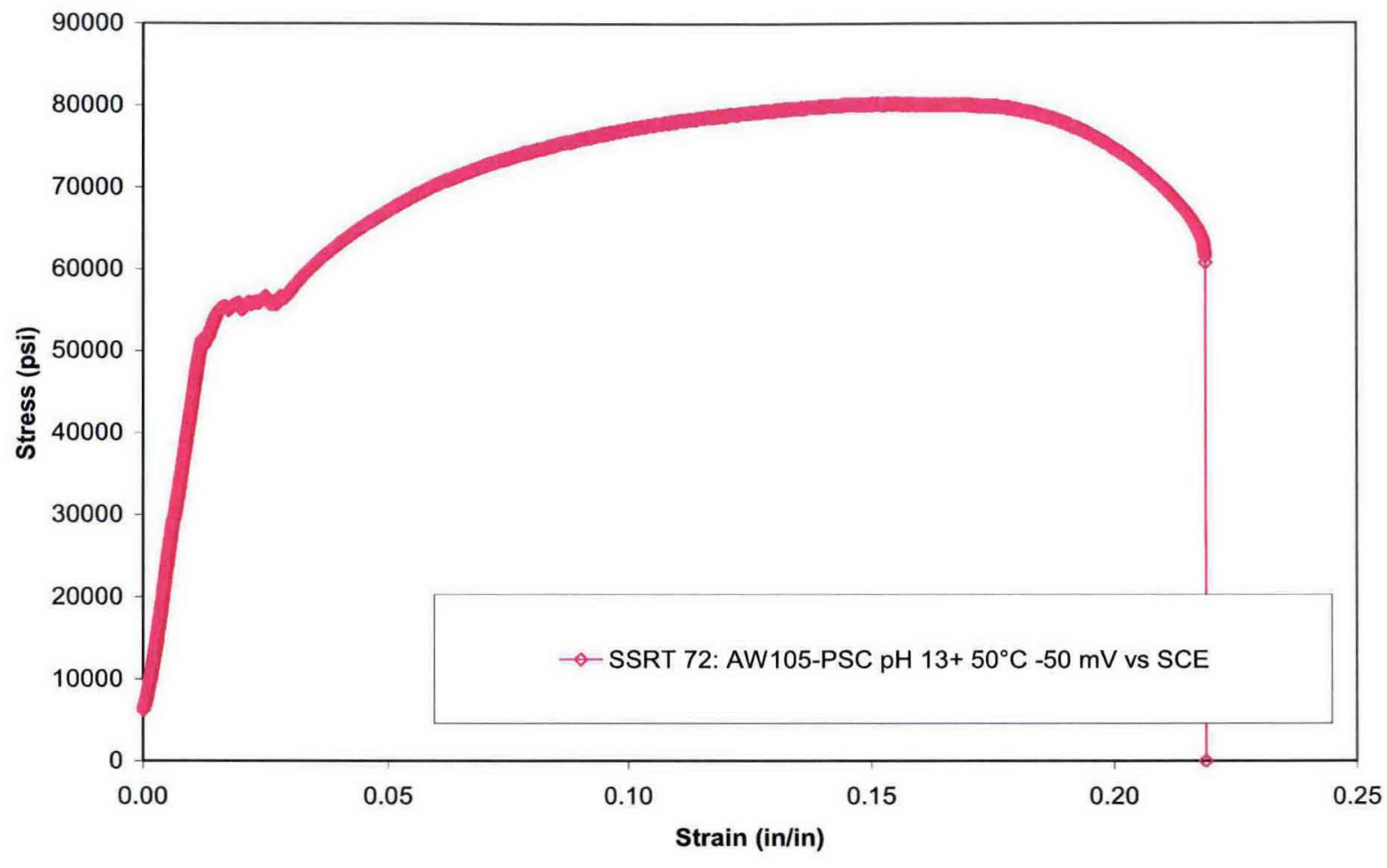

Figure C-70. A Stereo-Micrograph of the Sample from SSRT 72 Performed in AW105-PSC Simulant at $50^{\circ} \mathrm{C}$, pH 13+ and at $-50 \mathrm{mV}$ vs. SCE.

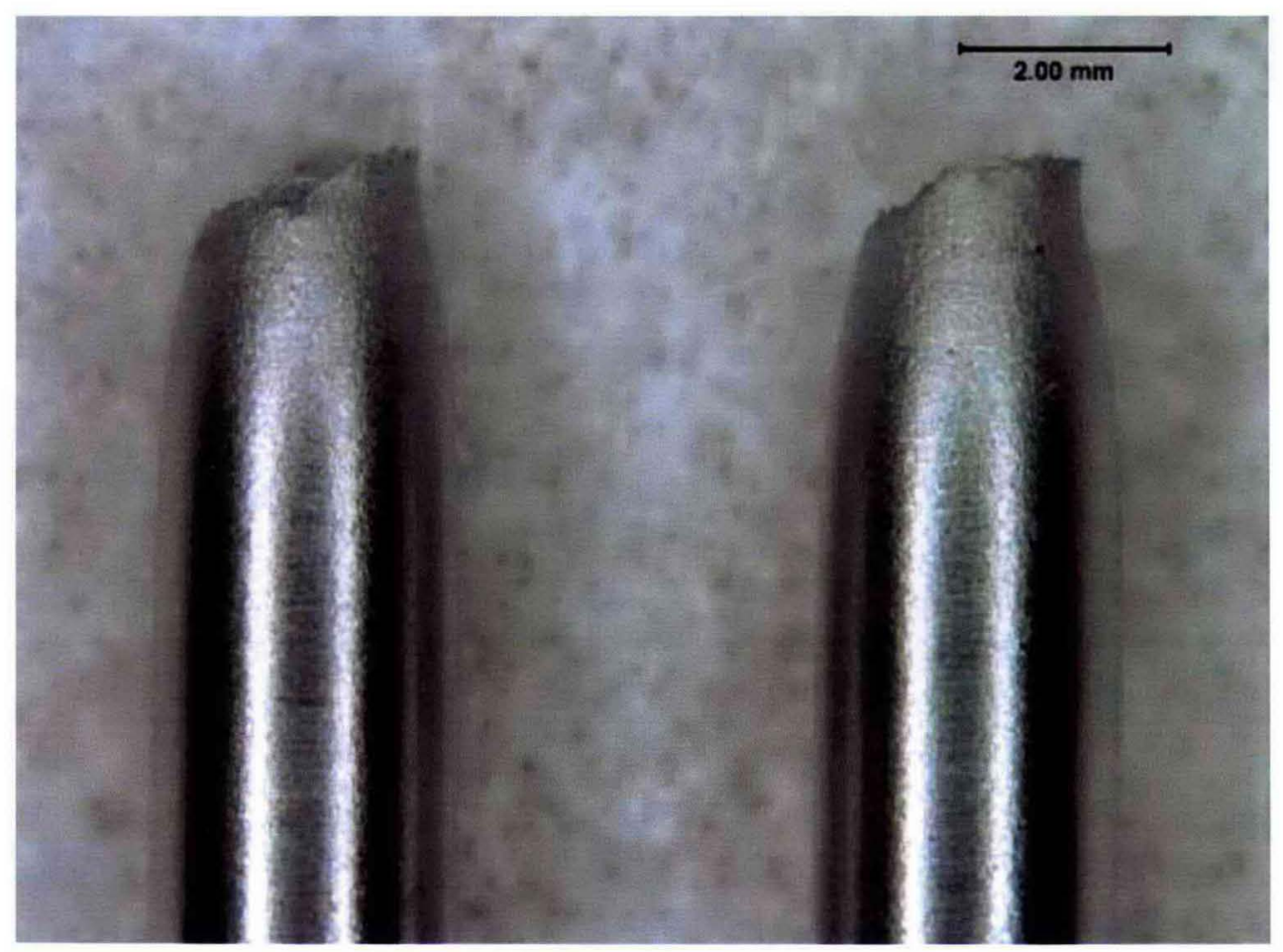


Figure C-71. An Electron-Micrograph of the Fracture Surface from SSRT 72 Performed in AW105-PSC Simulant at $50^{\circ} \mathrm{C}$, $\mathrm{pH} 13+$ and at $-50 \mathrm{mV}$ vs. SCE.

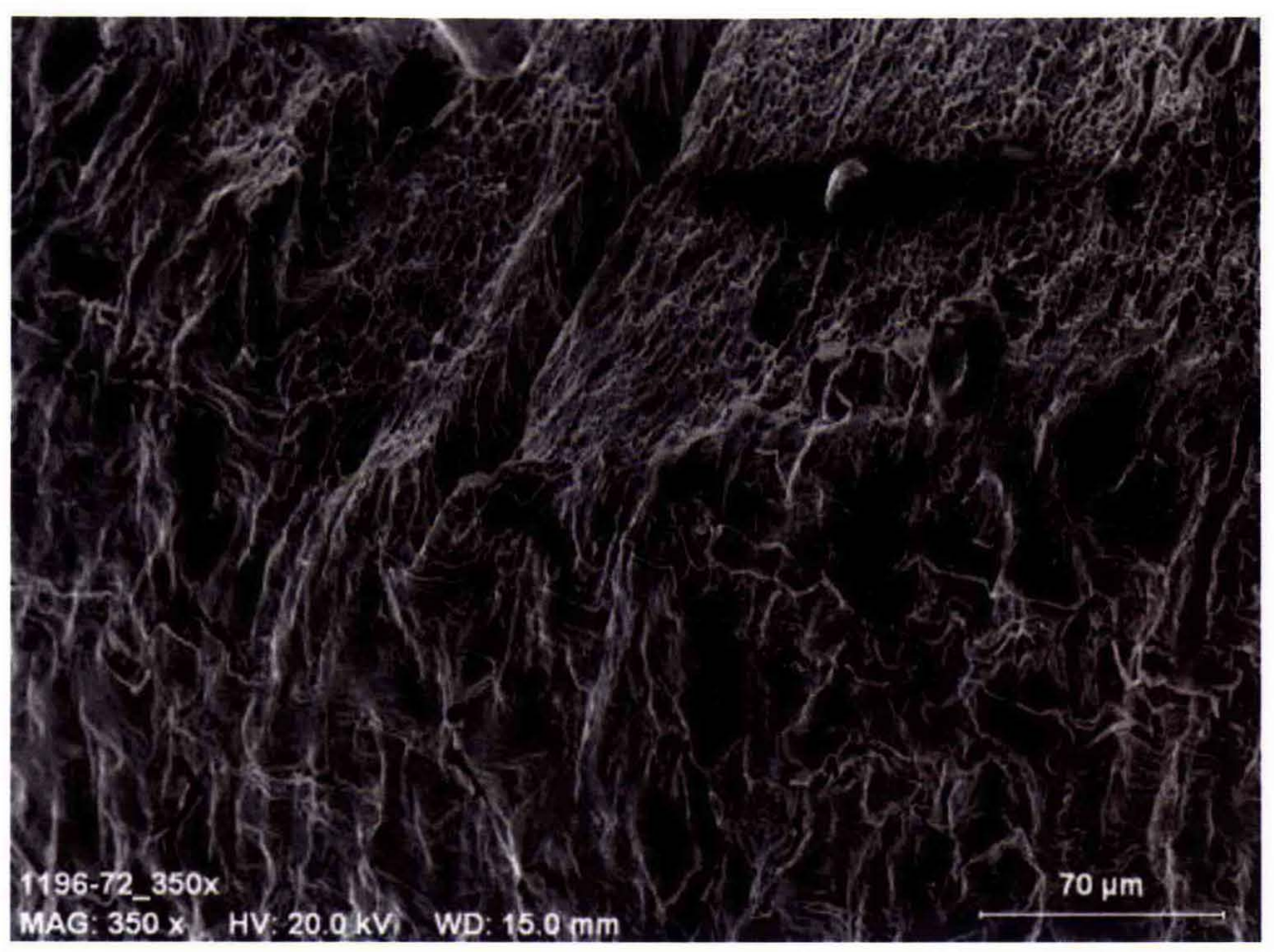


Figure C-72. The Stress-Strain Curve from SSRT 73 Performed in AW105-PSC Half Nitrite Simulant at $50^{\circ} \mathrm{C}, \mathrm{pH} 13+$ and at $-100 \mathrm{mV}$ vs. SCE.

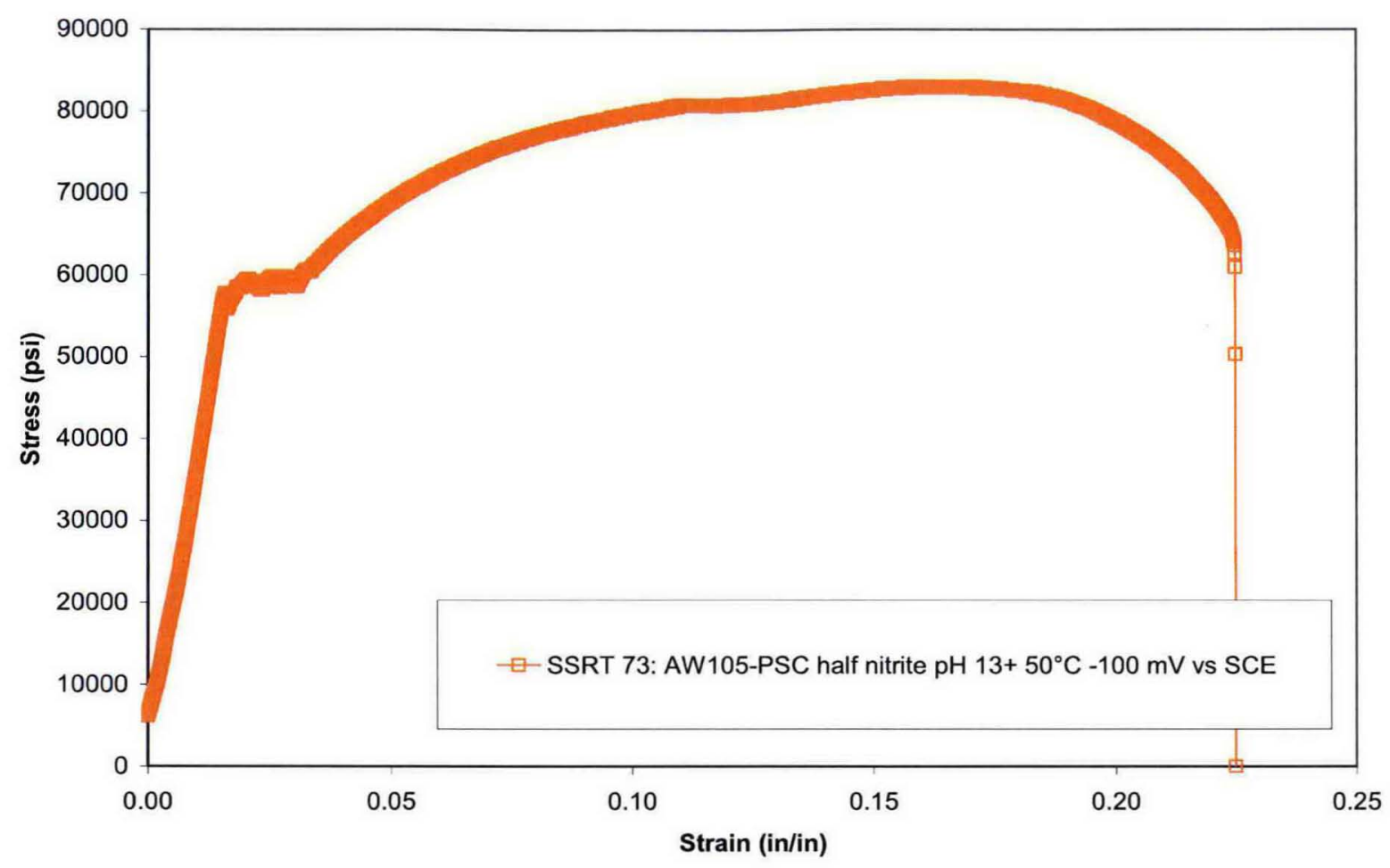

Figure C-73. A Stereo-Micrograph of the Sample from SSRT 73 Performed in AW105-PSC Half Nitrite Simulant at $50^{\circ} \mathrm{C}$, pH 13+ and at $-100 \mathrm{mV}$ vs. SCE.

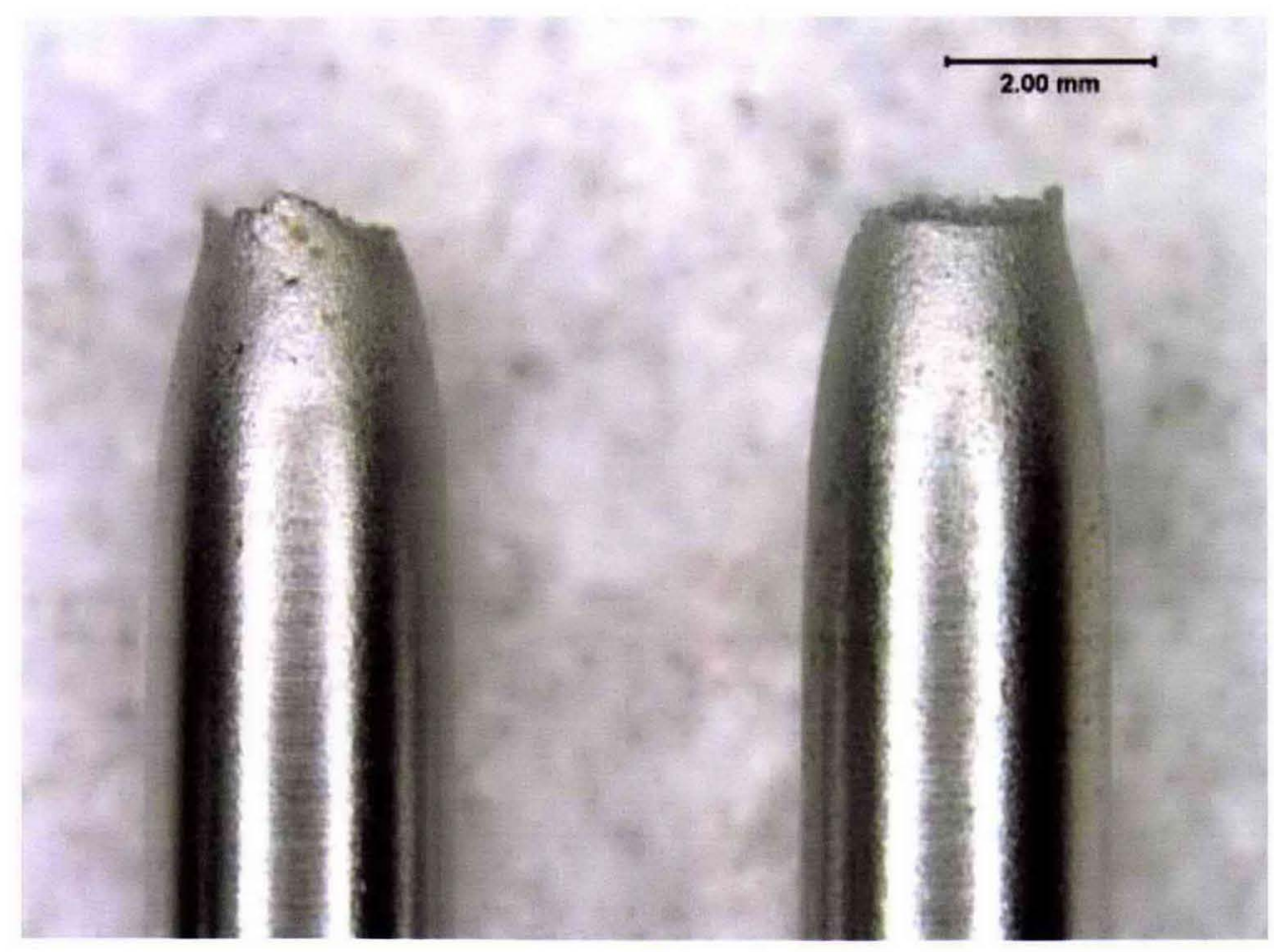


Figure C-74. An Electron-Micrograph of the Fracture Surface from SSRT 73 Performed in AW105-PSC Half Nitrite Simulant at $50^{\circ} \mathrm{C}$, pH $13+$ and at $-100 \mathrm{mV}$ vs. SCE.

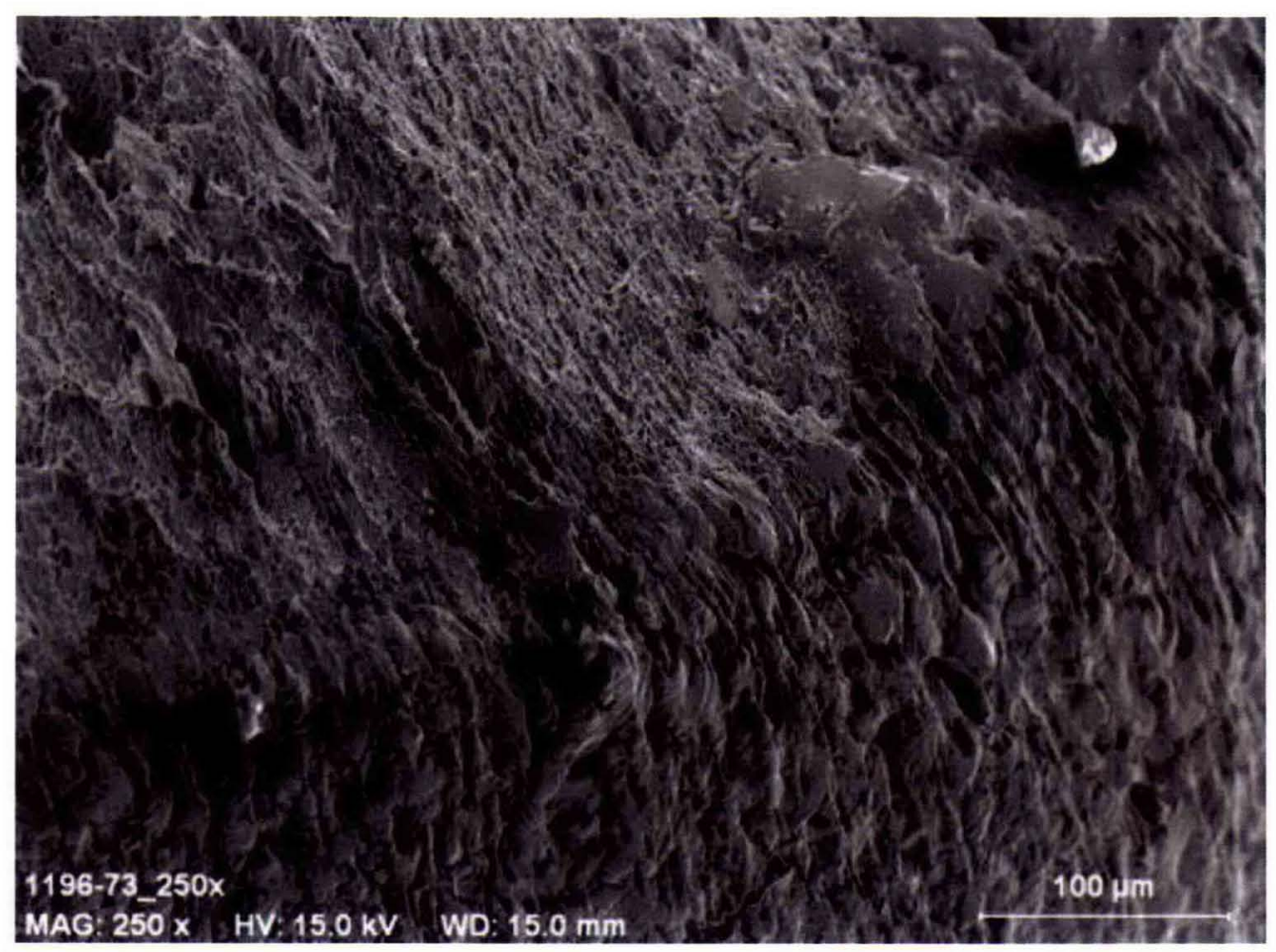


Figure C-75. The Stress-Strain Curve from SSRT 74 Performed in AW105-PSC 6X Simulant at $50^{\circ} \mathrm{C}, \mathrm{pH} 13+$ and at $-100 \mathrm{mV}$ vs. SCE.

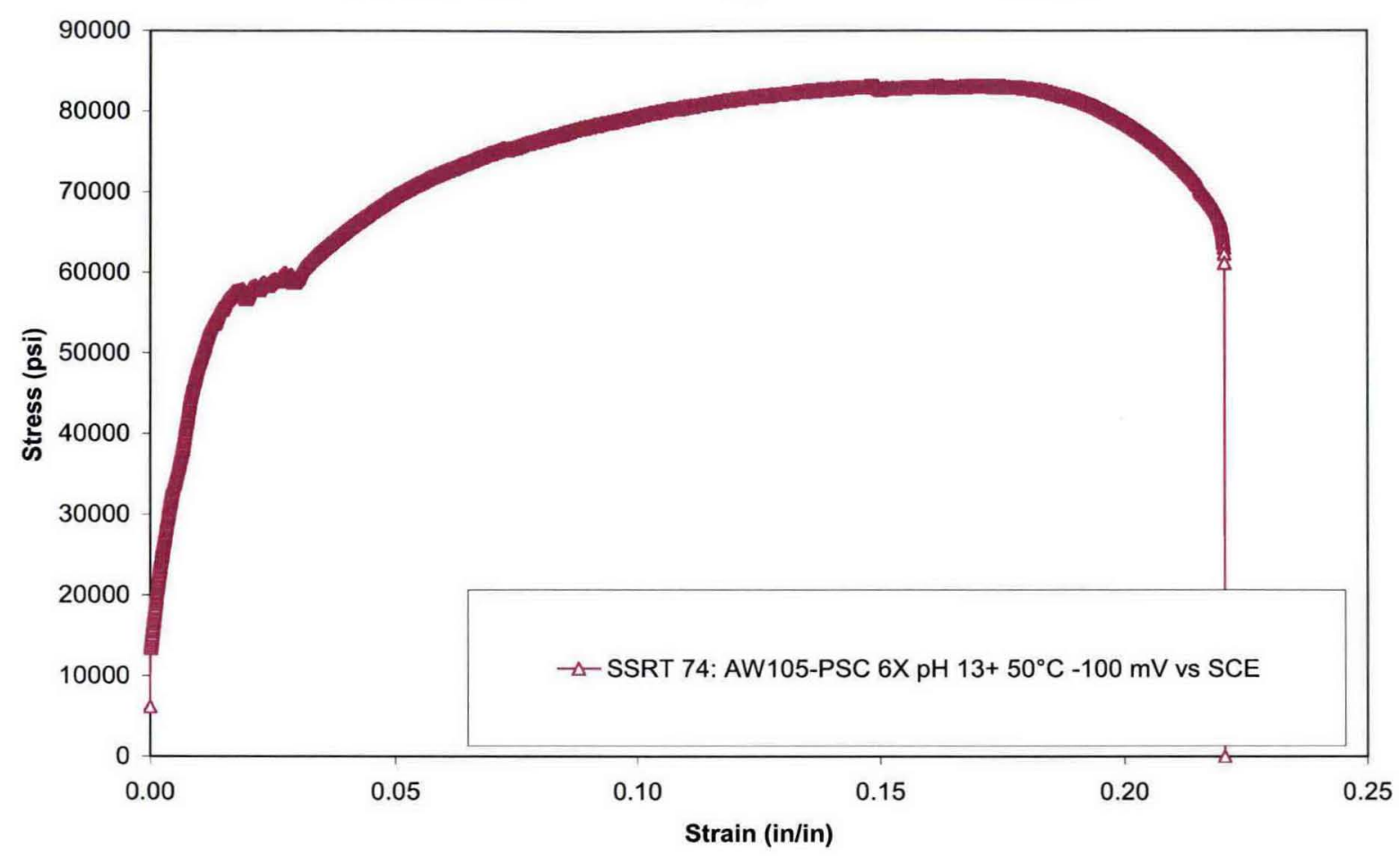

Figure C-76. A Stereo-Micrograph of the Sample from SSRT 74 Performed in AW105-PSC 6X Simulant at $50^{\circ} \mathrm{C}$, pH $13+$ and at $-100 \mathrm{mV}$ vs. SCE.

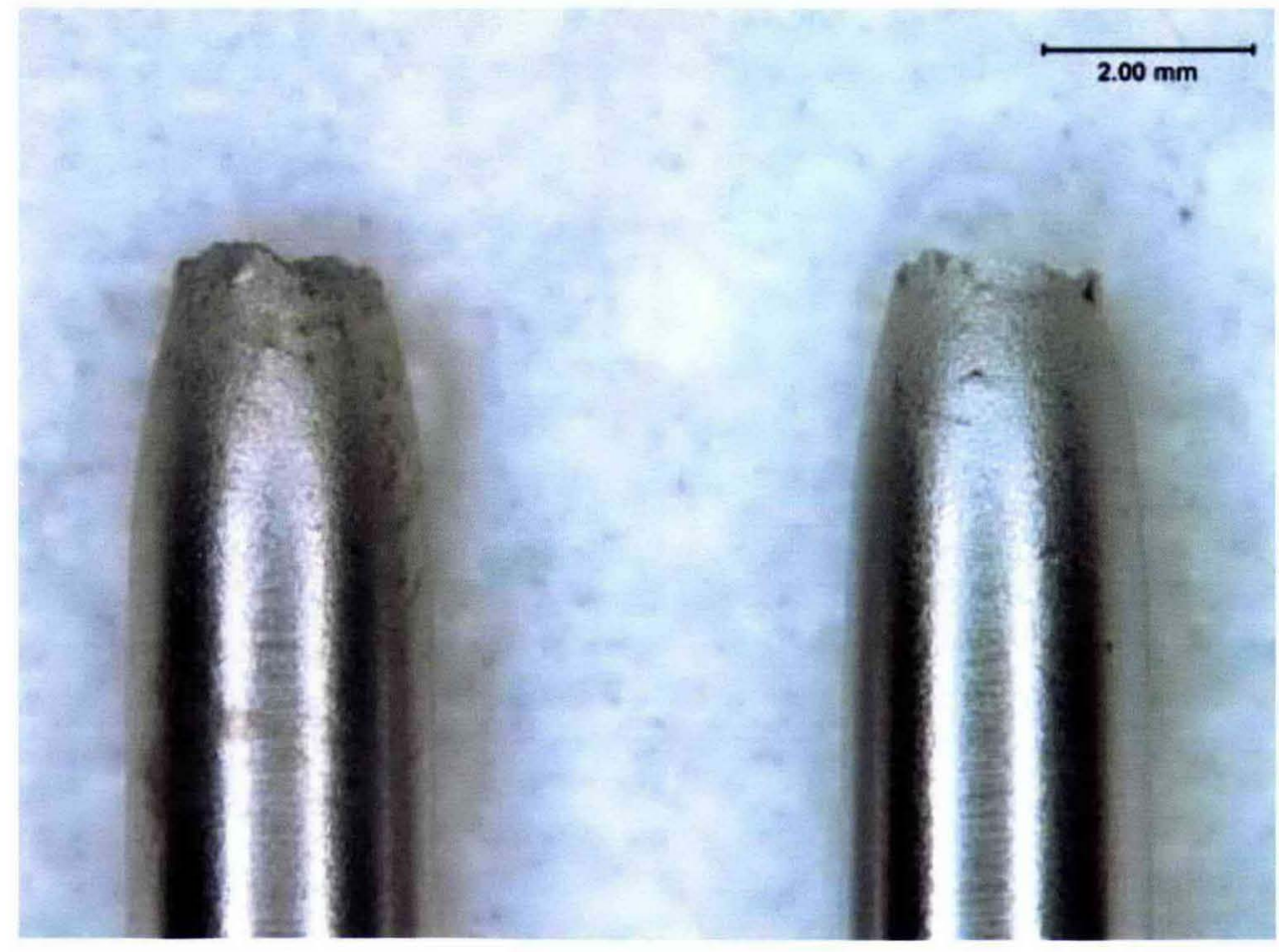


Figure C-77. An Electron-Micrograph of the Fracture Surface from SSRT 74 Performed in AW105-PSC 6X Simulant at $50^{\circ} \mathrm{C}$, pH $13+$ and at $-100 \mathrm{mV}$ vs. SCE.

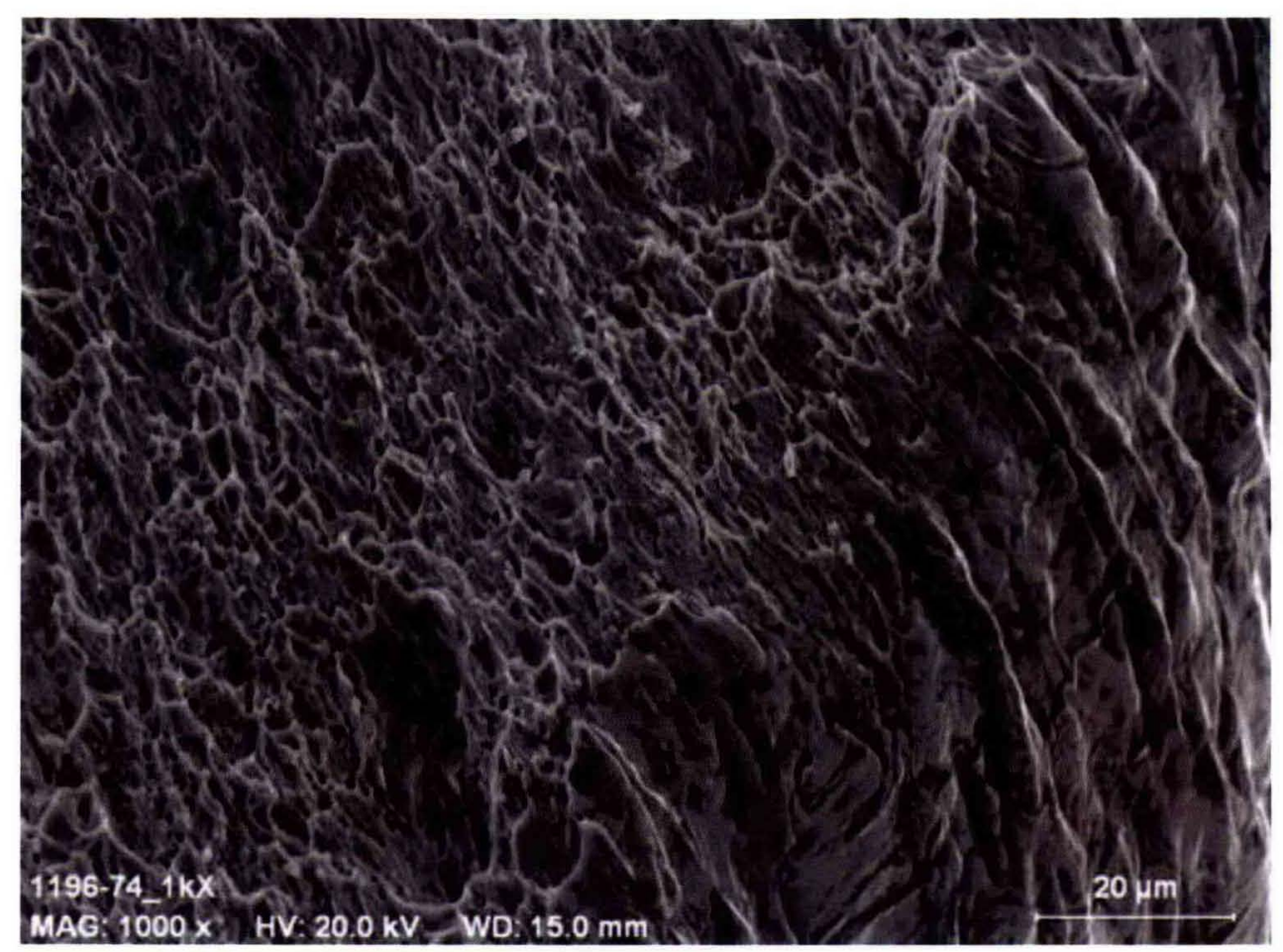


RPP-RPT-37505, Rev. 0

Figure C-78. The Stress-Strain Curve from SSRT 75 Performed in AW105-PSC $6 \mathrm{X}$ Simulant at $50^{\circ} \mathrm{C}, \mathrm{pH} 13+$ and at $-50 \mathrm{mV}$ vs. SCE.

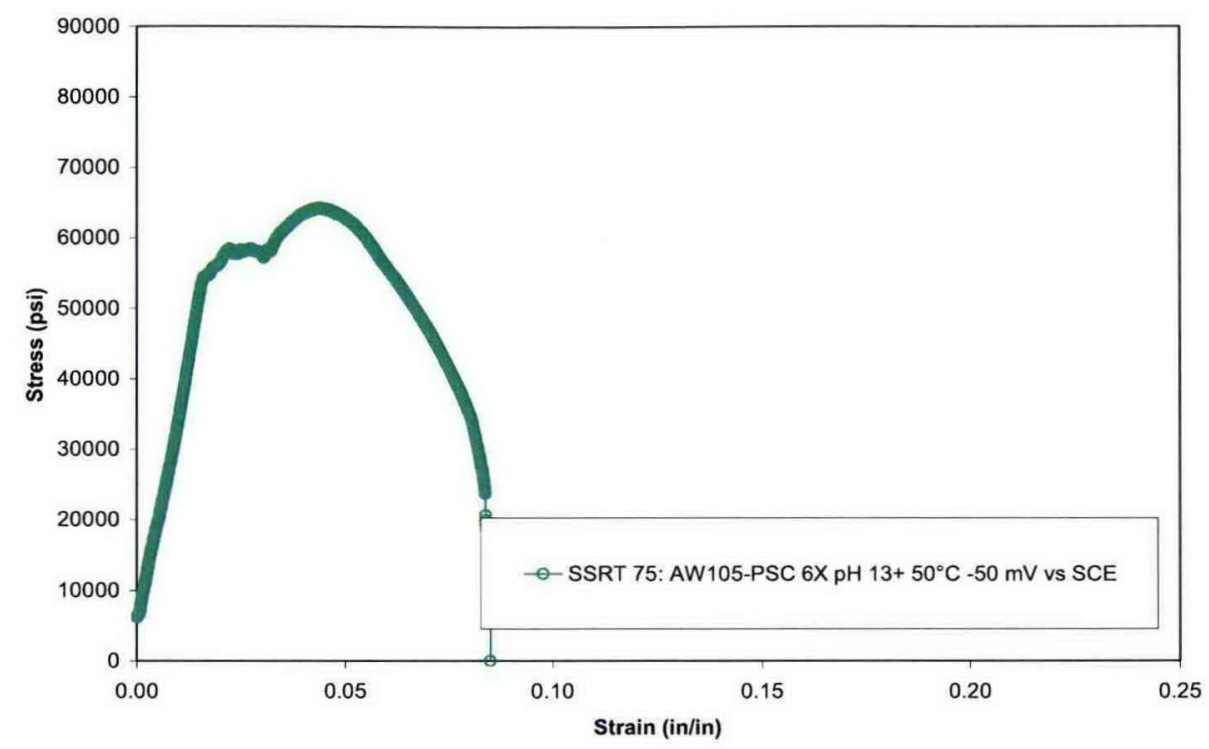

Figure C-79. A Stereo-Micrograph of the Sample from SSRT 75 Performed in AW105-PSC 6X Simulant at $50^{\circ} \mathrm{C}$, pH 13+ and at $-50 \mathrm{mV}$ vs. SCE.

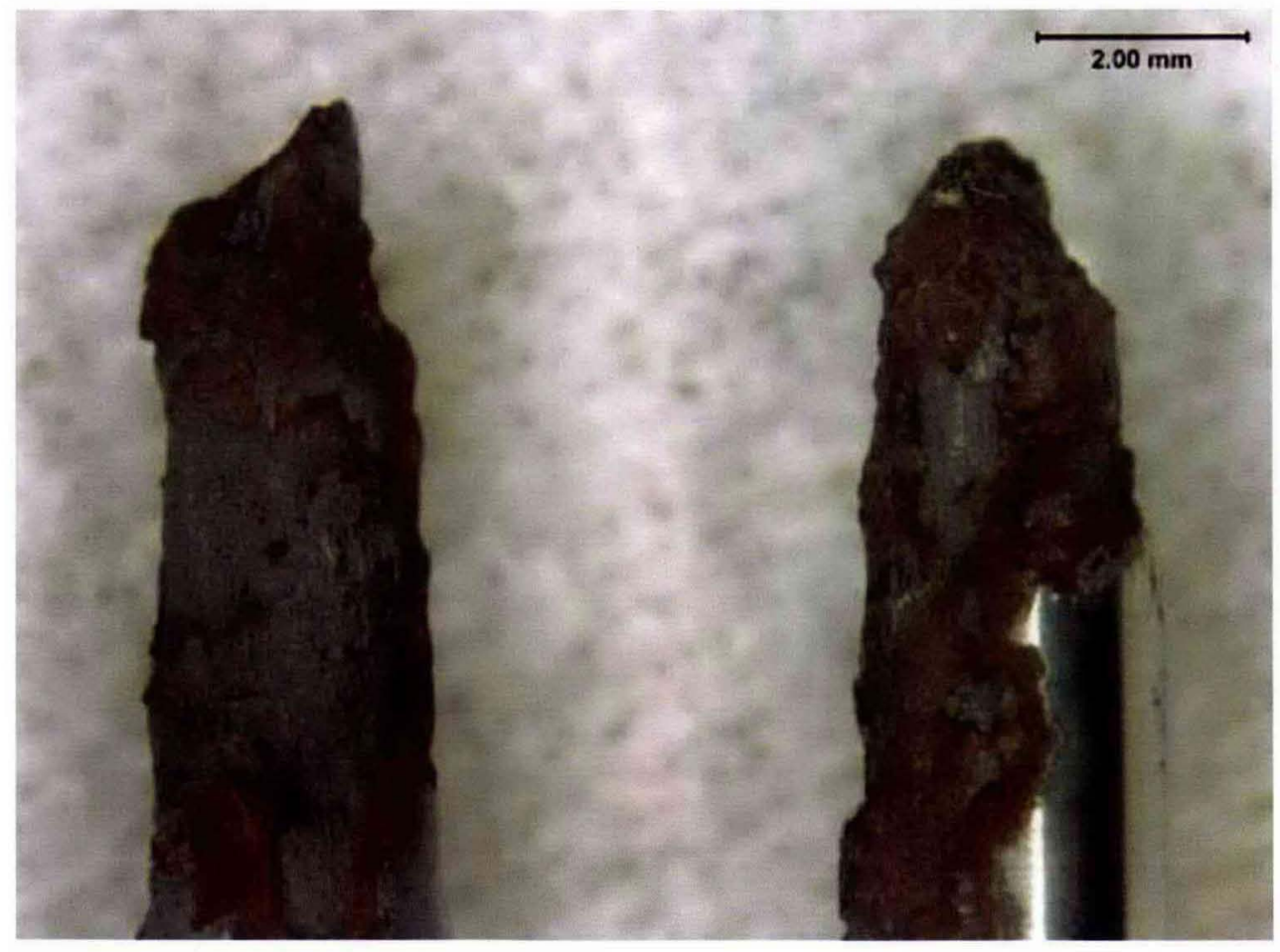


RPP-RPT-37505, Rev. 0

APPENDIX D

CRACK GROWTH RATE TEST DATA

D-1 
Figure D-1 The DCPD Calculated Crack Length vs. Time Plot from CT-17 Performed in $5 \mathrm{M} \mathrm{NaNO}{ }_{3}$ Solution at $50^{\circ} \mathrm{C}$ at $\mathrm{OCP}$. Loaded past crack initiation.

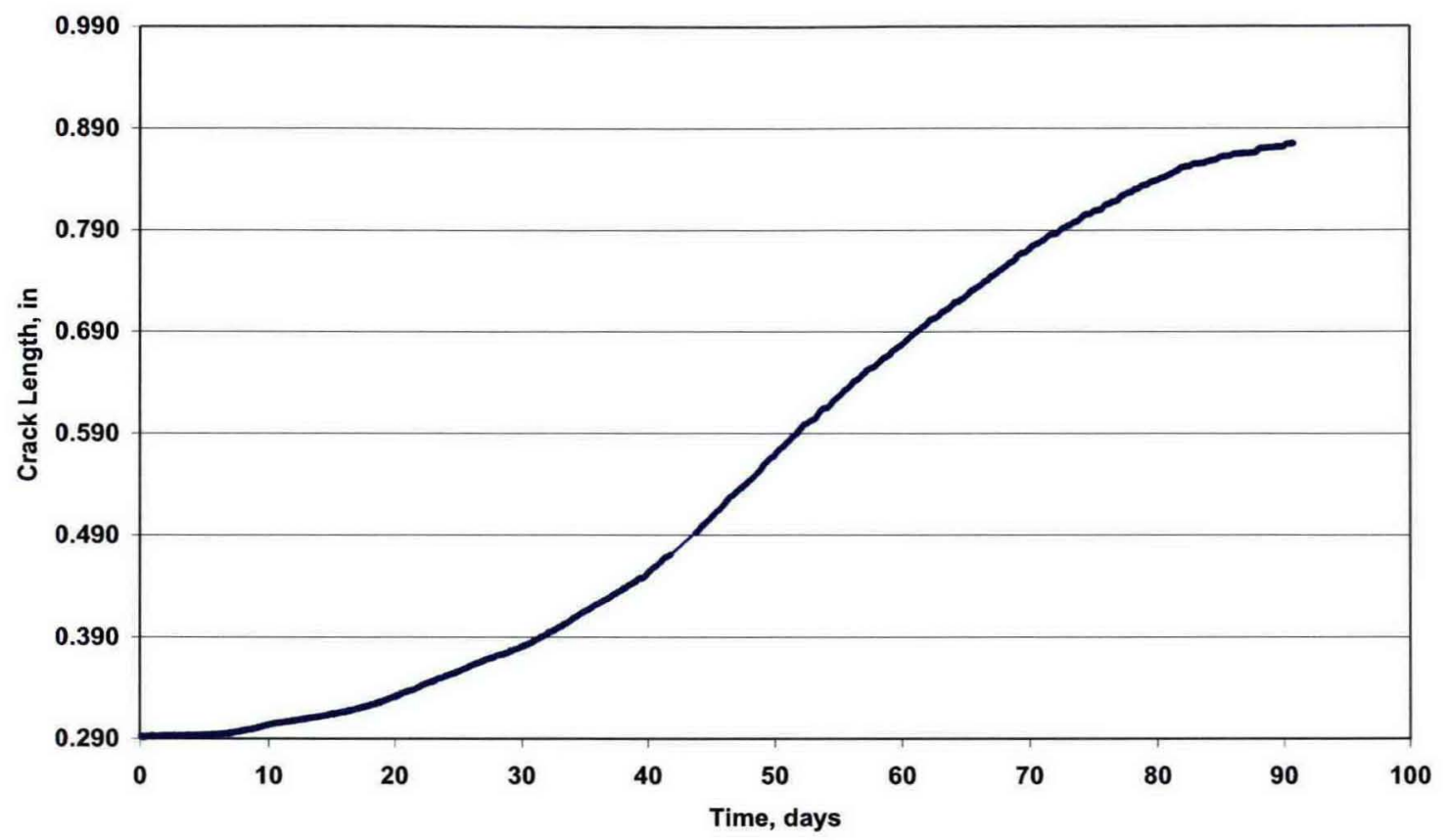

Figure D-2. The Load vs. Time Plot from CT-17 Performed in $5 \mathrm{M} \mathrm{NaNO}_{3}$ Solution at $50^{\circ} \mathrm{C}$ at $\mathrm{OCP}$. Loaded past crack initiation.

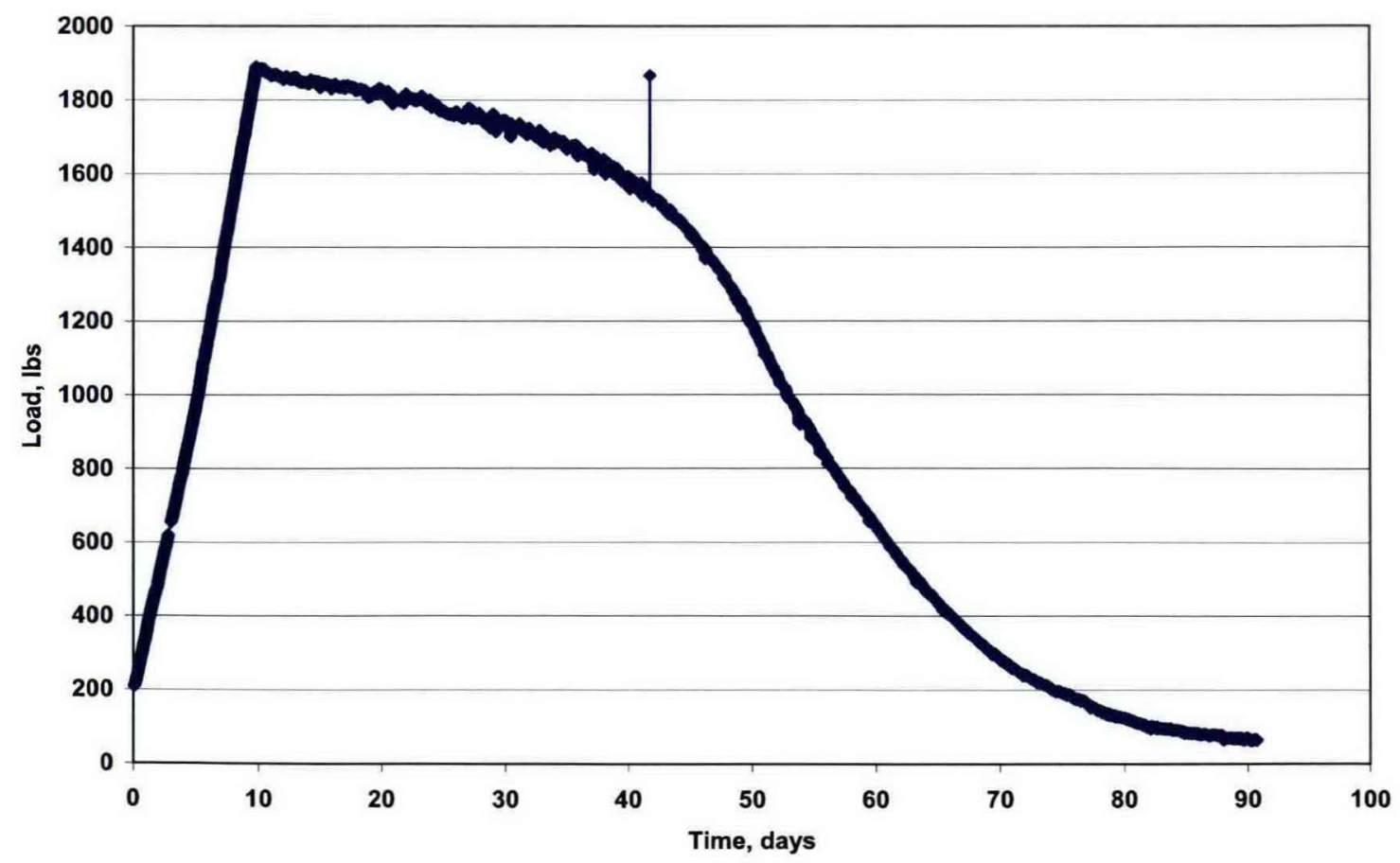

D-2 
Figure D-3. A Stereo-Micrograph of the Test Sample from CT-17 Performed in 5M $\mathrm{NaNO}_{3}$ Solution at $50^{\circ} \mathrm{C}$ at $\mathrm{OCP}$. Loaded past crack initiation.

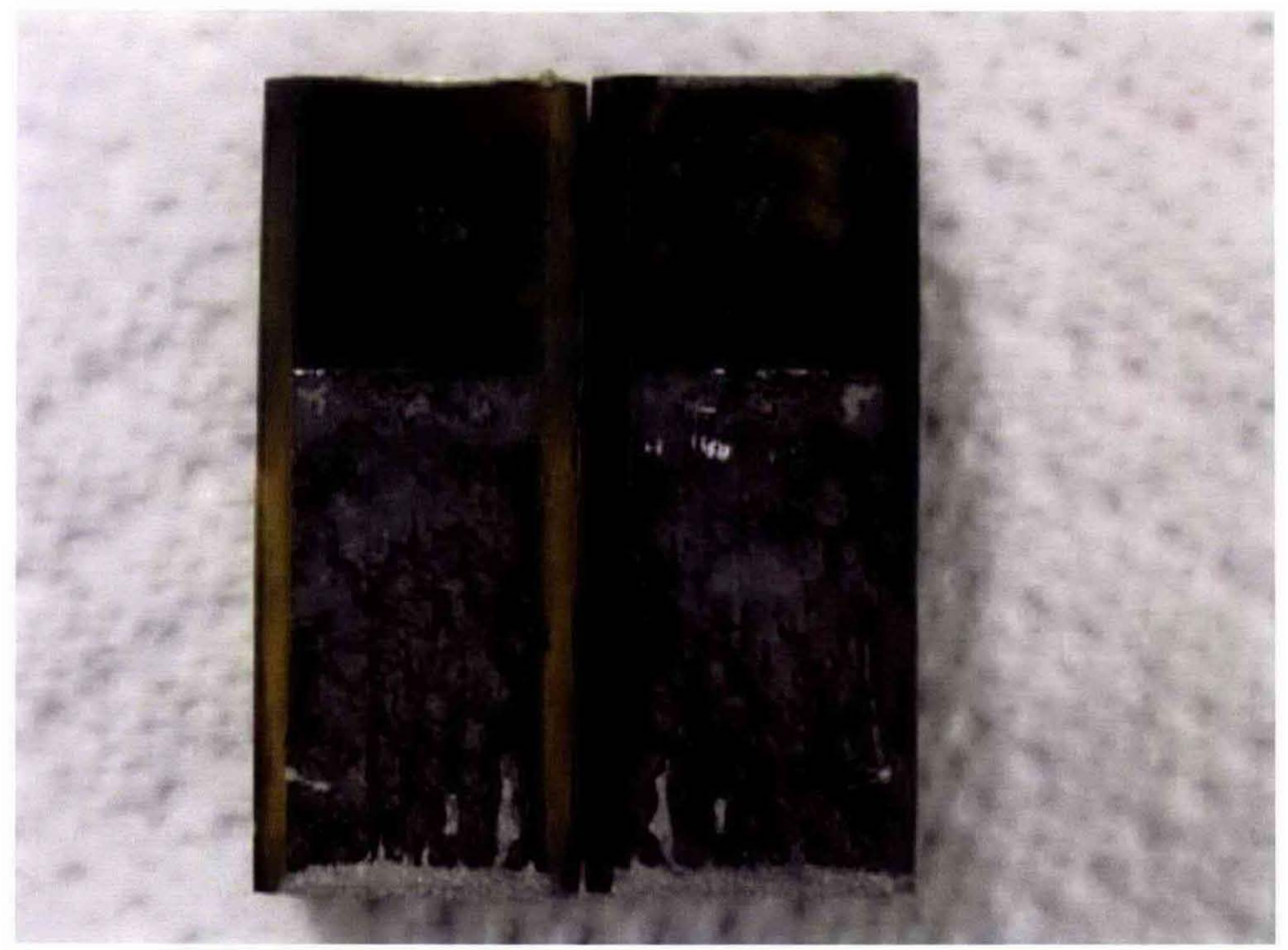

Figure D-4. An Electron-Micrograph of the Test Sample from CT-17 Performed in $5 \mathrm{M} \mathrm{NaNO}{ }_{3}$ Solution at $50^{\circ} \mathrm{C}$ at $\mathrm{OCP}$. Loaded past crack initiation.

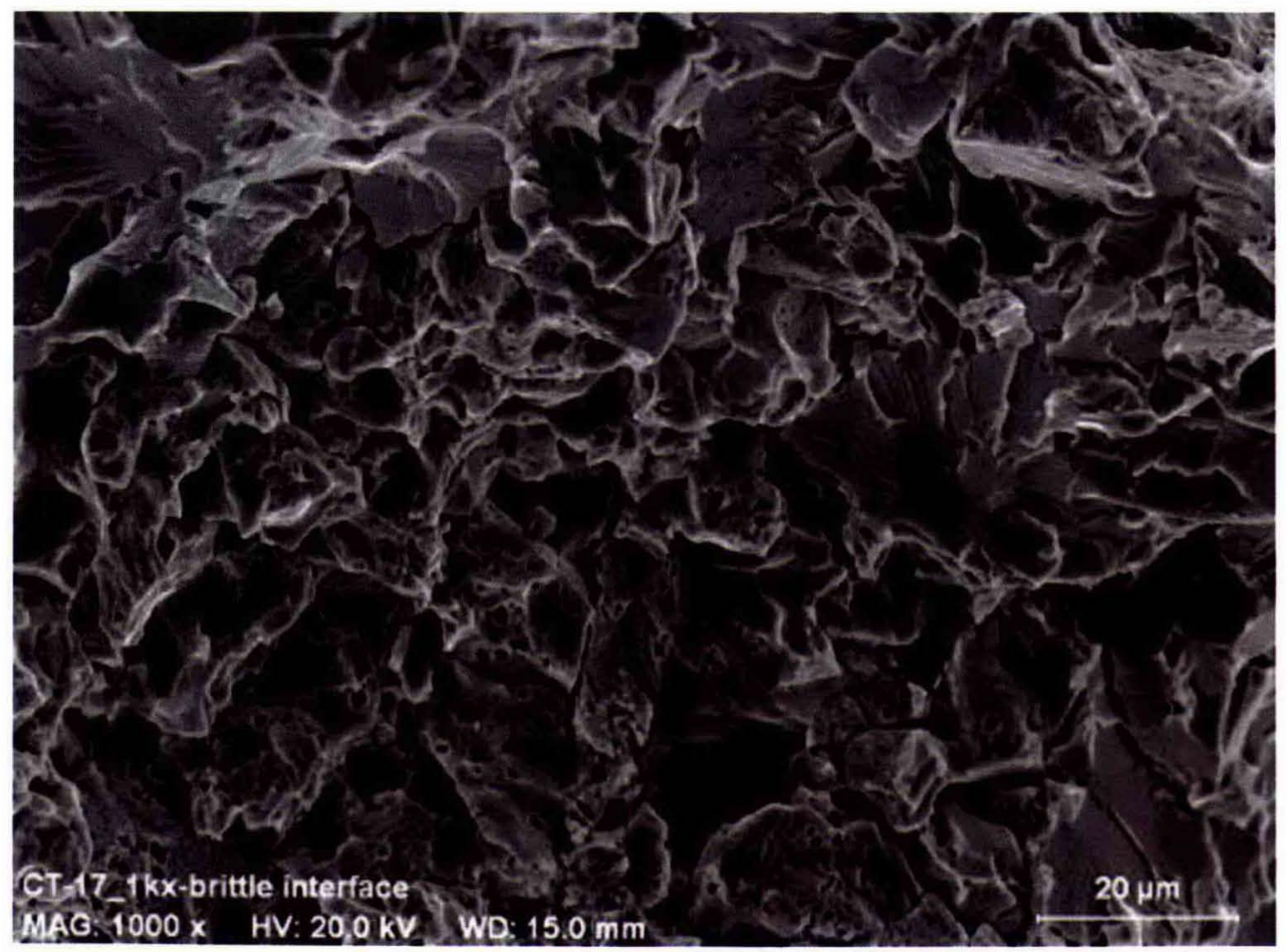

D-3 
Figure D-3 The DCPD Calculated Crack Length vs. Time Plot from CT-18 Performed in AY101-PSC Standard Simulant at $50^{\circ} \mathrm{C}$, pH 11 and at $0 \mathrm{mV}$ vs. SCE. Loaded to $K=45 \mathrm{ksi}$ in.

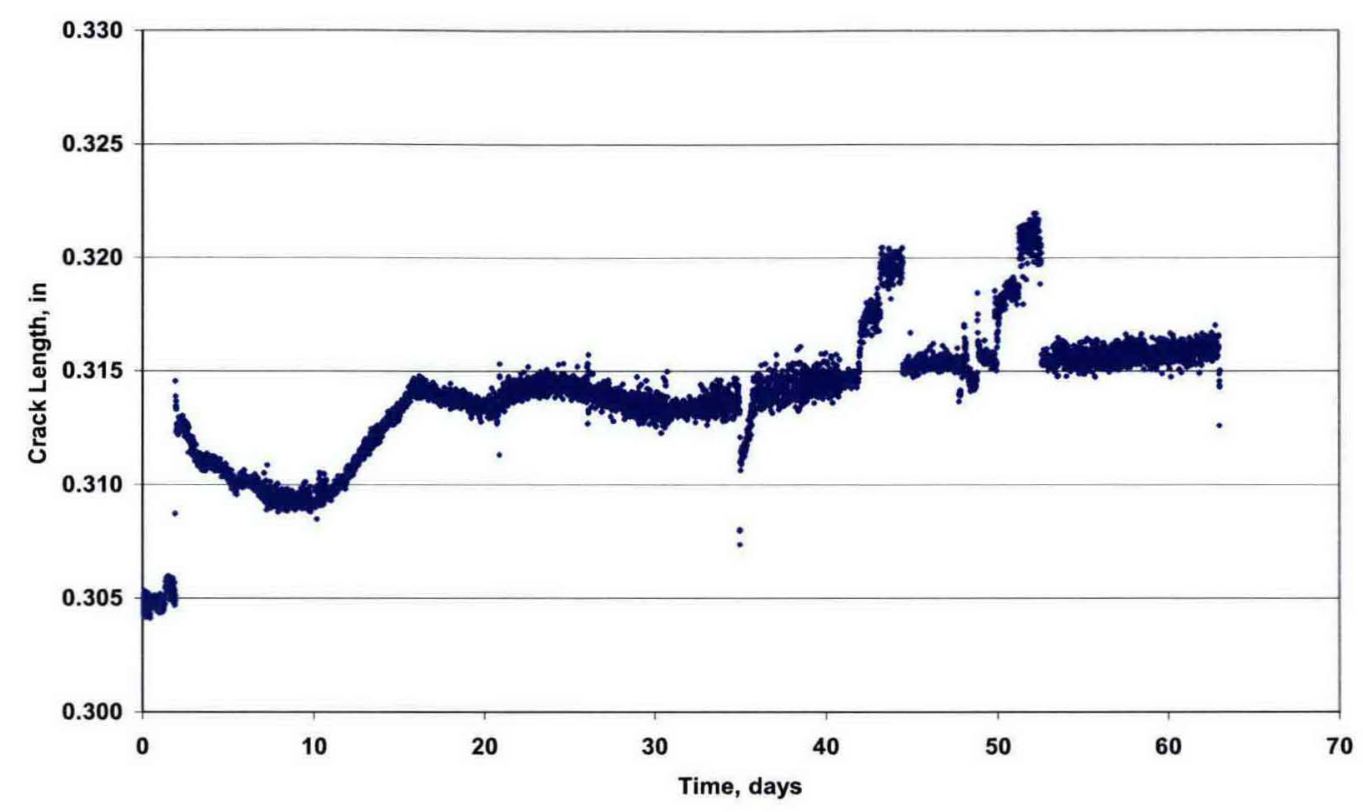

Figure D-4. The Load vs. Time Plot from CT-18 Performed in AY101-PSC Standard Simulant at $50^{\circ} \mathrm{C}$, pH 11 and at $0 \mathrm{mV}$ vs. SCE. Loaded to $\mathrm{K}=45 \mathrm{ksi}$ in.

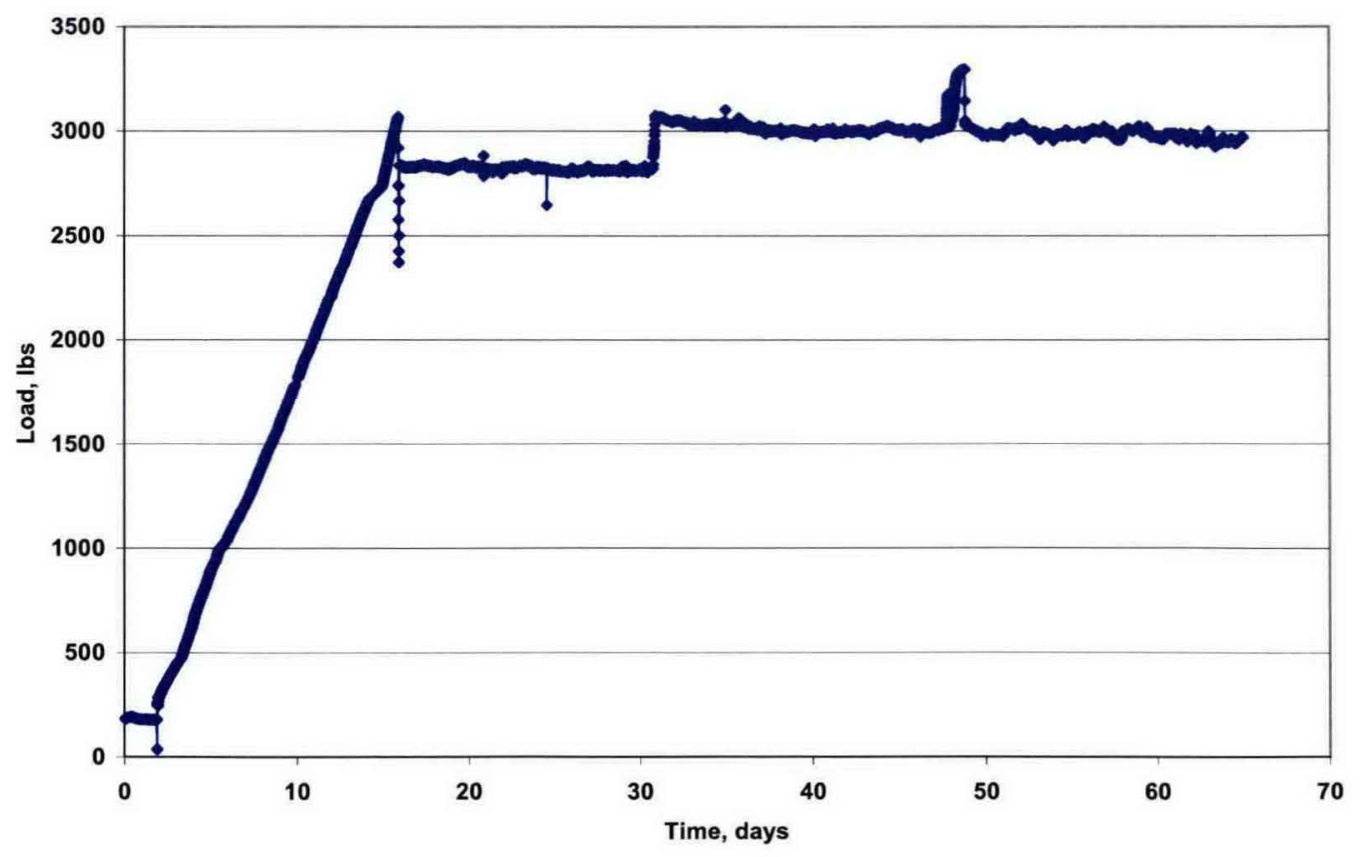


Figure D-5. An Electron-Micrograph of the Test Sample from CT-18 Performed in AY101-PSC Standard Simulant at $50^{\circ} \mathrm{C}$, pH 11 and at $0 \mathrm{mV}$ vs. SCE. Loaded to $K=45 \mathrm{ksi} V_{i n}$.

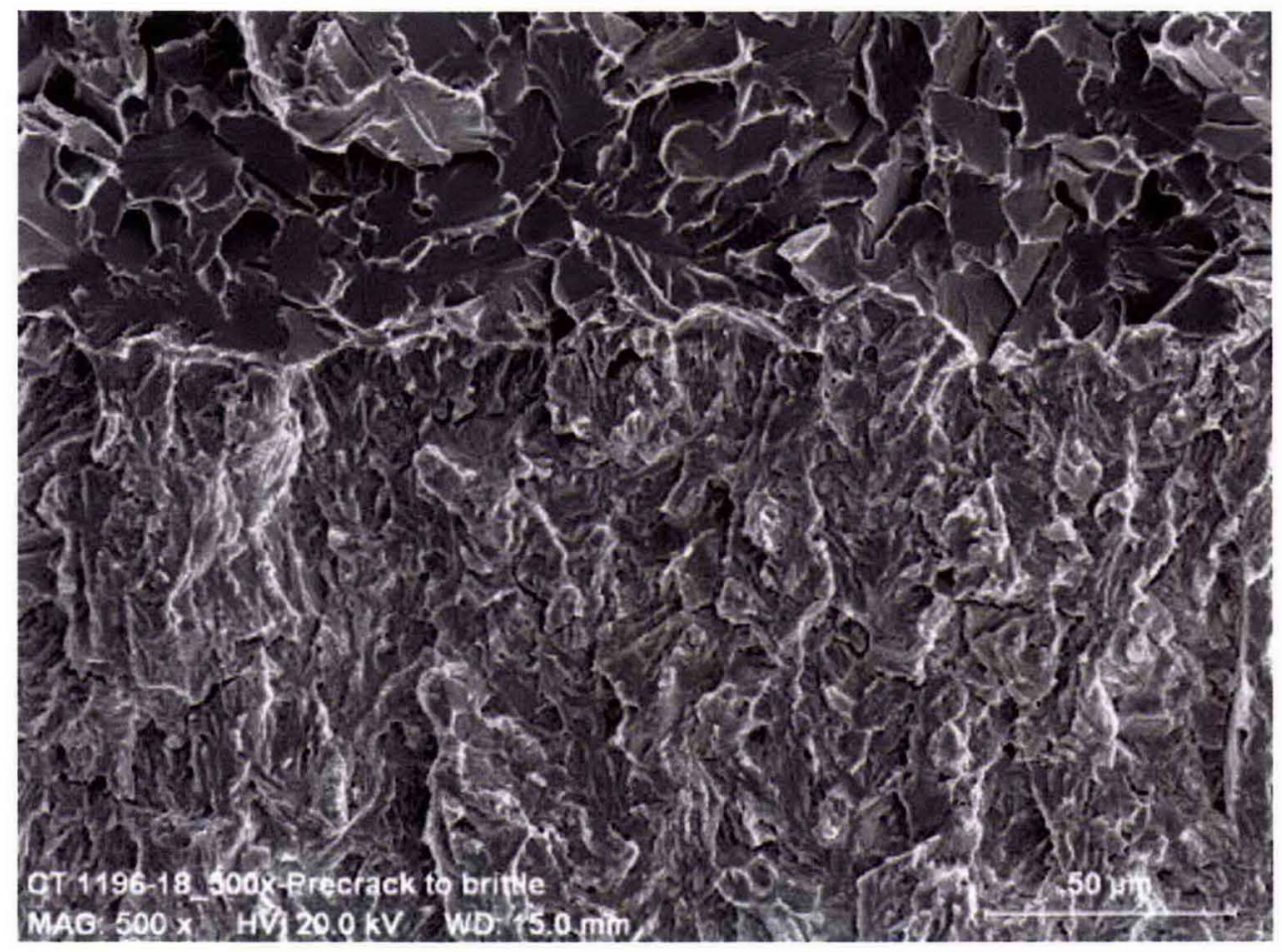

